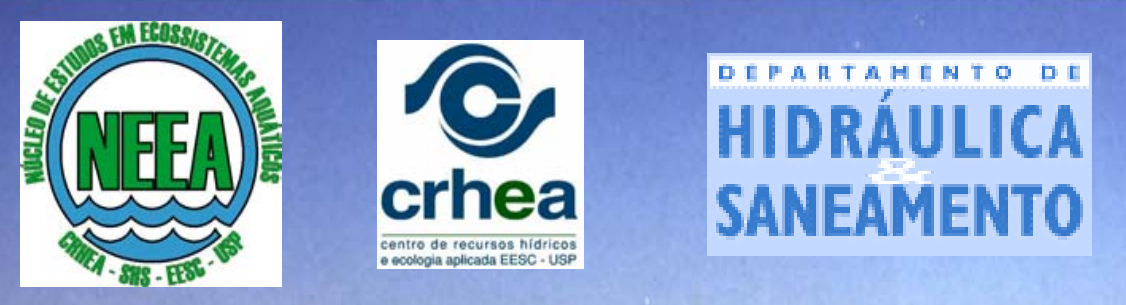

E E S C
Escola de Engenharia
de São Carlos

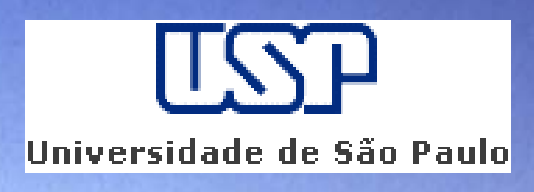

\title{
DISTRIBUIÇÃO E EFEITOS DE CROMO E COBRE EM ECOSSISTEMAS AQUÁTICOS: UMA ANÁLISE LABORATORIALE "IN SITU"
}

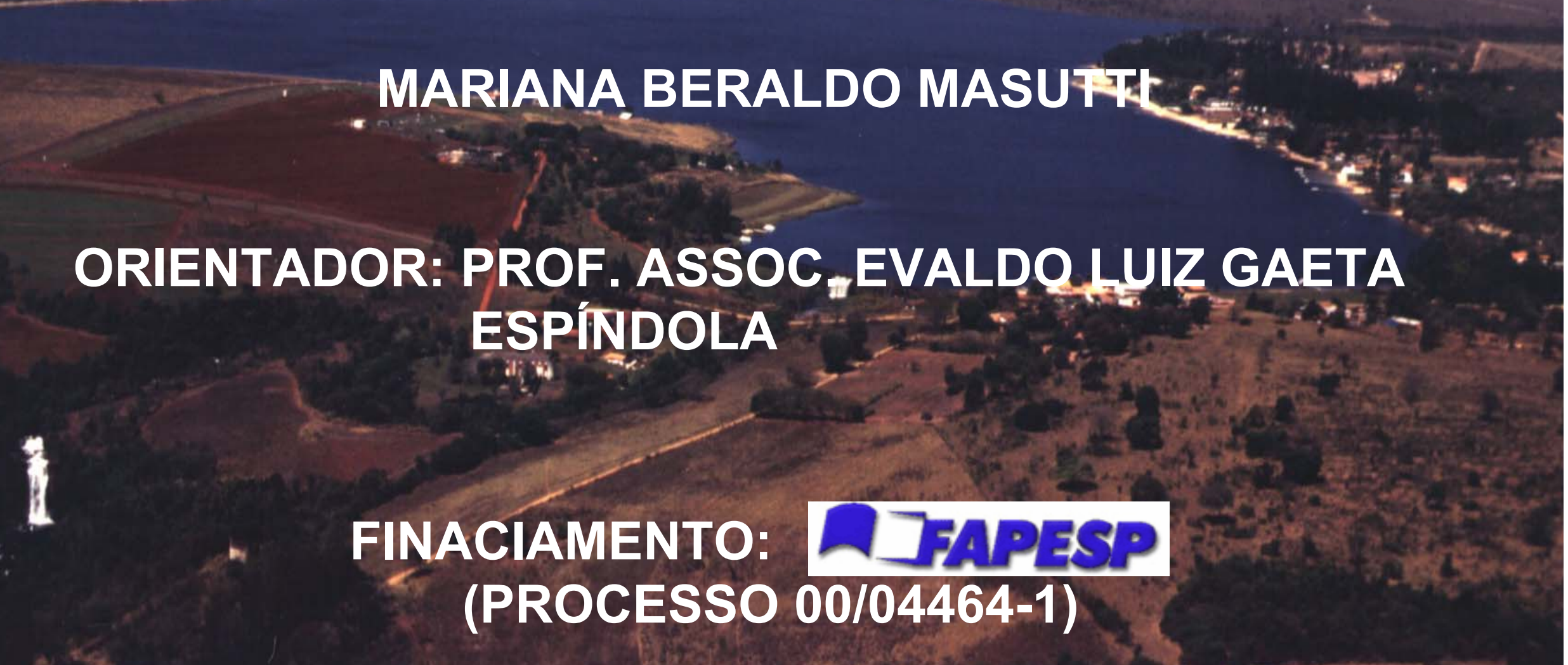




\section{DISTRIBUIÇÃO E EFEITOS DE CROMO E COBRE EM ECOSSISTEMAS AQUÁTICOS: UMA ANÁLISE LABORATORIAL E "IN SITU" (EXPERIMENTOS EM MICRO E MESOCOSMOS).}

Tese apresentada à Escola de Engenharia de São Carlos da Universidade de São Paulo como parte dos requisitos para obtenção do título de Doutor em Ciências da Engenharia Ambiental.

Orientador: Prof. Assoc. Evaldo Luiz Gaeta Espíndola 


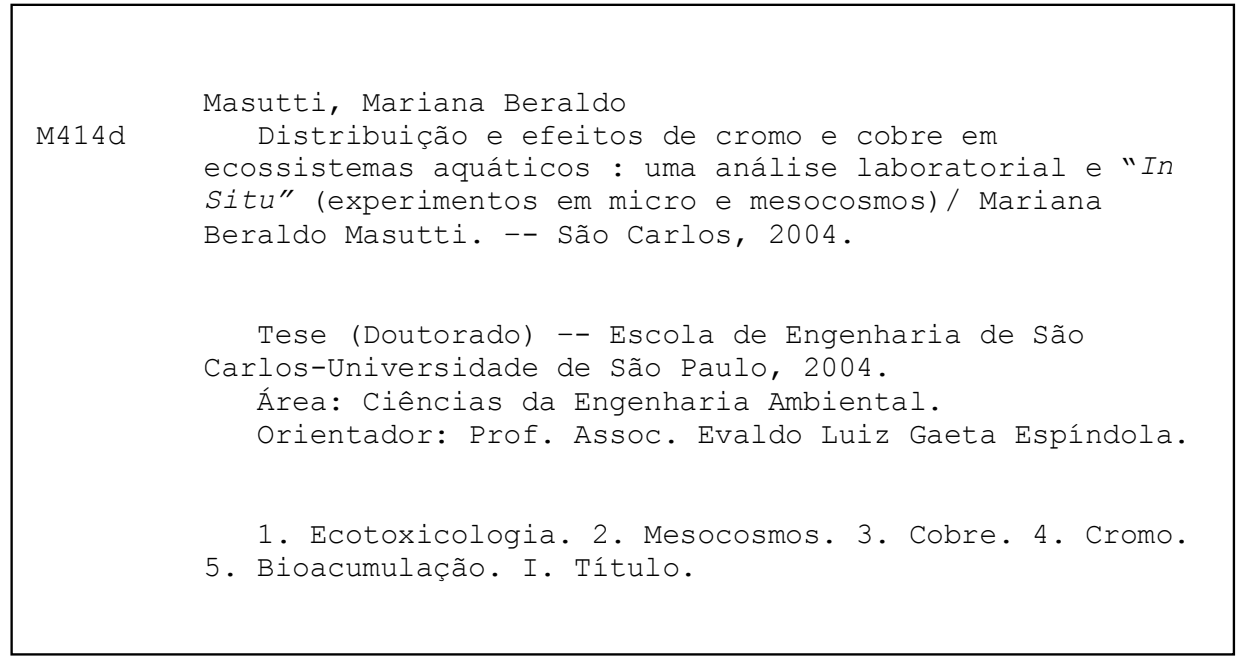


Dedico este trabalho ao Zuba e à toda minha família. 


\section{AGRADECIMENTOS}

À FAPESP, pela concessão da bolsa (Processo 00/04464-1);

Ao Prof. Dr. Evaldo Luiz Gaeta Espíndola, pela orientação, confiança e por tudo que este doutorado me proporcionou;

À todas as pessoas, e não foram poucas, que auxiliaram em alguma etapa do trabalho, no campo ou no laboratório:

aos técnicos do CRHEA Amândio, Marcelo, Luci, América e Miro e à Valéria, do IIE;

aos alunos e estagiários do CRHEA, na época de desenvolvimento do trabalho:

Alessandro, Aline, Davi, Domingos, Fernanda Simões, Fernanda Marciano, Ricardo Gentil;

às pessoas que trabalharam em conjunto: Ricardo Wagner Reis Filho, Luiz Felipe Mendes de Gusmão e Andréia Tucci;

aos que se tornaram grandes amigos: Julia e Rinaldo, Dani e André; Juliana e Caio, Cendi, Cássio, Clarice, Abílio, Carol e Maurício;

Ao pessoal dos laboratórios de Ecotoxicologia e Microscopia: Luci, Suze, Janete, Andréia, Viviane;

Ao pessoal do CRHEA: Mara, Claudete, Sonia, Rogério, Beto, Ivan, Paulo, Seu Maurício, Regina, Wellington, Nelson;

Aos meus pais, Silvia e Leonardo, meus sogros, Mariza e Victor, meus irmãos e cunhadas, Leonardo e Sabrina, Adriano e Nívia, Fabrício e Roseli, meus avós, Luiz, Josepina e $D^{a}$ Lia, por todo o apoio, interesse e carinho;

Ao Zuba, por tudo o que temos vivido. 
"Já é tempo de deixarmos de olhar por esse pequeno orifício do microscópio e elevarmos os olhos para a imensa claridade de tudo quanto foi criado"

Dr. E. Leonardi 
RESUMO

MASUTTI, M. B. (2004). Distribuição e efeitos de Cromo e Cobre em ecossistemas aquáticos: uma análise laboratorial e "in situ". Tese de Doutorado - Escola de Engenharia de São Carlos, Universidade de São Paulo, São Carlos, 2004.

O objetivo geral do trabalho foi avaliar a distribuição e os efeitos tóxicos dos metais $\mathrm{Cr}$ e Cu sobre os ecossistemas aquáticos lênticos, incluindo seus componentes bióticos e abióticos, utilizando-se sistemas com diferentes níveis de complexidade e organização. Os sistemas utilizados na avaliação da toxicidade de $\mathrm{Cr}$ e Cu foram: a) testes uniespecíficos com Selenastrum capricornutum (microalga), Daphnia similis e Ceriodaphnia dubia (Cladocera), Chironomus xanthus (Diptera, Chironomidae), Oreochromis niloticus (peixe) e Pistia stratiotes (macrófita); b) experimentos em microcosmos (testes multiespecíficos) com as comunidades naturais da represa do Lobo; c) experimentos em mesocosmos, contando com água, sedimento, plâncton, bentos, peixes e macrófitas naturais da represa do Lobo . Nos testes de toxicidade todas as espécies foram mais sensíveis ao $\mathrm{Cu}$ que ao $\mathrm{Cr}$, e a sequência de sensibilidade foi $D$. similis $>C$. dubia $>S$. capricornutum $>C$. xanthus $>$ $P$. stratiotes $>0$. niloticus. Nos experimentos em microcosmos e mesocosmos, as concentrações-teste foram definidas como o valor máximo permitido pela Resolução $\mathrm{n}^{\circ} 20 / 1986$ do CONAMA para $\mathrm{Cr}^{6+}$ e $\mathrm{Cu}^{2+}$ para corpos d'água Classe $2\left(50 \mu \mathrm{g} \cdot \mathrm{L}^{-1}\right.$ e 20 $\mu \mathrm{g} \cdot \mathrm{L}^{-1}$, respectivamente). Em todos os experimentos a concentração de clorofila foi reduzida significativamente após a adição dos metais. Os efeitos sobre a densidade e riqueza de espécies das comunidades zooplanctônicas foram mais severos para o $\mathrm{Cr}$ que para o $\mathrm{Cu}$; porém Cladocera foi mais sensível ao $\mathrm{Cu}$. Cromo provocou uma maior inibição na produção primária em abril de 2002, enquanto que em novembro/dezembro de 2002 a produção primária sofreu maior decréscimo após a adição de $\mathrm{Cu}$. Ambos os metais estudados apresentaram efeitos significativos sobre um grande número de variáveis da água, como oxigênio dissolvido, amônio, distribuição das formas fosfatadas, clorofila e material em suspensão, sendo os efeitos do $\mathrm{Cr}$ mais severos que os do $\mathrm{Cu}$, em relação ao número de variáveis afetadas e ao tempo de restauração do sistema. Os sedimentos não apresentaram alterações após a adição de metais. Foi observada a ocorrência de bioacumulação de $\mathrm{Cr}$ e $\mathrm{Cu}$ pelo plâncton, bentos, macrófitas e peixes. A toxicidade dos metais estudados foi reduzida após a inclusão de peixes e macrófitas, principalmente para $\mathrm{Cu}$. Apesar das concentrações de $\mathrm{Cr}$ e $\mathrm{Cu}$ relativamente baixas empregadas, os metais provocaram efeitos nos compartimentos bióticos e abióticos do sistema. Os resultados obtidos no presente trabalho podem ser 
úteis como subsídio para a avaliação dos valores máximos permitidos pela Resolução $n^{\circ} 20 / 1986$ do CONAMA para os metais estudados.

Palavras-chave: ecotoxicologia, mesocosmos, cobre, cromo, bioacumulação 


\section{ABSTRACT}

MASUTTI, M. B. (2004). Chromium and Copper distribution and effects in aquatic ecosystems: a laboratorial and "in situ" analysis. PhD Thesis. Escola de Engenharia de São Carlos, Universidade de São Paulo, São Carlos, 2004.

The general aim of this work was to evaluate the distribution and the toxic effects of the metals $\mathrm{Cr}$ and $\mathrm{Cu}$ on lenthic aquatic ecosystems, using systems of different complexity and organization levels. The systems used for $\mathrm{Cr}$ and $\mathrm{Cu}$ toxicity evaluations were: a) single-specific tests with Selenastrum capricornutum (microalgae), Daphnia similis e Ceriodaphnia dubia (Cladocera), Chironomus xanthus (Diptera, Chironomidae), Oreochromis niloticus (fish) and Pistia stratiotes (macrophyte); b) microcosms experiments (multi- specific tests) with the Lobo's reservoir natural communities; c) mesocosms experiments, with natural water, sediment, plankton, benthics, fishes and macrophytes from Lobo's reservoir. In the toxicity tests, all the species were more sensitive to $\mathrm{Cu}$ than to $\mathrm{Cr}$, and the sensitiviness sequence was $D$. similis $>$ C. dubia $>$ S. capricornutum $>C$. xanthus $>P$. stratiotes $>0$. niloticus. In the microcosms and mesocosms experiments, the test-concentrations were the maximum value allowed by the CONAMA Resolution $\mathrm{n}^{\circ} 20 / 1986$ to $\mathrm{Cr}^{6+}$ and $\mathrm{Cu}^{2+}$ to Class 2 water bodies (50 $\mu \mathrm{g} \cdot \mathrm{L}^{-1}$ and $20 \mu \mathrm{g} \cdot \mathrm{L}^{-1}$, respectively). In all experiments the chlorophyll concentration was significantly reduced after the metal addition. The effects on the Zooplankton density and richness were stronger to $\mathrm{Cr}$ than to $\mathrm{Cu}$; however Cladocera was more sensitive to $\mathrm{Cu}$. Chromium caused higher inhibition in primary production in April/ 2002, but in November/ December 2002 the primary production suffered higher inhibition by $\mathrm{Cu}$ addition. Both studied metals showed significant effects on several water variables, as dissolved oxygen, ammonium, phosphate forms distribution, chlorophyll and suspended material, being the $\mathrm{Cr}$ effects stronger than the $\mathrm{Cu}$ effects, in relation to the number of affected variables and the system restoration time. The sediments didn't show alterations after the metal addition. Chromium and $\mathrm{Cu}$ bioaccumulation was observed by plankton, benthic invertebrates, macrophytes and fishes. The toxicity of the studied metals was reduced by the fish and macrophyte inclusion, mainly to $\mathrm{Cu}$. Although the concentration of $\mathrm{Cr}$ and $\mathrm{Cu}$ were low, toxic effects were observed on both biotic and abiotic system compartments. The results obtained in this work may be useful as subsidy to evaluation of the maximum value allowed by the CONAMA Resolution $n^{\circ} 20 / 1986$ to the studied metals.

Key-words: ecotoxicology, mesocosms, copper, chromium, bioaccumulation. 


\section{LISTA DE ABREVIATURAS E SIGLAS}

CONAMA: Conselho Nacional do Meio Ambiente

ABNT: Associação Brasileira de Normas Técnicas

ISO: International Standardization Organization

US EPA: United States Environmental Protection Agency

OECD: Organization for Economic Cooperation and Development

ppb: partes por bilhão

ppm: partes por milhão

CE 50: Concentração efetiva mediana

CE (I) 50: Concentração inicial (nominal) efetiva mediana

CL 50: Concentração letal mediana

CL (I)50: Concentração letal (nominal) inicial mediana

CENO: Concentração de efeito não observado

CEO: Concentração de efeito observado

ANOVA: Analysis of Variance

MANOVA: Multivariate Analysis of Variance 
SUMÁRIO

CAPÍTULO 1: INTRODUÇÃO GERAL........................................................ 05

CAPÍTULO 2: TESTES DE TOXICIDADE COM ORGANISMOS PLANCTÔNICOS, BENTÔNICOS, PEIXES E MACRÓFITAS AQUÁTICAS COM

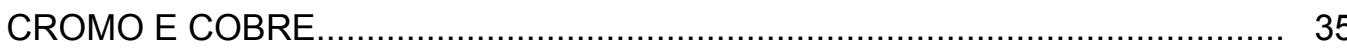

CAPÍTULO 3: EXPERIMENTOS EM MICRO E MESOCOSMOS ...................... 91

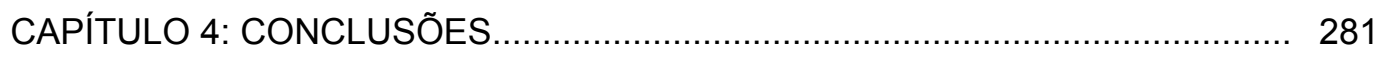

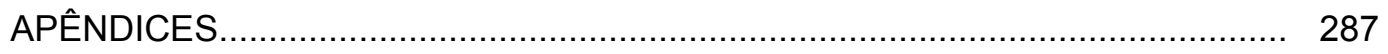




\section{APRESENTAÇÃO DA TESE}

O objetivo geral desta pesquisa foi avaliar a distribuição e os efeitos dos metais $\mathrm{Cr}$ e $\mathrm{Cu}$ sobre os ecossistemas aquáticos, incluindo os componentes bióticos e abióticos destes sistemas. Neste sentido, procurou-se avaliar diferentes endpoints utilizando-se sistemas com diferentes níveis de complexidade e organização.

A toxicidade de $\mathrm{Cr}$ e $\mathrm{Cu}$ foi avaliada em sistemas com grau de complexidade e escalas espaciais e temporais crescentes, partindo-se de sistemas uniespecíficos (testes de toxicidade), montados em laboratório, com todas as condições controladas, até experimentos em microcosmos e mesocosmos, montados em campo, incluindo água, sedimentos, fitoplâncton, zooplâncton, bentos, peixes e macrófitas de ocorrência natural na represa do Lobo (Itirapina/ Brotas - SP). Estes testes foram realizados com alguns objetivos comuns e alguns objetivos específicos a cada teste, tendo sido avaliados tanto os efeitos estruturais quanto os efeitos funcionais sob condições de exposição naturais ao elemento estressor. A Figura 01 apresenta um resumo das atividades desenvolvidas em cada fase do trabalho.

Devido à complexidade das informações pretendidas com este trabalho, que incluíram avaliações taxonômicas de diferentes tipos de organismos, assim como análises químicas de diversas substâncias em diferentes matrizes, o projeto inicial foi subdividido em outros projetos de pesquisa, dando origem uma monografia de graduação (SIMÕES, 2003), a duas dissertações de mestrado (GUSMÃO, 2004; REIS-FILHO, 2004) e uma pesquisa de Pós- Doutorado (TUCCl, 2004), sendo que alguns dados desta tese de doutorado já foram apresentados em outros trabalhos. Nesta tese, portanto, procurou-se reunir as informações sobre os diferentes experimentos realizados, possibilitando uma avaliação conjunta dos dados obtidos para sistema estudado, incluindo as pesquisas desenvolvidas pelos autores acima mencionados, que contribuíram para complementar os objetivos iniciais propostos no projeto de pesquisa financiado pela FAPESP (Processo 00/04464-1). 
FASE 1

Testes de Sensibilidade com $D$. simlis e C. dubia

FASE 2

Duração: 7 dias

Dezembro de 2001

FASE 3

Duração: 30 dias

Março/ Abril de 2002

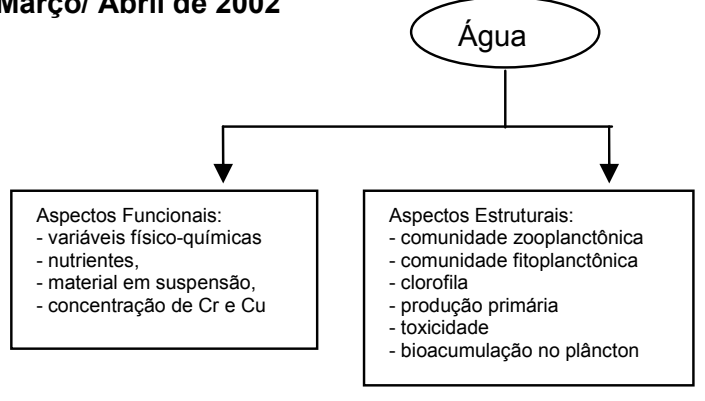

FASE 4

Duração: 45 dias

Dezembro de 2002

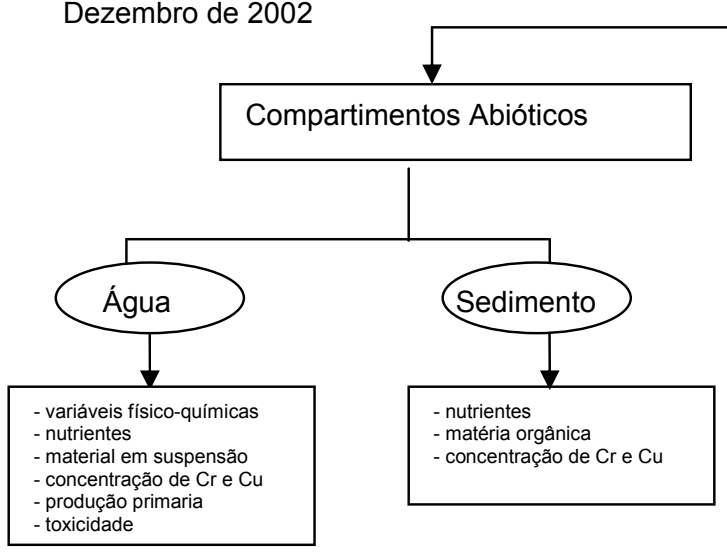

Experimentos em Mesocosmos (2)

Aspectos Estruturais:

- comunidade zooplanctônica

- comunidade fitoplanctônica

- nutrientes

- material em suspensão

-concentração de $\mathrm{Cr}$ e Cu

- clorofila

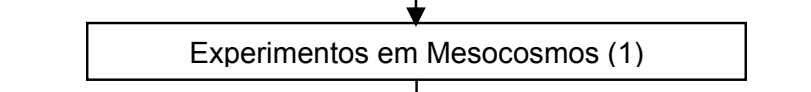


Inicialmente foram realizados testes de toxicidade aguda com $D$. similis e $C$. dubia, organismos padronizados e amplamente utilizados em testes de toxicidade com substâncias químicas e amostras ambientais, para orientação na escolha das concentrações teste utilizadas nos experimentos seguintes, em conjunto com outras informações, como os limites permitidos para $\mathrm{Cr}$ e $\mathrm{Cu}$ em corpos d'água (CONAMA 20/ 1986) e informações sobre a área de instalação dos experimentos. Optou-se então pela realização de testes de toxicidade aguda com outros organismos, de níveis tróficos diferentes, sendo $C$. xanthus, S. capricornutum, $P$. stratiotes e O. niloticus, com a finalidade de se comparar, posteriormente, os resultados destes testes com os realizados em campo, com concentrações muito mais baixas, e para se obter alguma informação sobre as diferenças de sensibilidade entre as diferentes espécies testadas.

Em seguida, em um nível intermediário, foram realizados experimentos em microcosmos, contendo apenas a água e o plâncton da represa do Lobo. Neste experimento, principalmente os endpoints estruturais puderam ser avaliados, como a densidade e diversidade de organismos fito e zooplanctônicos e a organização destas populações. Estes testes foram conduzidos utilizando-se uma única concentração de cada metal testado, sendo desejado nos experimentos uma concentração igual a máxima permitida pela Resolução $\mathrm{n}^{\circ} 20$ do CONAMA (1986).

Os experimentos em mesocosmos ( 1 e 2) foram conduzidos desejando-se esta mesma concentração. No primeiro experimento em mesocosmos (Mesocosmos 1) foram avaliados os efeitos sobre a comunidade zooplânctônica e sobre os organismos bentônicos. A ocorrência de bioacumulação também foi avaliada nestes grupos de organismos, além da análise dos parâmetros funcionais do sistema, como as variáveis físico-químicas, a concentração de nutrientes e a concentração de metais nos compartimentos abióticos (água e sedimentos).

No segundo experimento em mesocosmos (Mesocosmos 2) a estrutura das comunidades deixou de ser avaliada, sendo o objetivo principal desta parte do trabalho a observação da ocorrência de bioacumulação em peixes e macrófitas, além dos organismos avaliados no experimento anterior (plâncton e bentos).

Assim, este trabalho apresenta dados a respeito da toxicidade dos metais $\mathrm{Cr}$ e $\mathrm{Cu}$ obtidos a partir de experimentos de laboratório e em campo, avaliando os efeitos estruturais e funcionais destes metais sobre os ecossistemas aquáticos em exposição às concentrações ambientais e uma comparação de diferentes abordagens ecotoxicológicas sobre os mesmos contaminantes. 
CAPÍTULO 1 - INTRODUÇÃO GERAL 


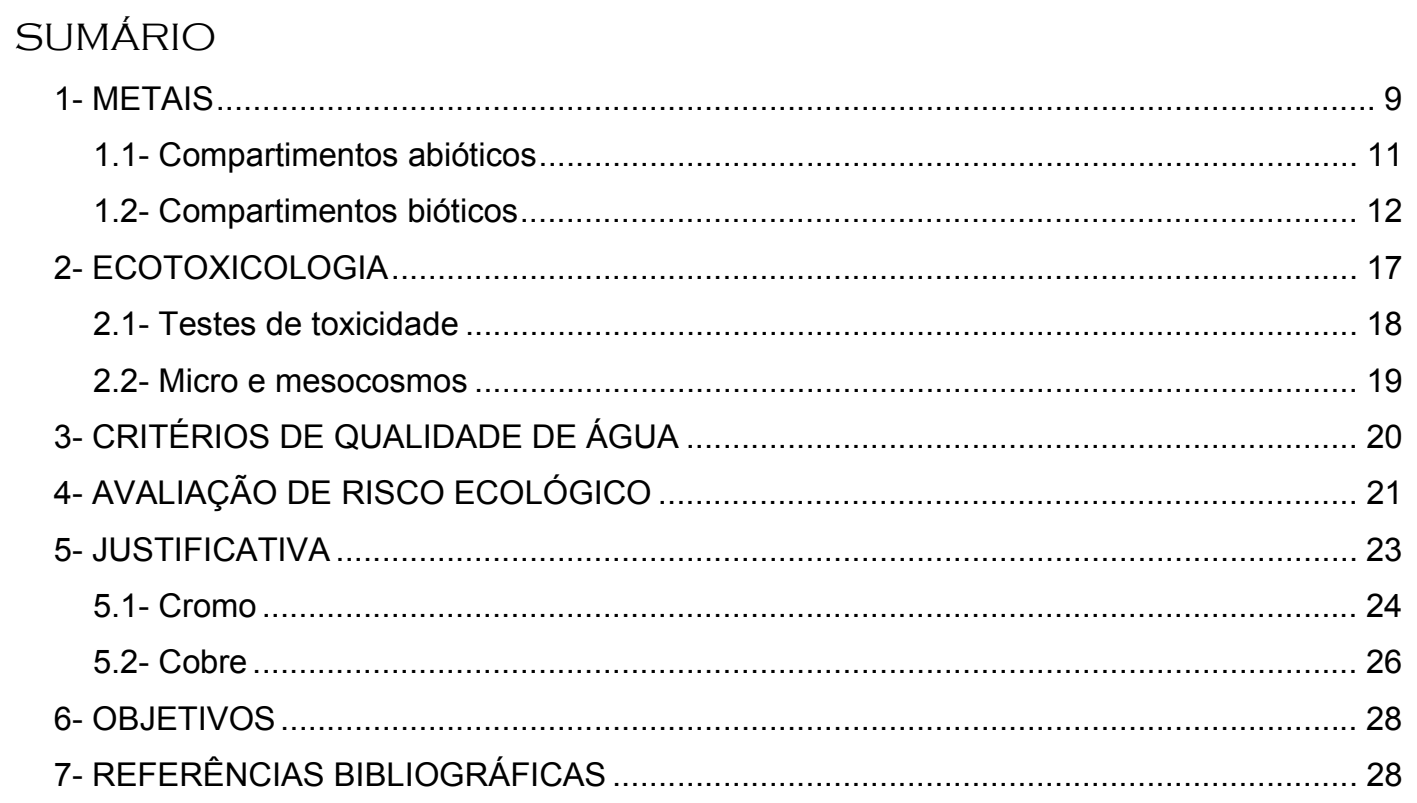

\section{LISTA DE FIGURAS}

Figura 01: Representação esquemática dos reservatórios de metais e suas interações nos sistema aquáticos e terrestres (SALOMONS \& FORSTNER, 1984).

Figura 02: Disponibilidade das formas metálicas para a biota (SALOMONS \& FORSTNER, 1984)...

Figura 03: Abordagem ecotoxicológica. Fonte: BOUDU \& RIBEYRE (1989) apud FERNICOLA et al. (2003).

\section{LISTA DE TABELAS}

Tabela 01: Alguns exemplos da contaminação por metais traço em ecossistemas brasileiros. 


\section{1- METAIS}

Desde o início da civilização, principalmente após a revolução industrial, o homem tem extraído, utilizado e descartado os mais diversos recursos naturais (OCHIAI, 1995), sendo que um grande número de substâncias químicas têm tido como destino os ecossistemas aquáticos.

Entre as substâncias químicas, os metais têm recebido atenção especial por se tratarem de poluentes conservativos, não biodegradáveis, que atravessam um ciclo hidrológico global, no qual a água é o principal caminho (TAM \& WONG, 1995). O acúmulo de metais nos ecossistemas aquáticos tem despertado interesse sob vários aspectos, como no destino e os efeitos desses contaminantes, seu comportamento nas cadeias alimentares e sua ciclagem biogeoquímica (REINFELDER et al., 1998).

Os metais ocorrem na natureza normalmente em pequenas concentrações, da ordem de ppb ou ppm. São introduzidos nos ecossistemas naturalmente, através do intemperismo das rochas, e antropogênicamente, através de diversas atividades humanas. Alguns deles, como magnésio, ferro, zinco, manganês, cobre, cobalto, molibdênio e boro são essenciais aos seres vivos, ainda que em concentrações muito pequenas, e atuam em diversos processos fisiológicos, porém, em altas concentrações, são geralmente tóxicos. Outros metais, como mercúrio, chumbo, cádmio, cromo e níquel não têm função biológica conhecida e comumente apresentam toxicidade aos organismos (ESTEVES, 1988; FREEDMAN, 1995; OCHIAI, 1995).

$O$ crescente desenvolvimento industrial e urbano tem provocado um aumento significativo nos estoques de metais presentes nos ecossistemas aquáticos. Nesses ambientes são identificados quatro compartimentos abióticos distintos: material em suspensão, sedimento, água superficial e água intersticial. Cada um desses compartimentos interage fortemente com outro (Figura 01). 


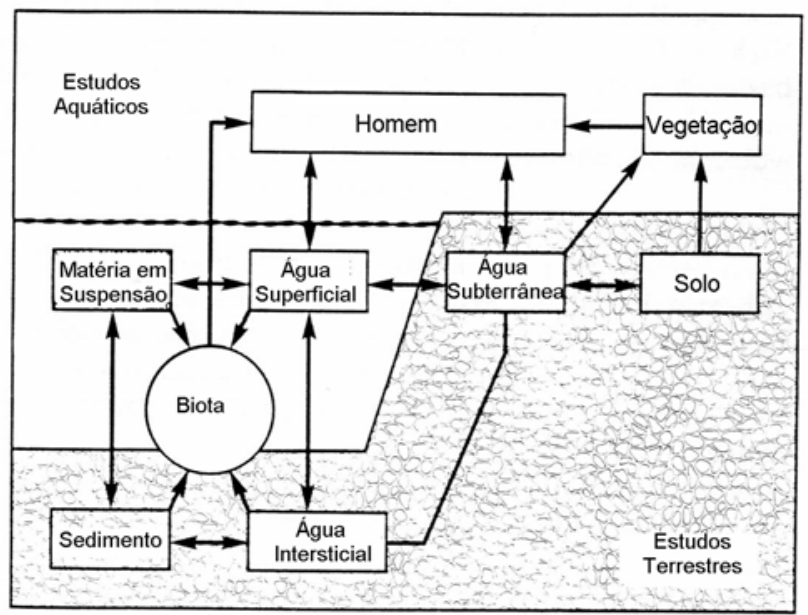

Figura 01: Representação esquemática dos reservatórios de metais e suas interações nos sistema aquáticos e terrestres (SALOMONS \& FORSTNER, 1984).

A determinação da fração disponível para a biota em cada um desses compartimentos é atualmente uma das principais áreas de interesse no estudo de metais em ecossistemas. Tanto a biodisponibilidade quanto as interações entre os processos abióticos são definidos pela forma físico-química em que cada elemento se encontra, assim como pela sua concentração no ambiente.

Uma vez inseridos no ambiente, os metais podem ser transportados e transformados através de diversos processos, em função de sua origem, suas propriedades físico-químicas e das quantidades introduzidas. Esses elementos podem causar efeitos adversos ao homem, assim como danos às biocenoses dos ecossistemas (SUNDA \& HUNTSMAN, 1998).

Por serem mais susceptíveis, os ecossistemas aquáticos têm recebido maiores estudos, pois recebem direta e indiretamente poluentes provenientes de despejos industriais e domésticos. Como metais são poluentes conservativos, a biota aquática pode estar sujeita à sua toxicidade por longos períodos de tempo.

Vários estudos sugerem que a maior fração de metais é imobilizada nos sedimentos sob formas não biodisponíveis, levando a um decréscimo na concentração disponível para a biota (CALMANO et al., 1993; TAM \& WONG, 1995; LACERDA, 1998). Porém, metais são tóxicos biocumulativos e alguns organismos, principalmente os filtradores e detrítivoros, podem apresentar concentrações muito mais altas em seus tecidos que a água em sua vizinhança, constituindo uma via de entrada certa para os metais na cadeia alimentar (REEVE, 1994). Apesar de serem bastante conhecidos os efeitos tóxicos dos metais pesados à saúde humana, a efetividade dos processos físico- 
químicos e biológicos que determinam seu comportamento no meio ambiente são pouco conhecidos

\section{1- Compartimentos abióticos}

O comportamento de metais traço em sistemas aquáticos é altamente complexo devido ao grande número de possíveis interações com componentes dissolvidos e particulados sob condições de não-equilíbrio. A maior parte das águas naturais possui uma certa capacidade de minimizar a toxicidade dos poluentes adicionados a elas, devido a presença de ligantes, como substâncias húmicas e minerais argilosos, tornando-os menos disponíveis para os organismos (SALOMONS \& FORSTNER, 1984).

Esse processo favorece a precipitação desses elementos, que são depositados e consolidados no sedimento, onde, após atingido equilíbrio, são imobilizados. Após a deposição podem ocorrer processos em que a água intersticial é enriquecida com altas concentrações de metais, que podem ser transferidos para águas superficiais através de difusão (BURTON, 1991).

A precipitação de metais comumente ocorre devido à alterações de $\mathrm{pH}$, no potencial de oxidação ou na concentração de substâncias precipitadas, quando ocorrem interações (CHUAN et al., 1996). Os principais tipos de reações que ocorrem causando a precipitação são a formação de óxidos, sulfetos metálicos, sulfatos e carbonatos, precipitação alcalina, adsorção ou co-precipitação em óxidos de Fe e Mn, argilas e matéria orgânica. Os principais processos envolvidos no transporte dos metais dissolvidos através do sedimento são sorção/desorção, quimiosorção, precipitação e troca iônica (SALOMONS \& FORSTNER, 1984).

A matéria particulada têm um importante papel na distribuição de metais traço entre as fases sólidas e dissolvidas. As interações entre essas fases são complexas devido à grande variedade de superfícies sedimentares e ligantes orgânicos e inorgânicos em solução, competindo pela complexação dos metais presentes (CALMANO et al., 1993).

Sedimentos podem ser, dependendo do ambiente em que se encontram, uma fonte ou um sumidouro para os metais provenientes das águas superficiais, uma vez que os metais não permanecem fixos nos sedimentos, mas podem ser reciclados através de agentes químicos e biológicos (CALMANO et al., 1993; CHUAN et al., 1996; LACERDA, 1998)

Um dos objetivos de se estudar a dinâmica dos processos que ocorrem com os sedimentos está na previsão do destino dos contaminantes que são transportados por ele. Após a deposição de constituintes sedimentáveis da coluna d'água, podem 
ocorrer mudanças na forma química dos elementos, através de um grande espectro de mecanismos e interações, alterando o equilíbrio entre sólidos e suas espécies dissolvidas (BURTON, 1991).

Como resultado desses processos, novos compostos metálicos são formados e as águas intersticiais também podem ser acrescidas nas concentrações de alguns metais. Os processos diagenéticos influenciam principalmente a composição das águas superficiais, os sedimentos depositados e suas águas intersticiais. As reações diagenéticas ocorrem de forma mais intensa em sedimentos suscetíveis a variações na condição redox. O ambiente diagenético é caracterizado por interações muito complexas entre íons metálicos, compostos metal-orgânicos, compostos sulfurosos e sólidos orgânicos e inorgânicos (SALOMONS \& FORSTNER, 1984).

É de importância fundamental considerar que a matéria orgânica pode alterar significativamente a distribuição entre as formas oxidadas e reduzidas de metais em sedimentos. Estudos recentes têm indicado uma correlação direta entre a velocidade de sedimentação e a concentração de matéria orgânica lábil em sedimentos. Uma alta taxa de sedimentação deverá limitar a difusão de oxigênio no sedimento até sua exaustão devido à respiração do carbono orgânico (SHINE, IKA \& FORD, 1995).

Outro importante fator à ser considerado no ambiente diagenético é a interação de metais com vários compostos de enxofre. A oxidação do FeS pode ser considerada como ponto inicial de muitas reações envolvidas (SALOMONS \& FORSTNER, 1984; CALMANO et al., 1993)

A fração biodisponível de metais é definida como a fração da concentração total em cada reservatório abiótico que é ingerida pelos organismos. Essa fração compreende os metais fracamente ligados ao sedimento, que podem ser facilmente mobilizados (PLETTE et al., 1999). Vários estudos sugerem que essa fração corresponde a uma pequena porcentagem da concentração total dos metais nos sedimentos, porém, como metais são bioacumulativos, não deve ser menosprezada (TAM \& WONG, 1995; TAM et al., 1995; LACERDA, 1998).

\section{2- Compartimentos bióticos}

Nos ambientes aquáticos, todos os organismos estão expostos aos metais. Organismos de diferentes níveis tróficos apresentam diferentes mecanismos de assimilação, que podem variar da ingestão de apenas íons em solução até metais incorporados em material biológico sólido, como representado na Figura 02 (SALOMONS \& FORSTNER, 1984). 


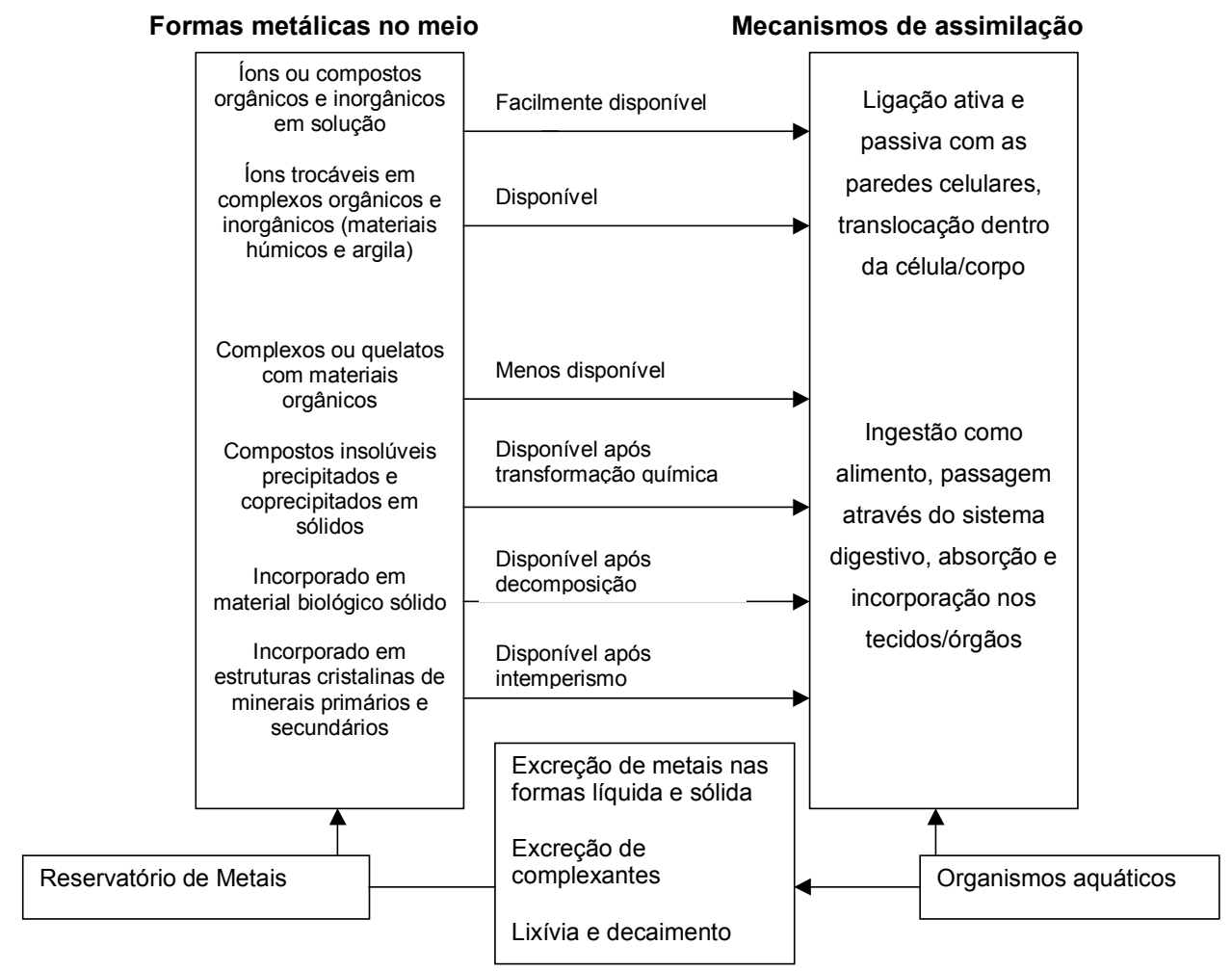

Mecanismos de retro-alimentação

Figura 02: Disponibilidade das formas metálicas para a biota (adaptado de SALOMONS \& FORSTNER, 1984)

A disponibilidade de elementos traço para os organismos pode ser influenciada por fatores como suas características fisiológicas e ecológicas (OCHIAI, 1995). acúmulo de metais por invertebrados marinhos é influenciado por um grande número de fatores intrínsecos, como tamanho, idade e sexo; e extrínsecos, como especiação metálica, salinidade, temperatura e a presença de outros poluentes (LU, 1996).

Os principais locais de ação dos metais são as enzimas e as organelas subcelulares. O mecanismo de toxicidade dos metais é freqüentemente relacionado à danos no sistema enzimático, através da ligação dos íons metálicos com enzimas, provocando alterações em sua configuração tridimensional e resultando na alteração de suas funções catalíticas. A ação mais comum dos metais é a inibição das enzimas, que ocorre comumente como o resultado da interação do metal com o grupo SH da enzima, ou pela substituição de um metal co-fator essencial por um metal tóxico. Os metais também podem inibir a síntese das enzimas.

As enzimas podem ser "protegidas" da ação dos metais através da administração de agentes quelantes, que formam ligações estáveis com os metais (LU, 1996). A intoxicação dos organismos pode também ser avaliada através de 
biomarcadores. Um biomarcador é definido como uma alteração numa resposta biológica que pode ser relacionada a exposição a substâncias tóxicas, em nível subindividual, medido num organismo ou em seus produtos, indicando um desvio do estado normal que não pode ser detectado num organismo intacto(STEGEMAN et al, 1992). Alguns exemplos de biomarcadores são as superóxido dismutases (SOD), as peroxidases, como a glutationa peroxidase, e as transferase, como a glutationa-Stransferase (GST). Diversos complexos são formados entre metais e proteínas nos organismos, a fim de torná-los inertes ou reduzir sua toxicidade, como as metalotioninas. Metalotioninas (MT) são proteínas de baixo peso molecular, ricas em cisteína, que podem ligar metais como $\mathrm{Zn}^{2+}, \mathrm{Cd}^{2+}$ e $\mathrm{Hg}^{2+}$. MT e seus análogos são grandemente distribuídos entre os organismos, de bactérias à mamíferos (OCHIAI, 1995).

No ataque às organelas das células, os efeitos tóxicos resultam de interações entre os metais e os componentes intracelulares, sendo que para o metal ser tóxico à célula ele tem que "entrar" na célula. A passagem através da membrana celular é facilitada se a forma do metal é lipofílica, como metilmercúrio, que quando é ligado por uma proteína, é absorvido por endocitose. Outra forma de entrada dos metais nas organelas é a difusão passiva. Depois de "entrar" na célula, os metais podem causar diferentes efeitos, como inibir as enzimas microssomais ( $\left.\mathrm{Cd}, \mathrm{Co}, \mathrm{Sn},\left(\mathrm{CH}_{3}\right)_{2} \mathrm{Hg}\right)$ ), romper o retículo endoplasmático, se acumular nos lisossomos, atacar a mitocôndria ou inibir as enzimas respiratórias (LU, 1996).

Os metais ainda afetam a fidelidade da polimerase envolvida na biosíntese do DNA, resultando em danos genéticos pela interrupção da transcrição, devido a uma inabilidade para produzir proteínas específicas, especialmente enzimas, ou por algum outro efeito tóxico (OCHIAI, 1995).

Geralmente, quanto maior o período e mais altos os níveis, maior é o efeito tóxico do elemento. Entretanto, além do aspecto quantitativo, diferenças na duração e nos níveis da exposição podem levar a diferenças no efeito tóxico. Por exemplo, a ingestão de uma única grande dose de Cd induz distúrbios gastrointestinais, enquanto que repetidas doses pequenas resultam em disfunções renais (LU, 1996).

Sintomas de toxicidade aguda para a biota podem incluir padrões anormais de crescimento e desenvolvimento, reprodução prejudicada, doenças e morte. Toxicidade crônica também pode ocorrer, mas os sintomas são mais difíceis de serem detectados, podendo unicamente consistir no decréscimo da produtividade REINFELDER et al., 1998).

A biota pode interagir de várias maneiras com sua vizinhança, modificando o equilíbrio entre as espécies químicas e suas formas sólidas e aquosas. A forma 
particular de cada metal assume um importante papel na assimilação desses elementos pelos organismos. Existem dois tipos de fatores que influenciam a concentração metálica em organismos: a concentração de metais nos compartimentos abióticos e os processos bioquímicos que ocorrem nos organismos (REINFELDER et al., 1998).

Alguns metais traço são elementos essenciais para plantas e animais. Entretanto, sob certas condições ambientais, esses elementos podem se bioacumular em concentrações tóxicas, causando danos ecológicos. Muitos organismos podem bioconcentrar metais traço proporcionalmente às concentrações encontradas no ambiente em que estão inseridos, não possuindo regulação da concentração de cátions em seus tecidos (RAINBOW \& PHILIPS, 1993). Organismos com essas características são bioindicadores em potencial.

Observações de campo também indicam que os níveis metálicos encontrados em organismos marinhos, como a craca $S$. balanoides, tendem a refletir a concentração de metais no ambiente. Entretanto, não é claro se esses organismos atingem um ponto de equilíbrio com as concentrações da água ou se seus níveis aumentam indefinidamente (POWELL \& WHITE, 1990).

A escolha de determinada espécie para ser usada como bioindicador depende de fatores como a regulação metabólica de poluentes e as interações destes com o organismo, além da capacidade de integração da poluição com o tempo e a capacidade de refletir efeitos locais ou em uma grande área. A principal característica que um bioindicador deve apresentar é refletir os níveis de contaminação do ambiente, e sua regulação metabólica dos poluentes deve ser inexistente ou fraca o bastante para que interações internas não influenciem a assimilação do contaminante pela espécie monitora (PHILLIPS \& SEGAR, 1986).

Entretanto, deve-se tomar cuidado no uso de organismos vivos para confirmar o status do ambiente como poluído ou não, pois os níveis de metais encontrados para organismos coletados em áreas não poluídas não são necessariamente baixos. Uma avaliação mais completa e confiável é feita se várias espécies são usadas simultaneamente como indicadoras, particularmente espécies com diferentes padrões de vida e que ocupem diferentes níveis na cadeia trófica (CARRAL et al, 1995).

$\mathrm{O}$ acúmulo de elementos traço nos organismos aquáticos tem sido estudado visando principalmente a previsão de seu comportamento na cadeia trófica. $\mathrm{O}$ uso do fator de concentração em organismos baseado nas concentrações da água ou do sedimento presume uma situação de equilíbrio entre as fases dissolvidas e sólidas. Esta aproximação pode gerar informações sobre como os organismos são enriquecidos em elementos particulares, mas não indica suas condições fisiológicas e 
ambientais. Para os organismos consumidores, esse processo é ainda mais complexo devido à presença tanto de fontes dissolvidas como relacionadas à alimentação. Para muitos invertebrados aquáticos, a transferência trófica conta com a maior parte do acúmulo total de metais traço (REINFELDER et al., 1998).

Para um melhor entendimento dos processos de bioacumulação, biotransferência e dos efeitos de metais traço nos ecossistemas, deve ser levado em consideração a assimilação de metais pela cadeia alimentar, com ênfase nos produtores primários, que constituem o ponto inicial da entrada de metais nessas cadeias (SUNDA \& HUNTSMAN, 1998).

A biomagnificação de elementos traço ocorre quando as concentrações nos tecidos de um dado organismo são maiores que as concentrações apresentadas por seu alimento ou pelos níveis tróficos adjacentes. Esse processo é resultado do balanço entre assimilação e eliminação. Alguns organismos apresentam velocidades de excreção maiores para elementos não essenciais do que para elementos essenciais (REINFELDER et al, op. cit.)

A grande maioria dos organismos aquáticos são afetados de alguma forma pela presença de metais, apresentando comportamentos muito diferentes variando-se a espécie e o elemento em questão. O zooplâncton tem o desenvolvimento populacional drasticamente inibido em presença de doses altas de metais, porém Copepoda parece ser menos sensível que Cladocera e Rotífera a esses elementos. Para o fitoplâncton, os metais parecem apresentar menor influência sobre a densidade, porém podem determinar a composição de espécies (LOEZ et al., 1995; JAK et al., 1996).

Invertebrados também são mais sensíveis que organismos mais complexos, como peixes, ao $\mathrm{Cu}, \mathrm{Cd}$ e $\mathrm{Pb}$, e para esses organismos a reprodução é um parâmetro mais sensível que a sobrevivência. Para organismos mais complexos, o crescimento parece ser o parâmetro mais sensível (JOP et al., 1995).

Muito pouco é conhecido sobre o comportamento de macroalgas em presença de altas concentrações de metais traço, porém algumas espécies têm sido utilizadas no biomonitoramento de certas regiões (RAINBOW \& PHILIPS, 1993). Alguns dos efeitos de altas concentrações de metais traço para as plantas superiores são o retardamento no crescimento, comprometimento da germinação de sementes, decréscimo na biomassa e mortalidade (WILLIAMS et al., 1994). Macrófitas podem apresentar grande variação em seu conteúdo metálico, mesmo considerando uma mesma espécie em uma mesma região. A capacidade de translocação e imobilização de elementos metálicos em seus órgãos, a velocidade de crescimento e a 
sazonalidade influenciam a assimilação de metais por essas plantas (DEBUSK et al., 1996).

A importância da transferência trófica para a bioacumulação de alguns metais $(\mathrm{Hg}, \mathrm{Cs}, \mathrm{Se})$ em peixes é atualmente bem documentada. Experimentos realizados em laboratório sugerem que metais ingeridos a partir da água tendem a refletir suas concentrações, enquanto que ingeridos através da alimentação tendem a ser regulados, não ocorrendo biomagnificação (REINFELDER et al., 1998).

\section{2- ECOTOXICOLOGIA}

A Ecotoxicologia e a Toxicologia Ambiental são termos usados para descrever o estudo científico dos efeitos adversos causados aos organismos vivos pelas substâncias químicas liberadas no ambiente. A expressão Toxicologia Ambiental é usada para definir os efeitos das substâncias químicas sobre os seres humanos após exposição ambiental e o termo Ecotoxicologia para os estudos dos efeitos das substâncias químicas e dos agentes físicos sobre os ecossistemas e seus componentes não humanos, especialmente nas populações e nas comunidades de um ecossistema definido (FERNICOLA et al. 2003; CHASIN \& PEDROSO, 2003).

O princípio da Ecotoxicologia é a análise dos processos de transferência de contaminantes nos ecossistemas e nos efeitos sobre sua estrutura e funcionamento. Ecossistemas são estruturas unitárias, limitadas no tempo e no espaço, resultante da combinação do ambiente físico, biótopo, com a comunidade de organismos vivos, biocenose (Figura 03). Os fatores bióticos e abióticos caracterizam os ecossitemas e definem a base para qualquer abordagem ecotoxicológica. Os contaminantes incluem agentes fisicos, químicos e biológicos que podem causar perturbações nos ecossistemas e em seus compartimentos.

Assim, a ecotoxicologia envolve diversas áreas de pesquisa, sendo que os mecanismos observados nos ecossistemas são resultantes de combinações de um infinito número de processos, que podem ser observados nos mais diversos níveis de organização. A ecotoxicologia é a ciência responsável pela geração do conhecimento que subsidiará a formulação segura de dispositivos legais, normas, programas e diretrizes gerenciais para enfrentar questões de risco ecotoxicológico potencial e real, geradas pela introdução de agentes químicos no ambiente. 


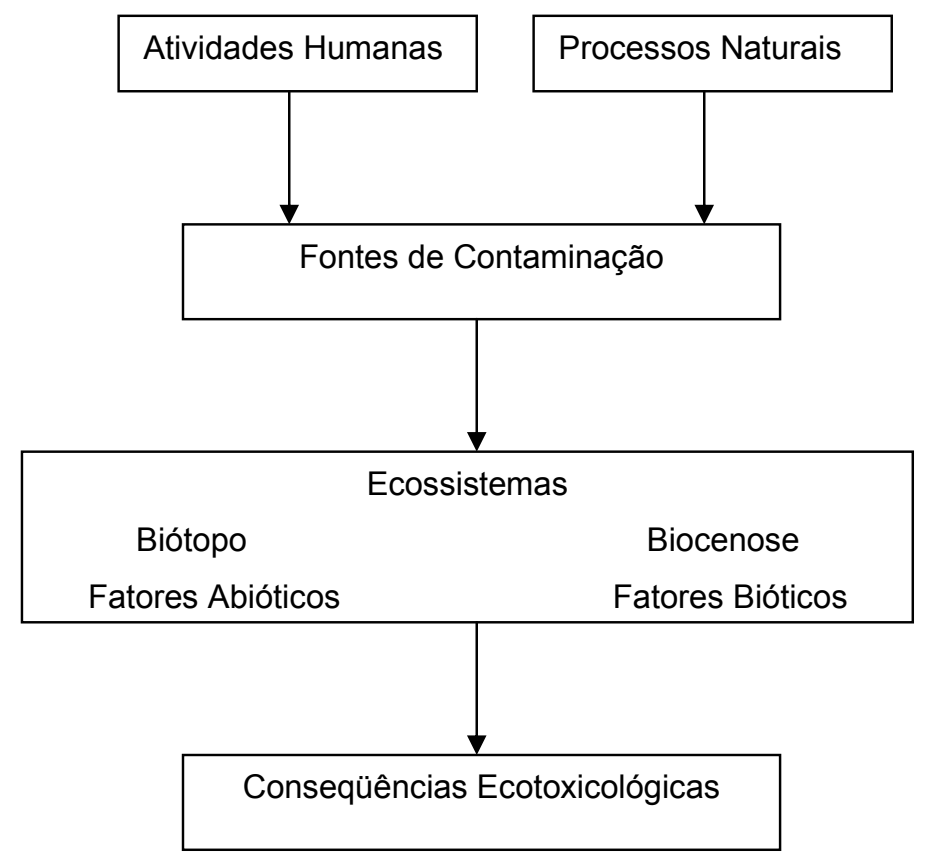

Figura 03: Abordagem ecotoxicológica. Fonte: BOUDU \& RIBEYRE (1989) apud FERNICOLA et al. (2003).

\section{1- Testes de toxicidade}

A avaliação da saúde ou o monitoramento de um determinado ambiente através da análise química de poluentes nos reportam a quantidade e a qualidade desses poluentes em diferentes compartimentos do sistema, mas não trazem informações a respeito de seus efeitos sobre as comunidades existentes e o funcionamento do sistema exposto à poluição. Os testes de toxicidade apresentam-se como mecanismos para a compreensão dos efeitos de impactos sobre os compartimentos bióticos, utilizando-se organismos vivos que atuam como biosensores. Os testes de toxicidade também podem prever antecipadamente impactos de um determinado poluente sobre a biota (CAIRNS et al., 1998).

O objetivo geral de um teste de toxicidade é a caracterização da resposta ecológica a uma determinada substância ou elemento químico. Entretanto, ao menos cinco propósitos distintos podem ser dados para qualquer teste de toxicidade: predição, diagnóstico, classificação, regulação e o mapeamento da contaminação (CAIRNS op cit.).

Os testes de toxicidade constituem-se basicamente da exposição de organismos aquáticos à substâncias potencialmente tóxicas, visando a observação e análise das respostas destes organismos ao contaminante testado. Os testes de toxicidade comumente usados são os testes de efeitos agudos, de curta duração, e 
crônico, de duração mais longa, podendo incluir todo o ciclo de vida do organismo. Em ambos os casos, efeitos letais e subletais da substância tóxica sobre os organismos podem ser avaliados (ZAGATTO, 1999).

Estes testes constituem uma importante ferramenta na determinação da susceptibilidade dos organismos aos contaminantes. O uso de biomonitores para estabelecer variações geográficas e espaciais na concentração biodisponível de elementos traço é atualmente bem estabelecida. Porém, os testes de toxicidade não podem prever o destino desses contaminantes nos ecossistemas. Estes testes podem avaliar a toxicidade relativa de diversos agentes químicos para uma ou diversas espécies, e a sensibilidade dessas espécies ao agente tóxico. São importantes ainda na determinação de concentrações seguras de agentes químicos para a preservação da vida aquática e para a qualidade das águas e sedimentos (ZAGATTO, 1999).

Os organismos mais utilizados na avaliação da toxicidade de substâncias na água são as algas e o zooplâncton. As algas, através da produção primária, são a base de diversas cadeias alimentares, e o zooplâncton constitui o elo entre os produtores primários e consumidores, além de influenciar a reciclagem de nutrientes e outros elementos nos ecossistemas (RAINBOW \& PHILIPS, 1993).

\section{2- Micro e mesocosmos}

Experimentos de laboratório podem simplificar a real situação do ambiente, uma vez que a exposição e as interações ecológicas podem ser muito diferentes. Neste sentido, os experimentos em mesocosmos permitem o estudo dos efeitos de contaminantes sobre os organismos e comunidades sob condições semi naturais, simuladas e controladas.

Comparado com testes com uma única espécie, o uso de mesocosmos permite a previsão do destino e do efeito de poluentes sob condições semelhantes às naturais, incluindo a presença de sedimentos, animais e plantas de ocorrência natural (JAK et al., 1996). Não apenas efeitos toxicológicos podem ser observados e quantificados, mas também as implicações ecológicas indiretas podem tornar-se aparentes. Assim, sistemas com diferentes graus de complexidade têm sido utilizados, sendo que aqueles contendo mais de um nível trófico apresentam uma maior semelhança com as situações de campo, mas implicam em uma maior variabilidade entre as réplicas.

O tamanho do mesocosmos limita a possível complexidade de cadeias alimentares e o grau de efeitos diretos e indiretos que podem ser testados. Os sistemas utilizados variam em tamanho, disposição física e complexidade biológica, assim como a duração da exposição (TODD \& JOSEPHSON, 1996). Com o aumento do tamanho, aumenta também a semelhança entre o mesocosmos e o ambiente 
natural, bem como a possibilidade de investigação dos ciclos de vida dos organismos e efeitos indiretos em níveis tróficos superiores .

Recentemente, diversos experimentos têm sido realizados em mesocosmos (CAQUET, 1996; JAK et al., 1996; MUNGER et al. 1999; TODD \& JOSEPHSON, 1996, entre outros). Grande parte desses estudos é referente à distribuição e ciclagem de metais e poluentes orgânicos, e ao comportamento das comunidades em presença desses estressores.

\section{3- CRITÉRIOS DE QUALIDADE DE ÁGUA}

A caracterização dos impactos de metais sobre os ecossistemas aquáticos usualmente envolve experimentos em laboratório sob condições controladas, ou seja, testes de toxicidade, e em menor extensão observações de campo sobre os impactos destes contaminantes sobre populações nativas do sistema. A avaliação de risco ecológico tradicionalmente baseia-se na comparação de "concentrações de efeito não previsto", derivadas de testes de laboratório, com "concentrações ambientais previstas". As "concentrações de efeito não previsto" têm sido derivadas de testes de laboratório uniespecíficos, cujos resultados são utilizados para estabelecer a sensibilidade de espécies a um metal em particular; assumindo que valores derivados de testes com uma única espécie representam a sensibilidade das espécies de uma comunidade aquática genérica e diversa.

Critérios de qualidade de água têm sido largamente baseados em testes de toxicidade nos quais os organismos são expostos aos metais dissolvidos, freqüentemente em concentrações que excedem em diversas ordens de magnitude aquelas que são encontradas em águas contaminadas, assumindo que os impactos ecológicos podem ser extrapolados de avaliações de toxicidade aguda (FISHER \& HOOK, 2002).

A regulamentação de substâncias tóxicas para proteção da vida aquática é conduzida utilizando dois tipos de critérios: narrativos e numéricos. Os critérios narrativos definem as "quantidades tóxicas", que se baseiam em uma porcentagem da CL 50 específica para um metal e uma espécie. Por exemplo, cádmio em águas superficiais pode ser considerado tóxico em concentrações maiores que 1/10 da CL 50 96 hs para uma espécie sensível, como Daphnia magna (FORAN \& FINK, 1993). Critérios numéricos de qualidade de água, como os definidos no Clean Water Act, nos Estados Unidos, foram desenvolvidos para substituir os critérios narrativos, criando um valor numérico específico para cada químico com a finalidade de proteção da vida 
aquática, e o conjunto de valores numéricos resulta nos critérios de qualidade de água.

Dados da toxicidade adquiridos a partir de testes agudos e crônicos realizados em laboratório com uma única espécie são utilizados para prevenir impactos inaceitáveis dos agentes químicos a curto ou longo prazo sobre espécies importantes, como peixes, invertebrados bentônicos e zooplâncton. No desenvolvimento destes critérios, devem ser utilizados, no mínimo, oito diferentes famílias de organismos aquáticos, como peixes, crustáceos planctônicos e bentônicos, insetos, moluscos, etc. Os valores finais, agudo e crônico, são valores numéricos desenvolvidos a partir dos dados de toxicidade disponíveis, indicando a toxicidade de uma substância definida via exposições a curto prazo e é uma estimativa da concentração do químico correspondente à probabilidade cumulativa de 0,05 nos valores de toxicidade aguda disponíveis na base de dados. Este valor deve proteger $95 \%$ das espécies na base de dados; ou seja, o valor final agudo deve ser maior que $5 \%$ da toxicidade aguda média e menor que $95 \%$ deste valor. O valor agudo médio é determinado após manipulação dos dados de toxicidade obtidos para cada espécie testada. Estas manipulações podem ser avaliadas em FORAN \& FINK (1993).

A toxicidade de algumas substâncias também é relacionada às características químicas e físicas do corpo d'água, como por exemplo, a dureza para a toxicidade de $\mathrm{Pb}, \mathrm{Ni}, \mathrm{Ag}$ e $\mathrm{Cu}$. A influência destas variáveis sobre a toxicidade da substância é determinada através de análise de regressão entre as variáveis e os dados de toxicidade. A partir destes dados, são definidos valores numéricos de critérios para máxima concentração e critérios para concentração contínua (FORAN \& FINK, op cit.)

\section{4- AVALIAÇÃO DE RISCO ECOLÓGICO}

A avaliação de risco ecológico é basicamente um processo que avalia o potencial da ocorrência de efeitos adversos, como o resultado da exposição à contaminantes ou outros estressores. Tal avaliação produz métodos sistemáticos de agrupar, organizar e avaliar a informação científica para dar suporte às decisões de manejo, reconhecendo, considerando e reportando incertezas na estimativa dos efeitos adversos dos estressores (CHAPMAN, 2002).

A avaliação de risco ecológico é definida como o procedimento pelo qual os reais efeitos de poluentes e atividades antropogênicas nos ecossistemas são estimados com um conhecido grau de certeza, utilizando metodologias específicas. Efeitos deletérios em populações são dificilmente detectáveis em organismos, uma vez que esses efeitos tendem a se manifestar unicamente após longos período de 
exposição. As respostas ao estresse causado por um poluente num sistema biológico segue uma sequência que se inicia a nível molecular e pode alcançar o ecossistema, passando antes pelos níveis celulares, órgãos, organismos, populações e comunidades (VAN DER OOST, BEYER \& VERMEULEN, 2003).

A utilização dos testes de toxicidade com uma única espécie tem seu mérito na avaliação de risco ecológico como uma avaliação preliminar, porém recentes avanços nas ciências ambientais não foram incorporados aos procedimentos de avaliação de risco ecológico. Esta aproximação, baseada em testes de toxicidade, não leva em conta todas as fases de assimilação e considera a toxicidade aguda, enquanto efeitos subletais podem ocorrer em concentrações muito menores e não afetar as populações em testes agudos, uma vez que as concentrações que causam efeitos letais e subletais podem variar de mais de uma ordem de magnitude (FISHER \& HOOK, 2002).

A extrapolação de valores de toxicidade baseados em testes de laboratório com uma única espécie para valores de proteção ambiental assume que os metais afetam as espécies alvo diretamente, pela exposição pela água ou pela alimentação. Também é possível que os efeitos de metais sobre organismos consumidores se dê indiretamente, através da cadeia trófica. Organismos consumidores podem exibir efeitos fisiológicos e reprodutivos relacionados a nutrição inadequada, em função de efeitos tóxicos sobre suas presas usuais (CAMPBELL et al., 2003). Como exemplo, metais acumulados em copépodos através da transferência trófica depositam-se em tecidos internos, e podem diminuir a capacidade reprodutiva destes organismos mesmo em concentrações inferiores aos valores background (FISHER \& HOOK, 2002). Esses tipos de efeitos não são considerados nos testes de toxicidade com organismos aquáticos.

Uma avaliação de risco ecológico consiste basicamente de quatro componentes seqüenciais. A primeira fase é a formulação do problema/ identificação do risco, onde as metas e procedimentos são definidos e a informação disponível é sumarizada. A utilização da ecotoxicologia ambiental pode ser apropriada nesta fase da avaliação, assim como previsões baseadas em modelos. A fase 2 corresponde a avaliação da exposição e identifica as concentrações de exposição (emissões, velocidades, vias), a biodisponibilidade e espécies/populações sensíveis, e requer informação e conhecimento ecológico. A fase 3 é a avaliação dos efeitos, sendo que nesta fase se identifica a natureza/caráter do risco, e é a fase onde a toxicologia ecológica é requerida para uma correta avaliação com mínima incerteza, através da utilização de ferramentas relacionadas a causa e efeito, como a identificação e avaliação da toxicidade (TIE). Técnicas de química analítica adequadas são 
requeridas durante todo o processo, e em particular nos estágios avançados da avaliação de risco, para a compreensão da química do sedimentos e nos testes de toxicidade e bioacumulação realizados em laboratório. Nesta fase também deve ser considerada a variabilidade natural, uma vez que sistemas naturais freqüentemente não obedecem as condições de equilíbrio previstas no planejamento do estudo. $O$ estágio final da avaliação de risco ecológico, a caracterização do risco, traz toda a informação dos estágios anteriores juntas para estimar o risco baseado na exposição comparada a efeitos e sumariza as incertezas principais (CHAPMAN, 2002).

Considerando a abordagem essencial desta pesquisa em relação à avaliação de risco, verifica-se que os experimentos em micro e mesocosmos introduzem a possibilidade da observação dos efeitos de contaminantes sobre as relações entre as espécies e entre diferentes níveis tróficos, permitindo a avaliação de potenciais danos ecológicos indiretos. Permitem, ainda, o estudo das relações entre os compartimentos bióticos e abióticos, além de contar com efeitos naturais como insolação, vento e precipitação, os quais são impossíveis de serem considerados nos testes de toxicidade realizados em laboratório. Além disso, estes experimentos contam com espécies de ocorrência natural nos ecossistemas, o que muitas vezes não ocorre quando são utilizados testes de toxicidade laboratoriais.

Outro fator a ser considerado é que, dependendo da duração do experimento, não apenas os efeitos tóxicos sobre as características estruturais e funcionais do sistema podem ser avaliados, mas também a restauração do sistema após a interrupção da introdução do agente tóxico.

A utilização de micro e mesocosmos têm sido sugerida como uma alternativa ou uma complementação na avaliação de risco, apesar do custo envolvido e da dificuldade na utilização de réplicas, pois estes estudos oferecem dados altamente relevantes ecologicamente e podem ser utilizados para validar e melhorar modelos teóricos (CAQUET et al., 1996).

\section{5- JUSTIFICATIVA}

Muitos trabalhos têm sido apresentados reportando a contaminação dos ecossistemas aquáticos por metais pesados, tanto nos países desenvolvidos como naqueles em desenvolvimento. Trabalhos realizados no Brasil revelam os problemas de contaminação tanto na região costeira (SILVA et al., 1996; PERIN et al., 1997; LACERDA, 1998) como nas águas continentais (AVELAR et al., 1997; CARVALHO et al., 1999; JORDÃO et al., 1999). Nesses trabalhos têm sido reportada a contaminação dos ecossistemas aquáticos principalmente por $\mathrm{Cd}, \mathrm{Cr}, \mathrm{Cu}, \mathrm{Hg}, \mathrm{Ni}$ e Pb (Tabela 01). 
As fontes de contaminação por metais traço mais comuns são os efluentes industriais, pesticidas, resíduos de mineração e processamento de produtos minerais e resíduos de curtume, além dos esgotos domésticos e resíduos sólidos.

A contaminação por $\mathrm{Cr}$ e $\mathrm{Cu}$ têm sido atribuída às mais diversas fontes, e ocorrido em ecossistemas brasileiros de diferentes regiões, como nos estados de São Paulo (BEVILACQUA; 1996), Rio de Janeiro (CARVALHO et al., op. cit) e Minas Gerais (JORDÃO et al., op. cit.).

Tabela 01: Alguns exemplos da contaminação por metais traço em ecossistemas brasileiros.

\begin{tabular}{|l|l|l|l|}
\hline \hline \multicolumn{1}{|c|}{ Local } & \multicolumn{1}{|c|}{ Metais } & \multicolumn{1}{c|}{ Fonte } & \multicolumn{1}{c|}{ Autor } \\
\hline \hline Baixo Jacuí - RS & $\begin{array}{l}\mathrm{Fe}, \mathrm{Cu}, \mathrm{Co}, \\
\mathrm{Cr} \text { e } \mathrm{Ni}\end{array}$ & $\begin{array}{l}\text { Processamento de } \\
\text { carvão e aço }\end{array}$ & TEIXEIRA et al., 1997 \\
\hline $\begin{array}{l}\text { Conselheiro Lafaiete - } \\
\text { MG }\end{array}$ & $\begin{array}{l}\mathrm{Mn}, \mathrm{Fe}, \mathrm{Cd}, \\
\mathrm{Cu}, \mathrm{Ni} \text { e Cr }\end{array}$ & Mineração & JORDÃO et al., 1999 \\
\hline Jacarepagua - RJ & $\mathrm{Zn}$ & & FERNANDES, 1997 \\
\hline MG & $\mathrm{Cr}$ & JORDÃO et al., 1999 \\
\hline Rio dos Sinos - RS & $\begin{array}{l}\mathrm{Cu}, \mathrm{Zn}, \mathrm{Cr}, \\
\mathrm{Cd}, \mathrm{Pb}\end{array}$ & $\begin{array}{l}\text { Efluentes } \\
\text { Industriais }\end{array}$ & HATJE et al., 1998 \\
\hline Rio Poxim - SE & $\mathrm{Ni}, \mathrm{Pb}$ e Zn & & SANTOS-FILHA \& SOUSA, 1996 \\
\hline $\begin{array}{l}\text { Rio Sapucaí Mirim - } \\
\text { SP }\end{array}$ & $\mathrm{Cr}, \mathrm{Zn}$ & $\begin{array}{l}\text { Efluentes } \\
\text { Industriais }\end{array}$ & AVELAR et al., 1997 \\
\hline Rio Tietê - SP & $\mathrm{Cr}, \mathrm{Cd}, \mathrm{Cu}$ & & REVILACQUA, 1996 \\
\hline $\begin{array}{l}\text { Sistema Acari - São } \\
\text { J. de Meriti - RJ }\end{array}$ & $\begin{array}{l}\mathrm{Hg}, \mathrm{Cd}, \mathrm{Pb}, \\
\mathrm{Zn}, \mathrm{Cu} \text { e Cr }\end{array}$ & & \\
\hline \hline
\end{tabular}

Com base nesses trabalhos foi feita a escolha dos metais a serem estudados ( $\mathrm{Cr}$ e $\mathrm{Cu}$ ). Além de representarem dois dos contaminantes inorgânicos mais comuns nos trabalhos citados, apresentam comportamento diferente nos organismos e, consequentemente, nos ecossistemas, uma vez que $\mathrm{Cr}$ é um elemento tóxico e Cu um micronutriente essencial, porém tóxico em altas concentrações (SUNDA \& HUNTSMANN, 1998).

Apesar de diversos trabalhos demonstrarem as elevadas concentrações de metais em ecossistemas aquáticos, pouco se sabe sobre as interações entre os compartimentos e os organismos. Nesse sentido, esse trabalho visa contribuir para um melhor conhecimento dos efeitos dos metais nos ecossistemas aquáticos e das interações entre os organismos .

\section{1- Cromo}

Cromo é um metal de transição localizado no grupo VI - B da tabela periódica. Apesar de poder existir sob diversos estados de oxidação, as formas mais comuns e estáveis são a trivalente $\mathrm{Cr}$ (III) e a hexavalente (VI), que apresentam propriedades químicas diferentes, sendo que $\mathrm{Cr}(\mathrm{VI})$ é considerada a forma mais tóxica e ocorre 
usualmente associado ao oxigênio como íons cromato $\left(\mathrm{CrO}_{4}{ }^{2-}\right)$ ou dicromato $\left(\mathrm{Cr}_{2} \mathrm{O}_{7}{ }^{2-}\right)$. Em contraste, $\mathrm{Cr}$ (III), na forma de óxidos, hidróxidos ou sulfatos é muito menos móvel e existe principalmente ligado a matéria orgânica do solo e dos ambientes aquáticos (CERVANTES et al., 2001). Há uma virtual ausência de cromo em organismos vivos (com exceção de moléculas de RNA e niacina), provavelmente devido à baixa estabilidade de seus complexos protéicos (MOORE \& RAMAMMORTHY, 1984).

$\mathrm{O}$ cromo é obtido principalmente da mineração de cromita $\left(\mathrm{FeOCr}_{2} \mathrm{O}_{3}\right)$, que apresenta por volta de $68 \%$ de $\mathrm{Cr}_{2} \mathrm{O}_{3}$. A utilização do cromo é documentada desde 1800, quando na França, Alemanha e Inglaterra era utilizado como pigmento, estando ainda presente em processos de coloração na indústria têxtil e em processos de curtimento de couro. A grande importância do cromo na indústria metalúrgica iniciouse por volta de 1910-1915, e desde esta época o consumo deste metal tem demonstrado contínuo crescimento. Seus principais usos são na indústria de refratários e produtos químicos, além da indústria metalúrgica (MOORE \& RAMAMMORTHY, op cit.).

$\mathrm{Na}$ metalurgia seu uso é principalmente na confecção de ligas com ferro, aumentando a resistência à corrosão, oxidação e resistência à tensão à altas temperaturas. Estas ligas de ferro são utilizadas principalmente na fabricação de aço inoxidável e aços resistentes à altas temperaturas, que são empregadas em ambientes corrosivos, em processos petroquímicos, partes de turbinas e forros, ferramentas mecânicas, etc. A cromita é utilizada geralmente junto à magnesita na confecção de tijolos refratários, armas e em fornos de alta temperatura (MOORE \& RAMAMMORTHY, op cit.).

$\mathrm{Na}$ indústria química é geralmente utilizado o dicromato de sódio. Os compostos de $\mathrm{Cr}$ são utilizados como mordentes (substâncias que aderem os pigmentos) e pigmentos na indústria têxtil; agentes de curtimento na indústria do couro; como oxidantes e catalisadores na manufatura de produtos como a sacarina; na purificação de óleos, gorduras e outros produtos químicos e como agente desumidificados em colas, tintas e géis (MOORE \& RAMAMMORTHY, op cit.).

As principais emissões de $\mathrm{Cr}$ em águas superficiais ocorrem pelos processos de finalização metálica, como cromagem e galvanoplastia. Emissões descontroladas têm grande potencial para a contaminação de ambientes de água doce com o Cr VI, sua forma mais tóxica. Outras formas de emissão menos importantes são a recirculação de água de resfriamento e produtos químicos de lavanderia. Fontes de $\mathrm{Cr}$ (III) incluem efluentes de curtimento de couro e tingimento têxtil. Outras fontes de compostos de cromo são: fitas magnéticas, cimento, papel, em sínteses químicas e orgânicas, processamento fotoquímico e tratamento de água industrial. É também 
utilizado contra a presença de lodos formados por bactérias e fungos em águas de processamento de aquecimento em cervejarias. Seus compostos ainda são utilizados como adstringentes e anti-sépticos na medicina (MOORE \& RAMAMMORTHY, 1984). Cromo está sempre presente nos efluentes de curtumes e galvanoplastias, além de indústrias de tinta, que utilizam seu óxido. Está presente também como poluição difusa devido à sua utilização em ligas e baterias.

Estudos sugerem a bioacumulação do $\mathrm{Cr}^{3+}$ na biomassa planctônica, que constitui um importante elo na transferência deste elemento (BARRETO, 1994). Efeitos crônicos da exposição ao cromo incluem decréscimo no crescimento e tamanho do corpo, podendo influenciar também as taxas de reprodução e sobrevivência da prole em organismos aquáticos. O Cr também tende a se acumular em sedimentos e materiais sobrenadantes, porém, sob certas condições ambientais, pode ser solubilizado e retornar ao meio. Cromo apresenta-se, na maioria das vezes, na forma trivalente, que é cerca de 100 vezes menos tóxica que a forma hexavalente, mas, nessa forma, é muito mais reativo biológicamente, ligando-se à ácidos nucléicos e iniciando o processo de carcinogênese. A forma hexavalente é corrosiva e causa úlceras na passagem nasal e na pele, além de induzir reações de hipersensibilidade cutânea em seres humanos (LU, 1996).

\section{2- Cobre}

Cobre é utilizado amplamente como fungicida na agricultura e como pigmento para a fabricação de tintas, estando sempre presente em efluentes industriais e domésticos. Apesar de ser essencial à todos os organismos é altamente tóxico à algas, fungos, sementes de plantas e invertebrados, sendo moderadamente tóxico aos mamíferos (BOWEN, 1966). Cobre é também freqüentemente utilizado como algicida em reservatórios (CALEFFI, 2000).

Cobre é um metal macio e flexível com condutividade elétrica e térmica alta. Pertence à terceira série dos metais de transição, apresentando grande variação em suas propriedades espectrais, magnéticas e nos estados de oxidação. Os estados de oxidação mais comuns são (I), (II) e (III), sendo o $\mathrm{Cu}^{2+}$ o mais comum e $\mathrm{Cu}^{+}$típico de ácidos fracos (MOORE \& RAMAMMORTHY, 1984).

O cobre é amplamente distribuído na natureza em estado livre e em sulfitos, arsenitos, cloretos e carbonatos. Em ambientes aquáticos o cobre ocorre nas formas solúvel, particulada e coloidal, sendo as últimas mais freqüentes. A fração solúvel pode conter tanto o íon livre quanto o cobre complexado a ligantes orgânicos e inorgânicos. Sua especiação em águas naturais é determinadas por características 
físicas, químicas, hidrodinâmicas e biológicas do ambiente (MOORE \& RAMAMMORTHY, op cit).

Seu transporte se dá principalmente pela adsorção nos sedimentos. As taxas de adsorção variam de acordo com o tipo de sedimento, pH, cátions competidores, presença de ligantes e óxidos de Fe e Mn. A desorção, por sua vez, também depende do $\mathrm{pH}$, salinidade e presença de compostos quelantes naturais ou artificiais (SALOMONS \& FORSTNER, 1984).

Cobre têm sido identificado em diversas proteínas, como a hemocianina. Cu e Fe estiveram envolvidos na seleção natural de células aeróbias e na evolução de metaloproteínas e metaloenzimas, sendo assim considerado como metal essencial em baixas concentrações em praticamente todos os organismos vivos (MOORE \& RAMAMMORTHY, 1984).

O fluxo total de cobre para a atmosfera é de aproximadamente $75000 \mathrm{~m}^{3}$ por ano, dos quais 5000 a 13000 são depositados nos oceanos por vias secas ou úmidas. Depósitos hidrotermais são responsáveis por $2 / 3$ de todas as reservas mundiais de $\mathrm{Cu}$, e estão localizadas principalmente às margens do Oceano Pacífico e nos cinturões de montanhas no sudeste europeu e Ásia Central. Certas áreas na Austrália e na Sibéria possuem também grandes depósitos de cobre. As principais fontes naturais de cobre são o spray marinho, a vegetação, queimadas de florestas e poeira. O tempo de residência do cobre nos oceanos varia de 1500 a 78000 anos, dependendo da concentração (MOORE \& RAMAMMORTHY, op cit.).

Os resíduos de mineração e a poeira são a principal fonte sólida de $\mathrm{Cu}$, seguida pela produção de fertilizantes e esgotos domésticos e industriais, que constituem a principal via de entrada do $\mathrm{Cu}$ nos sistemas aquáticos. Propriedades como maleabilidade, ductilidade, condutividade e resistência à corrosão fazem do cobre um metal amplamente utilizado nas indústrias elétricas, de construção e automotivas, consumindo cerca de $50 \%$ do cobre produzido (MOORE \& RAMAMMORTHY, op cit.).

As taxas de absorção de Cu por organismos planctônicos dependem das concentrações de cobre na água, assim como a absorção por organismos bentônicos depende das concentrações no sedimento. Dependendo das concentrações de exposição, Cu pode ser altamente tóxico aos organismos aquáticos, principalmente de água doce. Cobre pode ser acumulado em níveis tróficos mais altos, no entanto poucos estudos sobre a transferência trófica deste metal são reportados (CAMPBELL et al., 1988). 


\section{6- OBJETIVOS}

O objetivo geral deste trabalho foi avaliar os efeitos e a distribuição dos metais Cr e Cu nos ecossistemas aquáticos através de testes de toxicidade com espécies de diferentes níveis tróficos (Selenastrum capricornutum, alga; Daphnia similis, zooplâncton; Ceriodaphnia dubia, zooplâncton; Chironomus xanthus, inseto; Oreochromis niloticus, peixe e Pistia stratiotes, macrófita) e experimentos em micro e mesocosmos utilizando os componentes da represa do Lobo.

\section{7- REFERÊNCIAS BIBLIOGRÁFICAS}

AVELAR, W. E. P.; ROMA, F.; LONGO, L. D. (1997). Heavy metal pollution in basin of Sapucaí Mirim River (Northeast of São Paulo State, Brazil) by hide industry. Arquivos de Biologia e Tecnologia 40(1) 205- 212.

BARRETO, A. S. (1994). "Assimilação de cromo trivalente nas biomassas nanoplanctônicas e microplanctônicas e sua quantificação no sedimento e sobrenadante: experimento em microcosmos". Dissertação de mestrado. Escola de Engenharia de São Carlos, USP, 171p. São Carlos.

BEVILÁQUA, J. E. (1996). "Estudo sobre a caracterização e a estabilidade dos sedimentos do rio Tietê, SP". Tese de doutoramento, Instituto de Química, USP, 171 p. São Paulo.

BOWEN, H. J. M. (1966). "Trace metals in biochemistry". Academic Press. 241p. London.

BURTON, G. A. (1991). Assessing the toxicity of freshwater sediments. Environmental Toxicology and Chemistry, 10: 1585-1627.

CAIRNS JR, J.; NIEDERLEHNER, B. R.; BIDWELL, J. R. (1998). Ecological toxicity testing. In: "Encyclopedia of Environmental Analysis and Remediation". Meyers, R. A. (ed). John Wiley \& Sons, Inc.

CALEFFI, S. (2000).Impacto do uso de sulfato de cobre sobre o zooplâncton na represa de Guarapiranga. In: ESPÍNDOLA, E. L. G., BOTTA-PASCHOAL, C. M. R., ROCHA, O., BOHRER, M. B. C., L, OLIVEIRA NETO, A. "Ecotoxicologia: 
Perspectivas para o Século XXI". Editora Rima, São Carlos, p. 3-13.

CALMANO, W.; HONG, J.; FORSTNER, U. (1993). Binding and mobilization of heavy metal in contaminated sediments affected by $\mathrm{pH}$ and redox potential. Water Science Technology, 28 (8-9) : 223-235.

CAMPBELL, P. G. C.; HONTELA, A.; RASMUSSEN, J. B.; GIGUERE, A.; GRAVEL, A.; KRAEMER, L.; KOVESCES, J.; LACROIX, A.; LEVESQUE, H.; SHERWOOD, G. (2003). Differentiating between direct (physiological) and food chain mediated (bioenergetic) effects on fish in metal impacted lakes. Human and Ecologiacl Risk Assessment, 9 (4) : 847-866.

CAQUET, T.; LAGADIC, L.; JONOT, O.; BATURO, W.; KILANDA, M.; SIMON, P.; LE BRAS, S.; ECHAUBARD, M.; RAMADE, F. (1996). Outdoor experimental ponds (mesocosms) designed for long-term ecotoxicological studies in aquatic environments. Ecotoxicology and Environmental Safety, 34: 125- 133.

CARRAL, E.; VILLARES, R.; PUENTE, X; CABALLEIRA, A. (1995). Influence of watershed lithology on heavy metal levels in estuarine sediments and organisms in Galicia (North-West Spain). Marine Pollution Bulletin, 30 (9), pp. 604-608.

CARVAlHo, C. E. V.; OVAlle, A. R.C.; REZENDE, C. E.; MOLISANI, M. M.; SALOMÃO, M. S. M. B.; LACERDA, L. D. (1999). Seasonal variation of particulate heavy metals in the Lower Paraíba do sul river, R. J., Brazil. Environmental Geology, 37 (4) : 297-302.

CERVANTES, C.; CAMPOS-GARCÍA, J.; DEVARS, S.; GUITIÉRREZ-CORONA, F.; LOZA-TAVERA, H.; TORRES-GUZMÁN, J.; MORENO-SANCHÉZ, R. (2001). Interactions of chromium with microoganisms and plants. FEMS Microbiology reviews $25,335-347$.

CHAPMAN, P. M. (2002). Integrating toxicology and ecology: putting the "eco" into ecotoxicology. Marine Pollution Bulletin, 44: 7-15.

CHASIN, A. M.; PEDROSO, M. F. M. (2003).O estudo da toxicologia. In: AZEVEDO, F. A.; CHASIN, A. M. As bases toxicológicas da ecotoxicologia. Eds Rima/ Intertox. pp. 126. São Carlos. 
CHUAN, M. C; SHU, G. Y.; LIU, J. C. (1996). Solubility of heavy metals in a contaminated soil: effects of redox potential and $\mathrm{pH}$. Water, Air and Soil Pollution, 90: 543-556.

CONAMA - CONSELHO NACIONAL DO MEIO AMBIENTE. (1986). Resolução $n^{\circ}$ 020/86. 24 p. BRASIL.

DEBUSK, T. A.; LAUGHLIN JR, R. B.; SCHWARTZ, L. N. (1996). Retention and compartmentalization of lead and cadmium in wetland microcosms. Water Research, 30 (11) : 2707-2716.

ESTEVES. F. A. (1988)."Fundamentos de limnologia". FINEP. Ed. Interciência. Rio de Janeiro.

FERNADES, H. M. (1997). Heavy metal distribution in sediments ans ecological risk assessment: The role of diagenetic process in reducing metal toxicity in bottom sediments. Environmental Pollution 97: (3) 317-325.

FERNICOLA, N. A.G. G.; BOHRER-MOREL, M. B. C.; BAINY, A. D. (2003). Ecotoxicologia. In: AZEVEDO, F. A.; CHASIN, A. M. "As bases toxicológicas da ecotoxicologia". Eds Rima/ Intertox. pp. 221-244. São Carlos.

FISHER, N.; HOOK, S. E. (2002). Toxicology tests with aquatic animals need to consider the trophic transfer of metals. Toxicology, 181-182: 531-536.

FORAN, J. A.; FINK, L. E. (1993). "Regulating toxic substances in surface water". Lewis Publshers, 171p. Boca Raton.

FREEDMAN, B. (1995). "Environmental ecology - the ecological effects of pollution, disturbance and other stresses ". Chapter 3, p. 62-93. $2^{0}$ ed. Academic Press. San Diego.

GUSMÃO, L. F. M. (2004). "Efeitos do cobre e cromo na comunidade zooplanctônica: um estudo experimental em mesocosmos". Dissertação (Mestrado). Escola de engenharia de São Carlos. Universidade de São Paulo, 269 p. São Carlos. 
HATJE, V.; BIDONE, E. D.; MADDOCK, J. L. (1998). Estimation of the natural and anthropogenic componentsof heavy metal fluxes in fresh water Sinos river, Rio Grande do Sul State, South Brazil. Environmental Technology, 19: (5) 483-487.

JAK, R. G.; MAAS, J. L.; SCHOLTEN, M. C. T. (1996). Evaluation of laboratory derived toxic effect concentrations of a mixture of metals by testing fresh water plankton communities in enclosures. Water Research, 30 (5) 1215-1227.

JOP, K. M.; ASKEM, A. M.; FOSTER, R. B. (1995). Development of a water-effect ratio for copper, cadmium and lead for the Great Works river in Maine using Ceriodaphnia dubia and Salvelinus fontinalis Bull. Environ. Contam. Toxicol. 54, 29-35.

JORDÃO, C. P.; PEREIRA, J. L.; JHAM, G. N., BELLATO, C. R. (1999). Distribution of heavy metals in environmental samples near mining areas in Brazil . Environmental Technology, 20: (5) 489-498.

LACERDA, L. D. (1998). "Trace metals biogeochemistry and diffuse pollution in mangrove ecosystems". ISME Mangrove Ecosystems Occasional Papers $n^{\circ} 2.65 p$.

LOEZ, C. R.; TOPALIAN, M. L.; SALIBIAN, A. (1995). Effects of zinc on the structure and growth dynamics of a natural freshwater phytoplankton assemblage reared in the laboratory. Environmental Pollution, 88, 275-281.

LU, F. C. (1996). "Basic toxicology. Fundamentals, target organs and risk assessment". Ed. Taylor \& Francis, $3^{\circ}$ ed. Whashington.

MOORE, J. W.; RAMAMMORTHY, S. (1984). "Heavy metals in natural waters: applied monitoring and impact assessment". Springer-Verlag, New York, 268 p.

MUNGER, C.; HARE, LANDIS, TESSIER, A. (1999). Cadmium sources and exchange rates for Chaoborus larvae in nature. Limnol. Oceanogr. 44 (7) : 1763-1771.

OCHIAI. E. I. (1995). Toxicity of heavy metals and biological defense. Principles and applications in bioinorgânic chemistry - VII. Journal of Chemical Education, 72(6):479483. 
PERIN, G.; FABRIS, R.; MANENTE, S.; WAGENER, A. R.; HAMACHER, C.; SCOTTO, S. (1997). A five year study on the heavy metal pollution of Guanabara Bay sediments (Rio de Janeiro, Brazil) and evaluation of the metal bioavialability by means of geochemical speciation. Water Research , 31 (12) : 3017-3028.

PHILLIPS, D. J. H.; SEGAR, D. A. (1986). Use of bio-indicators in monitoring conservative contaminants: programme design imperatives. Marine Pollution Bulletin, 17: 10-17.

PLETTE, A. C. C.; NEDERLOF, M. M.; TEMMINGHOFF, E. J. M.; VAN RIEMSDIJK, W. H. (1999). Bioavailability of heavy metals in terrestrial and aquatic systems: a quantitative approach. Environmental Toxicology and Chemistry, 18 (9): 1882-1890.

POWELL, M. I.; WHITE, K. N. (1990). Heavy metal accumulation by Barnacles and its implications for their use as biological monitors. Marine Environmental Research 30: 91118.

RAINBOW, P. S. ; PHILIPS, D. J. H. (1993). Cosmopolitan biomonitors of trace metals. Marine Pollution Bulletin 26(11): 593-601.

REEVE, R. N. (1994). "Environmental Analysis" . ACOL. Ed. John Wiley \& Sons Ltd., West Sussex.

REGO, V. S.; PFEIfFER, W. C.; BARCElOS, C. C.; REZENDE, C. E.; MALM, O.; SOUZA, C. M. M. (1993). Heavy metal transport in the Acari- São João de Meriti River sistem, Brazil. Environmental Tecnology 14 (2): 167-174.

REID, J. W. (1985). Chave de identificação e lista de referências bibliográficas para as espécies continentais de vida livre da ordem Cyclopoida (Crustacea-Copepoda). Biol. Zool. 9:17-143.

REINFELDER, J. R.; FISHER, N. S.; LUOMA, S. N.; NICHOLS, J. W.; WANG, W. X. (1998). Trace element trophic tranfer in aquatic organisms: a critique of the kinetic model aproach. The Science of the Total Envirnonment, 219: 117-135.

REIS FILHO, R. W. (2004). "Avaliação ecotoxicológica do sedimento da represa do Lobo (SP) em mesocosmos submetidos aos metais cobre e cromo". Dissertação 
(Mestrado). Escola de Engenharia de São Carlos. Universidade de São Paulo, 114 p.. São Carlos.

SALOMONS, W.; FOSTNER, U. (1984). "Metals in the hydrocycle" . Springer-Verlag Berlin Heidelberg New York Tokyo, 349.

SANTOS FILHA; M. M. \& SOUSA, G. M. (1996). Metais Pesados na água intersticial do sedimento do estuário do rio Poxim (SE). Anais da $19^{\circ}$ Reunião Anual da Sociedade Brasileira de Química. AB-15. Poços de Caldas.

SHINE, J. P.; IKA, R. V. ; FORD, T. E. (1995). Multivariate statistical examination of spatial and temporal patterns of heavy metal contamination in New Bedford Harbor marine sediments. Env. Sci. Technol. (29),7, 1781-1788.

SILVA, M. R.; LAMOTTE, M.; DONARD, O. F. X.; SORIANO-SIERRA, E. J.; ROBERT, M. (1996). Metal contamination in surface sediments of mangroves, lagoons and southern bay in Florianópolis island. Environmental Technology, 17: 1035-1046.

STEGEMAN, J. J.; BROUWER, M.; RICHARD, T. D. G.; FORLIN, L. FOWLER, B. A.; SANDERS, B. M.; VAN VELD, P. A. (1992). Molecular responses to environmental contamination: enzime and protein systems as indicators of chemical exposure and effect. In: HUGETT, R. J.; KIMERLY, R. A.; MERHLE, P. M.; JR BERGMAN, H. L. (eds). "Biomarkers: biochemical, physiological and histological markers of anthropogenic stress". Lewis Publishers, Chelsea, MI, USA, pp. 235-335.

SUNDA, W. G.; HUNTSMAN, S. A. (1998). Processes regulating cellular metal accumulation and physiological effects: Phytoplankton as model systems. The Science of the Total Environment, 219 : 165-181.

TAM, N. F. Y.; LI, S. H.; CHEN, G. Z.; LI. M. S.; WONG, Y. S. (1995). Nutrients and heavy metal contamination of plants and sediments in Futian mangrove forest. Hydrobiologia, 295:149-158.

TAM, N. F. Y.; WONG, Y. S. (1995). Spatial and temporal variations of heavy metal contamination in mangrove swamp in Hong Kong. Marine Pollution Bulletin 31 (4-12): 254-261. 
TEIXEIRA, E. C.; SANCHEZ, J. D.; FERNANDES, I. D.; FORMOSO, M. L. L.; PEGORINI, M. H. D. (1997). Preliminary study of metals in sediments from areas influenced by coal processing and stell industry activities - Baixo Jacuí Region, RSBrasil Environmental Technology 18: (6) 581 - 591.

TODD, J.; JOSEPHSON, B. (1996). The design of living technologies for waste treatment. Ecological Engineering, 6: 109-136.

VAN DER OOST, R.; BEYER, J.; VERMEULEN, N. P. E. 2003. Fish bioaccumulation and biomarkers in environmental risk assesment: a review. Environmental Toxicology and Pharmacology 13: 57-149.

WILLIAMS, T. P.; BUBB, J. M.; LESTER, J. N. 1994. Metal accumulation within salt marsh environments: a review. Marine Pollution Bulletin, 28 (5):277-290.

ZAGATTO, P. A. (1999). "Mini-curso: ecotoxicologia aquática". VII Congresso Brasileiro de Limnologia, 124 p. Florianópolis. 
CAPÍTULO 2 - TESTES DE TOXICIDADE COM ORGANISMOS PLANCTÔNICOS, BENTÔNICOS, PEIXES E MACRÓFITAS AQUÁTICAS COM CROMO E COBRE 
SUMÁRIO

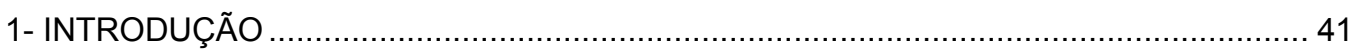

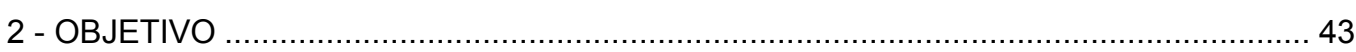

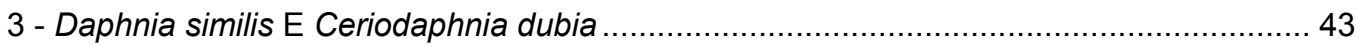

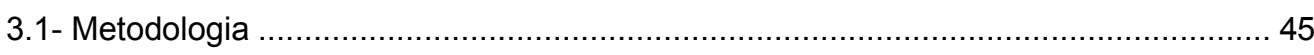

3.1.1- Cultivo e manutenção dos organismos teste................................................ 45

3.1.2- Controle de qualidade dos organismos-teste ................................................ 46

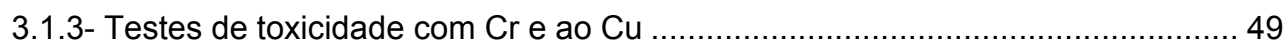

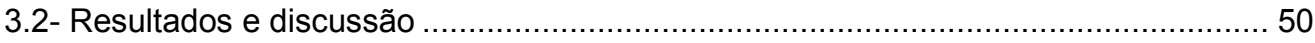

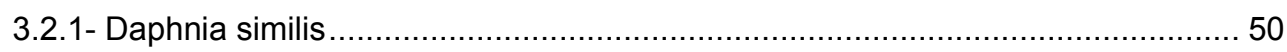

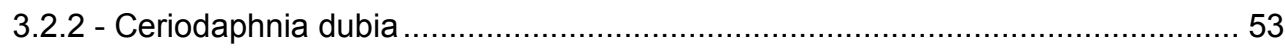

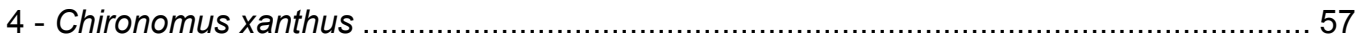

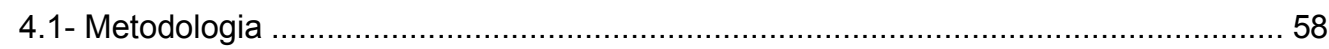

4.1.1- Cultivo e manutenção dos organismos-teste ................................................ 58

4.1.2- Controle de qualidade dos organismos-teste ................................................ 59

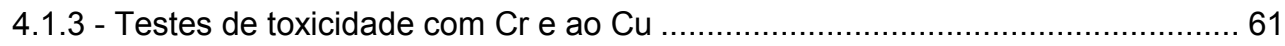

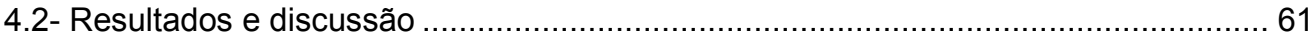

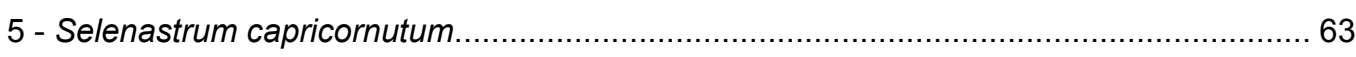

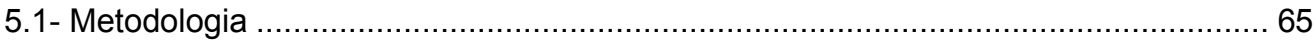

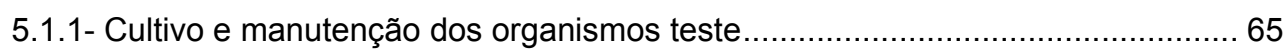

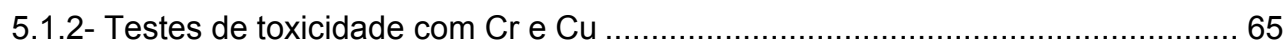

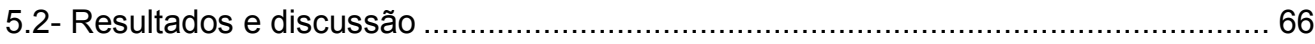

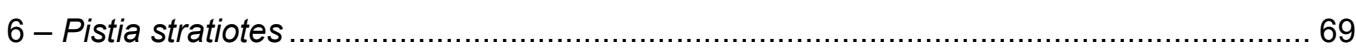

6.1 - Metodologia

6.1.1- Obtenção e manutenção dos organismos teste .............................................. 70

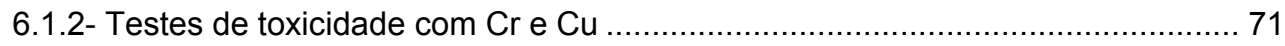

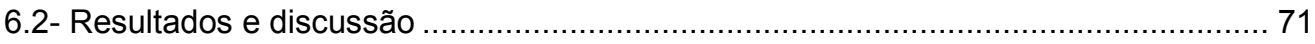

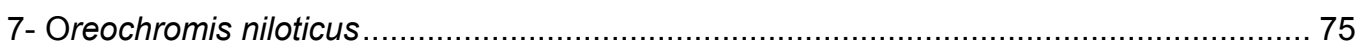

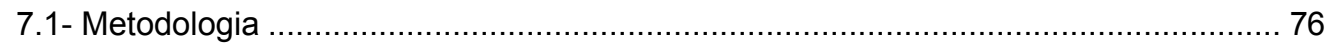

7.1.1- Obtenção e manutenção dos organismos teste ............................................ 76

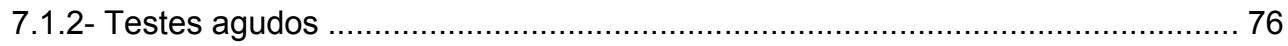

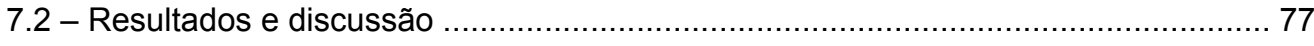

8 - CONSIDERAÇÕES SOBRE OS TESTES DE TOXICIDADE …................................... 79

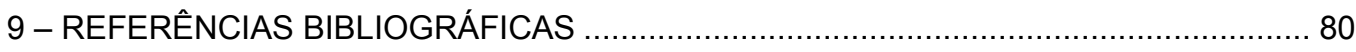




\section{LISTA DE FIGURAS}

Figura 01: Carta-controle da sensibilidade de $D$. similis ao $\mathrm{K}_{\mathrm{s}} \mathrm{Cr}_{2} \mathrm{O}_{7}$ no período de junho de 2001 a janeiro de 2002

Figura 02: Carta-controle da sensibilidade de C. dubia ao $\mathrm{NaCl}$ no período de maio de 2001 a fevereiro de 2002

Figura 03: Carta-controle da sensibilidade de $C$. xanthus ao $\mathrm{KCl}$ no período de janeiro de 2001 a setembro de 2002 .

Figura 04: Valores de CE/CL (I) 50 de $\mathrm{Cr}$ e $\mathrm{Cu}(\mathrm{mg} / \mathrm{L})$ determinados para cada uma das espécies estudadas (D. similis e C. dubia: 48 hs; $C$. xanthus, S. capricornutum, O. niloticus: $96 \mathrm{hs;}$ P. stratiotes: $168 \mathrm{hs})$....

\section{LISTA DE TABELAS}

Tabela 01: Carta controle da sensibilidade de $D$. similis ao dicromato de potássio.......... 47

Tabela 02: Carta controle da sensibilidade de C. dubia ao cloreto de sódio.

Tabela 03: Valores de CE (I) 50 48h obtidos nos testes de toxicidade com $\mathrm{Cr}$ com $D$. similis.

Tabela 04: Valores de CE (50) $\left(\mu \mathrm{g} \cdot \mathrm{L}^{-1} \mathrm{Cr}\right.$ ) para Daphnia determinados por diversos autores

Tabela 05: Valores de CE (I) 50 48h obtidos nos testes de toxicidade com Cu com $D$. similis

Tabela 06: Valores de CE (50) $\left(\mu \mathrm{g} \cdot \mathrm{L}^{-1} \mathrm{Cu}\right)$ para Daphnia determinados por diversos autores

Tabela 07: Valores de CE (I) 50 48h obtidos nos testes de toxicidade com Cr com C. dubia

Tabela 08: Valores de CE (50) $\left(\mu \mathrm{g} . \mathrm{L}^{-1} \mathrm{Cr}\right)$ para Ceriodaphnia determinados por diversos autores

Tabela 09: Valores de CE (I) 50 48h obtidos nos testes de toxicidade com Cu com C. dubia. 55

Tabela 11: Síntese dos resultados da análise de variância entre os valores de CE (50) de Cr e Cu determinados para D. similis e C. dubia 56

Tabela 12: Carta controle da sensibilidade de $C$. xanthus ao cloreto de potássio.... 60

Tabela 13: Valores de CE (I) 50 96h obtidos nos testes de toxicidade com $\mathrm{Cr}$ com $C$. xanthus. 62

Tabela 14: Valores de CE (I) 50 96h obtidos nos testes de toxicidade com Cu com C. xanthus

Tabela 15: Valores de CE (50) (mg. $\left.\mathrm{L}^{-1} \mathrm{Cu}\right)$ para Chironomidae determinados por diversos autores 
Tabela 16: Valores de CE (I) 50 96h obtidos nos testes de toxicidade com $\mathrm{Cr}$ com S. capricornutum. 66

Tabela 17: Valores de CE (I) 5096 obtidos nos testes de toxicidade com Cu com S. capricornutum.

Tabela 18: Valores de CE 50 determinados com culturas de $S$. capricornutum por diversos autores.

Tabela 19: Valores de CE 50 para compostos contendo Cu e Cr para diferentes espécies de algas 69

Tabela 20: Valores de CE(I) $50168\left(\mathrm{mg}^{-1} \mathrm{~L}^{-1}\right)$ hs obtidos nos testes de toxicidade com $\mathrm{Cr}$ com $P$. stratiotes. 72

Tabela 21: Valores de CE(I) $50168\left(\mathrm{mg}^{-\mathrm{L}^{-1}}\right)$ hs obtidos nos testes de toxicidade com Cu com $P$. stratiotes 73

Tabela 22: Síntese da análise de variância entre os valores de $\mathrm{CE}$ (50) de $\mathrm{Cr}$ e $\mathrm{Cu}$ determinados utilizando-se os diferentes parâmetros de efeito 74

Tabela 24: Valores de CE (I) 50 96h obtidos nos testes de toxicidade com $\mathrm{Cr}$ com $\mathrm{O}$. niloticus 77

Tabela 25: Valores de CE (I) 5096 hs Cu e Cr para diferentes espécies de peixes 78

Tabela 26: Valores de CE (I) 50 96h obtidos nos testes de toxicidade com Cu com O. niloticus 


\section{1- INTRODUÇÃO}

A avaliação da saúde ou o monitoramento de um determinado ambiente por meio da análise química de poluentes nos reportam a quantidade e a qualidade desses poluentes em diferentes compartimentos do sistema, mas não trazem informações a respeito dos efeitos sobre as comunidades existentes e sobre o funcionamento do sistema exposto à poluição. Neste sentido, os testes de toxicidade constituem-se em mecanismos para a compreensão dos efeitos de impactos sobre os compartimentos bióticos, utilizando-se organismos vivos que atuam como biosensores, e também, através dos resultados obtidos, podem ser previstos antecipadamente os impactos de um determinado poluente sobre a biota. Estes testes podem contribuir na avaliação da toxicidade relativa de diversos agentes químicos para uma ou diversas espécies e a sensibilidade dessas espécies ao agente tóxico, sendo ainda importantes na determinação de concentrações seguras de agentes químicos para a preservação da vida aquática e para a qualidade das águas e sedimentos (ZAGATTO, 1999).

O objetivo geral de um teste de toxicidade é a caracterização da resposta ecológica a uma determinada substância ou elemento químico. Os testes de toxicidade constituem-se basicamente da exposição de organismos aquáticos a substâncias potencialmente tóxicas, visando à observação e análise das respostas destes organismos ao contaminante testado. Os testes de toxicidade comumente usados são os testes agudos, de curta duração, e crônicos, de duração mais longa, podendo incluir todo o ciclo de vida do organismo. Em ambos os casos, efeitos letais e subletais da substância tóxica sobre os organismos podem ser avaliados (CAIRNS et al., 1998).

Apesar da avaliação dos efeitos das substâncias químicas realizada sob condições de campo ser mais realística, a avaliação do risco ambiental é mais freqüentemente baseada em testes de toxicidade com uma única espécie. Tais avaliações são conduzidas pela comparação das concentrações de exposição ambientais de um químico com sua concentração de não efeito estimada para o ecossistema Esta concentração de não efeito para o ecossistema é tipicamente extrapolada dos dados de testes de toxicidade com uma única espécie (VERSTEEG et al., 1997).

Em muitos casos, testes de toxicidade são conduzidos com organismos que podem ser facilmente obtidos, cultivados e testados, sendo a relevância ecológica destas espécies uma consideração secundária (CHAPMAN, 1995). Os organismos mais utilizados na avaliação da toxicidade de substâncias são as algas e o zooplâncton. As algas, através da produção primária, representam a base de diversas cadeias alimentares, e o zooplâncton constitui o elo entre os produtores primários e 
consumidores, além de influenciar a reciclagem de nutrientes e outros elementos nos ecossistemas (RAINBOW \& PHILIPS, 1993). Uma grande variedade de organismos aquáticos são comumente usados em testes de toxicidade, incluindo invertebrados (espécies de Daphnia, Gammarus, Brachionus e Ceriodaphnia), peixes (Poecilia sp., Leponis macrochirus, Brachdanio rerio e Oncorhyncus mykiss) e algas (Selenastrum, Chlorella, Microcystis e Navicula).

A seleção de espécies para testes de laboratório é feita com base em considerações tanto ecológicas quanto práticas. Organizações reguladoras oficiais (U.S. E.P.A., OECD, E. C.), juntamente com industriais, acadêmicas e de pesquisa têm desenvolvido e harmonizado métodos em cooperação com organizações de padronização nacionais (ABNT, CETESB, DIN, ASTM) e internacionais (ISO, CEN) (VERSTEEG et al., 1997). Uma combinação de critérios, incluindo considerações ecológicas, metodológicas e prático/econômicas, é usada na seleção de espécies para estudos de toxicidade em laboratório.

Os resultados de testes de toxicidade aquática são freqüentemente aplicados na avaliação do risco imposto pela liberação de compostos nos ambientes aquáticos. Assim, resultados de testes de toxicidade são idealmente baseados em espécies aquáticas importantes as quais são relativamente sensíveis aos xenobióticos e apresentam ampla distribuição. Espécies teste ainda devem ser adequadas para testes em laboratório com métodos apropriados, que apresentem uma variabilidade aceitável para os endpoints, relevantes biológicamente e eficiência aceitável nos testes intra e inter laboratoriais (VERSTEEG op cit.).

Neste trabalho, foi avaliada a sensibilidade aos metais $\mathrm{Cr}$ e $\mathrm{Cu}$ por diversos organismos, pertencentes a níveis tróficos diferentes, sendo algumas espécies padronizadas para testes em laboratório (Selenastrum capricornutum, Daphnia similis e Ceriodaphnia dubia). Outras espécies testadas foram provenientes da represa do Lobo e para estas novas metodologias foram desenvolvidas (Pistia stratiotes) ou adaptadas de testes padronizados com outras espécies (Oreochromis niloticus), além de Chironomus xanthus, que ainda não foi padronizado, mas segue a metodologia de C. tentans, de acordo com FONSECA (1997). Os testes foram realizados no Laboratório de Ecotoxicologia do Núcleo de Estudos em Ecossistemas Aquáticos (NEEA) do Centro de Recurso Hídricos e Ecologia Aplicada (CRHEA/ EESC/ USP), onde já são cultivadas rotineiramente a maior parte das espécies testadas.

No intuito de facilitar a análise e interpretação dos resultados obtidos nesta etapa inicial da pesquisa, procurou-se disponibilizar as informações em função das espécies testadas, considerando zooplâncton, bentos, fitoplâncton, macrófitas e peixes, sendo que cada item contém uma breve introdução, metodologia, resultado e 
discussão. Uma consideração geral sobre os testes de toxicidade é apresentada no final, seguida das referências bibliográficas.

\section{2 - OBJETIVO}

O objetivo desta pesquisa foi determinar as faixas de sensibilidade (CE (I) 50) à $\mathrm{Cu}$ e $\mathrm{Cr}$ de espécies pertencentes a diferentes níveis tróficos (Selenastrum capricornutum, Daphnia similis, Ceriodaphnia dubia, Chironomus xanthus, Oreochromis niloticus e Pistia stratiotes).

\section{3 - Daphnia similis e Ceriodaphnia dubia}

Apesar da diversidade de espécies teste disponíveis, a espécie mais utilizada para testes de toxicidade aguda é o Cladocera Daphnia magna, presumivelmente devido a sua sensibilidade aos contaminantes ambientais em relação a outras espécies de invertebrados (VERSTEEG et al., 1997) e também pela sua facilidade de cultivo e ampla distribuição nas regiões temperadas. Testes com o gênero Daphnia foram iniciados no início dos anos 70 e são amplamente aceitos na avaliação da toxicidade das substâncias químicas e dos ecossistemas aquáticos.

Testes com Ceriodaphnia foram considerados atrativos devido a seu curto ciclo de vida e curto ciclo reprodutivo, facilitando o teste com compostos química ou biológicamente instáveis e no monitoramento de efluentes. Desde a metade dos anos 80 a espécie Ceriodaphnia dubia tem sido extensivamente utilizada na América do Norte para testes de toxicidade aguda e crônica. As vantagens no uso de Ceriodaphnia incluem sua sensibilidade similar à apresentada por Daphnia para um grande número de substâncias (VERSTEEG et al., 1997), como esperado em função da semelhança taxonômica entre os gêneros.

Ambos os gêneros Daphnia e Ceriodaphnia habitam corpos d'água pequenos, levemente eutróficos, e em muitas regiões apresentam padrões de ciclo de vida similares. PENNAK (1989) agrupa Ceriodaphnia juntamente com Daphnia como espécies comuns em águas abertas e limnéticas. D. magna, D. pulex e C. laticaudata são consideradas espécies cosmopolitas, e muitas outras espécies de Ceriodaphnia são amplamente distribuídas, porém a falta de informação impede seu status como espécie cosmopolita.

A distribuição de C. dubia recobre as regiões Palearticas, Orientais, Etíopes e Neotropicais. A verdadeira extensão de sua distribuição é ainda relativamente desconhecida. Na literatura mais antiga, C. dubia é freqüentemente identificada como C. quadrangula (VERSTEEG et al., 1997). 
Diversos autores têm sugerido que vários membros da família Daphnidae são similares em sensibilidade. Baseado em dados de toxicidade aguda para 15 compostos diferentes, CANTON \& ADEMA (1978) reportaram que $D$. magna, $D$. cucullata e D. pulex são similares em sensibilidade. HICKEY (1989) comparou a toxicidade de vários compostos e efluentes na sensibilidade de 5 espécies de Cladocera (D. magna, D. carinata, S. vetulus, C. dubia e C. cf. pulchella). Simocephalus e Ceriodaphnia são reportados como sendo mais sensíveis que Daphnia (VERSTEEG et al., 1993). ELNABARAWY et al. (1986) comparou a toxicidade aguda e crônica de diversos compostos orgânicos e inorgânicos para $C$. reticulata, $D$. magna e $D$. pulex, e concluiu que essas três espécies de dafinídeos são igualmente sensíveis. Baseado nas observações destes autores pode-se propor que membros do gênero Ceriodaphnia e Daphnia podem ser considerados equivalentes em avaliações de risco ambiental.

Daphnia similis e Ceriodaphnia dubia são microcrustáceos de água doce, pertencentes à classe Crustácea, ordem Cladocera. Reproduzem-se por partenogênese e, durante a maior parte do ano, a população natural é constituída apenas de fêmeas. O número de ovos partenogenéticos é variável entre as espécies e mesmo entre indivíduos da mesma espécie, e está relacionado com a qualidade e quantidade de alimentos e outros fatores físico-químicos tais como temperatura, intensidade luminosa, $\mathrm{OD}, \mathrm{pH}$, concentração de íons e outros. Os ovos produzidos se desenvolvem rápida e diretamente em miniaturas dos adultos, sem um estágio larval intermediário. Após um número variável de ínstares (geralmente 5 ou 6 ) as fêmeas completam o ciclo partenogenético e, devido a um estímulo ambiental, alguns ovos se desenvolvem em machos e outros em fêmeas sexuadas, que após a fertilização dão origem aos ovos de resistência, denominados efípios, facilmente visualizados devido ao escurecimento de parte das valvas que cobrem a câmara incubadora e aumento dos tegumentos. O aparecimento de machos parece estar associado a condições de estresse causada por baixas temperaturas, alta densidade de organismos, com acúmulo subsequente de produtos de excreção e baixa disponibilidade de alimentos. Espécies dos gêneros Ceriodaphnia e Daphnia vivem, respectivamente, cerca de 30 e 40 dias a $25^{\circ} \mathrm{C}$ e 50 a 56 dias a $20^{\circ} \mathrm{C}$. Espécies do gênero Ceriodaphnia são morfologicamente semelhantes às do gênero Daphnia, só que menores e com ciclo de vida mais curto, o que permite maior rapidez de resposta nos testes crônicos (ALLAN, 1976; FONSECA, 1991; RAND, 1995).

A utilização de $D$. magna e $C$. dubia em testes de toxicidade é normatizada por diversas agências reguladoras nacionais e internacionais. No Brasil, com a revisão das normas ABNT NBR 13373:1995 e NBR 12713:1993 (ABNT a, b, 2003) esta agência 
passou a indicar as espécies $C$. silvestrii e $C$. dubia, principalmente para testes crônicos e $D$. similis e $D$. magna para testes agudos. A OECD sugere o uso de $D$. magna (OECD 202, OECD 1984) para testes agudos, e especifica o uso desta espécie em testes de reprodução (OECD 211, OECD 1998). Standard Methods (APHA, 1998) indica $D$. magna, D.pulex e C. dubia para testes de toxicidade aguda e crônica. A U. S. EPA (EPA 821-R-02-012, U. S. EPA, 2002a) indica estas três espécies para testes agudos e apenas C. dubia para testes crônicos (EPA-821-R-02-013, U. S. EPA 2002b).

\section{1- Metodologia}

\subsection{1- Cultivo e manutenção dos organismos teste}

A manutenção do cultivo de organismos em laboratório inclui o preparo da água de cultivo, bem como o acompanhamento de parâmetros como $\mathrm{pH}$, dureza e condutividade, e o preparo do alimento utilizado. O cultivo e manutenção dos organismos seguiram as recomendações descritas em CETESB (1991) e ABNT (1995), conforme descrito a seguir.

A água de cultivo utilizada foi preparada a partir de água proveniente de uma fonte natural, que após autoclavada para eliminação de propágulos de outras espécies, foi diluída na proporção de 1 parte de água natural para 6 partes de água destilada e deionizada, ajustando-se a dureza para $40-48 \mathrm{mg} \mathrm{CaCO}_{3} \mathrm{~L}^{-1}$.

O ajuste da dureza foi feito utilizando-se uma solução de sulfato de cálcio 1,5

g.L $\mathrm{L}^{-1}$ (solução 1) e uma segunda solução contendo $0,2 \mathrm{~g} \cdot \mathrm{L}^{-1}$ cloreto de potássio, 4,80 g.L $\mathrm{L}^{-1}$ de bicarbonato de sódio e $6,10 \mathrm{~g} \cdot \mathrm{L}^{-1}$ de sulfato de magnésio (solução 2). Para cada miligrama de dureza a ser aumentada, acrescentou-se $0,5 \mathrm{~mL}$ da solução $1 \mathrm{e}$ $0,25 \mathrm{~mL}$ da solução 2 por litro de água a ser ajustado. A medida da dureza da água foi feita por titulação com solução de EDTA e indicador negro de ericromo T (APHA, 1998; CETESB, 1991). Após o preparo, o meio de cultivo foi mantido sob aeração por $48 \mathrm{~h}$ antes de sua utilização, e o pH foi ajustado a 7,2-7,6. Os valores de dureza, $\mathrm{pH}$ e condutividade foram verificados todas as vezes em que o meio de cultivo foi utilizado.

Como alimento foram utilizadas as culturas de Selenastrum capricornutum em fase exponencial de crescimento e alimento composto de ração para truta e levedura. A suspensão de Selenastrum capricornutum foi decantada em geladeira, eliminandose o sobrenadante, sendo ressuspendida em água de manutenção das culturas. $O$ número de células da suspensão foi determinado através de contagem em microscópio óptico, utilizando-se câmaras de contagem. Foi fornecida uma quantidade 
igual a $10^{5}$ células por litro, por dia, para $D$. similis e $60 \%$ dessa quantidade para $C$. dubia.

O alimento composto foi preparado misturando-se partes iguais de ração para truta e levedura. Após o preparo, o alimento foi conservado em geladeira por um período máximo de uma semana, sendo utilizado diariamente junto com a suspensão de algas, o que fornece uma alimentação adequada aos organismos. A ração para truta foi preparada adicionando-se $5 \mathrm{~g}$ de ração em $1000 \mathrm{~mL}$ de água destilada, sendo mantida sob aeração contínua por uma semana. Durante esse período, o volume de água foi completado de modo a compensar a perda de água por evaporação. Após aeração e posterior decantação, filtrou-se o sobrenadante em rede de plâncton de aproximadamente $45 \mu \mathrm{m}$ e o material sedimentado foi descartado. A solução obtida foi distribuída em frascos de $200 \mathrm{~mL}$ devidamente etiquetados e mantidos em freezer a $-20^{\circ} \mathrm{C}$ até o momento de uso.

A levedura foi preparada adicionando-se $1,0 \mathrm{~g}$ de fermento biológico seco em $200 \mathrm{~mL}$ de água destilada, sendo mantida sob agitação por cerca de 5 minutos até dissolução completa e utilizada imediatamente no preparo do alimento composto.

Os organismos foram mantidos em cristalizadores com capacidade para 2 litros, mantendo-se a relação de no máximo 50 organismos/cristalizador para $D$. similis e 60 organismos/cristalizador para C. dubia, em estufa incubadora com controle de temperatura e luz (fotoperíodo de 16 horas de luz e 8 horas de escuro, intensidade luminosa de aproximadamente 1000 lux e temperatura de $22+/-2^{0}$ C). Os cristalizadores e o meio de cultivo são trocados 3 vezes por semana (às segundas, quartas e sextas-feiras), o que possibilita o descarte dos neonatos.

\subsection{2- Controle de qualidade dos organismos-teste}

\section{Daphnia similis}

A avaliação da sensibilidade das culturas de Daphnia similis foi feita mensalmente com solução de dicromato de potássio, de acordo com os procedimentos descritos em CETESB (1991). As concentrações teste $(0,02 ; 0,04$; 0,$\left.08 ; 0,16 ; 0,32 \mathrm{mg} \cdot \mathrm{L}^{-1}\right)$ foram preparadas com água de cultivo, a partir de duas soluções estoque $\left(1,0\right.$ e $\left.0,1 \mathrm{mg} \cdot \mathrm{L}^{-1}\right)$, em água destilada.

Neonatos com idade de 6 a 24 horas foram expostos às diferentes concentrações, mais um controle, com água de cultivo. Para cada concentração foram testadas 3 réplicas, com 5 organismos cada. Durante o período de teste, os organismos foram mantidos no escuro e sem alimento em sala com temperatura de 22 $\pm 2^{\circ} \mathrm{C}$. Após o período de exposição (24 horas), procedeu-se à contagem dos 
organismos imóveis, sendo considerados imóveis aqueles que não conseguiram nadar dentro de um intervalo de 15 segundos, após leve agitação da amostra.

A CE(I) 50 24h foi calculada através do método Trimmed Spearman - Karber (HAMILTON et al., 1977). A carta-controle da sensibilidade dos organismos teste à substância de referência no período em que foram realizados os testes está apresentada na Figura 01 e os valores de CE 50 e intervalos de confiança para cada teste estão apresentados na Tabela 01.

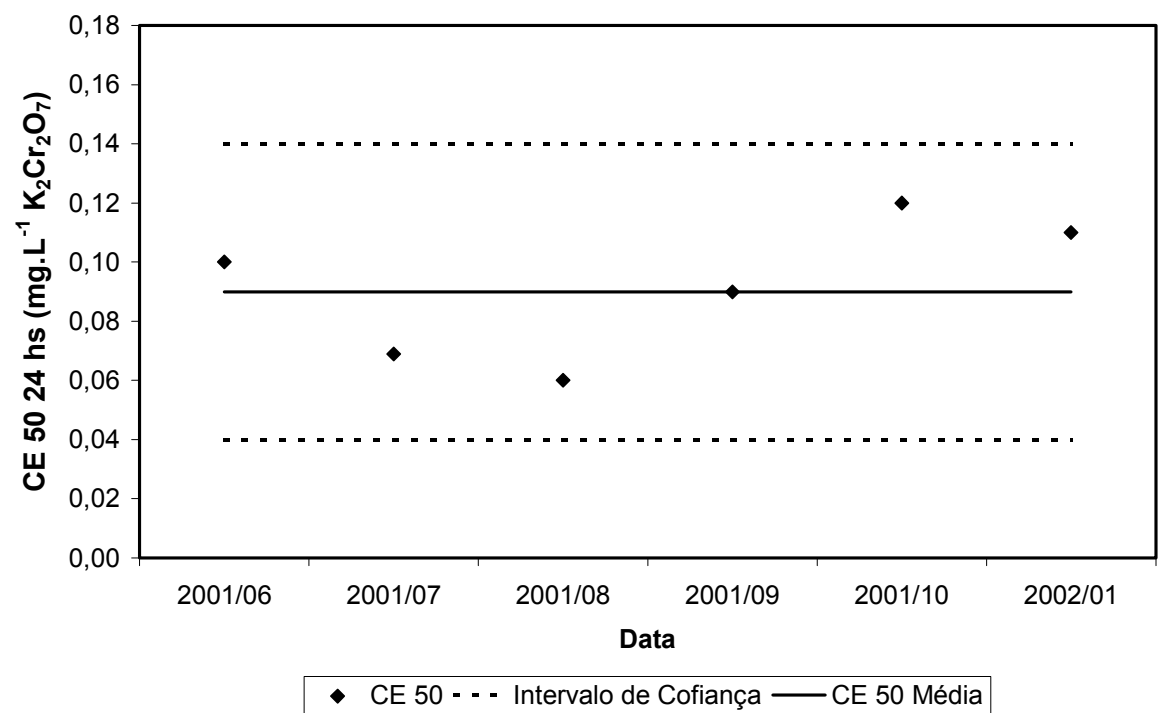

Figura 01: Carta-controle da sensibilidade de $D$. similis ao $\mathrm{K}_{\mathrm{s}} \mathrm{Cr}_{2} \mathrm{O}_{7}$ no período de junho de 2001 a janeiro de 2002.

Tabela 01: Carta controle da sensibilidade de $D$. similis ao dicromato de potássio.

\begin{tabular}{ccc}
\hline \multicolumn{3}{c}{ Dicromato de potássio - mg.. $\mathbf{~}^{-1}$} \\
\hline Data & CE50 24h & IC (95\%) \\
\hline $2001 / 06$ & 0,1 & $0,12-0,20$ \\
$2001 / 07$ & 0,069 & $0,03-0,08$ \\
$2001 / 08$ & 0,06 & $0,03-0,08$ \\
$2001 / 09$ & 0,09 & $0,07-0,09$ \\
$2001 / 10$ & 0,12 & $0,10-0,15$ \\
$2002 / 01$ & 0,11 & $0,07-0,13$ \\
\hline Média & & 0,09 \\
Desvio Padrão & 0,02 \\
Coeficiente de Variação & 25,53 \\
Faixa & $0,04-0,14$ \\
\hline \hline
\end{tabular}




\section{Ceriodaphnia dubia}

Os testes de toxicidade aguda para avaliação da sensibilidade da espécie Ceriodaphnia dubia ao Cloreto de Sódio $(\mathrm{NaCl})$ foram feitos de forma semelhante aos testes com Daphnia similis (CETESB, 1991). As concentrações teste $(1,0 ; 1,3 ; 1,6 ; 2,0$ e $2,2 \mathrm{~g} \cdot \mathrm{L}^{-1}$ ) foram preparadas com água de cultivo, a partir de uma solução estoque de $\mathrm{NaCl} 10 \mathrm{~g} \cdot \mathrm{L}^{-1} \mathrm{em}$ água destilada.

Foram consideradas adequadas para utilização em testes de toxicidade as culturas que apresentaram valores de $C E(I) 50$ 48h dentro da faixa de sensibilidade estabelecida para o Laboratório de Ecotoxicologia do NEEA/ CRHEA/ EESC/ USP (1,2 $-2,0 \mathrm{mg} . \mathrm{L}^{-1} \mathrm{NaCl}$,). A CE(I)50 24h foi calculada através do método Trimmed Spearman - Karber (HAMILTON et al., 1977). A carta-controle da sensibilidade dos organismos teste no período em que foram realizados os testes está apresentada na Figura 02 e os valores de CE 50 e intervalos de confiança para cada teste estão apresentados na Tabela 02.

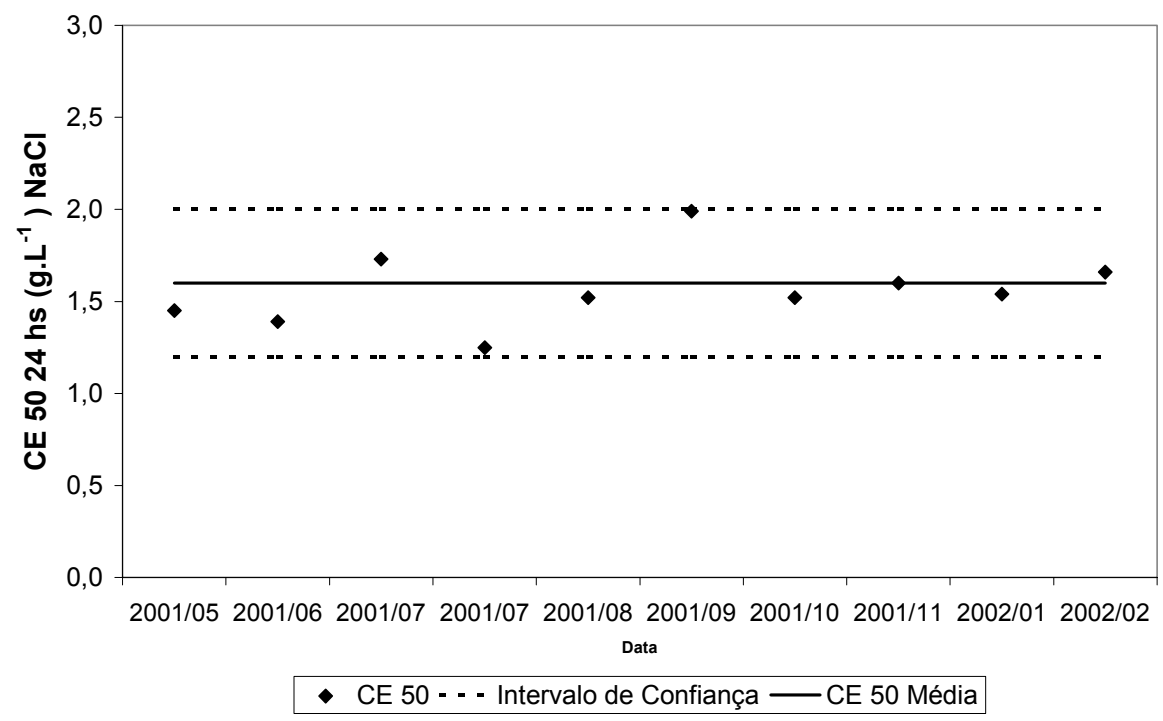

Figura 02: Carta-controle da sensibilidade de C. xanthus ao $\mathrm{KCl}$ no período de janeiro de 2001 a setembro de 2002 . 
Tabela 02: Carta controle da sensibilidade de C. dubia ao cloreto de sódio.

\begin{tabular}{|c|c|c|}
\hline \multicolumn{3}{|c|}{ Cloreto de Sódio - g. $\mathrm{L}^{-1}$} \\
\hline Data & CE50 24h & IC (95\%) \\
\hline $2001 / 05$ & 1,45 & $1,32-1,61$ \\
\hline $2001 / 06$ & 1,39 & $1,25-1,56$ \\
\hline $2001 / 07$ & 1,73 & $1,60-1,87$ \\
\hline $2001 / 07$ & 1,25 & $1,12-1,40$ \\
\hline $2001 / 08$ & 1,52 & $1,35-1,72$ \\
\hline $2001 / 09$ & 1,99 & $1,89-2,10$ \\
\hline $2001 / 10$ & 1,52 & $1,39-1,68$ \\
\hline $2001 / 11$ & 1,60 & $1,50-1,61$ \\
\hline 2002/01 & 1,54 & $1,37-1,74$ \\
\hline $2002 / 02$ & 1,66 & $1,52-1,82$ \\
\hline Média & & 1,60 \\
\hline Desvio Padrão & & 0,20 \\
\hline Coeficiente de Variação & & $12,5 \%$ \\
\hline Faixa & & $1,2-2,0$ \\
\hline
\end{tabular}

\subsection{3- Testes de toxicidade com $\mathrm{Cr}$ e ao $\mathrm{Cu}$}

Os testes de toxicidade com $\mathrm{Cr}$ e $\mathrm{Cu}$ foram efetuados segundo as normas CETESB (1991) e ABNT (1995). Para tanto, neonatos de D. similis e C. dubia, com idade de 0 a 24 horas, foram expostos às diferentes soluções-teste, além de um controle, com água de cultivo. Para cada concentração foram testadas 3 réplicas, com 5 organismos cada. Durante o período de teste, os organismos foram mantidos no escuro e sem alimento em sala com temperatura de $22 \pm 2^{0} \mathrm{C}$. Após o período de exposição (48 horas), procedeu-se à contagem dos organismos imóveis, sendo considerados imóveis aqueles que não conseguiram nadar dentro de um intervalo de 15 segundos, após leve agitação da amostra. A CE(I)50 48h foi calculada através do método Trimmed Spearman - Karber (HAMILTON et al., 1977).

\section{Daphnia similis}

Com base nos testes de toxicidade para $D$. similis, que utiliza $\mathrm{K}_{2} \mathrm{Cr}_{2} \mathrm{O}_{7}$, foi determinada a primeira faixa de concentração testada para $\mathrm{Cr}$ com essa espécie. As

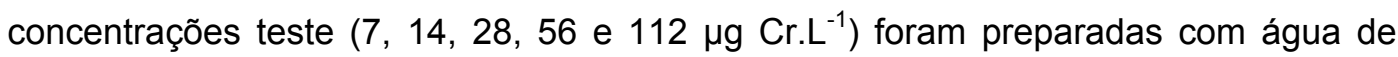
cultivo, a partir de soluções estoque de $\mathrm{K}_{2} \mathrm{Cr}_{2} \mathrm{O}_{7}$, com concentrações de $\mathrm{Cr}$ iguais a 0,1 e $1,0 \mathrm{mg} \cdot \mathrm{L}^{-1}$, em água destilada

Os primeiros testes de toxicidade do Cu para $D$. similis, foram realizados com concentrações iguais a 2,5, 5, 10, 20 e $40 \mu \mathrm{g} \mathrm{Cu} . \mathrm{L}^{-1}$. A partir dos resultados destes testes a faixa de concentrações testadas foi alterada, buscando-se como resultado uma faixa de sensibilidade mais restrita. Outras faixas de concentração testadas

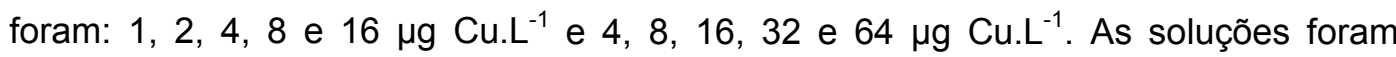


preparadas em meio de cultivo a partir de uma solução estoque de $\mathrm{CuSO}_{4} \cdot 5 \mathrm{H}_{2} \mathrm{O}$, contendo $0,1 \mathrm{mg} \mathrm{Cu} . \mathrm{L}^{-1}$, preparada em água destilada.

\section{Ceriodaphnia dubia}

Os primeiros testes de toxicidade ao $\mathrm{Cr}$ foram realizados com base nos resultados obtidos por OLIVEIRA NETO (2000) para C. silvestrii. A faixa de

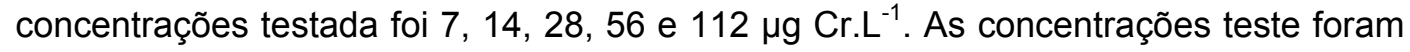

preparadas com água de cultivo, a partir de soluções estoque de $\mathrm{K}_{2} \mathrm{Cr}_{2} \mathrm{O}_{7}$, com concentrações de $\mathrm{Cr}$ iguais a 0,1 e 1,0 mg. $\mathrm{L}^{-1}$ em água destilada

Nos testes de toxicidade com $\mathrm{Cu}$, as faixas de concentração testadas foram: 1, 2, 4, 8 e $16 \mu \mathrm{g}$ e Cu. $\mathrm{L}^{-1}$ e $8,10,12,14$ e $16 \mu \mathrm{g} \mathrm{Cu} . \mathrm{L}^{-1}$. As soluções foram preparadas em meio de cultivo a partir de uma solução estoque de $\mathrm{CuSO}_{4} \cdot 5 \mathrm{H}_{2} \mathrm{O}$, contendo $0,1 \mathrm{mg} \mathrm{Cu} . \mathrm{L}^{-1}$, preparada em água destilada.

\section{2- Resultados e discussão}

\subsection{1- Daphnia similis}

Os testes de toxicidade com $\mathrm{Cr}$ e $\mathrm{Cu}$ para $D$. similis foram realizados em paralelo, no período de janeiro a outubro de 2001.

Os valores de $\mathrm{CE}(\mathrm{I}) 50$ 48h para $\mathrm{Cr}$, obtidos com as culturas de Daphnia similis, variaram entre 11,6 e $47,4 \mu \mathrm{g} . \mathrm{L}^{-1}$. Foram realizados um total de 14 testes, dentre os quais quatro apresentaram valores de CE 50 muito discrepantes $(11,6 ; 12,5$; 46,7 e 47,4 $\mu \mathrm{g} \cdot \mathrm{L}^{-1}$ ), devido as alterações na sensibilidade da cultura utilizada. A CE(I)50 média foi 22,6 ( $\left.\pm 6 \mu \mathrm{g} \cdot \mathrm{L}^{-1}\right)$, sendo que os valores citados acima não foram considerados para o cálculo da média pois foram significativamente diferentes dos demais valores obtidos (ANOVA, $\mathrm{p}<0,05$ ). Os valores de $\mathrm{CE}(\mathrm{I}) 5048 \mathrm{~h}$ para $\mathrm{Cr}$, obtidos com as culturas de Daphnia similis estão apresentados na Tabela 03. 
Tabela 03: Valores de CE (I) $5048 \mathrm{~h}$ obtidos nos testes de toxicidade com $\mathrm{Cr}$ com D. similis

\begin{tabular}{cc}
\hline $\mathrm{CE}(\mathrm{I}) 5048 \mathrm{~h}\left(\mu \mathrm{g} \cdot \mathrm{L}^{-1} \mathrm{Cr}\right)$ & $\mathrm{IC}(95 \%)$ \\
\hline 17,7 & $(17,0-20,5)$ \\
$11,6^{*}$ & $(10,5-14,0$ \\
18,6 & $(10,5-28,0)$ \\
25,2 & $(24,5-31,5)$ \\
19,6 & $(14,0-24,5)$ \\
15,1 & $(10,5-17,5)$ \\
28,7 & $(6,7-123,6)$ \\
35,8 & $(29,3-42,6)$ \\
$46,7^{*}$ & $(35,6-64,2)$ \\
$47,4^{*}$ & $(37,8-59,5)$ \\
$12,5^{*}$ & $(7,0-22,2)$ \\
18,7 & $(9,3-24,8)$ \\
26,0 & $(19,3-35,0)$ \\
21,2 & $(18,0-25,0)$ \\
\hline CE (50); 48 h médio & 22,6 \\
Faixa de Sensibilidade & $10,6-34,6$ \\
Desvio Padrão & 6,0 \\
Coeficiente de Variação & $26,5 \%$ \\
\hline \hline
\end{tabular}

*valores não utlizados no cálculo da CE (50) 48 hs média

A sensibilidade ao $\mathrm{K}_{2} \mathrm{Cr}_{2} \mathrm{O}_{7}$ para espécies do gênero Daphnia pode variar de espécie para espécie. Para $D$. magna as faixas de sensibilidade estabelecidas para esta substância pelas normas internacionais (ISO), francesas (AFNOR) e alemãs (DIN) são $0,9-2,0 \mathrm{mg} \cdot \mathrm{L}^{-1}, 0,9-1,5 \mathrm{mg} \cdot \mathrm{L}^{-1}$ e $0,9-1,9 \mathrm{mg} \cdot \mathrm{L}^{-1}$, respectivamente, para águas duras, contendo de $200-250 \mathrm{mg}^{-1} \mathrm{CaCO}_{3}$ (OLIVEIRA-NETO \& BOTTAPASCHOAL, 2000)

O valor de CE (50) médio determinado para $D$. Similis $\left(22,6 \mu \mathrm{g} \cdot \mathrm{L}^{-1} \mathrm{Cr}\right)$ é igual ao determinado para $D$. magna $\left(22 \mu \mathrm{g} \cdot \mathrm{L}^{-1} \mathrm{Cr}\right.$ ) por MOUNT \& NORBERG (1984), em dureza semelhante. Valores determinados para a mesma espécie, utilizando meios com durezas mais altas, por ELNABARAWY et al. (1986) e HICKEY (1989), com dureza igual a 240 e $250 \mathrm{mg} \mathrm{CaCO} \mathrm{L}^{-1}$, foram mais altos (112 e $224 \mu \mathrm{g} \cdot \mathrm{L}^{-1} \mathrm{Cr}$ ). Assim, a dureza do meio parece ser um importante fator na toxicidade de Cr para Daphnia, uma vez que este parâmetro pode interferir na disponibilidade dos metais para os organismos.

De acordo com trabalho de CONIGLIA \& BAUDO (1989), a exposição de $D$. obtusa ao $\mathrm{Cr}$, mesmo por um pequeno intervalo de tempo e a pequenas concentrações, reduz o tempo de vida, atrasa a primeira reprodução e diminui o tamanho da ninhada, porém não acarreta efeitos no tamanho médio da geração e na taxa de aumento populacional intrínseca. Mesmo que a população exposta ao $\mathrm{Cr}$ seja restaurada para condições não poluídas, em um tempo correspondente a expectativa de vida média, ocorre a mortalidade de $40 \%$ da população exposta a concentrações 
de $\mathrm{Cr}$ da ordem de $40 \mu \mathrm{g} . \mathrm{L}^{-1}$.Alguns valores de CE (50) $\left(\mu \mathrm{g} \cdot \mathrm{L}^{-1} \mathrm{Cr}\right.$ ) para Daphnia, determinados por diversos autores, podem ser visualizados na Tabela 4.

Tabela 04: Valores de CE (50) ( $\mu \mathrm{g} \cdot \mathrm{L}^{-1} \mathrm{Cr}$ ) para Daphnia determinados por diversos autores

\begin{tabular}{cccc}
\hline \hline Espécie & $\begin{array}{c}\text { Dureza } \\
\left(\mathrm{mg} \mathrm{CaCO}_{3} . \mathrm{L}^{-1}\right)\end{array}$ & $\begin{array}{c}\mathrm{CE}(50) \\
\left(\mu \mathrm{g} \mathrm{Cr.L^{-1 } )}\right.\end{array}$ & Autor \\
\hline \hline D. magna & 45 & 22 & MOUNT \& NORBERG, 1984 \\
D. magna & 240 & 112 & ELNABARAWY et al., 1986 \\
D. magna & 255 & 224 & HICKEY 1989 \\
D. pulex & 240 & 122 & ELNABARAWY et al., 1986 \\
D. similis & $40-48$ & 22,6 & Presente trabalho \\
\hline \hline
\end{tabular}

Em relação ao $\mathrm{Cu}$, foram realizados 13 testes de toxicidade com $D$. similis. Os valores de CE (50) para Cu, variaram entre 4,49 e 12,96 $\mu \mathrm{g} \cdot \mathrm{L}^{-1}$ (Tabela 5). A CE (50) média foi igual a $10 \mu \mathrm{g} \mathrm{Cu} . \mathrm{L}^{-1}$, com desvio padrão de $2,7 \mu \mathrm{g} \mathrm{Cu} \cdot \mathrm{L}^{-1}$. Alguns testes resultaram em valores de CE (50) bem menores que a média, demonstrando, nestes casos, uma maior sensibilidade dos organismos. As diferenças na sensibilidade ao $\mathrm{Cu}$ devem-se, provavelmente, à heterogeneidade genética entre os indivíduos utilizados ou, com maior probabilidade, a variações indesejadas nas condições de cultivo, como sugerem os altos valores de desvio padrão e coeficiente de variação apresentados pela carta controle, pois a heterogeneidade genética não deveria apresentar grande influência, uma vez que $D$. similis se reproduz por partenogênese.

Tabela 05: Valores de CE (I) 50 48h obtidos nos testes de toxicidade com Cu com $D$. similis

\begin{tabular}{cc}
\hline \hline CE (I) 50 48h $\left(\mu \mathrm{g} . \mathrm{L}^{-1} \mathrm{Cu}\right)$ & $\mathrm{IC}(95 \%)$ \\
\hline $5,58^{*}$ & $(4,56-6,82)$ \\
7,86 & $(5,74-10,77)$ \\
$4,49^{*}$ & $(3,72-5,42)$ \\
10,02 & $(6,41-15,69)$ \\
12,16 & $(10,09-14,67)$ \\
12,96 & $(11,06-15,21)$ \\
12,8 & $(10,6-14,3)$ \\
12,4 & $(11,8-16,5)$ \\
11,5 & $(9,8-13,3)$ \\
9,4 & $(7,8-10,2)$ \\
10,3 & $(9,2-12,7)$ \\
11,9 & $(9,8-13,2)$ \\
8,1 & $(7,4-12,6)$ \\
\hline CE (50); 48 h médio & 10,0 \\
Faixa de Sensibilidade & $4,6-15,4$ \\
Desvio Padrão & 2,7 \\
Coeficiente de Variação & $27 \%$ \\
\hline \hline
\end{tabular}

*valores não utlizados no cálculo da CE (50) 48 hs média 


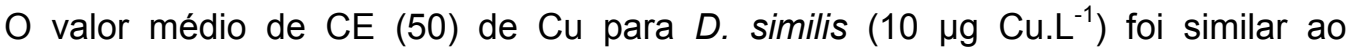
determinado por OLIVEIRA-FILHO et al. (2004), que utilizaram as mesmas condições destes. Entretanto, a CE (I) 50 média determinada foi muito menor que os valores determinados por MOUNT \& NORBERG (1984) para $D$. magna e $D$. pulex, em condições de dureza semelhantes (54 e $53 \mu \mathrm{g} \cdot \mathrm{L}^{-1} \mathrm{Cu}$, respectivamente). ELNABARAWY et al. (1986), trabalhando com dureza mais alta (240 mg $\mathrm{CaCO}_{3} . \mathrm{L}^{-1}$ ), determinaram valores de CE (50) menores para essas espécies, iguais a 41 e $31 \mu \mathrm{g}$. $\mathrm{L}^{-1} \mathrm{Cu}$, respectivamente. No entanto, os resultados apresentados por BARATA et al. (1998) para $D$. magna trazem valores de $C E(50)$ mais baixos $\left(3,2\right.$ e $15,4 \mu g$ Cu. $\left.L^{-1}\right)$, em cultivo com água moderadamente dura (Tabela 6).

Tabela 06: Valores de CE (50) $\left(\mu \mathrm{g} \cdot \mathrm{L}^{-1} \mathrm{Cu}\right)$ para Daphnia determinados por diversos autores

\begin{tabular}{cccc}
\hline \hline Espécie & $\begin{array}{c}\text { Dureza } \\
\left(\mathrm{mg} \mathrm{CaCO}_{3} \mathrm{~L}^{-1}\right)\end{array}$ & $\begin{array}{c}\mathrm{CE} \mathrm{ou} \mathrm{CL}(50) \\
\left(\mu \mathrm{g} \mathrm{Cu} \mathrm{L}^{-1}\right)\end{array}$ & Autor \\
\hline \hline D. similis & $40-48$ & 13 & OLIVEIRA-FILHO et al, 2004 \\
D. magna & 90 & $12,0-16,9$ & NADDY et al., 2003 \\
D. magna & 180 & $16,3-57,3$ & NADDY et al., 2003 \\
D. magna & 90 & 3,$2 ; 15,4$ & BARATA et al. , 1998 \\
D. magna & 180 & $23 ; 119$ & BARATA et al. ,1998 \\
D. pulex & 45 & 53 & MOUNT \& NORBERG, 1984 \\
D. magna & 45 & 54 & MOUNT \& NORBERG, 1984 \\
D. magna & 240 & 41 & ELNABARAWY et al., 1986 \\
D. pulex & 240 & 31 & ELNABARAWY et al., 1986 \\
D. similis & $40-48$ & 10,0 & Presente trabalho \\
\hline \hline
\end{tabular}

Observando-se os valores reportados pelos trabalhos citados, verifica-se que a dureza influencia mais na toxicidade do $\mathrm{Cr}$ para Daphnia que na toxicidade do $\mathrm{Cu}$. BARATA et al. (1998) afirma que a variabilidade genética na tolerância de $D$. magna ao Cu é maior que a variabilidade ambiental (variações na dureza, $\mathrm{pH}$, condutividade e alcalinidade), sendo responsáveis por 20 e 10\%, respectivamente, de variabilidade nos valores de LC (50).

\subsection{2 - Ceriodaphnia dubia}

Os testes de toxicidade com $\mathrm{Cr}$ e $\mathrm{Cu}$ foram realizados em paralelo, no período de maio de 2001 a janeiro de 2002.

Os valores de CE (I) 50 48h para $\mathrm{Cr}$, obtidos com as culturas de C. dubia, variaram entre 28,69 e $111,96 \mu \mathrm{g} . \mathrm{L}^{-1}$. Foram realizados 16 testes, dentre os quais três apresentaram valores de CE 50 fora da faixa de sensibilidade estabelecida $(28,69$, 111,96 e $\left.98,5 \mu \mathrm{g} \cdot \mathrm{L}^{-1} \mathrm{Cr}\right)$. A CE (I) 50 média foi igual a 55,6 $( \pm 6,4) \mu \mathrm{g} \cdot \mathrm{L}^{-1}$, sendo que os valores citados acima não foram considerados para o cálculo da média pois foram significativamente diferentes dos demais valores obtidos (ANOVA, $p<0,05$ ). Os valores 
de $\mathrm{CE}(\mathrm{I}) 50 ; 48 \mathrm{~h}$ para $\mathrm{Cr}$, obtidos com as culturas de C. dubia, estão apresentados na Tabela 07.

Tabela 07: Valores de CE (I) 5048 h obtidos nos testes de toxicidade com $\mathrm{Cr}$ com C. dubia

\begin{tabular}{cc}
\hline CE (I) 50 48h $\left(\mu \mathrm{g} \cdot \mathrm{L}^{-1} \mathrm{Cr}\right)$ & $\mathrm{IC}(95 \%)$ \\
\hline 47,44 & $(37,8-59,53)$ \\
49,2 & $(38,4-63,1)$ \\
$28,69^{*}$ & $(6,66-123,58)$ \\
$111,96^{*}$ & $(91,7-136,71)$ \\
67,34 & $(50,50-89,82)$ \\
58,5 & $(46,3-73,8)$ \\
$98,49^{*}$ & $(82,12-118,12)$ \\
55,7 & $(49,6-90,7)$ \\
59,3 & $(50,2-64,5)$ \\
55,2 & $(48,3-87,7)$ \\
62,7 & $(51,4-100,6)$ \\
59,2 & $(48,8-98,4)$ \\
48,5 & $(36,7-78,5)$ \\
60,6 & $(54,3-72,7)$ \\
51,4 & $(44,3-89,5)$ \\
47,4 & $(37,5-52,6)$ \\
\hline CE (50); 48 h médio & 55,6 \\
Faixa de Sensibilidade & $42,8-68,4$ \\
Desvio Padrão & 6,4 \\
Coeficiente de Variação & $11,5 \%$ \\
\hline \hline
\end{tabular}

*valores não utlizados no cálculo da CE (50) 48 hs média

O valor de CE (50) médio determinado com culturas de $C$. dubia para o $\mathrm{Cr}$ $\left(55,6 \mu \mathrm{g} \cdot \mathrm{L}^{-1} \mathrm{Cr}\right)$ foi um pouco superior ao apresentado por MOUNT \& NORBERG (1984) para C. reticulata (45 $\mu \mathrm{g} \cdot \mathrm{L}^{-1} \mathrm{Cr}$ ), e por OLIVEIRA-NETO \& BOTTA-PASCHOAL (2000) para C. silvestrii (46 $\mu \mathrm{g} \cdot \mathrm{L}^{-1} \mathrm{Cr}$ ), em condições de dureza semelhantes. Considerando a faixa de sensibilidade determinada esta diferença não é significativa. O valor determinado neste trabalho também é semelhante ao apresentado por HICKEY (1989) para C. dubia, igual a $53 \mu \mathrm{g} . \mathrm{L}^{-1} \mathrm{Cr}$, porém, o autor utilizou um meio de cultivo com dureza mais alta (250 mg $\left.\mathrm{CaCO}_{3} \cdot \mathrm{L}^{-1}\right)$. Alguns valores de $\mathrm{CE}(50)$ ( $\mu \mathrm{g} \cdot \mathrm{L}^{-}$ ${ }^{1} \mathrm{Cr}$ ) para Ceriodaphnia, determinados por diversos autores, são apresentados na Tabela 8.

Tabela 8: Valores de CE (50) ( $\mu \mathrm{g} . \mathrm{L}^{-1} \mathrm{Cr}$ ) para Ceriodaphnia determinados por diversos autores

\begin{tabular}{cccc}
\hline \hline Espécie & $\begin{array}{c}\text { Dureza } \\
\left(\mathrm{mg} \mathrm{CaCO}_{3} \mathrm{~L}^{-1}\right)\end{array}$ & $\begin{array}{c}\mathrm{CE}(50) \\
\left(\mu \mathrm{g} \mathrm{Cr} \mathrm{L}^{-1}\right)\end{array}$ & Autor \\
\hline \hline C. sivestrii & 48 & 46 & OLIVEIRA-NETO \& BOTTA-PASCHOAL, 2000 \\
C. reticulata & 45 & 45 & MOUNT \& NORBERG, 1984 \\
C. dubia & 240 & 195 & ELNABARAWY et al., 1986 \\
C. dubia & 250 & 53 & HICKEY 1989 \\
C. dubia & $40-48$ & 55,6 & Presente trabalho \\
\hline \hline
\end{tabular}


Os valores de CE (I) 50 48h para $\mathrm{Cu}$, obtidos com as culturas de C. dubia, variaram entre 4,14 e $24,6 \mu \mathrm{g} \cdot \mathrm{L}^{-1}$. Foram realizados 16 testes, dentre os quais três apresentaram valores de CE (50) fora da faixa de sensibilidade estabelecida $(4,14$; 15,5 e $\left.24,6 \mu \mathrm{g} . \mathrm{L}^{-1}\right)$, ou seja, muito acima ou abaixo do valor médio encontrado. A CE (50) média foi igual a $9,1( \pm 2,3) \mu \mathrm{g} . \mathrm{L}^{-1}$, sendo que os valores citados acima não foram considerados para o cálculo da média. Os valores de CE (I) 50 48h para Cu, obtidos com as culturas de C. dubia estão apresentados na Tabela 09.

Tabela 09: Valores de CE (I) 50 48h obtidos nos testes de toxicidade com Cu com C. dubia.

\begin{tabular}{cc}
\hline CE (I) 50 48h $\left(\mu \mathrm{g} \cdot \mathrm{L}^{-1} \mathrm{Cu}\right)$ & $\mathrm{IC}(95 \%)$ \\
\hline $15,5^{*}$ & $(11,9-20,1)$ \\
$24,6^{*}$ & $(21,17-28,53)$ \\
10,8 & $(10,53-11,09)$ \\
6,17 & $(5,41-7,04)$ \\
8,59 & $(7,88-9,49)$ \\
$4,14^{*}$ & $(2,76-6,21)$ \\
10,97 & $(9,64-12,49)$ \\
9,71 & $(7,6-12,43)$ \\
9,6 & $(7,2-10,4)$ \\
9,4 & $(8,6-11,3)$ \\
6,8 & $(5,6-7,8)$ \\
11,6 & $(7,6-13,5)$ \\
8,63 & $(7,3-9,8)$ \\
8,9 & $(7,1-9,5)$ \\
7,6 & $(6,4-10,2)$ \\
8,9 & $(5,4-11,7)$ \\
\hline CE (50); 48 h médio & 9,5 \\
Faixa de Sensibilidade & $4,9-14,1$ \\
Desvio Padrão & 2,3 \\
Coeficiente de Variação & $24 \%$ \\
\hline \hline
\end{tabular}

*valores não utlizados no cálculo da CE (50) 48 hs média

Em testes com C. reticulata, MOUNT \& NORBERG (1984) determinaram valor superior para CE (50) de $\mathrm{Cu}$, igual a $17 \mu \mathrm{g} \cdot \mathrm{L}^{-1} \mathrm{Cu}$, em condições de dureza semelhantes. ELNABARAWY et al. (1986) obteve um valor de $23 \mu \mathrm{g} \cdot \mathrm{L}^{-1} \mathrm{Cu}$, trabalhando com a mesma espécie, em dureza superior $\left(240 \mathrm{mg} \mathrm{CaCO}_{3} . \mathrm{L}^{-1}\right)$. Alguns valores de CE (50) ( $\mu \mathrm{g} . \mathrm{L}^{-1} \mathrm{Cu}$ ) para Ceriodaphnia, determinados por diversos autores, encontram-se na Tabela 10. 
Tabela 10: Valores de CE (50) $\left(\mu \mathrm{g} . \mathrm{L}^{-1} \mathrm{Cu}\right)$ para Ceriodaphnia determinados por diversos autores

\begin{tabular}{cccc}
\hline \hline Espécie & $\begin{array}{c}\text { Dureza } \\
\left(\mathrm{mg} \mathrm{CaCO}_{3} \mathrm{~L}^{-1}\right)\end{array}$ & $\begin{array}{c}\mathrm{CE}(50) \\
\left(\mu \mathrm{g} \mathrm{Cu} \mathrm{L}^{-1}\right)\end{array}$ & Autor \\
\hline \hline C. dubia & 180 & $7,9-17,5$ & NADDY et al., 2002 \\
C. reticulata & 45 & 17 & MOUNT \& NORBERG, 1984 \\
C. reticulata & 240 & 23 & ELNABARAWY et al., 1986 \\
C. dubia & $40-48$ & 9,5 & Presente trabalho \\
\hline \hline
\end{tabular}

Ambas as espécies de Cladocera estudadas apresentaram maior sensibilidade ao Cu que ao $\mathrm{Cr}$. As espécies $D$. similis e $C$. dubia apresentaram valores de CE (50) semelhantes para o Cu, não tendo sido observada diferenças estatisticamente significativas $(p<0,05)$ entre os valores obtidos para as duas espécies, como pode ser observado pelo resultado resumido da análise de variância (Tabela 11). Já para os testes com $\mathrm{Cr}$, a espécie $C$. dubia apresentou-se menos sensível que $D$. similis, gerando valor de $p<0,05$ e $F$ maior que $F$ crítico sendo que os valores de CE (50) determinados para este metal foram estatisticamente diferentes (Tabela 11).

Tabela 11: Síntese dos resultados da análise de variância entre os valores de CE (50) de Cr e Cu determinados para $D$. similis e $C$. dubia

\begin{tabular}{cccc}
\hline \hline & $\mathrm{F}$ & valor-P & $\mathrm{F}$ crítico \\
\hline $\mathrm{Cr}$ & 69,18201 & $1,57 \mathrm{E}-08$ & 4,259675 \\
$\mathrm{Cu}$ & 0,627992 & 0,435265 & 4,2252 \\
\hline \hline
\end{tabular}

F > F crítico: significativamente diferente.

Segundo VERSTEEG et al. (1997), valores de toxicidade aguda para Ceriodaphnia são em geral menores que para outros cladóceros, independente do material testado (substâncias orgânicas, inorgânicas ou efluentes). Entretanto, estas diferenças de sensibilidade entre as espécies de Cladocera são pequenas, sendo que Ceriodaphnia apresenta sensibilidade similar a outros cladóceros. Tal observação não se aplica aos resultados aqui apresentados para os testes com $\mathrm{Cr}$, onde $C$. dubia apresentou-se menos sensível que $D$. similis. Porém, a diferença na sensibilidade ao Cr para as duas espécies estudadas se dá por um fator 2 , que segundo o autor pode ser considerado como uma diferença pequena, sendo aceitável como sensibilidade similar para um composto uma diferença de até um fator 8 .

A toxicidade do $\mathrm{Cu}$ para $C$. dubia aparenta não ser afetada pela dureza, enquanto alguns autores apresentam diferença na toxicidade do $\mathrm{Cu}$ para de $D$. magna em função da dureza do meio (BARATA et al, 1998; NADDY et al, 2003).

NADDY et al. (2003), estudando a influência da razão Ca:Mg na toxicidade do Cu para diversas espécies, observou que tal característica não influencia a toxicidade 
de $\mathrm{Cu}$ para $C$. dubia, porém $\mathrm{Cu}$ foi mais tóxico para $D$. magna no tratamento com maior razão Ca:Mg (4:1). Magnésio parece ser o melhor inibidor do Cu para $D$. magna, em água dura, enquanto ambos (Ca e $\mathrm{Mg}$ ) são igualmente inibidores do $\mathrm{Cu}$ para $C$. dubia.

\section{4 - Chironomus xanthus}

Organismos da família Chironomidae são insetos (ordem Diptera) com uma ampla distribuição geográfica, grande riqueza de espécies e abundância nos ecossistemas de água doce (STRIXINO \& STRIXINO, 1981).

Dentre os organismos bentônicos, algumas espécies da família Chironomidae (Chironomus tentans, nos USA e Chironomus riparius, na Europa) têm sido utilizadas em testes de toxicidade com sedimentos, pois, além de apresentarem os requisitos básicos necessários para um organismo teste, tais como relevância ecológica, sensibilidade aos contaminantes e facilidade de cultivo, estão diretamente expostos aos possíveis contaminantes por viverem a maior parte do ciclo de vida em contato direto e alimentando-se das partículas aderidas ao sedimento. São organismos extremamente adaptáveis a diversos tipos de ambientes, apresentando uma grande riqueza de espécies; vivem em casulos a poucos centímetros da superfície do sedimento e constituem freqüentemente a proporção mais significativa da biomassa bentônica, além de desempenharem papel importante na reciclagem de nutrientes do sedimento e na alimentação de diversos animais (GIESY \& HOKE, 1989) .

Chironomus xanthus foi descrito inicialmente por REMPEL (1936) e possui sinonimia com Chironomus domizzi e Chironomus santicaroli (STRIXINO \& STRIXINO, 1982). Sua distribuição geográfica se restringe ao Brasil e à Argentina, até o momento, tendo sido relatada sua ocorrência na região de São Carlos (STRIXINO \& STRIXINO, 1981).

No Brasil, estudos realizados por STRIXINO \& STRIXINO (1981) e FONSECA (1997), mostraram que a espécie Chironomus xanthus possui os requisitos necessários para ser utilizado como organismo-teste, como fácil manutenção em laboratório, alta fecundidade e não têm necessidade do fenômeno do enxameamento para acasalar, além de apresentarem ciclo de vida curto. Esses organismos apresentam coloração vermelha, devido à presença de hemoglobina, o que os ajuda a tolerar ambientes com baixas concentrações de oxigênio. Essa espécie tem sido utilizada em diversos estudos ecotoxicológicos (RODGHER, 1998; ALMEIDA, 2002; DORNFELD, 2002).

O ciclo de vida de Chironomidae é dividido em quatro estádios distintos: ovo, larva, pupa, e adulto, sendo os dois últimos estádios com duração muito curta. A maior 
parte do ciclo de vida destes organismos é no estágio larval. Os principais fatores abióticos que influenciam o ciclo de vida destes organismos são: temperatura, nutrição e fotoperíodo (FONSECA, 1997). Os quironomídeos apresentam diversas formas de alimentação, podendo ingerir algas, detritos e microorganismos associados, macrófitas, detritos de madeira e invertebrados. A duração do ciclo de vida de $C$. xanthus é de aproximadamente 15 dias, a $23^{\circ} \mathrm{C}$ de temperatura (FONSECA, 1997).

Alguns protocolos e procedimentos já foram padronizados para a realização de testes de toxicidade com sedimentos para Chironomus tentans e Chironomus riparius (REYNOLDSON et al., 1995; EPA/600/R-94/024; U. S. EPA 2000). Os estudos realizados em água doce têm tido mais sucesso em relacionar a toxicidade do sedimento a metais individuais, encontrando correlações positivas entre a mortalidade dos indivíduos nos testes de toxicidade com as concentrações de metais nos sedimentos (CAMPBELL et al., 1988). Muitos autores sugerem que a distribuição de Chironomus, nos ambientes naturais, apresenta correspondência com os resultados obtidos em testes de toxicidade (WENTSEL, 1977).

Entre os efeitos dos metais aos Chironomidae, a deformação do mento é o mais freqüentemente descrito pela literatura. Aparentemente existe uma relação linear entre a ocorrência deste tipo de deformação e a concentração de metais no sedimento, deformidades que podem ser interpretadas como um sinal da contaminação em concentrações subletais. Quironomídeos não são hábeis em regular a concentração de metais não essenciais como $\mathrm{Pb}$ e $\mathrm{Cd}$, enquanto metais essenciais como $\mathrm{Cu}$ e $\mathrm{Zn}$ podem ser regulados em nível necessário para as funções biológicas, porém altas concentrações de $\mathrm{Cu}$ podem provocar efeitos tóxicos, impedindo a ocorrência de biorregulação (BISTHOVEN et al.; 1992).

\section{1- Metodologia}

\subsection{1- Cultivo e manutenção dos organismos-teste}

O cultivo e manutenção dos organismos-teste foram baseados em FONSECA \& ROCHA (2004), como descrito a seguir. O cultivo das larvas é feito a partir das desovas gelatinosas, depositadas pelas fêmeas adultas. Os ovos, cerca de 500 a 600 , são envolvidos por uma massa gelatinosa e ficam presos, por um pedúnculo, nas paredes das bandejas em contato com a água. Essas desovas, retiradas com auxílio de uma espátula, são colocadas em placas de Petri contendo água de manutenção, onde permanecem até a eclosão das larvas, o que ocorre entre 40 e 48 horas, a $23 \pm$ $2{ }^{0} \mathrm{C}$. 
Após a eclosão e posterior abandono da mucilagem gelatinosa, um total de 250 larvas foram transferidas para bandejas plásticas de $45 \times 35 \times 6 \mathrm{~cm}$ de tamanho, contendo uma camada de aproximadamente $1 \mathrm{~kg}$ de areia esterilizada e incinerada em mufla $\left(2 \mathrm{~h}, 500^{\circ} \mathrm{C}\right)$ e 4 litros de água de manutenção. As bandejas foram cobertas por gaiolas de nylon para retenção dos adultos e mantidas sob aeração contínua em sala com temperatura de $23-25^{\circ} \mathrm{C}$, fotoperíodo de 12 horas. O estágio larval dura em média de 12 a 15 dias e, para essas condições de alimento e temperatura, a emergência ocorre em torno do $15^{0}$ dia.

A água de cultivo é preparada a partir de água destilada e deionizada, ajustando-se a dureza para 10 a $15 \mathrm{mg}^{-\mathrm{L}^{-1}}$ de $\mathrm{CaCO}_{3}$ e $\mathrm{pH}$ entre 7,0 e 7,5. O ajuste da dureza foi feito utilizando-se uma solução contendo $1,5 \mathrm{~g} \cdot \mathrm{L}^{-1}$ de sulfato de cálcio (solução1) e uma segunda solução contendo $0,2 \mathrm{~g} \cdot \mathrm{L}^{-1}$ de cloreto de potássio, 4,80 g.L ${ }^{-1}$ de bicarbonato de sódio e 6,10 g. $\mathrm{L}^{-1}$ de sulfato de magnésio (solução 2), considerando que, para cada miligrama de dureza a ser aumentada, deve-se acrescentar $0,5 \mathrm{~mL}$ da solução 1 e 0,25 mL da solução 2 por litro de água a ser ajustado. A medida da dureza da água foi feita por titulação com solução de EDTA (CETESB, 1991; APHA, 1998).

No dia em que as larvas foram transferidas para as bandejas, elas foram alimentadas com cultura de Selenastrum capricornutum em fase exponencial de crescimento na mesma proporção de $1.10^{5}$ cél.L $^{-1}$. No decorrer do cultivo, os organismos foram alimentados com solução $10 \mathrm{~g} \cdot \mathrm{L}^{-1}$ de ração para peixes Tetramin, sendo adicionados $22 \mathrm{~mL}$ por bandeja dessa solução.

\subsection{2- Controle de qualidade dos organismos-teste}

Os testes de sensibilidade com cloreto de potássio foram feitos mensalmente, de acordo com os procedimentos descritos por FONSECA (1997). Larvas do $4^{0}$ ínstar (7/8 dias) foram adicionadas às diferentes concentrações da solução teste $(1,5 ; 2,25$; 3,$4 ; 5,0$ e 7,5 g. $\left.\mathrm{L}^{-1}\right)$, mais um controle, e mantidas por 96 horas em sala com temperatura variando de 22 a $25^{\circ} \mathrm{C}$, fotoperíodo de 12 horas e com alimento apenas no primeiro dia. Para cada concentração foram utilizadas 3 réplicas contendo, cada uma delas, $200 \mathrm{ml}$ de solução teste e 6 larvas de Chironomus xanthus.

Após o período de contato, foi registrado o número de organismos mortos em cada concentração e os valores de $\mathrm{CE}(\mathrm{I}) 50$ 96h foram calculados através do método Trimmed Spearman - Karber (HAMILTON et al., 1977). Medidas de $\mathrm{pH}$, condutividade, temperatura e dureza foram realizadas no início e término dos experimentos para as diferentes concentrações testadas. 
A carta-controle da sensibilidade de $\mathrm{C}$. xanthus ao $\mathrm{KCl}$ está apresentada na figura xx. Os valores de $\mathrm{CE}(\mathrm{I}) 50 ; 96 \mathrm{~h}$ para a substância referência, cloreto de potássio, obtidos com as culturas de Chironomus xanthus (Tabela 12), variaram de 3,08 a 6,6 g. $\mathrm{L}^{-1}$ de cloreto de potássio. As culturas que apresentaram valores de $\mathrm{CE}(\mathrm{I}) 50,96 \mathrm{~h}$ dentro da faixa de sensibilidade estabelecida, foram consideradas adequadas para serem utilizadas em testes de toxicidade (FONSECA, 1997).

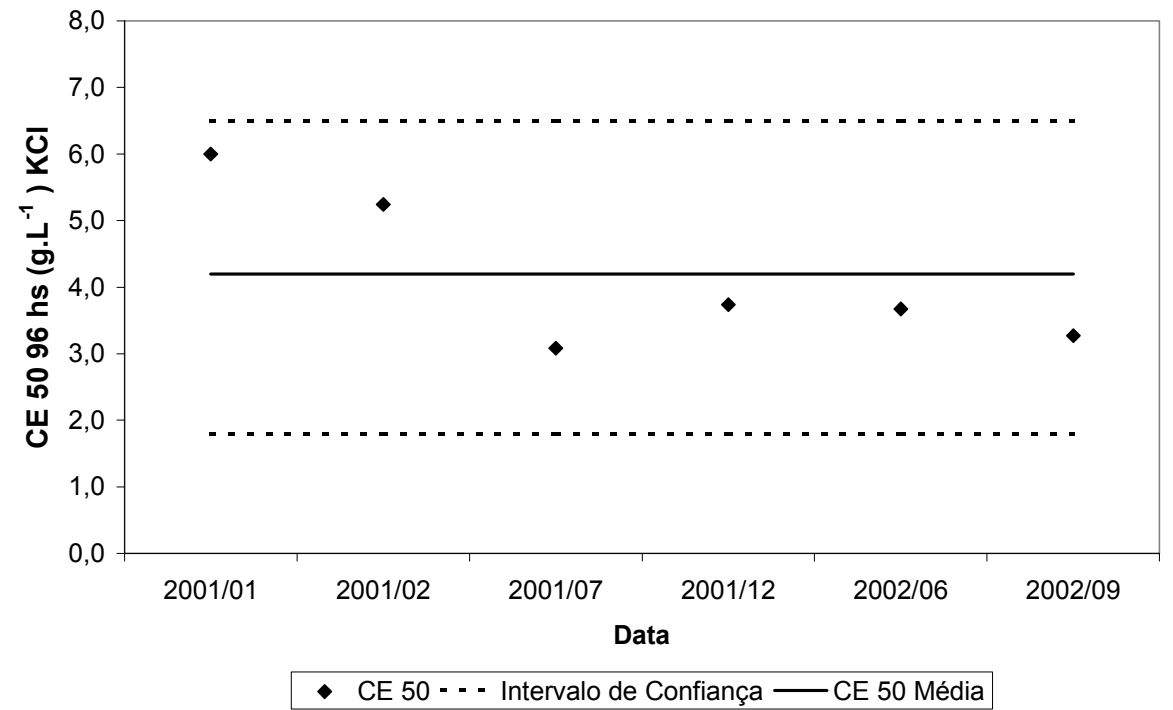

Figura 03: Carta-controle da sensibilidade de C. xanthus ao $\mathrm{KCl}$ no período de janeiro de 2001 a setembro de 2002.

Tabela 12: Carta controle da sensibilidade de $C$. xanthus ao cloreto de potássio.

\begin{tabular}{lcc}
\hline \multicolumn{3}{c}{ Cloreto de Potássio $-g \cdot \mathrm{L}^{-1}$} \\
\hline \multicolumn{1}{c}{ Data } & CE50 96hs & IC (95\%) \\
\hline $2001 / 01$ & 6,00 & $5,39-6,69$ \\
$2001 / 02$ & 5,24 & $4,70-5,84$ \\
$2001 / 07$ & 3,08 & $2,55-3,73$ \\
$2001 / 12$ & 3,74 & $2,71-5,15$ \\
$2002 / 06$ & 3,67 & $2,65-5,09$ \\
$2002 / 09$ & 3,27 & $2,42-4,30$ \\
\hline Média & & 4,2 \\
Desvio Padrão & & 1,2 \\
Coeficiente de Variação & & 28,2 \\
Faixa & & $1,8-6,5$ \\
\hline \hline
\end{tabular}




\subsection{3 - Testes de toxicidade com $\mathrm{Cr}$ e ao $\mathrm{Cu}$}

Os testes de toxicidade com $\mathrm{Cr}$ e $\mathrm{Cu}$ utilizando $\mathrm{C}$. xanthus foram realizados entre julho de 2001 e janeiro de 2002, seguindo a metodologia descrita em FONSECA (1997).

Larvas do $4^{0}$ ínstar (7/8 dias) foram adicionadas às diferentes concentrações da solução teste, mais um controle, e mantidas por 96 horas em sala com temperatura variando de 22 a $25^{\circ} \mathrm{C}$, fotoperíodo de 12 horas e com alimento apenas no primeiro dia. Para cada concentração foram feitas 3 réplicas contendo, cada uma delas, $200 \mathrm{ml}$ de solução teste e 6 larvas de $C$. xanthus.

Após o período de contato, foi registrado o número de organismos mortos em cada concentração e os valores de CE (I) 50;96h foram calculados através do método Trimmed Spearman - Karber (HAMILTON et al., 1977).

Os testes de toxicidade de $\mathrm{Cr}$ com $C$. xanthus foram realizados com a seguinte faixa de concentrações: 1, 2, 3, 4 e $5 \mathrm{mg} \mathrm{Cr} . \mathrm{L}^{-1}$. As concentrações teste foram preparadas com água de cultivo, a partir de soluções estoque de $\mathrm{K}_{2} \mathrm{Cr}_{2} \mathrm{O}_{7}$, com concentração de $\mathrm{Cr} 10$ e $100 \mathrm{mg} \cdot \mathrm{L}^{-1}$ em água destilada

Os testes de toxicidade do $\mathrm{Cu}$ para $C$. xanthus foram realizados com as seguintes concentrações: 0,$5 ; 1,2$, 4 , e $8 \mathrm{mg} \mathrm{Cu} \mathrm{L}^{-1}$. As soluções foram preparadas em meio de cultivo a partir de uma solução estoque de $\mathrm{CuSO}_{4} \cdot 5 \mathrm{H}_{2} \mathrm{O}$, contendo $10 \mathrm{e}$ $100 \mathrm{mg} \mathrm{Cu} . \mathrm{L}^{-1}$, preparada em água destilada.

Antes do preparo das soluções teste os valores de dureza e $\mathrm{pH}$ foram determinados na água de cultivo utilizada nas soluções, sendo o $\mathrm{pH}$ determinado novamente ao final do teste.

\section{2- Resultados e discussão}

Os valores de $\mathrm{CE}(\mathrm{I}) 5096$ hs para $\mathrm{Cr}$, obtidos com as culturas de $C$. xanthus, variaram entre 0,74 e $4,4 \mathrm{mg} \cdot \mathrm{L}^{-1}$. Foram realizados 12 testes, sendo que nos dois primeiros não se observou nenhum efeito sobre os organismos e em outros dois não foi possível calcular a CE (I) 50 pelo método Trimmed Spearman Karber. A CE(I)50 $96 \mathrm{~h}$ média foi igual a 2,4 $( \pm 1,4) \mathrm{mg} \cdot \mathrm{L}^{-1}$. Esses resultados indicam que $C$. xanthus não é um organismo sensível ao $\mathrm{Cr}$, com valores de CE (I) 50 apresentando grande variação (CV: 58\%) entre si, não sendo possível o cálculo do limite de sensibilidade inferior. Durante a realização dos testes observou-se grande variabilidade entre os resultados obtidos em diferentes testes com os organismos expostos às mesmas concentrações de $\mathrm{Cr}$ e entre as réplicas em um mesmo teste, sugerindo que os resultados podem estar sendo influenciados por características genéticas individuais, 
pois os testes foram realizados com larvas provenientes de uma mesma desova e cultivados numa mesma bandeja.

Tabela 13: Valores de CE (I) 50 96h obtidos nos testes de toxicidade com $\mathrm{Cr}$ com C. xanthus.

\begin{tabular}{cc}
\hline \hline CE (I) 50 96h (mg..$\left.^{-1} \mathrm{Cr}\right)$ & $\mathrm{IC}(95 \%)$ \\
\hline 0,74 & $(0,36-2,8)$ \\
4,4 & $(2,1-6,3)$ \\
1,3 & $(0,74-2,16)$ \\
2,9 & $(1,87-4,43)$ \\
2,0 & $(1,07-3,8)$ \\
0,8 & - \\
3,9 & - \\
3,6 & - \\
\hline \hline CE (50); 96 h médio & 2,4 \\
Faixa de Sensibilidade & $0-5,3$ \\
Desvio Padrão & 1,4 \\
Coeficiente de Variação & $58 \%$ \\
\hline \hline
\end{tabular}

Os valores de $\mathrm{CE}(\mathrm{I}) 50$ para $\mathrm{Cu}$, obtidos com as culturas de $C$. xanthus, variaram entre 0,16 e $0,48 \mathrm{mg} \cdot \mathrm{L}^{-1}$. Foram realizados 12 testes, sendo que em dois deles não foi possível calcular a CE (I) 50 pelo método Trimmed Spearman Karber. A $\mathrm{CE}(\mathrm{I}) 50$ 96h média foi igual a 0,27 $( \pm 0,09) \mathrm{mg} \cdot \mathrm{L}^{-1}$. Os valores de $\mathrm{CE}(\mathrm{I}) 5096 \mathrm{~h}$ para $\mathrm{Cu}$, obtidos com as culturas de C. xanthus, estão apresentados na Tabela 14.

Tabela 14: Valores de CE (I) 50 96h obtidos nos testes de toxicidade com Cu com C. xanthus

\begin{tabular}{cc}
\hline \hline CE (I) 50 96h (mg..$\left.^{-1} \mathrm{Cu}\right)$ & $\mathrm{IC}(95 \%)$ \\
\hline \hline 0,25 & $(0,12-0,39)$ \\
0,16 & $(0,09-0,45)$ \\
0,25 & $(0,1-0,6)$ \\
0,21 & $(0,12-0,51)$ \\
0,25 & $(0,16-0,39)$ \\
0,29 & $(0,21-0,40)$ \\
0,48 & - \\
0,32 & $(0,25-0,42)$ \\
0,2 & - \\
0,25 & $(0,11-0,6)$ \\
\hline \hline CE (50); 96 h médio & 0,27 \\
Faixa de Sensibilidade & $0,09-0,44$ \\
Desvio Padrão & 0,09 \\
Coeficiente de Variação & $32,9 \%$ \\
\hline \hline
\end{tabular}

ALMEIDA (2002), determinou a sensibilidade de $C$. xanthus para $\mathrm{K}_{2} \mathrm{Cr}_{2} \mathrm{O}_{7}$ e $\mathrm{CuSO}_{4}$, apresentando valores de CL 50 iguais a 7,12 (4,8-9,4) mg.L-1 e 1,5 (1,1-1,8) mg. $\mathrm{L}^{-1}$, respectivamente. Esses valores correspondem a $1,3 \mathrm{mg} \cdot \mathrm{L}^{-1}$ de $\mathrm{Cr}$ e $0,37 \mathrm{mg} \cdot \mathrm{L}^{-1}$ 
de $\mathrm{Cu}$, e são comparáveis aos determinados neste trabalho. A CE (I) 50 média determinada para $\mathrm{Cr}$ neste trabalho $\left(2,4 \mathrm{mg} \cdot \mathrm{L}^{-1}\right)$, foi superior ao valor citado, mas deve ser considerada a grande variabilidade nos resultados obtidos para este metal.

A CE (I) 50 média, determinada para o $\mathrm{Cr}$, foi aproximadamente uma ordem de grandeza maior que a determinada para o $\mathrm{Cu}$. Assim, apesar de $\mathrm{Cu}$ ser um micronutriente essencial, $C$. xanthus mostrou-se muito mais sensível ao $\mathrm{Cu}$ que ao $\mathrm{Cr}$, da mesma forma que os organismos zooplanctônicos testados.

Com base em dados reportados na literatura (Tabela 15), Chironomus xanthus apresentou maior sensibilidade ao $\mathrm{Cu}$ que outros Chironomidae, como $C$. crassiforceps, Polypedilum nubifer, C. riparius, C. decorus e C. tentans (PECK et al., 2002; HATAKEYAMA,1988; DOBBS et al., 1994; KOSALWAT \& KNIGHT, 1987; SUEDEL et al., 1996). C. xanthus apresentou também maior sensibilidade ao $\mathrm{K}_{2} \mathrm{Cr}_{2} \mathrm{O}_{7}$ que Chironomus tentans (CL/CE $5061,00 \mathrm{mg} / \mathrm{L} \mathrm{K}_{2} \mathrm{Cr}_{2} \mathrm{O}_{7}$ ).

Assim, pode-se dizer que $C$. xanthus apresenta maior sensibilidade a metais que outras espécies de quironomideos utilizados em testes de toxicidade, apesar dos valores de CE 50 serem bastante altos em comparação aos apresentados por outras espécies de organismos utilizadas em testes, como $D$. similis e $C$. dubia.

Tabela 15: Valores de CE (50) (mg. $\mathrm{L}^{-1} \mathrm{Cu}$ ) para Chironomidae determinados por diversos autores

\begin{tabular}{lcl}
\hline \hline Espécie & $\mathrm{CE}(\mathrm{I}) 50 \mathrm{mg} \cdot \mathrm{L}^{-1} \mathrm{Cu}$ & Autor \\
\hline \hline Chironomus crassiforceps & $0,64-2,3$ & PECK et al., 2002 \\
Polypedilum nubifer & 0,63 & HATAKEYAMA,1988 \\
Chironomus riparius & 1,2 & DOBBS et al., 1994 \\
Chironomus decorus & 0,7 & KOSALWAT \& KNIGHT, 1987 \\
Chironomus tentans & 0,53 & SUEDEL et al., 1996 \\
Chironomus xanthus & 0,27 & Presente trabalho \\
\hline \hline
\end{tabular}

\section{5 - Selenastrum capricornutum}

A utilização de microalgas em testes de toxicidade apresenta grande importância uma vez que as algas são os produtores primários das cadeias tróficas de ecossistemas aquáticos, e qualquer alteração da composição específica da comunidade fitoplanctônica pode afetar a estrutura e a função de todo o ecossistema. Através dos testes com algas pode-se obter informações a respeito da disponibilidade de substâncias químicas para esses organismos, e seus efeitos estimuladores ou inibidores, sendo o crescimento a resposta que retrata esses efeitos.

A escolha de espécies de algas para utilização em testes de toxicidade é feita considerando a morfologia, ecofisiologia e as propriedades de cultivo, incluindo classificação taxonômica, características de nutrição, a habilidade de formar 
suspensões homogêneas e propriedades de crescimento (KOMAREK \& MARVAN, 1979). Alguns autores sugerem que o uso de espécies sensíveis é mais importante que o uso de espécies nativas, enquanto outros sugerem que o uso de organismos padronizados é mais importante que o uso de espécies sensíveis (ROJCKOVÁPADRTOVÁ \& MARSALEK, 1999).

Selenastrum capricornutum, também denominada Pseudokirchneriella subcapitata e mais recentemente Raphidocelis subcapitata, foi isolada pela primeira vez na Noruega, em 1959, e é a espécie de alga sobre a qual a técnica de cultivo e dados de toxicidade são mais bem conhecidos em função de sua utilização em testes de toxicidade desde a década de 60 (LEWIS, 1993). Nestes testes normalmente são avaliados parâmetros como biomassa, taxa de crescimento e ainda modificações morfológicas na cor, tamanho e forma. Diversas agências reguladoras nacionais e internacionais apresentam normas de padronização para testes de toxicidade (OECD, 1984; ISO 8692:1989; ISO, 1989; NBR 12648:1992; ABNT, 1992; EPA-821-R-02-013 EPA 2002; OECD 2002).

As algas que vivem em águas contaminadas por metais normalmente apresentam resistência a estes compostos. O contato das algas com os metais se dá através da exposição direta, seguida por processos de adsorção na parede celular, distribuição no interior da célula, metabolismo e possível eliminação (MAGDALENO, 2001). A adsorção de metais na parede celular pode ser considerada um mecanismo de detoxificação, assim como o acúmulo e imobilização de metais nos vacúolos, a formação de complexos orgânicos e proteínas.

Em revisão sobre os efeitos tóxicos do $\mathrm{Cr}$ para algas, CERVANTES et al. (2001) citam a inibição no crescimento das culturas de S. capricornutum em 100 ppm de $\mathrm{Cr}(\mathrm{VI})$, o que não é observado com a mesma concentração de $\mathrm{Cr}$ (III). Os gêneros Chlorella. e Scenedesmus apresentam inibição na fotossíntese em presença de Cr. Porém, muitas algas apresentam tolerância ao Cr (VI), como Scenedesmus, Chlorella e Euglena, apesar de terem seu comportamento reprodutivo alterado. Oscillatoria, Phormidium, Scenedesmus e Pandorina apresentam aumento na população em concentrações entre 20 e 80 ppm de $\mathrm{Cr}$ (CERVANTES et al., op. cit).

Algumas algas podem ainda remover o $\mathrm{Cr}$ de soluções. Segundo BRADY et al (1994), Selenastrum reteve 39\% do $\mathrm{Cr}$ em solução de amostras de efluente de curtume. Em soluções artificiais, Scenedesmus, Selenastrum e Chlorella retiveram 83 - $99 \%$ do $\mathrm{Cr}$ (III), e apenas $18-22 \%$ do $\mathrm{Cr}(\mathrm{VI})$.

Alguns dos efeitos da exposição de algas ao $\mathrm{Cu}$ correspondem a desorganização dos cloroplastos, alta incidência de vácuolos, diminuição na 
concentração de clorofila e na densidade celular e peroxidação de lipídios (SCHIARITI et al, 2001).

\section{1- Metodologia}

\subsection{1- Cultivo e manutenção dos organismos teste}

Os inóculos de Selenastrum capricornutum foram mantidos em meio de ágar inclinado com peptona protease, em condições controladas de temperatura e luminosidade. O cultivo foi feito em meio L. C. Oligo, o qual foi autoclavado em erlenmeyer a $121^{\circ} \mathrm{C}$ por 15 minutos. Em condições assépticas foi transferida, com o auxílio de uma alça de platina flambada e esfriada, uma porção do inóculo da cultura

sólida de $S$. capricornutum para o frasco contendo o meio de cultura, que foi então incubada, a $24 \pm 2{ }^{\circ} \mathrm{C}$, com agitação e luminosidade contínuas (100 - 175 rpm e 5000 lux, respectivamente), por um período de 5 a 7 dias, até atingir a fase exponencial de crescimento (NBR 12648:1992; ABNT, 1992 e Projeto NBR 12648:2002; ABNT, 2000).

\subsection{2- Testes de toxicidade com $\mathrm{Cr}$ e $\mathrm{Cu}$}

Os testes de toxicidade com $\mathrm{Cr}$ e $\mathrm{Cu}$ foram realizados paralelamente, a partir da repicagem de um mesmo inóculo, entre maio e outubro de 2002. De acordo com ABNT (Projeto NBR 12648:2002; ABNT, 2000) o parâmetro utilizado na avaliação da CE (I) 50 é o crescimento algáceo. A determinação do crescimento algáceo pode ser realizada a partir da contagem celular, conteúdo de clorofila ou turbidez. Neste trabalho, o crescimento algáceo foi avaliado através da contagem do número de células da suspensão em microscópio óptico, utilizando-se câmaras de contagem de Neubauer, após 96 horas de exposição, e a CE (I) 50 calculada através do método Trimmed Spearman - Karber (HAMILTON et al., 1977) a partir das diferenças das densidades finais e iniciais, e de sua expressão em porcentagem em relação ao controle.

A partir do meio de cultivo normalmente utilizado para $S$. capricornutum, preparou-se soluções de $\mathrm{K}_{2} \mathrm{Cr}_{2} \mathrm{O}_{7}$ e $\mathrm{CuSO}_{4} .5 \mathrm{H}_{2} \mathrm{O}$ em cinco diferentes concentrações, sendo 100, 200, 400, 800 e $1600 \mu \mathrm{g} \cdot \mathrm{L}^{-1} \mathrm{Cr}^{6+}$ e 25, 50, 100, 200 e $400 \mu \mathrm{g} \cdot \mathrm{L}^{-1} \mathrm{Cu}^{2}$, respectivamente. Um volume de $100 \mathrm{ml}$ destas soluções foi transferido para erlenmeyers de $250 \mathrm{ml}$ de capacidade, em triplicata. Em seguida, todos os frascos contendo as soluções foram esterilizados sob luz ultravioleta por 30 minutos, após o que cada uma das soluções teste foi inoculada com uma concentração conhecida de células de $S$. capricornutum. 
As soluções teste foram mantidas em mesa agitadora, sem restrição de luz por 96 horas, durante a fase exponencial de crescimento das culturas. Ao final do teste, de cada erlenmeyer retirou-se uma alíquota para a contagem do número de células produzidas durante o teste, que foi preservada com Solução Transeou para posterior contagem.

\section{2- Resultados e discussão}

Os valores de CE (I) 50 96h para $\mathrm{Cr}$, obtidos com as culturas de $\mathrm{S}$. capricornutum, variaram entre 0,34 e $0,42 \mathrm{mg} \cdot \mathrm{L}^{-1}$. Foram realizados um total de 7 testes, sendo que em três deles não foi observada inibição no crescimento das algas em nenhuma das concentrações testadas. A CE (I) 50 96h média foi igual a 0,42 ( \pm $0,07) \mathrm{mg} \cdot \mathrm{L}^{-1}$. Os valores de $\mathrm{CE}(\mathrm{I}) 5096 \mathrm{~h}$ para $\mathrm{Cr}$, obtidos com as culturas de $S$. capricornutum, estão apresentados na Tabela 16.

Tabela 16: Valores de CE (I) 50 96h obtidos nos testes de toxicidade com $\mathrm{Cr}$ com $\mathrm{S}$. capricornutum.

\begin{tabular}{cc}
\hline \hline CE (I) 50;96 (mg..$\left.^{-1} \mathrm{Cr}\right)$ & $\mathrm{IC}(95 \%)$ \\
\hline \hline 0,41 & $(0,31-0,5)$ \\
0,34 & $(0,28-0,45)$ \\
0,5 & $(0,42-0,65)$ \\
0,42 & $(0,29-0,67)$ \\
\hline \hline CE (50); 96 h médio & 0,42 \\
Faixa de Sensibilidade & $0,28-0,0,56$ \\
Desvio Padrão & 0,07 \\
Coeficiente de Variação & $16,7 \%$ \\
\hline \hline
\end{tabular}

Os valores de $\mathrm{CE}(\mathrm{I}) 50$ 96h para $\mathrm{Cu}$, obtidos com as culturas de $\mathrm{S}$. capricornutum, variaram entre 0,03 e $0,08 \mathrm{mg} \cdot \mathrm{L}^{-1}$. Foram realizados um total de 5 testes, dentre os quais um foi descartado, não tendo sido possível o cálculo da CE (50) pelo método Trimmed Spearman - Karber (HAMILTON et al., 1977). A CE(I)50; $96 \mathrm{~h}$ média foi igual a $0,03( \pm 0,006) \mathrm{mg} \cdot \mathrm{L}^{-1}$. Os valores de $\mathrm{CE}(\mathrm{I}) 5096 \mathrm{~h}$ para $\mathrm{Cu}$, obtidos com as culturas de S. capricornutum, estão apresentados na Tabela 17. 
Tabela 17: Valores de CE (I) 5096 obtidos nos testes de toxicidade com Cu com S. capricornutum.

\begin{tabular}{cc}
\hline \hline CE (I) 50 96 (mg. $\left.{ }^{-1} \mathrm{Cu}\right)$ & IC $(95 \%)$ \\
\hline 0,025 & $(0,018-0,031)$ \\
0,032 & $(0,029-0,038)$ \\
0,027 & $(0,016-0,032)$ \\
0,038 & $(0,024-0,044)$ \\
\hline \hline CE (50); 96 h médio & 0,03 \\
Faixa de Sensibilidade & $(0,018-0,042)$ \\
Desvio Padrão & 0,006 \\
Coeficiente de Variação & $20 \%$ \\
\hline \hline
\end{tabular}

Em trabalho sobre a toxicidade de três compostos metálicos $\left(\mathrm{K}_{2} \mathrm{Cr}_{2} \mathrm{O}_{7}, \mathrm{ZnSO}_{4}\right.$ e $\mathrm{CuSO}_{4} .5 \mathrm{H}_{\mathrm{s}} \mathrm{O}$ ) e três herbicidas (Goal 2E, Stomp 400 SC e Zeazin S-40), utilizando 7 espécies de algas (Raphidocelis subcapitata, Scenedesmus quadricauda, Scenedesmus subscapitus, Chlamidomonas reinhardt, Synechococcus leopoliensis, Stichococcus bacillaris e Chlorella kessleri), ROJCKOVÁ-PADRTOVÁ \& MARSALEK (1999) concluíram que S.capricornutum ( $R$. subcapitata) foi a espécie mais sensível, considerando a sensibilidade média aos 6 compostos testados. O valor de CE (I) 50 obtido para $\mathrm{K}_{2} \mathrm{Cr}_{2} \mathrm{O}_{7}$ com as culturas de $\mathrm{S}$. capricornutum $\left(396,1 \mu \mathrm{g} \cdot \mathrm{L}^{-1} \mathrm{~K}_{2} \mathrm{Cr}_{2} \mathrm{O}_{7}\right)$ foi o menor em comparação com os valores determinados para as demais espécies e corresponde a $70 \mu \mathrm{g} . \mathrm{L}^{-1}$ de Cr. Já a CE (I) 50 determinada para Cu para esta espécie $\left(163,5 \mu \mathrm{g} \cdot \mathrm{L}^{-1} \mathrm{CuSO}_{4} .5 \mathrm{H}_{2} \mathrm{O}\right)$ foi maior que as determinadas para $\mathrm{S}$. leopoliensis e Chlamidomonas reinhardt, e corresponde a 41,6 $\mu \mathrm{g} \cdot \mathrm{L}^{-1}$ de $\mathrm{Cu}$. Comparando-se estes valores com os obtidos neste trabalho, observa-se que os valores médios da CE (I) 50 para Cu são similares, enquanto que para $\mathrm{Cr}$ os valores obtidos pelos autores citados são bem menores.

MAGDALENO (2001) comparou a toxicidade do $\mathrm{Cu}, \mathrm{Cd}$ e $\mathrm{Zn}$ entre $\mathrm{S}$. capricornutum e quatro espécies de algas (Scenedesmus acuminatus, Ankitrodesmus fusiformis, Chlorella ellipsoidea e Monoraphidium contortum) isoladas de um rio contaminado por metais provenientes de efluentes industriais, e constatou que apenas Ankitrodesmus fusiformis apresentou sensibilidade similar à de $S$. capricornutum, enquanto as outras foram muito mais resistentes. A CE (I) 5096 hs determinada para o $\mathrm{Cu}$ pelo autor foi igual a $88,4 \mu \mathrm{g} \cdot \mathrm{L}^{-1}$, quase três vezes maior que a determinada neste trabalho.

A densidade algácea no meio de cultivo pode influenciar na toxicidade do $\mathrm{Cu}$ para as culturas. As densidades utilizadas nos testes de toxicidade excedem em muitas ordens de grandeza a densidade encontrada nos ambientes naturais, mesmo 
em situações de bloom algal. A toxicidade do $\mathrm{Cu}$ à $\mathrm{S}$. capricornutum foi pelo menos duas vezes menor com densidade celular inicial igual a $10^{5}$ cel. $\mathrm{mL}^{-1}$ do que em $10^{2}$ ou $10^{4}$ cel. $\mathrm{mL}^{-1}$, gerando valores de CE (I) 50 de $17 \mu \mathrm{g} \cdot \mathrm{L}^{-1}$ e menores de 7,5 $\mu \mathrm{g} . \mathrm{L}^{-1}$, respectivamente (FRANKLIN et al., 2002). Na Tabela 18 são apresentados alguns valores de CE 50 determinados para de $S$. capricornutum por diversos autores e na Tabela 19 os valores de CE 50 para compostos contendo $\mathrm{Cu}$ e $\mathrm{Cr}$ para diferentes espécies de algas.

Tabela 18: Valores de CE 50 determinados com culturas de $S$. capricornutum por diversos autores.

\begin{tabular}{cccc}
\hline CE 50 & CE 50 & Tempo de & Referência \\
$\left(\mathrm{mg} . \mathrm{L}^{-1} \mathrm{Cr}\right)$ & $\left(\mathrm{mg} \cdot \mathrm{L}^{-1} \mathrm{Cu}\right)$ & Exposição & \\
\hline \hline & 0,137 & $96 \mathrm{hs}$ & OLIVEIRA - FILHO, 2004 \\
& $0,006-0,017$ & $72 \mathrm{hs}$ & FRANKLIN et al., 2002. \\
0,09 & $168 \mathrm{hs}$ & MAGDALENO, 2001 \\
0,07 & 0,042 & $72 \mathrm{hs}$ & ROJCKOVÁ-PADRTOVÁ \& MARSALEK, 1999 \\
0,42 & 0,03 & $96 \mathrm{hs}$ & Presente trabalho \\
\hline \hline
\end{tabular}

Apesar da tolerância relativa de $S$. capricornutum aos metais estudados, especialmente ao $\mathrm{Cr}$, esta espécie parece ser mais sensível que outras, também empregadas em testes de toxicidade. Os valores de CE (I) 50 obtidos, para ambos os casos, são muito superiores aos estabelecidos pelo CONAMA 20/ 1986, indicando que a avaliação da toxicidade de corpos receptores e efluentes não devem ser conduzidos unicamente com esta espécie. 
Tabela 19: Valores de CE 50 para compostos contendo Cu e Cr para diferentes espécies de algas.

\begin{tabular}{|c|c|c|c|c|}
\hline Espécie & $\begin{array}{c}\text { CE 50 } \\
\text { mg. }^{-1} \\
\text { CuSO }_{4} \cdot 5 \mathrm{H}_{2} \mathrm{O}\end{array}$ & $\begin{array}{c}\mathrm{CE} \mathrm{50} \\
\mathrm{mg} \cdot \mathrm{L}^{-1} \\
\mathrm{~K}_{2} \mathrm{Cr}_{2} \mathrm{O}_{7}\end{array}$ & $\begin{array}{l}\text { Tempo de } \\
\text { Exposição }\end{array}$ & Referência \\
\hline $\begin{array}{l}\text { Scenedesmus } \\
\text { quadricauda }\end{array}$ & $435,1^{*}$ & 2526,8 & $72 \mathrm{hs}$ & $\begin{array}{c}\text { ROJCKOVÁ-PADRTOVÁ \& } \\
\text { MARSALEK, } 1999\end{array}$ \\
\hline $\begin{array}{l}\text { Scenedesmus } \\
\text { subscapitus }\end{array}$ & $973,5^{\star}$ & 749,9 & 72 hs & $\begin{array}{l}\text { ROJCKOVÁ-PADRTOVÁ \& } \\
\text { MARSALEK, } 1999\end{array}$ \\
\hline $\begin{array}{l}\text { Chlamidomonas } \\
\text { reinhardt }\end{array}$ & $108,2^{*}$ & 812,8 & 72 hs & $\begin{array}{c}\text { ROJCKOVÁ-PADRTOVÁ \& } \\
\text { MARSALEK, } 1999\end{array}$ \\
\hline $\begin{array}{l}\text { Synechococcus } \\
\text { leopoliensis }\end{array}$ & $25,5^{*}$ & 3307,5 & 72 hs & $\begin{array}{c}\text { ROJCKOVÁ-PADRTOVÁ \& } \\
\text { MARSALEK, } 1999\end{array}$ \\
\hline $\begin{array}{l}\text { Stichococcus } \\
\text { bacillaris }\end{array}$ & $283,1^{*}$ & 1641,9 & $96 \mathrm{hs}$ & $\begin{array}{c}\text { ROJCKOVÁ-PADRTOVÁ \& } \\
\text { MARSALEK, } 1999\end{array}$ \\
\hline Chlorella kessleri & $1212,7^{*}$ & 575,4 & 72 hs & $\begin{array}{c}\text { ROJCKOVÁ-PADRTOVÁ \& } \\
\text { MARSALEK, } 1999\end{array}$ \\
\hline Espécie & $\begin{array}{l}\mathrm{CE}(\mathrm{I}) 50 \\
\mathrm{mg}^{-1} \mathrm{~L}^{-1} \mathrm{Cu}\end{array}$ & $\begin{array}{c}\mathrm{CE}(\mathrm{I}) 50 \\
\mathrm{mg} / . \mathrm{L}^{-1} \mathrm{Cr}\end{array}$ & $\begin{array}{l}\text { Tempo de } \\
\text { Exposição }\end{array}$ & Referência \\
\hline $\begin{array}{l}\text { Scenedesmus } \\
\text { acuminatus }\end{array}$ & $\begin{array}{c}170,3(137,1- \\
201,4)\end{array}$ & & $7 \mathrm{~d}$ & MAGDALENO, 2001 \\
\hline $\begin{array}{l}\text { Ankitrodesmus } \\
\text { fusiformis }\end{array}$ & $\begin{array}{c}72,0(51,4- \\
101,4)\end{array}$ & & $7 d$ & MAGDALENO, 2001 \\
\hline $\begin{array}{l}\text { Chlorella } \\
\text { ellipsoidea }\end{array}$ & 489 & & $7 d$ & MAGDALENO, 2001 \\
\hline $\begin{array}{c}\text { Monoraphidium } \\
\text { contortum }\end{array}$ & 164,1 & & $7 d$ & MAGDALENO, 2001 \\
\hline
\end{tabular}

* $1 \mathrm{mg} \mathrm{CuSO}{ }_{4} .5 \mathrm{H}_{2} \mathrm{O}$ contém 0,25 mg Cu; $1 \mathrm{mg} \mathrm{K}_{2} \mathrm{Cr}_{2} \mathrm{O}_{7}$ contém 0,18 mg de $\mathrm{Cr}$.

\section{6 - Pistia stratiotes}

Pistia stratiotes é uma planta aquática flutuante, sem caule, que pode atingir até $25 \mathrm{~cm}$ de diâmetro, nativa da América Tropical e amplamente distribuída por todo o Brasil. Apresenta crescimento vigoroso em reservatórios de água doce parada, principalmente em águas poluídas, sendo considerada séria planta daninha aquática, apesar de ocasionalmente ser cultivada em lagos decorativos com fins ornamentais (LORENZI \& MATOS, 2002). P. stratiotes tem sido também utilizada em pesquisas sobre biorremediação e pesquisas em bioquímica (TARLYN et al., 1998).

Os trabalhos realizados com $P$. stratiotes referem-se à sua distribuição, composição química e sua utilização em wetlands construídas para tratamento de efluentes. A utilização dessas plantas como biorremediadores no tratamento de águas residuárias e como indicadores de contaminação ambiental é mais comum que seu uso em testes de toxicidade, sendo que em tais testes é mais comum a verificação da ocorrência de bioacumulação (KLUMP et al., 2002; MAINE, et al., 2004).

Testes de toxicidade com macrófitas normalmente são realizados com Lemna sp. (APHA, AWWA, WEF, 1998; EPA -560/6-82-002, US EPA,1983; US EPA, 1996). Sobre a toxicidade de metais para $P$. stratiotes existem poucos dados disponíveis na 
literatura (ORME \& KEGLEY, 2004). Para estudos em fisiologia e bioquímica, Pistia apresenta características morfológicas mais adequadas que Lemna, além de se reproduzir por brotos, possibilitando a utilização de plantas geneticamente idênticas (TARLYN et al, 1998). A principal causa do pouco interesse na utilização de Pistia em testes de laboratório seria a dificuldade na obtenção e manutenção de culturas axênicas.

Cromo (VI) é altamente tóxico para as plantas, o que resulta em raízes, fitomassa e pigmentos fotossintéticos reduzidos, clorose e eventualmente a morte da planta (VAJPAYEE, 1999). Estágios progressivos de clorose e necrose são sintomas da toxicidade do $\mathrm{Cr}$ em plantas, sendo que os sintomas apresentados após exposição ao $\mathrm{Cr}$ (VI) são mais fortes que os causados por $\mathrm{Cr}$ (III), ocorrendo em menor tempo e em menores concentrações (CERVANTES et al., 2001). Cromo também prejudica a atividade da enzima nitrato redutase, sendo que as raízes sofrem uma inibição maior em relação às folhas.

\section{1 - Metodologia}

\subsection{1- Obtenção e manutenção dos organismos teste}

Os indivíduos de $P$. stratiotes utilizados nos testes foram coletados manualmente na porção sul da represa do Lobo, localizada nos municípios de Itirapina e Brotas, São Paulo, onde deságua o rio Itaqueri e ocorre o maior banco de macrófitas da represa. Após a coleta, as macrófitas foram mantidas em aquário, no laboratório de ecotoxicologia do NEEA/CRHEA/SHS/EESC/USP, com água coletada no mesmo ponto onde foram coletadas as plantas. Foram mantidos indivíduos adultos, que apresentavam brotos, os quais foram retirados no dia da montagem dos testes. Todas as plantas tiveram as folhas e raízes lavadas para a retirada de lagartas e pulgões, porém em alguns testes ocorreu a predação das folhas por alguns destes organismos. Quando da montagem dos testes, todos os indivíduos tiveram as raízes cortadas e a biometria determinada. A metodologia utilizada foi adaptada a partir das metodologias utilizadas em testes com Lemna sp (US EPA, 1983; 1996). O teste seguiu o mesmo desenho dos testes com Lemna sp., porém como o ciclo de vida de $P$. stratiotes é maior, outros parâmetros de efeito diferentes de número de frondes e letalidade foram investigados, como o comprimento e número das raízes.

Os indivíduos utilizados nos testes apresentavam 5-6 cm de altura, e entre 3 e 5 folhas. Os testes foram montados em recipientes plásticos com 2 litros de capacidade, e em cada recipiente foram colocados 5 indivíduos em 1 litro de solução. Os testes foram realizados em triplicata, com 3 concentrações, mais um controle para 
cada metal. Apenas um teste para cada metal foi realizado utilizando-se 5 diferentes concentrações.

Foram avaliadas as seguintes características após 7 dias de exposição: altura, diâmetro, número de folhas e número de raízes. A CE(I)50 168h foi calculada através do método Trimmed Spearman - Karber (HAMILTON et al., 1977). Foram considerados parâmetros de efeito o número de folhas final em comparação com o número de folhas inicial e o número de raízes desenvolvidas durante o tempo de exposição, reportando os efeitos como inibição em relação ao controle.

\subsection{2- Testes de toxicidade com $\mathrm{Cr}$ e $\mathrm{Cu}$}

Os testes de toxicidade com $P$. stratiotes foram realizados no período de agosto de 2003 a abril de 2004 . Os testes com Cr e Cu foram realizados em paralelo, utilizando organismos obtidos em uma mesma coleta.

As concentrações de $\mathrm{Cr}$ utilizadas nos testes com $P$. stratiotes foram baseadas em dados apresentados pela literatura (KAHKONEN \& MANNINEN, 1998; VAJPAYEE et al, 1999; GUTIÉRREZ, et al., 2000) em testes com outras macrófitas, como Lemna sp., Nelumbo nucifera e Elodea canadensis. As soluções foram preparadas a partir de água coletada na represa do Lobo, no mesmo local de onde foram coletadas as macrófitas. As concentrações teste utilizadas em dois testes preliminares foram 1,5 e $10 \mathrm{mg} \cdot \mathrm{L}^{-1}$ de $\mathrm{Cr}$, sendo que nenhum efeito foi observado, comparando-se com o controle. Em seguida foram realizados 2 testes com concentrações iguais a 10, 50 e $100 \mathrm{mg} \cdot \mathrm{L}^{-1} \mathrm{Cr}$ e um teste com concentrações de 10 , 20, 40, 60 e $80 \mathrm{mg} \cdot \mathrm{L}^{-1} \mathrm{Cr}$. Este último teste teve duração de 14 dias.

As soluções de Cu foram preparadas a partir da água coletada na represa do Lobo, do mesmo local onde foram coletadas as macrófitas. As concentrações teste utilizadas nos dois primeiros testes foram 1, 5 e $10 \mathrm{mg} \cdot \mathrm{L}^{-1}$, tendo ocorrido senescência completa nas plantas expostas à concentração mais alta. Foram realizados, então, 3 testes com concentrações mais baixas, entre 0,1 e $1,0 \mathrm{mg} \cdot \mathrm{L}^{-1}$, sendo em dois deles utilizadas 3 concentrações $\left(0,1 ; 0,5\right.$; e $\left.1,0 \mathrm{mg} \cdot \mathrm{L}^{-1}\right)$ e no último 5 concentrações $(0,2$; 0,$4 ; 0,6 ; 0,8$ e $1,0 \mathrm{mg} \cdot \mathrm{L}^{-1} \mathrm{Cu}$ ). Este último teste teve duração de 14 dias.

\section{2- Resultados e discussão}

Foram realizados 5 testes com $\mathrm{Cr}$ e $\mathrm{Cu}$. Dentre os parâmetros avaliados, o número de folhas e o número de raízes parecem ser os melhores indicadores de efeito para os contaminantes estudados. Assim sendo, a CE (I) 50 foi calculada em função destes parâmetros. Os resultados obtidos para cada um dos parâmetros estudados 
em cada teste estão apresentados em anexo. Nestes testes foram medidos a altura, o diâmetro, o número de folhas no início e final do experimento, e o desenvolvimento de raízes, que haviam sido previamente retiradas, ao final do teste. As características avaliadas, principalmente diâmetro e altura, apresentaram comportamentos muito diferentes entre os testes executados, sendo o aumento no numero de folhas e a produção de raízes os parâmetros escolhidos para a determinação da CE (50) 168 hs.

Nos primeiros testes realizados com $\mathrm{Cr}$, com concentrações entre 1 e 10 $\mathrm{mg} . \mathrm{L}^{-1}$ as plantas testadas não apresentaram sintomas de toxicidade, considerando-se os parâmetros avaliados, sendo que o número médio de raízes desenvolvido durante o período de exposição na solução de $5 \mathrm{mg} \cdot \mathrm{L}^{-1}$ foi maior que no controle, não tendo sido calculada a CE (I) 50. Nos testes com concentrações mais altas, observou-se o aumento no diâmetro médio das plantas em todas as concentrações de $\mathrm{Cr}$ testadas. $\mathrm{O}$ número de folhas aumentou apenas no controle, tendo apresentado um decréscimo nas plantas na última concentração-teste. A CE (I) 50 foi calculada usando como parâmetros de efeito o aumento no número de folhas, o número de raízes desenvolvidas no período de exposição aos contaminantes e o comprimento destas raízes. Os resultados obtidos estão apresentados na Tabela 20.

Tabela 20: Valores de CE(I) 50168 (mg. $\left.\mathrm{L}^{-1}\right)$ hs obtidos nos testes de toxicidade com $\mathrm{Cr}$ com $P$. stratiotes

\begin{tabular}{cccc}
\hline \hline & Número de raízes & Número de Folhas & $\begin{array}{c}\text { Comprimento das } \\
\text { Raízes }\end{array}$ \\
\hline \hline CE (I) 50 & \multicolumn{3}{c}{22,4} \\
IC (95\%) & $(9,4-53)$ \\
\hline CE (I) 50 & 52 & 33,7 & 32,8 \\
IC (95\%) & $(37,2-72,2)$ & $(25,1-45,3)$ & $(17,5-61,4)$ \\
\hline${ }^{*}$ CE (I) 50 & 21 & 39,4 & 28,2 \\
IC (95\%) & $(15,4-28,7)$ & $(27-56,7)$ & $(24,5-32,4)$ \\
\hline CE (I) 50 média & 36,5 & 31,8 & 30,5 \\
Faixa de Sensibilidade & $(0-80,3)$ & $(14,5-49,1)$ & $(24-37,0)$ \\
Desvio Padrão & 21,9 & 8,7 & 3,3 \\
Coeficiente de variação & $60,1 \%$ & $27,2 \%$ & $10,7 \%$ \\
\hline \hline & * teste realizado com 5 soluções-teste
\end{tabular}

As CE (I) 50 médias de Cr variaram entre 30,5 e 36,5 mg. $\mathrm{L}^{-1}$. Estes valores são um pouco maiores que os valores tóxicos para $P$. stratiotes reportados pela literatura, de 1 - 20 mg.L-1 (ORME \& KEGLEY, 2004), com base em efeitos bioquímicos, histológicos e mortalidade.

No primeiro teste realizado não foi possível calcular a CE (I) 50 através da avaliação das raízes das plantas, pois na primeira concentração a inibição do crescimento foi maior que $50 \%$ em relação ao controle. Entre os parâmetros utilizados 
nos cálculos de CE (I) 50, o comprimento das raízes foi o que gerou os menores valores para desvio padrão e coeficiente de variação. Os valores de CE (I) 50 calculados para cada um dos parâmetros analisados não apresentaram diferenças significativas entre si (ANOVA, $p<0,05)$, como pode ser visto pela análise de variância realizada utilizando-se todos os valores de obtidos pela avaliação dos 3 parâmetros (Tabela 22).

Nos testes realizados com soluções em concentrações mais altas, observouse aumento no diâmetro médio das plantas em todas as concentrações de $\mathrm{Cu}$ testadas. O desenvolvimento de raízes foi estimulado pela adição de $\mathrm{Cu}$ na concentração mais baixa de cada teste. Ao final das $168 \mathrm{hs}$ do teste, as plantas expostas à maior concentração de $\mathrm{Cu}\left(10 \mathrm{mg} \cdot \mathrm{L}^{-1}\right)$ apresentavam-se completamente senescentes. O número de folhas aumentou tanto no controle como nos testes, tendo apresentado um decréscimo nas plantas da última concentração-teste. O número de raízes foi maior no controle, e a partir de $5 \mathrm{mg} \cdot \mathrm{L}^{-1}$ de $\mathrm{Cu}$ as plantas não apresentaram nenhuma raiz. Os valores de CE (I) 50 determinados pelos testes com concentrações mais altas de Cu variaram entre 5,8 e 6,4 mg. $\mathrm{L}^{-1}$, porém somente em um dos casos foi possível calcular o intervalo de confiança, usando o número de folhas como parâmetro. Assim, como o limite inferior de sensibilidade não pode ser calculado, presume-se que efeitos de toxicidade podem estar ocorrendo em qualquer concentração menor que a primeira concentração teste. Os resultados obtidos estão apresentados na Tabela 21.

Tabela 21: Valores de CE(I) $50168\left(\mathrm{mg}^{\mathrm{L}} \mathrm{L}^{-1}\right)$ hs obtidos nos testes de toxicidade com Cu com $P$. stratiotes

\begin{tabular}{cccc}
\hline \hline & Número de raízes & Número de Folhas & $\begin{array}{c}\text { Comprimento das } \\
\text { Raízes }\end{array}$ \\
\hline \hline CE (I) 50 & & & 0,46 \\
IC (95\%) & 0,18 & $*$ & $(0,39-0,54)$ \\
\hline CE (I) 50 & $(0,14-0,25)$ & & 0,52 \\
IC (95\%) & 0,47 & $*$ & $(0,45-0,62)$ \\
CE (I) 50 & $(0,37-0,58)$ & & 0,51 \\
IC (95\%) & 0,45 & 0,42 & $(0,44-0,6)$ \\
\hline CE (I) 50 média & $(0,41-0,5)$ & $(0,23-0,8)$ & 0,50 \\
Faixa de Sensibilidade & 0,37 & 0,42 & $(0,43-0,56)$ \\
Desvio Padrão & $(0,043-0,69)$ & $*$ & 0,03 \\
Coeficiente de variação & 0,16 & $*$ & $6,47 \%$ \\
\hline \hline
\end{tabular}

*valores não obtidos

De forma similar ao observado para o $\mathrm{Cr}$, o comprimento das raízes foi o parâmetro estudado que gerou os menores valores de desvio padrão e coeficiente de variação dentre os parâmetros avaliados. O número de folhas desenvolvidas não 
parece ser um bom indicativo, pois o cálculo da CE (I) 50 só foi possível em um dos testes realizados, demonstrando a não reprodutibilidade do efeito entre os testes. A análise de variância realizada com os valores de CE (I) 50 determinados pelo número de raízes e comprimento médio das raízes demonstrou não haver diferenças significativas $(p<0,05)$ entre os valores gerados com cada um dos grupos de dados (Tabela 22).

$P$. stratiotes aparenta ser mais sensível que Lemna sp ao Cu. Os valores de CE 50 para Lemna minor, em testes de 5 dias, reportados pela literatura, são de 2,3 mg. L $^{-1}$ (ORME \& KEGLEY, 2004).

Tabela 22: Síntese da análise de variância entre os valores de $\mathrm{CE}$ (50) de $\mathrm{Cr}$ e $\mathrm{Cu}$ determinados utilizando-se os diferentes parâmetros de efeito

\begin{tabular}{clll}
\hline \hline & $\mathrm{F}$ & valor-P & F crítico \\
\hline $\mathrm{Cr}$ & 0,129361 & 0,882189 & 6,944276 \\
$\mathrm{Cu}$ & 1,859413 & 0,244391 & 7,70865 \\
\hline \hline
\end{tabular}

F > F crítico: significativamente diferente.

Em relação ao teste conduzido por 14 dias, o valor de CE (I) 50 determinado para $\mathrm{Cr}$ não foi diferente dos determinados para os testes de 7 dias, que variaram entre 27 e 30,5 mg. $\mathrm{L}^{-1}$ em função dos parâmetros avaliados. Já para o teste com Cu, os valores de CE (I) 50 foram maiores que os determinados para 7 dias, indicando o desenvolvimento de tolerância, ou a diminuição da sensibilidade, ao Cu ao longo do tempo de exposição. Os valores de CE (I) 50 referentes a estes testes estão apresentados na Tabela 23.

Tabela 23: Valores de CE (I) 5014 dias de $\mathrm{Cr}$ e Cu para $P$. stratiotes

\begin{tabular}{cccc}
\hline \hline & Número de Raízes & Número de Folhas & $\begin{array}{c}\text { Comprimento das } \\
\text { Raízes }\end{array}$ \\
\hline \hline $\mathrm{Cr}$ & 30,5 & 27,2 & 30,4 \\
$\mathrm{IC}(95 \%)$ & $(28,1-33,1)$ & & $(28,0-33,0)$ \\
\hline $\mathrm{Cu}$ & 0,9 & & 0,7 \\
$\mathrm{IC}(95 \%)$ & $(0,88-0,92)$ & $(0,63-0,75)$ \\
\hline \hline
\end{tabular}

Em geral, o número de raízes e seu comprimento apresentaram sensibilidade similar nos testes realizados, enquanto o número de folhas parece não ser um bom parâmetro de avaliação de efeito.

As maiores dificuldades encontradas na realização dos testes de toxicidade com $P$. stratiotes foram a obtenção de indivíduos semelhantes em relação ao número de folhas e à relação altura/diâmetro e sem a presença de lagartas e pulgões, em 
número suficiente para a realização de cada teste. Ao longo do desenvolvimento dos testes alguns indivíduos foram descartados devido a predação por estes insetos, e no final, dois testes inteiros foram perdidos por este motivo. As diferenças na biometria dos indivíduos também podem interferir na expressão dos efeitos pelas plantas, tendo sido observado que plantas com maior número de folhas começa a desenvolver raízes mais rápido que plantas com menos folhas.

Uma alternativa para eliminar estes efeitos seria o cultivo das plantas em laboratório. Culturas axênicas de Pistia apresentam indivíduos de menor tamanho, morfologia complexa representativa, alta taxa de crescimento, facilidade de manipulação e hábito de crescimento por clones, sendo em geral mais uniformes que plantas não axênicas, não apresentando alterações morfológicas e fisiológicas mesmo após muitas subculturas (repicagens) (TARLYN et al., 1998).

\section{7- Oreochromis niloticus}

A utilização de peixes em testes de toxicidade é bem documentada e normatizada por diversas agências reguladoras (EPA 821-R-02-12, US EPA, 2002; OECD 203, OECD 1991; ISO 7346-1:1996, ISO, 1996; ABNT Projeto 00:001.44-01, ABNT, 2003c).

Peixes são considerados bons indicadores de toxicidade devido à sua importância ecológica e comercial. Muitas espécies de peixes podem ser utilizadas em estudos de toxicidade e a seleção de espécies depende do objetivo do teste, da disponibilidade de espécies e da facilidade de cultivo e manuseio dos animais. Algumas espécies normatizadas e utilizadas em testes de toxicidade são Pimephales promelas, Brachydanio rerio, Cyprinus carpio, Poecilia reticulata e Oncorhynchus

mykiss. No Brasil, estudos sobre a toxicidade do $\mathrm{Cu}$ foram realizados com Prochilodus scrofa (MAZON et al., 2000; CARVALHO, 2003) e (Brachy) Danio rerio (OLIVEIRA FILHO et al.; 2004).

Apesar de não se tratar de uma espécie nativa, O. niloticus é amplamente distribuída nos reservatórios brasileiros e cultivada em piscicultura, sendo muito utilizada na alimentação humana. Em termos de biomassa é a espécie mais abundante na represa do Lobo (MARINELLI, 2002). A maioria dos trabalhos realizados com O. niloticus está relacionada ao estresse oxidativo induzido pela exposição a substâncias tóxicas ou efluentes (RIBEIRO et al., 2000; TAGLIARI et al., 2004), da bioacumulação de metais (CLEARWATER et al., 2002; ÇOGUN \& KARGM, 2004) e sobre técnicas de cultivo e alimentação (PAN et al., 2003; ÇOGUN \& KARGM, op cit.). 
Apesar de $\mathrm{Cu}$ e $\mathrm{Cr}$ serem utilizados em rações como suplemento alimentar para O. niloticus (PAN op. cit; CLEARWATER, op cit), diversos trabalhos têm demonstrado os efeitos tóxicos destes metais em peixes.

\section{1- Metodologia}

\subsection{1- Obtenção e manutenção dos organismos teste}

Indivíduos juvenis com comprimento médio de $4,1 \mathrm{~cm}$ e peso médio de $0,6 \mathrm{~g}$ foram coletados em tanques de cultivo de peixes mantidos pelo CRHEA/EESC/USP. Após a coleta, os peixes foram mantidos em laboratório em meio ASTM, com dureza entre 40 - 48 mg Ca e mg. $\mathrm{L}^{-1}$, e pH entre 7,2 e 7,6, até realização dos testes. Os peixes não foram alimentados nas 24 horas anteriores à realização dos testes.

\subsection{2- Testes agudos}

Os testes foram realizados baseando-se na metodologia descrita pela norma NBR 12714:1993 (ABNT, 1993, substituída por Projeto 00:001.44-001, ABNT 2001). Os testes foram realizados em duplicata, utilizando 2 litros de solução por réplica, mantendo-se uma proporção de $1 \mathrm{~g}$ de peixe por litro de solução. A utilização de apenas duas réplicas por concentração teste se justifica em função do volume de resíduos químicos gerados quando do descarte dos testes, ressaltando que as concentrações utilizadas nos testes são muito altas, até $200 \mathrm{mg} \cdot \mathrm{L}^{-1}$ de $\mathrm{K}_{2} \mathrm{Cr}_{2} \mathrm{O}_{7}$ e até $10 \mathrm{mg} \cdot \mathrm{L}^{-1}$ de $\mathrm{CuSO}_{4}$. A CE(I)50 96h foi calculada através do método Trimmed Spearman - Karber (HAMILTON et al., 1977).

Com base nos testes de sensibilidade para Danio rerio realizados rotineiramente no laboratório de Ecotoxicologia do NEEA/CRHEA/ USP, que utiliza $\mathrm{K}_{2} \mathrm{Cr}_{2} \mathrm{O}_{7}$, foi determinada a primeira faixa de concentração testada para $\mathrm{Cr}^{6+}$ com $\mathrm{O}$. niloticus. As concentrações teste $\left(60,90,120,150\right.$ e $\left.180 \mathrm{mg} \cdot \mathrm{L}^{-1} \mathrm{Cr}\right)$ foram preparadas com água de cultivo, a partir de soluções estoque de $\mathrm{K}_{2} \mathrm{Cr}_{2} \mathrm{O}_{7}$, com concentração de $\mathrm{Cr}^{6+} 1$ g. $\mathrm{L}^{-1}$ em água destilada.

Com base em dados de CE (I) 50 reportados pela literatura para outros peixes (MAZON et al., 2000; CARVALHO, 2003; OLIVEIRA-FILHO et al., 2004) foi escolhida a faixa de concentrações a ser testada $\left(0,2 ; 0,4 ; 0,6 ; 0,8\right.$ e $1,0 \mathrm{mg} \cdot \mathrm{L}^{-1}$ de Cu$)$. As soluções foram preparadas em meio de cultivo a partir de uma solução estoque de $\mathrm{CuSO}_{4} \cdot 5 \mathrm{H}_{2} \mathrm{O}$, contendo $1 \mathrm{~g} \mathrm{Cu}^{2+} \cdot \mathrm{L}^{-1}$, preparada em água destilada. 


\section{2 - Resultados e discussão}

Os valores de $\mathrm{CL}$ (50) para $\mathrm{Cr}$ obtidos com os indivíduos de O. niloticus variaram entre 107,2 e $164 \mathrm{mg} \cdot \mathrm{L}^{-1}$. Ao todo foram realizados 6 testes, porém a CL (50) somente pôde ser calculada para quatro destes testes. Os valores de CL (50) obtidos com O. niloticus expostos ao $\mathrm{Cr}$ estão apresentados na Tabela 24.

Tabela 24: Valores de CE (I) 50 96h obtidos nos testes de toxicidade com $\mathrm{Cr}$ com O. niloticus

\begin{tabular}{cc}
\hline \hline \multicolumn{1}{c}{ CE (I) 50 96 (mg. - $\left.^{-1} \mathrm{Cr}\right)$} & IC $(95 \%)$ \\
\hline 107,2 & $(86,5-132,8)$ \\
164 & $(117-188,4)$ \\
148 & $(67,21-196,21)$ \\
\hline 114,8 & 133,5 \\
CE (50); 96 h médio & $(79,5-187,5)$ \\
Faixa de Sensibilidade & 27,0 \\
Desvio Padrão & $20,2 \%$ \\
Coeficiente de Variação & \\
\hline \hline
\end{tabular}

Apesar do pequeno número de réplicas entre os testes, os valores de CE (I) 50 determinados apresentaram valores de desvio padrão e coeficiente de variação razoáveis (27 mg. $\mathrm{L}^{-1}$ e $20 \%$, respectivamente), considerando-se a variabilidade individual dos peixes.

O valor médio de CL (I) 50 determinado neste trabalho para O. niloticus é um pouco superior aos reportados pela literatura para outros peixes, como Pimephales $s p$, sugerindo a tolerância desta espécie ao metal em questão. Os valores de CL 50 de dicromato de potássio para peixes variam bastante em função das espécies utilizadas (Tabela 25), sendo o $\mathrm{Cr}$ considerado pouco tóxico para peixes, não apresentando toxicidade aguda nas concentrações ambientais (ORME \& KEGLEY, 2004). Apesar da aparente reduzida toxicidade do $\mathrm{Cr}$, valores entre 0,28 e $0,33 \mathrm{mg} \cdot \mathrm{L}^{-1}$ de dicromato de potássio são reportados como CE 50 para $O$. niloticus, considerando a inibição no crescimento como efeito. 
Tabela 25: Valores de CE (I) 5096 hs Cu e Cr para diferentes espécies de peixes

\begin{tabular}{|c|c|c|c|}
\hline Espécies & $\begin{array}{c}\mathrm{CL} 50 \\
\mathrm{mg} \cdot \mathrm{L}^{-1} \mathrm{Cr}\end{array}$ & $\begin{array}{c}\mathrm{CL} 50 \\
\mathrm{mg} \cdot \mathrm{L}^{-1} \mathrm{Cu}\end{array}$ & Referência \\
\hline $\begin{array}{c}\text { D. rerio } \\
\text { P. scrofa } \\
\text { Cichlasoma facetum } \\
\text { Pimephales sp. } \\
\\
\text { Pimephales sp. }\end{array}$ & $\begin{array}{c}20,7 \\
10-109\end{array}$ & $\begin{array}{c}0,083-0,152 \\
0,014-0,098 \\
1,4\end{array}$ & $\begin{array}{c}\text { OLIVEIRA-FILHO et al., } 2004 \\
\text { CARVALHO, 2003 } \\
\text { ROSSINI \& RONCO, } 2001 \\
\text { BARRON \& ADELMAN, 1984; } \\
\text { PICKERING \& HENDERSON, 1966, apud } \\
\text { ROSSINI \& RONCO, 2001 } \\
\text { ERICKSON, et al, 1997; } \\
\text { MOUNT \& STEPHAN, 1969, apud } \\
\text { ROSSINI \& RONCO, 2001 }\end{array}$ \\
\hline Espécies & $\begin{array}{c}\mathrm{CL}(\mathrm{I}) 50 \\
\mathrm{mg} \cdot \mathrm{L}^{-1-} \\
\mathrm{K}_{2} \mathrm{Cr}_{2} \mathrm{O}_{7}\end{array}$ & $\begin{array}{l}\mathrm{CL}(\mathrm{I}) 50 \\
\mathrm{mg}^{-1} \mathrm{~L}^{-1} \\
\mathrm{CuSO}_{4}\end{array}$ & Referência \\
\hline $\begin{array}{c}\text { Oncorhynchus } \\
\text { mvkiss }\end{array}$ & & $0,0021-1,4$ & \\
\hline Lepomis macrochirus & & $0,892-3,2$ & \\
\hline $\begin{array}{l}\text { Alburnus alburnus } \\
\text { Campostoma } \\
\text { anomalum }\end{array}$ & $\begin{array}{c}67,9-104 \\
41,4-63,4\end{array}$ & & ORME \& KEGLEY, 2004 \\
\hline $\begin{array}{c}\text { Carassius auratus } \\
\text { Channa punctata } \\
\text { Chelon labrosus }\end{array}$ & $\begin{array}{c}24-125 \\
15 \\
10-53,5\end{array}$ & & \\
\hline
\end{tabular}

Os valores de $\mathrm{CL}(50)$ de $\mathrm{Cu}$ obtidos com os indivíduos de O. niloticus variaram de 0,32 a $0,84 \mathrm{mg} \cdot \mathrm{L}^{-1}$ de $\mathrm{Cu}$. Ao todo foram realizados 7 testes, mas em dois deles não foi possível o cálculo da CL (I) 50 pelo método Trimmed Sperman Karber (HAMILTON et al, 1977). Os valores de CL (50) para espécimens de O. niloticus expostos a soluções contendo Cu estão apresentados na Tabela 26.

Tabela 26: Valores de CE (I) 50 96h obtidos nos testes de toxicidade com Cu com O. niloticus

\begin{tabular}{cc}
\hline \hline CE (I) 50 96 (mg.L $\left.{ }^{-1} \mathrm{Cu}\right)$ & IC $(95 \%)$ \\
\hline \hline 0,32 & $*$ \\
0,56 & $(0,21-1,22)$ \\
0,65 & $(0,36-1,2)$ \\
0,57 & $*$ \\
0,84 & $(0,55-1,29)$ \\
\hline \hline CE (50); 96 h médio & 0,59 \\
Faixa de Sensibilidade & $(0,21-0,96)$ \\
Desvio Padrão & 0,19 \\
Coeficiente de Variação & $32 \%$ \\
\hline \hline
\end{tabular}

*valores não obtidos 
O. niloticus apresentou sensibilidade muito maior ao $\mathrm{Cu}$ que ao $\mathrm{Cr}$, como observado também para os outros organismos estudados. Comparando-se os valores determinados para $O$. niloticus com os reportados para outros peixes, como $P$. scrofa, Cichlasoma facetum e Pimephales sp. (Tabela 25), esta espécie apresenta maior sensibilidade ao $\mathrm{Cu}$, apesar de sua aparente tolerância aos metais (CLEARWATER et al.; 2002).

\section{8 - CONSIDERAÇÕES SOBRE OS TESTES DE TOXICIDADE}

Todas as espécies testadas mostraram-se mais sensíveis ao $\mathrm{Cu}$ do que ao $\mathrm{Cr}$, apesar do $\mathrm{Cu}$ ser um micronutriente essencial e ocorrer naturalmente em concentrações mais altas que $\mathrm{Cr}$.

Entre as espécies estudadas, $D$. similis e $C$. dubia foram as mais sensíveis, enquanto $O$. niloticus foi a mais tolerante. As espécies testadas seguem a ordem decrescente de sensibilidade: $D$. similis $>C$. dubia $>S$. capricornutum $>C$. xanthus $>P$. stratiotes $>0$. niloticus (Figura 01). Resultados semelhantes foram obtidos por OLIVEIRA-FILHO et al. (2004), que estabeleceu a seguinte ordem $D$. similis> $R$. subcapitata (S. capricornutum) $>$ D. rerio, em testes de toxicidade com $\mathrm{Cu}$.

Os dados apresentados confirmam a maior susceptibilidade do plâncton à contaminação por metais em comparação com as espécies de outros níveis tróficos estudadas. Os demais organismos testados também se mostraram adequados para utilização em testes de toxicidade com metais, com a vantagem de serem organismos amplamente distribuídos em ecossistemas brasileiros.

Em relação aos testes com $P$. stratiotes, a metodologia empregada foi reprodutível e a avaliação do comprimento médio das raízes foi o melhor indicador da toxicidade dos metais estudados sobre as plantas. A utilização de organismos cultivados seria mais indicada do que os coletados no ambiente, diminuindo a variabilidade nas condições iniciais dos indivíduos e a variabilidade genética entre estes indivíduos.

Os resultados obtidos nos testes com $D$. similis e $C$. dubia foram úteis na escolha das concentrações de metais a serem utilizadas nos experimentos em mesocosmos. De forma geral, os valores de CE (I) 50 determinados fornecem um indicativo da sensibilidade/tolerância ao $\mathrm{Cr}$ e $\mathrm{Cu}$ para espécies importantes dos ecossistemas, especialmente em reservatórios, onde $C$. xanthus, $P$. stratiotes e $O$. niloticus são amplamente distribuídos. 


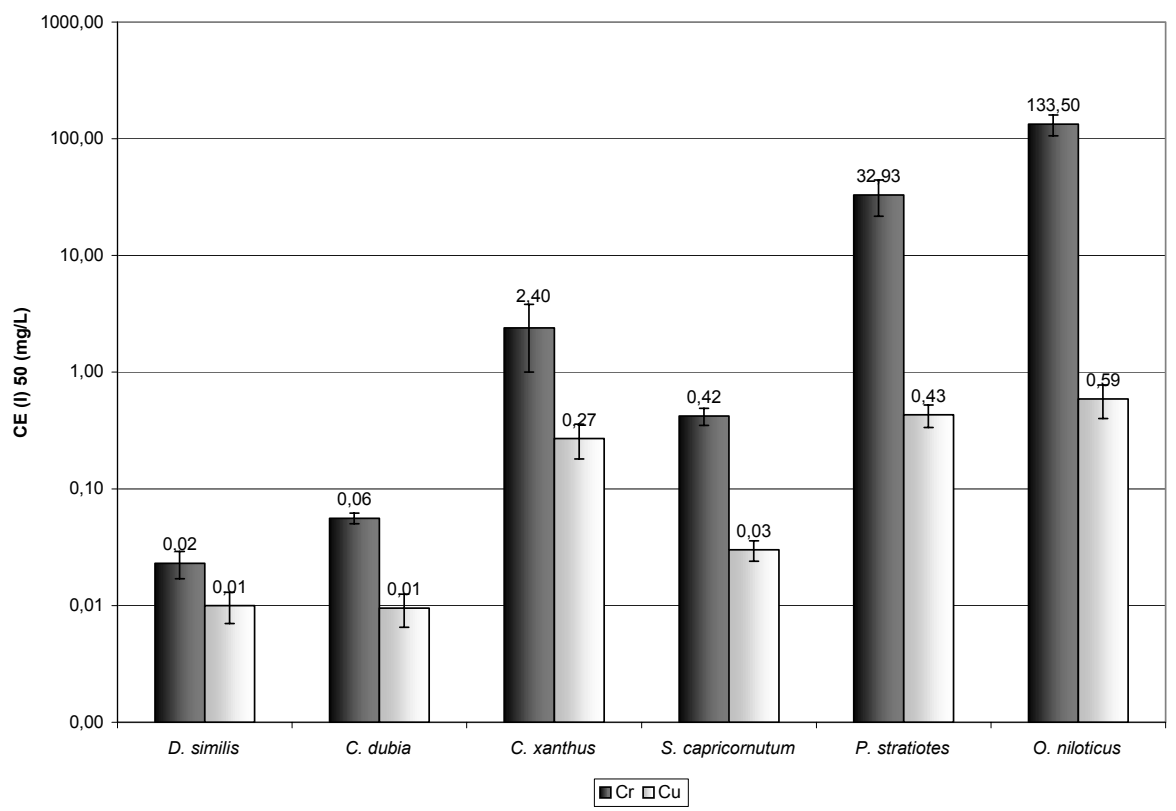

Figura 04: Valores de CE/CL (I) 50 de $\mathrm{Cr}$ e Cu (mg. $\mathrm{L}^{-1}$ ) determinados para cada uma das espécies estudadas (D. similis e C. dubia: 48 hs; $C$. xanthus, S. capricornutum, $O$. niloticus: 96hs; $P$. stratiotes: 168 hs; as barras de erros são referentes ao desvio padrão das réplicas)

\section{9 - REFERÊNCIAS BIBLIOGRÁFICAS}

ABNT - ASSOCIAÇÃO BRASILEIRA DE NORMAS TÉCNICAS (1993).. NBR 12715 Água, ensaio de toxicidade aguda com peixes. Parte I - Sistema Estático. Rio de Janeiro.

ABNT - ASSOCIAÇÃO BRASILEIRA DE NORMAS TÉCNICAS (1995). NBR 13373 Agua - Avaliação de toxicidade crônica, utilizando Ceriodaphnia dubia Richard, 1894 (Cladocera, Crustacea).

ABNT - ASSOCIAÇÃO BRASILEIRA DE NORMAS TÉCNICAS (2003a). Projeto NBR 12713 - Ecotoxicologia aquática - toxicidade aguda - método de ensaio com Daphnia spp (Cladocera, Crustacea). www.abnt.org.br

ABNT - ASSOCIAÇÃO BRASILEIRA DE NORMAS TÉCNICAS (2003b). Projeto NBR 13373 - Ecotoxicologia aquática - toxicidade crônica - método de ensaio com Ceriodaphnia spp (Crustacea, Cladocera). www.abnt.org.br 
ABNT - ASSOCIAÇÃO BRASILEIRA DE NORMAS TÉCNICAS. (2003c). Projeto NBR 00:001.44-001 - Ecotoxicologia aquática - toxicidade aguda - método de ensaio com peixes. www.abnt.org.br

ABNT - ASSOCIAÇÃO BRASILEIRA DE NORMAS TÉCNICAS. (2000) Projeto NBR 12648. Ecotoxicologia Aquática - Toxicidade Crônica - Método de ensaio com algas verdes. Brasil..www.abnt.org.br

ALLAN, J.D. (1976).Life history patterns in zooplankton. The American Naturalist, v.110, n.971, p.165-180.

ALMEIDA, C. A. (2002). "Estudo ecotoxicológico do sedimento de represas do Rio Tietê com o organismo - teste bentônico Chironomus xanthus Rempel (Insecta:Diptera)". Dissertação (Mestrado) - Escola de Engenharia de São Carlos Universidade de São Paulo, São Carlos.

APHA - AMERICAN PUBLIC HEALTH ASSOCIATION; AMERICAN WATER WORK ASSOCIATION; WATER POLLUTION CONTROL FEDERATION. (1998). "Standard methods for the examination of water and wastewater". 18.ed. New York. $1268 p$.

BARATA, C.; BAIRD, D. J.; MARKICH, S. J. (1998). Influence of genetic and environmental factors on the tolerance of Daphnia magna Straus to essential and nonessential metals. Aquatic toxicology 42: $115-137$.

BISTHOVEN, L. G. J.; TIMMERMANS, K. R.; OLLEVIER, F. (1992). The concentration of cadmium, lead, copper and zinc in Chironomus gr. Thummi larvae (Diptera, Chironomidae) with deformed versus normal menta. Hydrobiologia, 239: 141- 149.

BRADY, D.; LETEBELE, B.; DUNCAN, J. R.; ROSE, P. D. (1994) Bioaccumulation of metals by Scenedesmus, Selenastrum e Chlorella algae. Water S. A. 20, $213-218$.

CAIRNS JR, J.; NIEDERLEHNER, B. R.; BIDWELL, J. R. (1998). "Ecological toxicity testing". In: Encyclopedia of Environmental Analysis and Remediation. Meyers, R. A. (ed). John Wiley \& Sons, Inc. 
CAMPBELL, P. G. C. LEWIS, A. G.; CHAPMAN, P. M.; CROWDER, A. A.; FLETCHER, W. K.; IMBER, B.; LUOMA, S. N.; STOKES, P. M.; WINFREY, M. (1988). "Biologically available metals in sediments". NRCC No. 27694. National Research Council of Canada. 298 p.

CANTON, J. H.; ADEMA, D. M. M. (1978).Reproducibility of short term and reproduction toxicity experiments with Daphnia magna and comparison of the sensitivity of Daphnia magna with Daphnia pulex and Daphnia cucullata in short term experiments. Hydrobiologia 59: 135-140.

CARVALHO, C. S. (2003). "Influência do pH e da temperatura sobre os efeitos do cobre no sangue e no fígado de curimbatá, Prochilodus scrofa (Steindachner, 1881)". Tese (Doutorado). 106 p. PPG ERN. UFSCar, São Carlos.

CERVANTES, C.; CAMPOS-GARCÍA, J.; DEVARS, S.; GUITIÉRREZ-CORONA, F.; LOZA-TAVERA, H.; TORRES-GUZMÁN, J.; MORENO-SANCHÉZ, R. (2001). Interactions of chromium with microoganisms and plants. FEMS Microbiology reviews $25,335-347$.

CETESB. (1991). L5.018. Água- Testes de toxicidade aguda com Daphnia similis Claus, 1876 (Cladocera, Crustacea).

CHAPMAN, P. M. (1995). Ecotoxicology and pollution key issues. Marine polluion Bulletin, 31: 167-177.

CHAPMAN, P. M. (2002) Integrating toxicology and ecology: putting the "eco" into ecotoxicology. Marine Pollution Bulletin, 44: 7-15.

CLEARWATER, S. J.; FARAG, A. M.; MEYER, J. S. (2002). Bioavailability and toxicity of dietborne copper and zinc to fish. Comparative Biochemistry and Physiology Part $C$. $132: 269-313$.

ÇOGUN, H. Y.; KARGM, F. (2004). Effects of pH on the mortality and accumulation of copper in tissues of Oreochromis niloticus. Chemosphere, 55:277-282.

CONIGLIO, L.; BAUDO, R. (1989). Life tables of Daphnia obtusa (Kurz) surviving exposure to toxic concentrations of chromium. Hydrobiologia 188/189 : 407-410. 
DOBBS, M. G.; REASH, R. J.; CHERRY, D. S.; CAIRNS, J. JR. (1994).Evaluation of the resident species procedure for developing site-specific water quality criteria for copper in Blaine Creek, Kentuchy. Environ. Toxicol. Chem. 13: 963-971.

DORNFELD, C. B. (2002). "Utilização de análises limnológicas, bioensaios d toxiicdade e macroinvertebrados bentônicos para o diagnóstico ambiental do reservatório de Salto grande (Americana, SP)". 211 p. Dissertação de Mestrado. Escola de Engenharia de São Carlos - USP.

ELNABARAWY, M. T.; WELTER, A. N.; ROBIDEAU, R. R. (1986).Relative species of three daphnid species to selected organic and inorganic chemicals. Environ. Toxicol. Chem. 5: 393-398.

FONSECA, A. L.. (1991). "A biologia das espécies Daphnia laevis, Ceriodaphnia silvestri (Crustacea Cladocera) e Poecilia reticulata (Pisces Poecillidae) e o comportamento destes em testes de toxicidade aquática com efluentes industriais". Dissertação de Mestrado. Escola de Engenharia de São Carlos - USP.

FONSECA, A. L. (1997). "Avaliação da qualidade da água na bacia do rio Piracicaba através de testes de toxicidade com invertebrados". Tese (Doutorado) Escola de Engenharia de São Carlos, USP, 210p.. São Carlos.

FRANKLIN, N. M.; STAUBER, J. L.; APTE, S. C.; LIM, R. P. (2002). Effect of initial cell density on the bioavailability and toxicity of copper in microalgal bioassays. Environmental Toxicology and Chemistry, 21 (4): 747 - 751.

GIESY, J.P.; HOKE, R.H. (1989). Freshwater sediment toxicity bioassessment: rationale for species selection and test design. Journal of Great Lakes Research, 15(4): 539-569.

GUITIÉRREZ, P. A.; ONGAY, J. P.; VERCESI, M. L. (2000) Efectos de Cr (VI) sobre los umbrales experimentales y biológicos de tres especies de Lemna (Angiospermae: Lemnacea): una aproximácion comparatica. In: ESPÍNDOLA, E. L. G., BOTTAPASCHOAL, C. M. R., ROCHA, O., BOHRER, M. B. C., L, OLIVEIRA NETO, A. "Ecotoxicologia: Perspectivas para o Século XXI". Editora RIMA. São Carlos, p.309 314. 
HAMILTON, M. et al. (1977). "Trimmed Spearman - karber method for estimating median lethal concentrations in toxicity biossays". Environmental Science Technology. 11(7): $714-719$.

HATAKEYAMA, S. (1988). Chronic effects of Cu on reproduction of Polypendilum nubifer (Chironomidae) through water and food. Ecotoxicol. Environ Safety, 16: 1-10.

HICKEY, C. W. (1989). Sensitivity of four New Zealand cladoceran species and Daphnia magna to aquatic toxicants, New Zealand J. Mar. Fresh. Res. 23:131-137.

ISO - INTERNATIONAL ORGANIZATION FOR STANDARDIZATION. (1996). ISO 7346-1:1996. Water quality: determination of acute lethal toxicity of substances to a freshwater fish (Brachidanio rerio Hamilton:Buchanan (Teleostei, Cyprinidae)): part 1: static method. 2 ed.

ISO - INTERNATIONAL ORGANIZATION FOR STANDARDIZATION (1989). ISO 8692:1989. Water quality - Fresh water algal growth inhibition test with Scenedesmus subspicatus and Selenastrum capricornutum.

KÃHKÕNEN, M. A.; MANNINE, P. K. G. (1998). The uptake of nickel and chromium from water by Elodea canadensis at different nickel and chromium exposure levels. Chemosphere, 36 (6): 1381 - 1390.

KLUMPP, A.; BAUER, K.; FRANZ-GERSTEIN, C.; MENEZES, M. (2002). Variation of nutrient and metal conetrations in aquatic macrophytes along the Rio Cachoeira in Bahia (Brazil). Environmental International, 28: 165 - 171.

KOMAREK, J.; MARVAN, P. (1979). Selection and registration of strains of algae as assay organisms. In "Algal assays and monitoring eutrophication" (Edited byP. Marvan, S. Pribil and O. Lhotsy), pp. 87 - 102. E. Schweizerbart. Stuttgart.

KOSALWAT, PAK, KNIGHT, A. W. (1987).Chronic toxicity of copper to a partial life cicle of the midge, Chironomus decorus. Arch. Envrionm Contam Toxicol. 16: 283-290.

LEWIS, M. A. (1993). "Freshwater primary producers" pp 28-50. In: CALOW, P. (ed). "Handbook of ecotoxicology". Vol. 1, 478 p. Blackwell Science. Great Britain. 
LORENZI, H.; MATOS, F. J. A. (2002). "Plantas medicinais no Brasil: nativas e exóticas cultivadas". Instituto Plantarum, 512 p. Nova Odessa.

MAGDALENO, A. (2001). Resistencia a metales pesados em algas aisladas del rio Matanza-Riachuelo. In: HERKOVITS, J. (ed). Toxicología y Química Ambiental. Contribuiciones para un Desarrollo Sustentable, 42 - 44. Setac LA. Buenos Aires.

MAINE, M. A.; SUÑE, N. L.; LAGGER, S. (2004). Chromium bioaccumulation: comparison of the capacity of two floating aquatic macrophytes. Water Research (in press).

MARINELLI, C. E. (2002). "Introdução de espécies, estrutura das habitats e padrões de diversidade da ictiofauna em ecótonos do reservatório do Broa, SP”. Dissertação (Mestrado). Escola de Engenharia de São Carlos, Universidade de São Paulo, 225 p.. São Carlos.

MAZON, A. F.; PINHEIRO, G. D. H.; FERNANDES, M. N. (2000). Contaminação dos ecossistemas aquáticos pelo cobre e risco potencial à biodiversidade: estudo da toxicidade do cobre em Curimbatá, $P$. scrofa (Teleostei, Prochilodontidae) In: ESPÍNDOLA, E. L. G., BOTTA-PASCHOAL, C. M. R., ROCHA, O., BOHRER, M. B. C., L, OLIVEIRA NETO, A. "Ecotoxicologia: Perspectivas para o Século XXI". Editora Rima, p.327-342. São Carlos.

MOUNT, D. I.; NORBERG, T. J. (1984). A seven-day life cicle Cladoceran toxicity test. Environ. Toxicol. Chem., 3: 425-434.

NADDY, R. B.; STUBBLEFIELD, W. A.; MAY, J. R.; TUCKER, S. A.; HOCKETT, J. R. (2002). The effect of calcium and magnesium ratios on the toxicity of cooper to five aquatic species in freshwater. Environ. Tox. Chem., 21 (2): 347 - 352.

OECD (1984a). GUIDELINE FOR TESTING OF CHEMICALS 202. "Daphnia sp., Acute Immobilisation Test and Reproduction Test". 16 p.

OECD (1984b). GUIDELINE FOR TESTING OF CHEMICALS TG 201. "Algal, Growth Inhibition Test". $14 \mathrm{p}$. 
OECD (1998). GUIDELINE FOR TESTING OF CHEMICALS "Daphnia magna reproduction test". $21 \mathrm{p}$.

OECD (1992). GUIDELINE FOR TESTING OF CHEMICALS 203. "Fish acute toxicity Test". 22p.

OLIVEIRA-FILHO, E. C., LOPES, R. M., PAUMGARTTEN, F. J. R. (2004). Comparative study on the susceptibility of freshwater species to copper-based pesticides. Chemosphere, 56: 369-374.

OLIVEIRA-NETO, A.; BOTTA-PACHOAL, C. M. R. (2000). Sensibilidade do Cladocera lacustre planctônico Ceriodaphnia silvestrii (família Daphnidae) aos metais cádmio, cromo e chumbo. In: ESPÍNDOLA, E. L. G., BOTTA-PASCHOAL, C. M. R., ROCHA, O., BOHRER, M. B. C., L, OLIVEIRA NETO, A. "Ecotoxicologia: Perspectivas para o Século XXI". Editora Rima, São Carlos, p.537-543.

ORME, S. AND S. KEGLEY (2004). PAN Pesticide Database, Pesticide Action Network, North America (San Francisco, CA. 2004), http:www.pesticideinfo.org.

PAN, Q.; LIU, S.; TAN, Y. G.; BI, Y. Z. (2003). The effect of chromium piclinate on growth and carbohydrate utilization in tilapia, Oreochromis niloticus x Oreochromis aureus. Aquaculture, 225: $421-429$.

PECK, M. R.; KLESSA, D. A.; BAIRD, D. J. (2002). A tropical sediment toxicity test using the Dipteran Chironomus crassiforceps to test metal bioavailability with sediment $\mathrm{pH}$ change in tropical acid-sulfate sediments. Envion. Toxicol. Chem., 21 (4): 720 728.

PENNAK, R. W. (1989). "Fresh-water invertebrates of the United States: protozoa to mollusca." $3^{\circ}$ ed. John Wiley \& Sons, Inc. New York.

RAINBOW, P. S. ; PHILIPS, D. J. H. (1993) Cosmopolitan Biomonitors Of Trace Metals. Marine Pollution Bulletin, 26(11): 593-601.

RAND, G.M. (eds). (1995). "Fundamentals of aquatic toxicology - effects, environmental fate, and risk assessment”. Flórida, Taylor \& Francis. 
REMPEL, J. G. (1936). Nueu Chironomiden aus Nordostbrasilien .Zool Anz, v. 127, p. 109-216.

REYNOLDSON, T. B.; BAAILEY, R. C.; DAY, K. E.; NORRIS, R. H. (1995). Biological guidelines for freshwater sediment on Benthic Assesment (the BEAST) using a multivariate approach for predicting bilogical state. Austr. J. Ecol., 20: 198-219.

RIBEIRO, L.; TRIBESS, T.; TORRES, M. A.; SOARES, C. H. L.; PEDROSA, R. C.; AGOSTINI, J.; BUENO, A.; WILHEM FILHO, D. (2000) Estresse oxidativo em tilápia (Oreochromis niloticus) exposta ao efluente de industria têxtil. In: ESPÍNDOLA, E. L. G., BOTTA-PASCHOAL, C. M. R., ROCHA, O., BOHRER, M. B. C., L, OLIVEIRA NETO, A. "Ecotoxicologia: Perspectivas para o Século XXl". Ed. Rima, São Carlos, p.441-449.

RODGHER, S. (1998). "Determinação da faixa de sensibilidade de organismos aquáticos a uma substância de referência, o cloreto de sódio $(\mathrm{NaCl})$ e avaliação da qualidade da água da represa do Monjolinho (São Carlos, SP) através de testes de toxicidade aguada". Monografia. CCBS, DEBE. UFSCAR. São Carlos.

ROJCKOVÁ-PADRTOVÁ, R.; MARSALEK, B. (1999). Selection and sensitivity comparisons of alagal species for toxicity. Chemosphere, 38 (14): 3329-3338.

ROSSINI , G. D. B.; RONCO, A. E. (2001). Sensibilidad de Cichlasoma facetum (Ciclidae, Pisces) a metales pesados. In: HERKOVITS, J. (ed). "Toxicología y Química Ambiental. Contribuiciones para un Desarrollo Sustentable", 8 - 10. Setac LA. Buenos Aires

SCHIARITI, A.; JUÁREZ, A. B.; RODRÍGUEZ, M. C. (2001). Estres oxidativo inducido por cobre en cultivos de microalgas verdes. In: HERKOVITS, J. (ed). "Toxicología y Química Ambiental. Contribuiciones para un Desarrollo Sustentable", 156 - 158. Setac LA. Buenos Aires

STRIXINO, S. T.; STRIXINO, G. (1982). Ciclo de vida de Chironomus santicarioli Strixinno \& Strixino, (Diptera, Chironomidae). Ver. Bras. Ent, 26 (2): 183 - 189.

STRIXINO, S. T.; STRIXINO, G. (1981). Nova espécie do gênero Chironomus meigen do sul do Brasil (Diptera: Chironomidae). Ver. Bras. Ent., 25 (4): 333-340. 
SUEDEL, B. C.; DEAVER, E; RODGERS, J. H. JR (1992). Experimental factors that may affect toxicity of aqueous and sediment-bound copper to freshwater organisms. Arch. Envrionm Contam Toxicol, $30: 40-46$.

TARLYN, N. M.; KOSTMAN, T. A.; NAKATA, P. A.; KEATES, S. E.; FRANCESCHI, V. R. (1998). Axenic cultures of Pistia stratiotes for use in plant biochemical studies. Aquatic Botany, 60: 161 - 168.

TAGLIARI, K. C.; VARGAS, V. M. F., ZIMIANI, K., CECCHINI, R. Oxidative stress damage in the liver of fish and rats receiving an intraperitoneal injection of hexavalent chromium as evaluated by chemiluminescence. Environmental Toxicology and Pharmacology, 17: 149-157.2004.

U.S. EPA (2002a). ENVIRONMENTAL PROTECTION AGENCY- 821-R-02-012. "Methods for Measuring the Acute Toxicity of Effluents and Receiving Waters to Freshwater and Marine Organisms". Fifth Edition, Washington.

U. S. EPA (2002b). ENVIRONMENTAL PROTECTION AGENCY. EPA-821-R-02-013, "Short-term Methods for Estimating the Chronic Toxicity of Effluents and Receiving Waters to Freshwater Organisms". Fourth Edition. Whashington.

U. S. EPA (1983). ENVIRONMENTAL PROTECTION AGENCY. "Lemna Acute Toxicity test". EPA - 560/6 - 82 - 002, National Technical Information Service, Springfield.

U. S. EPA ENVIRONMENTAL PROTECTION AGENCY. US EPA/600/R-94/024. "Methods for measuring the toxicity and bioaccumulation of sediment associated contaminantes with freshwater invertebrates". Washington DC, $133 \mathrm{p}$.

U. S. EPA (1996). ENVIRONMENTAL PROTECTION AGENCY "Ecological Effects Test Guidelines OPPTS 850.4400 Aquatic Plant Toxicity Test Using Lemna spp., Tiers I and II".

VAJPAYEE, P.; SHARMA, S. C.; TRIPATHI, R. D.; RAI, U. N.; YUNUS,M. (1999). Bioaccumulation of chromium and toxicity to photosynthetic pigments, nitrate redutase activity and protein content of Nelumbo nucifera GAERTN. Chemosphere, 39 (12): 2159-2169. 
VERSTEEG, D. J.; STALMANS, M.; DYER, S. D.; JANSEN, C. (1997). Ceriodaphnia and Daphnia: a comparison of their sensitivity to xenobiotics and utility as a test species. Chemosphere, 34 (4): 869-892.

WENTSEL, R. ; MCINTOSH, A.; MCCAFFERTY, W. P.; ATCHISON, G.; ANDERSON, V. (1977). Avoidance response of midge larvae Chironomus tentans to sediments containing heavy metals. Hydrobiologia, 55: $171-175$.

ZAGATTO, P.A. (1988). Sensibilidade de Daphnia similis: controle e qualidade de culturas. Ambiente, 2(2): 79-83.

ZAGATTO, P. A. (1999). "Mini-curso: ecotoxicologia aquática". VII Congresso Brasileiro de Limnologia, 124 p.. Florianópolis. 
CAPÍTULO 3: EXPERIMENTOS EM MICRO E MESOCOSMOS 


\section{SUMÁRIO}

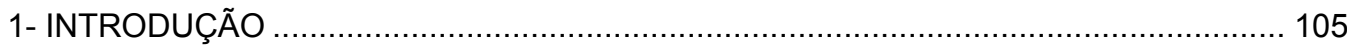

1.1- O princípio dos testes de toxicidade em micro e mesocosmos ............................... 108

1.2- Orientações para testes em micro e mesocosmos................................................... 109

1.3- Objetivos do desenvolvimento de experimentos em micro e mesocosmos .............. 110

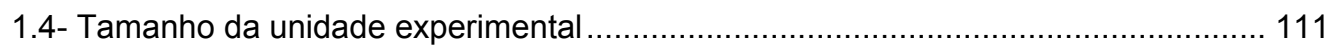

1.5- Validação dos testes em micro e mesocosmos.................................................... 112

1.6- As unidades experimentais: confecção, montagem e os componentes ................... 113

1.7- Aplicação do contaminante nas unidades experimentais ...................................... 114

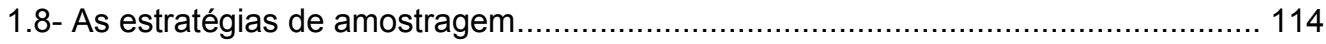

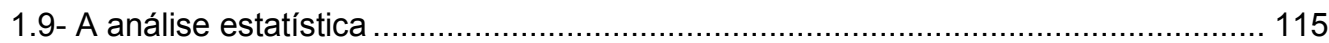

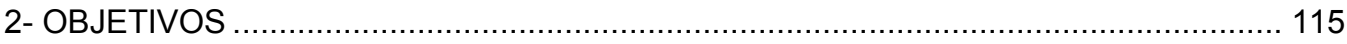

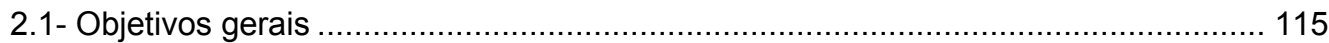

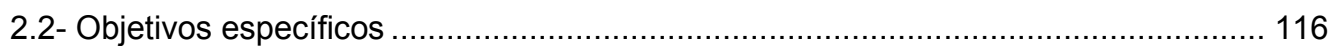

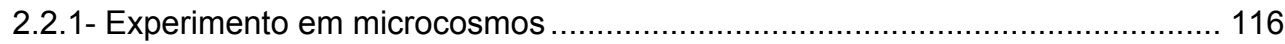

2.2.2- Experimentos em mesocosmos 1- Aspectos funcionais e estruturais .............. 116

2.2.3- Experimentos em mesocosmos 2- Aspectos funcionais e bioacumulação....... 116

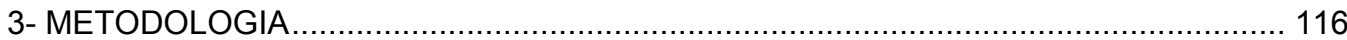

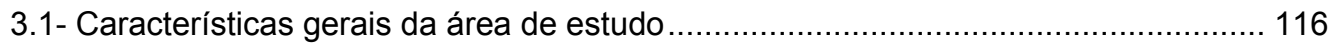

3.2- Escolha da área para a instalação dos mesocosmos e caracterização preliminar da

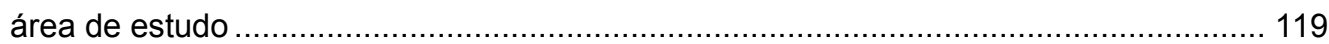

3.3- Experimento em microcosmos: design e instalação............................................. 123

3.4- Experimento em mesocosmos: design e instalação............................................... 124

3.5- Coleta, preservação e análises químicas das amostras de água, sedimento e

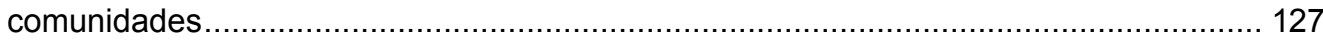

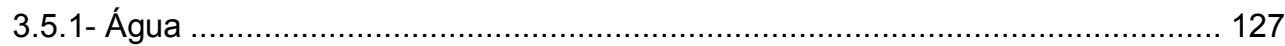

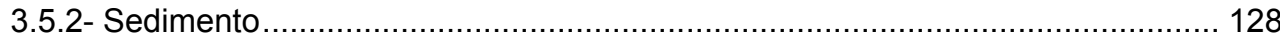

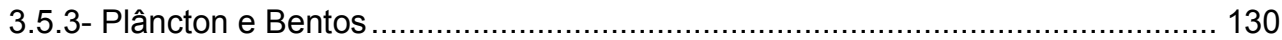

3.5.4- Macrófitas (P. stratiotes) e peixes (O. niloticus) ........................................ 131

3.6- Coleta, preservação e análise do fitoplâncton, zooplâncton e bentos: análise

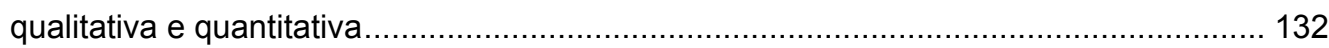

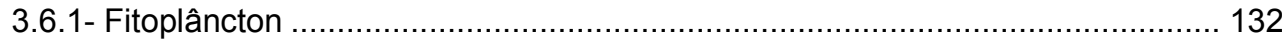

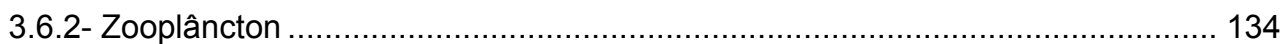

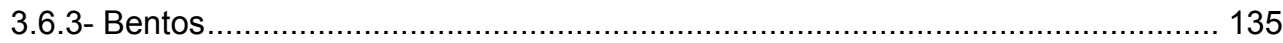

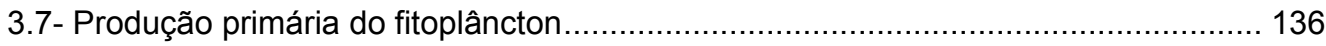

3.7.1- Método do ${ }^{14} \mathrm{C}$ (GOLTERMAN \& CLIMO,1969)......................................... 136

3.7.2- Método do Oxigênio Dissolvido (GAARDNER \& GRAN, 1972) ....................... 136

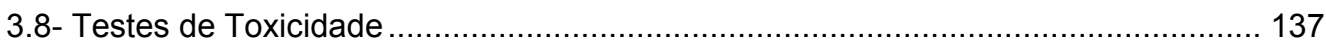

3.9- Período e freqüência das amostragens............................................................... 137 


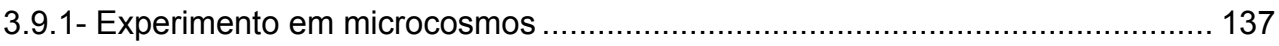

3.9.2- Experimentos em Mesocosmos 1- Aspectos Funcionais e Estruturais............. 138

3.9.3- Experimentos em Mesocosmos 2- Aspectos Funcionais e Bioacumulação ..... 139

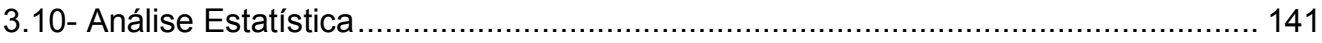

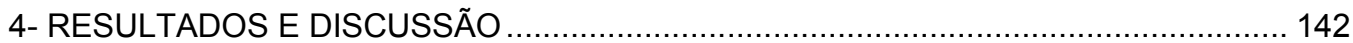

4.1- Análise dos efeitos de cromo e cobre em ecossistemas aquáticos: um estudo em

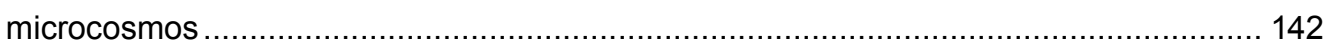

4.1.1- Variáveis físico-químicas, químicas e biológicas (clorofila) da água ............... 142

4.1.2- Análise da comunidade planctônica ........................................................... 156

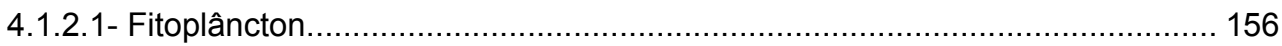

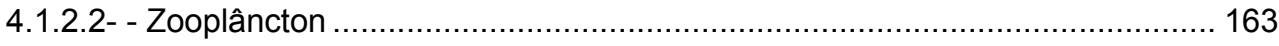

4.1.3- Avaliação da metodologia empregada nos experimentos em microcosmos .... 170

4.2- Análise dos efeitos de $\mathrm{Cr}$ e $\mathrm{Cu}$ em ecossistemas aquáticos através de estudos em mesocosmos: aspectos funcionais e estruturais .................................................. 172

4.2.1- Variáveis físico-químicas, químicas e biológicas (clorofila) da água ................ 172

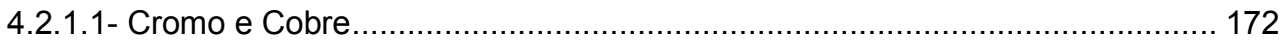

4.2.1.2- Oxigênio dissolvido, condutividade, $\mathrm{pH}$ e temperatura da água ..................... 173

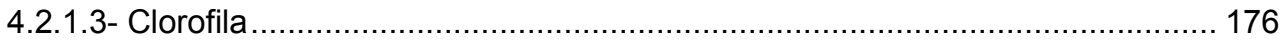

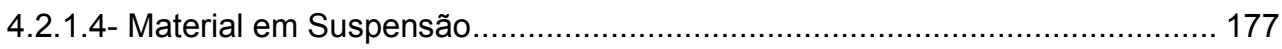

4.2.1.5- Nutrientes nitrogenados, fosfatados e silicato ........................................ 179

4.2.1.6- - Análise Estatística das variáveis físico-químicas, químicas e biológicas

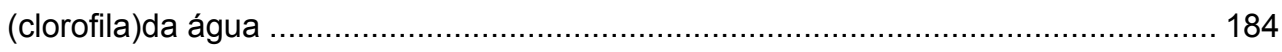

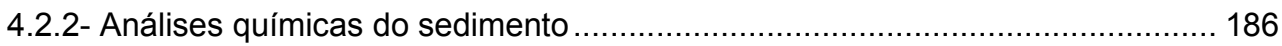

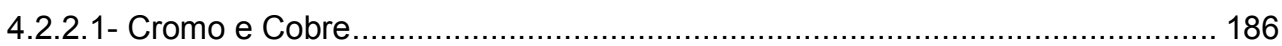

4.2.2.2- Matéria orgânica e nutrientes (fósforo e nitrogênio) …................................. 190

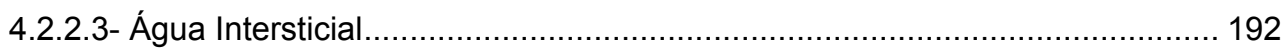

4.2.2.4- Análise estatística das variáveis químicas do sedimento .............................. 193

4.2.3- Análises de $\mathrm{Cr}$ e Cu nas comunidades planctônica e bentônica ....................... 195

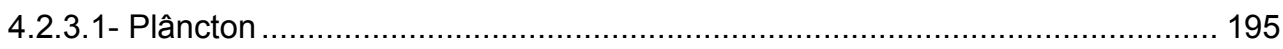

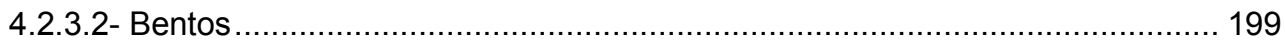

4.2.4- Efeitos dos metais $\mathrm{Cr}$ e Cu no fitoplâncton, zooplâncton e bentos ................... 202

4.2.4.1 - Produção primária do fitoplâncton ............................................................ 202

4.2.4.2 - Composição e densidade do zooplâncton ................................................ 205

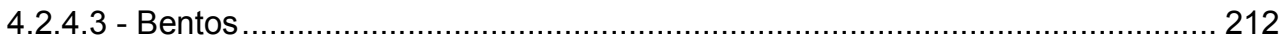

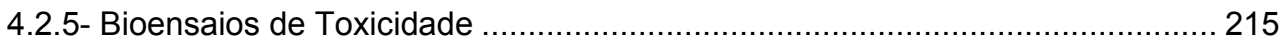

4.2.6- Avaliação da metodologia empregada nos experimentos em mesocosmos

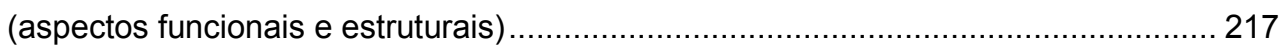

4.3- Análise dos efeitos de $\mathrm{Cr}$ e $\mathrm{Cu}$ em ecossistemas aquáticos através de estudos em mesocosmos: aspectos funcionais e bioacumulação ................................................ 219

4.3.1- Variáveis físico-químicas, químicas e biológicas (clorofila) da água ................ 219 


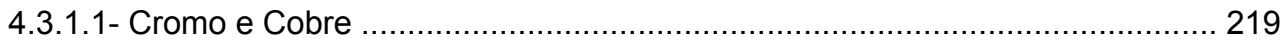

4.3.1.2- Oxigênio dissolvido, condutividade, $\mathrm{pH}$ e temperatura da água ..................... 220

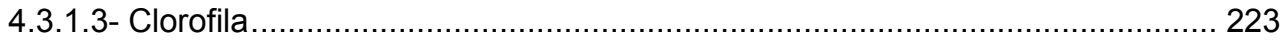

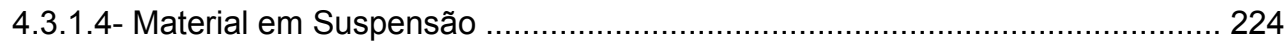

4.3.1.5- Nutrientes nitrogenados, fosfatados e silicato ...................................... 226

4.3.1.6- - Análise Estatística das variáveis físico-químicas, químicas e biológicas

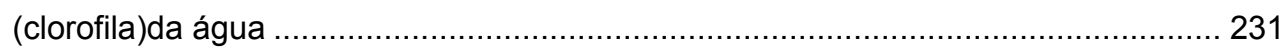

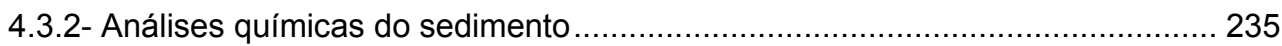

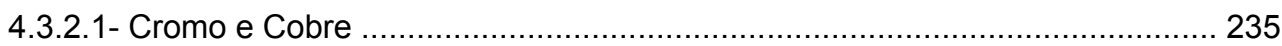

4.3.2.2- Matéria orgânica e nutrientes (fósforo e nitrogênio) .................................... 238

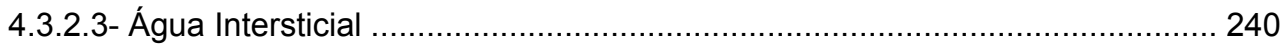

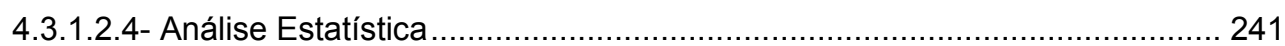

4.3.3- Análise de $\mathrm{Cr}$ e Cu nos componentes biológicos .......................................... 241

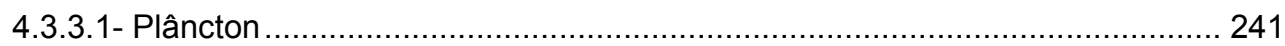

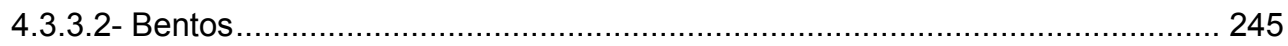

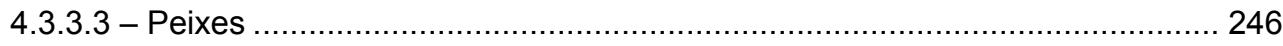

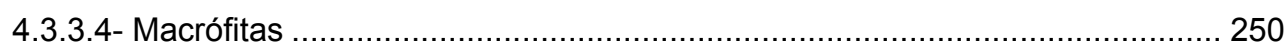

4.3.2- Produção Primária do Fitoplâncton ................................................................ 256

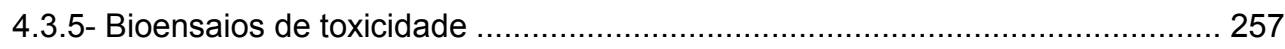

4.3.6- Avaliação da metodologia empregada nos experimentos em mesocosmos

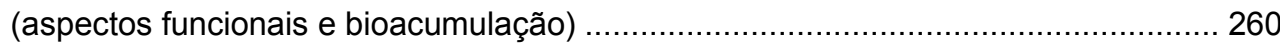

5- CONSIDERAÇÕES FINAIS SOBRE OS EXPERIMENTOS EM MICRO E

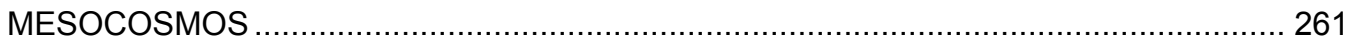

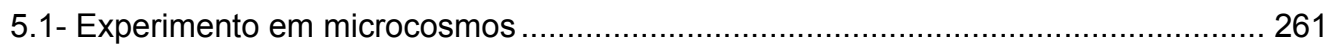

5.2- Experimentos em mesocosmos 1- Aspectos funcionais e estruturais ...................... 262

5.3- Experimentos em Mesocosmos 2- Aspectos Funcionais e Bioacumulação .............. 266

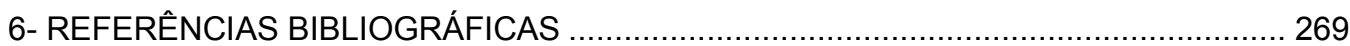

\section{LISTA DE FIGURAS}

Figura 01: Representação esquemática das metodologias e aproximações complementares usadas em toxicologia ambiental e ecotoxicologia (Adaptado de CAQUET et al, op.

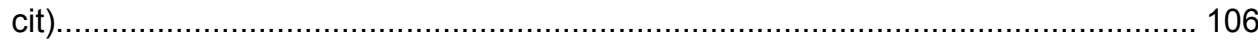

Figura 02: Ecossistemas experimentais como ligação para a avaliação de campo (Adaptado de Brock et al, 2000) 110

Figura 03: Localização da represa do Lobo (Itirapina/ Brotas, SP) e da área de instalação dos

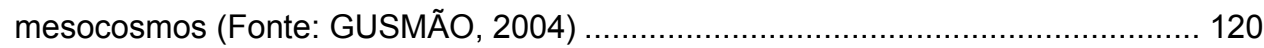

Figura 04: Aspecto geral do experimento em microcosmos. ................................................ 123

Figura 05: Disposição dos tanques controle e contaminados com $\mathrm{Cr}$ e Cu. ........................... 124

Figura 06: Representação esquemática dos tanques utilizados nos experimentos em mesocosmos, instalados na represa do Lobo.................................................... 125 
Figura 07: Configuração final do mesocosmo a ser instalado na represa do Lobo. 125

Figura 08: Instalação dos mesocosmos na represa do Lobo..... 126

Figura 09: Disposição dos mesocosmos em relação à margem da represa do Lobo. 126

Figura 10: Coleta de água e determinação das variáveis físico-químicas nos mesocosmos. . 127

Figura 11: Coleta de fito e zooplâncton nos mesocosmos. 130

Figura 12: Coleta dos peixes e macrófitas inseridos nos mesocosmos com o auxilio dos tanques-rede internos. 131

Figura 13: Disposição dos tanques no experimento na represa do Lobo (ordenados de 1 a 9 da

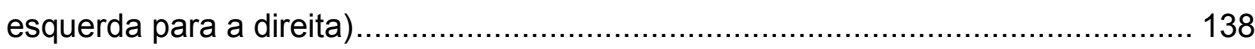

Figura 14: Disposição dos tanques no experimento na represa do Lobo. 140

Figura 15: Concentração média $\left(\mu \mathrm{g} \cdot \mathrm{L}^{-1}\right)$ de $\mathrm{Cu}$ determinada nas amostras de água nos controles e nos microcosmos contaminados com $\mathrm{Cu}$ 143

Figura 16: Concentração média $\left(\mu \mathrm{g} \cdot \mathrm{L}^{-1}\right)$ de $\mathrm{Cr}$ determinada nas amostras de água dos microcosmos contaminados. 144

Figura 17: Valores médios de $\mathrm{pH}$ determinados nas amostras de água dos microcosmos durante o período de estudo 145

Figura 18: Concentrações médias $\left(\mathrm{mg}^{\mathrm{L}} \mathrm{L}^{-1}\right)$ de silicato determinadas nas amostras de água no controle e nos microcosmos contaminados com $\mathrm{Cr}$ e $\mathrm{Cu}$. 145

Figura 19: Concentrações médias $\left(\mu \mathrm{g} \cdot \mathrm{L}^{-1}\right)$ de nitrato determinadas nas amostras de água no controle e nos microcosmos contaminados com $\mathrm{Cr}$ e $\mathrm{Cu}$. 146

Figura 20: Concentrações médias $\left(\mu \mathrm{g} \cdot \mathrm{L}^{-1}\right)$ de nitrito determinadas nas amostras de água no controle e nos microcosmos contaminados com $\mathrm{Cr}$ e $\mathrm{Cu}$. 147

Figura 21: Concentrações médias $\left(\mu \mathrm{g} \cdot \mathrm{L}^{-1}\right)$ de amônio determinadas nas amostras de água no controle e nos microcosmos contaminados com $\mathrm{Cr}$ e $\mathrm{Cu}$. 148

Figura 22: Concentrações médias de nitrogênio total $\left(\mathrm{mg}^{\mathrm{L}} \mathrm{L}^{-1}\right)$ determinadas nas amostras de água no controle e nos microcosmos contaminados com $\mathrm{Cr}$ e $\mathrm{Cu}$. 148

Figura 23: Concentrações médias ( $\mu \mathrm{g} \cdot \mathrm{L}^{-1}$ ) de fosfato inorgânico determinadas nas amostras de água no controle e nos microcosmos contaminados com $\mathrm{Cr}$ e $\mathrm{Cu}$. 149

Figura 24: Concentrações médias $\left(\mu \mathrm{g} \cdot \mathrm{L}^{-1}\right)$ de fosfato total dissolvido determinadas nas amostras de água no controle e nos microcosmos contaminados com $\mathrm{Cr}$ e Cu..... 150

Figura 25: Concentrações médias $\left(\mu \mathrm{g} \cdot \mathrm{L}^{-1}\right)$ de fósforo total determinadas nas amostras de água no controle e nos microcosmos contaminados com $\mathrm{Cr}$ e $\mathrm{Cu}$. 151

Figura 26: Concentrações médias $\left(\mathrm{mg} \mathrm{L}^{-1}\right)$ de material em suspensão total determinadas nas amostras de água no controle e nos microcosmos contaminados com $\mathrm{Cr}$ e $\mathrm{Cu}$...... 152

Figura 27: Concentrações médias $\left(\mathrm{mg} \mathrm{L}^{-1}\right)$ de material em suspensão orgânico determinadas nas amostras de água no controle e nos microcosmos contaminados com $\mathrm{Cr}$ e $\mathrm{Cu}$. 152

Figura 28: Concentrações médias (mg L-1) de material em suspensão inorgânico determinadas nas amostras de água no controle e nos microcosmos contaminados com $\mathrm{Cr}$ e $\mathrm{Cu}$. 
Figura 29: Concentrações médias $\left(\mu \mathrm{g} \cdot \mathrm{L}^{-1}\right)$ de clorofila determinadas nas amostras de água no controle e nos microcosmos contaminados com $\mathrm{Cr}$ e $\mathrm{Cu}$. 153

Figura 30: Densidade total do fitoplâncton (ind.mL-1) em cada tratamento durante o período de estudo. 159

Figura 31: Variação na densidade do fitoplâncton no controle durante o período de estudo. . 159

Figura 32: Variação na densidade do fitoplâncton no tratamento com $\mathrm{Cr}$ durante o período de estudo. 160

Figura 33: Variação na densidade do fitoplâncton no tratamento com Cu durante o período de estudo. 160

Figura 34: Concentrações médias de $\mathrm{Cu}\left(\mu \mathrm{g} \cdot \mathrm{L}^{-1}\right)$ determinadas no controle e nos mesocosmos contaminados com $\mathrm{Cu}$ durante o período de estudo. 172

Figura 35: Concentrações médias de $\mathrm{Cr}\left(\mu \mathrm{g} \cdot \mathrm{L}^{-1}\right)$ determinadas nos mesocosmos contaminados com $\mathrm{Cr}$ durante o período de estudo 173

Figura 36: Concentrações médias de oxigênio dissolvido $\left(\mathrm{mg}^{-\mathrm{L}^{-1}}\right)$ determinadas no controle e nos mesocosmos contaminados com $\mathrm{Cr}$ e $\mathrm{Cu}$ durante o período de estudo. 174

Figura 37: Condutividade média $\left(\mu \mathrm{S} . \mathrm{cm}^{-1}\right)$ determinadas no controle e nos mesocosmos contaminados com $\mathrm{Cr}$ e Cu durante o período de estudo. 175

Figura 38: Valores médios de $\mathrm{pH}$ determinados no controle e nos mesocosmos contaminados com $\mathrm{Cr}$ e Cu durante o período de estudo. 175

Figura 39: Valores médios de temperatura $\left({ }^{\circ} \mathrm{C}\right)$ determinados no controle e nos mesocosmos contaminados com $\mathrm{Cr}$ e Cu durante o período de estudo. 176

Figura 40: Concentrações ( $\mu \mathrm{g} \cdot \mathrm{L}^{-1}$ ) médias de clorofila determinadas no controle e nos mesocosmos contaminados com $\mathrm{Cr}$ e $\mathrm{Cu}$ durante o período de estudo. 177

Figura 41: Concentrações médias ( $\mathrm{mg}^{\mathrm{L}} \mathrm{L}^{-1}$ ) de material em suspensão total determinadas no controle e nos mesocosmos contaminados com $\mathrm{Cr}$ e Cu durante o período de estudo.

Figura 42: Concentrações médias $\left(\mathrm{mg}^{-\mathrm{L}^{-1}}\right.$ ) de material em suspensão orgânico determinadas no controle e nos mesocosmos contaminados com $\mathrm{Cr}$ e $\mathrm{Cu}$ durante o período de estudo. 178

Figura 43: Concentrações médias $\left(\mathrm{mg}^{\mathrm{L}} \mathrm{L}^{-1}\right)$ de material em suspensão inorgânico determinadas no controle e nos mesocosmos contaminados com $\mathrm{Cr}$ e $\mathrm{Cu}$ durante o período de estudo. 179

Figura 44: Concentrações médias (mg. $\mathrm{L}^{-1}$ ) de silicato dissolvido determinadas no controle e nos mesocosmos contaminados com $\mathrm{Cr}$ e Cu durante o período de estudo.

Figura 45: Concentrações médias $\left(\mu \mathrm{g} \cdot \mathrm{L}^{-1}\right)$ de nitrato determinadas no controle e nos mesocosmos contaminados com $\mathrm{Cr}$ e Cu durante o período de estudo.................. 180

Figura 46: Concentrações médias $\left(\mu \mathrm{g} \cdot \mathrm{L}^{-1}\right)$ de nitrito determinadas no controle e nos mesocosmos contaminados com $\mathrm{Cr}$ e Cu durante o período de estudo.................. 180

Figura 47: Concentrações médias $\left(\mu \mathrm{g} \cdot \mathrm{L}^{-1}\right)$ de amônio determinadas no controle e nos mesocosmos contaminados com $\mathrm{Cr}$ e Cu durante o período de estudo. 
Figura 48: Concentrações médias $\left(\mathrm{mg}^{\mathrm{L}} \mathrm{L}^{-1}\right)$ de nitrogênio total determinadas no controle e nos mesocosmos contaminados com $\mathrm{Cr}$ e Cu durante o período de estudo. 181

Figura 49: Concentrações médias $\left(\mu \mathrm{g} \cdot \mathrm{L}^{-1}\right)$ de fosfato inorgânico determinadas no controle e nos mesocosmos contaminados com $\mathrm{Cr}$ e Cu durante o período de estudo......

Figura 50: Concentrações médias ( $\mu \mathrm{g} \cdot \mathrm{L}^{-1}$ ) de fosfato total dissolvido determinadas no controle e nos mesocosmos contaminados com $\mathrm{Cr}$ e $\mathrm{Cu}$ durante o período de estudo. 183

Figura 51: Concentrações médias $\left(\mu \mathrm{g} \cdot \mathrm{L}^{-1}\right)$ de fósforo total determinadas no controle e nos mesocosmos contaminados com $\mathrm{Cr}$ e $\mathrm{Cu}$ durante o período de estudo. 184

Figura 52: Concentrações médias $\left(\mathrm{mg}^{\mathrm{kg}}{ }^{-1}\right)$ de $\mathrm{Cr}$ na fração fracamente ligada do sedimento dos mesocosmos controle e contaminados com $\mathrm{Cr}$. 187

Figura 53: Concentrações médias $\left(\mathrm{mg}^{\mathrm{kg}}{ }^{-1}\right)$ de $\mathrm{Cu}$ na fração fracamente ligada do sedimento dos mesocosmos controle e contaminados com $\mathrm{Cu}$. 188

Figura 54: Concentrações totais médias $\left(\mathrm{mg} \mathrm{kg}^{-1}\right)$ de $\mathrm{Cr}$ no sedimento dos mesocosmos controle e contaminados com $\mathrm{Cr}$.

Figura 55: Concentrações totais médias $\left(\mathrm{mg}^{\mathrm{kg}}{ }^{-1}\right)$ de $\mathrm{Cu}$ no sedimento dos mesocosmos controle e contaminados com $\mathrm{Cu}$...... 189

Figura 56: Teores médios de matéria orgânica (\%) determinados nos sedimentos dos mesocosmos controle e contaminados com $\mathrm{Cu}$. 190

Figura 57: Concentrações médias de nitrogênio (\%) determinadas nos sedimentos dos mesocosmos controle e contaminados com $\mathrm{Cu}$. 190

Figura 58: Concentrações médias de fósforo $\left(\mathrm{mg}^{\mathrm{kg}}{ }^{-1}\right)$ determinadas nos sedimentos nos sedimentos dos mesocosmos controle e contaminados com $\mathrm{Cu}$. 191

Figura 59: Concentrações de $\mathrm{Cu}\left(\mathrm{mg}^{-1} \mathrm{~L}^{-1}\right)$ determinadas na água intersticial dos mesocosmos controle e contaminados com $\mathrm{Cu}$ 193

Figura 60: Concentrações de $\mathrm{Cu}\left(\mu \mathrm{g} \cdot \mathrm{g}^{-1}\right)$ determinadas nas amostras de plâncton da coleta preliminar (28/03) e nos dias 19 e 30/04 nos mesocosmos controle e contaminados com $\mathrm{Cu}$...... 196

Figura 61: Concentrações de $\mathrm{Cr}\left(\mu \mathrm{g} \cdot \mathrm{g}^{-1}\right)$ determinadas nas amostras de plâncton da coleta preliminar (28/03) e nos dias 19 e 30/04 nos mesocosmos controle e contaminados com $\mathrm{Cr}$. 197

Figura 62: Concentrações de $\mathrm{Cu}\left(\mu \mathrm{g} \cdot \mathrm{g}^{-1}\right)$ determinadas nas amostras de bentos da coleta preliminar (28/03) e no dia 30/04 nos mesocosmos controle e contaminados com Cu. 200

Figura 63: Concentrações de $\mathrm{Cr}\left(\mu \mathrm{g} \cdot \mathrm{g}^{-1}\right)$ determinadas nas amostras de bentos da coleta preliminar (28/03) e no dia 30/04 nos mesocosmos controle e contaminados com Cr. 201

Figura 64: Produção primária do fitoplâncton determinada em 26/03 e 01/04, 2 horas após a contaminação dos mesocosmos. 204

Figura 65: Densidade numérica de Cladocera (ind $\mathrm{m}^{-3}$ ) nos mesocosmos controle, cromo e cobre. 208 
Figura 66: Densidade numérica de Copepoda (ind. $\mathrm{m}^{-3}$ ) nos mesocosmos controle, cromo e cobre. 208

Figura 67: Densidade numérica de Rotifera (ind $\mathrm{m}^{-3}$ ) nos mesocosmos controle, cromo e cobre. 208

Figura 68: Abundância relativa de Cladocera, Copepoda e Rotifera no controle no decorrer do experimento 209

Figura 69: Abundância relativa de Cladocera, Copepoda e Rotifera no tratamento com Cu no decorrer do experimento 209

Figura 70: : Abundância relativa de Cladocera, Copepoda e Rotifera no tratamento com $\mathrm{Cr}$ no decorrer do experimento. 209

Figura 71: Abundância relativa dos grupos identificados nas amostras de sedimentos dos mesocosmos no início do experimento, antes da contaminação dos mesocosmos. 214

Figura 72: Abundância relativa dos grupos identificados nas amostras de sedimentos dos mesocosmos no final do experimento após a contaminação dos mesocosmos. ..... 214

Figura 73 : Concentrações médias de $\mathrm{Cr}\left(\mu \mathrm{g} \cdot \mathrm{L}^{-1}\right)$ determinadas nas amostras de água nos mesocosmos contaminados com $\mathrm{Cr}$ durante o período de estudo. 219

Figura 74: Concentrações médias de $\mathrm{Cu}\left(\mu \mathrm{g} \cdot \mathrm{L}^{-1}\right)$ determinadas nas amostras de água nos controles e nos mesocosmos contaminados com Cu durante o período de estudo.220

Figura 75: Concentrações médias de oxigênio dissolvido (mg. $\left.\mathrm{L}^{-1}\right)$ determinadas nas amostras de água no controle e nos mesocosmos contaminados com $\mathrm{Cr}$ e $\mathrm{Cu}$ durante o período de estudo. 221

Figura 76: Condutividade média $\left(\mu \mathrm{S} . \mathrm{cm}^{-1}\right)$ determinadas nas amostras de água no controle e nos mesocosmos contaminados com $\mathrm{Cr}$ e $\mathrm{Cu}$ durante o período de estudo 222

Figura 77: Valores médios de $\mathrm{pH}$ determinados nas amostras de água no controle e nos mesocosmos contaminados com $\mathrm{Cr}$ e Cu durante o período de estudo. 222

Figura 78: Valores médios de temperatura $\left({ }^{\circ} \mathrm{C}\right)$ determinados nas amostras de água no controle e nos mesocosmos contaminados com $\mathrm{Cr}$ e Cu durante o período de estudo.

223

Figura 79: Concentrações ( $\mu \mathrm{g} \cdot \mathrm{L}^{-1}$ ) médias de clorofila determinadas nas amostras de água no controle e nos mesocosmos contaminados com $\mathrm{Cr}$ e $\mathrm{Cu}$ durante o período de estudo.

223

Figura 80: Concentrações médias $\left(\mathrm{mg}^{-\mathrm{L}^{-1}}\right)$ de material em suspensão total determinadas nas amostras de água no controle e nos mesocosmos contaminados com $\mathrm{Cr}$ e Cu durante o período de estudo. 225

Figura 81: Concentrações médias $\left(\mathrm{mg}^{\mathrm{L}} \mathrm{L}^{-1}\right)$ de material em suspensão orgânico determinadas nas amostras de água no controle e nos mesocosmos contaminados com $\mathrm{Cr}$ e $\mathrm{Cu}$ durante o período de estudo. 225

Figura 82: Concentrações médias (mg.L-1) de material em suspensão inorgânico determinadas nas amostras de água no controle e nos mesocosmos contaminados com $\mathrm{Cr}$ e $\mathrm{Cu}$ durante o período de estudo. 226 
Figura 83: Concentrações médias ( $\mathrm{mg}^{\mathrm{L}} \mathrm{L}^{-1}$ ) de silicato dissolvido determinadas nas amostras de água no controle e nos mesocosmos contaminados com $\mathrm{Cr}$ e $\mathrm{Cu}$ durante o período de estudo. 226

Figura 84: Concentrações médias $\left(\mu \mathrm{g} \cdot \mathrm{L}^{-1}\right)$ de nitrato determinadas nas amostras de água no controle e nos mesocosmos contaminados com $\mathrm{Cr}$ e Cu durante o período de estudo.

Figura 85: Concentrações médias $\left(\mu \mathrm{g} \cdot \mathrm{L}^{-1}\right.$ ) de nitrito determinadas nas amostras de água no controle e nos mesocosmos contaminados com $\mathrm{Cr}$ e Cu durante o período de estudo.

Figura 86: Concentrações médias $\left(\mu \mathrm{g} \cdot \mathrm{L}^{-1}\right)$ de amônio determinadas nas amostras de água no controle e nos mesocosmos contaminados com $\mathrm{Cr}$ e Cu durante o período de estudo.

Figura 87: Concentrações médias $\left(\mathrm{mg}^{\mathrm{L}} \mathrm{L}^{-1}\right)$ de nitrogênio total determinadas nas amostras de água no controle e nos mesocosmos contaminados com $\mathrm{Cr}$ e $\mathrm{Cu}$ durante o período de estudo. 229

Figura 88: Concentrações médias $\left(\mu \mathrm{g} \cdot \mathrm{L}^{-1}\right)$ de fosfato inorgânico determinadas nas amostras de água no controle e nos mesocosmos contaminados com $\mathrm{Cr}$ e $\mathrm{Cu}$ durante o período de estudo. 230

Figura 89: Concentrações médias $\left(\mu \mathrm{g} \cdot \mathrm{L}^{-1}\right)$ de fosfato total dissolvido determinadas nas amostras de água no controle e nos mesocosmos contaminados com $\mathrm{Cr}$ e Cu durante o período de estudo.

Figura 90: Concentrações médias $\left(\mu \mathrm{g} \cdot \mathrm{L}^{-1}\right)$ de fósforo total determinadas nas amostras de água no controle e nos mesocosmos contaminados com $\mathrm{Cr}$ e $\mathrm{Cu}$ durante o período de estudo.

Figura 91: Concentrações médias $\left(\mathrm{mg}^{\mathrm{kg}}{ }^{-1}\right)$ de $\mathrm{Cu}$ na fração fracamente ligada do sedimento dos mesocosmos controle e contaminados com $\mathrm{Cu}$ (as barras de erros referem-se ao desvio padrão da média entre as réplicas dos mesocosmos).

Figura 92: Concentrações totais médias $\left(\mathrm{mg} \mathrm{kg}^{-1}\right)$ de $\mathrm{Cr}$ no sedimento dos mesocosmos controle e contaminados com $\mathrm{Cr}$.

Figura 93: Concentrações totais médias $\left(\mathrm{mg}^{\mathrm{kg}}{ }^{-1}\right)$ de $\mathrm{Cu}$ no sedimento dos mesocosmos controle e contaminados com $\mathrm{Cu}$ 237

Figura 94: Teores médios de matéria orgânica (\%) determinados nos sedimentos dos mesocosmos controle e contaminados com $\mathrm{Cu}$. 238

Figura 95: Concentrações médias de nitrogênio (\%) determinadas nos sedimentos coletados nos tanques em cada uma das coletas. 239

Figura 96: Concentrações médias de fósforo $\left(\mathrm{mg}^{\mathrm{kg}}{ }^{-1}\right)$ determinadas nos sedimentos nos sedimentos dos mesocosmos controle e contaminados com $\mathrm{Cu}$. 239

Figura 97: Concentrações de $\mathrm{Cr}\left(\mu \mathrm{g} \cdot \mathrm{L}^{-1}\right)$ determinadas na água intersticial dos mesocosmos controle e contaminados com $\mathrm{Cr}$. 240 
Figura 98: Concentrações de $\mathrm{Cu}\left(\mu \mathrm{g} \cdot \mathrm{L}^{-1}\right)$ determinadas na água intersticial dos mesocosmos controle e contaminados com $\mathrm{Cu}$. 240

Figura 99: Concentrações médias de $\mathrm{Cr}\left(\mu \mathrm{g} \cdot \mathrm{g}^{-1}\right)$ determinadas nas amostras de plâncton dos mesocosmos controle e contaminados com $\mathrm{Cr}$. 242

Figura 100: Concentrações médias de $\mathrm{Cu}\left(\mu \mathrm{g} \cdot \mathrm{g}^{-1}\right)$ determinadas nas amostras de plâncton dos mesocosmos controle e contaminados com $\mathrm{Cu}$. 242

Figura 101: Regressão linear entre as concentrações de $\mathrm{Cr}$ na água e no plâncton dos mesocosmos. 244

Figura 102: Regressão linear entre as concentrações de $\mathrm{Cu}$ na água e no plâncton dos mesocosmos. 244

Figura 103: Concentração média $\left(\mu \mathrm{g} \cdot \mathrm{g}^{-1}\right)$ de $\mathrm{Cr}$ determinada nas amostras de peixes coletadas nos tanques controle e contaminados com $\mathrm{Cr}$ ao final do experimento. 248

Figura 104: Concentração média $\left(\mu \mathrm{g} \cdot \mathrm{g}^{-1}\right)$ de Cu determinada nas amostras de peixes coletadas nos tanques controle e contaminados com $\mathrm{Cu}$ ao final do experimento. 248

Figura 105: Regressão linear entre as concentrações de $\mathrm{Cr}$ e peso e comprimento dos peixes. 250

Figura 106: Regressão linear entre as concentrações de Cu e peso e comprimento dos peixes. 250

Figura 107: Concentração média $\left(\mu \mathrm{g} \cdot \mathrm{g}^{-1}\right)$ de $\mathrm{Cr}$ determinada nas amostras de macrófitas coletadas nos tanques controle e contaminados com $\mathrm{Cr}$ ao final do experimento... 252

Figura 108: Concentração média $\left(\mu \mathrm{g} \cdot \mathrm{g}^{-1}\right)$ de $\mathrm{Cu}$ determinada nas amostras de macrófitas coletadas nos tanques controle e contaminados com $\mathrm{Cu}$ ao final do experimento ..253

Figura 109: Regressão linear entre as concentrações de $\mathrm{Cr}$ na parte aérea das plantas e parâmetros biométricos 254

Figura 110: Regressão linear entre as concentrações de $\mathrm{Cr}$ na parte submersa das plantas e parâmetros biométricos 254

Figura 111: Regressão linear entre as concentrações de $\mathrm{Cu}$ na parte aérea das plantas e parâmetros biométricos 255

Figura 112: Regressão linear entre as concentrações de Cu na parte submersa das plantas e parâmetros biométricos 255

Figura 113: Produção primária média do fitoplâncton $\left(\mathrm{mg}^{-\mathrm{L}^{-1}} \mathrm{O}_{2}\right)$ antes e após a contaminação dos tanques na primeira etapa do experimento (18 e 20 de novembro). 256

Figura 114: Produção primária média do fitoplâncton $\left(\mathrm{mg}^{\mathrm{L}} \mathrm{L}^{-1} \mathrm{O}_{2}\right)$ antes e após a contaminação dos tanques na segunda etapa do experimento (10 e 12 de dezembro). 257

Figura 115: Porcentagem de mortalidade de $D$. similis em amostras de água dos mesocosmos (as setas indicam a data da contaminação dos mesocosmos). 258

Figura 116: Regressão linear entre as concentrações de $\mathrm{Cr}$ e mortalidade de $D$. similis nas amostras de água dos mesocosmos. 259

Figura 117: Regressão linear entre as concentrações de $\mathrm{Cu}$ e mortalidade de $D$. similis nas amostras de água dos mesocosmos. 259 
Figura 118: Efeitos do Cr sobre os compartimentos bióticos dos mesocosmos. Clorofila e Cr:

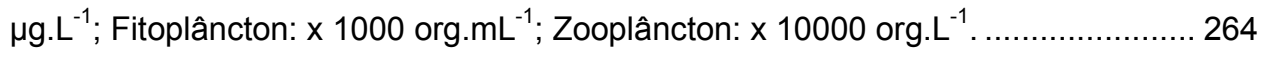

Figura 119: Efeitos do Cu sobre os compartimentos bióticos dos mesocosmos. Clorofila e Cu:

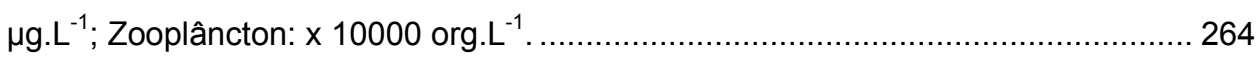

Figura 120: Influência da adição de $\mathrm{Cr}$ na concentração de clorofila e na toxicidade para D. similis. 267

Figura 121: Influência da adição de Cu na concentração de clorofila e na toxicidade para $D$. similis. 267

\section{LISTA DE TABELAS}

Tabela 01: Dados gerais e morfométricos da represa do Lobo. 117

Tabela 02: Variáveis físico-químicas da coluna d'água na área de instalação dos mesocosmos

Tabela 03: Concentrações de $\mathrm{Cr}$ e Cu avaliadas na água intersticial e na fração potencialmente disponível do sedimento da área de instalação dos mesocosmos 122

Tabela 04: Metodologias utilizadas nas determinações das concentrações nutrientes totais e dissolvidos. 128

Tabela 05: Cronograma de coleta de amostras dos microcosmos ..................................... 137

Tabela 06: Volumes dos mesocosmos após a instalação na represa do Lobo. ....................... 138

Tabela 07: Análises realizadas e freqüência das coletas nos mesocosmos instalados na

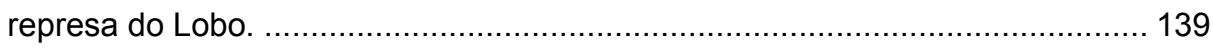

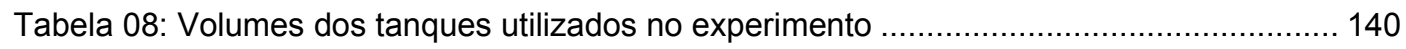

Tabela 09: Análises realizadas e freqüência das coletas nos mesocosmos instalados na represa do Lobo.

Tabela 10: Resultados das análises físico-químicas, metais, clorofila, material em suspensão (total, orgânico e inorgânico) obtidos no início dos experimentos em microcosmos $(\mathrm{t}=0)$.

Tabela 11: Composição, densidade (ind. $\mathrm{mL}^{-1}$ ) e abundância relativa (\%) do fitoplâncton identificado antes do início do experimento 156

Tabela 12: Riqueza, diversidade, uniformidade e dominância do fitoplâncton antes do início do experimento. 157

Tabela 13: Ocorrência dos taxa do fitoplâncton no controle e nos microcosmos contaminados com $\mathrm{Cr}$ e $\mathrm{Cu}$ em todo o período de estudo. 158

Tabela 14: Densidade total do fitoplâncton (DT), riqueza (R) e índices de diversidade ( $\left.H^{\prime}\right)$, uniformidade (U') e dominância (D') para a comunidade fitoplanctônica dos microcosmos controle e contaminados com $\mathrm{Cr}$ e Cu....................................... 162

Tabela 15: Composição, densidade e abundância relativa do zooplâncton no início dos experimentos em microcosmos 164 
Tabela 16: Densidade total (DT), riqueza (S), diversidade (H'), uniformidade (U') e dominância (D') para o zooplâncton total, microcrustáceos e rotíferos na avaliação preliminar do zooplâncton. 164

Tabela 17: Densidades médias (ind. $\mathrm{m}^{-3}$ ) das espécies zooplanctônicas nos microcosmos controle e contaminados com $\mathrm{Cr}$ e $\mathrm{Cu}$ (\%: abundância relativa ao total de indivíduos. DP: desvio padrão)................................................................. 166

Bosmina hagmani. 166

Tabela 18: Densidade (N), riqueza $(S)$, diversidade ( $\left.H^{\prime}\right)$, uniformidade (U') e dominância (D') para o zooplâncton total nos microcosmos controle e contaminados com $\mathrm{Cr}$ e $\mathrm{Cu}$. 168

Tabela 19: Densidade $(\mathrm{N})$, riqueza $(\mathrm{S})$, diversidade $\left(\mathrm{H}^{\prime}\right)$, uniformidade $\left(\mathrm{U}^{\prime}\right)$ e dominância $\left(\mathrm{D}^{\prime}\right)$ para microcrustáceos nos microcosmos controle e contaminados com $\mathrm{Cr}$ e $\mathrm{Cu}$.

Tabela 20: Densidade $(N)$, riqueza $(S)$, diversidade (H'), uniformidade (U') e dominância (D') para Rotifera nos microcosmos controle e contaminados com $\mathrm{Cr}$ e $\mathrm{Cu}$. 169

Tabela 21: Variáveis que sofreram efeito significativo após a adição de Cu nos mesocosmos (ANOVA, $p<0,05$ ). 186

Tabela 22: Variáveis que sofreram efeito significativo após a adição de $\mathrm{Cr}$ nos mesocosmos

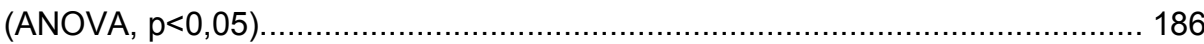

Tabela 23: Concentrações $\left(\mathrm{mg} \cdot \mathrm{kg}^{-1}\right)$ de $\mathrm{Cr}$ e $\mathrm{Cu}$ recuperadas após digestão e análise de sedimento certificado IAEA - SL1 188

Tabela 24: Síntese da análise de variância das concentrações de $\mathrm{Cu}$ em organismos planctônicos 196

Tabela 25: Síntese da análise de variância das concentrações de $\mathrm{Cr}$ em organismos planctônicos 197

Tabela 26: Fatores de concentração de Cu e $\mathrm{Cr}$ pelo plâncton dos mesocosmos 198

Tabela 27: Síntese da análise de variância das concentrações de $\mathrm{Cu}$ em organismos bentônicos 200

Tabela 28: Síntese da análise de variância das concentrações de $\mathrm{Cr}$ em organismos bentônicos 201

Tabela 29: Fatores de concentração de $\mathrm{Cu}$ e $\mathrm{Cr}$ pelo bentos dos mesocosmos ..................... 202

Tabela 30: Medidas de luminosidade, temperatura, $\mathrm{pH}$, oxigênio dissolvido e condutividade determinadas no dia 26 de março de 2002 203

Tabela 31: Medidas de luminosidade, temperatura, $\mathrm{pH}$, oxigênio dissolvido e condutividade determinadas no dia 01 de abril de 2002 203

Tabela 32: Composição do zooplâncton nos mesocosmos controle e contaminados com $\mathrm{Cr}$ e Cu durante o tempo de experimento. 206

Tabela 33: Densidade $(N)$, riqueza $(S)$, diversidade $\left(H^{\prime}\right)$, uniformidade (U') e dominância (D) no controle e nos tratamentos com $\mathrm{Cr}$ e Cu durante o período de estudo 
Tabela 34: Densidade média dos grupos de macroinvertebrados bentônicos no controle e nos mesocosmos contaminados com $\mathrm{Cr}$ e $\mathrm{Cu}$.

Tabela 35: Índices ecológicos calculados para a comunidade bentônica no início e no final do experimento.

Tabela 36: Resultados dos testes de toxicidade aguda para $D$. similis das amostras coletadas nos mesocosmos controle e contaminados com $\mathrm{Cr}$ e $\mathrm{Cu}$ (\% de mortalidade). ... 215

Tabela 37: Concentrações de $\mathrm{Cr}\left(\mu \mathrm{g} \cdot \mathrm{L}^{-1}\right)$ determinadas nas amostras de água utilizadas nos testes de toxicidade aguda com $D$. similis. 216

Tabela 38: Concentrações de $\mathrm{Cu}\left(\mu \mathrm{g} \cdot \mathrm{L}^{-1}\right)$ determinadas nas amostras de água utilizadas nos testes de toxicidade aguda com $D$. similis. 217

Tabela 39: Variáveis que sofreram efeito significativo após a adição de $\mathrm{Cr}$ (antes da inclusão de peixes e macrófitas). (ANOVA, $p<0,05$ ). 233

Tabela 40: Variáveis que sofreram efeito significativo após a adição de $\mathrm{Cr}$ (após a inclusão de peixes e macrófitas).

Tabela 41: Variáveis que sofreram efeito significativo após a adição de Cu (após a inclusão de peixes e macrófitas).

Tabela 42: Concentrações $\left(\mathrm{mg} \mathrm{kg}^{-1}\right)$ de $\mathrm{Cr}$ e Cu recuperadas após digestão e análise de sedimento certificado IAEA - SL1 237

Tabela 43: Fatores de concentração de $\mathrm{Cu}$ e $\mathrm{Cr}$ pelo plâncton dos mesocosmos. 243

Tabela 44: Valores médios da biomassa total, peso individual, comprimento e número de indivíduos no início e término do experimento.

Tabela 45: Síntese da análise de variância das concentrações de $\mathrm{Cr}$ nas amostras de peixe. 248

Tabela 46: Síntese da análise de variância das concentrações de Cu nas amostras de peixe.

Tabela 47: Avaliação biométrica (valores médios) das macrófitas utilizados no experimento. 251

Tabela 48: Síntese da análise de variância $(p<0,05)$ das concentrações de $\mathrm{Cr}$ nas amostras de macrófita. 252

Tabela 49: Síntese dos efeitos do $\mathrm{Cr}$ nos experimentos em microcosmos. 261

Tabela 50: Síntese dos efeitos do Cu nos experimentos em microcosmos. O: observado; NO: não observado. 262

Tabela 51: Síntese dos efeitos do $\mathrm{Cr}$ nos experimentos em mesocosmos (aspectos funcionais e estruturais). O: observado; NO: não observado. 265

Tabela 52: Síntese dos efeitos do Cu nos experimentos em mesocosmos (aspectos estruturais e funcionais). O: observado; NO: não observado. 266

Tabela 53: Síntese dos efeitos do Cr nos experimentos em mesocosmos (aspectos estruturais e bioacumulação). O: observado; NO: não observado. 268

Tabela 54: Síntese dos efeitos do Cu nos experimentos em mesocosmos (aspectos estruturais e bioacumulação). O: observado; NO: não observado. 269 


\section{1- INTRODUÇÃO}

Os testes de toxicidade em laboratório são essenciais na avaliação dos produtos químicos, e são facilmente replicáveis, porém sua representatividade ecológica é muito baixa. A utilização de testes in situ, micro e mesocosmos têm sido sugerida como uma alternativa ou uma complementação na avaliação de risco, apesar do custo envolvido e da dificuldade na utilização de réplicas, pois estes estudos oferecem dados altamente relevantes ecologicamente e podem ser utilizados para validar e melhorar modelos teóricos (CAQUET, 1996).

Microcosmos podem ser definidos como "modelos em escala reduzida de ecossistemas naturais ou porções destes ecossistemas residentes em containers artificiais mantidos em ambiente controlado ou semi controlado". O termo microcosmos aparece em publicações desde 1963, em estudo sobre o metabolismo microbiano no tratamento de esgotos, porém já havia sido utilizado desde 1887 (HALFFMAN, 1995). Mesocosmos podem ser definidos como "o enclausuramento físico de uma porção de um ecossistema natural ou estruturas construídas ao ar livre como represas ou canais que simulam o ambiente natural" (KENNEDY et al., 1995).

Alguns autores dividem os ecossistemas simulados em microcosmos e mesocosmos em função do seu tamanho. Alguns pesquisadores consideram os estudos em microcosmos como sistemas em escala pequena mantidos em laboratório, outros não fazem distinção entre mesocosmos e microcosmos pois ambos apresentam alto nível de organização biológica e realismo ambiental (CAIRNS, 1988). O comitê organizador do European Workshop on Freshwater Field Tests (EWOFFT) categoriza os sistemas simulados por seu tamanho, sendo chamados de microcosmos sistemas que contém até $15 \mathrm{~m}^{3}$ de água ou até $15 \mathrm{~m}$ de comprimento, no caso de canais, e chamados de mesocosmos os sistemas com mais de $15 \mathrm{~m}^{3}$ de água ou mais longos que $15 \mathrm{~m}$ de comprimento, no caso de canais (KENNEDY op cit.).

A regulamentação de testes em micro e mesocosmos tem sido discutida e avaliada desde a década de 80 pela SETAC (Society of Environmental Toxicology and Chemistry) e por agências reguladoras como a US EPA (HALFFMAN, op cit.)

Comparado com testes com uma única espécie, o uso de mesocosmos permite a previsão do destino e do efeito de poluentes sob condições semelhantes às naturais, incluindo a presença de sedimentos, animais e plantas de ocorrência natural (JAK et al., 1996; BROCK et al, 2000). Não apenas efeitos toxicológicos podem ser observados e quantificados, mas também as implicações ecológicas indiretas podem tornar aparentes. O domínio da toxicologia em geral inclui o entendimento dos tipos de efeitos causados pelos contaminantes, os processos bioquímicos e fisiológicos responsáveis por estes efeitos, as sensibilidades relativas de diferentes tipos de 
organismos 'a exposição química e as toxicidades relativas de cada classe de produtos químicos (CHAPMAN, 1995).

Sistemas de diferentes graus de complexidade têm sido utilizados. Aqueles contendo mais de um nível trófico apresentam uma maior semelhança com as situações de campo, mas implicam na variabilidade entre réplicas. Atualmente, tanto estudos ecológicos como ecotoxicológicos nos ambientes aquáticos têm utilizado mesocosmos para um melhor conhecimento da estrutura e função destes ecossistemas, para desenvolver e validar modelos preditivos sobre o destino e os efeitos de contaminantes e para determinar as concentrações de um contaminante que são inócuas para o ecossistema. Mesocosmos são muitas vezes requeridos no registro de novos químicos, especialmente pesticidas (CROSSLAND, 1994, CAQUET, 1996; BROCK et al., 2000). Estudos complexos como os testes em mesocosmos e a melhor escolha dos organismos teste são essenciais para prever a toxicidade para organismos nativos sob condições de exposição reais (CHAPMAN, 1995).

Mesocosmos são considerados como um nível intermediários entre os estudos de campo e laboratório (Figura 01). Em laboratório, efeitos potenciais de poluentes nos organismos aquáticos podem ser observados utilizando testes de toxicidade mono ou pluri específicos, cadeias tróficas experimentais e microcosmos (CALOW, 1993; CAQUET, 1996). Porem, enquanto estudos em mesocosmos são mais próximos da realidade que testes com uma única espécie, apresentam outras limitações, como a baixa significância estatística na detecção de efeitos e a grande influência do meio (CHAPMAN, 1995)

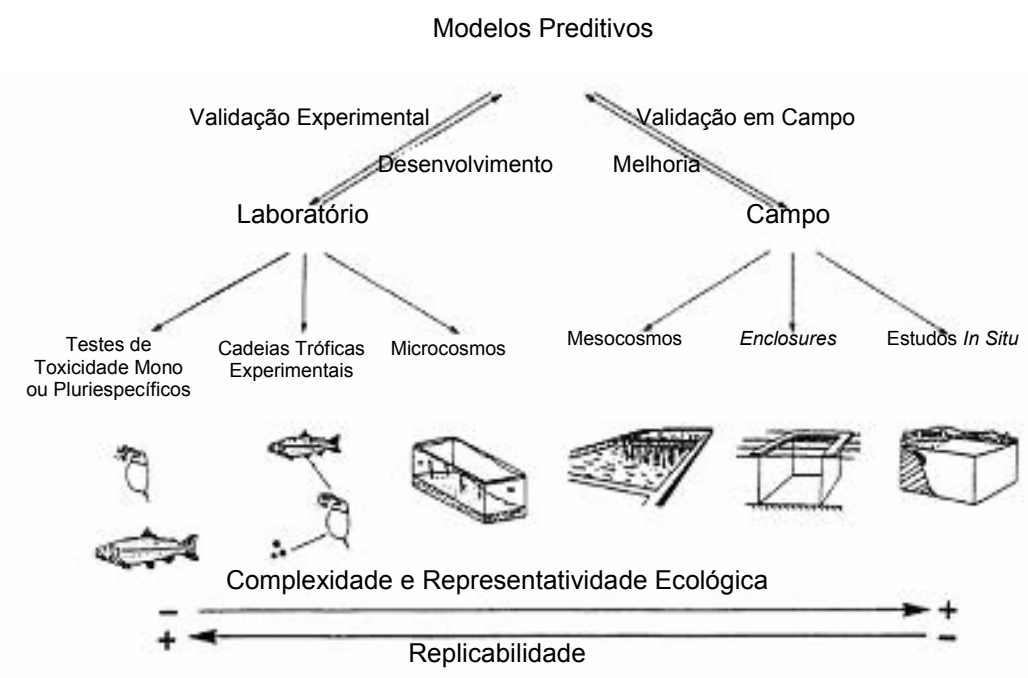

Figura 01: Representação esquemática das metodologias e aproximações complementares usadas em toxicologia ambiental e ecotoxicologia (Adaptado de CAQUET et al, op. cit). 
Diversos experimentos têm sido realizados em mesocosmos. Grande parte desses estudos são referentes à distribuição e ciclagem de metais e poluentes orgânicos, e ao comportamento das comunidades em presença destes estressores. Alguns exemplos de testes realizados em micro e mesocosmos são citados a seguir.

A determinação das fontes de $\mathrm{Cd}$ para um inseto aquático, Chaoborus punctipennis, assim como taxas de assimilação e detoxificação foram determinadas por MUNGER et al. (1999) em experimento em mesocosmos utilizando testes de toxicidade in situ. O experimento consistiu na exposição de larvas do inseto provenientes de um lago com baixas concentrações de $\mathrm{Cd}$ tanto à água quanto ao alimento contaminado por esse metal. Os autores concluíram que a principal fonte de Cd para o inseto é sua alimentação, e que quando transferidos para um meio pobre em $\mathrm{Cd}$ as concentrações acumuladas pelo organismo diminuíram. Os mesocosmos utilizados neste experimento foram construídos com malha de $64 \mu \mathrm{m}$ de abertura, para que a água passasse livremente, mas restringisse a passagem de crustáceos planctônicos, que constituem a principal forma de alimento para esses insetos.

Em um ecossistema de marisma (Mardsiep e Delfzijl, Holanda), LEENDERTSE, SCHOLTEN \& VAN DER WAL (1996) estudaram durante três anos o destino e os efeitos da adição de nitrogênio e fósforo, e dos metais $\mathrm{Zn}$, Cu e $\mathrm{Cd}$, introduzidos no ambiente através do sedimento. A adição de sedimentos ricos em nutrientes e metais causou o aumento das concentrações destes na camada superior do solo, enquanto que o crescimento de plantas típicas de marisma e a assimilação desses elementos por essas plantas foi pouco afetado, não sendo observadas grandes diferenças entre os tratamentos. Os autores concluíram ainda que aproximadamente $50 \%$ da carga de nutrientes e metais adicionada foi retida nos sedimentos. Neste experimento foram utilizadas três bases de concreto, de $15 \times 5 \mathrm{~m}$, com $1 \mathrm{~m}$ de profundidade, simulando a entrada da maré .

Os efeitos da acidificação sobre a variação no tamanho do fitoplâncton e zooplâncton (HAVENS, 1992) também foram observados em experimentos em mesocosmos. Estes experimentos foram realizados em 12 recipientes plásticos, com capacidade para 60 litros, que foram completados com água natural contendo fitoplâncton e zooplâncton (protozoários, náuplios e rotíferos, sendo depois adicionados crustáceos). Os recipientes foram mantidos suspensos a $2 \mathrm{~m}$, com o uso de flutuadores. Através desses experimentos, os autores observaram que em pH 6,5 não ocorreram alterações significativas no tamanho dos indivíduos planctônicos, porém em $\mathrm{pH}$ 5,5 e 4,5 o tamanho médio do fitoplâncton aumentou, enquanto o tamanho do zooplâncton diminuiu, indicando a dominância de espécies maiores de fitoplâncton e menores de zooplâncton em baixo valor de $\mathrm{pH}$. 
JAK et al. (1996) estudaram o comportamento de Daphnia magna, adicionada a uma comunidade planctônica natural, em presença de concentrações diferentes de uma mistura de metais. O desenvolvimento da população de $D$. magna foi drasticamente reduzido em resposta às dosagens mais altas da mistura de metais. Alterações na composição da comunidade zooplanctônica também foram observadas. A presença de Bosmina sp. e Brachionus sp , por exemplo, foi observada apenas ao final do experimento.

As interações de peixes herbívoros de diferentes hábitos alimentares com a interface sedimento/água e sua influência sobre a produção bentônica e planctônica também foram estudadas em experimentos em mesocosmos (CLINE et al., 1994). Os autores observaram que esses organismos podem alterar as propriedades da coluna d'água de formas distintas, por meio da perturbação do sedimento (aumentando a turbidez na coluna d'água), consumo dos organismos bentônicos e reciclagem de nutrientes.

Além de sua aplicação em trabalhos de pesquisa, mesocosmos também têm sido utilizados no tratamento de efluentes, principalmente de esgotos domésticos. Esses sistemas podem, inclusive, servir simultaneamente à produção de hortaliças e peixes (TODD \& JOSEPHSON, 1996).

\section{1- O princípio dos testes de toxicidade em micro e mesocosmos}

Microcosmos e mesocosmos são construídos para simular partes dos ecossistemas aquáticos naturais, sendo geralmente estabelecidos pela coleta de organismos e sua colocação em tanques ou pelo enclausuramento de partes de ecossistemas existentes. Entretanto, a introdução de contaminantes em ecossistemas não poluídos envolve um problema ético (CAQUET et al, 1996).

A maior vantagem na utilização destes testes é a possibilidade de se trabalhar com réplicas e com várias concentrações do contaminante ao mesmo tempo, além de apresentar a possibilidade de comparação das respostas com um controle. O sistema teste contém, assim, uma comunidade aquática naturalmente desenvolvida, usualmente contendo sedimentos, organismos como zooplâncton e fitoplâncton, macro invertebrados pelágicos e bentônicos e macrófitas de origem natural. Pode ser apropriado adicionar certos organismos, como peixes, de fontes externas. Porém, quando grandes partes de ecossistemas são enclausuradas, o espaço limitado e suas barreiras podem influenciar e afetar os organismos e processos ocorrentes no mesocosmos, provocando divergências entre o sistema experimental e o ecossistema maior (BROCK et al., 2000). 
O regime de exposição ao contaminante testado deve permitir a determinação de uma relação dose-resposta sobre uma faixa de concentrações, incluindo aquelas que refletem a exposição ambiental. A exposição deve ser expressa em termos da concentração do químico na água, como nos testes em laboratório, preferivelmente, ou em termos do montante do químico adicionado por unidade de área de superfície ou volume. Um número suficiente de réplicas podem ser usadas para permitir a detecção de diferenças de forma significativa (OECD, 2004).

Endpoints estruturais e funcionais podem ser considerados. Endpoints estruturais são relacionados a abundância de todas as populações e sua organização espacial, taxonômica e trófica. Endpoints funcionais são relacionados aos aspectos dos materiais não vivos, como níveis de nutrientes, oxigênio, taxa de respiração, concentrações de minerais, $\mathrm{pH}$, alcalinidade, condutividade e conteúdo de matéria orgânica. O tempo de exposição deve considerar um período pós tratamento suficientemente longo, de duas ou três gerações, para permitir a avaliação da ocorrência de repovoamento. A determinação do grau de recuperação de um táxon afetado é uma das diferenças chave entre estudos em mesocosmos e outros estudos ecotoxicológicos de alta complexidade e requer conhecimento ecológico substancial para ser interpretado (BROCK et al, 2000).

\section{2- Orientações para testes em micro e mesocosmos}

Apesar do pequeno número de trabalhos em mesocosmos apresentados na literatura, recomendações e orientações para tais experimentos já existem a mais de uma década (SETAC - EUROPE, 1992, apud CAQUET et al., 1996). Com base em métodos propostos em uma série de encontros e whorkshops realizados na Europa e na América do Norte, a OECD apresenta um esboço de orientações básicas na condução de experimentos em campo simulando ecossistemas de água doce (OECD, 2003 e 2004). As orientações apresentadas a seguir são baseadas neste documento. Os estudos realizados em mesocosmos com o objetivo de avaliação de risco se referem em quase sua totalidade aos efeitos de pesticidas sobre os ecossistemas (BROCK et al., 2000).

Experimentos em micro e mesocosmos são úteis na avaliação de risco quando testes realizados em laboratório indicam riscos potenciais para uma determinada espécie por um determinado produto, sendo ferramentas importantes na correlação destes estudos em laboratório com o ambiente natural. Ou seja, mesocosmos fazem a ligação entre a reprodutibilidade experimental e o realismo ecológico (Figura 02). 


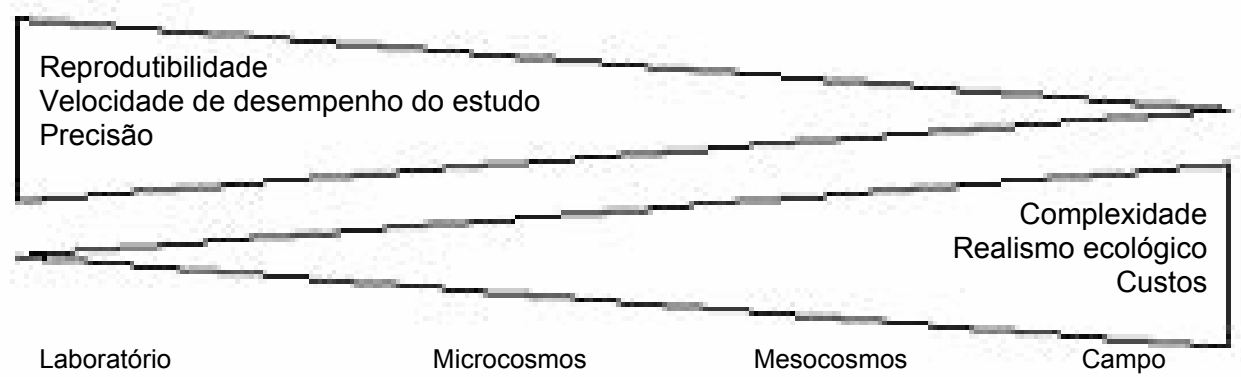

Figura 02: Ecossistemas experimentais como ligação para a avaliação de campo (Adaptado de Brock et al, 2000)

Todo estudo em micro ou mesocosmos deve ser projetado para testar uma hipótese específica, utilizando a informação obtida nas etapas prévias na avaliação de risco. Essa especificidade faz com que cada estudo nesses sistemas seja único em pelo menos um aspecto de seu desenho. Sendo assim, orientações na condução destes testes em mesocosmos são necessariamente genéricas e flexíveis.

Uma razão importante para os experimentos em micro e mesocosmos é a determinação da relevância ecológica dos efeitos identificados em laboratório, pois podem incluir uma variedade de espécies, grupos funcionais ou tipos de habitats. Estes estudos avaliam os efeitos nos níveis de comunidade e ecossistema, os efeitos indiretos potenciais e a recuperação potencial de endpoints sensíveis. Uma segunda importante razão para a condução destes estudos é a medida de efeitos dos químicos sob condições de exposição mais realísticas ambientalmente, como a influência da partição do contaminante nos sedimentos e plantas, fotólise e outros processos que podem influenciar o destino do químico, além de incorporar condições abióticas naturais (temperatura, luz, $\mathrm{pH}$, etc) que podem influenciar as respostas de certos organismos.

\section{3- Objetivos do desenvolvimento de experimentos em micro e mesocosmos}

Antes do início de qualquer teste em micro ou mesocosmos, objetivos claros devem ser definidos para determinar quais endpoints são relevantes e que desenho experimental (nível de replicação, número de tratamentos) é apropriado para atingir estes objetivos. Algumas propriedades de efeito do contaminante testado devem ser conhecidas, como os dados ecotoxicológicos já existentes a seu respeito. Assim, o conhecimento de dados de sensibilidade de espécies aquáticas ao contaminante em questão pode ser útil na escolha de que populações e comunidades devem ser 
estudadas em maior detalhe. Devem também ser determinados os parâmetros de interesse para cada endpoint, como $\mathrm{CE}_{50}, \mathrm{CE}_{\mathrm{x}}$ ou CENO (OECD, 2004).

A definição dos objetivos do teste também deve incluir o nível de precisão que pretende ser obtida para os parâmetros estimados, e o tamanho dos efeitos que são considerados de significância ecológica, em relação aos endpoints de interesse.

A definição dos objetivos do experimento permite determinar:

- o número de tratamentos e escolha das doses

- como os tratamentos serão designados para o mesocosmos (randômico, em blocos)

- número de réplicas por tratamento

- os organismos que serão amostrados, o tamanho das amostras e como as amostragens devem ser realizadas

- o método de análise estatística que será utilizado

Definidos os objetivos do teste em micro ou mesocosmos, pode ser estabelecido um regime de exposição que permita atingir estes objetivos e outras questões referentes à exposição, como as vias e a freqüência de entrada do químico nos sistemas aquáticos.

As propriedades físico-químicas e de destino do contaminante devem ser consideradas em conjunto com a informação biológica disponível para a seleção dos tempos de amostragem e para identificar os componentes ecológicos de maior risco. Um método analítico validado deve estar disponível antes da realização do teste em mesocosmos (OECD, 2004).

\section{4- Tamanho da unidade experimental}

O tamanho do mesocosmos limita a possível complexidade de cadeias alimentares e o grau de efeitos diretos e indiretos que podem ser testados. Os sistemas utilizados variam em tamanho, disposição física e complexidade biológica, assim como a duração da exposição (TODD \& JOSEPHSON, 1996). Com o aumento do tamanho, aumenta também a semelhança entre o mesocosmos e o ambiente natural, e a possibilidade de investigação dos ciclos de vida dos organismos e efeitos indiretos em níveis tróficos superiores .

Mesocosmos podem ser definidos como um ecossistema artificial de pequena escala mantido sob condições ambientais naturais (ODUM, 1984). Muitas características biológicas destes sistemas dependem de seu tamanho, assim, diversos autores têm sugerido categorizar estes os experimentais de acordo com o volume de água. Entretanto este limite não faz referência aos parâmetros ecológicos relevantes, como estabilidade e auto-sustentabilidade, com a possibilidade de integrar os 
principais processos ecológicos e tolerar as simplificações substanciais da estrutura da comunidade. O termo mesocosmo poderia caracterizar melhor ecossistemas artificiais localizados sob condições ambientais naturais, com suficiente complexidade e estabilidade para ser auto sustentável.

A Setac - Europe propõe o termo mesocosmos para represamentos artificiais maiores que $15 \mathrm{~m}^{3}$ (CAQUET et al., 1996). Outros autores propõe volumes entre $1 \mathrm{e}$ $10 \mathrm{~m}^{3}$ (LALLI, 1990), 0,1 e $1000 \mathrm{~m}^{3}$ (GRANEY et al., 1995) 1 e $300 \mathrm{~m}^{3}$ (LA POINT et al., 1989). Um tamanho de 1 a $20 \mathrm{~m}^{3}$ é apropriado para estes estudos, e quando as espécies planctônicas são o interesse principal, microcosmos entre 100 e 1000 litros podem ser utilizados (OECD, 2003; 2004). É também possível a utilização de mesocosmos muito maiores, os quais demandam uma logística maior que os sistemas pequenos. O tamanho do sistema depende dos objetivos do estudo e do tipo de ecossistema que será simulado. Estudos em sistemas pequenos são mais adequados para estudos curtos e para estudos com organismos pequenos.

\section{5 - Validação dos testes em micro e mesocosmos}

De acordo com as orientações apresentadas pela OECD (2004) para estudos em mesocosmos simulando ecossistemas lênticos, as considerações mínimas necessárias para a validação dos testes em micro e mesocosmos são:

- o estudo deve focar endpoints de organismos que estão potencialmente sob risco, os quais devem ter sido identificados em outros estudos

- uma concentração-resposta clara deve ser estabelecida para os endpoints de interesse. Um nível de efeito evidente para pelo menos os organismos de interesse deve ser incluído e ao menos um nível que não cause efeito deve ser considerado ecologicamente significante

- a variabilidade deve ser a menor possível. Se a variação entre as réplicas for grande, as conclusões do estudo são menos precisas.

- a concentração de exposição na coluna d'água deve ser determinada analiticamente em um tempo inicial de exposição $(\mathrm{t}=0)$. Se as concentrações serão determinadas ou não em outras matrizes depende dos objetivos do estudo

- a duração do estudo deve ser apropriada para o ciclo de vida dos organismos de interesse e o tempo necessário para sua recuperação, se este for um objetivo do estudo 


\section{6- As unidades experimentais: confecção, montagem e os componentes}

Estudos em mesocosmos ou microcosmos podem ser realizados com tanques artificiais ou pelo enclausuramento de partes de um ecossistema existente. A profundidade média dos sistemas depende dos objetivos do estudo, mas geralmente devem estar entre 0,3 e $1 \mathrm{~m}$. Em sistemas pequenos, grandes flutuações diárias de temperatura podem ser reduzidas enterrando-se os sistemas parcialmente no solo ou pela imersão num tanque (BROCK et al, 2000).

Os microcosmos ou mesocosmos podem ser construídos com algum substrato natural ou material inerte, como concreto, fibra de vidro ou aço inoxidável, podendo ser também recobertos com PVC inerte para prevenir a troca de água com o meio externo. Deve ser tomado cuidado na lixívia de materiais plásticos para as águas teste, e em alguns casos os sistemas devem ser recobertos para evitar o distúrbio provocado pelas aves aquáticas (OECD, 2004).

A re-utilização dos tanques depois do tratamento com produtos químicos depende das características do produto, particularmente na sua persistência, e na variabilidade biológica. Os tanques podem ser esvaziados por um período de tempo ou recobertos com novo sedimento (OECD, 2004).

Os sedimentos devem sempre ser incluídos nos sistemas teste pois eles provem um importante elemento tampão para os sistemas. O sedimento deve ser caracterizado por análises químicas, incluindo metais, conteúdo de $\mathrm{N}, \mathrm{P}$ e matéria orgânica, capacidade de troca catiônica, pela determinação do pH e pela distribuição de tamanho de partícula. Assim como o sedimento, a água utilizada nos testes deve ser caracterizada para contaminantes, nutrientes, $\mathrm{pH}$, dureza, oxigênio e turbidez e, quando na utilização de grandes sistemas, a água pode ser intercambiada entre as unidades experimentais antes da contaminação, para a obtenção de réplicas mais homogêneas. Após a contaminação, não deve ocorrer troca de água entre os sistemas (OECD, op cit.).

Os organismos presentes nos sistemas devem ser uma comunidade aquática naturalmente desenvolvida, com organismos apropriados como zoo e fitoplâncton, perifiton, bactérias, macroinvertebrados pelágicos e bênticos. A inclusão de peixes não é recomendada se o foco do estudo são os efeitos sobre os zooplâncton ou macro invertebrados, pois em sistemas confinados tendem a ter uma influência não natural no restante do sistema e a predação pode influenciar a resposta da comunidade ao contaminante. Se um dos objetivos do estudo é a avaliação dos efeitos sobre peixes, o uso de mesocosmos grandes é recomendado, assim como a manutenção de uma densidade baixo de espécimens. A inclusão de macrófitas é aconselhada na maioria dos casos, pois são uma parte estrutural e funcional importante dos ecossistemas 
aquáticos, provendo habitat para organismos, contribuindo na reciclagem de macro e micro nutrientes e influenciando as condições físico-químicas do sistema (OECD, op cit.).

O período de tempo de adaptação do sistema antes da adição do contaminante varia com o tamanho do sistema e com a origem do sedimento e água utilizados. Um grau de diversidade suficiente deve ser atingido pelo sistema e uma certa homogeneidade entre as réplicas devem ser estabelecidas antes do início do experimento (OECD, op cit.).

\section{7- Aplicação do contaminante nas unidades experimentais}

Duas aproximações diferentes podem ser identificadas na aplicação de substâncias tóxicas nos mesocosmos. A primeira, uma aproximação toxicológica, consiste na aplicação direta da substância teste na água, incluindo a agitação para atingir uma distribuição uniforme. A exposição é expressa em termos de concentração da substância na água, como nos testes de toxicidade. A segunda é uma aproximação de simulação, imitando a rota de entrada real da substância no sistema, como a aplicação por spray ou através do escoamento superficial e erosivo, mais importante na avaliação de risco de pesticidas e outras substâncias utilizadas na agricultura (BROCK et al., 2000).

Em ambos os casos, a concentração da substância teste na água deve ser determinada analiticamente. A carga, a freqüência e o número de réplicas por tratamento depende da natureza do contaminante, dos padrões de uso, das rotas de entrada no ecossistema e do endpoint de interesse do estudo.

\section{8- As estratégias de amostragem}

As amostragens são baseadas nos métodos de amostragem estabelecidos para populações e comunidades. É recomendado a coleta de amostras antes do início do experimento, para a avaliação da adequabilidade do sistema, e continuamente até o final do experimento. A duração total do teste e o regime de amostragem dependem do objetivo de estudo, das propriedades de destino do contaminante, do tempo de recuperação da população (OECD, 2004).

A estratégia de amostragem deve assegurar que a coleta de amostra de água não altere significativamente o volume dos sistemas, assim como a coleta de organismos não deve diminuir significativamente o standing-stock das espécies amostradas ou alterar as relações tróficas existentes na cadeia alimentar. Se peixes 
são adicionados ao sistema, devem ser observados freqüentemente, mas coletados apenas ao final do experimento (OECD, op cit.).

As medidas de qualidade de água e as concentrações de nutrientes auxiliam da definição do funcionamento do sistema e na interpretação do destino do contaminante e sua biodisponibilidade. O contaminante testado deve ser analisado analiticamente para confirmar que a substância foi exatamente aplicada ao sistema, para quantificar a exposição ao químico e relacionar as respostas observadas e para avaliar o destino da substância no ambiente sob condições semi-naturais. A substância teste deve ser quantificada pelo menos 5 vezes antes do desaparecimento de $90 \%$ da concentração inicial. Se a substância teste é bioacumulativa, é necessário a coleta de amostras de macroinvertebrados, insetos emergentes ou peixes para tal avaliação (OECD, op cit.).

\section{9- A análise estatística}

Métodos analíticos univariados, como ANOVA ou análise de regressão, são os melhores na investigação de dados paramétricos nos efeitos em nível populacional de uma espécie ou táxon. Análises multivariadas são apropriadas para descrever efeitos na comunidade e também podem ser empregadas para indicar quais espécies são particularmente sensíveis ao tratamento e merecem uma análise univariada específica. Outro método de avaliação dos estudos em micro e mesocosmos é pela determinação de índices de diversidade ou similaridade (OECD, 2004).

É recomendada a análise dos dados dos testes em microcosmos ou mesocosmos por ambas as técnicas, univariada e multivariada, para permitir uma avaliação em nível populacional e do conjunto. A avaliação dos efeitos dos tratamentos pode ser convertida para um valor de CENO comunidade com significância estatística. Valores de CENO para espécies individuais podem ser menores que valores de CENO para a comunidade (OECD, op cit.).

\section{2- OBJETIVOS}

\section{1- Objetivos gerais}

Os objetivos gerais dos experimentos em micro e mesocosmos foram avaliar as alterações estruturais e funcionais do sistema, representando a represa do Lobo, após a adição de $\mathrm{Cr}$ e $\mathrm{Cu}$, considerando os limites máximos permitidos pela resolução 20/1986 do CONAMA (CONAMA, 1986) para rios de classe 2. Os experimentos foram conduzidos em três etapas, em ordem crescente de complexidade, com alguns 
objetivos comuns a todos os experimentos e alguns objetivos específicos a um experimento em particular.

\section{2- Objetivos específicos}

\subsection{1- Experimento em microcosmos}

- Avaliar as alterações nas concentrações de clorofila, nutrientes e pH na água da represa do Lobo após a adição de $\mathrm{Cr}$ e $\mathrm{Cu}$

- Avaliar as alterações na composição do plâncton (fito e zooplâncton) após a adição de $\mathrm{Cr}$ e $\mathrm{Cu}$

\subsection{2- Experimentos em mesocosmos 1- Aspectos funcionais e estruturais}

- Avaliar as alterações na concentração de clorofila e na produção primária (experimento in situ com ${ }^{14} \mathrm{C}$ ), nas variáveis físico-químicas da água e nas variáveis biogeoquímicas do sedimento da represa do Lobo após a adição de $\mathrm{Cr}$ e $\mathrm{Cu}$

- Verificar a ocorrência de bioacumulação de Cu e Cr nas comunidades planctônicas e bentônicas

- Avaliar as alterações na composição do plâncton (fito e zooplâncton) e do bentos após a adição de $\mathrm{Cr}$ e $\mathrm{Cu}$

\subsection{3- Experimentos em mesocosmos 2- Aspectos funcionais e} bioacumulação

- Avaliar as alterações na concentração de clorofila e na produção primária (experimento in situ pelo método do oxigênio dissolvido), nas variáveis físico-químicas da água e nas variáveis biogeoquímicas do sedimento da represa do Lobo após a adição de $\mathrm{Cr}$ e $\mathrm{Cu}$

- Correlacionar a ocorrência de bioacumulação de $\mathrm{Cu}$ e $\mathrm{Cr}$ nas comunidades planctônicas e bentônicas existentes nos mesocosmos e nos peixes e macrófitas (incluídos posteriormente) com as concentrações de $\mathrm{Cr}$ e Cu na água e no sedimento.

\section{3- METODOLOGIA}

\section{1- Características gerais da área de estudo}

Os experimentos em micro e mesocosmos foram realizados na represa do Lobo (Broa), na área pertencente ao Centro de Recursos Hídricos e Ecologia Aplicada, da Escola de Engenharia de São Carlos, Universidade de São Paulo. 
O reservatório foi escolhido pela proximidade dos laboratórios de Limnologia e Ecotoxicologia do Núcleo de Estudos em Ecossistemas Aquáticos (CRHEA/ EESC? USP), apresentando a infra-estrutura necessária à realização das coletas freqüentes e proporcionando um controle e acompanhamento mais efetivo dos experimentos. Além da infra-estrutura, a represa do Lobo é um dos ecossistemas de água doce que detém o maior volume de informação científica do Brasil, com inúmeras pesquisas ecológicas desde 1971.

A represa do Lobo está situada na região centro-oeste do estado de São Paulo, entre os municípios de Itirapina e Brotas, a $22^{\circ} 15^{\prime}$ de latitude sul e $47^{\circ} 49^{\prime}$ de longitude oeste, a 705 metros de altitude, estando inserida na sub-bacia hidrográfica do Ribeirão do Lobo. É afluente do rio Jacaré-Guaçu e têm como principais tributários o ribeirão do Lobo e o rio Itaqueri, além dos córregos do Geraldo, das Perdizes, do Limoeiro e da Água Branca. Os cursos d'água que fluem para a represa estão enquadrados como Classe 2, e a região pertence à Área de Proteção Ambiental (APA) do CorumbataíBotucatu-Tejupá. As águas enquadradas na Classe 2 são as águas destinadas ao abastecimento doméstico após tratamento convencional; à proteção das comunidades aquáticas, à recreação de contato primário; à irrigação de hortaliças e plantas frutíferas e à criação natural e/ou intensiva (aquicultura) de espécies destinadas à alimentação humana (CONAMA, 1986)

O reservatório foi construído em 1936 para a geração de energia elétrica, sendo atualmente gerenciada pela empresa Elektro S. A., e utilizada principalmente para atividades de recreação e lazer. O reservatório é pequeno e raso, apresentando características longitudinais bem definidas e declive longitudinal mediano pouco acentuado no sentido cabeceira-barragem, onde são observadas profundidades de ate 11,5 metros (ARGENTON, 2004). Algumas características do sistema estão apresentadas na tabela 01 .

Tabela 01: Dados gerais e morfométricos da represa do Lobo

\begin{tabular}{cc}
\hline \hline Latitude & $22^{\circ} 15^{\prime} \mathrm{S}$ \\
\hline Longitude & $47^{\circ} 49^{\prime} \mathrm{W}$ \\
\hline Comprimento Máximo & $8,0 \mathrm{~km}$ \\
\hline Largura Máxima & $2,0 \mathrm{~km}$ \\
\hline Largura Média & $0,9 \mathrm{~km}$ \\
\hline Profundidade Máxima & $12 \mathrm{~m}$ \\
\hline Profundidade Média & $3 \mathrm{~m}$ \\
\hline Área de Superfície & $6,8 \mathrm{~km}^{2}$ \\
\hline Perímetro & $21 \mathrm{~km}^{3}$ \\
\hline Volume & $22 \times 10^{6} \mathrm{~m}^{3}$ \\
\hline \hline Tempo de Residência Hidráulico & $20-40 \mathrm{dias}^{2}$
\end{tabular}

Fonte: TUNDISI \& MATUSUMURA TUNDISI, 1995 
O sistema era caracterizado como oligotrófico na porção inferior e mesotrófico no compartimento superior, devido às concentrações de nutrientes relativamente baixas, e atualmente está classificado entre mesotrófico e eutrófico (ARGENTON, 2004). A área de instalação dos tanques, próximo à barragem, é um ponto de monitoramento presente em vários estudos (TUNDISI, 1977; MORAES, 1978; CALIJURI, 1985; OISHI, 1990; OLIVEIRA, 1993; QUEIRÓZ, 2000; ARGENTON, 2004), sendo os primeiros trabalhos realizados na década de 70 . Em relação às concentrações de nutrientes, observa-se um aumento acentuado ao longo do tempo, com valores máximos de nitrato variando de $1 \mu \mathrm{g} . \mathrm{L}^{-1}$ em 1972-73 a $53 \mu \mathrm{g} \mathrm{L}^{-1}$ em 2001 02, e valores máximos de fósforo de $12 \mu \mathrm{g} \mathrm{L}^{-1}$ a $66 \mu \mathrm{g} \mathrm{L}^{-1}$ nestas datas respectivamente, como reportado no trabalho de ARGENTON (op cit.).

Em relação ao Índice de Estado Trófico, o valor médio obtido para a área de instalação do experimento em 2001/02 por ARGENTON (op cit.) foi 22,24, classificando esta área como oligotrófica.

Os sedimentos da represa são em geral ácidos, com pH variando entre 4,5 e 6,0. Em estudo realizado por TRINDADE (1980) não foi observada a contaminação dos sedimentos da represa por metais traço, como chumbo, cádmio, cobalto, níquel, cobre, manganês e zinco. Porém, DORNFELD et al (2002), em estudo recente, determinaram concentrações altas de $\mathrm{Pb}$ na fração biodisponível dos sedimentos da represa do Lobo coletados próximo à barragem e ao rio Itaqueri, além de toxicidade aguda para $D$. similis e $C$. xanthus em diversos pontos de amostragem do reservatório.

Diversos estudos foram realizados sobe a comunidade fitoplanctônica da represa do Lobo (WATANABE, 1981; OLIVEIRA, 1993; OLIVEIRA-NETO, 1993), sendo o mais recente o trabalho realizado por CARVALHO (2002). O autor identificou a ocorrência de 226 taxa, pertencentes a 7 classes taxonômicas (20 famílias da classe Chlorophyceae, 13 de Bacillariophyceae; 7 de Cyanophyceae, 3 de Crysophyceae, 1 de Euglenophyceae e 1 de Dynophyceae),observando que o maior número de táxons foi apresentado pela classe Chlorophyceae (107 táxons), seguido por Bacillariophyceae (80 táxons).

A comunidade zooplanctônica da represa do Lobo têm sido largamente estudada (MATSUMURA TUNDISI \& TUNDISI, 1976; ROCHA \& MATUSUMURATUNDISI, 1976; ROCHA \& MATUSUMURA-TUNDISI, 1984; SEIXAS, 1981; RIETZLER, 1991; OLIVEIRA-NETO, 1993), tendo sido identificadas 17 espécies de rotíferos, 7 espécies de protozoários, 6 espécies de Cladocera e 3 espécies de copépodos (ARGENTON, 2004).

A ictiofauna do reservatório do Lobo apresenta riqueza e diversidade altas, sendo composta por um elevado número de espécies pouco abundantes, basicamente 
formada por espécies de pequeno porte adaptadas às condições lacustres. MARINELLI (2002) registrou 24 espécies de peixes no reservatório, destacando Astyanax altiparanae, como espécie dominante, Geophagus brasiliensis, como espécies de maior biomassa, e quatro espécies exóticas introduzidas (Cichla monoculus, Tilapia rendalli, Oreochromis niloticus e Cyprinus carpio), que juntas totalizaram $28,5 \%$ da biomassa total.

As principais espécies de macrófitas aquáticas da represa do Lobo, na década de 80, foram Nymphoides indica, Pontederia cordata e Mayaca fluviatilis, ocorrendo também Nymphaea ampla, Panicum rivulare e Utricularia breviscapa (CAMARGO, 1984). MARINELLI (2002) reporta a primeira ocorrência de $P$. stratiotes no reservatório em 2000, apresentando um crescimento considerável num curto espaço de tempo, passando a constituir um dos grupos de macrófitas mais abundantes.

\section{2- Escolha da área para a instalação dos mesocosmos e caracterização preliminar da área de estudo}

A área onde foram instalados os mesocosmos foi escolhida procurando-se uma região relativamente protegida, e com profundidades homogêneas ao longo da margem.

A área escolhida está localizada próximo à barragem, a uma distância de aproximadamente 3 metros da margem esquerda da represa do Lobo, com uma profundidade de 1,4 a 1,6 m. As profundidades medidas nos pontos demarcados para a instalação do experimento apresentaram-se relativamente irregulares, com variações ocorrendo em direção ao fundo da represa e ao longo das margens. A localização da represa e da área de instalação dos tanques está apresentada na figura 03. 


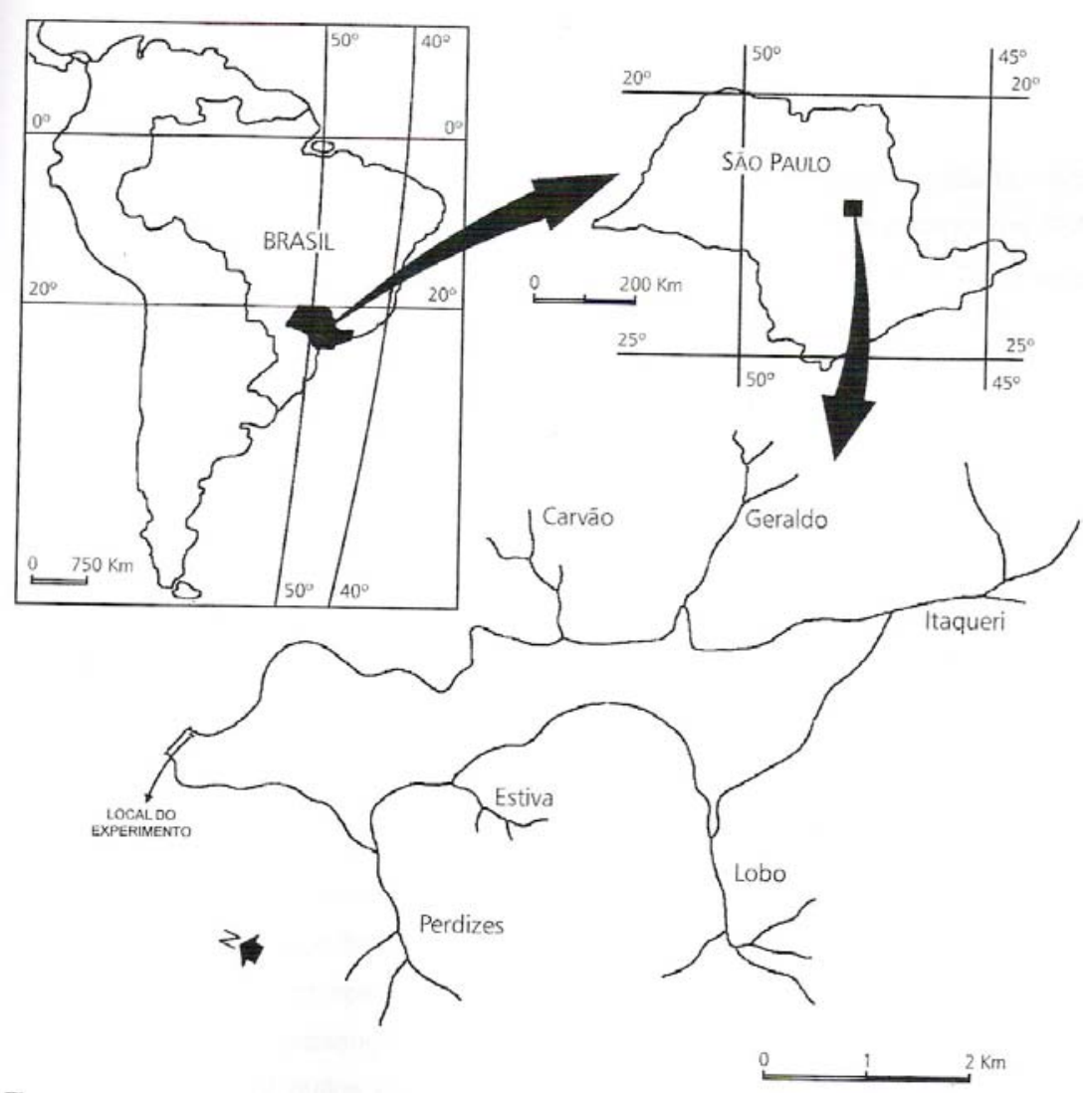

Figura 03: Localização da represa do Lobo (Itirapina/ Brotas, SP) e da área de instalação dos mesocosmos (Fonte: GUSMÃO, 2004)

Com o objetivo de se obter maiores informações sobre o local de instalação dos mesocosmos, efetuou-se uma avaliação preliminar em 18/09/2001, determinandose as concentrações potencialmente disponíveis de $\mathrm{Cu}$ e $\mathrm{Cr}$ no sedimento e na água intersticial (amostras coletadas em triplicata). Na mesma data, foram coletadas amostras das comunidades planctônicas e bentônicas. Simultaneamente foram efetuadas medidas de $\mathrm{pH}$, condutividade, $\mathrm{OD}$ e temperatura na água com o auxílio de um multi-sensor da marca Horiba, modelo U-10.

Os resultados da avaliação preliminar são apresentados previamente, uma vez que foram consideradas essenciais para a sequência dos testes.

$\mathrm{Na}$ tabela 02 são apresentados os valores obtidos para as variáveis físicoquímicas da coluna d'água na área de instalação dos mesocosmos. Com exceção do $\mathrm{pH}$, todos os parâmetros avaliados foram homogêneos ao longo da coluna d'água. Os valores de $\mathrm{pH}$ determinados nesta data são mais altos que os reportados para a represa por outros autores em trabalhos recentes (CARVALHO, 2002; ARGENTON, 2004). 
Tabela 02: Variáveis físico-químicas da coluna d'água na área de instalação dos mesocosmos

\begin{tabular}{ccccc}
\hline \hline $\begin{array}{c}\text { Profundidade } \\
(\mathrm{m})\end{array}$ & $\mathrm{pH}$ & $\begin{array}{c}\text { Condutividade } \\
\left(\mu \mathrm{S} . \mathrm{cm}^{-1}\right)\end{array}$ & $\begin{array}{c}\mathrm{OD} \\
\left(\mathrm{mg} \cdot \mathrm{L}^{-1}\right)\end{array}$ & $\begin{array}{c}\mathrm{T} \\
{ }^{\circ} \mathrm{C}\end{array}$ \\
\hline \hline 0 & 7,44 & 10 & 10,53 & 20,2 \\
0,5 & 7,22 & 10 & 10,47 & 20,1 \\
1,0 & 7,06 & 10 & 9,99 & 20,0 \\
1,5 & 6,81 & 10 & 10,18 & 20,0 \\
2,1 & 6,67 & 10 & 10,26 & 20,0 \\
\hline \hline
\end{tabular}

Os valores de $\mathrm{pH}$ determinados na represa do Lobo por diversos autores tem demonstrado a característica ácida de suas águas. CARVALHO (2002) obteve valores de pH entre 5,6 e 6,2, no período de junho de 1999 a maio de 2000, e ARGENTON (2004) obteve valores entre 4,6 e 7,1 no período de dezembro de 2001 a dezembro de 2002 na área próxima a barragem. Os valores determinados por ambos os autores estiveram abaixo da faixa estabelecida pela resolução CONAMA 20/ 1986, entre 6,0 e 9,0 para corpos d'água Classe 2. A acidez das águas da represa, porém, é relacionada à características naturais, como a geologia e a acidez do solo circundante (TUNDISI, 1977).

Nos dois trabalhos citados, a condutividade apresentou uma variação sazonal muito pequena (em torno de $10 \mu \mathrm{S} . \mathrm{cm}^{-1}$ ). A concentração de oxigênio dissolvido varia ao longo do ano, porém sem apresentar concentrações muito baixas em nenhuma época (5,6 - 9,9 mg. $\mathrm{L}^{-1}$; ARGENTON, op. cit). As concentrações de oxigênio relativamente altas nas águas da represa do Lobo têm sido reportada por diversos autores (TUNDISI, 1977; CARVALHO, 2002; ARGENTON, 2004).

Alterações nas características físico-químicas da água, como $\mathrm{pH}$ e oxigênio dissolvido podem causar alterações na disponibilidade de metais para organismos, alterando também a distribuição destes elementos entre as fases dissolvidas e precipitadas ou adsorvidas. Da mesma forma, a distribuição dos organismos aquáticos é fortemente influenciada pelas características físico-químicas da água.

Em relação ao sedimento, foram avaliadas as concentrações de $\mathrm{Cr}$ e $\mathrm{Cu}$ na água intersticial e na fração potencialmente disponível ou fracamente ligada do sedimento. Os resultados referentes à estas análises estão apresentadas na tabela 03. 
Tabela 03: Concentrações de $\mathrm{Cr}$ e $\mathrm{Cu}$ avaliadas na água intersticial e na fração potencialmente disponível do sedimento da área de instalação dos mesocosmos.

\begin{tabular}{lcc}
\hline \hline & $\begin{array}{c}\text { Sedimento } \\
\left(\mathrm{mg}_{\mathrm{kg}}{ }^{-1}\right)\end{array}$ & $\begin{array}{c}\text { Água Intersticial } \\
\left(\mu \mathrm{gg} \mathrm{L}^{-1}\right)\end{array}$ \\
\hline \hline $\mathrm{Cu}$ & $11,3 \pm 0,9$ & $47,03 \pm 3,9$ \\
$\mathrm{Cr}$ & $\mathrm{ND}$ & $0,49 \pm 0,2$ \\
\hline \hline
\end{tabular}

A concentração de Cu determinada nesta amostra de sedimento foi semelhante à determinada por DORNFELD et al (2002), em amostras coletadas na mesma área em outubro de 2000. Cr não foi detectado na fração biodisponível do sedimento, porém no trabalho citado foi obtido $1,25 \mathrm{mg} \cdot \mathrm{kg}^{-1}$ de $\mathrm{Cr}$ nessa fração.

Os autores reportam ainda a contaminação do sedimento desta área pelo $\mathrm{Pb}$ $\left(60,7 \mathrm{mg} \cdot \mathrm{kg}^{-1}\right)$, e a toxicidade aguda do sedimento para $D$. similis e $C$. xanthus. A alta concentração de $\mathrm{Pb}$ e a toxicidade do sedimento foram relacionadas ao alto conteúdo de matéria orgânica presente no sedimento (29 \%). Outros metais, como Cd e Zn, não foram detectados ou apresentaram baixas concentrações.

As amostras de fitoplâncton foram avaliadas pelo Biól. MSc Davi Perez Carvalho e nesta avaliação preliminar (18/09/2001) verificou-se a dominância da alga cianofícia Aphanocapsa delicatíssima, contribuindo com $67,37 \%$ dos organismos identificados. A diatomácea Aulacoseira varians e a Clorofícea Scytomonas sp. contribuiram com 7,22 e $8,95 \%$ da abundância relativa. No total, foram identificados 26 taxa.

Em relação ao zooplâncton, verificou-se a dominância dos gêneros Daphnia, Ceriodaphnia, Bosmina, Moina e Diaphanosoma entre os Cladocera, sendo o primeiro mais abundante que os demais. Entre os copépodos, o genêro Argyrodiaptamus foi o mais representativo, com maior abundância das fases de copepodito e náuplio. O gênero Keratelloa foi o mais representativo entre os Rotifera.

A comunidade bentônica foi avaliada pela Biól. MSc. Carolina Buso Dornfeld, e nesta avaliação preliminar verificou-se a dominância da ordem Diptera, com 96,7\% dos organismos identificados. Dentre estes, a família Chironomidae foi a mais representativa, com maior abundância das subfamílias Tanypodinae e Chironominae. Apenas 4,35\% dos organismos identificados eram pertencentes à ordem Annelidae. No total, somente 46 organismos. $\mathrm{m}^{-2}$ foram encontrados nas amostras de sedimento, sendo Aslabesmyia (Tanypodinae) e Polypedilum (Chironominae) os genêros mais abundantes. 


\section{3- Experimento em microcosmos: design e instalação}

Conforme mencionado anteriormente, previamente aos estudos em mesocosmos, montados na represa do Lobo, efetuou-se um estudo em 9 tanques cilíndricos de fibra de vidro, com aproximadamente 72 litros de capacidade $(45 \mathrm{~cm}$ de diâmetro e $0,16 \mathrm{~m}^{2}$ de área superficial), sendo o experimento montado em triplicata para cada tratamento. Os tanques de fibra de vidro utilizados no experimento foram previamente lavados com $\mathrm{HNO}_{3} 5 \%$ e água destilada.

Com o intuito de manter as condições ambientais próximas às observadas em campo, os tanques experimentais foram colocados dentro de um tanque de concreto construído às margens da represa do Lobo. Esse tanque foi mantido com água corrente da represa, na altura dos tanques experimentais, de forma que a temperatura destes permanecesse semelhante à da represa (Figura 04). Com o auxílio de uma bomba de sucção, coletou-se 600 litros de água da represa do Lobo, em galões de 200 litros, que foram transportados imediatamente até o local de instalação do experimento. Essa água foi distribuída nos nove tanques, já inseridos no tanque de concreto.



Figura 04: Aspecto geral do experimento em microcosmos.

Os tanques foram deixados em repouso por aproximadamente 2 horas, e então adicionou-se as soluções de metais desejando-se uma concentração final de 0,02

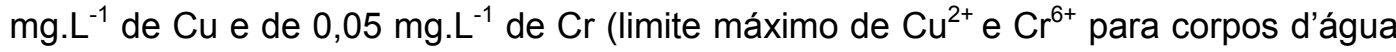
classe 2, segundo a Resolução n ${ }^{\circ} 20 / 1986$ do CONAMA). Os tanques foram dispostos na seguinte ordem: controle, contaminados com cromo e contaminados com $\mathrm{Cu}$, intercalando as réplicas como apresentado na Figura 05 . Os tanques foram 
contaminados pela adição direta das soluções de metais, em uma única aplicação, sendo os experimentos acompanhados durante 7 dias.

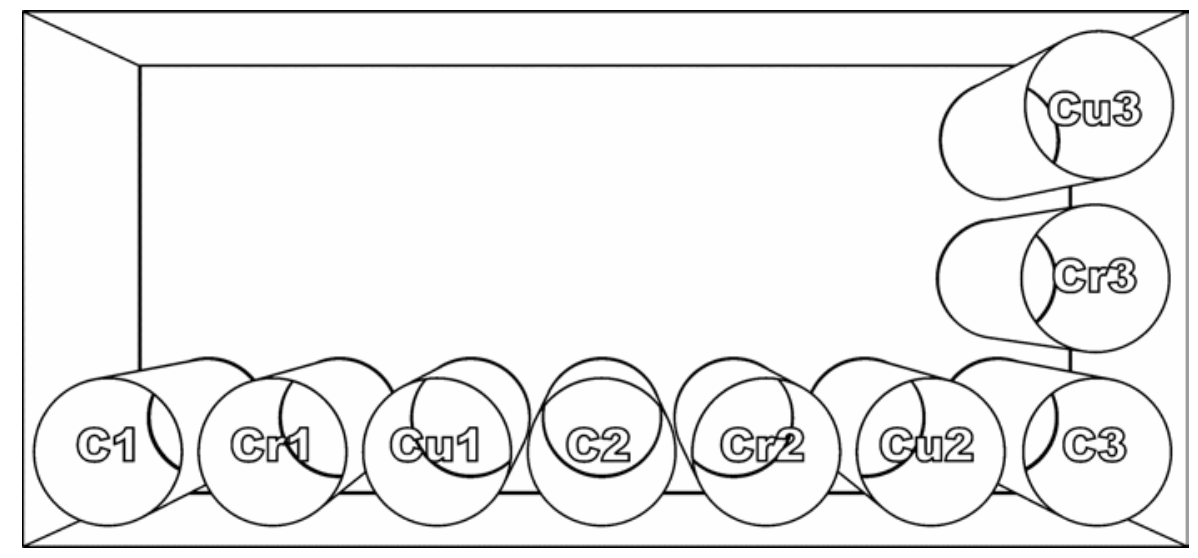

Figura 05: Disposição dos tanques controle (C) e contaminados com $\mathrm{Cr}$ e Cu.

\section{4- Experimento em mesocosmos: design e instalação}

Os experimentos foram realizados em triplicata para cada tratamento, utilizando-se unidades experimentais construídas de PVC, de fundo aberto (em contato com o sedimento de fundo), com capacidade máxima de 6000 litros, instalados na represa do Lobo.

Os mesocosmos foram construídos pela equipe técnica do CRHEA/USP, utilizando-se filme de PVC de $30 \mathrm{~mm}$ de espessura e seladora de plástico a quente. Cada mesocosmo foi construído com $2 \mathrm{~m}$ de altura e $2 \mathrm{~m}$ de diâmetro, com 6 bolsas para instalação de canos de PVC de $3 / 4$ de diâmetro, por onde foram instaladas as estacas de fixação. Para a fixação do fundo, foram soldadas seis "saias", as quais foram presas ao fundo com 18 corpos de prova de concreto com aproximadamente 12 $\mathrm{kg}$ cada um. A Figura 06 apresenta, de forma esquemática, o mesocosmo utilizadono experimento, e a Figura 07 apresenta um dos mesocosmos utilizados antes da instalação. A Figura 08 corresponde à fase de instalação dos tanques na represa do Lobo. 


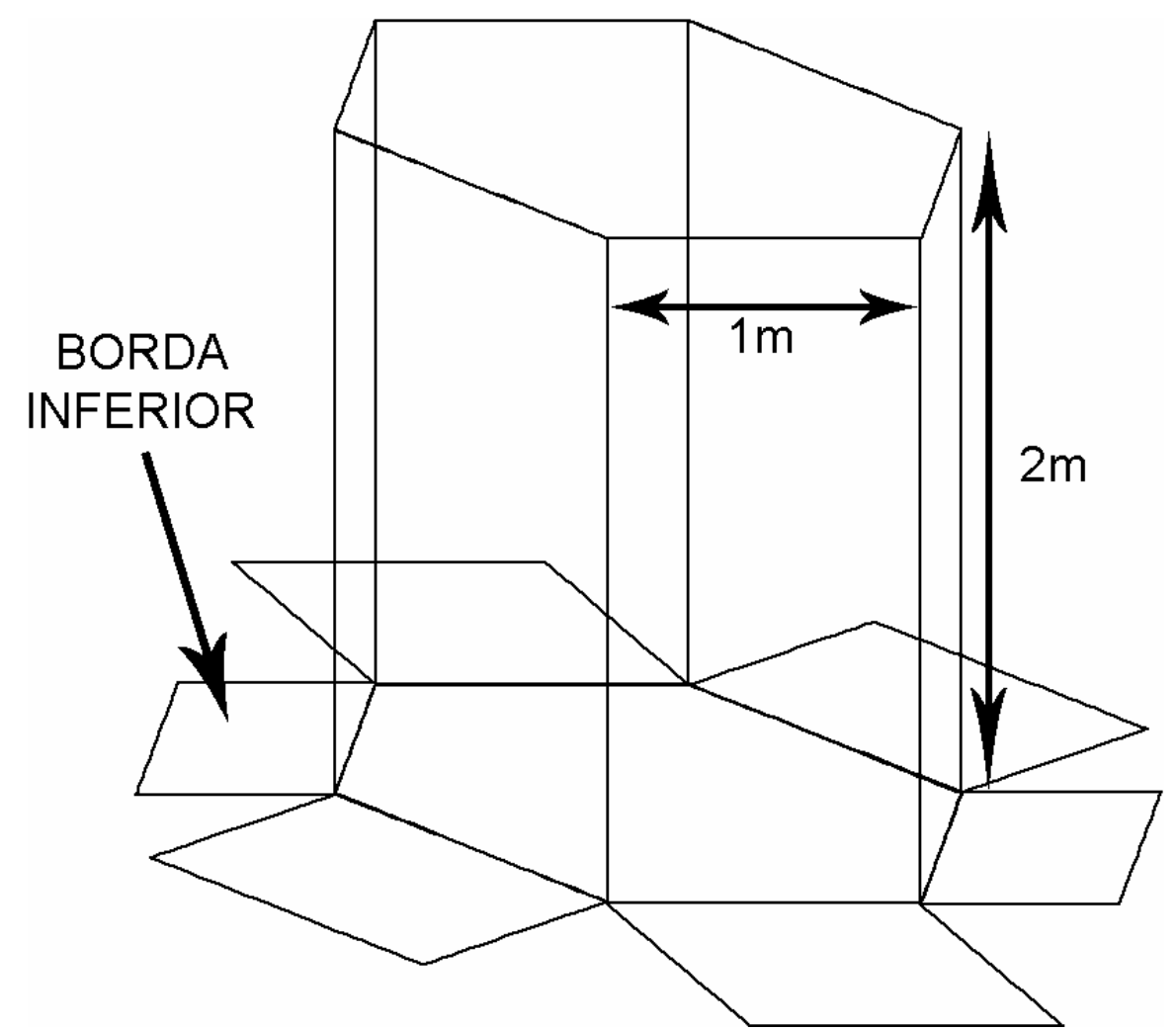

Figura 06: Representação esquemática dos tanques utilizados nos experimentos em mesocosmos, instalados na represa do Lobo.

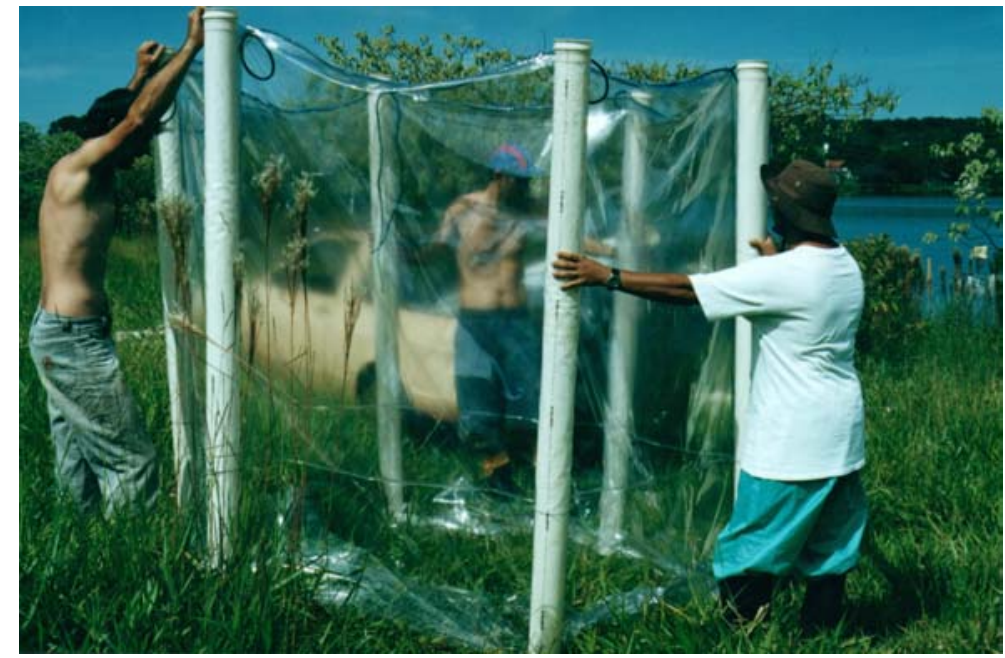

Figura 07: Configuração final do mesocosmo a ser instalado na represa do Lobo. 


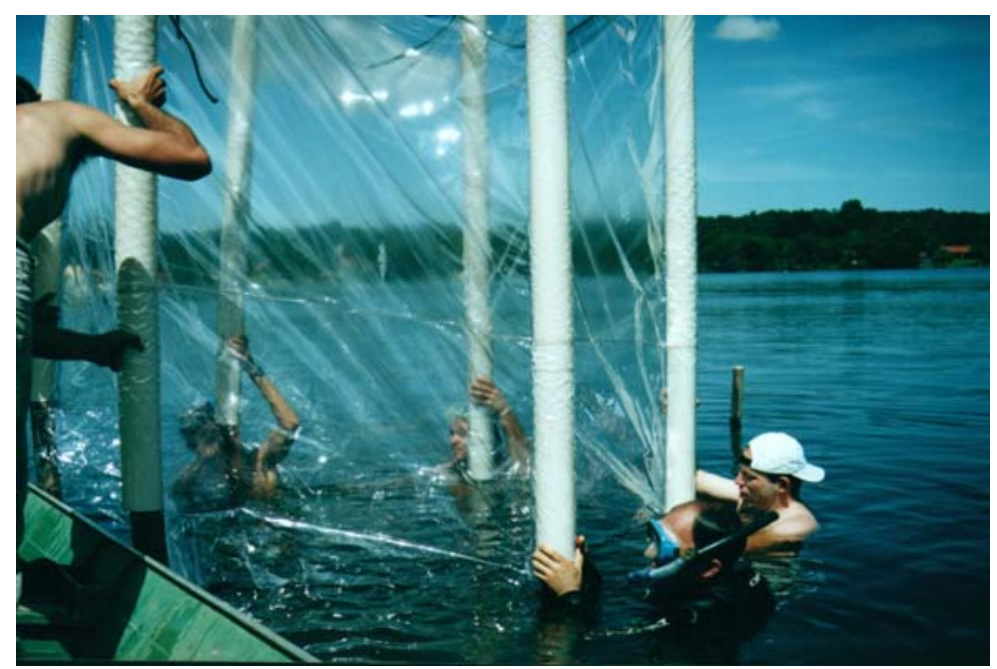

Figura 08: Instalação dos mesocosmos na represa do Lobo

Para a instalação dos mesocosmos foi construída uma guia de ferro fundido representando os locais onde deveriam ser encaixadas as estacas. Com o auxilio da guia construída, as estacas foram previamente fixadas nas suas posições definitivas. Os tanques foram instalados no dia seguinte, sendo abertos acima da água, e encaixados nas estacas pelos canos de PVC já encaixados nos mesocosmos. A disposição dos mesocosmos em relação à margem da represa está apresentada na Figura 09.

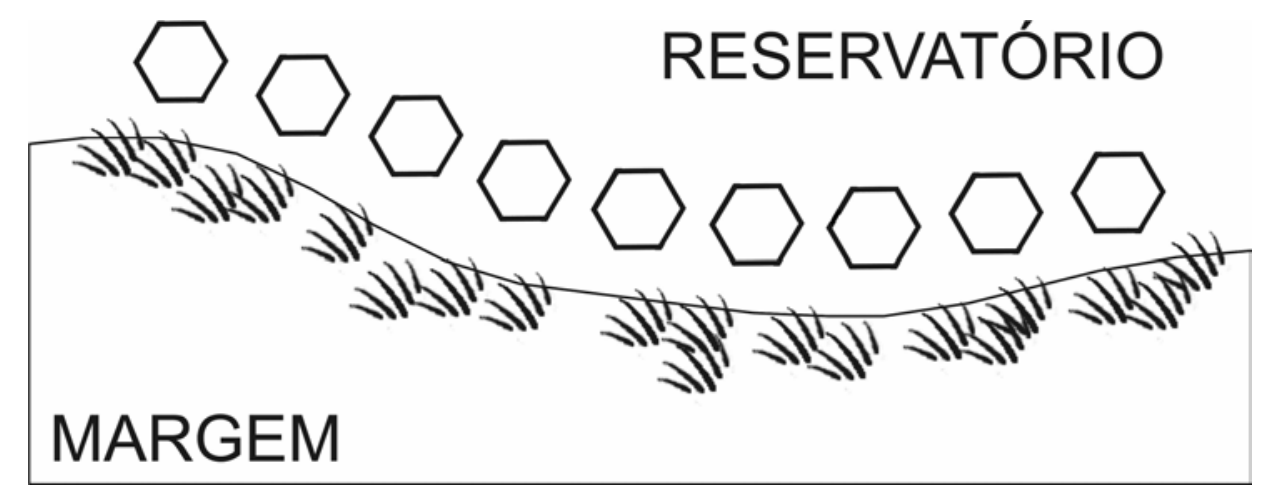

Figura 09: Disposição dos mesocosmos em relação à margem da represa do Lobo.

Assim, os mesocosmos, após fixados, enclausuraram porções da represa contendo água, sedimento e comunidades biológicas, exceto macrófitas e peixes. $\mathrm{A}$ contaminação dos mesocosmos foi realizada após um período de estabilização, pela 
adição direta das soluções de metais. Da mesma forma que nos experimentos em microcosmos, foi utilizada apenas uma concentração dos contaminantes, desejandose uma concentração final de $0,02 \mathrm{mg} \cdot \mathrm{L}^{-1}$ de $\mathrm{Cu}$ (limite máximo de $\mathrm{Cu}^{2+}$ para corpos d'água Classe 2, segundo a Resolução $\mathrm{n}^{\circ} 20 / 1986$ do CONAMA) e de 0,05 mg. $\mathrm{L}^{-1}$ de Cr (limite máximo de $\mathrm{Cr}^{6+}$ para corpos d'água Classe 2, segundo a Resolução $\mathrm{n}^{\circ} 20$ / 1986 do CONAMA)

$\mathrm{Na}$ segunda fase dos experimentos em mesocosmos (Mesocosmos 2) foram instalados tanques-rede, confeccionados de tule, no interior de cada unidade experimental, o que permitiria a retirada dos peixes e macrófitas no final do experimento.

\section{5- Coleta, preservação e análises químicas das amostras de água, sedimento e comunidades}

\subsection{1- Água}

As amostras de água foram coletadas com o auxílio de garrafa de van'Dorn a meia altura dos mesocosmos (Figura 10), sendo coletados $200 \mathrm{~mL}$ para as análises de metais e $1 \mathrm{~L}$ para as análises de nutrientes, clorofila e material em suspensão, os quais foram transferidos para frascos plásticos previamente lavados com $\mathrm{HNO}_{3} \quad 10 \% \mathrm{e}$ $\mathrm{HCl} 10 \%$, respectivamente. Após a coleta, as amostras foram mantidas sob refrigeração até seu processamento.

No momento das coletas, as variáveis físico-químicas $(\mathrm{pH}$, temperatura, oxigênio dissolvido, condutividade) da água da represa foram determinadas utilizandose multieletrodo Horiba U-10.

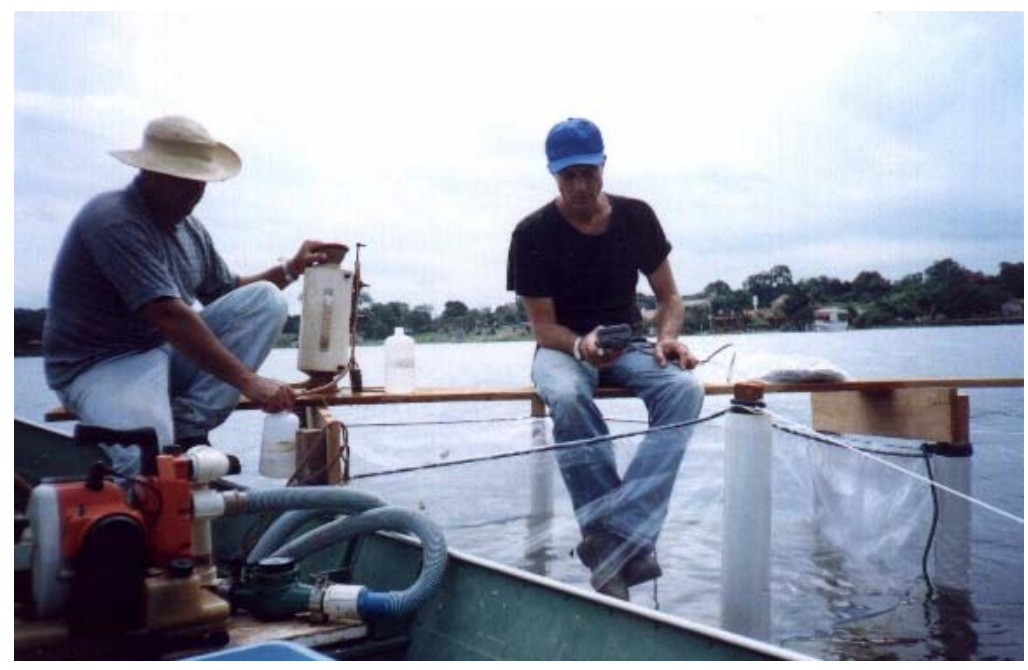

Figura 10: Coleta de água e determinação das variáveis físico-químicas nos mesocosmos. 
As amostras coletadas para análise de metais $(\mathrm{Cu}$ ou $\mathrm{Cr}$ ) foram filtradas em membrana de acetato de celulose $(0,45 \mu \mathrm{m}$ de porosidade), imediatamente após a coleta. O filtrado foi então acidificado até $\mathrm{pH} 1$ com $\mathrm{HNO}_{3}$ concentrado $\left(1 \mathrm{~mL}\right.$ de $\mathrm{HNO}_{3}$ em $250 \mathrm{~mL}$ de amostra). As concentrações de $\mathrm{Cu}$ e $\mathrm{Cr}$ foram determinadas através de espectrofotômetria de absorção atômica com forno de grafite, utilizando-se equipamento Varian AA 220. O aparelho foi calibrado com padrões externos, solução Titrisol (MERK). Os limites de detecção e quantificação, calculados de acordo com CIENFUEGOS \& VAITSMAN (2000), foram respectivamente 0,7 e $2 \mu \mathrm{g} . \mathrm{L}^{-1}$, tanto para Cr como para $\mathrm{Cu}$.

Para as análises de nutrientes considerou-se as frações total (nitrogênio e fósforo) e dissolvida (nitrato, nitrito, amônio, fosfato inorgânico, fósforo total dissolvido e silicato), sendo que para esta última as amostras foram previamente filtradas em filtro de fibra de vidro (GF/C Millipore) de 1,2 $\mu \mathrm{m}$ de porosidade. As análises de nutrientes foram realizadas de acordo com as metodologias apresentadas na tabela 04.

Tabela 04: Metodologias utilizadas nas determinações das concentrações nutrientes totais e dissolvidos.

\begin{tabular}{ccc}
\hline \hline Análise & Metodologia & Instrumentação \\
\hline \hline Nitrito & GOLTERMAN et al., 1978 & Espectrofotometria uv/vis \\
\hline Nitrato & MACKERETH et al., 1978 & Espectrofotometria uv/vis \\
\hline Amônio & KOROLEFF, 1976 & Espectrofotometria uv/vis \\
\hline Nitrogênio Total & VALDERRAMA, 1981 & Titulação \\
\hline Fosfato Total Dissolvido & STRICKLAND \& PARSONS, 1960 & Espectrofotometria uv/vis \\
\hline Fosfato Inorgânico & STRICKLAND \& PARSONS, 1960 & Espectrofotometria uv/vis \\
\hline Fósforo Total & VALDERRAMA, 1981 & Espectrofotometria uv/vis \\
\hline Silicato & GOLTERMAN et al., 1978 & Espectrofotometria uv/vis \\
\hline \hline
\end{tabular}

As amostras coletadas para a análise do material em suspensão e clorofila foram imediatamente filtradas em filtro de fibra de vidro (GF/C, Millipore) de 1,2 $\mu \mathrm{m}$ de porosidade.

As concentrações de material em suspensão foram determinadas por gravimetria, em balança analítica, de acordo com WETZEL \& LIKENS (1991).

As concentrações de clorofila foram determinadas segundo a metodologia descrita em NUSCH (1980), com extração em etanol $80 \%$ a quente.

\subsection{2- Sedimento}

As amostras de sedimento foram coletadas utilizando-se draga de EckmanBirge. Em cada mesocosmos foram coletadas duas amostras, sendo o sedimento 
homogeneizado, obtendo-se uma amostra composta, que foi armazenada em frasco de polietileno, previamente limpo com $\mathrm{HNO}_{3} 10 \%$.

Das amostras de sedimento foram determinadas as concentrações de matéria orgânica, nitrogênio, fósforo, e metais ( $\mathrm{Cr}$ e $\mathrm{Cu}$ ). As concentrações de metais foram determinadas nas frações total e fracamente ligada do sedimento e na água intersticial.

O teor de matéria orgânica foi determinado gravimetricamente por perda ao fogo a $550^{\circ} \mathrm{C}$ (TRINDADE, 1980).

As concentrações de nitrogênio (Kjeldahl) foram determinadas após digestão ácida com $\mathrm{H}_{2} \mathrm{SO}_{4}$ concentrado e $\mathrm{CuSO}_{4}$ e $\mathrm{K}_{2} \mathrm{SO}_{4}$ como catalisadores. Após a digestão da amostra, o nitrogênio amoniacal foi recuperado em ácido bórico por destilação com água destilada e $\mathrm{NaOH}$. A solução final foi titulada com $\mathrm{H}_{2} \mathrm{SO}_{4} 0,01 \mathrm{~N}$, utilizando-se indicador misto.

As concentrações de fósforo total no sedimento foram determinadas através do método de incineração (ANDERSEN, 1976). As amostras foram calcinadas em mufla com $\mathrm{NaCO}_{3}$ e ressuspendidas em $\mathrm{HCl} 25 \mathrm{M}$.

Os sedimentos foram secos em estufa até peso constante. Para a análise das concentrações totais de $\mathrm{Cu}$ e $\mathrm{Cr}$, as amostras foram digeridas com $\mathrm{HF}(5 \mathrm{~mL})$ e $\mathrm{HNO}_{3}$ (10 mL) e $\mathrm{H}_{2} \mathrm{O}_{2}$, em bombas de teflon, a $100^{\circ} \mathrm{C}$, e evaporadas em banho de areia. As amostras foram ressuspendidas em $\mathrm{HNO}_{3} 1 \%$.

Para a análise da concentração de metais disponível ou fracamente ligada, 1,0 $\mathrm{g}$ de sedimento seco foi mantido sob agitação em $25 \mathrm{~mL}$ de HCL 0,1 M durante 2 hs, em temperatura ambiente (adaptado de FISMAN et al., 1984), sendo posteriormente filtrado em papel de filtro (Whattman 44).

Todos os procedimentos foram acompanhados de branco analítico. As amostras foram analisadas por espectrofotometria de absorção atômica com chama (Varian AA 220). Os limites de detecção e quantificação, calculados de acordo com CIENFUEGOS \& VAITSMAN (2000), foram respectivamente 3,0 e $8,5 \mathrm{mg} \cdot \mathrm{kg}^{-1}$ para $\mathrm{Cr}$ e 11 e $37 \mathrm{mg} \cdot \mathrm{kg}^{-1}$ para Cu para as amostras referentes à concentração total e 0,5 e 1,5 mg. $\mathrm{kg}^{-1}$ para $\mathrm{Cr}$ e 0,3 e 0,8 mg. $\mathrm{kg}^{-1}$ para Cu para a fração fracamente ligada.

A água intersticial foi separada por centrifugação, sendo posteriormente filtrada em papel de filtro (Whatman 44) e preservada com $\mathrm{HNO}_{3}$ até $\mathrm{pH} 1$ (aproximadamente $0,4 \%$ de $\mathrm{HNO}_{3}$ ). Todos os procedimentos foram acompanhados de branco analítico. As amostras foram analisadas por espectrofotometria de absorção atômica com chama (Varian AA 220). Os limites de detecção e quantificação, calculados de acordo com CIENFUEGOS \& VAITSMAN (2000), foram respectivamente 1 e $2 \mu \mathrm{g} \cdot \mathrm{L}^{-1}$ tanto para $\mathrm{Cr}$ como para Cu para as análises realizadas por AAS com forno de grafite e 0,06 
e $0,2 \mathrm{mg} \cdot \mathrm{L}^{-1}$ para $\mathrm{Cr}$ e 0,03 e $0,11 \mathrm{mg} \cdot \mathrm{L}^{-1}$ para $\mathrm{Cu}$ para as análises realizadas por AAS com chama.

\subsection{3- Plâncton e Bentos}

O plâncton, para análises químicas, foi amostrado filtrando-se 100 litros de água em rede de $20 \mu \mathrm{m}$ de abertura de malha (Figura 11), concentrando-se para aproximadamente $100 \mathrm{~mL}$. As amostras foram armazenadas em frascos de polietileno de $100 \mathrm{~mL}$ de capacidade, previamente limpos com $\mathrm{HNO}_{3} 10 \%$, e mantidas sob refrigeração até processamento.
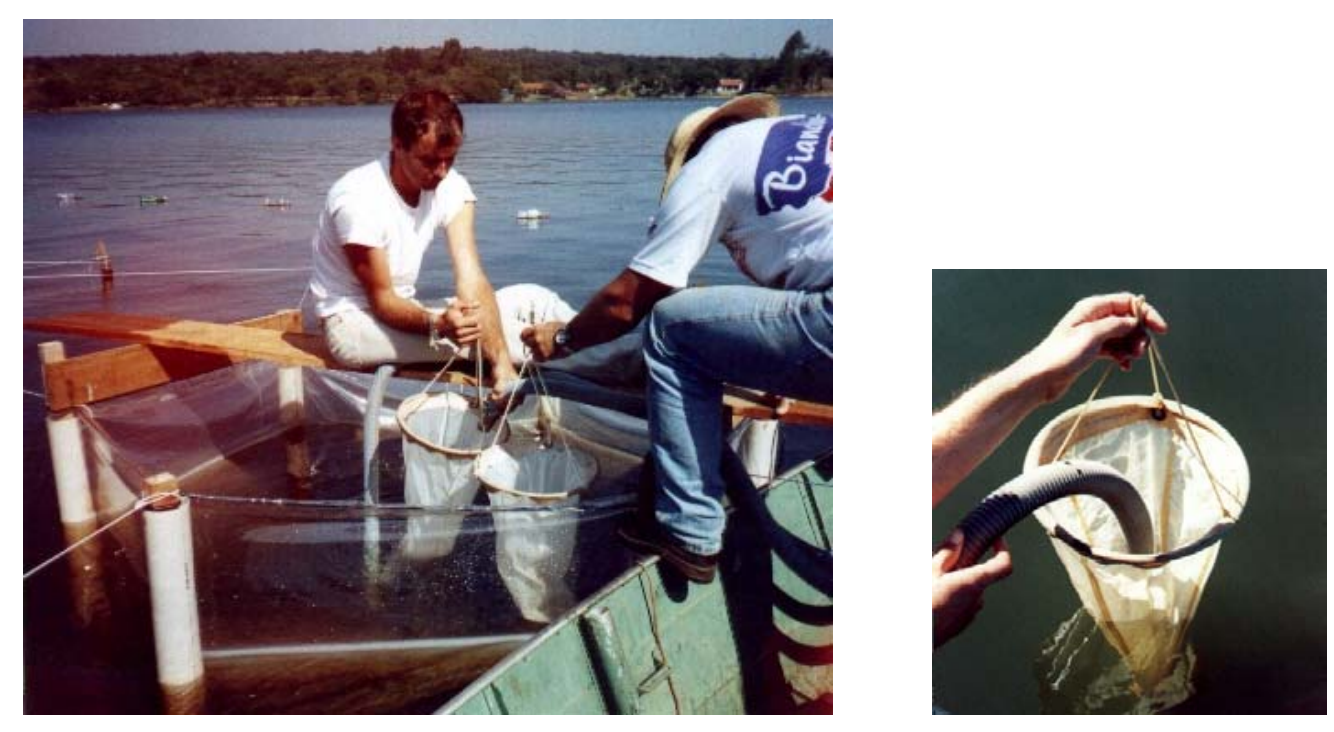

Figura 11: Coleta de fito e zooplâncton nos mesocosmos.

As amostras da comunidade bentônica foram coletadas com auxílio de draga de Eckman-Birge, sendo o sedimento lavado no campo em rede de $210 \mu \mathrm{m}$ de malha. As amostras foram armazenadas em frascos de polietileno, previamente limpos com $\mathrm{HNO}_{3} 10 \%$. Os organismos foram triados vivos e armazenados em frascos de $25 \mathrm{~mL}$ contendo etanol $70 \%$, sendo mantidos sob refrigeração até processamento.

Para a determinação dos metais $(\mathrm{Cr}$ e $\mathrm{Cu}$ ), concentrado da amostra de plâncton ou bentos foi filtrado em filtro de fibra de vidro previamente queimado e pesado. Os filtros contendo o material foram então secos em estufa a $60^{\circ} \mathrm{C}$ e pesados para a determinação da massa de plâncton ou bentos, sendo consideradas apenas as amostras com peso maior que $5 \mathrm{mg}$. As amostras foram digeridas em bequers de vidro com $\mathrm{HNO}_{3}\left(120^{\circ} \mathrm{C}, 4 \mathrm{hs}\right)$ e $\mathrm{H}_{2} \mathrm{O}_{2}\left(60^{\circ} \mathrm{C}, 2 \mathrm{hs}\right)$ concentrados. Todos os procedimentos foram acompanhados de branco analítico, sendo que para as amostras de bentos os filtros utilizados para os brancos foram lavados com $25 \mathrm{ml}$ de etanol $70 \%$. As amostras foram analisadas por espectrofotometria de absorção atômica com chama (Varian AA 
220). Os limites de detecção e quantificação, calculados de acordo com CIENFUEGOS \& VAITSMAN (2000), foram respectivamente 2 e $7 \mu \mathrm{g} / \mathrm{L}$ para $\mathrm{Cr}$ e 4 e $12 \mu \mathrm{g} / \mathrm{L}$ para $\mathrm{Cu}$.

\subsection{4- Macrófitas ( $P$. stratiotes) e peixes (O. niloticus)}

As amostras de macrófitas e peixes foram coletadas manualmente quando os tanques-rede instalados dentro dos mesocosmos foram retirados (Figura 12), e foram armazenadas em sacos de polietileno, previamente limpos com $\mathrm{HNO}_{3} 10 \%$.

No laboratório, as plantas tiveram seu peso úmido determinado e foram secas ao ar, inicialmente, e em estufa a $60^{\circ} \mathrm{C}$ posteriormente.

Em relação aos peixes, foi realizada a biometria de cada indivíduo e então as amostras foram congeladas até processamento. Os peixes foram eviscerados e foram formadas 3 amostras compostas para cada unidade experimental.

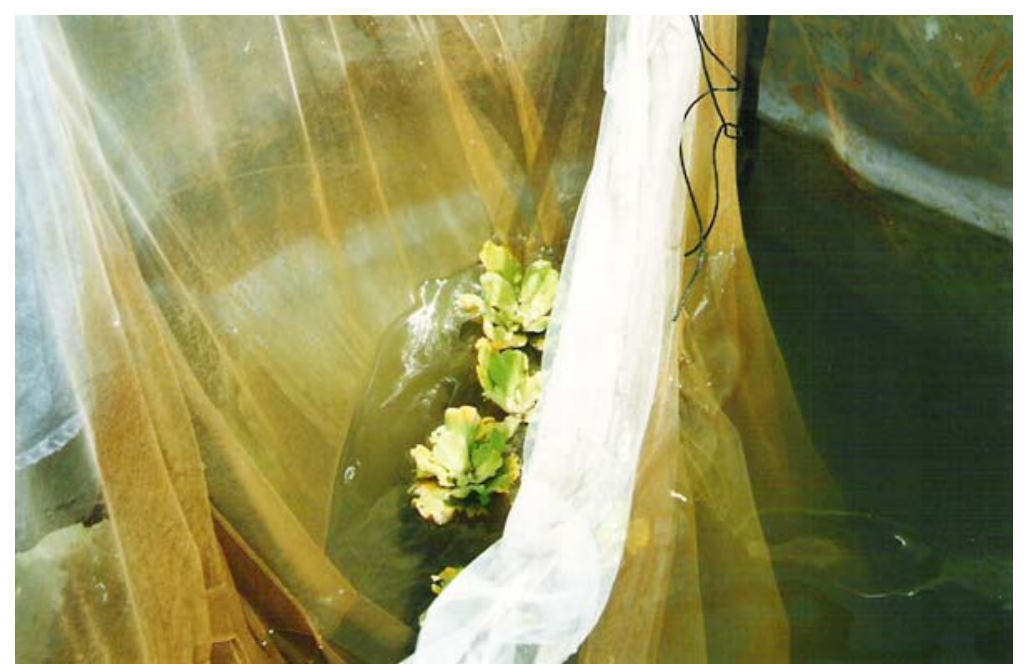

Figura 12: Coleta dos peixes e macrófitas inseridos nos mesocosmos com o auxilio dos tanques-rede internos.

Todos os indivíduos coletados (peixes e macrófitas) tiveram suas características biométricas (comprimento e peso úmido para os peixes; altura diâmetro, número de brotos e peso úmido para as macrófitas) determinadas. As amostras de peixes e macrófitas coletadas para análise das concentrações de $\mathrm{Cu}$ e $\mathrm{Cr}$ foram secas em estufa a $60^{\circ} \mathrm{C}$ por $48 \mathrm{hs}$, sendo então pesadas para a determinação do teor de umidade.

Para cada tanque foi formada uma amostra composta com todos os indivíduos coletados, a qual foi dividida em três subamostras, para os peixes e para as macrófitas. Em função da dificuldade de separação de tecidos específicos, como músculo e fígado, devido ao tamanho dos peixes, estes foram apenas eviscerados e 
digeridos inteiros. As macrófitas tiveram as partes aéreas e subterrâneas separadas, sendo os procedimentos de digestão e análises realizados individualmente com cada uma destas frações. As amostras foram digeridas em béqueres de vidro com $\mathrm{HNO}_{3}$ (120 ${ }^{\circ} \mathrm{C}, 4$ hs) e $\mathrm{H}_{2} \mathrm{O}_{2}\left(60{ }^{\circ} \mathrm{C}, 2 \mathrm{hs}\right)$ concentrados. Todos os procedimentos foram acompanhados de um branco analítico. As amostras foram analisadas por espectrofotometria de absorção atômica com forno de grafite (Varian AA 220). Os limites de detecção e quantificação, calculados de acordo com CIENFUEGOS \& VAITSMAN (2000), foram respectivamente 0,1 e $0,2 \mu \mathrm{g} \cdot \mathrm{g}^{-1}$ para $\mathrm{Cr}$ e 2 e $6 \mu \mathrm{g} \cdot \mathrm{g}^{-1}$ para $\mathrm{Cu}$ para as amostras de peixes e 1 e $2 \mu \mathrm{g} \cdot \mathrm{g}^{-1}$ para $\mathrm{Cr}$ e 1 e $4 \mu \mathrm{g} \cdot \mathrm{g}^{-1}$ para Cu para as amostras de macrófitas.

\section{6- Coleta, preservação e análise do fitoplâncton, zooplâncton e bentos: análise qualitativa e quantitativa}

\subsection{1- Fitoplâncton}

As amostras para a análise quantitativa foram coletadas a meia altura dos tanques por sifonamento nos microcosmos e com garrafa do tipo "Van Dorn" nos mesocosmos, sendo coletados $200 \mathrm{~mL}$ para o fitoplâncton total. As amostras foram preservadas com lugol acético $1 \%$.

A contagem do fitoplâncton foi realizada de acordo a metodologia descrita por UTERMÖHL (1958), em microscópio invertido Microscópio Zeiss AXIOPLAN 2Axioplan, aumento de 40 vezes, do Departamento de Ecologia e Biologia Evolutiva da Universidade Federal de São Carlos. O tempo de sedimentação das amostras foi determinado segundo LUND et al. (1958), sendo cerca de 3 horas para cada centímetro de altura da câmara. O volume da câmara utilizado foi determinado em função da concentração dos organismos na amostra, sendo que na maioria das amostras foi de $25 \mathrm{~mL}$. A contagem foi realizada em transectos horizontais e verticais e o limite da contagem, ou seja, o número mínimo de campos contados da câmara de sedimentação, foi determinado através de dois critérios: a) o critério de gráfico de espécies, obtido a partir de espécies novas adicionadas com o número de campos contados e b) o de espécies mais abundantes, obtido pela contagem de até 100 indivíduos da espécie mais comum. (TUCCI, 2002). Cada célula, colônia, cenóbio e filamento foi considerado como um indivíduo. Os resultados foram expressos em densidade e calculados de acordo com a fórmula recomendada pela agência de proteção ambiental dos Estados Unidos, descrita em WEBER (1973): 
organismos. $\mathrm{mL}^{-1}=(\mathrm{n} / \mathrm{sc}) \cdot(1 / \mathrm{h}) \cdot(\mathrm{F})$, onde:

$\mathrm{n}=$ número de indivíduos efetivamente contados;

$\mathrm{s}=$ área do campo em $\mathrm{mm}^{2}$ no aumento de 40X. $(0,1847398)$

$\mathrm{c}=$ número de campos contados;

$\mathrm{h}=$ altura da câmara de sedimentação em mm (50)

$\mathrm{F}=$ fator de correção para mililitro $\left(10^{3} \mathrm{~mm}^{3} / 1 \mathrm{~mL}\right)$

A partir dos resultados de densidade (org. $\mathrm{mL}^{-1}$ ) do fitoplâncton foram calculados os seguintes índices:

Riqueza (S): foi considerado o número total de táxons encontrados por amostra.

Índice de Diversidade $\left(\mathbf{H}^{\prime}\right)$ (bits.ind $\left.{ }^{-1}\right)$ : estimada pelo índice de SHANNON \& WEAVER (1963).

$$
H^{\prime}=-\sum_{i=1}^{n} p i \log _{e} p i \text {, onde: }
$$

$\mathrm{pi}=\mathrm{ni} / \mathrm{n}$

$\mathrm{ni}=$ número total de indivíduos de cada táxon na amostra.

$\mathrm{n}$ = número total de indivíduos na amostra.

Índice de Equitabilidade (E'): avaliada de acordo com LLOYD E GHELARDI (1964):

$$
E^{\prime}=H^{\prime} / \log _{2} S \text {, onde: }
$$

$\mathrm{H}^{\prime}$ = Diversidade da amostra.

$S=$ número de táxons na unidade amostral.

Índice de Dominância (DS): estimada através da fórmula de SIMPSON (1949):

$$
D=\frac{\Sigma n i(n i-1)}{n(n-1)}, \quad \text { onde: }
$$

$\mathrm{ni}=$ número total de indivíduos de cada táxon na amostra.

$\mathrm{n}=$ número total de indivíduos na amostra.

A identificação e contagem dos organismos foram realizadas pela $\mathrm{Dr}^{\mathrm{a}}$ Ana Claudia Perez nos experimentos em microcosmos e pela $\mathrm{Dr}^{\mathrm{a}}$ Andréia Tucci nos experimentos em mesocosmos. 


\subsection{2- Zooplâncton}

O zooplâncton foi amostrado filtrando-se um volume determinado com auxílio de bomba com hidrômetro em rede de plâncton de $68 \mu \mathrm{m}$ de abertura de malha. Nos experimentos em microcosmos o volume total contido nos tanques (aproximadamente 65 litros) foi utilizado, ao final do $7^{\circ}$ dia, e nos experimentos em mesocosmos para cada amostra filtrou-se 80 litros de água. A rede utilizada na filtração foi mantida dentro dos tanques durante a coleta, retornando a água para os tanques. As amostras foram fixadas com formol $4 \%$, sendo preservados para posterior identificação.

As amostras de zooplâncton foram avaliados pelo Oceanólogo Luiz Felipe Mendes de Gusmão, em projeto de mestrado vinculado aos experimentos em micro e mesocosmos (GUSMÃO, 2004).

Os Copepoda e Cladocera foram contados sob microscópio estereoscópio utilizando-se câmara de acrílico quadriculada do tipo Dolfus adaptada, e sua identificação foi feita sob microscópio binocular. A bibliografia utilizada para a identificação dos Copepoda foi ROCHA \& MATSUMURA-TUNDISI (1976), REID (1985), MATSUMURA-TUNDISI (1986), MONTÚ \& GLOEDEN (1986), PENNAK (1989) e MORALES et al. (1996) e para a identificação dos Cladocera foi utilizado MONTÚ \& GLOEDEN (1986), GEORGE MICHAEL E SHARMA (1988), PENNAK (1989) e ELMOOR-LOUREIRO (1997).

Os rotifera foram contados em câmara de Sedgewick-Rafter quadriculada com volume de $1 \mathrm{ml}$ sob microscópio binocular de acordo com RODRÍGUEZ \& MATSUMURA-TUNDISI (2000). As contagens dos indivíduos foram feitas de alíquotas retiradas das amostras através de sub-amostragem obtida por pipeta de boca larga (DOWING \& RIGLER, 1984). A identificação foi feita em termos de espécies, quando possível, ou então em termos de gênero. A bibliografia utilizada para a identificação do grupo foi KOSTE (1978), PENNAK (1989), SEGERS (1995), SEGERS \& DUMONT (1995) e KOSTE \& TERLUTTER (2001).

Para cada amostra foram determinadas a densidade e abundância relativa dos organismos e os seguintes índices puderam ser calculados:

$S=$ riqueza em número de spécies

$\mathrm{N}=$ densidade total de indivíduos

Índice de Diversidade de Shannon (log base 2):

$$
H^{\prime}=-\sum_{i=1}^{n} p i \log _{e} p i \text {, onde: }
$$


$\mathrm{pi}=\mathrm{ni} / \mathrm{n}$

$\mathrm{ni}=$ número total de indivíduos de cada espécie

$\mathrm{n}$ = número total de indivíduos na amostra.

Índice de Equitatividade de Pielou (log base 2): $J^{\prime}=\frac{H^{\prime}}{\log _{2} S}$

Índice de Simpson (Dominância de Simpson): $D=\Sigma(p i)^{2}$, onde:

$\mathrm{pi}=$ número total de indivíduos de cada espécie na amostra/ número total de indivíduos na amostra.

\subsection{3- Bentos}

As amostras da comunidade bentônica foram coletadas com auxílio de draga de Eckman-Birge, sendo o sedimento lavado no campo em rede de $210 \mu \mathrm{m}$ de malha. As amostras foram preservadas com formalina com concentração final de $5 \%$, e coradas com corante Rosa de Bengala. Os organismos bentônicos foram identificados com o auxílio de lupa ou microscópio e com base em bibliografia específica (MERRITT \& CUMMINS, 1984; TRIVINHO-STRIXINO \& STRIXINO, 1993).

Os taxa presentes foram separados utilizando-se iluminação direta em bandejas de fundo branco (para melhor contraste), sendo preservados em frascos com álcool $70 \%$ para posterior identificação. Para cada tratamento foram determinadas a densidade e abundância relativa dos organismos e os seguintes índices puderam ser calculados:

Índice de diversidade de Shannon: $\mathrm{H}^{\prime}=-\Sigma \mathrm{ni} / \mathrm{N}^{*} \log _{2}(\mathrm{ni} / \mathrm{N})$, onde:

$\mathrm{N}=$ número total de indivíduos;

ni= número de indivíduos da espécie $\mathrm{i}$

Índice de equitabilidade de Pielou: $\mathrm{E}=\mathrm{H}^{\prime} / \log _{2} \mathrm{~S}$, onde:

$H^{\prime}=$ índice de diversidade de Shannon;

$\mathrm{S}=$ número de espécies

A comunidade bentônica foi identificada pelo oceanógrafo MSc Ricardo Wagner Reis Filho, em trabalho de mestrado vinculado aos experimentos em mesocosmos (REIS FILHO, 2004). 


\section{7 - Produção primária do fitoplâncton}

\subsection{1- Método do ${ }^{14} \mathrm{C}$ (GOLTERMAN \& CLIMO,1969)}

A produção primária foi medida através da técnica do ${ }^{14} \mathrm{C}$ descrita por GOLTERMAN \& CLIMO (1969), e adaptada por TEIXEIRA (1973).

As amostras foram incubadas no campo, sendo utilizados um frasco transparente e um frasco escuro para cada amostra, com $1 \mathrm{~mL}$ de $\mathrm{NaH}^{14} \mathrm{CO}_{3}$ com 5 $\mu \mathrm{Ci}$ de atividade específica para $60 \mathrm{~mL}$ de amostra, durante 4 horas, utilizando-se suportes dispostos horizontalmente a $1 \mathrm{~m}$ de profundidade de cada tanque.

No momento da incubação e da retirada das amostras foram tomadas medidas de luminosidade, temperatura, $\mathrm{pH}$, oxigênio dissolvido e condutividade. A produção primária do fitoplâncton foi avaliada antes da adição das soluções de metal nos tanques e 2 hs após a adição.

Em laboratório, as amostras foram filtradas em filtros de éster de celulose de $0,22 \mu \mathrm{m}$ de porosidade (Millipore) e após secos, os filtros foram dissolvidos no líquido cintilador Bray (BRAY, 1960). A determinação da atividade das amostras foi feita em cintilador líquido (Beckman LS 100).

\subsection{2- Método do oxigênio Dissolvido (GAARDNER \& GRAN, 1972)}

Em virtude das dificuldades encontradas para a aquisição de $\mathrm{NaH}^{14} \mathrm{CO}_{3}$, utilizado para a determinação da produção primária do fitoplâncton segundo metodologia descrita por GOLTERMAN \& CLIMO (1969), utilizada no primeiro experimento em mesocosmos, optou-se na segunda fase pelo método do oxigênio dissolvido, introduzido por GAARDNER \& GRAN (1972). Este método consiste na estimativa do oxigênio liberado durante a fotossíntese em condições experimentais. oxigênio é determinado pelo método de Winkler, modificado pela azida sódica (GOLTERMAN \& CLIMO, 1969).

As amostras foram incubadas no campo, sendo utilizados um frasco transparente e um frasco escuro para cada amostra durante 3 horas, utilizando-se suportes dispostos horizontalmente a $1 \mathrm{~m}$ de profundidade de cada tanque.

No momento da incubação e da retirada das amostras foram tomadas medidas de temperatura, $\mathrm{pH}$, oxigênio dissolvido e condutividade. A produção primária do fitoplâncton foi avaliada antes da adição das soluções de metal nos tanques e 3 hs após a adição.

Para a avaliação da produção primária, procedeu-se a determinação da concentração inicial de oxigênio na coluna d' água, e posteriormente a determinação da concentração final de oxigênio, após o período de incubação, nos frascos claros e escuros. A quantidade de oxigênio produzida pela fotossíntese pode ser calculada 
considerando-se a respiração da comunidade como a diferença entre a concentração inicial de oxigênio nas amostras e a concentração de oxigênio no frasco escuro após o período de incubação; a produção primária bruta como a diferença entre as concentrações de oxigênio determinadas nos frascos claro e escuro após o período de incubação e a produção primária líquida como a diferença entre a produção primária bruta e a respiração da comunidade (OLIVEIRA, 1993).

\section{8 - Testes de Toxicidade}

A toxicidade aguda das amostras de água dos tanques para $D$. similis foi avaliada de acordo com a metodologia descrita em CETESB (1991) conforme descrito no Capítulo 2.

\section{9- Período e freqüência das amostragens}

\subsection{1- Experimento em microcosmos}

Os experimentos foram realizados em dezembro de 2001, sendo as coletas efetuadas à partir de 3 hs da adição de $\mathrm{Cr}$ e $\mathrm{Cu}$, durante 7 dias, segundo o cronograma apresentado na tabela 05.

Tabela 05: Cronograma de coleta de amostras dos microcosmos

\begin{tabular}{|c|c|c|c|c|c|c|c|c|c|}
\hline \hline \multirow{2}{*}{ Componentes avaliados } & \multicolumn{7}{|c|}{ Tempo (horas) } \\
\cline { 2 - 10 } & $\mathrm{0}$ & 3 & 24 & 48 & 72 & 96 & 120 & 144 & 168 \\
\hline \hline Água para análise de metais (Cu e Cr) & $\mathrm{X}$ & $\mathrm{X}$ & $\mathrm{X}$ & $\mathrm{X}$ & $\mathrm{X}$ & $\mathrm{X}$ & $\mathrm{X}$ & $\mathrm{X}$ & $\mathrm{X}$ \\
\hline $\begin{array}{c}\text { Água para análise de nutrientes, material } \\
\text { em suspensão e clorofila }\end{array}$ & & & & $\mathrm{X}$ & & $\mathrm{X}$ & & $\mathrm{X}$ & \\
\hline Fitoplâncton & $\mathrm{X}$ & $\mathrm{X}$ & $\mathrm{X}$ & $\mathrm{X}$ & $\mathrm{X}$ & $\mathrm{X}$ & $\mathrm{X}$ & $\mathrm{X}$ & $\mathrm{X}$ \\
\hline Zooplâncton & $\mathrm{X}$ & & & & & & & & $\mathrm{X}$ \\
\hline \hline
\end{tabular}

Em relação ao tempo 0 (zero), para o caso do zooplâncton foram consideradas amostras iniciais coletadas na represa, filtrando-se um volume igual a $300 \mathrm{~L}$. Da mesma forma, as amostras referentes ao tempo 0 (zero) para análise de metais, clorofila e material em suspensão também foram coletadas na represa, quando da coleta de água para preenchimento dos microcosmos. 


\subsection{2- Experimentos em Mesocosmos 1- Aspectos Funcionais e}

\section{Estruturais}

Após aproximadamente um mês de instalados, os mesocosmos foram contaminados no dia 01 de abril de 2002, com soluções de $\mathrm{CuSO}_{4} \cdot 5 \mathrm{H}_{2} \mathrm{O}$ e $\mathrm{K}_{2} \mathrm{Cr}_{2} \mathrm{O}_{7}$, desejando-se uma concentração final de $0,02 \mathrm{mg} \cdot \mathrm{L}^{-1} \mathrm{Cu}$ e $0,05 \mathrm{mg} \cdot \mathrm{L}^{-1} \mathrm{de} \mathrm{Cr}$.

Em função da heterogeneidade da área de instalação, foi determinado o volume de cada mesocosmo, e diferentes volumes de solução foram adicionados. Os volumes determinados para os mesocosmos estão apresentados na Tabela 06, sendo a que disposição final de cada tratamento está apresentada na Figura 13.

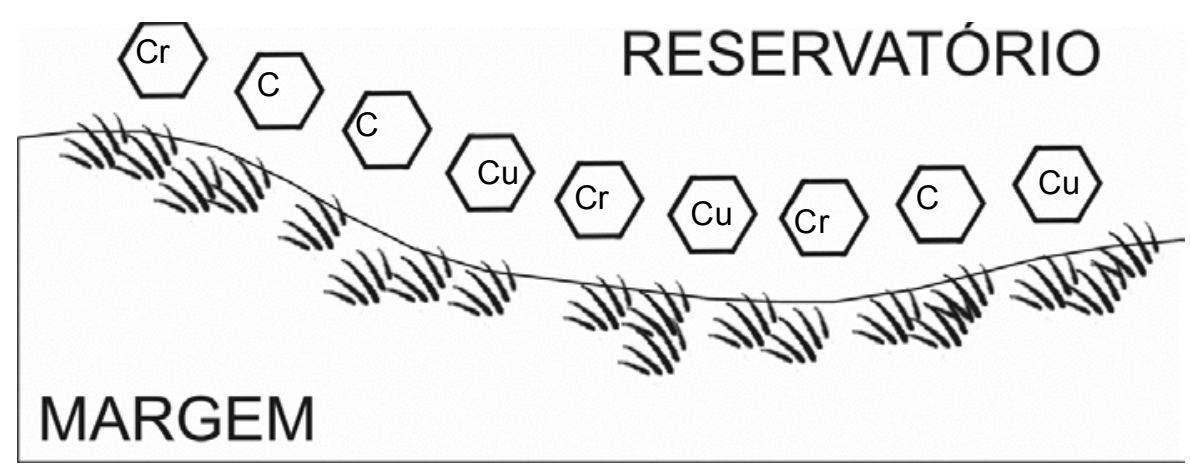

Figura 13: Disposição dos tanques no experimento na represa do Lobo (ordenados de 1 a 9 da esquerda para a direita)

Tabela 06: Volumes dos mesocosmos após a instalação na represa do Lobo.

\begin{tabular}{cc}
\hline \hline Mesocosmos & Volume $\left(\mathrm{m}^{3}\right)$ \\
\hline \hline 1 & 4,5 \\
2 & 4,8 \\
3 & 5,1 \\
4 & 5,0 \\
5 & 4,7 \\
6 & 4,9 \\
7 & 4,8 \\
8 & 4,8 \\
9 & 4,6 \\
\hline \hline
\end{tabular}

Antes do início do experimento foram realizadas 3 coletas de amostras de água e 1 coleta de amostras de sedimento em todos os tanques, para uma avaliação preliminar. Essas coletas foram realizadas nos dias 21 e 28 de março e no dia 01 de abril de 2002. Os tanques foram contaminados no dia 01 de abril de 2002 e foram coletadas amostras 2 e 4 hs após a contaminação e, após 24 hs, duas vezes por semana. As análises e freqüência de amostragem encontram-se descritas na Tabela 07. 
Tabela 07: Análises realizadas e freqüência das coletas nos mesocosmos instalados na represa do Lobo.

\begin{tabular}{|c|c|c|c|c|c|c|c|c|c|c|c|c|c|c|c|}
\hline & 21.03 & 26.03 & 28.03 & $\begin{array}{l}01.04 \\
0 \mathrm{~h}\end{array}$ & $\begin{array}{l}01.04 \\
2 \mathrm{~h}\end{array}$ & $\begin{array}{l}01.04 \\
4 \mathrm{~h}\end{array}$ & 02.04 & 05.04 & 09.04 & 12.04 & 16.04 & 19.04 & 23.04 & 26.04 & 30.04 \\
\hline \multicolumn{16}{|l|}{ Água } \\
\hline $\mathrm{Cu}$ ou $\mathrm{Cr}$ & $x$ & & $x$ & $x$ & $x$ & $\mathrm{x}$ & $x$ & $x$ & $x$ & $x$ & $x$ & $x$ & $x$ & $x$ & $x$ \\
\hline $\mathrm{FQ}^{*}$ & $\mathrm{x}$ & & $x$ & $x$ & $x$ & $x$ & $x$ & $x$ & $x$ & $x$ & $x$ & $x$ & $x$ & $x$ & $x$ \\
\hline Nutrientes & $x$ & & $x$ & & & & $x$ & $\mathrm{x}$ & $x$ & $x$ & $x$ & $x$ & $x$ & $x$ & $x$ \\
\hline Toxicidade & & & & $x$ & $x$ & $x$ & & & $x$ & & $x$ & & & & \\
\hline $\begin{array}{l}\text { Produção } \\
\text { Primária }\end{array}$ & & $x$ & & & $x$ & & & & & & & & & & \\
\hline \multicolumn{16}{|l|}{ Plâncton } \\
\hline $\mathrm{Cu}$ e $\mathrm{Cr}$ & & & $x$ & & & & & & & & & $x$ & & & $x$ \\
\hline Identificação & $x$ & & $x$ & $x$ & & $x$ & $x$ & $x$ & $x$ & $x$ & $x$ & $x$ & $x$ & $x$ & $x$ \\
\hline \multicolumn{16}{|l|}{ Sedimento } \\
\hline $\mathrm{Cu}$ ou $\mathrm{Cr}$ & $x$ & & & & & & & & $x$ & & & $x$ & & & $X$ \\
\hline Nutrientes & $x^{*}$ & & & & & & & & $x$ & & & $x$ & & & $x$ \\
\hline $\begin{array}{l}\text { Água } \\
\text { Intersticial }\end{array}$ & $\mathrm{X}$ & & & & & & & & $\mathrm{X}$ & & & $\mathrm{X}$ & & & $\mathrm{X}$ \\
\hline \multicolumn{16}{|l|}{ Bentos } \\
\hline $\mathrm{Cu}$ e $\mathrm{Cr}$ & $x$ & & & & & & & & $x$ & & & $x$ & & & $x$ \\
\hline Identificação & $x$ & & & & & & & & $\mathrm{x}$ & & & $x$ & & & $x$ \\
\hline
\end{tabular}

${ }^{*}$ coleta realizada em $22 / 03 / 02$

\subsection{3- Experimentos em Mesocosmos 2- Aspectos Funcionais e Bioacumulação}

Após o término do experimento realizado em abril de 2002, os tanques foram retirados da represa e lavados para a retirada do perifiton aderido e para evitar a contaminação de experimentos posteriores. Em seguida, foram realizados reparos nos tanques danificados ou que tiveram a solda aberta durante sua retirada, utilizando-se fita adesiva Aero Tape, uma vez que não foi possível soldar novamente as partes danificadas.

Os tanques foram instalados novamente na represa do Lobo nos dias 5 e 6 de novembro de 2002, e o experimento aqui descrito teve início no dia 18 de novembro de 2002.

A disposição dos tanques está apresentada na figura 14. Em função da heterogeneidade da área de instalação e da variação no nível da represa, o volume de cada tanque foi novamente determinado e diferentes volumes de solução foram adicionados. Os volumes determinados para os mesocosmos estão apresentados na tabela 08. 


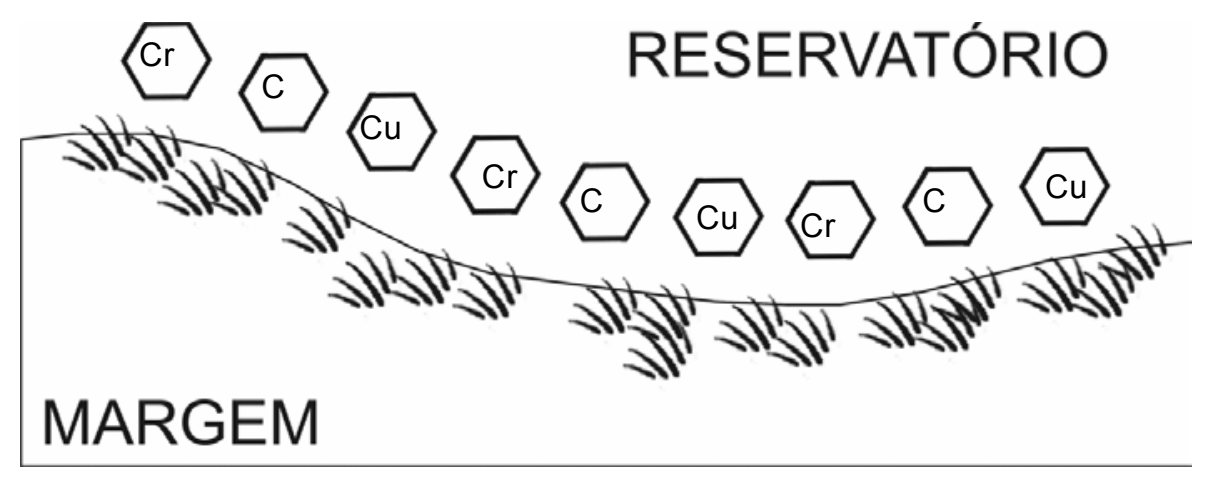

Figura 14: Disposição dos tanques no experimento na represa do Lobo

Os mesocosmos foram contaminados uma primeira vez no dia 20 de novembro de 2002, com soluções de $\mathrm{CuSO}_{4} .5 \mathrm{H}_{2} \mathrm{O}$ e $\mathrm{K}_{2} \mathrm{Cr}_{2} \mathrm{O}_{7}$. Essa fase do experimento, sem a inclusão de peixes e macrófitas, foi acompanhada até dia 6 de dezembro de 2002, quando as concentrações de $\mathrm{Cu}$ e $\mathrm{Cr}$ dissolvidas na água dos tanques foram restauradas às concentrações iniciais.

\begin{tabular}{cc} 
Tabela 08: Volumes dos tanques utilizados no experimento \\
\hline \hline Tanque & Volume $\left(\mathrm{m}^{3}\right)$ \\
\hline 1 & 3,1 \\
2 & 3,5 \\
3 & 3,7 \\
4 & 3,2 \\
5 & 3,8 \\
6 & 3,5 \\
7 & 3,4 \\
8 & 3,5 \\
9 & 3,2 \\
\hline \hline
\end{tabular}

$\mathrm{Na}$ segunda fase do experimento foram instalados tanques-rede dentro de cada um dos mesocosmos, antes da inclusão dos peixes, com a finalidade de facilitar sua coleta. Os tanques-rede foram instalados e os peixes (Oreochromis niloticus) e macrófitas (Pistia stratiotes) incluídos no dia 9 de dezembro. Após a inclusão dos indivíduos, os mesocosmos foram novamente contaminados no dia 12 de dezembro, e o experimento foi acompanhado até dia 27 de dezembro de 2002. Nessa segunda contaminação dos mesocosmos foram considerados os mesmos volumes apresentados na tabela 08 , não tendo sido observada variação no nível d'água da represa.As análises realizadas e a freqüência da amostragem estão descritas na tabela 09. 
Tabela 09: Análises realizadas e freqüência das coletas nos mesocosmos instalados na represa do Lobo.

\begin{tabular}{l|l|l|l|l|l|l|l|l|l|l|l|l|l|l|l|l|l|l|l|l|l|l|l|l|l|l}
\hline \hline & \\
\hline
\end{tabular}

\subsection{0- Análise Estatística}

Os efeitos dos metais sobre as variáveis químicas e físico-químicas dos tanques contaminados foram avaliados através de análise de variância univariada (ANOVA), análise de variância multivariada (MANOVA) e análise de correlação linear utilizando o software Minitab 13 (MINITAB INC, 2000).

A análise de correlação também foi utilizada na avaliação da influência da concentração de metal no meio sobre a bioacumulação no plâncton e para avaliação dos efeitos sobre os parâmetros biométricos dos peixes e macrófitas.

A variabilidade entre as réplicas foi avaliada por análise de variância multivariada (considerando-se todos os parâmetros avaliados ao mesmo tempo) e univariada (considerando-se cada parâmetro avaliado individualmente), comparandose os dados obtidos em cada uma das réplicas de cada tratamento. 


\section{4- RESULTADOS E DISCUSSÃO}

\section{1- Análise dos efeitos de cromo e cobre em ecossistemas aquáticos: um estudo em microcosmos}

\subsection{1- Variáveis físico-químicas, químicas e biológicas (clorofila) da água}

Como mencionado anteriormente, os estudos em microcosmos foram efetuados de forma a subsidiar a realização dos experimentos em mesocosmos. Sendo assim, algumas variáveis foram monitoradas continuamente como o $\mathrm{pH}$ e as concentrações de $\mathrm{Cr}$ e $\mathrm{Cu}$, enquanto outras, como clorofila, material em suspensão e nutrientes foram quantificadas em intervalos maiores (48 horas).

Deve-se salientar, ainda, que considerou-se como valores iniciais, para todas as variáveis, os resultados obtidos em três amostras de água da represa do Lobo, conforme apresentado na tabela 10 e como $t=0$ em todas as figuras que apresentam a variação temporal após a contaminação dos microcosmos com os metais cobre e cromo.

As variáveis físico-químicas, as concentrações de clorofila, material em suspensão e cobre foram determinados na água da represa do Lobo quando da coleta de água para montagem do experimento, e correspondem à coleta realizada a $\mathrm{t}=0$ (início do experimento).

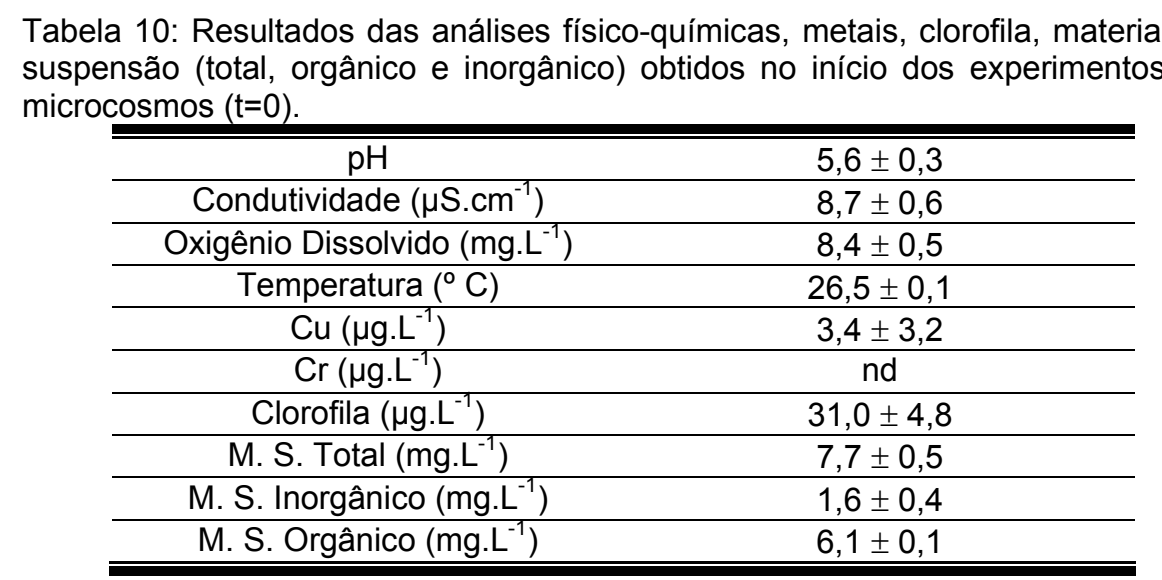

Algumas variáveis, como temperatura e oxigênio dissolvido, não foram quantificadas no decorrer do experimento, uma vez que considerou-se não essenciais nesta avaliação inicial. O principal interesse foi relacionado com a variação temporal dos metais e seus efeitos imediatos nas comunidades biológicas. 
As concentrações de cobre determinadas em cada coleta e unidade experimental estão apresentadas em Apêndice, sendo que os valores médios estão apresentadas na Figura 15

A concentração inicial de Cu foi de $3,4( \pm 3,2) \mu g \cdot \mathrm{L}^{-1}$, obtendo-se valor máximo do $\mathrm{Cu}$ dissolvido $\left(22,0 \mu \mathrm{g} \cdot \mathrm{L}^{-1}\right) 24$ hs após a adição da solução de sulfato de cobre. Durante o tempo do experimento verificou-se variação acentuada, sendo que ao final do experimento as concentrações determinadas no experimento com $\mathrm{Cu}$ e no controle foram semelhantes $\left( \pm 10 \mu \mathrm{g} \cdot \mathrm{L}^{-1}\right)$.

As réplicas do controle apresentaram maiores valores de desvio padrão para as concentrações de $\mathrm{Cu}$ (até $80 \%$ ) do que as réplicas do experimento com Cu (até $50 \%)$.

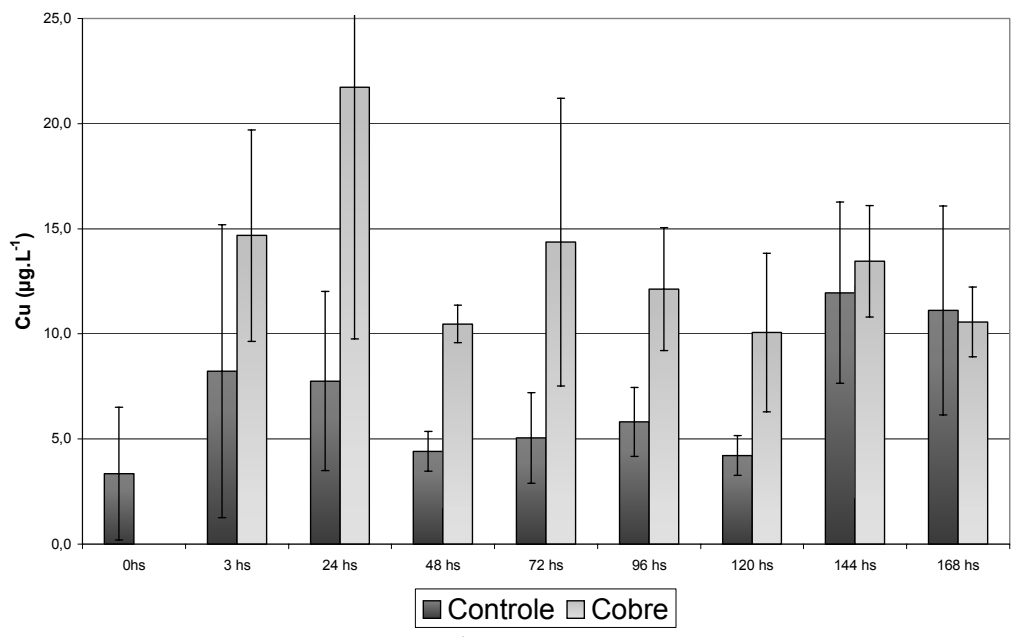

Figura 15: Concentração média $\left(\mu \mathrm{g} \cdot \mathrm{L}^{-1}\right)$ de $\mathrm{Cu}$ determinada nas amostras de água nos controles e nos microcosmos contaminados com Cu (as barras de erros referem-se ao desvio padrão da média entre as réplicas dos microcosmos).

A concentração máxima de $\mathrm{Cr}$ na água foi determinada após 3 hs da adição da solução (Figura 16). As concentrações de $\mathrm{Cr}$ desejadas $\left(50 \mu \mathrm{g} \cdot \mathrm{L}^{-1}\right)$ não foram recuperadas em nenhuma das réplicas. Durante o experimento as concentrações de $\mathrm{Cr}$ apresentaram reduzida variação. Verificou-se um pequeno decréscimo até o final do experimento, porém, as concentrações iniciais (abaixo do limite de detecção do método) não foram restauradas. 


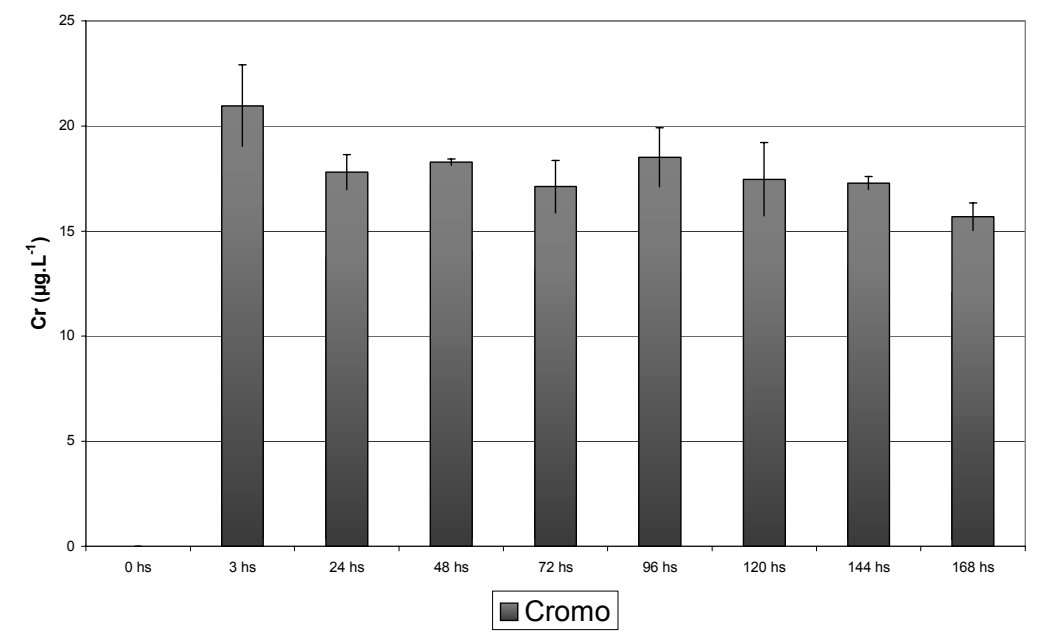

Figura 16: Concentração média $\left(\mu g \cdot \mathrm{L}^{-1}\right)$ de $\mathrm{Cr}$ determinada nas amostras de água dos microcosmos contaminados (nos controles os valores estiveram abaixo do limite de detecção do método utilizado; as barras de erros referem-se ao desvio padrão da média entre as réplicas dos microcosmos).

Os valores de $\mathrm{pH}$ determinados na água superficial de cada unidade experimental, em cada uma das coletas, estão apresentadas em Apêndice. Os valores médios estão apresentadas na Figura 17.

As maiores alterações no $\mathrm{pH}$ ocorreram antes da adição dos metais aos microcosmos, sendo observado um aumento semelhante nestes valores em todos os tanques. Após o isolamento da água da represa dentro dos tanques, observou-se aumento no $\mathrm{pH}$ de 5,6 para 7,1, em média, para o controle; de 5,4 para 6,6, em média, para os microcosmos com $\mathrm{Cr}$ e de 5,5 para 7,3 para os microcosmos com Cu. Durante o experimento, os valores de $\mathrm{pH}$ apresentaram a mesma variação nos controles e nos microcosmos contaminados com $\mathrm{Cr}$ e $\mathrm{Cu}$. O desvio padrão dos valores de $\mathrm{pH}$ para cada triplicata, calculado com base nas análises individuais de cada microcosmo, foram muito baixos, indicando uma boa reprodutibilidade entre as réplicas, quanto a essa variável. 


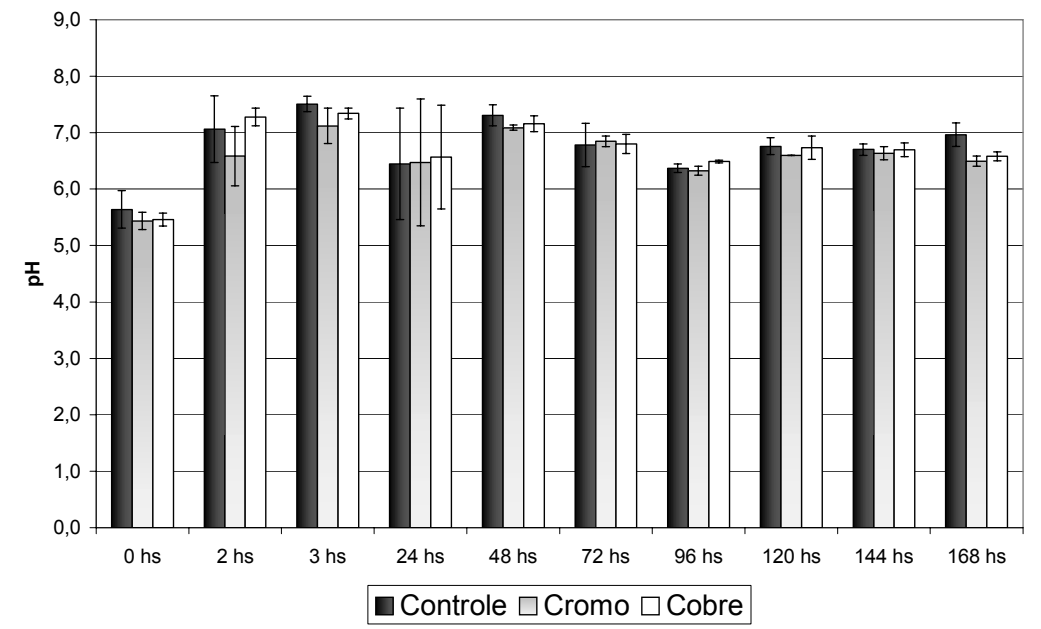

Figura 17: Valores médios de $\mathrm{pH}$ determinados nas amostras de água dos microcosmos durante o período de estudo (as barras de erros referem-se ao desvio padrão da média entre as réplicas dos microcosmos).

Em relação aos nutrientes, foram quantificadas as concentrações de silicato e das formas nitrogenadas e fosfatadas em cada um dos microcosmos, conforme apresentado em Apêndice.

As concentrações médias determinadas para silicato estão apresentadas na Figura 18. As concentrações de silicato determinadas no experimento com $\mathrm{Cr}$ apresentaram um decréscimo pronunciado no início do experimento (48 hs), verificando-se, ao final do experimento, concentrações próximas às apresentadas pelo controle. As concentrações determinadas nos microcosmos contaminados com $\mathrm{Cu}$ apresentaram pouca variação nos diferentes dias de coleta (entre 0,3 e $0,4 \mathrm{mg} \cdot \mathrm{L}^{-1}$ ).

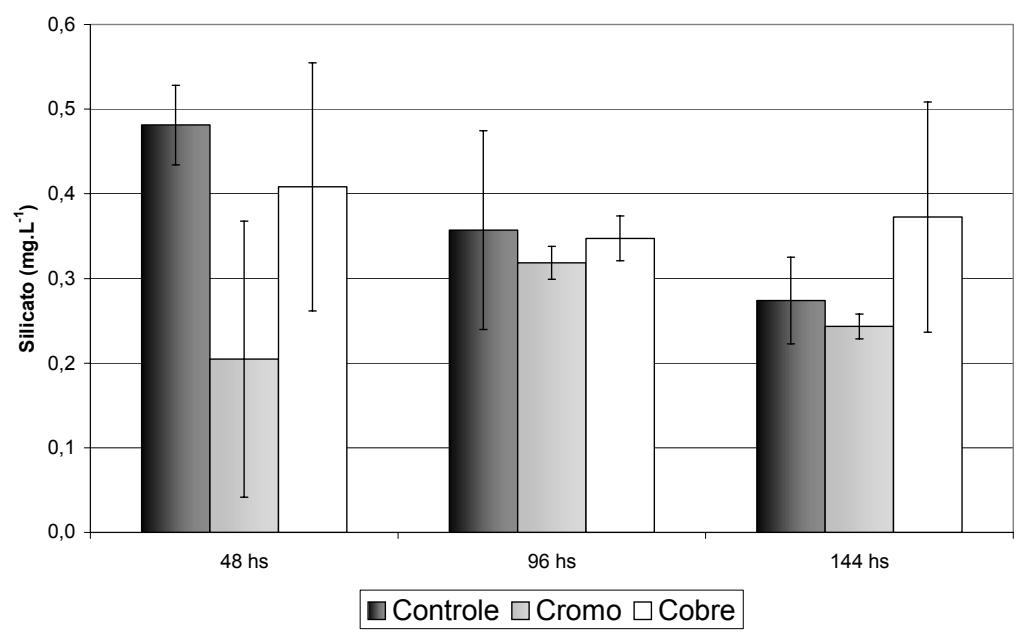

Figura 18: Concentrações médias $\left(\mathrm{mg}^{-1} \mathrm{~L}^{-1}\right)$ de silicato determinadas nas amostras de água no controle e nos microcosmos contaminados com $\mathrm{Cr}$ e $\mathrm{Cu}$ (as barras de erros referemse ao desvio padrão da média entre as réplicas dos microcosmos). 
As amostras coletadas após 48 hs do início do experimento apresentaram valores altos de desvio padrão entre as réplicas dos microcosmos contaminados com Cr (acima de 50\%) e para as amostras coletadas a 48 e 144 hs do início do experimento para os microcosmos contaminados com $\mathrm{Cu}(36$ e $50 \%$, respectivamente). Os valores individuais de cada réplica, os valores médios e desvio padrão estão apresentados em Apêndice.

Os valores médios das concentrações de nitrato, nitrito, amônio e nitrogênio total estão apresentados nas figuras 19, 20, 21 e 22.

As concentrações de nitrato (Figura 19) nos experimentos com $\mathrm{Cr}$ e $\mathrm{Cu}$ apresentaram, inicialmente, um decréscimo bastante pronunciado em relação ao controle logo após a adição das soluções de $\mathrm{Cr}$ e Cu $\left(273,9 \mu \mathrm{g} \cdot \mathrm{L}^{-1}\right.$ no controle, 147,8 e $143,5 \mu \mathrm{g} \cdot \mathrm{L}^{-1}$ nos experimentos com $\mathrm{Cr}$ e $\mathrm{Cu}$, respectivamente), aumentando posteriormente. O controle apresentou comportamento inverso. Todas as triplicatas apresentaram desvios padrão elevados para as concentrações de nitrato (Apêndice).

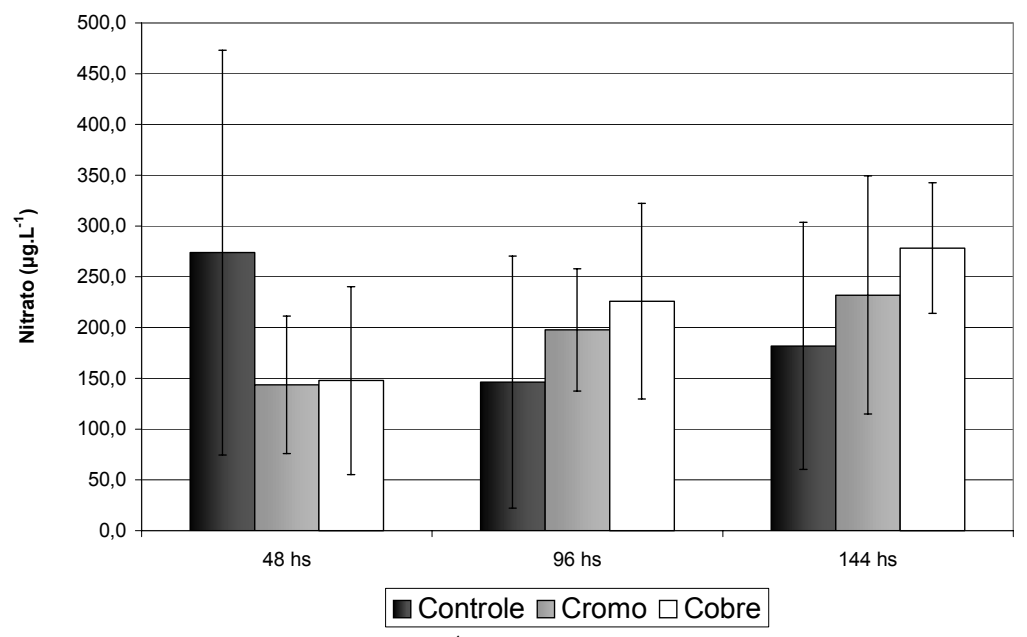

Figura 19: Concentrações médias $\left(\mu \mathrm{g} \cdot \mathrm{L}^{-1}\right)$ de nitrato determinadas nas amostras de água no controle e nos microcosmos contaminados com $\mathrm{Cr}$ e $\mathrm{Cu}$ (as barras de erros referem-se ao desvio padrão da média entre as réplicas dos microcosmos).

As concentrações de nitrito (Figura 20) no experimento com Cu apresentaram o mesmo padrão do controle, com valores crescentes no decorrer do experimento, enquanto um decréscimo após 96 hs foi observado no experimento com $\mathrm{Cr}$. As amostras coletadas no controle após 144 hs do início do experimento apresentaram valores altos de desvio padrão (70\%), o que não foi observado em nenhuma outra data. As triplicatas dos experimentos com $\mathrm{Cr}$ e $\mathrm{Cu}$ não apresentaram valores de desvio padrão altos para nitrito (Apêndice). 


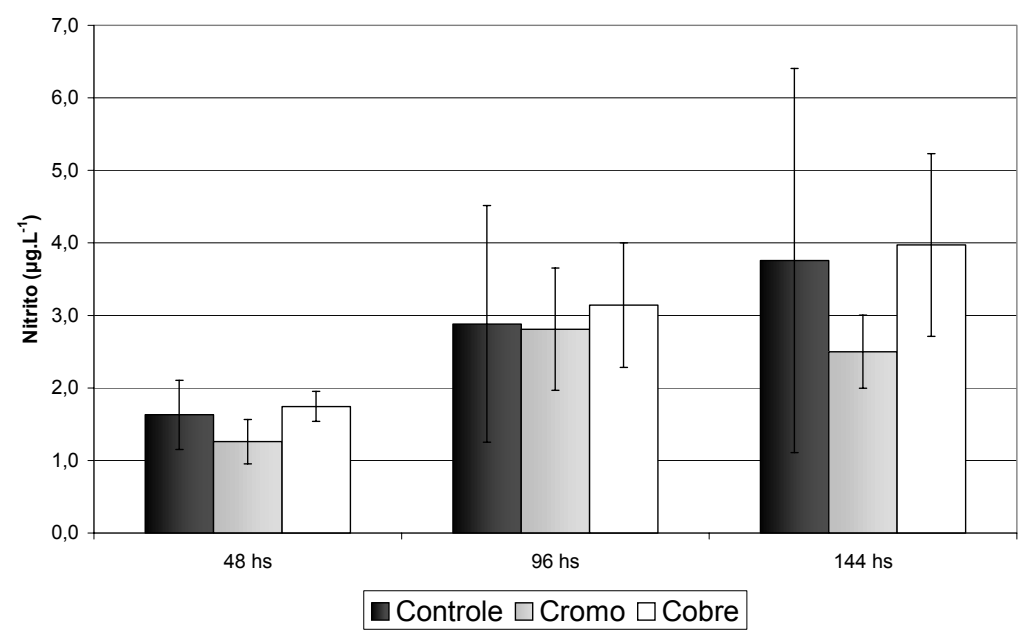

Figura 20: Concentrações médias $\left(\mu \mathrm{g} \cdot \mathrm{L}^{-1}\right)$ de nitrito determinadas nas amostras de água no controle e nos microcosmos contaminados com $\mathrm{Cr}$ e $\mathrm{Cu}$ (as barras de erros referemse ao desvio padrão da média entre as réplicas dos microcosmos).

Tanto no controle como os experimentos com $\mathrm{Cr}$ e $\mathrm{Cu}$ verificou-se um aumento nas concentrações de amônio (Figura 21) nas amostras coletadas após 96 hs do início do experimento, atingindo $114 \mu \mathrm{g} \cdot \mathrm{L}^{-1}$ nos experimentos com $\mathrm{Cr}$ e $100 \mu \mathrm{g} \cdot \mathrm{L}^{-1}$ nos experimentos com $\mathrm{Cu}$, apresentando posterior decréscimo. Ao final do experimento, porém, o controle apresentou menores concentrações $\left(76 \mu \mathrm{g} \cdot \mathrm{L}^{-1}\right)$, que os microcosmos contaminados com $\mathrm{Cr}\left(96,7 \mu \mathrm{g} \cdot \mathrm{L}^{-1}\right)$ e $\mathrm{Cu}\left(97,4 \mu \mathrm{g} \cdot \mathrm{L}^{-1}\right)$.

As réplicas do controle apresentaram os maiores desvios padrão para as concentrações de amônio (100\% em 144 hs) sendo que nos microcosmos contaminados com $\mathrm{Cr}$ e Cu estes desvios foram menores. 


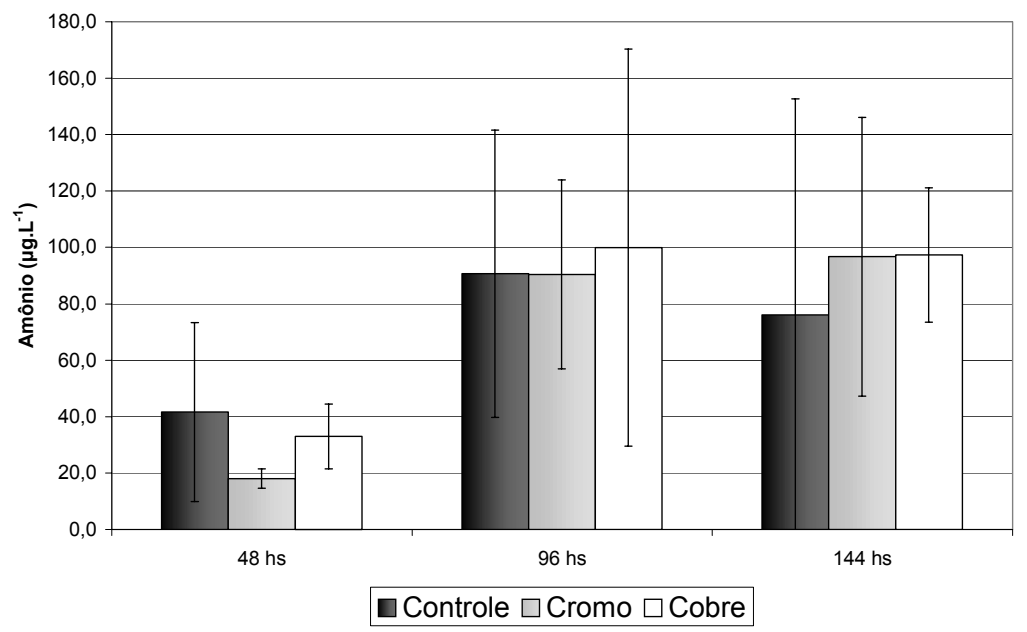

Figura 21: Concentrações médias $\left(\mu \mathrm{g} \cdot \mathrm{L}^{-1}\right)$ de amônio determinadas nas amostras de água no controle e nos microcosmos contaminados com $\mathrm{Cr}$ e $\mathrm{Cu}$ (as barras de erros referemse ao desvio padrão da média entre as réplicas dos microcosmos).

As concentrações de nitrogênio total (Figura 22) determinadas nos experimentos com $\mathrm{Cu}$ apresentaram o mesmo padrão que as determinadas para o controle. Nos microcosmos contaminados com $\mathrm{Cr}$ essas concentrações foram crescentes durante todo o experimento (de 0,3 a $0,6 \mathrm{mg} . \mathrm{L}^{-1}$ ).

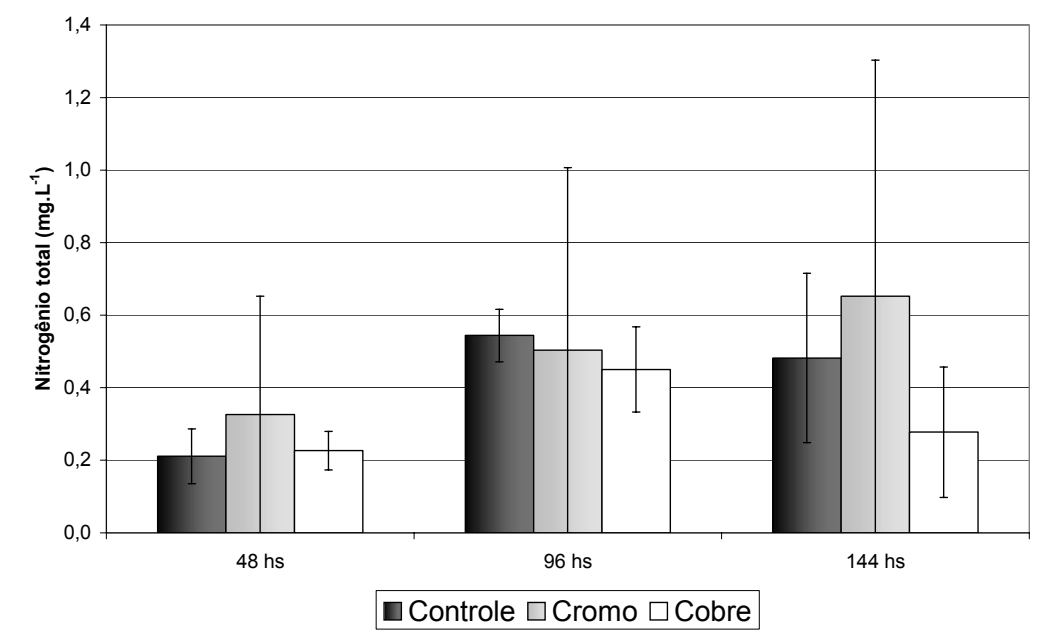

Figura 22: Concentrações médias de nitrogênio total $\left(\mathrm{mg}^{-1} \mathrm{~L}^{-1}\right)$ determinadas nas amostras de água no controle e nos microcosmos contaminados com $\mathrm{Cr}$ e $\mathrm{Cu}$ (as barras de erros referem-se ao desvio padrão da média entre as réplicas dos microcosmos).

As réplicas do controle apresentaram desvio padrão alto (50 \%) apenas na coleta após 144 hs do início do experimento, enquanto as réplicas do experimento com $\mathrm{Cr}$ apresentaram valores altos de desvio padrão para o nitrogênio total nas coletas de 48 e 96 hs (100 e 50 \%, respectivamente). O experimento com $\mathrm{Cu}$ 
apresentou desvio padrão alto para as concentrações de nitrogênio total apenas na última coleta $(65 \%)$

As concentrações de fosfato inorgânico, fosfato total dissolvido e fósforo total determinadas em cada coleta e unidade experimental estão apresentadas em Apêndice. As médias das concentrações determinadas estão apresentadas nas Figuras 23, 24 e 25.

A variação nas concentrações de fosfato inorgânico ao longo do experimento ocorreu de forma diferenciada no controle e nos tratamentos com $\mathrm{Cr}$ e $\mathrm{Cu}$. O controle apresentou concentrações decrescentes entre 48 e 144 horas (de 6,4 para $1,3 \mu \mathrm{g} \cdot \mathrm{L}^{-1}$ ). O experimento com $\mathrm{Cr}$ apresentou um acréscimo nas concentrações de fosfato inorgânico em 96 hs (de 2,8 para 3,2 $\mu \mathrm{g} \cdot \mathrm{L}^{-1}$ ), com posterior decréscimo em 144 horas $\left(1,0 \mu \mathrm{g} \cdot \mathrm{L}^{-1}\right)$, enquanto no experimento com $\mathrm{Cu}$ ocorreu o contrário, as concentrações de fosfato inorgânico inicialmente decresceram (de 3,4 para 2,0 $\mu \mathrm{g} . \mathrm{L}^{-1}$ ) seguida de um pequeno acréscimo em 144 hs $\left(2,8 \mu \mathrm{g} \cdot \mathrm{L}^{-1}\right)$. Todas as triplicatas apresentaram desvios padrão bastante altos para as concentrações de fosfato inorgânico (Apêndice).

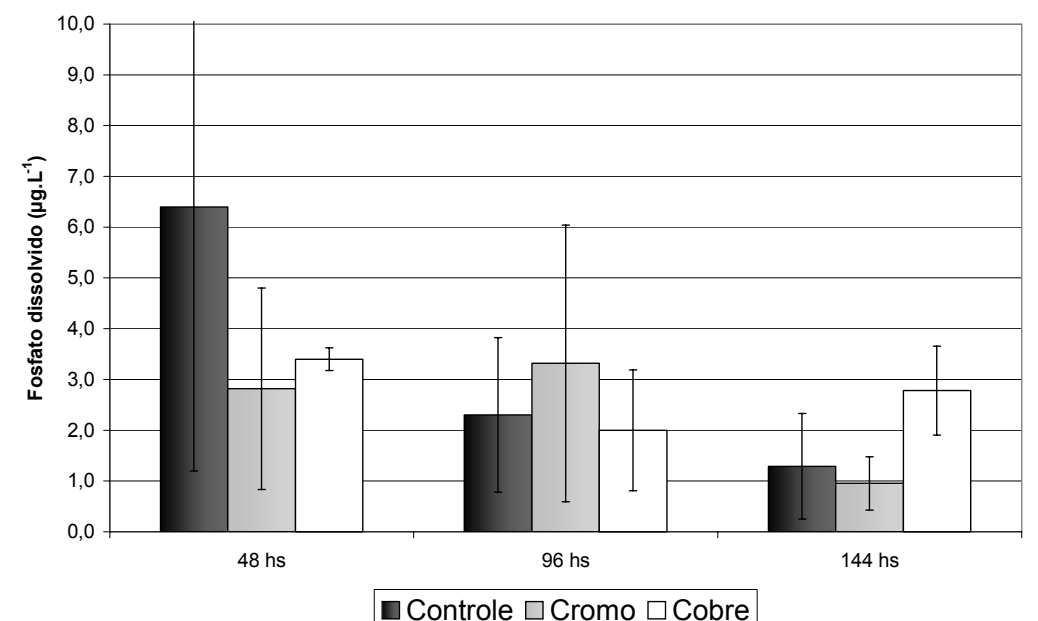

Figura 23: Concentrações médias $\left(\mu \mathrm{g} \cdot \mathrm{L}^{-1}\right)$ de fosfato inorgânico determinadas nas amostras de água no controle e nos microcosmos contaminados com $\mathrm{Cr}$ e $\mathrm{Cu}$ (as barras de erros referem-se ao desvio padrão da média entre as réplicas dos microcosmos). 
O experimento com $\mathrm{Cu}$ apresentou comportamento semelhante ao do controle, apresentando decréscimo nas concentrações de fosfato total dissolvido em 96 hs, com posterior acréscimo (10 $\mu \mathrm{g} \cdot \mathrm{L}^{-1}$ em $48 \mathrm{hs} ; 5,0 \mu \mathrm{g} \cdot \mathrm{L}^{-1}$ em $96 \mathrm{hs}$ e $8,5 \mu \mathrm{g} \cdot \mathrm{L}^{-1}$ em $\left.144 \mathrm{hs}\right)$. O experimento com $\mathrm{Cr}$ apresentou concentrações de fosfato total dissolvido sempre decrescentes $\left(9,0 ; 5,5\right.$ e 3,9 $\mu \mathrm{g} . \mathrm{L}^{-1}$, respectivamente), conforme apresentado na Figura 24.

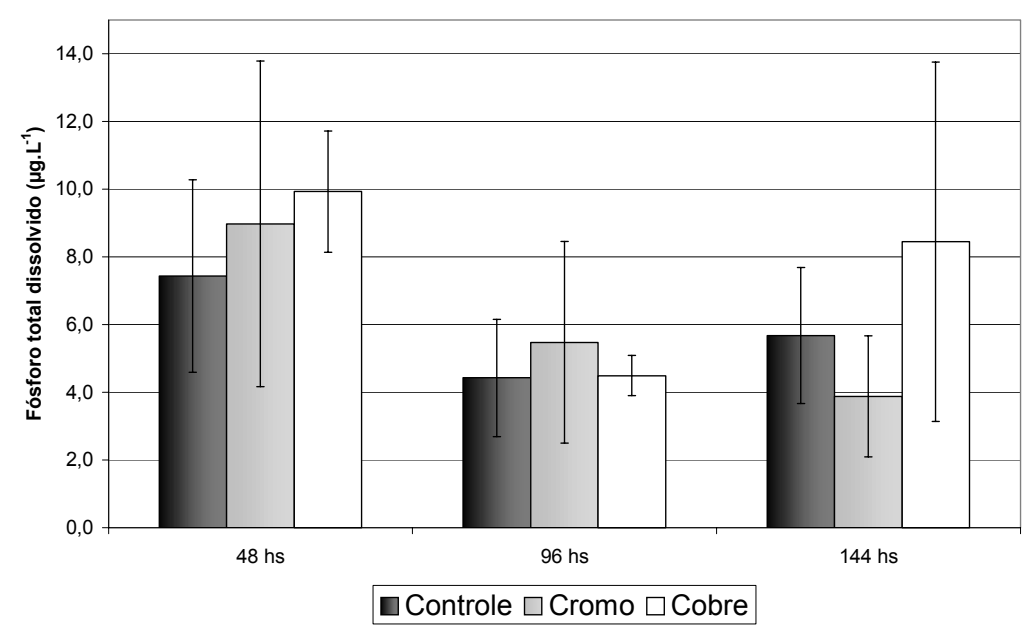

Figura 24: Concentrações médias $\left(\mu \mathrm{g} \cdot \mathrm{L}^{-1}\right)$ de fosfato total dissolvido determinadas nas amostras de água no controle e nos microcosmos contaminados com $\mathrm{Cr}$ e $\mathrm{Cu}$ (as barras de erros referem-se ao desvio padrão da média entre as réplicas dos microcosmos).

Os experimentos com $\mathrm{Cr}$ e $\mathrm{Cu}$ apresentaram variação semelhante em relação às concentrações de fósforo total, sofrendo decréscimo a 96 hs (de 31,0 para 17,1 $\mu \mathrm{g} . \mathrm{L}^{-1}$ no tratamento com $\mathrm{Cr}$ e de 26,0 para $19,3 \mu \mathrm{g} \cdot \mathrm{L}^{-1}$ no tratamento com $\mathrm{Cu}$ ), com posterior acréscimo, não muito pronunciado (21 $\mu \mathrm{g} \cdot \mathrm{L}^{-1} \mathrm{em}$ ambos os tratamentos). $\mathrm{O}$ controle apresentou um pequeno decréscimo nas concentrações de fósforo total ao longo do tempo do experimento (de $23,5 \mu \mathrm{g} \cdot \mathrm{L}^{-1} \mathrm{em} 48 \mathrm{hs}$ para $20,0 \mu \mathrm{g} \cdot \mathrm{L}^{-1} \mathrm{em} 144 \mathrm{hs}$ ). 


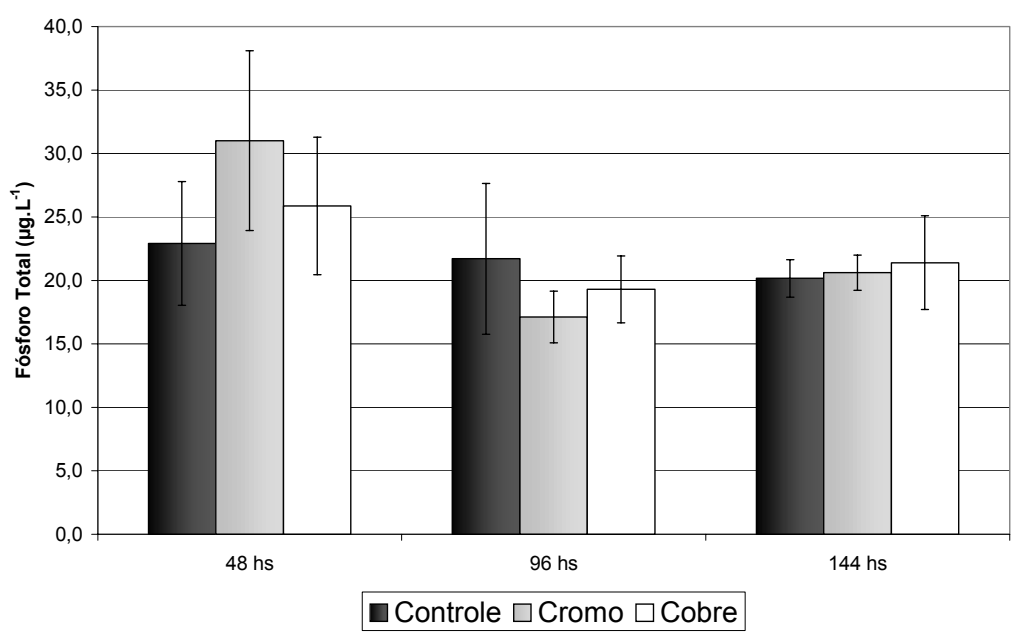

Figura 25: Concentrações médias $\left(\mu \mathrm{g} \cdot \mathrm{L}^{-1}\right)$ de fósforo total determinadas nas amostras de água no controle e nos microcosmos contaminados com $\mathrm{Cr}$ e $\mathrm{Cu}$ (as barras de erros referem-se ao desvio padrão da média entre as réplicas dos microcosmos).

As concentrações de material em suspensão total (MST), orgânico (MO) e inorgânico (MI) determinadas em cada unidade experimental, estão apresentadas em apêndice, sendo que os valores médios estão apresentadas nas figuras 26, 27 e 28, respectivamente.

Verifica-se, para o material em suspensão total e orgânico, que os valores iniciais $(\mathrm{t}=0)$ foram maiores $\left(7,7\right.$ e $6,1 \mathrm{mg} \cdot \mathrm{L}^{-1}$, respectivamente), em relação às concentrações obtidas nas demais coletas para o controle e para os microcosmos contaminados com $\mathrm{Cr}$ e $\mathrm{Cu}$, demonstrando uma maior sedimentação do material em suspensão orgânico. No entanto, apesar do reduzido decréscimo após 48 hs do início do experimento, verificou-se um aumento nos valores de material em suspensão inorgânico, principalmente no controle e nos microcosmos contaminados com Cr. Nos microcosmos contaminados com $\mathrm{Cu}$, após redução de $1,6 \mathrm{mg} \cdot \mathrm{L}^{-1}(\mathrm{em} \mathrm{t}=0$ ) para 0,4 mg. $\mathrm{L}^{-1}$ (em $48 \mathrm{hs}$ ), os valores permaneceram constantes.

Os maiores desvios-padrão calculados entre as réplicas foram determinados para a triplicata do controle nas coletas a 96 e 144 hs do início do experimento. As outras triplicatas não apresentaram valores de desvio-padrão altos, demonstrando a reprodutibilidade do experimento (Apêndice). 


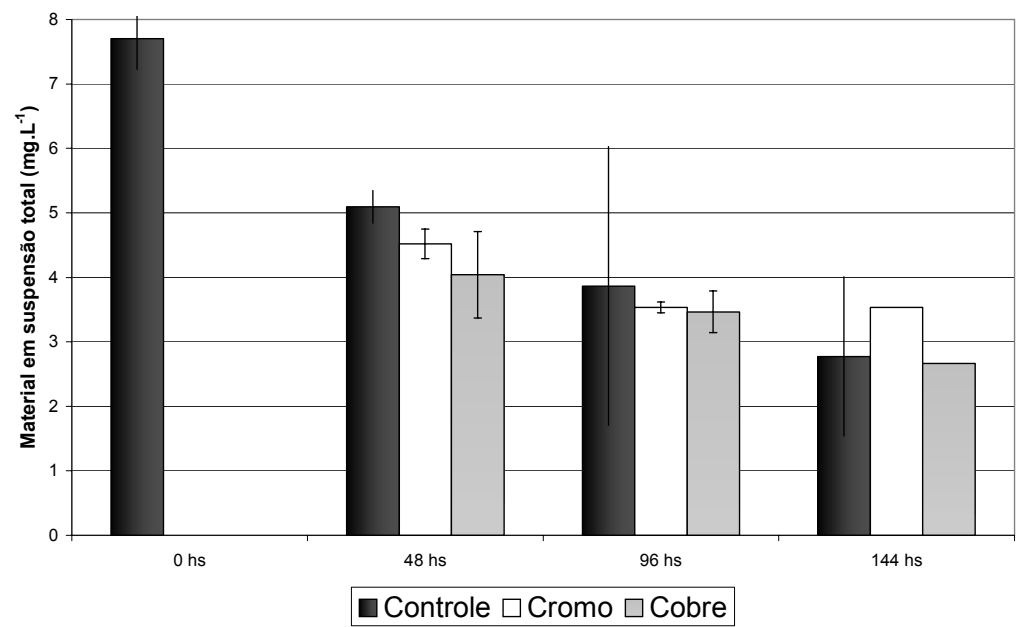

Figura 26: Concentrações médias $\left(\mathrm{mg} \mathrm{L}^{-1}\right)$ de material em suspensão total determinadas nas amostras de água no controle e nos microcosmos contaminados com $\mathrm{Cr}$ e $\mathrm{Cu}$ (as barras de erros referem-se ao desvio padrão da média entre as réplicas dos microcosmos).

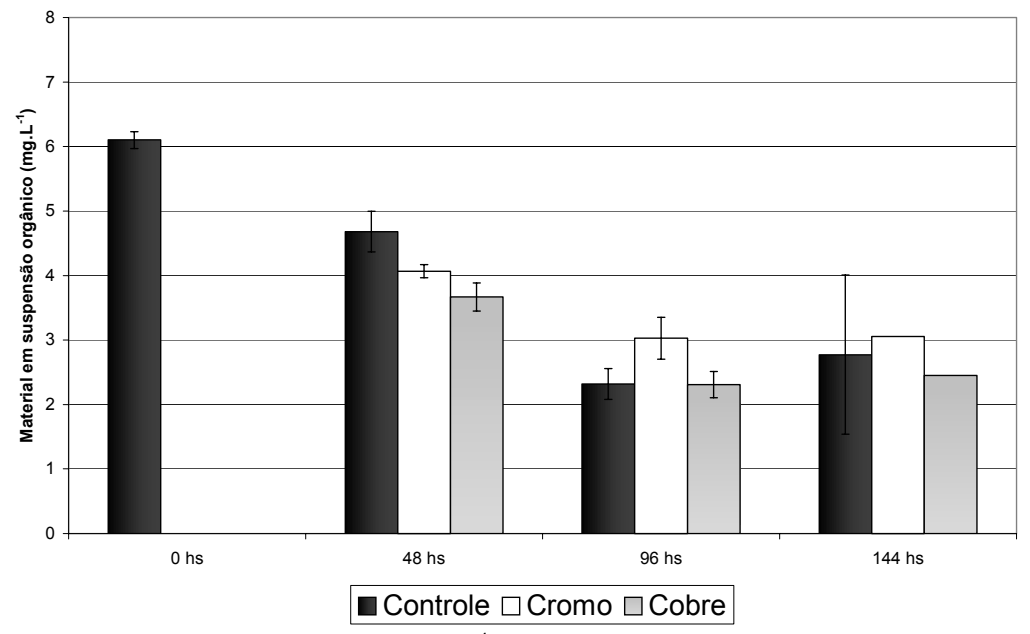

Figura 27: Concentrações médias $\left(\mathrm{mg} \mathrm{L}^{-1}\right)$ de material em suspensão orgânico determinadas nas amostras de água no controle e nos microcosmos contaminados com $\mathrm{Cr}$ e $\mathrm{Cu}$ (as barras de erros referem-se ao desvio padrão da média entre as réplicas dos microcosmos). 


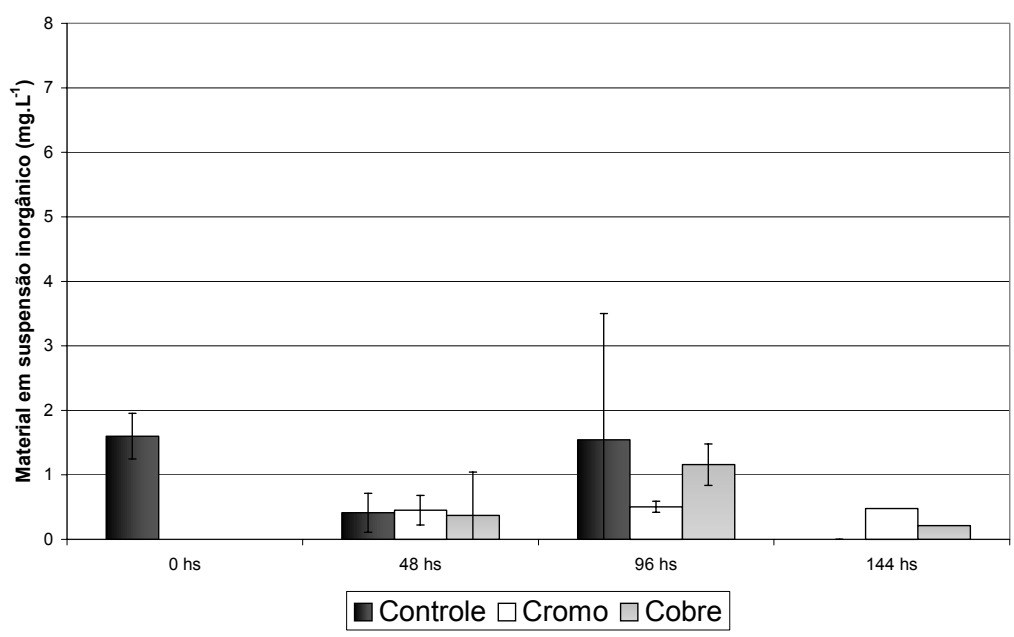

Figura 28: Concentrações médias (mg L-1) de material em suspensão inorgânico determinadas nas amostras de água no controle e nos microcosmos contaminados com $\mathrm{Cr}$ e $\mathrm{Cu}$ (as barras de erros referem-se ao desvio padrão da média entre as réplicas dos microcosmos).

As concentrações de clorofila determinadas na água superficial de cada unidade experimental, estão apresentadas em apêndice, sendo que os valores médios estão apresentados na Figura 29. As concentrações de clorofila determinadas nos tratamentos com $\mathrm{Cr}$ e $\mathrm{Cu}$ foram menores que as determinadas no controle. As concentrações de clorofila no controle variaram em média de 15,3 a 29,5 $\mu \mathrm{g} . \mathrm{L}^{-1}$, durante o experimento, enquanto que nos microcosmos com $\mathrm{Cr}$ essa concentração variou de $11,9 \mu \mathrm{g} \cdot \mathrm{L}^{-1}$, no início do experimento, à $5,2 \mu \mathrm{g} \cdot \mathrm{L}^{-1}$ ao final, e nos experimentos com Cu de 16,4 a 10,8 $\mu \mathrm{g} \cdot \mathrm{L}^{-1}$, observando-se um acentuado decréscimo em relação à concentração inicial $\left(31 \pm 4,8 \mu \mathrm{g} \cdot \mathrm{L}^{-1}\right)$.

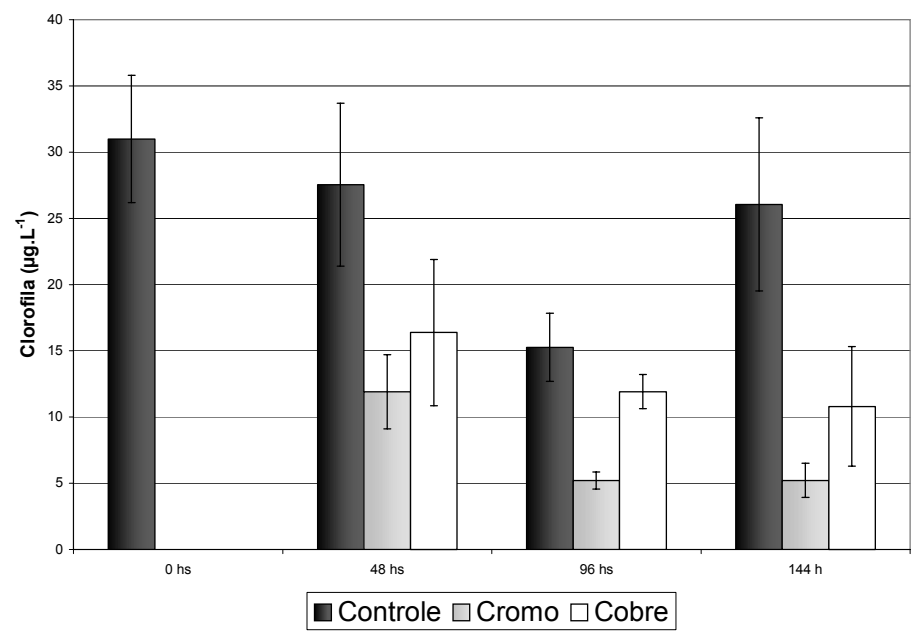

Figura 29: Concentrações médias $\left(\mu \mathrm{g} \cdot \mathrm{L}^{-1}\right)$ de clorofila determinadas nas amostras de água no controle e nos microcosmos contaminados com $\mathrm{Cr}$ e $\mathrm{Cu}$ (as barras de erros referem-se ao desvio padrão da média entre as réplicas dos microcosmos). 
Para avaliar o efeito da adição de $\mathrm{Cr}$ e $\mathrm{Cu}$ à água da represa do Lobo procedeu-se a uma análise de variância multivariada (MANOVA), comparando-se os resultados obtidos nos microcosmos contaminados com $\mathrm{Cr}$ e $\mathrm{Cu}$ com os resultados obtidos para o controle. Para os controles foram usados os valores médios das triplicatas, e para os experimentos os valores individuais, sendo escolhido 0 nível de significância a $p<0,05$. A análise foi realizada com o auxílio dos softwares FITOPAC e SYSTAT.

A adição de $\mathrm{Cr}$ no experimento causou efeitos significativos a $p=0,017$ para os testes de Wilks Lambda, Pillai Trace e Hotteling Lawley Trace. Através da análise estatística multivariada observou-se que a adição de $\mathrm{Cr}$ causou efeito significativo apenas sobre as concentrações de clorofila $(p=0,001)$ e de silicato $(p=0,013)$.

Partículas, devido à sua grande área superficial, são agregadoras de íons metálicos e, freqüentemente são elementos ativos em seu transporte. Superfícies de oxi-hidróxidos e silicatos de alumínio, assim como superfícies orgânicas, contém grupos funcionais que agem como sítios de coordenação. Em sistemas com presença de matéria orgânica, a concentração do íon livre diminui, porém estudos indicam que a ligação do $\mathrm{Cu}$ com a matéria orgânica pode aumentar sua toxicidade (STUMM \&. MORGAN, 1981).

Interações entre o material particulado e metais desempenham um importante papel na regulação das concentrações de metais dissolvidas, sendo o primeiro passo na remoção de metais da solução (SALOMONS \& FORSTNER, 1984). O pH é provavelmente o fator de maior influência na adsorção de metais em superfícies orgânicas. $\mathrm{O}$ aumento do $\mathrm{pH}$ causa a adsorção de determinados metais com a matéria em suspensão, diminuindo as concentrações dissolvidas. As relações identificadas entre $\circ \mathrm{pH}$ e o material em suspensão nos microcosmos estão de acordo com esta observação. $\mathrm{Na}$ análise de correlação realizada com os valores obtidos nos microcosmos, observa-se correlação muito significativa entre material em suspensão orgânico e $\mathrm{pH}$ para os dois tratamentos $(r=0,837 ; p=0,000$, para $\mathrm{Cr}$ e $r=0,763, p=0,000$ para o $\mathrm{Cu}$ ). $\mathrm{O}$ material em suspensão total também apresentou correlação positiva com o $\mathrm{pH}$ a $\mathrm{p}<0,05$ para o $\mathrm{Cu}$ e a $\mathrm{p}<0,1$ para o $\mathrm{Cr}(r=0,474, \mathrm{p}=0,047$ e $r=0,421$, $\mathrm{p}=0,082$, respectivamente).

O material em suspensão não apresentou correlação com as concentrações de $\mathrm{Cr}$ dissolvido. As concentrações de $\mathrm{Cr}$ se mantiveram praticamente constantes ao longo do experimento, demonstrando a não regulação pelo material em suspensão, possivelmente devido ao $\mathrm{pH}$ relativamente baixo. A concentração de $\mathrm{Cr}$ apresentou correlação negativa significativa com a concentração de silicato e de clorofila ( $r=-$ $0,497, p=0,036$ e $r=-0,808, p=0,000$ respectivamente), sendo tais efeitos já 
observados pela análise de variância. No experimento com $\mathrm{Cr}$, a concentração de clorofila foi relacionada fortemente com a concentração de material em suspensão orgânico e $\mathrm{pH}(r=0,600 ; p=0,008$ e $r=0,561, p=0,015$, respectivamente), demonstrando a contribuição da clorofila para o material em suspensão orgânico e a regulação destes parâmetros pelo $\mathrm{pH}$.

A adição de $\mathrm{Cu}$ apresentou efeito significativo apenas sobre a concentração de clorofila $(p=0,003)$, gerando valores de $p=0,013$ para os testes de Wilks Lambda, Pillai Trace e Hotteling Lawley Trace.

Segundo SIBLEY, SHOTT \& CHANG (1994) em valores baixos de $\mathrm{pH}$ as principais espécies de $\mathrm{Cu}$ solúvel são o íon livre $\mathrm{Cu}^{2+}$ e complexos orgânicos. Os autores observaram ainda que as concentrações de cobre dissolvido geralmente declinam com o tempo, e flutuações no pH causam significantes diferenças entre as concentrações de Cu iônico e dissolvido, acarretando variações diurnas na toxicidade do $\mathrm{Cu}$. O efeito do $\mathrm{Cu}$ no crescimento das algas depende de como o elemento está presente no meio, se como o íon $\mathrm{Cu}^{2+}$ ou como carbonatos ou complexos orgânicos, o que é bem exemplificado em estudos sobre a toxicidade do Cu na forma iônica para o fitoplâncton.

Como a quantidade de material em suspensão declinou com o tempo de experimento, pode-se supor que a fração do $\mathrm{Cu}$ em solução retirada pelo material em suspensão também diminui com o decorrer do experimento. Corroborando esta hipótese, a concentração de material em suspensão total foi o único parâmetro avaliado a apresentar correlação significativa a $p<0,05$ com as concentrações de cobre ( $r=-0,519, p=0,027$ ), ou seja, com a diminuição da concentração de material em suspensão aumentam as concentrações do $\mathrm{Cu}$ dissolvido, considerando-se as análises realizadas nos microcosmos controle e nos contaminados com $\mathrm{Cu}$. Apesar da concentração de clorofila não apresentar correlação significativa com as concentrações de $\mathrm{Cu}$, tal correlação foi observada com a quantidade de material em suspensão orgânico ( $r=0,504 ; p=0,033)$, demonstrando a contribuição da quantidade de clorofila para o material em suspensão.

$\mathrm{O} \mathrm{pH}$ e o material em suspensão total foram as variáveis analisadas que apresentaram correlação significativa $(a p<0,05)$ com o maior número de variáveis, tanto na matriz de correlação realizada para os resultados referentes ao controle e ao tratamento com $\mathrm{Cr}$ como na matriz com os resultados do controle e do tratamento com $\mathrm{Cu}$. Nos dois casos, a concentração de nitrito foi relacionada com a concentração de material em suspensão e a concentração de clorofila com o material em suspensão e o pH. A matriz de correlação obtida, considerando-se todas as variáveis, com os respectivos valores de $p$, está apresentada em Apêndice. 


\subsection{2- Análise da comunidade planctônica}

\subsubsection{1- Fitoplâncton}

De forma similar às variáveis físico-químicas também considerou-se a análise inicial do fitoplâncton com sendo aquela comunidade presente na amostra de água coletada na represa do Lobo antes de ser adicionada nos microcosmos.

Nesta análise inicial foram identificados 21 taxa, como uma densidade total de 2774 ind. $\mathrm{mL}^{-1}$.O número de indivíduos pertencente a cada taxa e sua abundância relativa estão apresentados na tabela 11, verificando-se que Aulacoseira granulata foi a espécie mais abundante, contando com $53 \%$ da densidade total de indivíduos. Outras espécies que foram relativamente abundantes foram Radiococcus $s p$. (12,4\%), Quadrigula sp.p. (9,9\%), Aphanocapsa sp. (5,4\%), Sphaerocystis schoeterie (4,9\%), Euglena sp. (2,6 \%), Geitlerinema sp (2,5\%), Coelastrtum reticulatum (2,5\%), Monoraphydium circinale $(2,2 \%)$ e Microcystis sp. (1,2 \%). As demais espécies contaram com menos de $1 \%$ da densidade total.

Tabela 11: Composição, densidade (ind. $\mathrm{mL}^{-1}$ ) e abundância relativa (\%) do fitoplâncton identificado antes do início do experimento .

\begin{tabular}{ccc}
\hline \hline Táxon & ind. $\mathrm{mL}^{-1}$ & Abundância Relativa (\%) \\
\hline \hline Aphanocapsa sp. & 150 & 5,4 \\
Aulacoseira granulata & 1.470 & 53,0 \\
Chlamydomonas sp. & 4 & 0,2 \\
Chlorella sp. & 21 & 0,8 \\
Coelastrtum reticulatum & 68 & 2,5 \\
Cosmarium sp. & 8 & 0,3 \\
Dictyosphaerium pulchellum & 17 & 0,6 \\
Euglena sp. & 73 & 2,6 \\
Geitlerinema sp & 68 & 2,5 \\
Isthmocloron lobulatum & 4 & 0,2 \\
Microcystis sp. & 34 & 1,2 \\
Monoraphydium arcuatum & 9 & 0,3 \\
Monoraphydium circinale & 60 & 2,2 \\
Peridinium sp & 4 & 0,2 \\
Quadrigula sp.p. & 274 & 9,9 \\
Radiococcus sp. & 343 & 12,4 \\
Scenedesmus sp. & 9 & 0,3 \\
Sphaerocystis schoeterie & 137 & 4,9 \\
Staurastrum cf. incus & 4 & 0,2 \\
Staurastrum mamillatum & 9 & 0,3 \\
Synedra sp. & 4 & 0,2 \\
\hline \hline Densidade Total & 2.774 & 100 \\
\hline \hline
\end{tabular}


Com base nestes dados, foram calculados a riqueza e os índices de diversidade H', uniformidade U' e dominância D'. Os valores obtidos para estes índices estão apresentados na tabela 12.

Tabela 12: Riqueza, diversidade, uniformidade e dominância do fitoplâncton antes do início do experimento.

\begin{tabular}{cc}
\hline \hline Riqueza & 21 \\
Diversidade $\left(\mathrm{H}^{\prime}\right)$ & 2,5 \\
Uniformidade $\left(\mathrm{U}^{\prime}\right)$ & 0,6 \\
Dominância $\left(\mathrm{D}^{\prime}\right)$ & 0,3 \\
\hline \hline
\end{tabular}

Após a montagem do experimento e a contaminação dos microcosmos com $\mathrm{Cr}$ e Cu foram realizadas coletas diárias em todas as unidades experimentais, sendo que somente foi analisada uma das réplicas de cada tratamento (Controle, $\mathrm{Cr}$ e $\mathrm{Cu}$ ). $\mathrm{A}$ relação dos taxa identificados durante todo o período de estudo encontra-se na tabela 13, e uma descrição mais detalhada está apresentada em Apêndice.

Em uma análise preliminar dos resultados obtidos, observa-se que a maior riqueza ocorreu no controle (42) em relação aos tratamentos com $\mathrm{Cr}$ (26) e Cu (32), sendo todos os valores mais elevados quando comparados com a riqueza de espécies inicial (21 taxa). No entanto, vários gêneros ou espécies foram encntrados nos quatro componentes de dados, como Aulacoseira granulata, Chlamydomonas sp, Coelastrum reticulatum e Synedra sp., entre outros, embora em diferentes proporções.

Comparando-se com o controle, os tanques contaminados com $\mathrm{Cr}$ e com $\mathrm{Cu}$ apresentaram uma menor densidade 24 hs após a contaminação (Figura 30). A densidade de indivíduos no tratamento com $\mathrm{Cr}$ foi decrescente durante todo $\mathrm{O}$ experimento, atingindo o menor valor em 144 hs (181 ind. $\mathrm{mL}^{-1}$ ). Nos microcosmos contaminados com Cu, observa-se uma redução significativa 48 hs após a contaminação dos tanques (826 ind. $\mathrm{mL}^{-1}$ ), com o aumento na densidade de indivíduos na coleta seguinte (1698 ind. $\mathrm{mL}^{-1}$ ) e novo decréscimo em 96 hs (532 ind. $\mathrm{mL}^{-1}$ ). O controle apresenta um pico na densidade de organismos em 48 hs (2694 ind. $\mathrm{mL}^{-1}$ ), sendo que nas coletas realizadas em 96 e 120 hs todos os tratamentos apresentaram uma redução na densidade total de indivíduos. 
Tabela 13: Ocorrência dos taxa do fitoplâncton no controle e nos microcosmos contaminados com $\mathrm{Cr}$ e $\mathrm{Cu}$ em todo o período de estudo.

\begin{tabular}{|c|c|c|c|}
\hline Espécie & Controle & Cromo & Cobre \\
\hline Aphanocapsa sp. & $\mathrm{X}$ & $\mathrm{X}$ & \\
\hline Asterococcus sp. & $x$ & & $\mathrm{x}$ \\
\hline Aulacoseira granulata & $\mathrm{x}$ & $\mathrm{x}$ & $\mathrm{x}$ \\
\hline Aulacoseira italica & & $\mathrm{X}$ & $\mathrm{X}$ \\
\hline Botryococcus braunii & & $\mathrm{x}$ & \\
\hline Carteria sp. & & & $\mathrm{X}$ \\
\hline Chlamydomonas sp & $\mathrm{x}$ & $\mathrm{x}$ & $\mathrm{x}$ \\
\hline Chlorella sp. & $\mathrm{X}$ & $\mathrm{X}$ & $\mathrm{X}$ \\
\hline Coelastrum reticulatum & $\mathrm{x}$ & $x$ & $\mathrm{x}$ \\
\hline Coelastrum sphaericum & $\mathrm{x}$ & & $x$ \\
\hline Coenochloris sp. & $\mathrm{X}$ & $\mathrm{X}$ & $\mathrm{X}$ \\
\hline Cosmarium sp. & $x$ & $\mathrm{x}$ & $\mathrm{x}$ \\
\hline Crucigenia fenestrada & $\mathrm{x}$ & & \\
\hline Crucigenia tetrapedia & $\mathrm{x}$ & $\mathrm{X}$ & \\
\hline Cryptomonas sp & $\mathrm{X}$ & & $\mathrm{X}$ \\
\hline Cyclotela sp & & & $\mathrm{X}$ \\
\hline Dictyosphaerium pulchellum & $\mathrm{x}$ & $\mathrm{x}$ & $x$ \\
\hline Didimocystis fina & $\mathrm{X}$ & $\mathrm{X}$ & $\mathrm{x}$ \\
\hline Elakatothrix gelatinosa & $\mathrm{x}$ & $\mathrm{x}$ & $\mathrm{x}$ \\
\hline Euglena sp & $\mathrm{x}$ & $\mathrm{X}$ & \\
\hline Eunotia sp & $\mathrm{x}$ & & \\
\hline Eutetramorus fottii & $\mathrm{X}$ & & $\mathrm{x}$ \\
\hline Geitlerinema sp & $\mathrm{X}$ & & \\
\hline Golenkinia radiata & & & $\mathrm{x}$ \\
\hline Isthmocloron lobulatum & $\mathrm{x}$ & & \\
\hline Kirchneriella lunaris & $\mathrm{x}$ & & \\
\hline Lepocincles ovum & & & $\mathrm{X}$ \\
\hline Mallomonas sp & $\mathrm{X}$ & & $\mathrm{x}$ \\
\hline Micractinium pusilum & & & $\mathrm{x}$ \\
\hline Microcystis sp. & $\mathrm{x}$ & & \\
\hline Monoraphydium arcuatum & $\mathrm{x}$ & $\mathrm{x}$ & $\mathrm{X}$ \\
\hline Monoraphydium circinale & $\mathrm{X}$ & $\mathrm{X}$ & $\mathrm{X}$ \\
\hline Monoraphydium kormakovae & $\mathrm{x}$ & $\mathrm{X}$ & $\mathrm{X}$ \\
\hline Oocystis lacustris & $\mathrm{X}$ & $\mathrm{x}$ & $\mathrm{x}$ \\
\hline Oocystis sp & $x$ & & \\
\hline Pediastrum duplex & $\mathrm{x}$ & $\mathrm{x}$ & \\
\hline Peridinium sp. & $\mathrm{X}$ & & $\mathrm{X}$ \\
\hline Quadrigula sp & $\mathrm{x}$ & $\mathrm{X}$ & $\mathrm{x}$ \\
\hline Radiococcus sp & $\mathrm{x}$ & $\mathrm{x}$ & $\mathrm{x}$ \\
\hline Rizosolenia longiseta & $\mathrm{x}$ & & \\
\hline Scenedesmus sp. & $\mathrm{x}$ & & $\mathrm{X}$ \\
\hline Sphaerocystis schroeteri & $\mathrm{x}$ & $\mathrm{X}$ & $\mathrm{X}$ \\
\hline Staurastrum cf. incus & $x$ & $\mathrm{x}$ & $\mathrm{x}$ \\
\hline Staurastrum mamillatum & $\mathrm{X}$ & & \\
\hline Staurastrum sebaldi & & $\mathrm{x}$ & \\
\hline Staurastrum sp & $\mathrm{X}$ & & $\mathrm{X}$ \\
\hline Synedra sp. & $\mathrm{X}$ & $\mathrm{X}$ & \\
\hline Tetraedron caudatum & $\mathrm{x}$ & & \\
\hline Tetrastrum heteracanthum & $\mathrm{x}$ & & \\
\hline Trachelomonas volvocina & $\mathrm{x}$ & $\mathrm{x}$ & $x$ \\
\hline Total de taxa & 42 & 26 & 32 \\
\hline
\end{tabular}




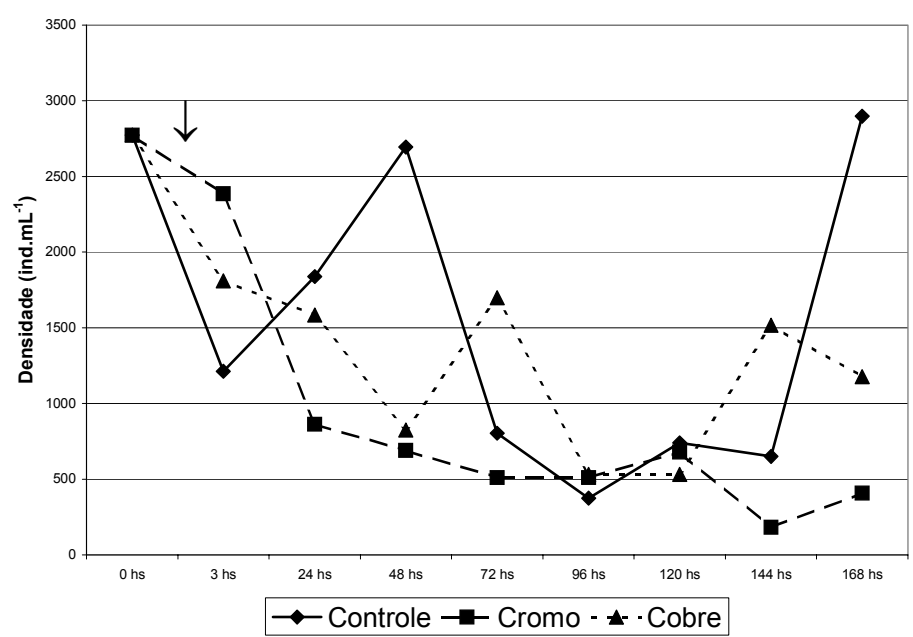

Figura 30: Densidade total do fitoplâncton (ind.mL-1) em cada tratamento durante o período de estudo ( $\mathrm{t}=\mathrm{Oh}$ corresponde a densidade inicial do fitoplâncton, a seta aponta a contaminação)

Em todos os tratamentos, Chlorophyceae foi a classe mais abundante, sendo que as demais classes praticamente desapareceram, principalmente no tratamento com $\mathrm{Cr}$, como apresentado nas figuras 31,32 e 33.

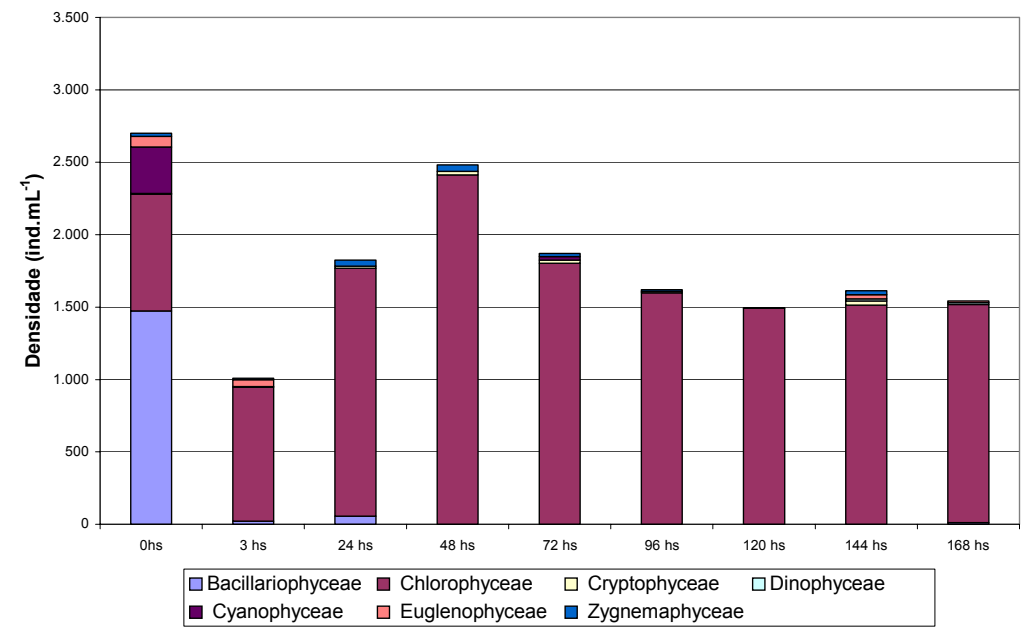

Figura 31: Variação na densidade do fitoplâncton no controle durante o período de estudo. 


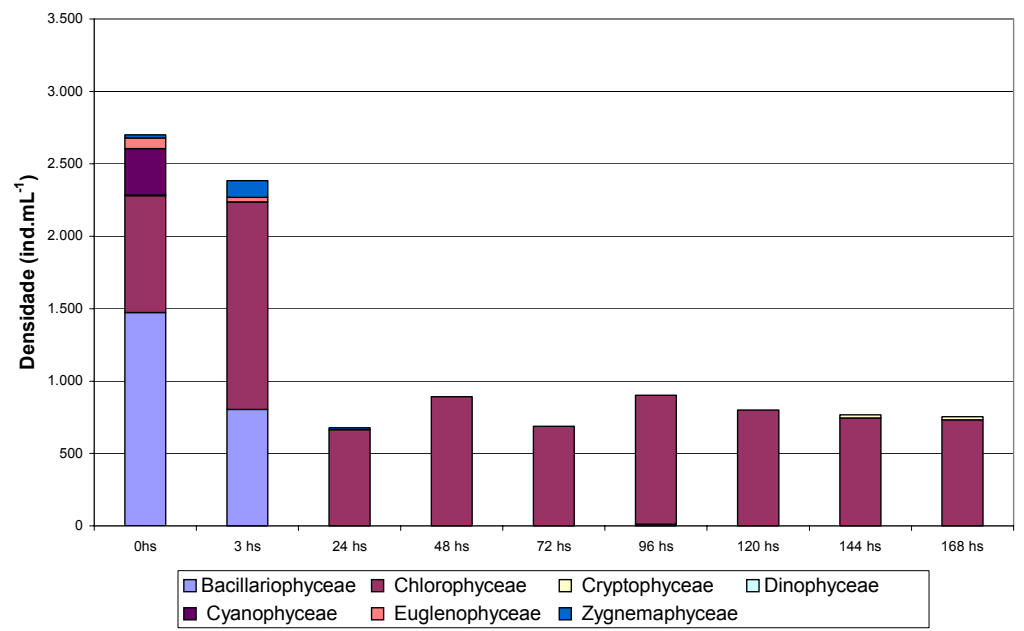

Figura 32: Variação na densidade do fitoplâncton no tratamento com $\mathrm{Cr}$ durante o período de estudo.

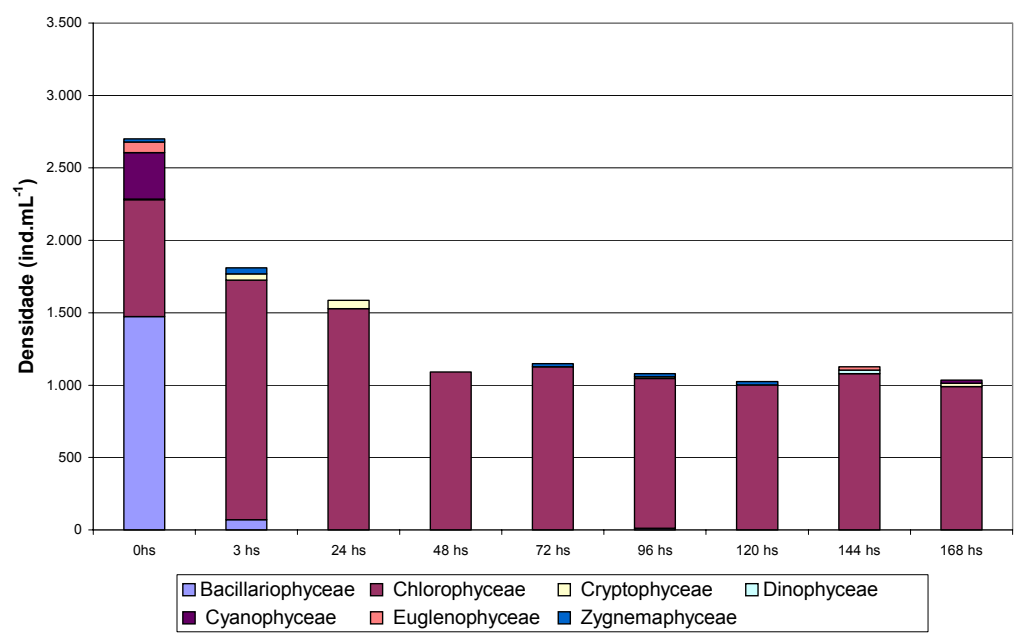

Figura 33: Variação na densidade do fitoplâncton no tratamento com Cu durante o período de estudo.

Considerando os valores obtidos para as densidades do fitoplâncton no início e após a adição dos contaminantes, além do controle, verifica-se, inicialmente uma redução no número de organismos, o que é ocasionado principalmente pela redução numérica de Aulacoseira granulata. Esta diatomácea representou $53 \%$ da densidade total do fitoplâncton na amostra inicial, mas a redução no material em suspensão pode ter implicado na sedimentação da espécie. No entanto, possibilitou que algas clorofíceas se tornassem numericamente dominantes no controle e nos tratamentos com $\mathrm{Cu}$ e $\mathrm{Cr}$, embora a densidade inicial tenha sido maior em relação ao controle, $\mathrm{Cr}$ e $\mathrm{Cu}$. 
Pela análise das figuras 31, 32 e 33 verifica-se que, em termos de densidade, o efeito maior ocorreu no tratamento com $\mathrm{Cr}$ (abaixo de 1000 ind. $\mathrm{mL}^{-1}$ após 3 horas), enquanto no controle e no tratamento com $\mathrm{Cu}$ as densidades estiveram entre $1000 \mathrm{e}$ 2500 ind. $\mathrm{mL}^{-1}$ (controle) e entre 1000 e 1600 ind. $\mathrm{mL}^{-1}$ (tratamento com Cu).

A abundância relativa das espécies variou bastante em todos os tratamentos. Quadrigula sp. e Radiococcus sp. estiveram presentes na maior parte das amostras, representando entre 10 e $27 \%$ do total de indivíduos. Coelastrum reticulatum e Sphaerocystis schoeterie estiveram presentes em densidades altas nas amostras coletadas após 72 (14,1 e 33,8 \%, respectivamente) e 96 hs $(21,2$ e 24,2 \%, respectivamente) do ínicio do experimento. Monoraphydium circinale apresentou as maiores porcentagens de abundância relativa, sendo $63,1 \%, 91,1 \%$ e $82,3 \%$ nas amostras coletadas a 24,120 e $168 \mathrm{hs,} \mathrm{respectivamente.}$

Assim como no controle, Quadrigula sp., Radiococcus sp., Coelastrum reticulatum e Sphaerocystis schoeterie estiveram presentes com uma abundância relativamente alta na maior parte das amostras coletadas dos microcosmos contaminados com $\mathrm{Cr}$, representando nestes casos entre 9 e 29\% do total de indivíduos. Coenocloris $s p$. representou $36 \%$ do total de indivíduos na amostra coleta a 72 hs do início do experimento, apesar de não ter representação expressiva nas outras amostras. Chlorella sp. apresentou abundância relativa de até $37 \%$ do total de indivíduos para as amostras coletadas a 120 e 144hs. Chlamydomonas sp e Sphaerocystis schoeterie também foram espécies representativas do sistema.

No tratamento com $\mathrm{Cu}$, Sphaerocystis schoeterie foi a espécie mais abundante nas amostras coletadas a 3 e 24 hs, contribuindo com 27 e $28 \%$ do total de indivíduos, respectivamente. $\mathrm{Na}$ amostra seguinte, as maiores abundâncias corresponderam a Chlamydomonas sp e Radiococcus sp (22\%, para ambas as espécies), sendo que em 72 hs Radiococcus sp representou $48 \%$ do total de indivíduos. Chlorella sp. foi a espécie dominante na amostra coletada a 96 hs (48\%) e Coenocloris sp. nas amostras dos três dias seguintes $(57,36$ e 48\% do total de indivíduos para 120, 144 e 168 hs respectivamente).

Os valores referentes à densidade total do fitoplâncton, riqueza e aos índices de diversidade (H'), uniformidade (U') e dominância (D') referentes a cada uma das coletas estão apresentados na Tabela 14. 
Tabela 14: Densidade total do fitoplâncton (DT), riqueza (S) e índices de diversidade $\left(H^{\prime}\right)$, uniformidade (U') e dominância (D') para a comunidade fitoplanctônica dos microcosmos controle e contaminados com $\mathrm{Cr}$ e $\mathrm{Cu}$.

\begin{tabular}{llcccccccc}
\hline \hline & & $3 \mathrm{hs}$ & $24 \mathrm{hs}$ & $48 \mathrm{hs}$ & $72 \mathrm{hs}$ & $96 \mathrm{hs}$ & $120 \mathrm{hs}$ & $144 \mathrm{hs}$ & $168 \mathrm{hs}$ \\
\hline \hline & $\mathrm{C}$ & 1213 & 1839 & 2694 & 804 & 373 & 740 & 651 & 2897 \\
$\mathrm{DT}$ & $\mathrm{Cr}$ & 2385 & 863 & 690 & 509 & 509 & 679 & 181 & 407 \\
& $\mathrm{Cu}$ & 1810 & 1584 & 826 & 1698 & 532 & 532 & 1517 & 1177 \\
\hline \multirow{3}{*}{$\mathrm{S}$} & $\mathrm{C}$ & 15 & 12 & 14 & 9 & 11 & 10 & 15 & 13 \\
& $\mathrm{Cr}$ & 16 & 8 & 9 & 8 & 10 & 7 & 5 & 8 \\
& $\mathrm{Cu}$ & 14 & 9 & 10 & 11 & 12 & 9 & 12 & 10 \\
\hline \multirow{3}{*}{} & $\mathrm{C}$ & 2,01 & 2,00 & 2,83 & 2,59 & 2,96 & 0,61 & 3,37 & 1,13 \\
$\mathrm{H}$ & $\mathrm{Cr}$ & 2,63 & 2,44 & 1,80 & 2,61 & 1,98 & 2,40 & 2,11 & 2,75 \\
& $\mathrm{Cu}$ & 2,95 & 2,81 & 2,90 & 2,53 & 2,69 & 2,14 & 2,58 & 2,30 \\
\hline \multirow{3}{*}{} & $\mathrm{C}$ & 0,51 & 0,56 & 0,74 & 0,82 & 0,85 & 0,18 & 0,86 & 0,31 \\
& $\mathrm{Cr}$ & 0,66 & 0,81 & 0,57 & 0,87 & 0,60 & 0,86 & 0,91 & 0,92 \\
& $\mathrm{Cu}$ & 0,77 & 0,89 & 0,87 & 0,73 & 0,75 & 0,67 & 0,72 & 0,69 \\
\hline \multirow{2}{*}{$\mathrm{D}$} & $\mathrm{C}$ & 0,18 & 0,42 & 0,19 & 0,21 & 0,16 & 0,83 & 0,14 & 0,70 \\
& $\mathrm{Cr}$ & 0,22 & 0,21 & 0,25 & 0,20 & 0,21 & 0,23 & 0,25 & 0,16 \\
& $\mathrm{Cu}$ & 0,17 & 0,17 & 0,15 & 0,27 & 0,25 & 0,36 & 0,23 & 0,30 \\
\hline \hline
\end{tabular}

Comparando-se os índices obtidos para o controle e os microcosmos contaminados com $\mathrm{Cr}$ através da análise de variância, observa-se que apenas a riqueza $(R)$ apresentou diferença significativa entre os dois tratamentos $(p=0,02)$. Em relação à contaminação por $\mathrm{Cu}$, nenhuma diferença foi observada entre os índices aí determinados e os determinados para o controle. Apesar de ser observada uma redução na densidade total para os tratamentos com $\mathrm{Cr}$ e $\mathrm{Cu}$ no início e no final do experimento, em relação ao controle, essas diferenças não foram significativas estatisticamente, considerando todas as datas. O resultado resumido das análises de variância estão apresentados em Apêndice. Essas análises foram realizadas considerando-se os índices obtidos em todas as datas, uma vez que não foram analisadas réplicas das amostras.

Conforme mencionado anteriormente, verifica-se que após o início do experimento ocorreu uma alteração na composição e densidade de espécies do fitoplâncton. Estas alterações são evidentes quanto a riqueza de espécies $(R)$, dominância, abundância e densidade, com a presença de diatomáceas no início do experimento e maior contribuição de clorofíceas após a contaminação, com maior efeito no tratamento com $\mathrm{Cr}$ em relação ao $\mathrm{Cu}$.

A estrutura e função das comunidades fitoplanctônicas de reservatórios são organizadas segundo o grau de trofia destes ambientes sendo geralmente dominada por clorofíceas em sistemas oligotróficos Nos ambientes aquáticos lênticos a comunidade fitoplanctônica ocupa função primordial como principal componente da base da cadeia trófica da região, tronando-se portanto crítico o estudo dos efeitos de metais pesados nestes organismos. 
Diversos estudos reportam a tolerância a metais por determinadas espécies de algas (MAGDALENO, 2001; CERVANTES et al. ,2001), especialmente ao Cr. Porém, neste estudo a comunidade parece ser menos sensível ao $\mathrm{Cu}$ que ao $\mathrm{Cr}$, pois a adição de $\mathrm{Cr}$ provocou um menor índice de riqueza, o que não foi observado pela adição de Cu. Estas observações são contrárias aos resultados obtidos pelos testes de toxicidade (Capítulo 02), onde S. capricornutum foi mais sensível ao $\mathrm{Cu}$.

Tal fato pode estar relacionado às diferenças de sensibilidade entre as espécies, uma vez que os diferentes grupos fitoplanctônicos respondem de maneira bastante diferenciada à presença de metais no ambiente, havendo dentro de um mesmo grupo ou gênero, espécies bastante tolerantes e muito sensíveis às mesmas concentrações de um elemento (OLIVEIRA-NETO, 2000).

Deve-se considerar, ainda, que as condições individuais se diferenciaram no decorrer do experimento, com variações significativas (como demonstrado pela análise estatística) nas concentrações de nutrientes. Nos experimentos verificou-se um aumento nas concentrações de nitrato e amônio e redução na concentração das formas dissolvidas de fósforo, o que pode ter favorecido ou suprimido determinadas espécies de algas, em adição aos efeitos dos metais.

\subsubsection{2- - Zooplâncton}

A mesma forma de análise do fitoplâncton foi utilizada para o zooplâncton, considerando-se como avaliação inicial os resultados obtidos na análise preliminar, ou seja, na análise das amostras de água da represa com volume conhecido, filtradas em rede de plâncton.

Verifica-se pela análise dos resultados (Tabela 15), a dominância de Rotífera $(90,2 \%)$, seguido de Cladocera $(5,0 \%)$ e Copepoda e 4,8 \%. A comunidade de microcrustáceos planctônicos foi composta praticamente por $52 \%$ de Cladocera e $48 \%$ de Copepoda, sendo estes últimos representados por $37 \%$ de Calanoida e $11 \%$ de Cyclopoida.

Entre os Copepoda, três espécies foram identificadas, sendo que Argyrodiaptomus furcatus foi a mais abundante (acima de 60\%). Ceriodaphnia silvestrii apresentou maior abundância relativa (acima de $80 \%$ ) entre os Cladocera e as espécies Ptygura libera, Filinia pejleri e Trichocerca pusilla entre os Rotifera, com abundância relativa superior a $20 \%$. Na Tabela 15 são apresentadas as principais a composição de espécies, densidade numérica e abundância relativa (em relação ao zooplâncton total). 
Tabela 15: Composição, densidade e abundância relativa do zooplâncton no início dos experimentos em microcosmos

\begin{tabular}{ccc}
\hline \hline Copepoda & Densidade (ind. ${ }^{-3}$ ) & Abundância relativa (\%) \\
\hline \hline Argyrodiaptomus furcatus & 7630 & 3,64 \\
Thermocyclops minutus & 1844 & 0,88 \\
Mesocyclops longisetus & 516 & 0,25 \\
\hline Total Copepoda & 9990 & 4,77 \\
\hline \hline Cladocera & & \\
\hline \hline Ceriodaphnia silvestrii & 9220 & 4,40 \\
Bosmina longirostris & 660 & 0,31 \\
Bosmina hagmani & 40 & 0,02 \\
Diaphanosoma birgei & 600 & 0,29 \\
Daphnia gessneri & 40 & 0,02 \\
\hline Total Cladocera & 10560 & 5,04 \\
\hline \hline Rotifera & & \\
\hline \hline Ptygura libera & 49500 & 23,62 \\
Lepadela quadricarinata & 500 & 0,24 \\
Conochilus unicornis & 1500 & 0,72 \\
Collotheca longicauda & 4000 & 1,91 \\
Keratella cochlearis & 18500 & 8,83 \\
Keratella americana & 1500 & 0,72 \\
Kellicotia bostoniensis & 200 & 0,10 \\
Filinia pejleri & 44000 & 21,00 \\
Trichocerca pusilla & 30000 & 14,32 \\
Trichocerca similis & 9000 & 4,29 \\
Trichocerca chattonni & 6000 & 2,86 \\
Trichocercabicristata & 1500 & 0,72 \\
Cephalodella sp. & 3000 & 1,43 \\
Notommata sp. & 1500 & 0,72 \\
Synchaeta sp. & 500 & 0,24 \\
\hline Total Rotifera & 18900 & 90,2 \\
\hline \hline Total & 209550 & 100 \\
\hline \hline
\end{tabular}

A partir dos resultados obtidos foram calculados a riqueza $(S)$, diversidade $\left(H^{\prime}\right)$, uniformidade (U') e dominância (D') para o zooplâncton total e independentemente para os microcrustáceos (Cladocera e Copépoda) e Rotifera. Estes índices estão apresentados na tabela 16 .

Tabela 16: Densidade total (DT), riqueza (S), diversidade (H'), uniformidade (U') e dominância (D') para o zooplâncton total, microcrustáceos e rotíferos na avaliação preliminar do zooplâncton.

\begin{tabular}{lccc}
\hline \hline & Zooplâncton & Microcrustacea & Rotifera \\
\hline \hline $\mathrm{N}$ & 209550 & 20550 & 189000 \\
$\mathrm{~S}$ & 23 & 7 & 15 \\
$\mathrm{H}^{\prime}$ & 3,17 & 1,84 & 2,78 \\
$\mathrm{U}^{\prime}$ & 0,70 & 0,61 & 0,71 \\
$\mathrm{D}^{\prime}$ & 0,16 & 0,35 & 0,19 \\
\hline \hline
\end{tabular}

A composição e densidade do zooplâncton foi avaliada somente após 7 dias depois da contaminação dos microcosmos, considerando a impossibilidade de 
amostragem freqüentes devido ao volume $(80 \mathrm{~L})$ dos microcosmos. Para tanto, a água de cada microcosmo foi filtrada totalmente, de forma individual, contemplando as réplicas do controle, $\mathrm{Cr}$ e $\mathrm{Cu}$. Os valores médios obtidos para cada tratamento estão apresentados na tabela 16, e os valores referentes a cada uma das réplicas estão apresentados em Apêndice.

Após os 7 dias do experimento, verificou-se a presença de 30 espécies, sendo 4 espécies de Copepoda, 5 de Cladocera e 21 de Rotifera, com variações na ocorrência e densidade em cada tratamento.

Nos controles a comunidade de microcrustáceos foi representada numericamente por Cladocera (71\%), seguidos de Copepoda Calanoida (19\%) e Cyclopoida (10\%). Nos microcosmos contaminados verificou-se que a comunidade demonstrou uma grande alteração em relação ao controle e ao início do experimento. Os Cladocera sofreram uma grande redução, proporcionalmente ao resto da comunidade, representando apenas $6 \%$ nos microcosmos com cromo e $1 \%$ nos microcosmos com cobre. Os Copepoda foram dominantes numericamente nos tanques contaminados com cobre e cromo, sendo que os Calanoida representaram $46 \%$ e $54 \%$ e os Cyclopoida $53 \%$ e $40 \%$, respectivamente.

Após uma semana de enclausuramento, as populações de Cladocera apresentaram uma redução no número total de espécies, não sendo observadas nos tanques controle, ao final do experimento, as espécies $B$. longirostris e $B$. hagmani. As três espécies encontradas no final do experimento nos microcosmos controle tiveram um aumento em sua densidade. Os Cladocera foram drasticamente reduzidos nos microcosmos contaminados, sendo observada somente $C$. silvestrii nos tanques contaminados ao final do experimentos, que apresentaram também menores densidades em relação ao controle. Entre os tratamentos, a maior redução na densidade de Cladocera ocorreu pela exposição ao $\mathrm{Cu}$. As densidades de Cladocera foram de $31185 \pm 24442$ ind. $\mathrm{m}^{-3}$, no controle, $65 \pm 66$ ind. $\mathrm{m}^{-3}$, no tratamento com Cu e $977 \pm 1275$ ind. $\mathrm{m}^{-3}$ no tratamento com $\mathrm{Cr}$, bem menores que a densidade determinada na amostra inicial, 10560 ind. $\mathrm{m}^{-3}$. 
Tabela 17: Densidades médias (ind. $\mathrm{m}^{-3}$ ) das espécies zooplanctônicas nos microcosmos controle e contaminados com $\mathrm{Cr}$ e Cu (\%: abundância relativa ao total de indivíduos. DP: desvio padrão).

\begin{tabular}{|c|c|c|c|c|c|c|c|c|c|}
\hline Copepoda & \multicolumn{2}{|c|}{ Controle } & $\%$ & \multicolumn{2}{|c|}{ Cromo } & $\%$ & \multicolumn{2}{|c|}{ Cobre } & $\%$ \\
\hline Argyrodiaptomus furcatus & 1423 & \pm 109 & 0,4 & 2097 & \pm 2153 & 0,4 & 1634 & & 1,9 \\
\hline Notodiaptomus iheringi & 7690 & \pm 1850 & 2,2 & 6787 & \pm 757 & 1,2 & 4182 & \pm 3656 & 4,9 \\
\hline Thermocyclops minutus & 1309 & \pm 541 & 0,4 & 6616 & \pm 5532 & 1,1 & 5029 & \pm 3571 & 5,8 \\
\hline Mesocyclops longisetus & 3628 & \pm 1972 & 1,0 & & & 0,0 & 777 & \pm 135 & 0,9 \\
\hline Total Copepoda & 13139 & \pm 2619 & 3,8 & 15500 & \pm 2653 & 2,7 & 10273 & \pm 4014 & 11,9 \\
\hline \multicolumn{10}{|l|}{ Cladocera } \\
\hline $\begin{array}{l}\text { Ceriodaphnia silvestrii } \\
\text { Bosmina longirostris } \\
\text { Bosmina hagmani }\end{array}$ & 30991 & \pm 24180 & 8,9 & 977 & \pm 1275 & 0,2 & 65 & \pm 66 & 0,1 \\
\hline Diaphanosoma birgei & 222 & \pm 216 & 0,1 & & & & & & \\
\hline Daphnia gessneri & 139 & & 0,0 & & & & & & \\
\hline Total Cladocera & 31185 & \pm 24442 & 9,0 & $\overline{9977}$ & \pm 1275 & 0,2 & 65 & \pm \pm 66 & 0,1 \\
\hline \multicolumn{10}{|l|}{ Rotifera } \\
\hline Ptygura libera & 83796 & \pm 17764 & 24,1 & 271296 & \pm 18754 & 46,4 & 6944 & \pm 4312 & 8,1 \\
\hline Lepadela quadricarinata & 2778 & & 0,8 & & & & & & \\
\hline Conochilus unicornis & 694 & & 0,2 & 4167 & \pm 3674 & 0,7 & 278 & \pm 0 & 0,3 \\
\hline Collotheca longicauda & 45370 & \pm 12506 & 13,1 & 33796 & \pm 18443 & 5,8 & 1389 & \pm 786 & 1,6 \\
\hline Collotheca sp & 111343 & \pm 33537 & 32,1 & 9259 & \pm 10237 & 1,6 & 1389 & \pm 786 & 1,6 \\
\hline Keratella cochlearis & 26852 & \pm 20238 & 7,7 & 25000 & \pm 5008 & 4,3 & 17130 & \pm 8481 & 19,9 \\
\hline Keratella americana & & & & 3473 & \pm 982 & 0,6 & 833 & \pm 735 & 1,0 \\
\hline Kellicotia bostoniensis & & & & & & 0,0 & 1018 & \pm 579 & 1,2 \\
\hline Filinia pejleri & 5208 & \pm 4419 & 1,5 & 23611 & \pm 7217 & 4,0 & 30555 & \pm 12143 & 35,5 \\
\hline Trichocerca pusilla & 5787 & \pm 2439 & 1,7 & 2778 & & 0,5 & 1945 & \pm 392 & 2,3 \\
\hline Trichocerca similis & 2546 & \pm 1446 & 0,7 & 1852 & \pm 802 & 0,3 & 926 & \pm 578 & 1,1 \\
\hline Trichocerca chattonni & 5324 & \pm 1748 & 1,5 & 2315 & \pm 802 & 0,4 & 3704 & \pm 2837 & 4,3 \\
\hline Trichocerca myersi & & & & & & & 278 & & 0,3 \\
\hline Trichocerca bicristata & 1389 & \pm 0 & 0,4 & & & & & & \\
\hline Lecane stichaeta & 694 & & 0,2 & & & & 278 & & 0,3 \\
\hline Lecane bulla & & & & 2778 & \pm 1389 & 0,5 & 2500 & \pm 1547 & 2,9 \\
\hline Lecane lunaris & 1042 & \pm 491 & 0,3 & & & & 1387 & & 1,6 \\
\hline Lecani luna & & & & 1389 & & 0,2 & & & \\
\hline Mytilina bicristata & 1389 & & 0,4 & & & & 5000 & \pm 6285 & 5,8 \\
\hline Cephalodella sp. & 2083 & & 0,6 & 2084 & \pm 982 & 0,4 & 1389 & & 1,6 \\
\hline Anuraeopsis navicula & & & & & & & 1667 & \pm 1572 & 1,9 \\
\hline Total Rotifera & 303008 & \pm 81627 & 87,2 & 568057 & \pm 81377 & 97,2 & 75832 & \pm 27170 & 88,0 \\
\hline Total & 347333 & \pm 93312 & 100,0 & 584534 & \pm 84523 & 100,0 & 86170 & \pm 31188 & $\overline{100,0}$ \\
\hline
\end{tabular}

Após uma semana de exposição, as densidades de Copepoda nos microcosmos foram de $13139 \pm 2619$ ind $\mathrm{m}^{-3}$, para o controle, $10273 \pm 4014$ ind. $\mathrm{m}^{-3}$ para o tratamento com Cu e $15500 \pm 2653$ ind. $\mathrm{m}^{-3}$ para o tratamento com $\mathrm{Cr}$, enquanto na amostra analisada previamente ao experimento foi de 9990 ind. $\mathrm{m}^{-3}$. Os Calanoida apresentaram apenas duas espécies ao longo do experimento: Notodiaptomus iheringi e Argyrodiaptomus furcatus, sendo que no início do experimento, em todos os tratamentos, a maior contribuição foi de $A$. furcatus e no final $N$. iheringi apresentou 
maior abundância, indicando diferenças na dominância de espécies após o enclausuramento, que provocou alterações na densidade e composição da população em relação ao início) e contaminação. A densidade final de Cyclopoida foi superior a densidade observada no início do experimento, tendo sido observadas alterações nas relações de abundância entre as espécies no controle. Na amostra preliminar observou-se o predomínio de Thermocyclops minutos sobre Mesocyclops longisetus, e esta condição foi mantida nos tratamentos com $\mathrm{Cu}$ e $\mathrm{Cr}$, mas não no controle.

As densidades de Rotifera sofreram um aumento no controle (288657 \pm 79545 ind. $\left.\mathrm{m}^{-3}\right)$ e no tratamento com $\mathrm{Cr}\left(379630 \pm 43797\right.$ ind. $\left.\mathrm{m}^{-3}\right)$ em relação à densidade inicial $\left(173000\right.$ ind. $\left.\mathrm{m}^{-3}\right)$, enquanto no tratamento com Cu essa densidade foi reduzida a $42 \%\left(72036 \pm 2161\right.$ ind. $\left.\mathrm{m}^{-3}\right)$. No entanto, o tratamento com Cu apresentou o mesmo número de espécies que a amostra inicial, enquanto o controle e o tratamento com $\mathrm{Cr}$ apresentaram um número inferior de espécies em relação à essa amostra. As espécies Ptygura libera, Keratella cochlearis, Trichocerca similis, Trichocerca chattoni, Conochillus unicornis, Collotheca longicauda, Colotheca sp., Filinia pejleri e Trichocerca pusilla estiveram presentes em todos os tratamentos ao longo do experimento.

Os índices ecológicos foram calculados para cada uma das réplicas de cada tratamento. Estes índices foram calculados para a comunidade zooplanctônica total e independentemente para os microcrustáceos e Rotifera, e estão apresentados nas tabelas 18,19 e 20.

Ao final do experimento, verificaram-se em todos os tanques que os valores de riqueza e diversidade foram inferiores aos encontrados para a comunidade zooplanctônica total antes do início do experimento. As menores diversidades foram observadas nos microcosmos com $\mathrm{Cr}$ e as maiores nos microcosmos com $\mathrm{Cu}$, sendo estas últimas semelhantes às observadas para o controle. De acordo com a análise de variância (ANOVA), ocorreram diferenças significativas entre os índices calculados para o controle e para o tratamento com Cr para os seguintes índices: Shannon H'log base $2(p=0,000)$, uniformidade de Pielou $(p=0,001)$ e dominância de Simpson $(p=$ 0,001 ). Todas as diferenças foram muito significativas, com valores de $p$ menores de 0,001 . Apenas o índice Shannon H'log base 2 e a densidade de organismos apresentaram diferenças significativas entre o tratamento com $\mathrm{Cu}$ e o controle, com valores de $p$ iguais a 0,028 e 0,01, respectivamente. Com base nesta análise, pode-se concluir que os efeitos do $\mathrm{Cr}$ sobre a comunidade zooplanctônica total foram muito mais expressivos que os efeitos do $\mathrm{Cu}$, pois além do maior número de índices afetados pelo $\mathrm{Cr}$, os resultados das análises individuais foram mais significativos. 
Com relação somente aos microcrustáceos, os maiores valores de riqueza e diversidade foram observados na análise inicial da comunidade. Os microcosmos controle apresentaram os maiores valores de riqueza e os microcosmos com $\mathrm{Cr}$ apresentaram os menores valores para dominância. Não foram observadas diferenças significativas entre os valores obtidos para nenhum dos índices para os microcrustáceos zooplanctônicos nos microcosmos controle e nos contaminados com Cr e Cu pela análise de variância (ANOVA, $p<0,05$ ).

Para os Rotifera, os maiores valores de diversidade foram obtidos no início dos experimentos. Após o início do experimento, os índices de Shannon H' foram próximos nos controles e nos microcosmos contaminados com $\mathrm{Cu}$, e foram menores nos tanques contaminados com $\mathrm{Cr}$. No entanto, os valores de dominância para os tanques com $\mathrm{Cr}$ foram superiores aos outros tratamentos e ao início do experimento. Os resultados da comparação dos índices obtidos para o controle com os índices obtidos nos tratamentos com $\mathrm{Cr}$ e $\mathrm{Cu}$ através da análise de variância foram semelhantes aos obtidos para a comunidade zooplanctônica total. O tratamento com $\mathrm{Cr}$ apresentou diferenças significativas em relação ao controle para os seguintes índices: Shannon H'log base $2(p=0,003)$, uniformidade de Pielou $(p=0,001)$ e dominância de Simpson $(p=0,004)$. Da mesma forma que considerando a comunidade zooplanctônica total, comparando-se os índices do tratamento com $\mathrm{Cu}$ com os índices do controle, as diferenças foram significativas apenas para o índice Shannon H'log base $2(p=0,055)$ e para a densidade total $(p=0,01)$.

O resultado resumido da análise de variância entre os índices obtidos para o controle e cada um dos tratamentos estão apresentados em apêndice.

Tabela 18: Densidade $(\mathrm{N})$, riqueza $(\mathrm{S})$, diversidade $\left(\mathrm{H}^{\prime}\right)$, uniformidade $\left(\mathrm{U}^{\prime}\right)$ e dominância (D') para o zooplâncton total nos microcosmos controle e contaminados com $\mathrm{Cr}$ e $\mathrm{Cu}$.

\begin{tabular}{cccccccccc}
\hline \hline & $\mathrm{C} 1$ & $\mathrm{C} 2$ & $\mathrm{C} 3$ & $\mathrm{Cr} 1$ & $\mathrm{Cr} 2$ & $\mathrm{Cr} 3$ & $\mathrm{Cu} 1$ & $\mathrm{Cu} 2$ & $\mathrm{Cu3}$ \\
\hline \hline $\mathrm{N}$ & 233416 & 356221 & 409306 & 344805 & 436904 & 406612 & 83733 & 111861 & 51527 \\
$\mathrm{~S}$ & 14,0 & 16,0 & 18,0 & 17,0 & 14,0 & 15,0 & 16,0 & 21,0 & 14,0 \\
$\mathrm{H}^{\prime}$ & 2,6 & 2,6 & 2,7 & 1,7 & 1,9 & 1,8 & 2,8 & 2,9 & 2,8 \\
$\mathrm{U}^{\prime}$ & 0,7 & 0,6 & 0,7 & 0,4 & 0,5 & 0,5 & 0,7 & 0,7 & 0,7 \\
$\mathrm{D}$ & 0,2 & 0,2 & 0,2 & 0,5 & 0,5 & 0,5 & 0,2 & 0,2 & 0,2 \\
\hline \hline
\end{tabular}


Tabela 19: Densidade $(\mathrm{N})$, riqueza $(\mathrm{S})$, diversidade $\left(\mathrm{H}^{\prime}\right)$, uniformidade $\left(\mathrm{U}^{\prime}\right)$ e dominância (D') para microcrustáceos nos microcosmos controle e contaminados com $\mathrm{Cr}$ e $\mathrm{Cu}$.

\begin{tabular}{cccccccccc}
\hline \hline & $\mathrm{C} 1$ & $\mathrm{C} 2$ & $\mathrm{C} 3$ & $\mathrm{Cr} 1$ & $\mathrm{Cr} 2$ & $\mathrm{Cr} 3$ & $\mathrm{Cu} 1$ & $\mathrm{Cu} 2$ & $\mathrm{Cu} 3$ \\
\hline \hline $\mathrm{N}$ & 23000 & 70111 & 39861 & 12861 & 18847 & 17722 & 9847 & 14639 & 6527,8 \\
$\mathrm{~S}$ & 3 & 6 & 5 & 3 & 3 & 3 & 3 & 4 & 4 \\
$\mathrm{H}^{\prime}$ & 1,6 & 1,1 & 1,3 & 1,2 & 1,6 & 1,2 & 0,7 & 1,6 & 1,1 \\
$\mathrm{U}^{\prime}$ & 1,0 & 0,4 & 0,5 & 0,6 & 0,8 & 0,6 & 0,4 & 0,7 & 0,6 \\
$\mathrm{D}$ & 0,3 & 0,6 & 0,6 & 0,5 & 0,4 & 0,5 & 0,7 & 0,4 & 0,6 \\
\hline \hline
\end{tabular}

Tabela 20: Densidade $(N)$, riqueza $(S)$, diversidade $\left(H^{\prime}\right)$, uniformidade $\left(U^{\prime}\right)$ e dominância (D') para Rotifera nos microcosmos controle e contaminados com $\mathrm{Cr}$ e $\mathrm{Cu}$.

\begin{tabular}{cccccccccc}
\hline \hline & $\mathrm{C} 1$ & $\mathrm{C} 2$ & $\mathrm{C} 3$ & $\mathrm{Cr} 1$ & $\mathrm{Cr} 2$ & $\mathrm{Cr} 3$ & $\mathrm{Cu} 1$ & Cu2 & Cu3 \\
\hline \hline $\mathrm{N}$ & 210416 & 286110 & 369445 & 73886 & 97223 & 45000 & 331944 & 418057 & 388890 \\
$\mathrm{~S}$ & 11 & 9 & 12 & 13 & 16 & 10 & 13 & 10 & 11 \\
$\mathrm{H}^{\prime}$ & 2,2 & 2,0 & 2,4 & 2,5 & 2,5 & 2,4 & 1,5 & 1,6 & 1,6 \\
$\mathrm{U}^{\prime}$ & 0,6 & 0,6 & 0,7 & 0,7 & 0,6 & 0,7 & 0,4 & 0,5 & 0,5 \\
$\mathrm{D}$ & 0,3 & 0,3 & 0,2 & 0,3 & 0,3 & 0,2 & 0,6 & 0,5 & 0,5 \\
\hline \hline
\end{tabular}

Os índices calculados utilizando-se a comunidade total de zooplâncton e os calculados utilizando-se somente os rotíferos foram os melhores descritores dos efeitos do $\mathrm{Cr}$ e $\mathrm{Cu}$ sobre o zooplâncton. Entre os índices, o índice de diversidade de Shannon (log base 2) mostrou-se o mais sensível, sendo o único dos índices calculados a reportar os efeitos do Cu sobre a comunidade planctônica, em relação ao controle. Apesar do $\mathrm{Cr}$ apresentar maiores efeitos sobre a estrutura da comunidade que o $\mathrm{Cu}$, em relação à densidade de indivíduos é observado o inverso, sendo a densidade inibida nos microcosmos com $\mathrm{Cu}$, o que não foi observado no tratamento com $\mathrm{Cr}$, sempre em comparação com o controle.

A comunidade zooplanctônica dos microcosmos apresentou uma dominância de Rotifera, em densidade, em relação à Cladocera e Copepoda, tanto na amostra avaliada preliminarmente quanto no final do experimento. Tal observação já foi reportada para a represa do Lobo (MATSUMURA-TUNDISI, 1976; MATSUMURA et al., 1989; OLIVEIRA-NETO, 1993) assim como para outros reservatóiros do estado de São Paulo (SENDACZ, 1985).

Após uma semana de enclausuramento, o controle apresentou diminuição na proporção de rotíferos e, menos expressivamente, de Copepoda, enquanto a proporção de Cladocera aumentou. Nos tanques contaminados, a redução de Cladocera foi mais significativa, principalmente no experimento com $\mathrm{Cu}$, onde ocorreu o aumento na população de Copepoda. Nos tanques contaminados com $\mathrm{Cr}$ a população de Copepoda foi reduzida, apresentando uma maior contribuição de Rotifera. 
Os Cladocera apresentaram maior sensibilidade ao $\mathrm{Cu}$ que ao $\mathrm{Cr}$, como pode ser observado a partir das densidades apresentadas para cada tratamento, sendo também o mais sensível aos dois metais em comparação a Copepoda e Rotifera. Aparentemente Copepoda é mais sensível ao $\mathrm{Cr}$ que ao $\mathrm{Cu}$.

Pela observação dos índices ecológicos determinados para a comunidade total de zooplâncton, pode-se dizer que a comunidade zooplanctônica apresentou dominância por poucas espécies no experimento com $\mathrm{Cr}$. De modo geral, os índices foram afetados de forma mais contundente pela adição de $\mathrm{Cr}$ que pela adição de $\mathrm{Cu}$, apresentando, neste caso, diferenças significativas em relação aos índices obtidos para o controle, apesar da redução na densidade observada nos experimentos com $\mathrm{Cu}$.

Os índices calculados considerando-se a comunidade total do zooplâncton e apenas os rotíferos foram mais sensíveis para descrever os efeitos da contaminação pelos metais estudados do que os índices calculados considerando-se apenas a comunidade de microcrustáceos.

\subsection{3- Avaliação da metodologia empregada nos experimentos em microcosmos}

Uma característica inerente aos experimentos em enclosures é a alteração da dinâmica dos processos físicos, químicos e biológicos em função da limitação espacial e da limitação das trocas com os outros compartimentos do sistema. Comparando-se com o ecossistema natural que se tenta reproduzir, os experimentos em microcosmos também sofrem restrição dos efeitos de determinadas características climáticas e hidrodinâmicas.

Os experimentos em micro e mesocosmos obedecem a duas escalas: temporal e espacial. Quanto maior o sistema em espaço, maior a semelhança com o sistema natural, porém quanto maior o tempo de experimento, maiores são as diferenças entre as características experimentais e naturais (KEMP et al., 2001). Com o aumento da escala espacial a variabilidade entre as réplicas dos experimentos também tende a aumentar (CAIRNS, 1995).

A metodologia utilizada neste experimento apresentou-se adequada para os objetivos propostos. Como ambas as escalas, de tempo e espaço, foram pequenas, a reprodutibilidade entre as réplicas foi grande, e apesar da redução na diversidade e densidade dos organismos fito e zooplanctônicos em relação à comunidade natural da represa, as classes presentes nos microcosmos foram representativas do ecossistema. 
Em relação aos parâmetros químicos e físico-químicos analisados $(\mathrm{pH}$, material em suspensão total, orgânico e inorgânico, clorofila, nitrato, nitrito, amônio, nitrogênio total, ortofosfato dissolvido, fósforo total dissolvido, fósforo total, silicato, cromo e cobre) não foram observadas diferenças significativas estatisticamente entre os conjuntos de réplicas em nenhum dos casos (ANOVA, $p<0,05$; resultado resumido em anexo), apesar dos grandes desvios padrão observados em algumas determinações. Assim, pode-se assumir que em se tratando de um experimento em campo, com diversas variáveis não controladas, a reprodutibilidade do experimento foi muito alta.

Em relação à comunidade de fitoplâncton, apesar da redução na diversidade e densidade das espécies, todas as classes mais freqüentes na represa foram representadas ao longo do experimento (Chlorophyceae, Bacillariophyceae, Cyanophyceae, Criptophyceae, Chrysophyceae, Dynophyceae e Euglenophyceae). O mesmo pode ser dito em relação à comunidade de zooplâncton, não tendo sido observada uma grande redução no número de táxons determinados no experimento em relação à comunidade identificada na represa, apesar da redução na densidade de organismos. No caso da avaliação biológica, não foi possível a comparação entre as réplicas por análise estatística uma vez que para o fitoplâncton foi avaliada apenas uma das réplicas de cada tratamento e para o zooplâncton foi obtida apenas uma amostra final.

O tempo de experimento foi suficiente para que as concentrações de cobre fossem restauradas às iniciais, mas não para a eliminação do $\mathrm{Cr}$ na fase dissolvida. Assim, a utilização de um período mais longo de acompanhamento é indicada, possibilitando a avaliação da capacidade de restabelecimento do sistema após a contaminação pontual.

A metodologia utilizada foi considerada como uma ferramenta plenamente adequada, não se verificando variabilidade significativa entre as réplicas para as variáveis limnológicas, e com grande representatividade das comunidades naturais, além de possibilitar a observação de efeitos ecológicos relevantes em uma escala de espaço e tempo relativamente pequena e facilmente reprodutível. 


\section{2- Análise dos efeitos de $\mathrm{Cr}$ e $\mathrm{Cu}$ em ecossistemas aquáticos através} de estudos em mesocosmos: aspectos funcionais e estruturais

\subsection{1- Variáveis físico-químicas, químicas e biológicas (clorofila) da água}

\subsubsection{1- Cromo e Cobre}

As concentrações de cobre determinadas na água superficial de cada unidade experimental, em cada uma das coletas, estão apresentadas em Apêndice. As médias das concentrações determinadas estão apresentadas na Figura 34.

Antes da adição da solução de $\mathrm{Cu}$, as concentrações determinadas nos tanques controle foram maiores que as determinadas nos tanques que seriam contaminados. A concentração de $\mathrm{Cu}$ desejada nos tanques $\left(0,02 \mathrm{mg} \cdot \mathrm{L}^{-1} \mathrm{Cu}\right)$ foi recuperada 4 horas após a contaminação. A concentração inicial de $\mathrm{Cu}$ nos tanques contaminados foi restaurada a partir de 09/04, oito dias após a contaminação, apesar das concentrações de $\mathrm{Cu}$ voltarem a crescer ao final do experimento.

As concentrações de $\mathrm{Cr}$ determinadas na água superficial de cada unidade experimental, em cada uma das coletas, estão apresentadas em Apêndice. Cromo não foi detectado em nenhuma das amostras controle. As médias das concentrações determinadas nos tanques contaminados estão apresentadas na Figura 35.
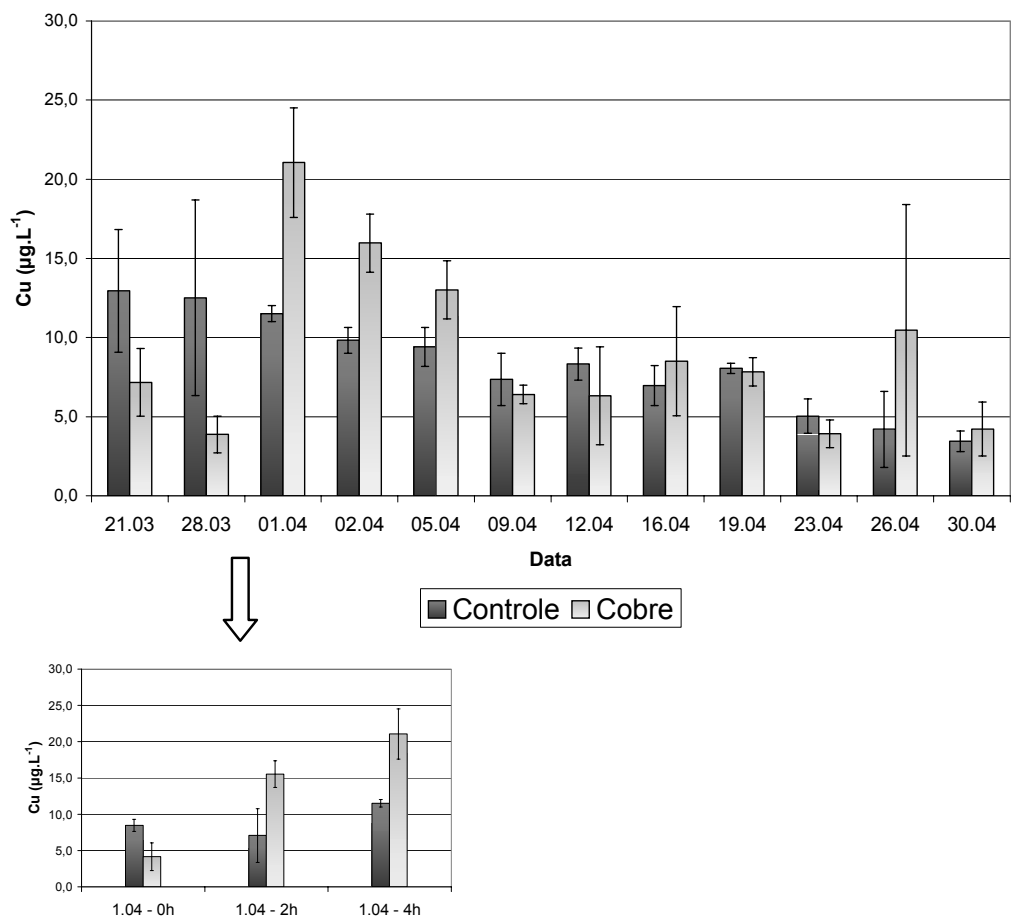

Figura 34: Concentrações médias de $\mathrm{Cu}\left(\mu \mathrm{g} \cdot \mathrm{L}^{-1}\right)$ determinadas nas amostras de água no controle e nos mesocosmos contaminados com Cu durante o período de estudo (as barras de erros referem-se ao desvio padrão da média entre as réplicas dos mesocosmos). 

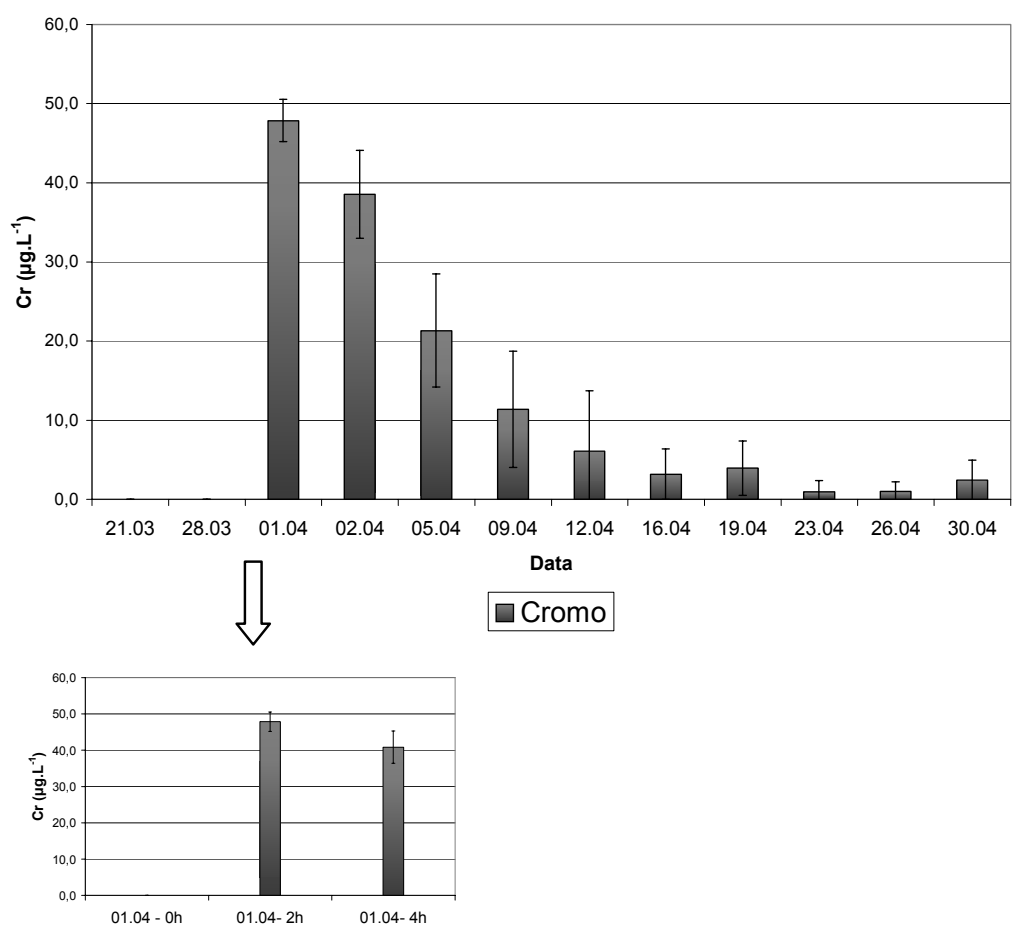

Figura 35: Concentrações médias de $\mathrm{Cr}\left(\mu \mathrm{g} \cdot \mathrm{L}^{-1}\right)$ determinadas nas amostras de água nos mesocosmos contaminados com Cr durante o período de estudo (as barras de erros referem-se ao desvio padrão da média entre as réplicas dos mesocosmos).

A concentração adicionada de $\mathrm{Cr}\left(50 \mu \mathrm{g} \cdot \mathrm{L}^{-1}\right)$ foi recuperada na coleta realizada 2 horas após a contaminação dos mesocosmos. Após a contaminação as concentrações de $\mathrm{Cr}$ decresceram até o final do experimento, porém a concentração inicial, que ficou abaixo do limite de detecção do método $\left(0,7 \mu \mathrm{g} \cdot \mathrm{L}^{-1}\right)$, não foi restaurada até o final do experimento.

\subsubsection{2- Oxigênio dissolvido, condutividade, $\mathrm{pH}$ e temperatura da água}

Os valores das variáveis oxigênio dissolvido, condutividade, $\mathrm{pH}$ e temperatura, determinados em cada unidade experimental, em cada uma das coletas realizadas, estão apresentadas em apêndice. Os valores médios obtidos estão apresentados nas figuras $36,37,38$ e 39 .

As concentrações de oxigênio dissolvido determinadas no experimento com $\mathrm{Cu}$ foram semelhantes às do controle. No experimento com $\mathrm{Cr}$ observou-se um decréscimo nas concentrações de oxigênio dissolvido $\left(5,8 \mathrm{mg} \cdot \mathrm{L}^{-1}\right.$ inicialmente, atingindo 2,9 mg. $\mathrm{L}^{-1}$ em 12 de abril) após a contaminação dos tanques, sendo que essas concentrações permanecem baixas até o fim do experimento. Todas as 
determinações de oxigênio dissolvido apresentaram desvios padrão baixos para as réplicas.
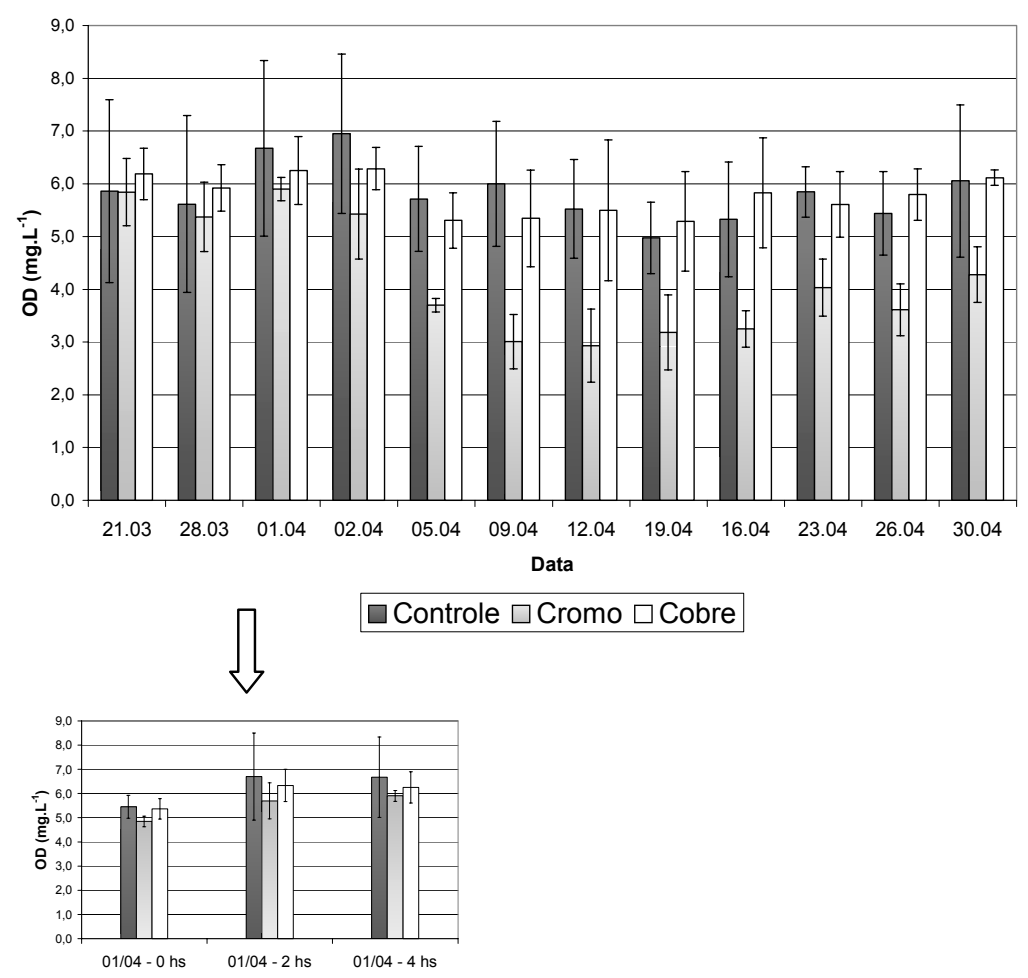

Figura 36: Concentrações médias de oxigênio dissolvido $\left(\mathrm{mg}^{-\mathrm{L}^{-1}}\right)$ determinadas nas amostras de água no controle e nos mesocosmos contaminados com $\mathrm{Cr}$ e $\mathrm{Cu}$ durante o período de estudo (as barras de erros referem-se ao desvio padrão da média entre as réplicas dos mesocosmos).

Após a contaminação dos tanques, observou-se o aumento da condutividade (Figura 37) da água do experimento com $\mathrm{Cr}$ (de 8,3 $\mu \mathrm{S} . \mathrm{cm}^{-1}$ em 28 de março para 12,7 $\mu \mathrm{S} . \mathrm{cm}^{-1} ; 2$ horas após a contaminação), que manteve-se mais alta que a condutividade apresentada pelo controle (entre 7,7 e $12 \mu \mathrm{S} . \mathrm{cm}^{-1}$ ) durante todo o tempo do experimento. A condutividade da água dos tanques contaminados com Cu foi (entre 7,7 e $10 \mu \mathrm{S} . \mathrm{cm}^{-1}$ ) menor que a apresentada pelo controle. As réplicas do controle apresentaram os maiores desvios padrão entre os grupos, com valores de até $28 \%$.

Os valores de $\mathrm{pH}$ determinados no controle e nos mesocosmos com $\mathrm{Cr}$ e $\mathrm{Cu}$ apresentaram variação similar, com valores entre 5,0 e 7,0, independente do tratamento, sem alterações significativas após a contaminação dos tanques. 

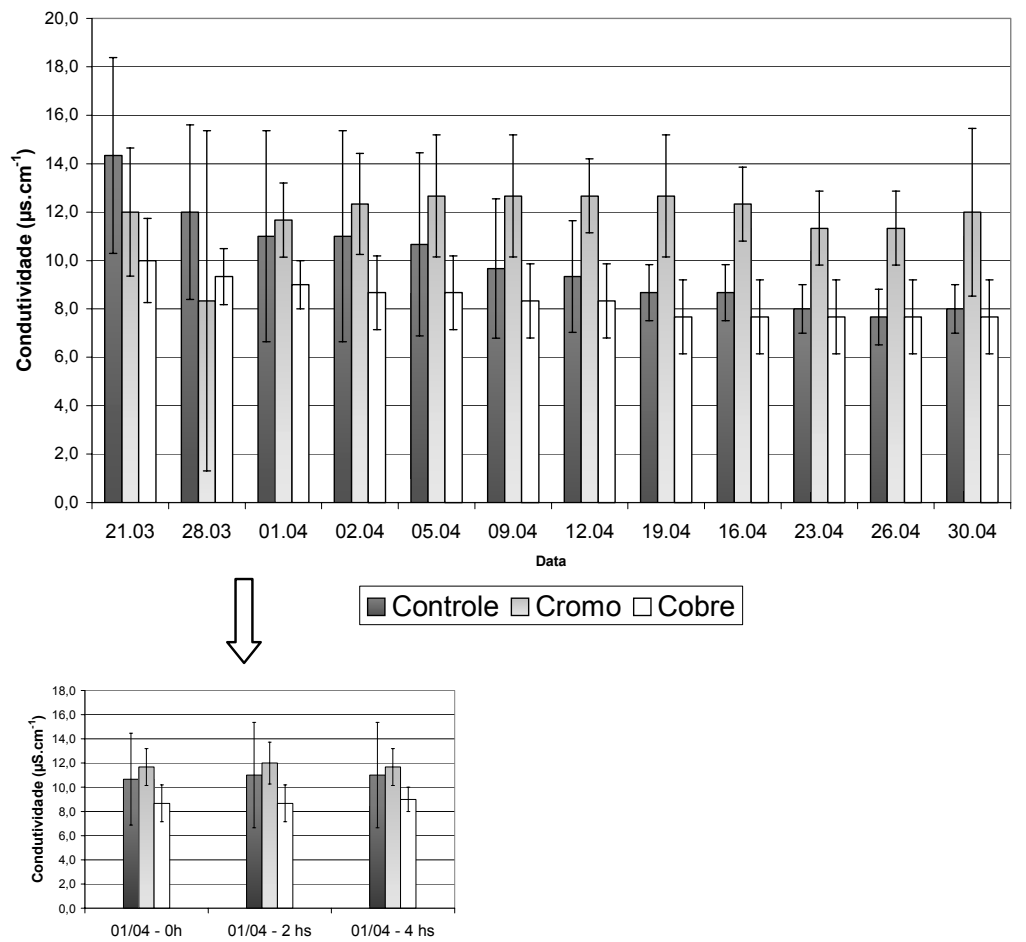

Figura 37: Condutividade média $\left(\mu \mathrm{S} . \mathrm{cm}^{-1}\right)$ determinadas nas amostras de água no controle e nos mesocosmos contaminados com $\mathrm{Cr}$ e $\mathrm{Cu}$ durante o período de estudo(as barras de erros referem-se ao desvio padrão da média entre as réplicas dos mesocosmos).
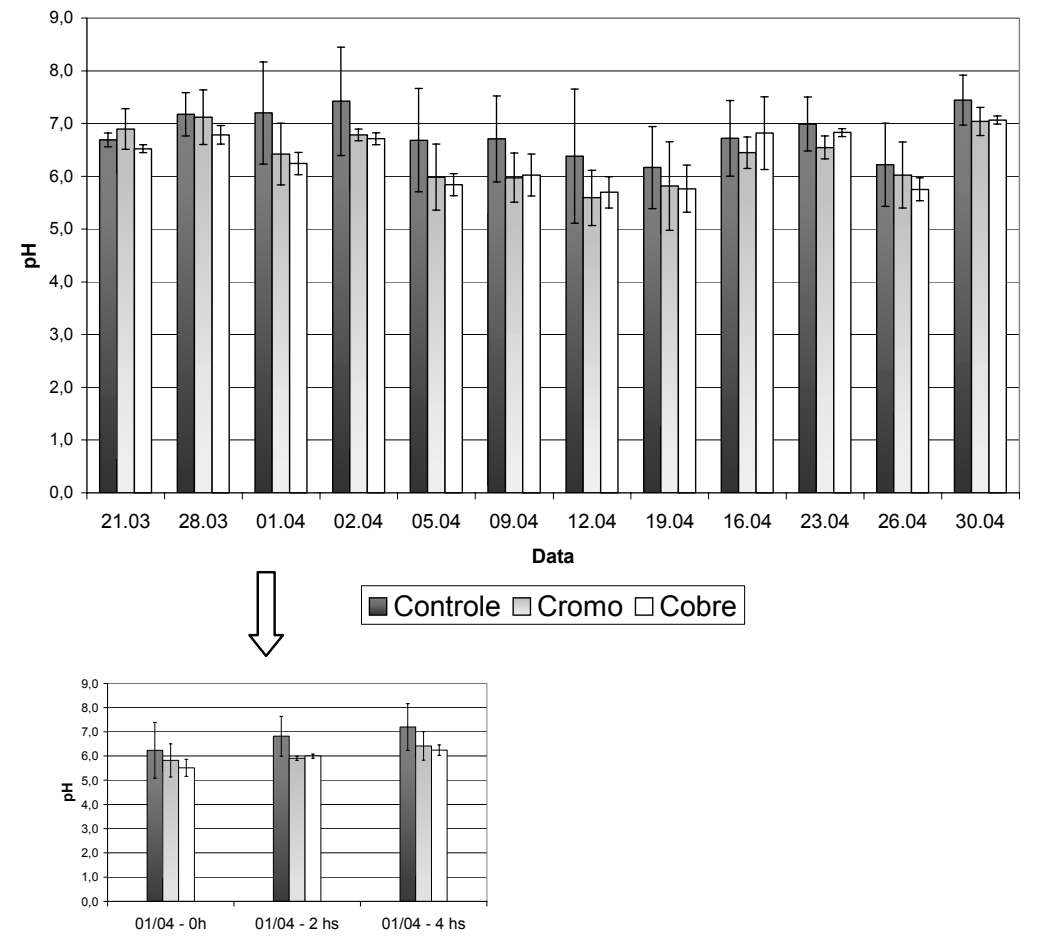

Figura 38: Valores médios de $\mathrm{pH}$ determinados nas amostras de água no controle e nos mesocosmos contaminados com $\mathrm{Cr}$ e Cu durante o período de estudo (as barras de erros referem-se ao desvio padrão da média entre as réplicas dos mesocosmos). 
A temperatura da água dos experimentos com $\mathrm{Cr}$ e $\mathrm{Cu}$ também foi similar ao controle, com valores entre 24 e $28^{\circ} \mathrm{C}$, não sendo observadas diferenças entre os tratamentos.

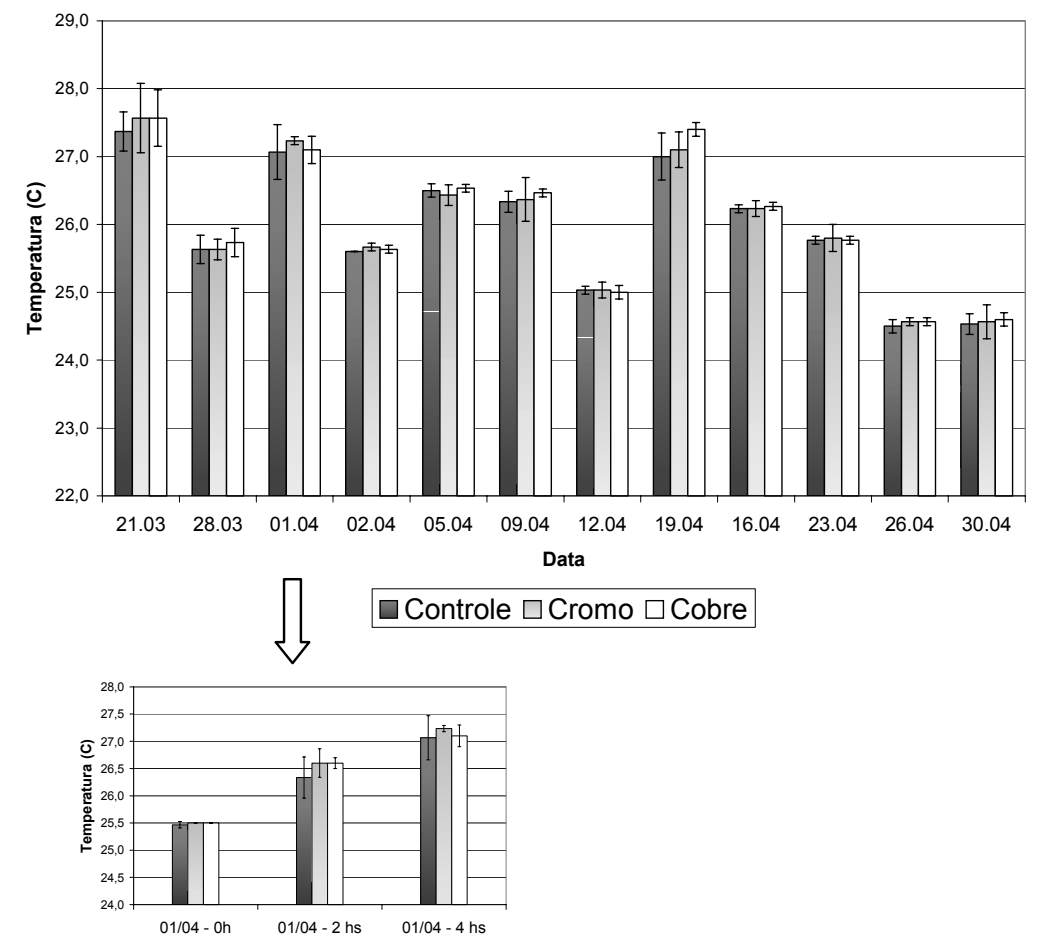

Figura 39: Valores médios de temperatura $\left({ }^{\circ} \mathrm{C}\right)$ determinados nas amostras de água no controle e nos mesocosmos contaminados com $\mathrm{Cr}$ e $\mathrm{Cu}$ durante o período de estudo (as barras de erros referem-se ao desvio padrão da média entre as réplicas dos mesocosmos).

\subsubsection{3- Clorofila}

As concentrações de clorofila determinadas em cada unidade experimental durante o período de estudo estão apresentadas em Apêndice. Os valores médios estão apresentados na Figura 40.

Imediatamente após a contaminação dos tanques, observou-se um acentuado decréscimo nas concentrações de clorofila, nos tratamentos com $\mathrm{Cu}$ e com Cr. Após 19 dias (09/04) foram determinadas concentrações de clorofila semelhantes ao início do experimento, antes da contaminação, para o tratamento com $\mathrm{Cu}$. Nos tanques contaminados com $\mathrm{Cr}$, a concentração de clorofila foi praticamente constante após 21 dias (12/04), não tendo sido restauradas aos valores originais até o final do experimento. Nos tanques contaminados com $\mathrm{Cr}$, as concentrações de clorofila foram de $0,9 \mu \mathrm{g} \cdot \mathrm{L}^{-1}$ no dia seguinte à contaminação, tendo apresentado um valor médio de $16,2 \mu \mathrm{g} \cdot \mathrm{L}^{-1}$ no início do experimento. No tratamento com $\mathrm{Cu}$ os valores estiveram abaixo de $10 \mu \mathrm{g} \cdot \mathrm{L}^{-1}$, exceto em 21 de março (antes da contaminação) até 09 de abril. 
A partir desta data as concentrações de clorofila no tratamento com $\mathrm{Cu}$ aumentaram, sendo da mesma ordem que as determinadas no controle ou maiores.

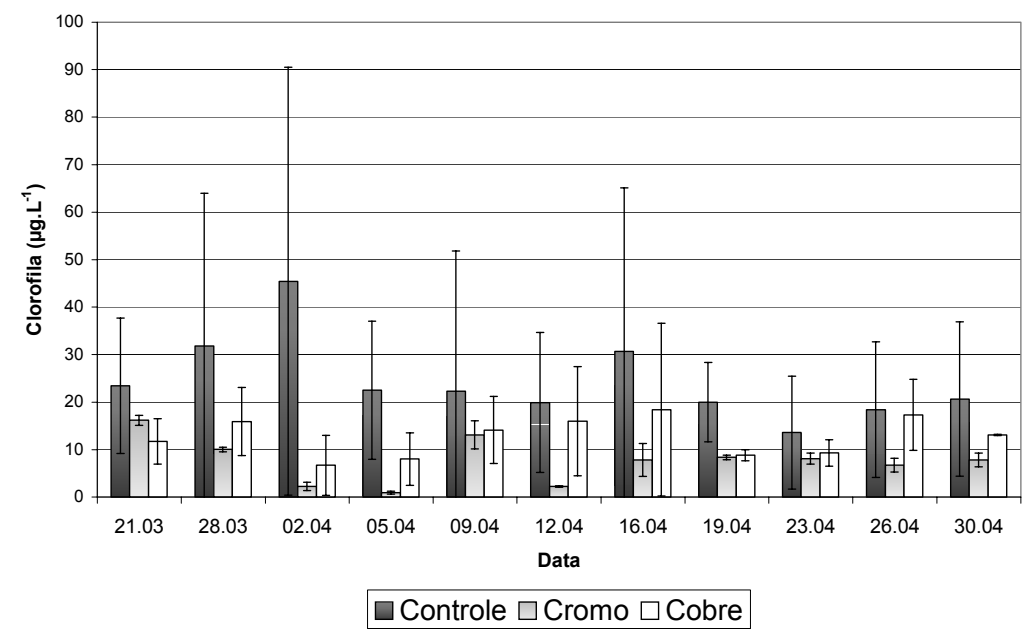

Figura 40: Concentrações $\left(\mu \mathrm{g} \cdot \mathrm{L}^{-1}\right)$ médias de clorofila determinadas nas amostras de água no controle e nos mesocosmos contaminados com $\mathrm{Cr}$ e $\mathrm{Cu}$ durante o período de estudo(as barras de erros referem-se ao desvio padrão da média entre as réplicas dos mesocosmos).

\subsubsection{4- Material em Suspensão}

As concentrações de material em suspensão total, orgânico e inorgânico determinadas em cada unidade experimental, durante o período de estudo estão apresentadas em Apêndice. As médias das concentrações determinadas estão apresentadas nas figuras 41, 42 e 43.

As menores concentrações de material total em suspensão foram determinadas no tratamento com $\mathrm{Cr}$. Nas primeiras coletas após a contaminação, as concentrações de material em suspensão total no tratamento com $\mathrm{Cu}$ também apresentaram um decréscimo, com posterior aumento no decorrer do experimento. $\mathrm{O}$ desvio padrão para as concentrações de material em suspensão total foi relativamente alto $(>30 \%)$ para a maioria das réplicas.

O experimento com $\mathrm{Cr}$ apresentou o maior decréscimo nas concentrações de material em suspensão orgânico após a contaminação (de 3,7 mg.. ${ }^{-1}$ em 21 de março até $0,3 \mathrm{mg} \cdot \mathrm{L}^{-1}$ em 26 de abril), sendo que essas concentrações permaneceram baixas (durante todo o experimento. Nos mesocosmos com $\mathrm{Cu}$ ocorreu um acréscimo nas concentrações de material em suspensão orgânico após a contaminação até 9 de abril (de 2,5 a $9 \mathrm{mg} \cdot \mathrm{L}^{-1}$ ), porém com o passar do tempo os valores obtidos foram similares ao controle.

As concentrações de material em suspensão inorgânico oscilaram muito durante o experimento, com valores entre 0 e $0,9 \mathrm{mg} \cdot \mathrm{L}^{-1}$ para o controle, entre 0 e 0,7 
mg. $\mathrm{L}^{-1}$ para o tratamento com $\mathrm{Cr}$ e entre 0 e 0,9 para o tratamento com $\mathrm{Cu}$, sendo que as concentrações determinadas no experimento com $\mathrm{Cr}$ foram menores que as determinadas no tratamento com $\mathrm{Cu}$ e no controle.

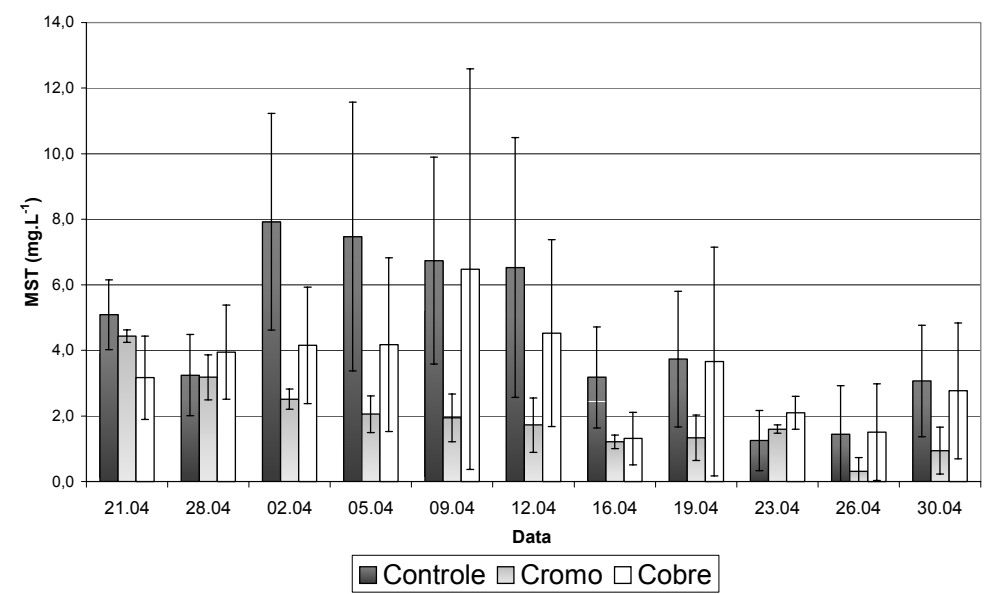

Figura 41: Concentrações médias $\left(\mathrm{mg}^{-\mathrm{L}^{-1}}\right)$ de material em suspensão total determinadas nas amostras de água no controle e nos mesocosmos contaminados com $\mathrm{Cr}$ e $\mathrm{Cu}$ durante o período de estudo (as barras de erros referem-se ao desvio padrão da média entre as réplicas dos mesocosmos).

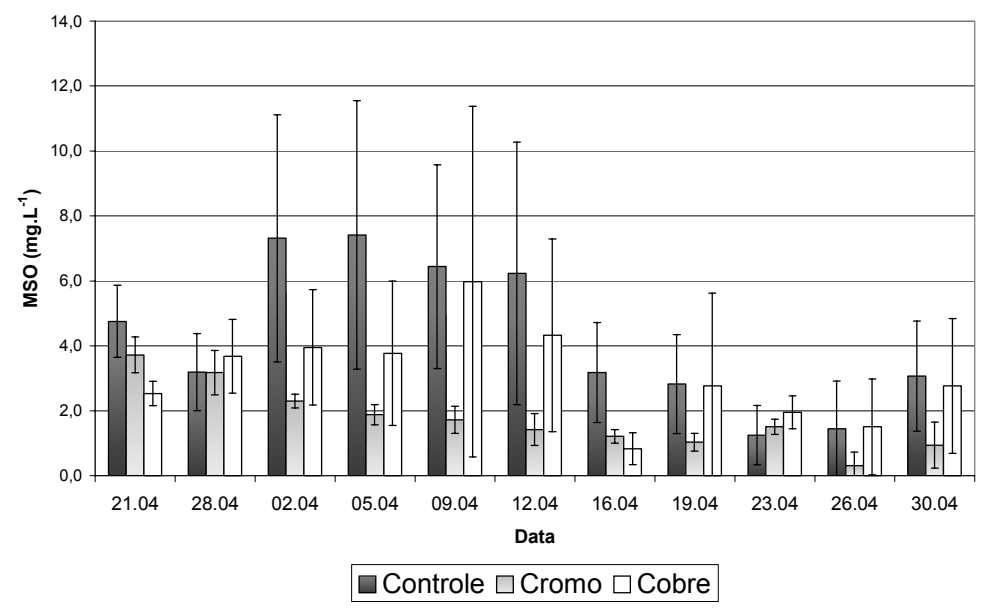

Figura 42: Concentrações médias $\left(\mathrm{mg}^{-\mathrm{L}^{-1}}\right)$ de material em suspensão orgânico determinadas nas amostras de água no controle e nos mesocosmos contaminados com $\mathrm{Cr}$ e $\mathrm{Cu}$ durante o período de estudo (as barras de erros referem-se ao desvio padrão da média entre as réplicas dos mesocosmos). 


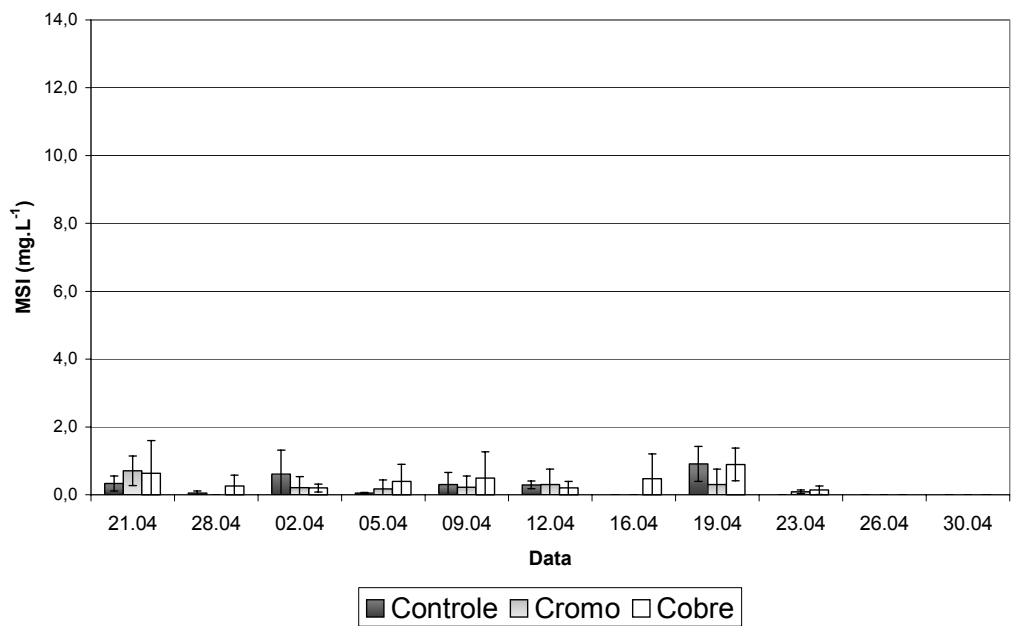

Figura 43: Concentrações médias $\left(m g \cdot \mathrm{L}^{-1}\right)$ de material em suspensão inorgânico determinadas nas amostras de água no controle e nos mesocosmos contaminados com $\mathrm{Cr}$ e $\mathrm{Cu}$ durante o período de estudo (as barras de erros referem-se ao desvio padrão da média entre as réplicas dos mesocosmos).

\subsubsection{5- Nutrientes nitrogenados, fosfatados e silicato}

As concentrações de silicato dissolvido determinadas em cada unidade experimental, durante o período de estudo estão apresentadas em Apêndice, sendo que as médias das concentrações estão apresentadas na Figura 44.

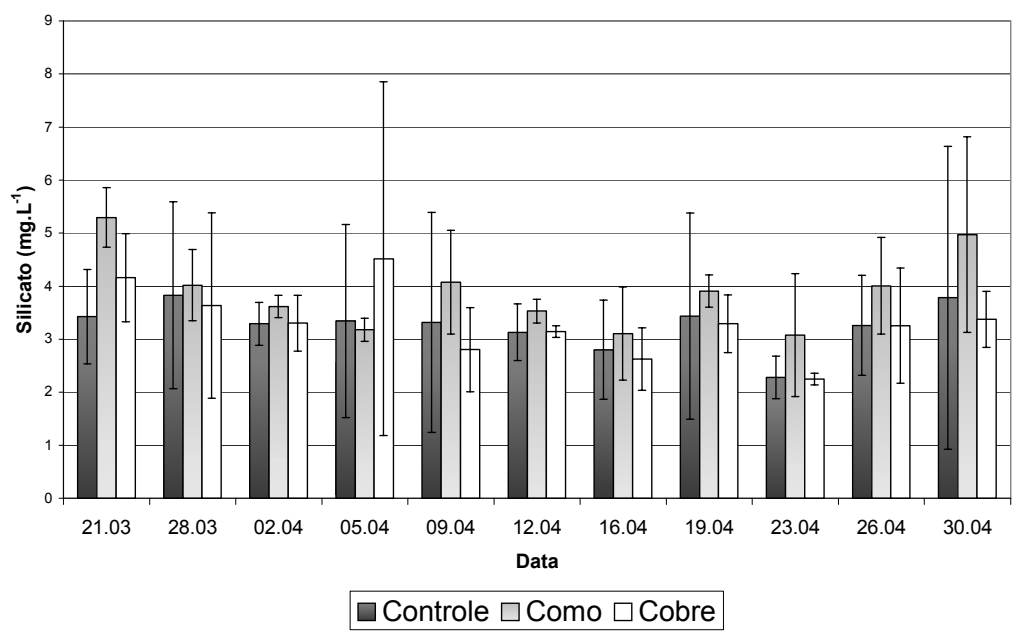

Figura 44: Concentrações médias $\left(\mathrm{mg}^{\mathrm{L}} \mathrm{L}^{-1}\right)$ de silicato dissolvido determinadas nas amostras de água no controle e nos mesocosmos contaminados com $\mathrm{Cr}$ e Cu durante o período de estudo (as barras de erros referem-se ao desvio padrão da média entre as réplicas dos mesocosmos).

Verifica-se que as concentrações de silicato não variaram muito entre os tratamentos com $\mathrm{Cr}\left(3,1\right.$ a $\left.5,3 \mathrm{mg} \cdot \mathrm{L}^{-1}\right)$ e $\mathrm{Cu}\left(2,2\right.$ a $\left.4,5 \mathrm{mg} \cdot \mathrm{L}^{-1}\right)$ e o controle $(2,3$ a 3,8 $\left.\mathrm{mg} \cdot \mathrm{L}^{-1}\right)$. Apenas o experimento com $\mathrm{Cu}$ apresentou um aumento nas concentrações de silicato após o dia 05/04. 
As concentrações de nitrato, nitrito, amônio e nitrogênio total determinadas em cada unidade experimental, constam do Apêndice, sendo que os valores médios estão apresentadas nas Figuras 45, 46, 47 e 48.

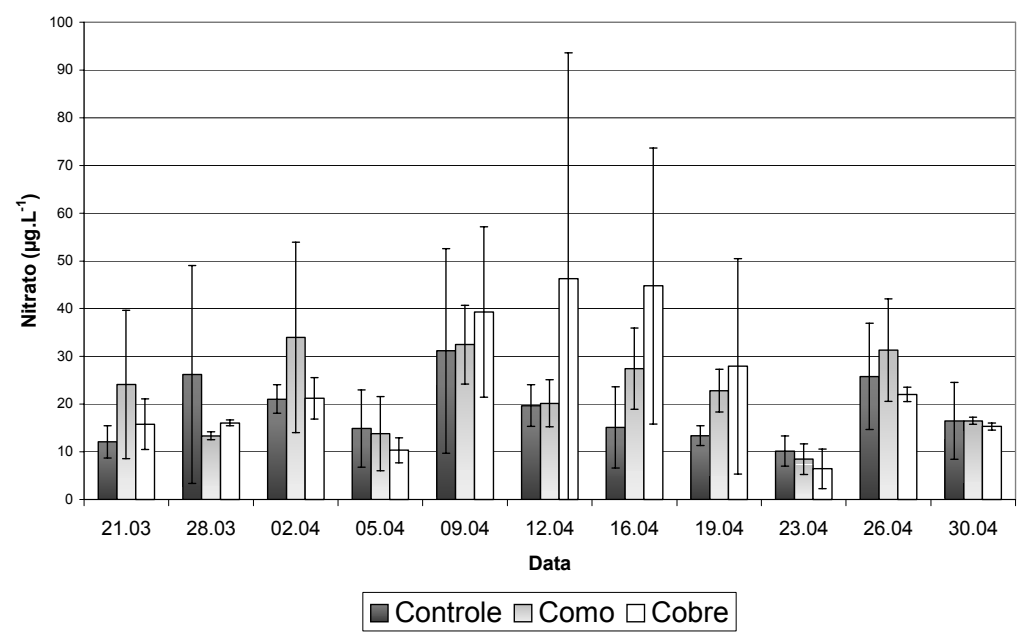

Figura 45: Concentrações médias $\left(\mu \mathrm{g} \cdot \mathrm{L}^{-1}\right)$ de nitrato determinadas nas amostras de água no controle e nos mesocosmos contaminados com $\mathrm{Cr}$ e $\mathrm{Cu}$ durante o período de estudo (as barras de erros referem-se ao desvio padrão da média entre as réplicas dos mesocosmos).

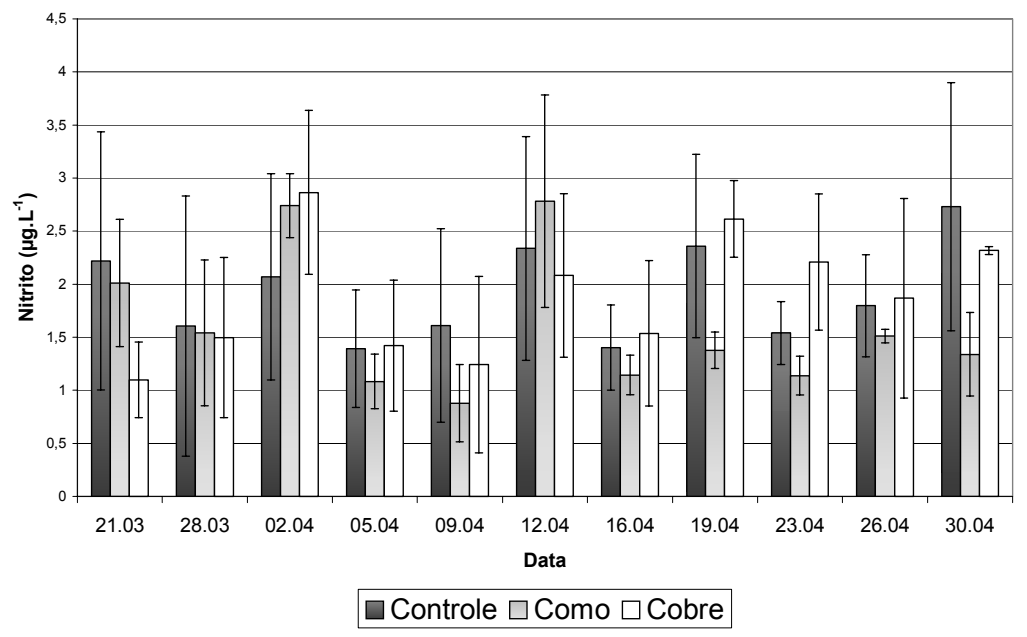

Figura 46: Concentrações médias $\left(\mu \mathrm{g} \cdot \mathrm{L}^{-1}\right)$ de nitrito determinadas nas amostras de água no controle e nos mesocosmos contaminados com $\mathrm{Cr}$ e $\mathrm{Cu}$ durante o período de estudo (as barras de erros referem-se ao desvio padrão da média entre as réplicas dos mesocosmos). 


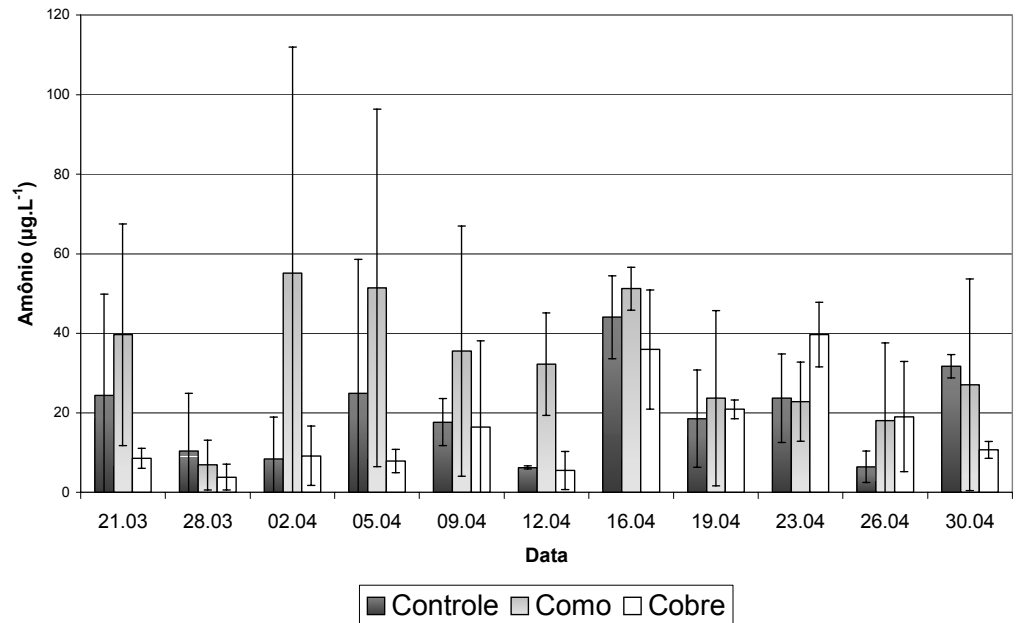

Figura 47: Concentrações médias $\left(\mu \mathrm{g} \cdot \mathrm{L}^{-1}\right)$ de amônio determinadas nas amostras de água no controle e nos mesocosmos contaminados com $\mathrm{Cr}$ e $\mathrm{Cu}$ durante o período de estudo (as barras de erros referem-se ao desvio padrão da média entre as réplicas dos mesocosmos).

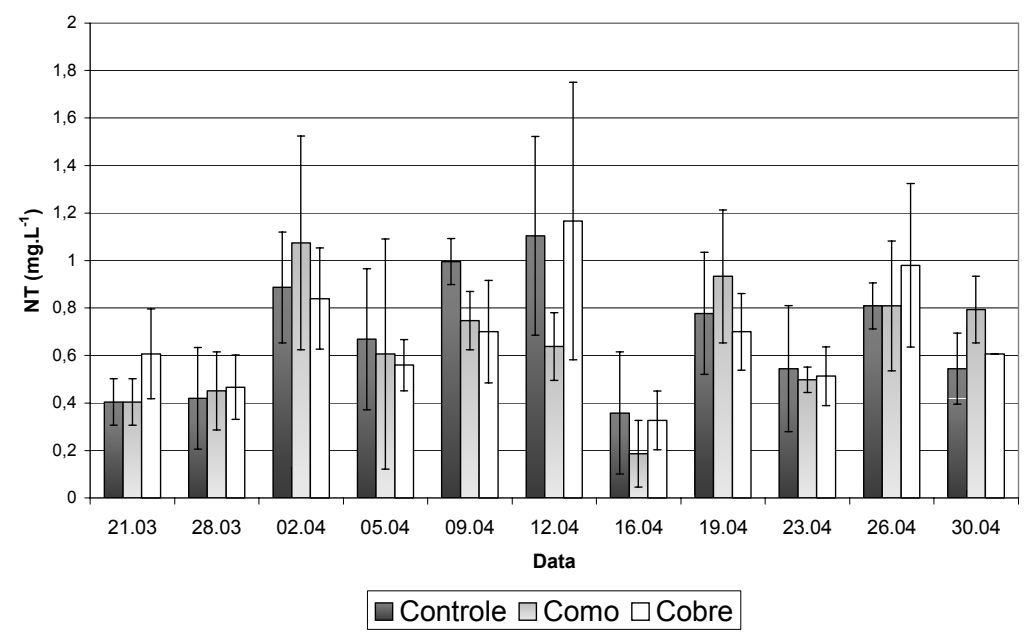

Figura 48: Concentrações médias $\left(\mathrm{mg}^{-1} \mathrm{~L}^{-1}\right)$ de nitrogênio total determinadas nas amostras de água no controle e nos mesocosmos contaminados com $\mathrm{Cr}$ e $\mathrm{Cu}$ durante o período de estudo (as barras de erros referem-se ao desvio padrão da média entre as réplicas dos mesocosmos).

As concentrações de nitrato variaram muito entre as datas e os tratamentos, mesmo antes da contaminação dos tanques (de 10,1 a 31,2 $\mu \mathrm{g} \cdot \mathrm{L}^{-1}$ no controle; de 8,5 a $34 \mu \mathrm{g} \cdot \mathrm{L}^{-1}$ no tratamento com $\mathrm{Cr}$ e de 6,5 a $46,3 \mu \mathrm{g} \cdot \mathrm{L}^{-1}$ no tratamento com $\mathrm{Cu}$ ). Ao final do experimento, porém, ambos os experimentos com $\mathrm{Cr}$ e $\mathrm{Cu}$ apresentaram o mesmo comportamento que o controle, inclusive concentrações semelhantes.

Nos dois tratamentos ocorreu um aumento nas concentrações de nitrito após a contaminação dos mesocosmos. Os dois tratamentos apresentaram concentrações de nitrito iguais a 1,5 $\mu \mathrm{g} \cdot \mathrm{L}^{-1}$ em 28 de março, antes da contaminação, e 2,7 e 2,9, 
respectivamente para os tratamentos com $\mathrm{Cr}$ e Cu, em 2 de abril, 24 horas após a contaminação. Assim mesmo, os dois experimentos apresentaram condições semelhantes ao controle, durante todo o período de estudo.

Após a contaminação dos tanques, as concentrações de amônio apresentaram um acréscimo significativo no tratamento com $\mathrm{Cr}$, atingindo $55,1 \mu \mathrm{g} \cdot \mathrm{L}^{-1}$ no dia seguinte à contaminação, mantendo-se elevadas no decorrer do experimento. Já no experimento com $\mathrm{Cu}$, as concentrações de amônio (entre 3,8 e 35,9 $\mu \mathrm{g} \cdot \mathrm{L}^{-1}$ ) estiveram sempre abaixo das determinadas para o controle (entre 6,4 e $44,0 \mu \mathrm{g} \cdot \mathrm{L}^{-1}$ ), até a coleta do dia 23/04, quando foram determinadas concentrações maiores.

As concentrações de nitrogênio total oscilaram bastante ao longo do experimento nas amostras coletadas nos mesocosmos com $\mathrm{Cr}$ e $\mathrm{Cu}$ e no controle, porém todos os tratamentos apresentaram o variação similar durante o experimento.

As concentrações de fosfato inorgânico, fósforo total dissolvido e fósforo total determinadas em cada unidade experimental, durante o período de estudo estão apresentadas em Apêndice. As médias das concentrações determinadas estão apresentadas nas figuras 49, 50 e 51, respectivamente.

As concentrações de fosfato inorgânico (Figura 49) oscilaram bastante ao longo do tempo nas amostras coletadas nos mesocosmos contaminados com $\mathrm{Cr}$ e $\mathrm{Cu}$ e no controle, porém todos os tratamentos apresentaram variações similares durante o experimento.

Todos os tratamentos apresentaram um acréscimo nas concentrações de fósforo total dissolvido ao final do experimento. Os tratamentos com $\mathrm{Cr}$ e $\mathrm{Cu}$, e o controle apresentaram alterações semelhantes, com valores entre 1,9 e $17,3 \mu \mathrm{g} . \mathrm{L}^{-1}$ no controle; entre 1,6 e $11,3 \mu \mathrm{g} . \mathrm{L}^{-1}$ no tratamento com $\mathrm{Cr}$ e entre 1,3 e $13,9 \mu \mathrm{g} \cdot \mathrm{L}^{-1}$ no tratamento com $\mathrm{Cu}$.

As concentrações de fósforo total determinadas em todos os tratamentos oscilaram de forma homogênea durante todo o experimento, sendo observados aumento ou redução na concentração nas mesmas datas para os diferentes tratamentos. 


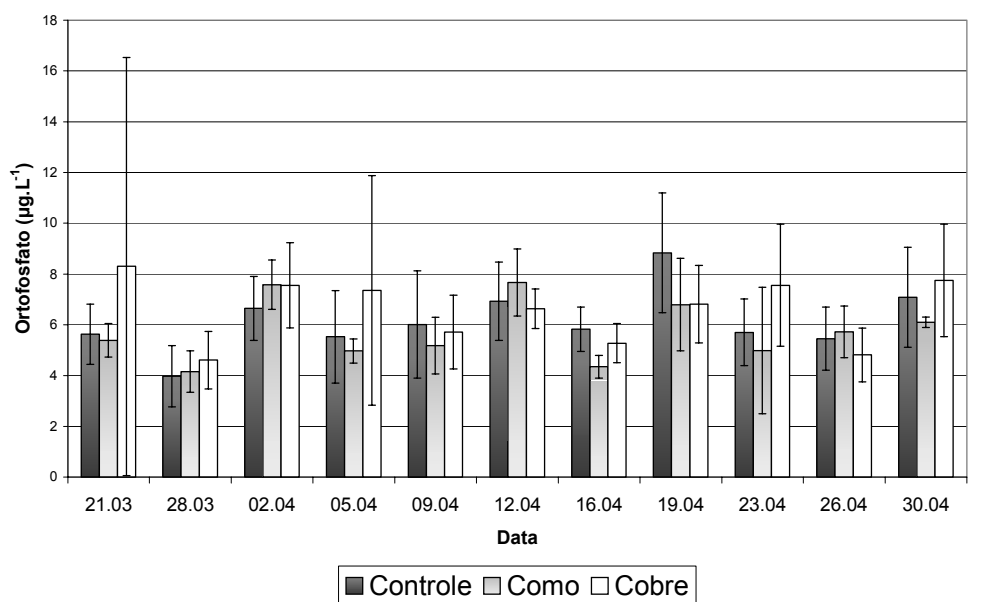

Figura 49: Concentrações médias ( $\left.\mu \mathrm{g} \cdot \mathrm{L}^{-1}\right)$ de fosfato inorgânico determinadas nas amostras de água no controle e nos mesocosmos contaminados com $\mathrm{Cr}$ e Cu durante o período de estudo (as barras de erros referem-se ao desvio padrão da média entre as réplicas dos mesocosmos).

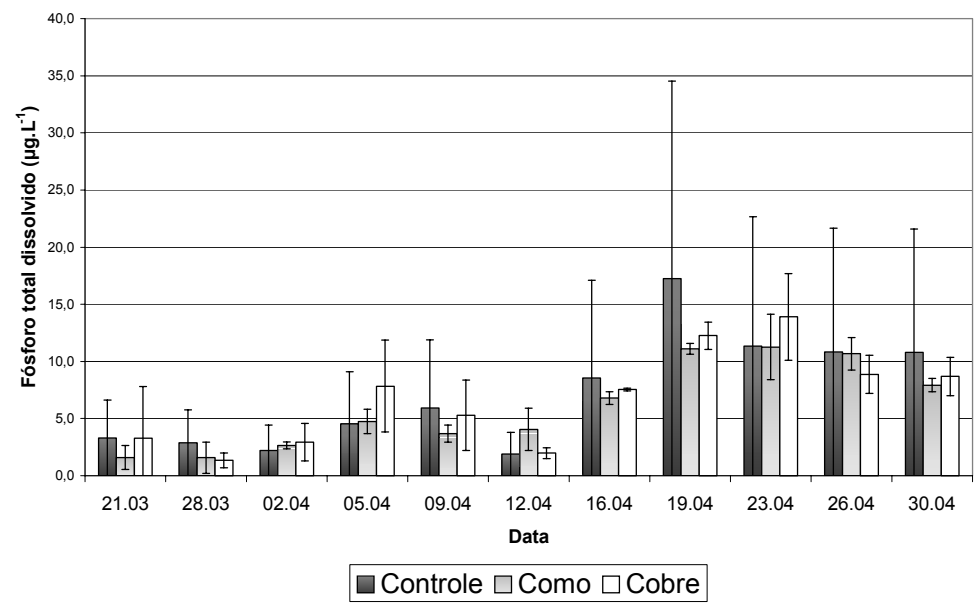

Figura 50: Concentrações médias $\left(\mu \mathrm{g} \cdot \mathrm{L}^{-1}\right)$ de fosfato total dissolvido determinadas nas amostras de água no controle e nos mesocosmos contaminados com $\mathrm{Cr}$ e $\mathrm{Cu}$ durante o período de estudo (as barras de erros referem-se ao desvio padrão da média entre as réplicas dos mesocosmos). 


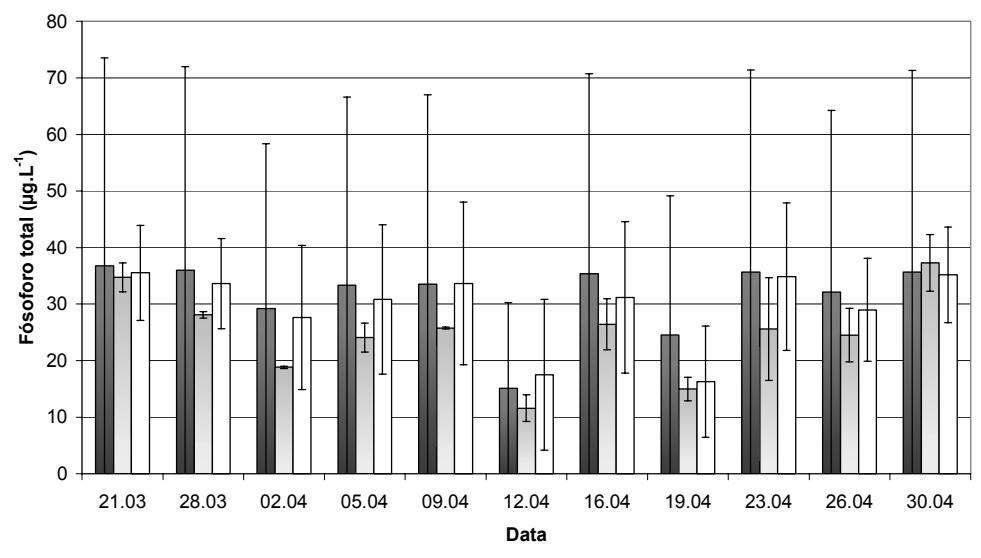

$\square$ Controle $\square$ Como $\square$ Cobre

Figura 51: Concentrações médias $\left(\mu \mathrm{g} \cdot \mathrm{L}^{-1}\right)$ de fósforo total determinadas nas amostras de água no controle e nos mesocosmos contaminados com $\mathrm{Cr}$ e $\mathrm{Cu}$ durante o período de estudo (as barras de erros referem-se ao desvio padrão da média entre as réplicas dos mesocosmos).

\subsubsection{6- - Análise Estatística das variáveis físico-químicas, químicas e biológicas (clorofila)da água}

Para a avaliação da influência das variáveis analisadas entre si, foi construída uma matriz de correlação, utilizando-se todos os dados gerados em cada réplica de cada tratamento. Todos os valores de correlação e p estão apresentados em apêndice.

Analisando-se os dados obtidos através da Correlação de Pearson observa-se que a concentração de $\mathrm{Cu}$ na água superficial relaciona-se positivamente com os valores de condutividade $(r=0,325 ; p=0,008)$ e negativamente com os valores de fósforo total dissolvido ( $r=-0,272 ; p=0,027)$, enquanto que adição de $\mathrm{Cr}$ aos microcosmos correlaciona-se a concentração de amônio ( $r=0,316 ; p=0,010)$, nitrogênio total $(r=0,259 ; p=0,036)$, fósforo total $(p=-0,337 ; p=0,006)$ e clorofila $(r=-0,304$; $p=0,013)$. A correlação negativa entre as concentrações de $\mathrm{Cr}$ e clorofila e fósforo total demonstram o decréscimo na concentração destas variáveis em função da concentração de $\mathrm{Cr}$ na água, enquanto a correlação positiva com os outros parâmetros indicam o aumento na concentração de nitrogênio, principalmente na forma de amônio, na água superficial após a adição de $\mathrm{Cr}$, o que pode ser um efeito da contaminação.

Em ambos os tratamentos, as variáveis físico-químicas avaliadas apresentaram forte correlação entre si e com as outras variáveis analisadas. De forma geral, as concentrações de oxigênio dissolvido apresentaram correlação positiva com o pH, com a concentração de material em suspensão total e orgânico, fósforo total e clorofila, e 
negativas com as concentrações de amônio, gerando valores de $p$ semelhantes para ambos os tratamentos (anexo).

No tratamento com $\mathrm{Cu}$, a condutividade também apresentou correlação significativa com o $\mathrm{pH}(r=0,429 ; p=0,000)$, material em suspensão total e orgânico $(r=0,372 ; p=0,002$ e $r=0,306 ; p=0,013$, respectivamente), silicato $(r=0,486 ; p=0,000)$, fósforo total dissolvido ( $r=-0,326 ; p=0,003$ ) e clorofila $(r=0,325 ; p=0,008)$. No tratamento com $\mathrm{Cr}$, a condutividade influenciou um número menor de variáveis, tendo em comum a correlação positiva com o pH $(r=0,245 ; p=0,048)$ e negativa com a concentração de fósforo total dissolvido $(r=-0,295 ; p=0,016)$.

Os valores de $\mathrm{pH}$, por sua vez, foram fortemente correlacionados com os determinados para o material em suspensão orgânico, silicato e clorofila. Os valores de $\mathrm{p}$ obtidos para ambos os tratamentos indicam uma influência muito significativa do pH sobre a concentração de clorofila ( $p=0,000$, em ambos os casos).

Da mesma forma que foi observado para os experimentos em microcosmos, o material em suspensão mostrou correlação com diversas outras variáveis. Além das variáveis físico-químicas já citadas, o material em suspensão total apresentou forte correlação linear negativa com as concentrações de fósforo total dissolvido, e positiva com a clorofila em ambos os casos. Nos experimentos com $\mathrm{Cu}$, a concentração de material em suspensão orgânico mostrou forte influência sobre a distribuição tanto das formas nitrogenadas como fosfatadas, enquanto que no tratamento com $\mathrm{Cr}$ tal fato foi observado apenas para as formas fosfatadas. A concentração de clorofila também foi fortemente influenciada pela concentração de material em suspensão orgânico em ambos os tratamentos, como visto nos experimentos em microcosmos.

Para avaliar o efeito da adição de $\mathrm{Cr}$ e $\mathrm{Cu}$ à água da represa do Lobo procedeu-se a uma análise de variância multivariada (MANOVA), tendo sido escolhido o nível de significância a $p<0,05$. A análise foi realizada com o auxílio do software MINITAB 13. A adição de cobre não apresentou efeitos sobre o sistema , comparandose os dados com o controle, de acordo com os testes de Wilk's, Lawey-Hotelling, Pillai's e Roys, gerando valor de $p=0,175$. Em relação à análise de variância univariada (ANOVA) entre os controles e os mesocosmos contaminados para cada parâmetro, foram observados efeitos nas variáveis apresentadas na tabela 21. 
Tabela 21: Variáveis que sofreram efeito significativo após a adição de Cu nos mesocosmos (ANOVA, $\mathrm{p}<0,05$ ).

\begin{tabular}{lc}
\hline \hline Variável & valor-P \\
\hline pH & 0,012 \\
Condutividade & 0,013 \\
Clorofila & 0,007 \\
\hline \hline
\end{tabular}

Os efeitos da adição de $\mathrm{Cr}$ no sistema foram significativos a $p=0,000$ para os testes de de Wilk's, Lawey-Hotelling, Pillai's e Roys (MANOVA). Através da análise estatística univariada observou-se que a adição de $\mathrm{Cr}$ causou efeito significativo sobre diversas variáveis, apresentando valores significativamente diferentes dos obtidos para os controles. Estas variáveis estão apresentadas na Tabela 22.

Tabela 22: Variáveis que sofreram efeito significativo após a adição de $\mathrm{Cr}$ nos mesocosmos (ANOVA, $\mathrm{p}<0,05$ ).

\begin{tabular}{lc}
\hline Variável & valor-P \\
\hline Material em Suspensão Total & 0,000 \\
Material em Suspensão Orgânico & 0,000 \\
Oxigênio Dissolvido & 0,000 \\
pH & 0,011 \\
Condutividade & 0,007 \\
Silicato & 0,033 \\
Amônio & 0,006 \\
Fósforo Total Dissolvido & 0,040 \\
Fósforo Total & 0,000 \\
Clorofila & 0,000 \\
Cromo & 0,000 \\
\hline \hline
\end{tabular}

Da mesma forma que observado para o experimento em microcosmo, a adição de Cr provocou maior influência sobre as características funcionais do sistema que a adição de $\mathrm{Cu}$, tanto considerando-se o resultado da análise de variância multivariada (MANOVA) como das análises de variância univariadas (ANOVA).

As diferenças mais significativas entre os valores obtidos nos controles e no tratamento com $\mathrm{Cr}$ foram em relação à concentração de material em suspensão, oxigênio dissolvido, clorofila, amônio e entre a distribuição das formas fosfatadas.

\subsection{2- Análises químicas do sedimento}

\subsubsection{1- Cromo e Cobre}

Os resultados das análises da fração potencialmente disponível ou fracamente ligada de $\mathrm{Cu}$ e $\mathrm{Cr}$ nos sedimentos coletados nos tanques estão apresentados em Apêndice. As concentrações médias para cada tratamento estão apresentadas nas figuras 52 e 53. 
Cromo não foi detectado em nenhuma das amostras coletadas nos dias 28 de março e 30 de abril. Na primeira coleta (28/04), antes da contaminação dos tanques (01/04), as amostras referentes ao controle apresentaram concentrações de $\mathrm{Cr}$ potencialmente disponível maiores que os outros tanques $\left(1,5 \mathrm{mg} \cdot \mathrm{kg}^{-1}\right.$ para o controle e $0,35 \mathrm{mg} \cdot \mathrm{kg}^{-1}$ para o tratamento com $\mathrm{Cr}$ ). Já nas amostras coletadas no dia 19 de abril, ou seja, 18 dias após a contaminação dos tanques, os sedimentos do tratamento com $\mathrm{Cr}$ apresentaram concentrações de $\mathrm{Cr}$ potencialmente disponível $\left(1,25 \mathrm{mg} \cdot \mathrm{kg}^{-1}\right)$ maiores que os controles $\left(0,4 \mathrm{mg} \cdot \mathrm{kg}^{-1}\right)$.

As concentrações de Cu determinadas na fração potencialmente disponível dos sedimentos coletados nos tanques controle e no tratamento com $\mathrm{Cu}$, foram semelhantes durante todo o experimento, ou seja, não apresentaram variações significativas entre os tratamentos e entre as datas de coleta.

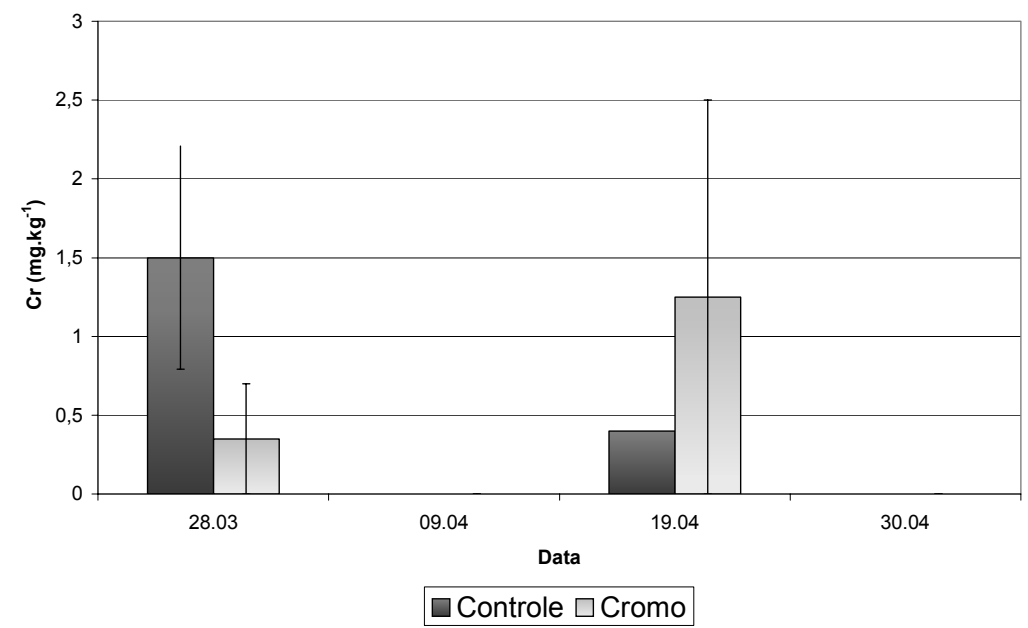

Figura 52: Concentrações médias $\left(\mathrm{mg}^{\mathrm{kg}}{ }^{-1}\right)$ de $\mathrm{Cr}$ na fração fracamente ligada do sedimento dos mesocosmos controle e contaminados com $\mathrm{Cr}$ (as barras de erros referem-se ao desvio padrão da média entre as réplicas dos mesocosmos). 


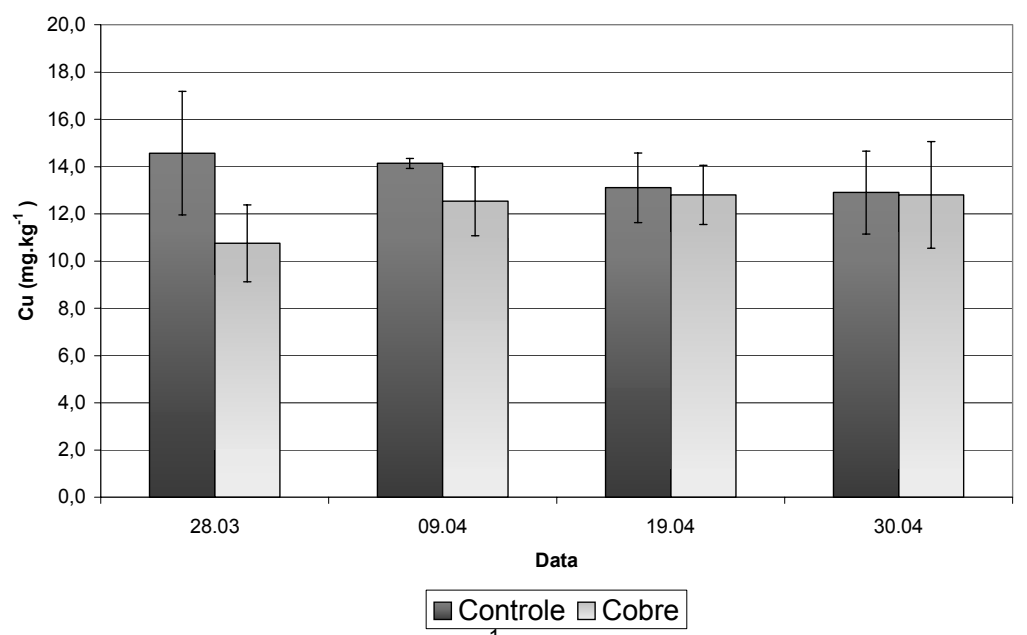

Figura 53: Concentrações médias $\left(\mathrm{mg}^{\mathrm{kg}}{ }^{-1}\right)$ de $\mathrm{Cu}$ na fração fracamente ligada do sedimento dos mesocosmos controle e contaminados com $\mathrm{Cu}$ (as barras de erros referem-se ao desvio padrão da média entre as réplicas dos mesocosmos).

A solubilização das amostras de sedimento para a análise das concentrações totais de $\mathrm{Cr}$ e $\mathrm{Cu}$ foi acompanhada da solubilização de uma amostra de sedimento de lago certificada (IAEA -SL1), com a finalidade de avaliar a eficiência do procedimento de digestão e da técnica analítica. Os valores referentes à recuperação das concentrações de $\mathrm{Cr}$ e $\mathrm{Cu}$ no sedimento certificado estão apresentados na tabela 23.Com base nos resultados referentes a essa análise, pode-se concluir que os procedimentos de digestão e análise de metais totais em sedimento foram eficientes.

Tabela 23: Concentrações $\left(\mathrm{mg} \mathrm{kg}^{-1}\right)$ de $\mathrm{Cr}$ e $\mathrm{Cu}$ recuperadas após digestão e análise de sedimento certificado IAEA - SL1

\begin{tabular}{lcc}
\hline & Certificado & Determinado \\
\hline $\mathrm{Cr}$ & $104 \pm 9$ & 115,9 \\
\hline $\mathrm{Cu}$ & $29,4 \pm 5,6$ & 30,7 \\
\hline \hline
\end{tabular}

As concentrações totais de $\mathrm{Cr}$ e $\mathrm{Cu}$ determinadas nos sedimentos coletados nos tanques constam do Apêndice, sendo que as concentrações médias para cada tratamento estão apresentadas nas Figura 54 e 55.

Antes da contaminação, a concentração média determinada para $\mathrm{Cr}$ no controle (30 mg. $\mathrm{kg}^{-1}$ ) foi um pouco maior que nos mesocosmos contaminados (25 $\left.\mathrm{mg} \cdot \mathrm{kg}^{-1}\right)$. No final do experimento, porém, verifica-se concentrações maiores nos mesocosmos contaminados $\left(39,4 \mathrm{mg} \cdot \mathrm{kg}^{-1}\right)$ que no controle $\left(20 \mathrm{mg} \cdot \mathrm{kg}^{-1}\right)$. O controle e o tratamento com $\mathrm{Cu}$ apresentaram concentrações de $\mathrm{Cu}$ semelhantes antes da contaminação para (58 mg. $\mathrm{kg}^{-1}$ ), sendo que nas duas últimas coletas os sedimentos dos mesocosmos contaminados apresentaram concentrações mais elevadas que os controles (35 e $40 \mathrm{mg} \cdot \mathrm{kg}^{-1}$ em 19 e 30 de abril, respectivamente, para o controle e 54 e 
57 mg. $\mathrm{kg}^{-1}$ em 19 e 30 de abril, respectivamente, para o tratamento com $\mathrm{Cu}$ ). As concentrações de $\mathrm{Cu}$ nos sedimentos dos tanques contaminados com $\mathrm{Cu}$ não variaram muito ao longo do experimento.

A fração disponível em relação à concentração total permaneceu constante entre os tratamentos, variando entre 20 e $25 \%$ para o $\mathrm{Cu}$, tanto no controle como nos tanques contaminados, e abaixo de $5 \%$ para o $\mathrm{Cr}$, para o controle e para o tratamento com Cr.

Como já discutido anteriormente, Cu está presente naturalmente na água e nos sedimentos da represa do Lobo, e assim a adição deste metal nas concentrações utilizadas neste trabalho não provocaram variações nas concentrações do metal no sedimento, em ambas as fases avaliadas, a fase potencialmente disponível e a concentração total.

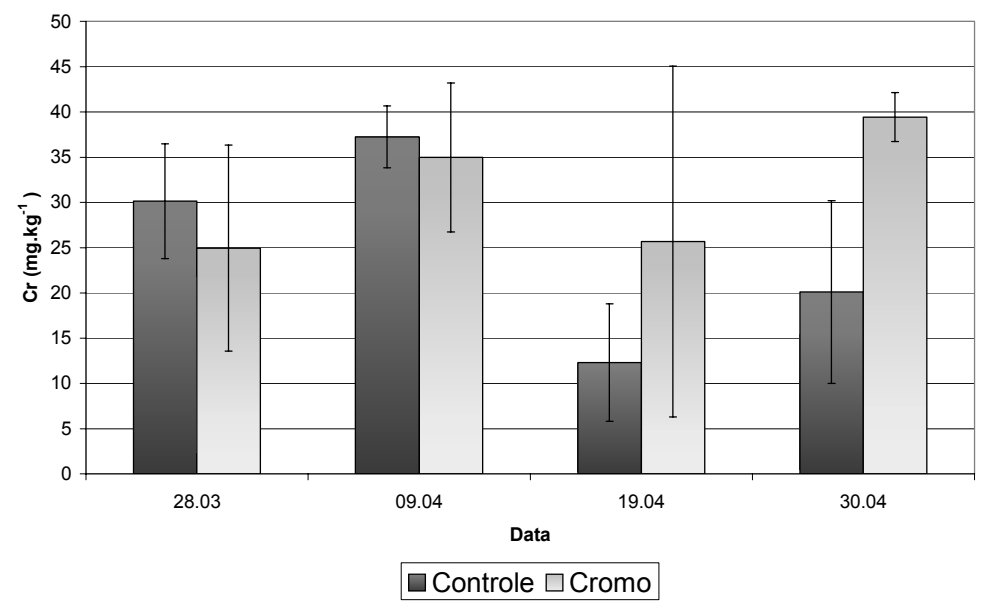

Figura 54: Concentrações totais médias $\left(\mathrm{mg}^{\mathrm{kg}} \mathrm{kg}^{-1}\right)$ de $\mathrm{Cr}$ no sedimento dos mesocosmos controle e contaminados com $\mathrm{Cr}$ (as barras de erros referem-se ao desvio padrão da média entre as réplicas dos mesocosmos).

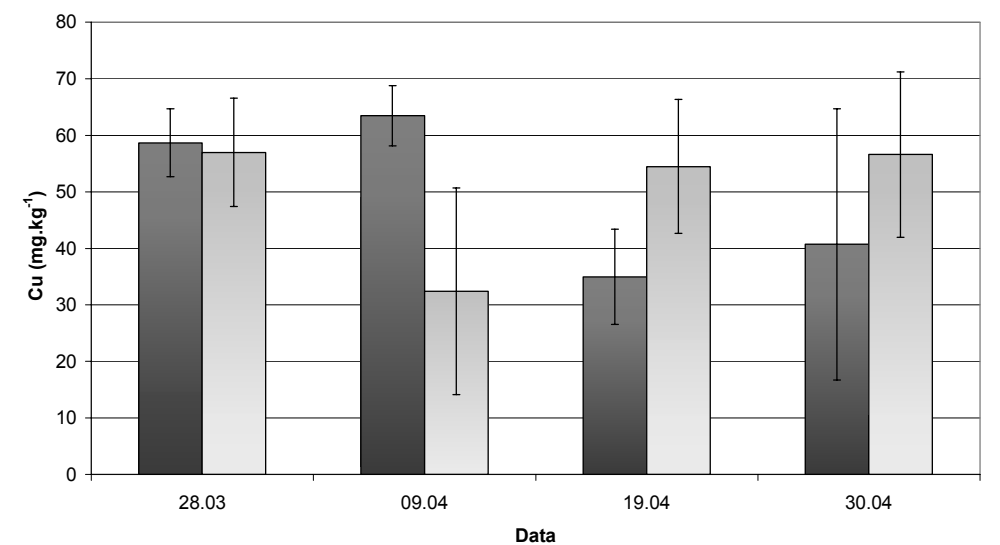

$\square$ Controle $\square$ Cobre

Figura 55: Concentrações totais médias $\left(\mathrm{mg} \mathrm{kg}^{-1}\right)$ de $\mathrm{Cu}$ no sedimento dos mesocosmos controle e contaminados com $\mathrm{Cu}$ (as barras de erros referem-se ao desvio padrão da média entre as réplicas dos mesocosmos). 


\subsubsection{2- Matéria orgânica e nutrientes (fósforo e nitrogênio)}

Os resultados obtidos para o teor de matéria orgânica (\%) nos sedimentos coletados nos tanques estão apresentados em apêndice, e as concentrações médias para estão apresentadas na Figura 56. Os teores de matéria orgânica determinados nos sedimentos variaram entre 13,7 e 16,9 \%, não tendo sido observadas grandes diferenças entre os tratamentos, mas sim um pequeno decréscimo ao longo do tempo.

As concentrações médias de nitrogênio determinadas no sedimento dos tanques controle e nos contaminados com cromo e cobre, em cada uma das coletas, estão apresentadas na figura 57 , onde verifica-se a homogeneidade dos valores obtidos (entre 0,1 e $0,14 \%$ ) nos diferentes tratamentos.

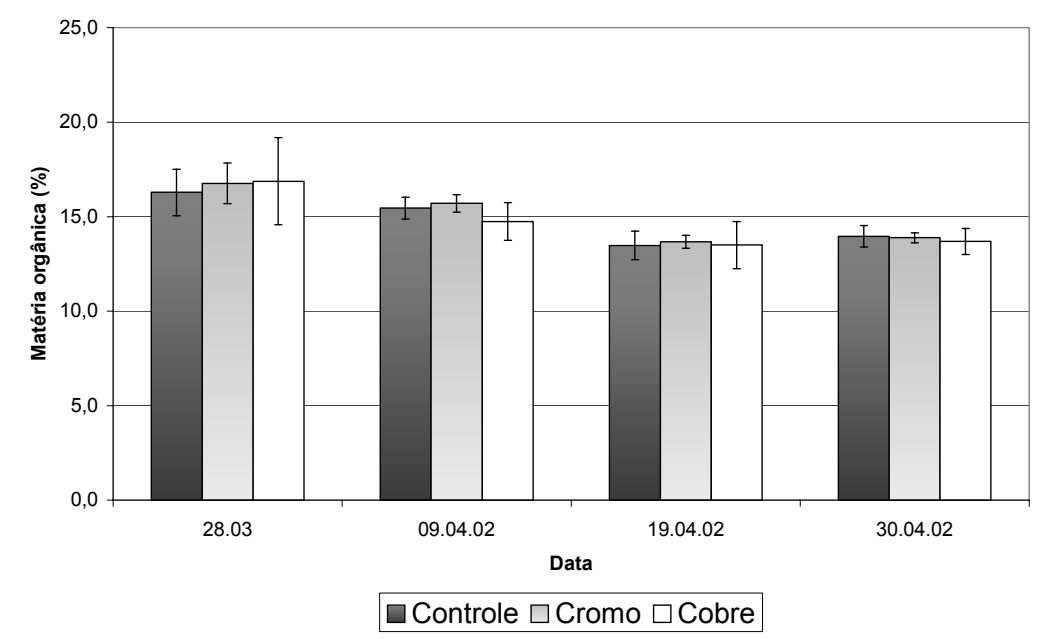

Figura 56: Teores médios de matéria orgânica (\%) determinados nos sedimentos dos mesocosmos controle e contaminados com $\mathrm{Cu}$ e $\mathrm{Cr}$ (as barras de erros referem-se ao desvio padrão da média entre as réplicas dos mesocosmos).

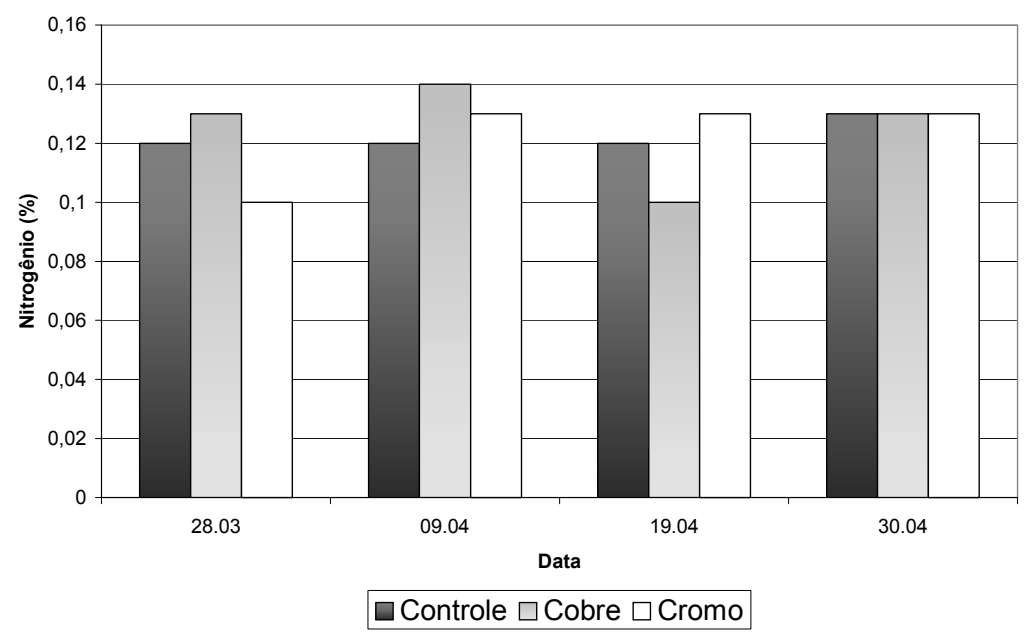

Figura 57: Concentrações médias de nitrogênio (\%) determinadas nos sedimentos dos mesocosmos controle e contaminados com $\mathrm{Cu}$ e $\mathrm{Cr}$. 
As concentrações médias de fósforo nos sedimentos estão apresentadas na Figura 58, verificando-se um pequeno aumento do início ao térmico do experimento (entre 200 e 300 mg.kg-1 em 28 de março, antes da contaminação, para 300 a 350 mg.kg ${ }^{-1}$ em 30 de abril, 30 dias após a contaminação) e valores próximos em todos os tratamentos.

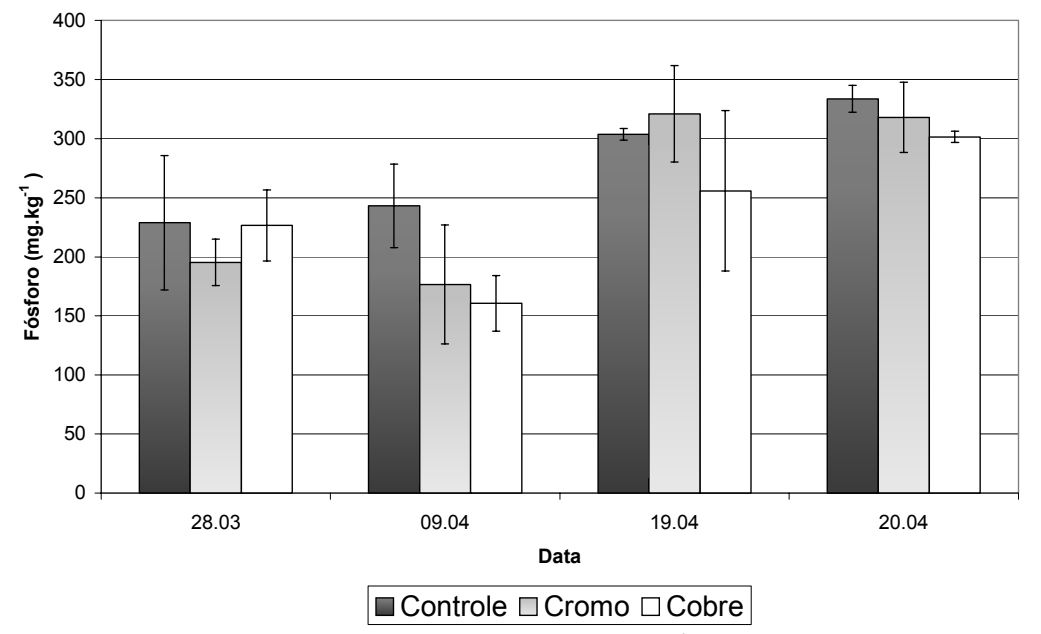

Figura 58: Concentrações médias de fósforo $\left(\mathrm{mg} \cdot \mathrm{kg}^{-1}\right)$ determinadas nos sedimentos nos sedimentos dos mesocosmos controle e contaminados com $\mathrm{Cu}$ e $\mathrm{Cr}$ (as barras de erros referem-se ao desvio padrão da média entre as réplicas dos mesocosmos).

A importância da determinação do conteúdo de matéria orgânica nos sedimentos expostos à metais está na sua capacidade de adsorver os contaminantes, além de poder interferir nas propriedades mecânicas destes, e provocar alterações nas suas características físico-químicas, afetando diretamente a disponibilidade de metais para a coluna d'água (SALOMONS \& FORSTNER, 1984). Os sedimentos dos mesocosmos apresentaram em todos os casos conteúdo de matéria orgânica acima de $10 \%$, podendo ser considerados sedimentos orgânicos.

REIS FILHO (2004) determinou também a granulometria dos sedimentos dos mesocosmos, assim como suas características físico-químicas. Em relação à distribuição granulométrica, todos os mesocosmos apresentaram sedimentos com perfil semelhante, sendo as principais frações granulométricas presentes areia fina + areia muito fina (56-60\%), e site+argila (24-32\%). A dominância da fração arenosa é natural, uma vez que os tanques foram instalados na região litorânea da represa, sujeita ao aporte de material proveniente das margens. Um dos principais fatores no controle da imobilização/mobilização de metais em sedimentos é a fração de finos, como silte/argila $(<64 \mu \mathrm{m})$, já amplamente discutido na literatura (SALOMONS \& 
FORSTNER, 1984; DASKALAKIS \& O'CONNOR, 1995 e outros). Assim, a homogeneidade granulométrica é um ponto importante nos estudos em mesocosmos, e pode-se afirmar que os sedimentos dos nove tanques estudados apresentaram capacidades similares de agregar os metais adicionados ao sistema, em relação à esta característica.

Os sedimentos analisados foram sempre reduzidos, sendo que apenas na primeira coleta as concentrações de oxigênio não foram nulas, mas muito baixas, com médias de 1,2; 1,2 e 1,1 mg. $\mathrm{L}^{-1}$ para o controle e para os tratamentos com cobre e o com cromo, respectivamente (dados apresentados por REIS FILHO, 2004). As condições de anoxia apresentadas pelos sedimentos podem ser responsáveis pelas elevadas razões $\mathrm{C} / \mathrm{N}$ e pelas concentrações de fósforo relativamente baixas determinadas nos sedimentos durante todo o experimento, uma vez que em condições reduzidas o fósforo tende a ser mobilizado do sedimento para a coluna d'água.

Além dos valores de oxigênio, os valores de potencial redox e sulfetos volatilizáveis por ácido (SVA) determinados nos sedimentos dos tanques reforçam sua característica anóxica. Os potenciais redox determinados foram negativos em todos os casos, variando de $-192 \mathrm{a}-133 \mathrm{mV}$, e as concentrações de SVA variaram entre 48 e $236 \mathrm{mg} \cdot \mathrm{kg}^{-1}$. A variação na concentração de SVA ocorreu principalmente em função da data, não tendo sido observadas diferenças entre as amostras de cada tratamento numa mesma coleta. REIS FILHO op cit. encontrou uma forte correlação entre os valores de SVA e potencial redox nos mesocosmos.

\subsubsection{3- Água Intersticial}

A água intersticial representa a fase solúvel do sedimento, onde nutrientes, metais e outras substâncias encontram-se dissolvidas, sendo fundamental nas trocas entre a fase particulada e a coluna d'água. Alguns autores consideram a água intersticial como a fração verdadeiramente biodisponível do sedimento (SILVÉRIO, 2003).

Cromo não foi detectado em nenhuma das amostras de água intersticial analisadas e $\mathrm{Cu}$ foi detectado apenas nas duas últimas coletas. Os valores de $\mathrm{Cu}$ obtidos para as amostras dos tanques controle e dos tanques contaminados com $\mathrm{Cu}$ estão apresentadas na Figura 59, verificando-se valores médios entre 0,25 e 0,35 $\mathrm{mg} \cdot \mathrm{L}^{-1}$ no controle e entre 0,3 e $0,35 \mathrm{mg} \cdot \mathrm{L}^{-1}$ no tratamento com $\mathrm{Cu}$ 


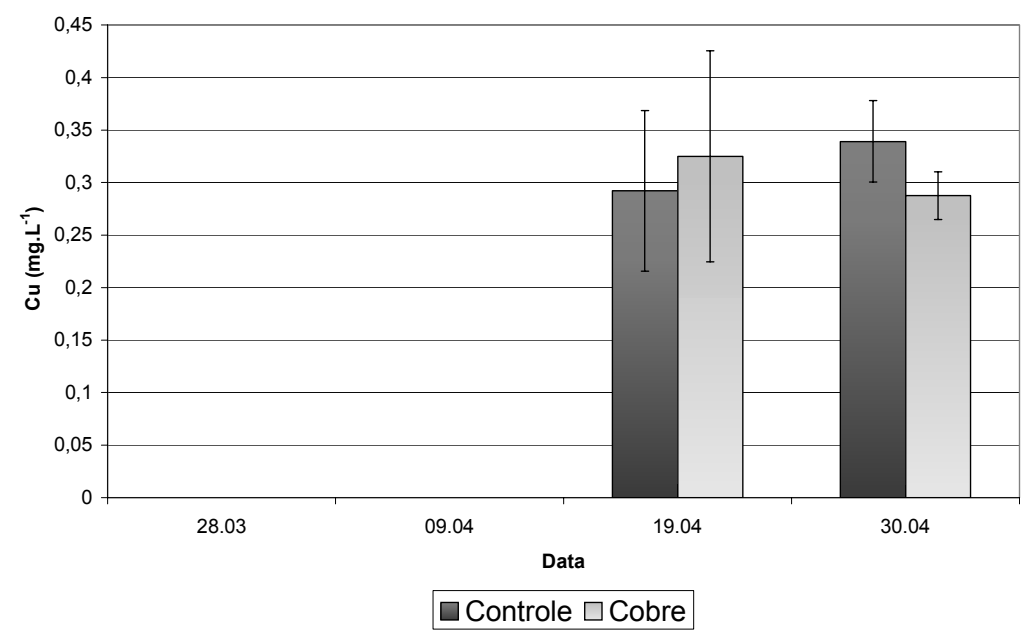

Figura 59: Concentrações de $\mathrm{Cu}\left(\mathrm{mg}^{-\mathrm{L}^{-1}}\right)$ determinadas na água intersticial dos mesocosmos controle e contaminados com $\mathrm{Cu}$ (as barras de erros referem-se ao desvio padrão da média entre as réplicas dos mesocosmos).

A concentração de metais na água intersticial dos sedimentos é controlada por uma série de fatores, como $\circ \mathrm{pH}$, concentração de sulfetos, matéria orgânica e outras superfícies ligantes. Nos sedimentos analisados, os valores obtidos para o controle e para os tanques submetidos à adição de $\mathrm{Cu}$ apresentaram padrões semelhantes, sugerindo que a influência da data de coleta foi maior que a influência da adição do metal.

REIS FILHO (2004) menciona que os sedimentos dos mesocosmos apresentam $\mathrm{pH}$ estável em uma faixa tendendo à neutralidade e baixa condutividade, caracterizando o ambiente como sulfídrico anóxico, o que favorece a adsorção ou complexação dos metais por sulfetos, matéria orgânica ou colóides, indisponibilizando esses elementos para a fase solúvel.

\subsubsection{4- Análise estatística das variáveis químicas do sedimento}

As variáveis analisadas nos sedimentos coletados nos mesocosmos foram avaliados estatisticamente através da matriz de Correlação de Pearson e de análise de variância multivariada (MANOVA) e univariada (ANOVA), utilizando-se o software MINITAB 13. A matriz de correlação de Pearson foi construída com os valores determinados para teor de matéria orgânica, nitrogênio, fósforo e análise de metais, juntamente com os dados de potencial redox (Eh), $\mathrm{pH}$, condutividade e oxigênio dissolvido obtidos por REIS FILHO (op cit.).

Os efeitos comuns aos dois experimentos foram a influência do potencial redox sobre a concentração de matéria orgânica e fósforo, e do oxigênio dissolvido sobre a matéria orgânica. Tanto as correlações obtidas entre a matéria orgânica e o potencial 
redox quanto entre matéria orgânica e oxigênio dissolvido são positivas, indicando que a oxidação favorece a deposição de matéria orgânica. Em relação ao fósforo total as correlações obtidas foram negativas, sugerindo que quanto mais negativo o potencial redox maiores as concentrações de fósforo no sedimento. Altas concentrações de fósforo dissolvido são observadas nas águas intersticiais da camada reduzida do sedimento, podendo migrar para a água superficial em função do gradiente de concentrações entre essas fases (SALOMONS \& FORSTNER, 1984).

O teor de matéria orgânica e o potencial redox apresentaram fortes correlações $(p<0,04)$ positivas $(r=0,458 ; p=0,024$ e $r=0,428 ; p=0,037$, respectivamente) com a concentração total de $\mathrm{Cr}$ no sedimento, demonstrando o favorecimento da imobilização de metais pela matéria orgânica, amplamente reportado pela literatura (SALOMONS \& FORSTNER, op cit.; DASKALAKIS \& O'CONNOR, 1995).

No tratamento com cobre não foi observada correlação entre as concentrações do metal no sedimento e as demais variáveis, porém a concentração de Cu na água intersticial apresentou correlações negativas muito significativas com o conteúdo de matéria orgânica $(r=-0,675 ; p=0,000)$, o potencial redox $(r=-0,769 ; p=0,000)$ e oxigênio dissolvido $(r=-0,619 ; p=0,001)$.

Estudos sobre a especiação do $\mathrm{Cu}$ indicam uma crescente solubilidade em águas intersticiais anóxicas comparadas com águas superficiais oxidadas (SALOMONS \& FORSTNER, op cit.), sugerindo a maior disponibilidade do metal nestas condições.

Os resultados da análise de variância multivariada (MANOVA) indicaram não haver diferenças significativas entre os sedimentos dos mesocosmos controle e dos tratamentos com $\mathrm{Cr}$ e $\mathrm{Cu}$, gerando valores de $\mathrm{p}=0,140$ e $p=0,437$, respectivamente, para os testes de Wilk's, Lawley-Hotelling, Pillai's e Roy's.

A análise de variância univariada, entretanto, indica diferenças significativas $(p=0,018)$ entre as concentrações totais de $\mathrm{Cr}$ nos controles e no tratamento com $\mathrm{Cr}$. O mesmo pode ser observado para as concentrações de $\mathrm{Cu}$ potencialmente biodisponível $(p=0,055)$, porém com menor significância.

A análise multivariada, porém, apresenta diferenças significativas entre as variáveis analisadas em função da data $(p=0,000)$ para ambos os experimentos. No tratamento com $\mathrm{Cr}$ todos os parâmetros analisados, com exceção das concentrações totais e biodisponíveis de $\mathrm{Cr}$ e da condutividade, variaram em função do período de coleta. Da mesma forma, no experimento com $\mathrm{Cu}$ apenas as concentrações totais e potencialmente biodisponíveis de $\mathrm{Cu}, \mathrm{o} \mathrm{pH}$ e a condutividade não apresentaram diferenças em função das datas de coleta. 


\subsection{3- Análises de $\mathrm{Cr}$ e $\mathrm{Cu}$ nas comunidades planctônica e bentônica}

A concentração de $\mathrm{Cr}$ e $\mathrm{Cu}$ foi determinada nos organismos planctônicos e bentônicos com o objetivo de se verificar a ocorrência de bioacumulação dos metais adicionados, e comparar os resultados obtidos pelos organismos expostos ao $\mathrm{Cr}$ e $\mathrm{Cu}$ com os resultados obtidos no controle.

Bioacumulação ou bioconcentração pode ser conceituada como a rede de absorção de substâncias pelos organismos a partir de seu entorno (água, sedimento, solo, dieta). A concentração das substâncias na biota é determinada pelo equilíbrio entre absorção, biotransformação e excreção, dependendo, portanto, da substância e do organismo (CHASIN \& PEDROZO, 2003).

Bioconcentração é o fenômeno em que, no equilíbrio, a concentração da substância no organismo é maior que no meio. O termo bioacumulação é utilizado para se referir à concentração da substância no organismo considerando todas as vias de exposição (ar, água, sedimento, solo, alimento)

\subsubsection{1- Plâncton}

Os valores de biomassa planctônica (plâncton > $20 \mu \mathrm{m}$ ) obtidos nos diferentes tratamentos estão apresentados em Apêndice, sendo que somente foram consideradas para análise amostras com peso mínimo de $5 \mathrm{mg}$.

A biomassa média obtida nas amostras para análise de Cu foi de $31,2 \mathrm{mg}$, e a concentração média de Cu nestas amostras, antes da contaminação, foi de 61,2 \pm $32,4 \mu \mathrm{g} \cdot \mathrm{g}^{-1}$, considerando as análises referentes aos mesocosmos controle, cobre e um amostra externa aos mesocosmos. As concentrações de $\mathrm{Cu}$ determinadas nas amostras de plâncton estão apresentadas na figura 60 , onde verifica-se maiores concentrações nas amostras do controle em 28 de março e 19 de abril (77 e 121 нg.g $\left.{ }^{1}\right)$ em relação às amostras dos mesocosmos contaminadas. Apenas nas amostras referentes ao dia 30 de abril (30 dias após a contaminação dos mesocosmos) as concentrações foram maiores nos mesocosmos contaminados $\left(108 \mu \mathrm{g} \cdot \mathrm{g}^{-1}\right)$ que no controle $\left(78 \mu \mathrm{g} \cdot \mathrm{g}^{-1}\right)$

Comparando-se os resultados obtidos nos controles e nos experimentos com $\mathrm{Cu}$, através da análise de variância (ANOVA), observa-se que os dados não apresentaram diferenças significativas $(p<0,05)$, conforme apresentado na Tabela 24 . 


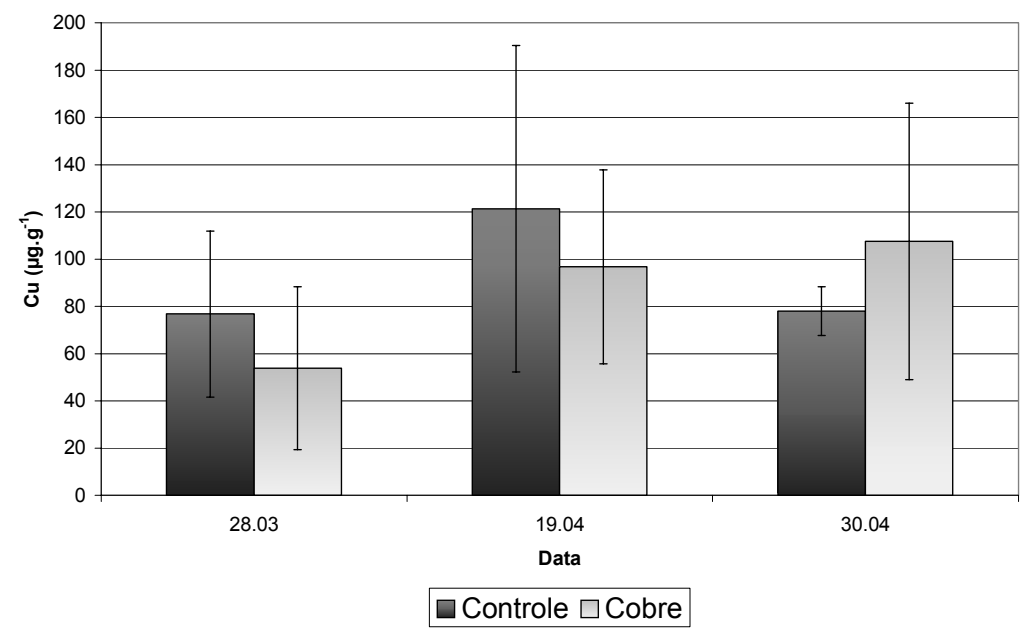

Figura 60: Concentrações de $\mathrm{Cu}\left(\mu \mathrm{g} \cdot \mathrm{g}^{-1}\right)$ determinadas nas amostras de plâncton da coleta preliminar (28/03) e nos dias 19 e 30/04 nos mesocosmos controle e contaminados com Cu (as barras de erros referem-se ao desvio padrão da média entre as réplicas dos mesocosmos).

Tabela 24: Síntese da análise de variância das concentrações de $\mathrm{Cu}$ em organismos planctônicos

\begin{tabular}{lccc}
\hline \hline & $F$ & valor-P & F crítico \\
\hline $19 / 04$ & 0,279425 & 0,625049 & 7,70865 \\
$30 / 04$ & 0,743729 & 0,437105 & 7,70865 \\
\hline \hline
\end{tabular}

F > F crítico: significativamente diferente.

A biomassa média obtida nas coletas de plâncton para análise de $\mathrm{Cr}$ foi de 29,1 mg. Foram consideradas para análise amostras com no mínimo $5 \mathrm{mg}$. As concentrações de $\mathrm{Cr}$ determinadas nas amostras de plâncton estão apresentadas na Figura 61. Para um dos mesocosmos controle não foi obtida massa suficiente para a análise.

A concentração média de $\mathrm{Cr}$ determinada no dia 19/04 nos tanques controle foi $21,6 \mu \mathrm{g} \cdot \mathrm{g}^{-1}( \pm 5,5)$. Nos tanques contaminados com $\mathrm{Cr}$, apenas a amostra coletada no em um dos mesocosmos apresentou massa suficiente para a análise, determinandose concentração igual a $75,0 \mu \mathrm{g} \cdot \mathrm{g}^{-1}$. As concentrações médias de $\mathrm{Cr}$ determinadas no dia 30/04 nos tanques controle e nos contaminados foram, respectivamente, $2,2( \pm 1,2)$ e $5,0( \pm 5,9) \mu g \cdot g^{-1}$.

Comparando-se os resultados obtidos nos controles e nos experimentos com Cr no dia 19/04 através da análise de variância (ANOVA) observa-se que os dados apresentaram diferenças significativas $(p<0,05)$, ou seja, as concentrações determinadas nas amostras expostas ao $\mathrm{Cr}$ foram significativamente maiores que as determinadas para o controle, o que não foi observado para as amostras do dia 30/04 (Tabela 25). 


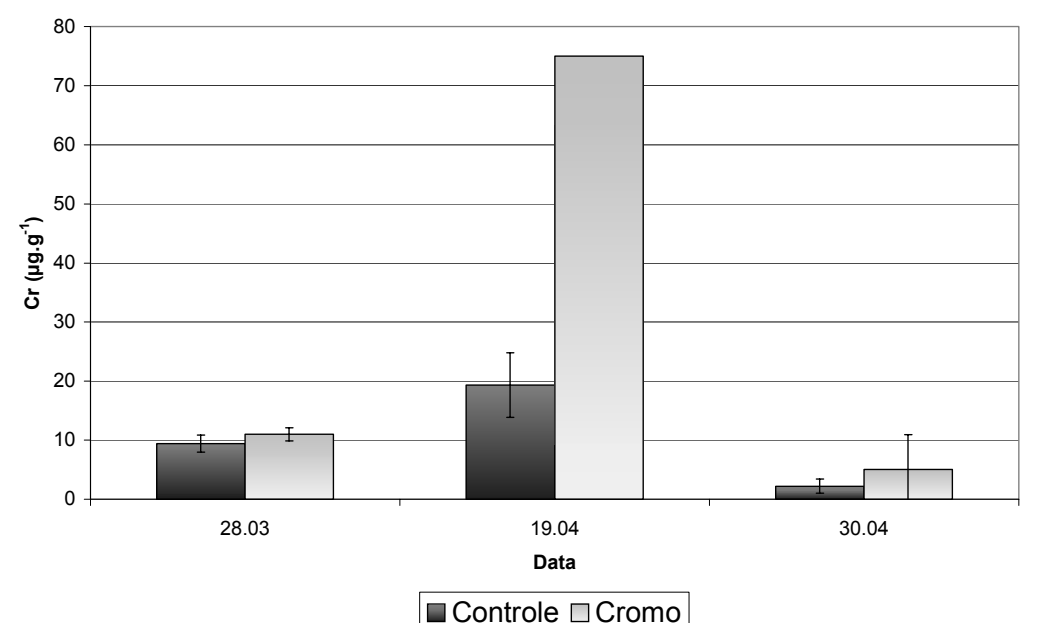

Figura 61: Concentrações de $\mathrm{Cr}\left(\mu \mathrm{g} \cdot \mathrm{g}^{-1}\right)$ determinadas nas amostras de plâncton da coleta preliminar (28/03) e nos dias 19 e 30/04 nos mesocosmos controle e contaminados com $\mathrm{Cr}$ (as barras de erros referem-se ao desvio padrão da média entre as réplicas dos mesocosmos).

Tabela 25: Síntese da análise de variância das concentrações de $\mathrm{Cr}$ em organismos planctônicos

\begin{tabular}{lccc}
\hline \hline & $F$ & valor-P & $F$ crítico \\
\hline $19 / 04$ & 70,00057 & 0,013987 & 18,51276 \\
$30 / 04$ & 1,013797 & 0,388169 & 10,12796 \\
\hline \hline
\end{tabular}

F > F crítico: significativamente diferente.

STUMM \& MORGAN (1981) apresentam concentrações de Cu muito menores para o fitoplâncton (> 76 mesh), entre 3,2 e $11 \mu \mathrm{g} \cdot \mathrm{g}^{-1}$, assim como SALOMONS \& FORSTNER (1984) que apresentam concentrações menores que $30 \mu \mathrm{g} \cdot \mathrm{g}^{-1} \mathrm{Cu}$ em algas de lagos, porém BOWEN (1966) reporta um valor médio de $200 \mu \mathrm{g}^{-1} \mathrm{~g}^{-1} \mathrm{Cu}$ no plâncton composto principalmente por diatomáceas.

Concentrações de $\mathrm{Cu}$ significativamente altas foram determinadas por FARKAS et al. (2003) no zooplâncton natural do lago Balaton, Hungria, com médias entre 3,7 - 12,5 $\mu \mathrm{g} \cdot \mathrm{g}^{-1}$, mas com concentrações de até $276,3 \mu \mathrm{g} \cdot \mathrm{g}^{-1} \mathrm{em}$ algumas amostras. Os autores observaram ainda correlação positiva significativa estatisticamente entre a concentração de metais na água e no zooplâncton. Em trabalho sobre a assimilação de cobre por Daphnia magna (ANDREW et al., 1977), os autores observaram que as principais formas de $\mathrm{Cu}$ na causa da toxicidade são os íons livres e os hidroxi-complexos, e que em alguns casos a complexação do metal pode aumentar sua assimilação. 
As concentrações de Cu relativamente altas determinadas no plâncton coletado durante o experimento, inclusive nos tanques controle, pode ser devida a presença natural deste metal na represa do Lobo, sendo que na área de instalação do experimento o sedimento apresentou $10,2 \mathrm{mg} \cdot \mathrm{kg}^{-1}$ de $\mathrm{Cu}$ em estudo realizado por DORNFELD et al. (2002) em outubro de 2000, e nos sedimentos dos tanques a concentração de $\mathrm{Cu}$ potencialmente biodisponível esteve acima deste valor em todas as análises. A água da represa também apresenta concentrações de Cu relativamente altas, como pode ser observado pelas concentrações determinadas nos controles e as amostras coletadas antes da contaminação dos tanques.

As concentrações de $\mathrm{Cr}$ determinadas no controle são semelhantes às concentrações naturais de $\mathrm{Cr}$ em algas de lagos, $12-20 \mu \mathrm{g} \cdot \mathrm{g}^{-1}$ (SALOMONS \& FORSTNER, 1984). BOWEN (1966), porém, reporta uma concentração de $3,5 \mu \mathrm{g} . \mathrm{g}^{-1}$ de $\mathrm{Cr}$ no plâncton. As concentrações determinadas nos tanques contaminados neste trabalho estão na mesma ordem de grandeza, porém quase 4 vezes maiores.

Em trabalho realizado em microcosmos sobre o acúmulo de $\mathrm{Cr}$ pelo fitoplâncton, BARRETO (1994) apresentou concentrações de até $12 \mathrm{mg} \cdot \mathrm{g}^{-1}$ de $\mathrm{Cr}$ na biomassa microplanctônica e até $8 \mathrm{mg} / \mathrm{g}$ na biomassa nanoplanctônica, expostos a concentrações entre 100 e $600 \mu \mathrm{g} \cdot \mathrm{L}^{-1}$ de $\mathrm{Cr}$ no meio. As concentrações utilizadas por BARRETO (op cit.) são muito maiores que as testadas no presente trabalho, mas demonstram a capacidade de bioconcentração de $\mathrm{Cr}$ pelo fitoplâncton.

A partir dos dados obtidos para a concentração dos metais $\mathrm{Cu}$ e $\mathrm{Cr}$ na água e nos organismos planctônicos calculou-se os fatores de concentração. Foram utilizadas as concentrações médias determinadas na água superficial coletada na mesma data que o plâncton (Tabela 26).

Os fatores de concentração de $\mathrm{Cr}$ para o plâncton dos tanques controle e na coleta anterior à contaminação dos tanques não pode ser calculada pois as concentrações de $\mathrm{Cr}$ na água dos tanques estiveram abaixo do limite de detecção.

\begin{tabular}{llccc}
\multicolumn{4}{c}{ Tabela 26: Fatores de concentração de Cu e Cr pelo plâncton dos mesocosmos } \\
\hline \hline & & 28.03 & 19.04 & 30.04 \\
\hline \hline $\mathrm{Cu}$ & Controle & 6000 & 15000 & 23000 \\
& Cobre & 14000 & 12000 & 25000 \\
\hline $\mathrm{Cr}$ & Controle & & & \\
& Cromo & & 19000 & 2100 \\
\hline \hline
\end{tabular}

$\overline{\mathrm{FC}}=\mathrm{ppm}$ no organismo $/ \mathrm{ppm}$ na água

Para as amostras coletadas nos dias 19 (19 dias após a contaminação) e 30/04 (30 dias após a contaminação), os fatores de concentração de $\mathrm{Cr}$ no plâncton em 
relação à água foram iguais a 19000 e 2100 respectivamente. Pode-se observar que o maior fator de concentração determinado corresponde à data de amostragem em que o plâncton coletado nos tanques contaminados com $\mathrm{Cr}$ apresentou concentrações significativamente maiores que o coletado nos tanques controle. Assim, pode-se sugerir que o plâncton foi um bom indicador da contaminação da água superficial da represa do Lobo por Cr.

No experimento com $\mathrm{Cu}$, os fatores de concentração determinados para as amostras coletadas nos tanques contaminados foram similares aos determinados para os controles em todas as datas.

Fatores de concentração de $\mathrm{Cu}$ e Cr muito semelhantes aos apresentados aqui são reportados por BOWEN (1966) para o plâncton marinho, com valor igual a 17000, para ambos os metais estudados.

As concentrações de metais utilizadas na água dos experimentos são iguais ao limite estabelecido para corpos d'água destinados ao abastecimento público e proteção da vida aquática, entre outros usos, pela Resolução n ${ }^{0} 20 / 1986$ do CONAMA (CONAMA, 1986), não sendo esperados efeitos muito pronunciados nos organismos naturais do sistema. Entretanto foi observado o aumento na concentração de $\mathrm{Cr}$ no plâncton exposto a este metal. Em relação à contaminação por $\mathrm{Cu}$, como a água da represa já apresenta concentrações naturalmente altas deste elemento, o que não ocorre com $\mathrm{Cr}$, o plâncton dos controles e dos tanques contaminados não apresentaram diferenças entre si.

\subsubsection{2- Bentos}

Foram consideradas para análise de metais as amostras de bentos com no mínimo $5 \mathrm{mg}$, sendo que a biomassa média obtida nas coletas de bentos para análise de Cu foi de 25,6 mg.

Para as amostras coletadas para a análise preliminar foi formada uma amostra composta para cada grupo de tanques (controles 1, 2, 3 e cobre 1, 2, 3), uma vez que não se obteve massa suficiente para as análises no bentos de cada mesocosmos individualmente.

As concentrações de Cu nas amostras de bentos da coleta preliminar foram 3,8 e $15,1 \mu \mathrm{g} \cdot \mathrm{g}^{-1}$, respectivamente para as amostras compostas para o controle e para o experimento com $\mathrm{Cu}$. As concentrações de $\mathrm{Cu}$ determinadas nas amostras de bentos coletadas no dia 30 de abril (29 dias após a contaminação dos tanques) estão apresentadas na Figura 62. Não foi obtida massa suficiente para análise em um dos mesocosmos contaminados com $\mathrm{Cu}$. 


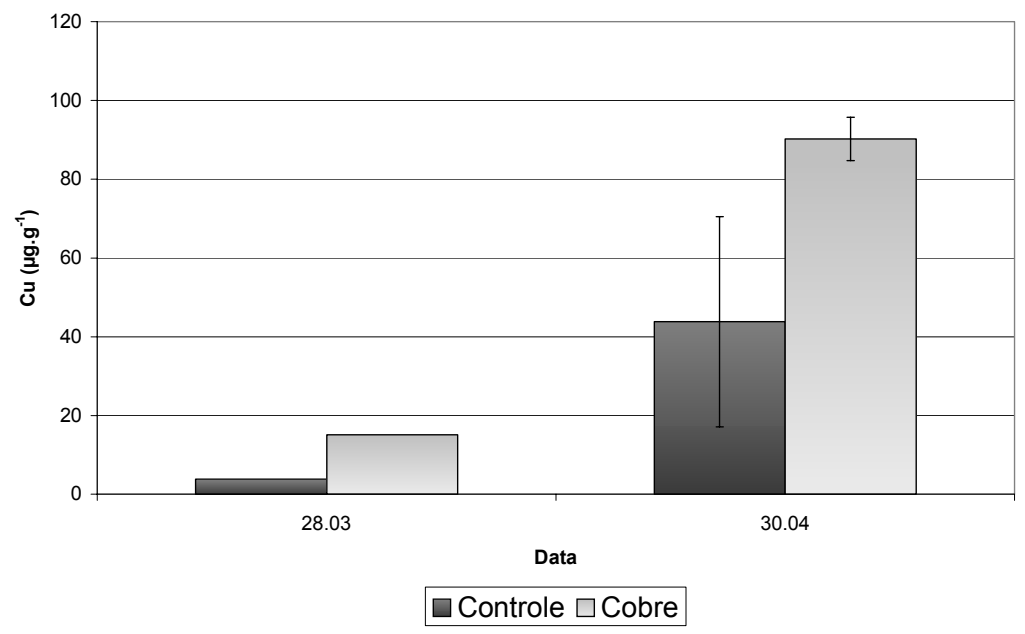

Figura 62: Concentrações de $\mathrm{Cu}\left(\mu \mathrm{g} \cdot \mathrm{g}^{-1}\right)$ determinadas nas amostras de bentos da coleta preliminar (28/03) e no dia 30/04 nos mesocosmos controle e contaminados com Cu (as barras de erros referem-se ao desvio padrão da média entre as réplicas dos mesocosmos).

As concentrações médias de $\mathrm{Cu}$ determinadas no dia 30/04 nos tanques controle e nos contaminados com $\mathrm{Cu}$ foram, respectivamente, 43,8 $( \pm 26,7)$ e 90,2 $( \pm 5,5) \mu \mathrm{g} \cdot \mathrm{g}^{-1}$. Comparando-se os resultados obtidos nos controles e nos experimentos com Cu no dia 30/04 através da análise de variância (ANOVA) observa-se que os dados apresentaram diferenças significativas $(p<0,05)$, ou seja, as concentrações determinadas nas amostras expostas ao $\mathrm{Cu}$ foram significativamente maiores que as determinadas para o controle (Tabela 27).

Tabela 27: Síntese da análise de variância das concentrações de $\mathrm{Cu}$ em organismos bentônicos

\begin{tabular}{cccc}
\hline \hline & $F$ & valor-P & F crítico \\
\hline $30 / 04$ & 8,341036935 & 0,0446487 & 7,7086497 \\
\hline \hline
\end{tabular}

F > F crítico: significativamente diferente.

As concentrações de Cu determinadas nos organismos bentônicos foram muito menores que as determinadas por QUINN et al (2003) para bentos sujeitos à drenagem ácida de mineração, que determinou $512 \mu \mathrm{g} \cdot \mathrm{g}^{-1}$ de $\mathrm{Cu}$ em amostras coletadas no canal Fisher Creek (Montana). KRANTZBERG (1989) determinou concentrações da ordem de $60 \mu \mathrm{g} \cdot \mathrm{g}^{-1}$ de Cu para larvas de Chironomus coletadas em um lago oligotrófico (Plastic Lake, Canadá), sendo da mesma ordem de grandeza das determinadas neste experimento.

A biomassa média obtida nas coletas de bentos para análise de $\mathrm{Cr}$ foi de 21,2 mg, sendo consideradas para análise somente amostras com no mínimo 5 mg. 
Para as amostras coletadas na análise preliminar foi formada uma amostra composta para cada grupo de tanques (controles 1, 2, 3 e cromo 1, 2, 3), uma vez que não foi obtido massa suficiente para as análises individuais dos tanques.

A concentração de $\mathrm{Cr}$ na amostra de bentos da coleta preliminar foi $4,1 \mu \mathrm{g} \cdot \mathrm{g}^{-1}$ na amostra composta para o controle, e esteve abaixo do limite de detecção para o experimento com $\mathrm{Cr}$.

As concentrações médias de $\mathrm{Cr}$ determinadas no dia 30/04 nos tanques controle e nos contaminados com Cr foram respectivamente $12,1( \pm 0,4)$ e $22,9( \pm 4,0)$ $\mu g \cdot g^{-1}$ (Figura 63). Não obteve-se massa suficiente para análise em um dos mesocosmos controle

Comparando-se os resultados obtidos nos controles e nos experimentos com $\mathrm{Cr}$ no dia 30/04 através da análise de variância (ANOVA) observa-se que os valores apresentaram diferenças significativas $(p<0,05)$, ou seja, as concentrações determinadas nas amostras expostas ao $\mathrm{Cr}$ foram significativamente maiores que as determinadas para o controle (Tabela 28).

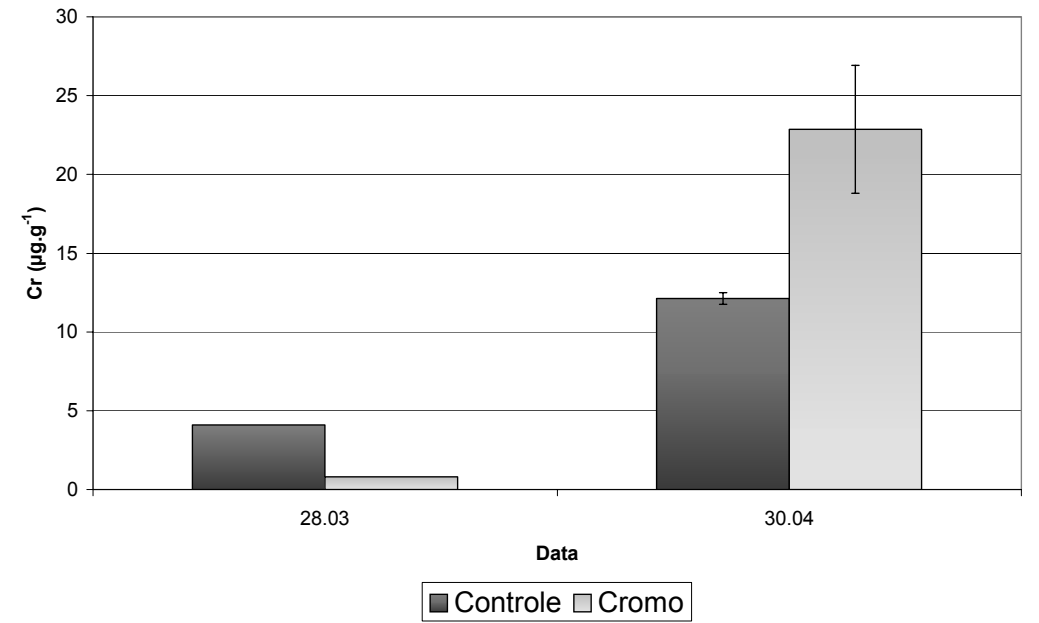

Figura 63: Concentrações de $\mathrm{Cr}\left(\mu \mathrm{g} \cdot \mathrm{g}^{-1}\right)$ determinadas nas amostras de bentos da coleta preliminar (28/03) e no dia 30/04 nos mesocosmos controle e contaminados com $\mathrm{Cr}$ (as barras de erros referem-se ao desvio padrão da média entre as réplicas dos mesocosmos).

Tabela 28: Síntese da análise de variância das concentrações de $\mathrm{Cr}$ em organismos bentônicos

\begin{tabular}{llrc}
\hline & \multicolumn{1}{l}{$\mathrm{F}$} & valor-P & $\mathrm{F}$ crítico \\
\hline $30 / 04$ & 8,878177 & 0,040754 & 7,70865 \\
\hline \hline
\end{tabular}

F > F crítico: significativamente diferente. 
Os organismos bentônicos detritívoros estão diretamente expostos as metais ligados ao sedimento, e são capazes de acumular metais tanto das águas intersticiais como pela ingestão de sedimentos. Fatores de concentração com respeito aos sedimentos são geralmente maiores para organismos sésseis, tendo sido propostos como bioindicadores da contaminação do sedimento por metais (CAMPBELL et al., 1988). O acúmulo de metais por invertebrados bentônicos é afetado por fatores geoquímicos e biológicos. As concentrações de metais nos organismos bentônicos são melhor relacionadas com as frações facilmente extraídas dos sedimentos que com as concentrações totais.

No cálculo dos fatores de concentração (Tabela 29) de Cr para as amostras de bentos do dia 30/04 foram utilizados os valores de $\mathrm{Cr}$ potencialmente disponível no sedimento referentes às amostras do dia 19/04, pois nas amostras de sedimento do dia 30/04 a concentrações de Cr nesta fase do sedimento estiveram abaixo do limite de detecção.

Tabela 29: Fatores de concentração de Cu e Cr pelo bentos dos mesocosmos

\begin{tabular}{cccc}
\hline \hline & & 28.03 & 30.04 \\
\hline \hline $\mathrm{Cu}$ & Controle & 0,3 & 3 \\
& Cobre & 1 & 7 \\
\hline $\mathrm{Cr}$ & Controle & 3 & 20 \\
& Cromo & 2 & 18 \\
\hline \hline
\end{tabular}

$\overline{\mathrm{FC}}=\mathrm{ppm}$ no organismo /ppm no sedimento

Nas amostras analisadas 30 dias após a contaminação dos tanques os fatores de concentração foram maiores para todas as amostras incluindo o controle. Apesar de terem sido observadas diferenças significativas entre as concentrações nos organismos dos tanques contaminados e do controle, o mesmo não pode ser dito em relação aos fatores de concentração.

\subsection{4- Efeitos dos metais $\mathrm{Cr}$ e Cu no fitoplâncton, zooplâncton e bentos}

\subsubsection{1 - Produção primária do fitoplâncton}

A produção primária foi determinada em apenas um tanque de cada triplicata, em função das dificuldades encontradas na obtenção do $\mathrm{NaH}^{14} \mathrm{CO}_{3}$ usado na inoculação das amostras.

As medidas de luminosidade, temperatura, $\mathrm{pH}$, oxigênio dissolvido e condutividade foram determinadas no dia 26 de março, em avaliação prévia antes da contaminação dos mesocomsos, no momento da inoculação das amostras (por volta 
de 9 hs), e na retirada destas (por volta de 13 hs). Estes resultados estão apresentadas na Tabela 30, verificando-se diferenças apenas para luminosidade em função do horário final dos experimentos.

Tabela 30: Medidas de luminosidade, temperatura, $\mathrm{pH}$, oxigênio dissolvido e condutividade determinadas no dia 26 de março de 2002.

\begin{tabular}{|c|c|c|c|c|c|}
\hline & Luminosidade & Temperatura & $\mathrm{pH}$ & OD & Condutividade \\
\hline & Lux & ${ }^{\circ} \mathrm{C}$ & & $\mathrm{mg} \cdot \mathrm{L}^{-1}$ & $\mu S . \mathrm{cm}^{-1}$ \\
\hline \multirow{2}{*}{$\begin{array}{c}\text { Controle início } \\
\text { fim }\end{array}$} & 180 & 25,2 & 6,9 & 5,8 & 9 \\
\hline & 1250 & 26,5 & 7,3 & 6,6 & 9 \\
\hline \multirow[t]{2}{*}{ Cromo } & 160 & 25,2 & 6,5 & 5,8 & 10 \\
\hline & 1000 & 26,5 & 7,4 & 6,8 & 10 \\
\hline \multirow[t]{2}{*}{ Cobre } & 260 & 25,2 & 7,5 & 6,2 & 8 \\
\hline & 1350 & 26,5 & 7,3 & 6,6 & 8 \\
\hline
\end{tabular}

Os três tanques testados apresentaram valores aproximados para a produção primária, sendo que a média entre estes valores foi de $3,3( \pm 0,6) \mathrm{mgC} \cdot \mathrm{m}^{-3} \cdot \mathrm{h}^{-1}$.

As medidas de luminosidade, temperatura, $\mathrm{pH}$, oxigênio dissolvido e condutividade determinadas no dia 01 de abril, 2 hs após a contaminação dos mesocosmos, no momento da inoculação das amostras, por volta de 11 hs, e na retirada destas, por volta de 15 hs, estão apresentadas na tabela 31.

Tabela 31: Medidas de luminosidade, temperatura, $\mathrm{pH}$, oxigênio dissolvido e condutividade determinadas no dia 01 de abril de 2002

\begin{tabular}{|c|c|c|c|c|c|}
\hline & Luminosidade & Temperatura & $\mathrm{pH}$ & OD & Condutividade \\
\hline & Lux & ${ }^{\circ} \mathrm{C}$ & & $\mathrm{mg} \cdot \mathrm{L}^{-1}$ & $\mu \mathrm{S} . \mathrm{cm}^{-1}$ \\
\hline \multirow[t]{2}{*}{ Controle } & 600 & 26,6 & 5,8 & 6,1 & 8 \\
\hline & 400 & 27,3 & 6,6 & 6,0 & 8 \\
\hline \multirow[t]{2}{*}{ Cromo } & 570 & 26,7 & 5,8 & 6,5 & 10 \\
\hline & 400 & 27,0 & 5,9 & 6,2 & 10 \\
\hline \multirow[t]{2}{*}{ Cobre } & 600 & 26,5 & 6,0 & 6,2 & 8 \\
\hline & 570 & 27,2 & 6,4 & 7,6 & 7 \\
\hline
\end{tabular}

Os resultados da produção primária do fitoplâncton determinada em 26 de março e em 1 de abril, 2 horas após a contaminação dos tanques, estão apresentadas na Figura 64.

As diferenças observadas entre as determinações realizadas no dia 26 de março e o controle no dia 01 de abril são devidas às diferenças no horário de instalação do experimento, consequentemente às diferenças na luminosidade.

No entanto, considerando-se os resultados obtidos no controle e nos tanques após a adição de Cu e Cr, verifica-se uma inibição acentuada na produção primária do 
fitoplâncton sob exposição ao $\mathrm{Cr}$ (acima de 90\%) e uma inibição de $60 \%$ sob exposição ao $\mathrm{Cu}$.

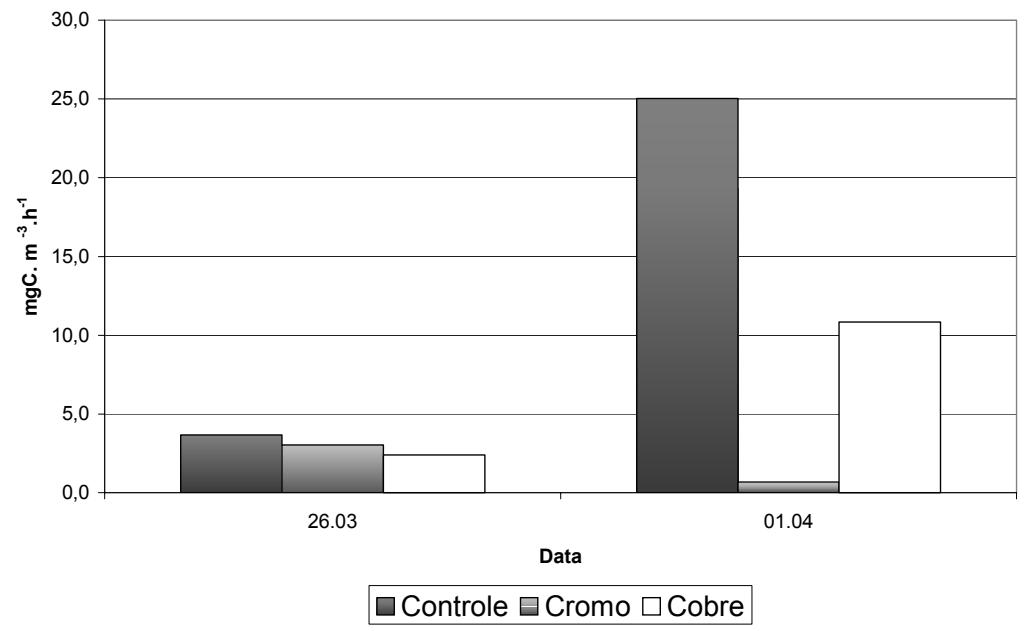

Figura 64: Produção primária do fitoplâncton determinada em 26/03 e 01/04, 2 horas após a contaminação dos mesocosmos.

Em trabalho realizado por OLIVEIRA NETO (2000) sobre a influência de metais na produção primária do fitoplâncton da represa do Lobo, concentrações de $\mathrm{Cr}$ de 0,05 mg. $\mathrm{L}^{-1}$ provocaram uma redução de $22 \%$ deste processo. Em concentrações maiores, como 1 e 5 mg.L ${ }^{-1}$ a porcentagem de redução foi de 20,7 e 21,8 \%, respectivamente. A redução na produção primária pela adição de $\mathrm{Cr}$ observada neste trabalho foi muito maior, o que pode ser devido às diferenças no design experimental, já que o autor adicionou as soluções de metais diretamente nas amostras, enquanto neste trabalho as soluções foram adicionadas ao tanques, e a amostra coletada após a contaminação é que foi avaliada.

A produção primária do fitoplâncton determinada antes da contaminação dos tanques, no dia 26 de março, foi em média 3,3 $( \pm 0,6) \mathrm{mgC} \cdot \mathrm{m}^{-3} \cdot \mathrm{h}^{-1}$. Este valor é inferior às taxas de assimilação determinadas em trabalho anterior realizado na represa do Lobo (CALIJURI, 1985), que apresentou, para amostras incubadas na mesma profundidade e em horários semelhantes, valores de $24,63 \mathrm{mgC} \cdot \mathrm{m}^{-3} \cdot \mathrm{h}^{-1}$, em maio de 1983; 12,17 em outubro de 1983 e 11,98 em fevereiro de 1984. As diferenças observadas entre os valores citados e o valor médio determinado neste trabalho para a produção primária do fitoplâncton podem ser devidos a alterações nas comunidades fitoplanctônicas presentes na represa, uma vez que os trabalhos comparados foram realizados com uma diferença de quase 20 anos, além de terem sido realizados em épocas do ano diferentes. 
A produção primária determinada para o controle no dia da contaminação dos tanques foi semelhante ao valores citados acima (CALIJURI, 1985, op cit.) para determinação realizada em maio de $1983\left(24,63 \mathrm{mgC} \cdot \mathrm{m}^{-3} \cdot \mathrm{h}^{-1}\right.$, no trabalho citado e $25,03 \mathrm{mgC} \cdot \mathrm{m}^{-3} \cdot \mathrm{h}^{-1}$ no controle no dia 01 de abril de 2002). HENRY et al. (1998) determinou valores máximos entre 5 e $20 \mathrm{mgC} \cdot \mathrm{m}^{-3} \cdot \mathrm{h}^{-1}$ para a produção primária em amostras de água coletadas na superfície da Represa de Jurumirim em 1994, sendo estes valores da mesma ordem que os determinados neste trabalho antes da contaminação dos tanques.

Entre os metais estudados, $\mathrm{Cr}$ ocasionou a maior inibição na produção de clorofila, assim como maior inibição na produção primária do fitoplâncton, sendo determinados valores próximos a zero após à contaminação dos mesocosmos.

\subsubsection{2 - Composição e densidade do zooplâncton}

Os dados apresentados neste item são decorrentes da dissertação de mestrado do Ocean. MSc Luiz Felipe Mendes de Gusmão, em trabalho de mestrado vinculado a este trabalho. Neste trabalho somente serão considerados os resultados obtidos para o zooplâncton total, não sendo utilizados os índices calculados para os microcrustáceos e rotíferos de forma separada. Informações mais detalhadas pode ser encontradas em GUSMÃO (2004).

A composição das espécies nos mesocosmos de cada tratamento está apresentada na Tabela 32, que apresenta as espécies presentes no decorrer do estudo, considerando-se todas as datas. Foram encontradas 36 espécies no controle, 34 no tratamento com $\mathrm{Cr}$ e 39 no tratamento com $\mathrm{Cu}$ e pode-se observar, ainda, diferenças em relação a composição das espécies, sendo que somente os copepodos (Calanoida e Cyclopoida) ocorreram em todos os tratamentos. 
Tabela 32: Composição do zooplâncton nos mesocosmos controle e contaminados com $\mathrm{Cr}$ e Cu durante o tempo de experimento.

\begin{tabular}{|c|c|c|c|c|}
\hline & Espécie & Controle & Cromo & Cobre \\
\hline \multirow[t]{4}{*}{ Copepoda } & Notodiaptomus iheringi & $\mathrm{X}$ & $\mathrm{X}$ & $\mathrm{X}$ \\
\hline & Argyrodiaptomus furcatus & $\mathrm{X}$ & $\mathrm{X}$ & $\mathrm{X}$ \\
\hline & Mesocyclops longisetus & $\mathrm{X}$ & $\mathrm{x}$ & $\mathrm{X}$ \\
\hline & Termocyclops minutus & $\mathrm{X}$ & $\mathrm{X}$ & $\mathrm{X}$ \\
\hline \multirow[t]{11}{*}{ Cladocera } & Ceriodaphnia silvestrii & $\mathrm{X}$ & $\mathrm{X}$ & $\mathrm{X}$ \\
\hline & Ceridaphnia cornuta & $x$ & $x$ & $x$ \\
\hline & Bosmina hagmani & $x$ & $x$ & $\mathrm{X}$ \\
\hline & Bosmina Longirostris & $x$ & $x$ & $\mathrm{x}$ \\
\hline & Diaphanosoma birgei & $x$ & $x$ & $x$ \\
\hline & Ilyocryptus spinifer & $x$ & $x$ & $x$ \\
\hline & Simocephalus serrulatus & & $x$ & $x$ \\
\hline & $\begin{array}{l}\text { Alona retangula pulchra } \\
\text { Moina minuta }\end{array}$ & $\mathrm{X}$ & $x$ & $\mathrm{X}$ \\
\hline & Daphnia gessneri & & & $x$ \\
\hline & Bosminopsis deitersi & & & $x$ \\
\hline & Streblocerus pygmaeus & & & $\mathrm{X}$ \\
\hline \multirow[t]{31}{*}{ Rotifera } & Ptygura libera & $\mathrm{X}$ & $\mathrm{X}$ & $\mathrm{X}$ \\
\hline & Polyartha vulgaris & $\mathrm{x}$ & $x$ & $\mathrm{X}$ \\
\hline & Keratella cochlearis & $x$ & $x$ & $x$ \\
\hline & Keratella americana & $\mathrm{X}$ & $\mathrm{x}$ & $\mathrm{X}$ \\
\hline & Kellicotia bostoniensis & $\mathrm{X}$ & $\mathrm{x}$ & $\mathrm{X}$ \\
\hline & Trichocerca pusilla & $\mathrm{X}$ & $\mathrm{x}$ & $\mathrm{X}$ \\
\hline & Trichocerca similis & $\mathrm{X}$ & $\mathrm{x}$ & $\mathrm{X}$ \\
\hline & Trichocerca chattonni & $\mathrm{X}$ & $\mathrm{x}$ & $\mathrm{X}$ \\
\hline & Trichocerca myersi & $\mathrm{X}$ & & \\
\hline & Trichocerca bicristata & $x$ & & $\mathrm{X}$ \\
\hline & Filina pejleri & $x$ & $x$ & $x$ \\
\hline & Lecane bulla & $x$ & $x$ & $x$ \\
\hline & Lecane lunaris & $x$ & $x$ & $\mathrm{X}$ \\
\hline & Lecane stichaeta & $x$ & $x$ & $X$ \\
\hline & Lecane subtilis & $\mathrm{X}$ & & \\
\hline & Lecane luna & & $\mathrm{X}$ & \\
\hline & Lecane ludwigi & & $\mathrm{X}$ & \\
\hline & Lecane leontina & & & $\mathrm{X}$ \\
\hline & Lepadela quadricarinata & $\mathrm{X}$ & $\mathrm{X}$ & $\mathrm{X}$ \\
\hline & Conochilus unicornis & $\mathrm{X}$ & $\mathrm{x}$ & $\mathrm{X}$ \\
\hline & Collotheca longicauda & $x$ & $x$ & $x$ \\
\hline & Collotheca sp. & & $x$ & $x$ \\
\hline & Cephalodella sp. & $x$ & $x$ & $x$ \\
\hline & Cephalodella mucronata & $x$ & $x$ & \\
\hline & Brachionus mirus & $x$ & $x$ & $x$ \\
\hline & Anuraeopsis navicula & $x$ & $x$ & $x$ \\
\hline & Scaridium sp. & $x$ & & $X$ \\
\hline & Mytilina sp. & $x$ & & \\
\hline & Machrochaetus sp. & $\mathrm{X}$ & & \\
\hline & Notommata sp. & & & $x$ \\
\hline & Total de taxa & 36 & 34 & 39 \\
\hline
\end{tabular}

Entre os Cladocera, apenas C. Cornuta, C. silvestrii, B. hagmani, B. longirostris, D. birgei, I. Spinifer e A. retangula pulcra ocorreram em todos os tratamentos. controle apresentou o menor número de espécies de Cladocera (7) e o tratamento com Cr o maior (9).

No controle foram observadas 25 espécies de rotíferos e 22 espécies nos tratamentos com $\mathrm{Cr}$ e com $\mathrm{Cu}$, porém com diferentes composições. As espécies de Rotífera comuns à todos os tratamentos foram P. libera, $P$. vulgaris, $K$. cochlearis, $K$. americana, K. bostoniensis, T. pusilla, T. similis, T. chattonni, F. pejleri, L. bulla, L. 
Iunaris, L. stichaet, L. quadricarinata, C. unicornis, C. Iongicauda, Cephalodella sp., B. mirus e A. navicula.

A análise quantitativa do zooplâncton dos mesocosmos, considerando os principais grupos, em cada tratamento está apresentada nas Figuras 65 a 67.

Rotifera apresentou as maiores densidades em todos os tanques. As densidades iniciais foram de 790.000 ind $\mathrm{m}^{-3}$ para o controle; 209.000 ind. $\mathrm{m}^{-3}$ para o tanque com $\mathrm{Cu}$ e 353.500 ind. $\mathrm{m}^{-3}$ para o tanque com Cr. Após a contaminação dos tanques a densidade de rotiferos foi reduzida em ambos os tratamentos. A maior densidade para este grupo foi encontrada no tanque contaminado com $\mathrm{Cr}$ no início do experimento (2.799.000 ind. $\mathrm{m}^{-3}$ ), porém após a contaminação o tratamento com $\mathrm{Cr}$ apresentou as menores densidades até o final do experimento. No final do experimento a maior densidade de rotiferos foi apresentada pelo tratamento com $\mathrm{Cu}$.

Cladocera foi o segundo grupo em relação à densidade. No início do experimento as maiores densidades de Cladocera foram observadas no tratamento com Cu (30507 ind. $\left.\mathrm{m}^{-3}\right)$, seguido pelo controle $\left(12100\right.$ ind. $\left.\mathrm{m}^{-3}\right)$. O tratamento com $\mathrm{Cr}$ apresentou as menores densidades durante todo o experimento, atingindo a densidade máxima a $96 \mathrm{hs}$ do experimento $\left(6710\right.$ ind $\left.\mathrm{m}^{-3}\right)$, antes da contaminação e a menor a 192 hs (210 ind. $\left.\mathrm{m}^{-3}\right)$.

As maiores densidades de Copepoda ocorreram no tratamento com $\mathrm{Cr}$ durante todo o experimento, apesar da significativa redução nessas densidades após a contaminação do tanque, de 114.246 para 71607 ind. $\mathrm{m}^{-3}$. O controle apresentou as menores densidades no início do experimento, e apenas nas duas últimas coletas apresentou densidades maiores que o tratamento com $\mathrm{Cu}$.

A abundância relativa do zooplâncton pode ser observada nas figuras 68 a 70 . No início do experimento o zooplâncton do controle foi composta principalmente por Rotifera (98\% - antes da contaminação), com a contribuição de Cladocera aumentando ao longo do experimento, atingindo o máximo de $65 \%$. O mesmo foi observado para Copepoda, porem com menor contribuição.

No tratamento com $\mathrm{Cu}$, a contribuição de Rotifera no início do experimento foi de $68 \%$, atingindo um máximo de 95\% (360 h). Após a contaminação foi observada uma acentuada redução na abundância de Cladocera (0,4 \% - 288 hs). A abundância de Copeopoda também apresentou redução, de $22 \%$ no início do experimento para $4,3 \%$, em 360 hs. 


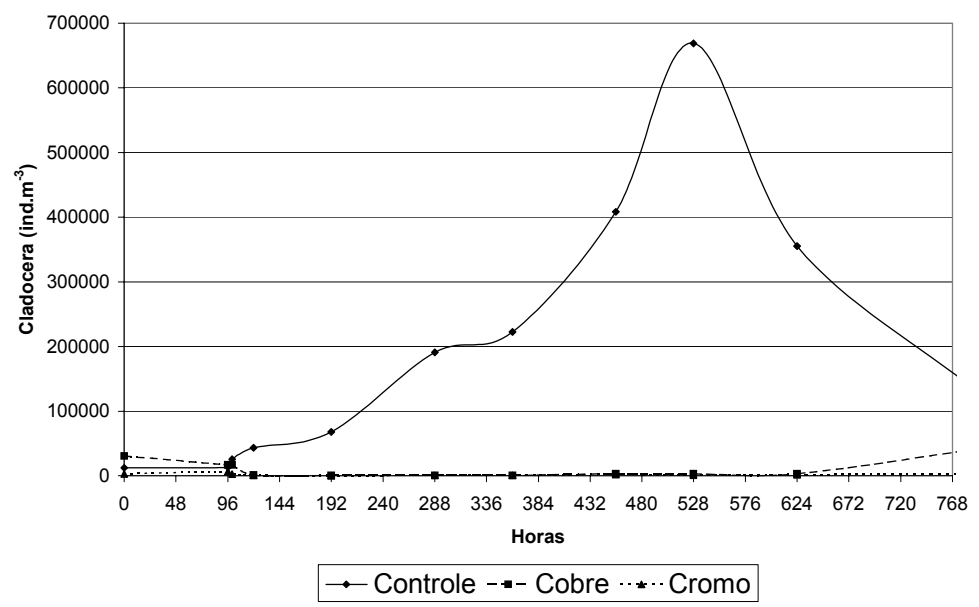

Figura 65: Densidade numérica de Cladocera (ind. $\mathrm{m}^{-3}$ ) nos mesocosmos controle, cromo e cobre.

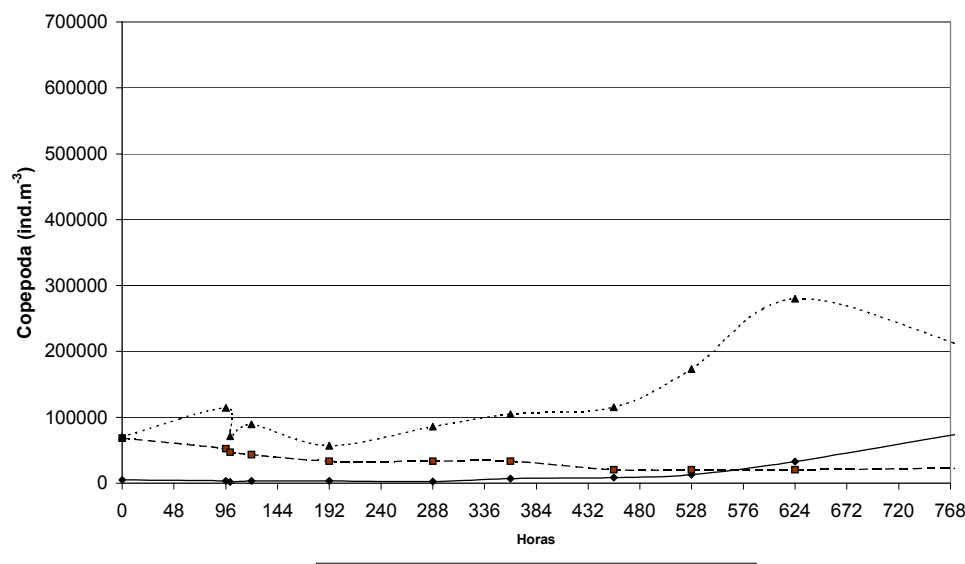

$\rightarrow$ Controle $-\because-$ Cobre $\cdots * \cdot \cdot$ Cromo

Figura 66: Densidade numérica de Copepoda (ind. $\mathrm{m}^{-3}$ ) nos mesocosmos controle, cromo e cobre.

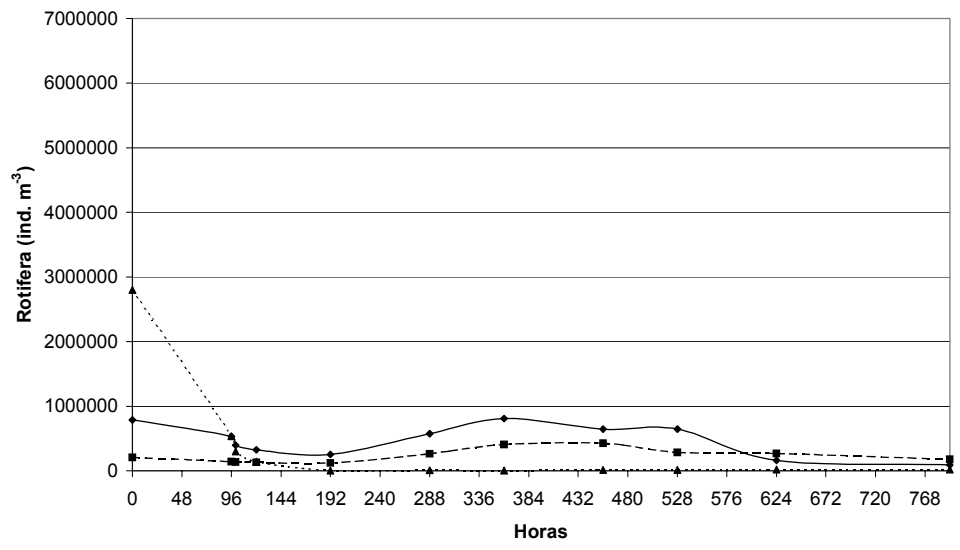

$\rightarrow$ Controle -- Cobre $\cdots \cdots$ Cromo

Figura 67: Densidade numérica de Rotifera (ind $\mathrm{m}^{-3}$ ) nos mesocosmos controle, cromo e cobre. 


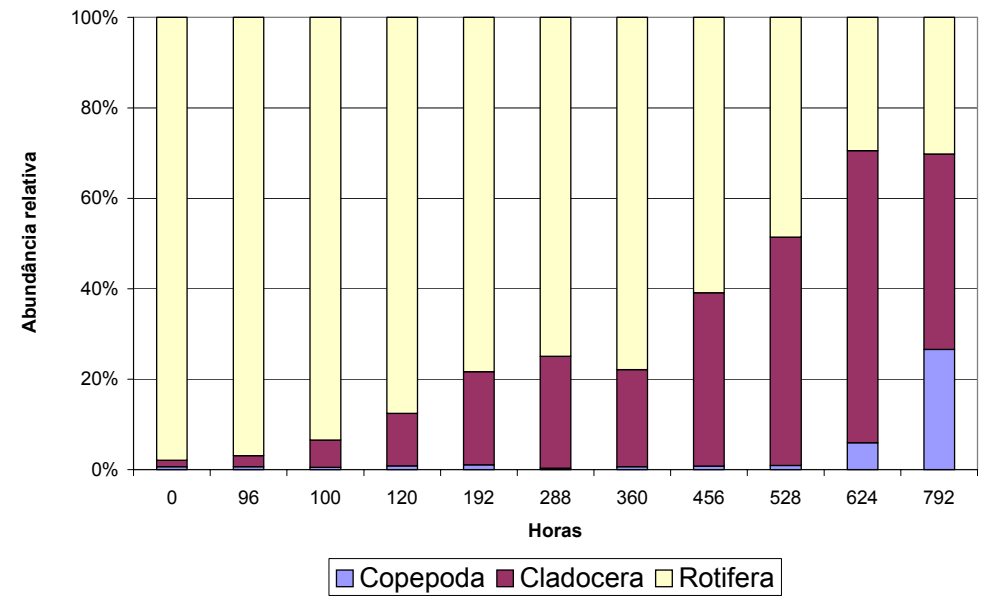

Figura 68: Abundância relativa de Cladocera, Copepoda e Rotifera no controle no decorrer do experimento. Colocar gráficos coloridos

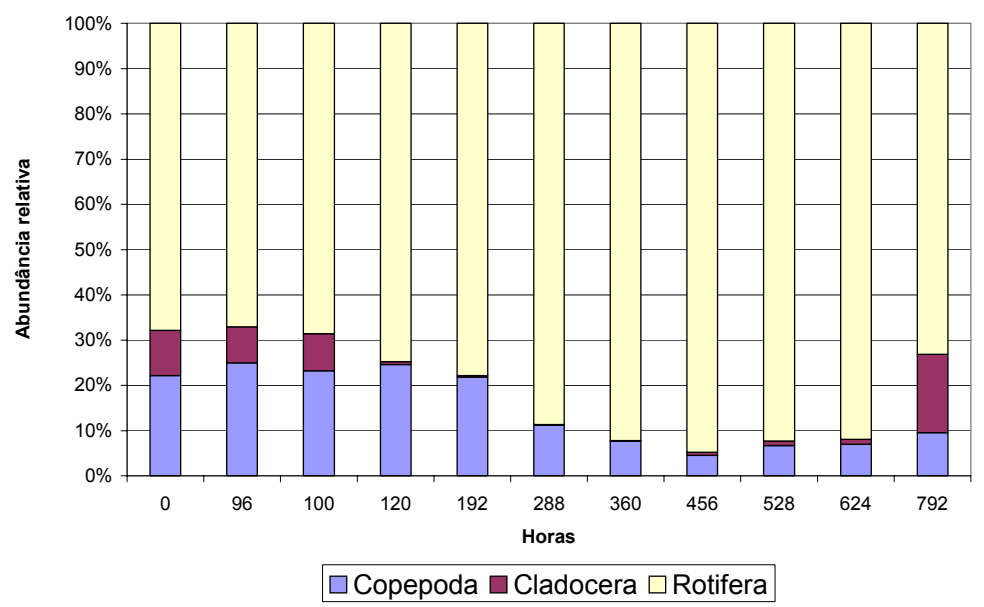

Figura 69: Abundância relativa de Cladocera, Copepoda e Rotifera no tratamento com Cu no decorrer do experimento.

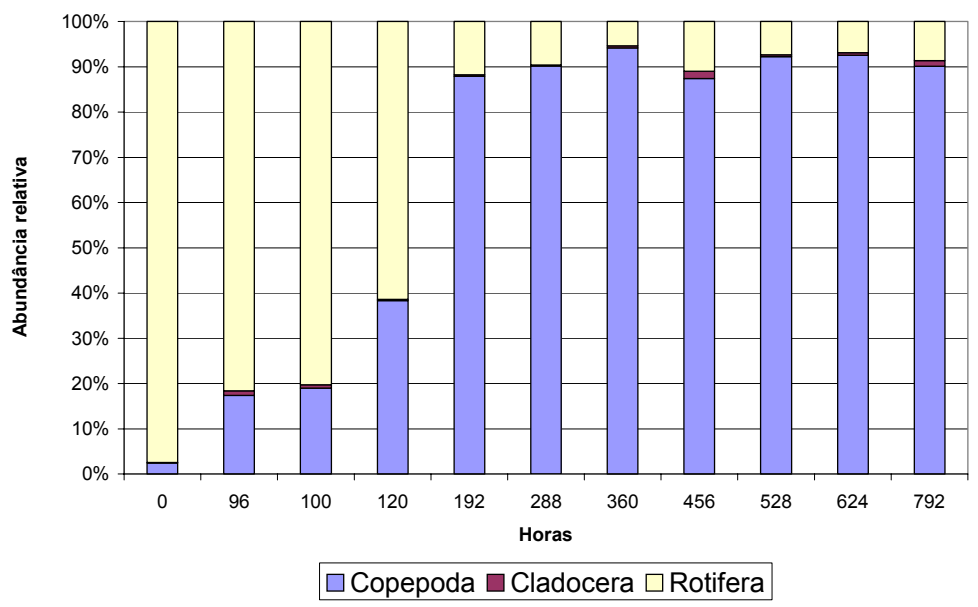

Figura 70: : Abundância relativa de Cladocera, Copepoda e Rotifera no tratamento com $\mathrm{Cr}$ no decorrer do experimento. 
No tratamento com Cr observou-se uma contribuição percentual muito reduzida dos Cladocera. Da mesma foram que nos outros tratamentos, no início do experimento a maior contribuição foi de Rotifera (97\%), ocorrendo um acentuado declínio após a contaminação, atingindo valores mínimos a 360 hs do início, representando apenas $5,4 \%$ da comunidade. Os Copepoda apresentaram uma contribuição muito mais significativa no tratamento com $\mathrm{Cr}(94 \%)$ que nos outros, atingindo

Os índices ecológicos foram calculados para a comunidade zooplanctônica total e estão apresentados na tabela 33.

O controle apresentou comportamento similar para os índices H', U', e D ao longo de todo o experimento, com valores finais e iniciais similares, tendo sido observadas variações principalmente nas amostras coletadas a 96, 360 e 624 hs do início do experimento. A riqueza, que apresentou valor superior no final do experimento em relação ao início.

Os maiores valores de $\mathrm{H}^{\prime}$ e U' foram obtidos para o tratamento com $\mathrm{Cu}$, e esses índices apresentaram valores finais e iniciais semelhantes, apresentando pequena variação no decorrer do experimento. Os valores de $D$ foram relativamente baixos com aumento após a contaminação dos tanques, apresentando um valor maior ao final do experimento que no início. A riqueza apresentou valores similares para o início e o final do experimento, verificando-se um declínio após a contaminação, nas amostras referentes a $120 \mathrm{~h}$.

$\mathrm{O}$ tratamento com $\mathrm{Cr}$ também apresentou resposta similar para a diversidade ao longo de todo o experimento, com valores finais superiores aos iniciais, tendo sido observado o aumento dos valores logo após a contaminação. O índice D apresentou decréscimo nos valores após a contaminação, com valores iniciais superiores aos iniciais. A riqueza apresentou valor final superior ao inicial, apesar de sofrer uma pequena redução após a contaminação. 
Tabela 33: Densidade $(\mathrm{N})$, riqueza $(\mathrm{S})$, diversidade $\left(\mathrm{H}^{\prime}\right)$, uniformidade $\left(\mathrm{U}^{\prime}\right)$ e dominância (D) no controle e nos tratamentos com $\mathrm{Cr}$ e Cu durante o período de estudo.

\begin{tabular}{|c|c|c|c|c|c|c|}
\hline \multicolumn{7}{|l|}{ Controle } \\
\hline Data & Horas & $\mathrm{H}^{\prime}$ & $U^{\prime}$ & $\mathrm{D}$ & $\mathrm{N}$ & $\mathrm{S}$ \\
\hline 28.03 & 0 & 2,5 & 0,6 & 0,2 & 807089,4 & 21 \\
\hline 01.040 & 96 & 1,9 & 0,4 & 0,5 & 554130 & 21 \\
\hline 01.044 & 100 & 2,1 & 0,5 & 0,4 & 425780 & 21 \\
\hline 02.04 & 120 & 2,0 & 0,5 & 0,4 & 373470 & 20 \\
\hline 05.04 & 192 & 2,7 & 0,6 & 0,2 & 328060 & 23 \\
\hline 09.04 & 288 & 2,6 & 0,6 & 0,2 & 771000 & 25 \\
\hline 12.04 & 360 & 2,9 & 0,6 & 0,2 & 1037300 & 24 \\
\hline 16.04 & 456 & 2,3 & 0,5 & 0,3 & 1066010 & 25 \\
\hline 19.04 & 528 & 2,1 & 0,4 & 0,3 & 1326970 & 25 \\
\hline 23.04 & 624 & 1,9 & 0,4 & 0,4 & 550270 & 24 \\
\hline 30.04 & 792 & 2,7 & 0,6 & 0,2 & 298200 & 22 \\
\hline \multicolumn{7}{|l|}{ Cromo } \\
\hline Data & Horas & $\mathrm{H}^{\prime}$ & $U^{\prime}$ & $\mathrm{D}$ & $\mathrm{N}$ & $\mathrm{S}$ \\
\hline 28.03 & 0 & 1,4 & 0,3 & 0,6 & 2872330 & 18 \\
\hline 01.040 & 96 & 2,3 & 0,5 & 0,4 & 656456 & 24 \\
\hline 01.044 & 100 & 2,5 & 0,6 & 0,3 & 376667 & 18 \\
\hline 02.04 & 120 & 2,3 & 0,6 & 0,3 & 233710 & 14 \\
\hline 05.04 & 192 & 2,0 & 0,5 & 0,4 & 64630 & 18 \\
\hline 09.04 & 288 & 1,8 & 0,4 & 0,4 & 95130 & 17 \\
\hline 12.04 & 360 & 1,4 & 0,4 & 0,5 & 111290 & 14 \\
\hline 16.04 & 456 & 1,9 & 0,4 & 0,4 & 131780 & 19 \\
\hline 19.04 & 528 & 1,5 & 0,4 & 0,5 & 188060 & 17 \\
\hline 23.04 & 624 & 2,2 & 0,5 & 0,3 & 302640 & 18 \\
\hline 30.04 & 792 & 2,3 & 0,5 & 0,3 & 224635 & 20 \\
\hline \multicolumn{7}{|l|}{ Cobre } \\
\hline Data & Horas & $\mathrm{H}^{\prime}$ & $U^{\prime}$ & D & $\mathrm{N}$ & $S$ \\
\hline 28.03 & 0 & 3,4 & 0,7 & 0,1 & 307867 & 30 \\
\hline 01.040 & 96 & 3,7 & 0,7 & 0,1 & 209572,3 & 31 \\
\hline 01.044 & 100 & 3,8 & 0,8 & 0,1 & 203117 & 31 \\
\hline 02.04 & 120 & 3,3 & 0,7 & 0,1 & 175913,7 & 23 \\
\hline 05.04 & 192 & 3,3 & 0,7 & 0,2 & 154263,3 & 26 \\
\hline 09.04 & 288 & 3,2 & 0,7 & 0,2 & 281793 & 29 \\
\hline 12.04 & 360 & 3,5 & 0,7 & 0,1 & 427070 & 33 \\
\hline 16.04 & 456 & 2,7 & 0,5 & 0,3 & 453663,3 & 32 \\
\hline 19.04 & 528 & 2,3 & 0,5 & 0,4 & 306380 & 26 \\
\hline 23.04 & 624 & 3,4 & 0,7 & 0,2 & 317440 & 32 \\
\hline 30.04 & 792 & 3,1 & 0,6 & 0,2 & 240557 & 31 \\
\hline
\end{tabular}

Comparando-se os índices obtidos para o controle como os índices obtidos para o tratamento com $\mathrm{Cr}$ através de análise de variância (ANOVA) pode-se concluir que ocorreram diferenças significativas a $p<0,05$ para a maioria dos índices calculados para a comunidade zooplanctônica. Apenas os índices U' $(p=0,17)$ e a densidade de organismos $(p=0,444)$, não apresentaram diferenças significativas entre os tratamentos, indicando a não ocorrência de efeitos sobre a diversidade da comunidade após a adição de $\mathrm{Cr}$. 
Foram observadas diferenças significativas entre todos os índices calculados para o controle e para o tratamento com $\mathrm{Cu}$, gerando valores de $\mathrm{p}$ sempre menores que 0,02. Assim, conclui-se que a exposição ao $\mathrm{Cu}$ provocou efeitos sobre a comunidade zooplanctônica tanto em relação à diversidade e riqueza, quanto em relação à abundância e equitabilidade. Os resultados de todas as avaliações estatísticas realizadas estão apresentados em apêndice.

Ao contrário do observado pelos experimentos em microcosmos, a adição de Cu provocou efeitos significativos sobre um número maior de índices que a adição de Cr.

\subsubsection{3 - Bentos}

Segundo GIESY \& HOOK (1989) a observação em campo da presença/ausência de organismos bentônicos é uma forma eficiente de se avaliar a contaminação de sedimentos. A análise da comunidade bentônica permite uma relevante abordagem ecológica dos sedimentos expostos à contaminação.

A avaliação dos organismos bentônicos presentes nos sedimentos dos tanques foi realizada pelo Ocean. MSc. Ricardo Wagner Reis Filho, em dissertação de mestrado relacionado a este trabalho, e já foram apresentados em REIS FILHO (2004).

As amostras foram avaliadas em grandes grupos, com o objetivo de aplicar uma abordagem rápida para a observação de alterações na estrutura em função da adição de metais aos sistemas. Na triagem das amostras, foram identificados os seguintes grupos: Chironomidae, Chaoboridae (Diptera); Polycentropodidae (Trichoptera) e Oligochaeta. As densidades médias obtidas para cada grupo no início e no final do experimento estão apresentadas na Tabela 34.

Foram observadas alterações na estrutura da comunidade para todos os tratamentos, porém, com redução mais acentuada nos mesocosmos contaminados. Após a contaminação por $\mathrm{Cr}$ e por $\mathrm{Cu}$, Chaoboridae e Oligochaeta foram encontrados em número muito menor nestes tratamentos que no controle, com acentuado decréscimo de todos os organismos nos sedimentos dos mesocosmos contaminados. Nos mesocosmos contaminados com $\mathrm{Cr}$ ocorreu uma redução de $86 \%$ na densidade total e no mesocosmos com $\mathrm{Cu}$ essa redução foi de $79 \%$. No controle ocorreu uma redução de $27 \%$, bem inferior ao observado nos demais tratamentos, indicando efeitos agudos pela exposição aos metais. 
Tabela 34: Densidade média dos grupos de macroinvertebrados bentônicos no controle e nos mesocosmos contaminados com $\mathrm{Cr}$ e Cu.

\begin{tabular}{|c|c|c|c|c|}
\hline & Grupo & 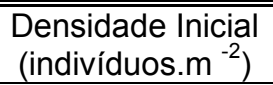 & $\begin{array}{l}\text { Densidade Final } \\
\text { (indivíduos. } \mathrm{m}^{-2} \text { ) }\end{array}$ & $\begin{array}{l}\% \text { de } \\
\text { Efeito }\end{array}$ \\
\hline \multirow[t]{5}{*}{ Controle } & Chironomidae & 720 & 1200 & +40 \\
\hline & Oligochaeta & 1600 & 240 & 85 \\
\hline & Chaoboridae & 440 & 480 & $+8,3$ \\
\hline & Policenropodidae & 80 & 160 & +50 \\
\hline & Total & 2840 & 2080 & 26,7 \\
\hline \multirow[t]{5}{*}{ Cromo } & Chironomidae & 480 & 200 & 58 \\
\hline & Oligochaeta & 1840 & 120 & 93 \\
\hline & Chaoboridae & 400 & 40 & 90 \\
\hline & Policenropodidae & & & \\
\hline & Total & 2720 & $3 \overline{6} 0$ & 86 \\
\hline \multirow[t]{5}{*}{ Cobre } & Chironomidae & 720 & 400 & 44,4 \\
\hline & Oligochaeta & 1320 & 40 & 96,9 \\
\hline & Chaoboridae & 240 & 40 & 83,3 \\
\hline & Policenropodidae & & & \\
\hline & Total & 2280 & $4 \overline{8} 0$ & 79,8 \\
\hline
\end{tabular}

A abundância relativa de cada grupo nas duas coletas estão apresentadas nas Figuras 71 e 72. No início do experimento a comunidade foi composta predominantemente por Oligochaeta em todos os tanques, sendo ao final do experimento o mesmo observado para Chironomidae. No início do experimento a distribuição dos grupos foi mais homogênea entre as amostras analisadas, o que não foi observado ao final, sugerindo a alteração nesta estrutura após a contaminação. Verifica-se que Oligochaeta e Chaoboridae foram mais afetados pela adição de metais (93\% no tratamento com $\mathrm{Cr}$ e $97 \%$ no tratamento com Cu, para Oligochaeta; e $90 \%$ no tratamento com $\mathrm{Cr}$ e $83 \%$ no tratamento com $\mathrm{Cu}$ para Chaoboridae), com maior resistência de Chironomidae (58 \% no tratamento com $\mathrm{Cr}$ e $44 \%$ no tratamento com $\mathrm{Cu}$ ). No entanto, no controle, Oligochaeta apresentou maior redução (85\%) do que Chaoboridae e Chironomidae, nos quais se verificou um aumento populacional (8,3 e $40 \%$, respectivamente). Assim, outros fatores podem ter ocorrido para a redução de Oligochaeta. 


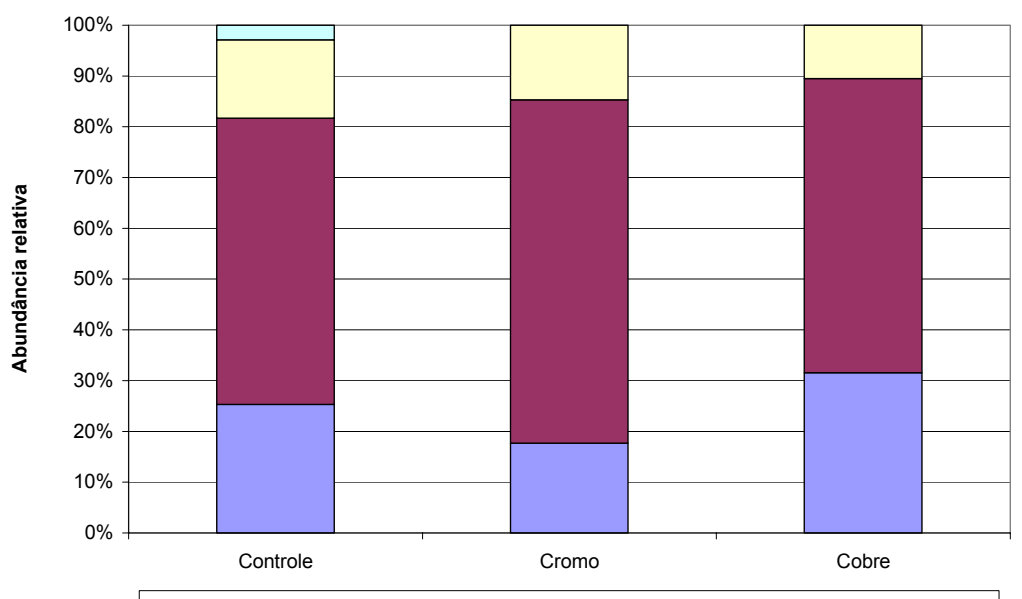

$\square$ Chironomidae $\square$ Oligochaeta $\square$ Chaoboridae $\square$ Policenropodidae

Figura 71: Abundância relativa dos grupos identificados nas amostras de sedimentos dos mesocosmos no início do experimento, antes da contaminação dos mesocosmos.

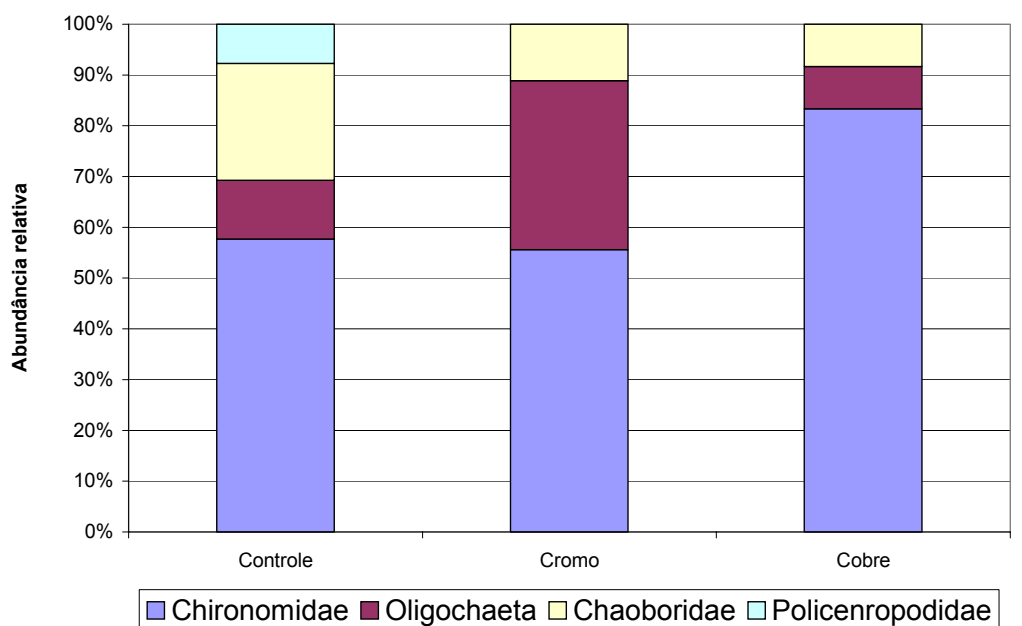

Figura 72: Abundância relativa dos grupos identificados nas amostras de sedimentos dos mesocosmos no final do experimento após a contaminação dos mesocosmos.

A partir dos dados obtidos para a comunidade bentônica fora calculados os índices de diversidade de Shannon e de equitabilidade de Pielou. Estes índices estão apresentados na tabela 35.

Tabela 35: Índices ecológicos calculados para a comunidade bentônica no início e no final do experimento.

\begin{tabular}{cccc|ccc}
\hline \hline & & 22.04 & & 30.04 & \\
\hline & Controle & Cromo & Cobre & Controle & Cromo & Cobre \\
\hline $\mathrm{N}$ & 2840 & 2280 & 2720 & 2080 & 480 & 360 \\
$\mathrm{~S}$ & 4 & 3 & 3 & 4 & 3 & 3 \\
$\mathrm{H}^{\prime}$ & 1,53 & 1,32 & 1,23 & 1,3 & 0,8 & 1,4 \\
$\mathrm{~J}^{\prime}$ & 0,8 & 0,8 & 0,8 & 0,7 & 0,5 & 0,9 \\
\hline \hline
\end{tabular}


As maiores alterações estruturais foram observadas nos tanques contaminados com $\mathrm{Cr}$, onde o índice de diversidade $\mathrm{H}^{\prime}$ foi reduzido de 1,23 para 0,8 e o de equitabilidade de 0,8 para 0,5 . O tratamento com $\mathrm{Cu}$ apresentou valores maiores para os índices finais do que para os índices iniciais. A densidade total de organismos $\left(\mathrm{org} / \mathrm{m}^{2}\right)$ apresentou uma redução significativa para ambos os tratamentos, sendo o número a densidade final equivalente a $13 \%$ da inicial para o tratamento com $\mathrm{Cr}$ e $21 \%$ para o $\mathrm{Cu}$.

As alterações na estrutura da comunidade bentônica não puderam ser avaliadas estatisticamente devido ao pequeno número de dados obtidos, uma vez que foi realizada apenas uma coleta após a contaminação. O decréscimo na densidade de organismos parece ser o parâmetro mais sensível dentre os avaliados para representar alterações na estrutura da comunidade.

\subsection{5- Bioensaios de Toxicidade}

Adicionalmente à avaliação das comunidades biológicas, bioensaios de toxicidade aguda com $D$. similis foram realizados com amostras coletadas imediatamente antes da contaminação, 2 e 4 hs depois da contaminação, e uma vez por semana até a perda da toxicidade. O resultados destes testes, em porcentagem de imobilidade, estão apresentados na tabela 36.

Tabela 36: Resultados dos testes de toxicidade aguda para $D$. similis das amostras coletadas nos mesocosmos controle e contaminados com $\mathrm{Cr}$ e $\mathrm{Cu}$ (\% de imobilidade).

\begin{tabular}{cccccc}
\hline & \multicolumn{5}{c}{ Data de Coleta } \\
\cline { 2 - 6 } Tanque & $01 / 04-0$ hs & $01 / 04-2$ hs & $01 / 04$ hs & $09 / 04$ & $16 / 04$ \\
\hline \hline Controle 1 & 20 & 0 & 6 & 0 & 0 \\
Controle 2 & 0 & 0 & 0 & 0 & 0 \\
Controle 3 & 0 & 0 & 0 & 13 & 0 \\
\hline Média & 7 & 0 & 2 & 4 & 0 \\
\hline Cromo 1 & 13 & 100 & 93 & 0 & 0 \\
Cromo 2 & 7 & 100 & 100 & 0 & 0 \\
Cromo 3 & 7 & 100 & 100 & 13 & 0 \\
\hline Média & 9 & 100 & 98 & 4 & 0 \\
\hline Cobre 1 & 0 & 100 & 87 & 0 & 5 \\
Cobre 2 & 0 & 80 & 66 & 6 & 0 \\
Cobre 3 & 0 & 100 & 93 & 0 & 5 \\
\hline Média & 0 & 93 & 82 & 2 & 3 \\
\hline \hline
\end{tabular}

Imediatamente após a contaminação dos mesocosmos, todas as amostras, exceto o controle, apresentaram toxicidade aguda para $D$. similis. A toxicidade das amostras dos tanques contaminados com Cu já diminuiu após 4 hs de contaminação, 
o que não foi observado para as amostras dos tanques com $\mathrm{Cr}$. Após 15 dias da contaminação, nenhuma amostra apresentou toxicidade aguda para $D$. similis. Verificou-se, no entanto, a necessidade de reduzir o intervalo de realização dos testes para a avaliação da perda de toxicidade com o tempo.

As concentrações de $\mathrm{Cr}$ determinadas nas amostras de água utilizada nos testes estão apresentadas na Tabela 37. Comparando-se com os valores de CE (50) de $\mathrm{Cr}$ determinados para $D$. similis nos testes realizados com soluções preparadas em laboratório a partir do meio de cultivo, os organismos apresentaram sensibilidade similar nos dois testes. O valor médio de CE (50) para $\mathrm{Cr}$ foi $22,6 \mu \mathrm{g} \cdot \mathrm{L}^{-1}$. Nos dois primeiros testes realizados com as amostras dos tanques as concentrações de $\mathrm{Cr}$ variaram entre 36,7 e $50 \mu \mathrm{g} \cdot \mathrm{L}^{-1}$ de $\mathrm{Cr}$, muito superiores aos valores de CE (50), e provocaram $100 \%$ de imobilidade nos organismos testados. Nos testes seguintes, com concentrações a partir de 19,8 $\mu \mathrm{g} \cdot \mathrm{L}^{-1}$, as amostras já deixaram de ser tóxicas.

Tabela 37: Concentrações de $\mathrm{Cr}\left(\mu \mathrm{g} \cdot \mathrm{L}^{-1}\right)$ determinadas nas amostras de água utilizadas nos testes de toxicidade aguda com $D$. similis.

\begin{tabular}{cccccc}
\hline \hline & $01 / 04-$ Oh & $01 / 04-2$ hs & $01 / 04-4$ hs & $09 / A b r$ & $16 / A b r$ \\
\hline \hline Cromo 1 & 0,0 & 44,9 & 40,2 & 7,7 & 3,8 \\
Cromo 2 & 0,0 & 48,5 & 36,7 & 6,6 & 0,6 \\
Cromo 3 & 0,0 & 50,1 & 45,6 & 19,8 & 7,5 \\
\hline Média & 0,0 & 47,9 & 40,8 & 11,4 & 3,9 \\
\hline Desvio Padrão & 0,0 & 2,7 & 4,5 & 7,3 & 3,4 \\
\hline \hline
\end{tabular}

Nos testes realizados com as amostras dos mesocosmos contaminados com $\mathrm{Cu}$, apesar da maior \% de imobilidade observada para as amostras de $2 \mathrm{~h}$, as maiores concentrações de $\mathrm{Cu}$ foram determinadas nas amostras coletadas 4 hs após a contaminação dos tanques. As amostras do tanque controle apresentaram concentrações de Cu entre 3,6 e $12 \mu \mathrm{g} . \mathrm{L}^{-1}$, sem porém apresentar toxicidade para os organismos testados. As amostras coletadas 2 hs após a contaminação dos mesocosmos apresentaram concentrações de $\mathrm{Cu}$ entre 13,6 e 17,2 $\mu \mathrm{g} \cdot \mathrm{L}^{-1}$, e provocaram entre 80 e $100 \%$ de imobilidade nos organismos. A CE (50) determinada para $\mathrm{Cu}$ com as culturas de $D$. similis foi igual a $10 \mu \mathrm{g} \cdot \mathrm{L}^{-1}$. O fato de não ter sido observada toxicidade aguda para os controles sugere que a toxicidade do $\mathrm{Cu}$ tenha sido menor quando adicionado a águas naturais do que à água de cultivo. Porém, o intervalo entre as concentrações não tóxicas e tóxicas do Cu para $D$. similis aparenta ser bastante restrito, pois concentrações não muito superiores às determinadas nos controles provocaram toxicidade aguda para os organismos expostos às amostras dos mesocosmos contaminados com $\mathrm{Cu}$. 
Tabela 38: Concentrações de $\mathrm{Cu}\left(\mu \mathrm{g} \cdot \mathrm{L}^{-1}\right)$ determinadas nas amostras de água utilizadas nos testes de toxicidade aguda com $D$. similis.

\begin{tabular}{lccccc}
\hline \hline & $01 / 04-$ Oh & 01/04 - 2 hs & $01 / 04-4$ hs & 09/Abr & 16/Abr \\
\hline \hline Controle 1 & 9,2 & 6,6 & 10,9 & 7,4 & 8,2 \\
Controle 2 & 8,6 & 11,0 & 11,7 & 5,7 & 7,7 \\
Controle 3 & 7,6 & 3,6 & 11,9 & 9,0 & 8,3 \\
\hline Média & 8,5 & 7,1 & 11,5 & 7,4 & 8,0 \\
\hline Desvio Padrão & 0,8 & 3,7 & 0,5 & 1,7 & 0,3 \\
\hline \hline Cobre 1 & 6,3 & 13,6 & 17,8 & 6,3 & 6,8 \\
Cobre 2 & 2,9 & 15,8 & 20,6 & 7,0 & 8,3 \\
Cobre 3 & 3,2 & 17,2 & 24,7 & 5,9 & 8,4 \\
\hline Média & 4,2 & 15,5 & 21,0 & 6,4 & 7,8 \\
\hline Desvio Padrão & 1,9 & 1,8 & 3,5 & 0,6 & 0,9 \\
\hline \hline
\end{tabular}

\subsection{6 - Avaliação da metodologia empregada nos experimentos em mesocosmos (aspectos funcionais e estruturais)}

A comparação entre os valores gerados para cada parâmetro estudado em cada uma das réplicas de cada tratamento foi avaliada através da análise de variância (ANOVA, $p<0,05)$ com auxílio dos softwares Excel e MINITAB 13.

Em relação às variáveis avaliadas na água superficial, foram observadas diferenças significativas para o maior número de variáveis entre as réplicas do controle. Estas diferenças foram observadas para $\mathrm{pH}$, oxigênio dissolvido, material em suspensão total, material em suspensão orgânico, fósforo total, nitrato, silicato, e clorofila. O tratamento com $\mathrm{Cr}$ apresentou diferenças significativas entre as réplicas apenas para $\mathrm{o} \mathrm{pH}$, a condutividade e silicato. Cabe ressaltar que os valores de condutividade e silicato foram significativamente diferentes entre as réplicas de todos os tratamentos. As réplicas do tratamento com $\mathrm{Cu}$ também apresentaram diferenças significativas para um grande número de parâmetros, sendo: oxigênio dissolvido, condutividade, material em suspensão total, orgânico e inorgânico, fósforo total, silicato e clorofila. As concentrações de $\mathrm{Cr}$ ou $\mathrm{Cu}$ não variaram entre as réplicas em nenhum dos tratamentos.

A variabilidade da concentração de metais nos organismos e nas amostras de água intersticial analisadas não pôde ser avaliada em função do número muito reduzido de amostras coletadas, e a não possibilidade de se trabalhar com réplicas em alguns casos. 
Os sedimentos apresentaram concentrações de matéria orgânica, fósforo total, nitrogênio total e metais totais praticamente homogêneas a todos os tanques, não apresentando diferenças entre as réplicas.

Como não foram analisadas réplicas das amostras referentes à comunidade biológica, a reprodutibilidade da metodologia empregada não pôde ser avaliada quanto a esse aspecto; o mesmo tendo ocorrido nas avaliações da produtividade primária. Em relação à comunidade zooplanctônica os mesocosmos apresentaram maior riqueza e diversidade de espécies que os microcosmos, como era esperado, em função do tamanho dos experimentos.

$\mathrm{O}$ tempo de experimento possibilitou a restauração do $\mathrm{Cu}$ às concentrações inicias, o que não foi observado para o $\mathrm{Cr}$. Em ambos os casos a riqueza de espécies na comunidade zooplanctônica apresentou valores similares aos iniciais no final do experimento, apesar do decréscimo observado após a contaminação dos mesocosmos.

Comparando-se a variabilidade entre as réplicas dos mesocosmos e dos microcosmos, observa-se o aumento da variabilidade com o aumento das escalas espacial e temporal, de acordo com o já relatado pela literatura (CAIRNS, 1995). Segundo KEMP et al. (2001), a semelhança com o sistema natural aumenta com o tamanho do sistema em espaço, porém quanto maior o tempo de experimento, maiores são as diferenças entre as características experimentais e naturais.

A metodologia utilizada neste experimento apresentou-se adequada para os objetivos propostos. Apesar da variabilidade entre as réplicas observada, efeitos sobre as características estruturais e funcionais do sistema puderam ser observados, devendo-se ressaltar que as principais diferenças observadas foram nas variáveis analisados na água superficial, suscetível, naturalmente, a variações rápidas em função das características. 


\section{3- Análise dos efeitos de $\mathrm{Cr}$ e $\mathrm{Cu}$ em ecossistemas aquáticos através de estudos em mesocosmos: aspectos funcionais e bioacumulação}

\subsection{1- Variáveis físico-químicas, químicas e biológicas (clorofila) da água}

\subsubsection{1- Cromo e Cobre}

As concentrações médias de $\mathrm{Cr}$ e $\mathrm{Cu}$ nos mesocosmos em cada data estão apresentadas nas figuras 73 e 74 (valores individuais em Apêndice).

Cromo não foi detectado em nenhuma das amostras coletadas antes da contaminação dos tanques, assim como em nenhuma das amostras coletadas no controle durante todo o experimento. As maiores concentrações (47 $\mu \mathrm{g} \cdot \mathrm{L}^{-1}$ em 20/11 e 12/12) foram determinadas nas amostras coletadas após 3 horas de contaminação dos tanques em ambas as fases do experimento. Cromo deixou de ser detectado nas amostras de água dos tanques após cerca de cinco dias da contaminação.

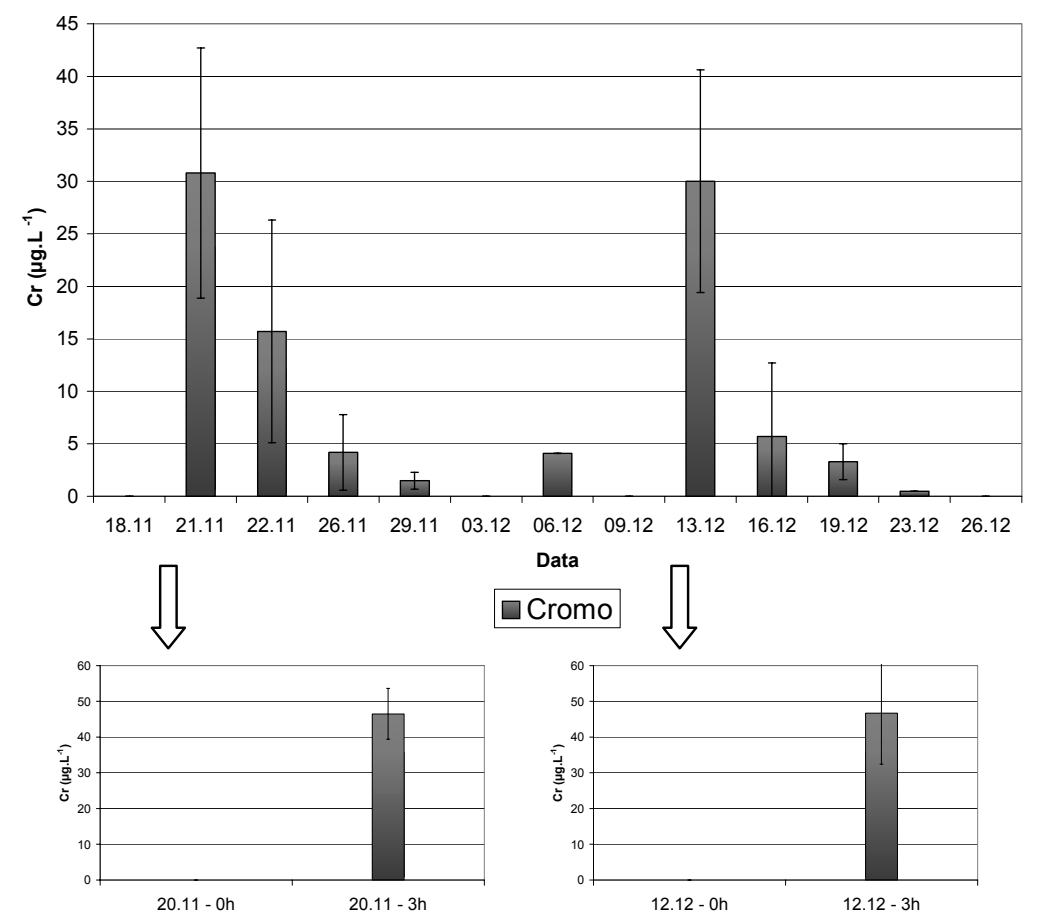

Figura 73 : Concentrações médias de $\mathrm{Cr}\left(\mu \mathrm{g} \cdot \mathrm{L}^{-1}\right)$ determinadas nas amostras de água nos mesocosmos contaminados com $\mathrm{Cr}$ durante o período de estudo (as barras de erros referem-se ao desvio padrão da média entre as réplicas dos mesocosmos).

A maior concentração de $\mathrm{Cu}$ foi determinada nas amostras coletadas 3 horas após a contaminação dos tanques, nas duas fases do experimento, sendo que na 
segunda fase essas concentrações foram maiores que na primeira $\left(37,3\right.$ e $23,4 \mu \mathrm{g} \cdot \mathrm{L}^{-1}$, respectivamente). A concentração de $\mathrm{Cu}$ na água dos tanques contaminados foi restaurada à concentração inicial após 10 dias da contaminação na primeira fase e após 4 dias na segunda fase.

As concentrações de $\mathrm{Cu}$ determinadas na água superficial de cada unidade experimental, em cada uma das coletas constam do Apêndice. As médias das concentrações determinadas estão apresentadas na figura 74 .
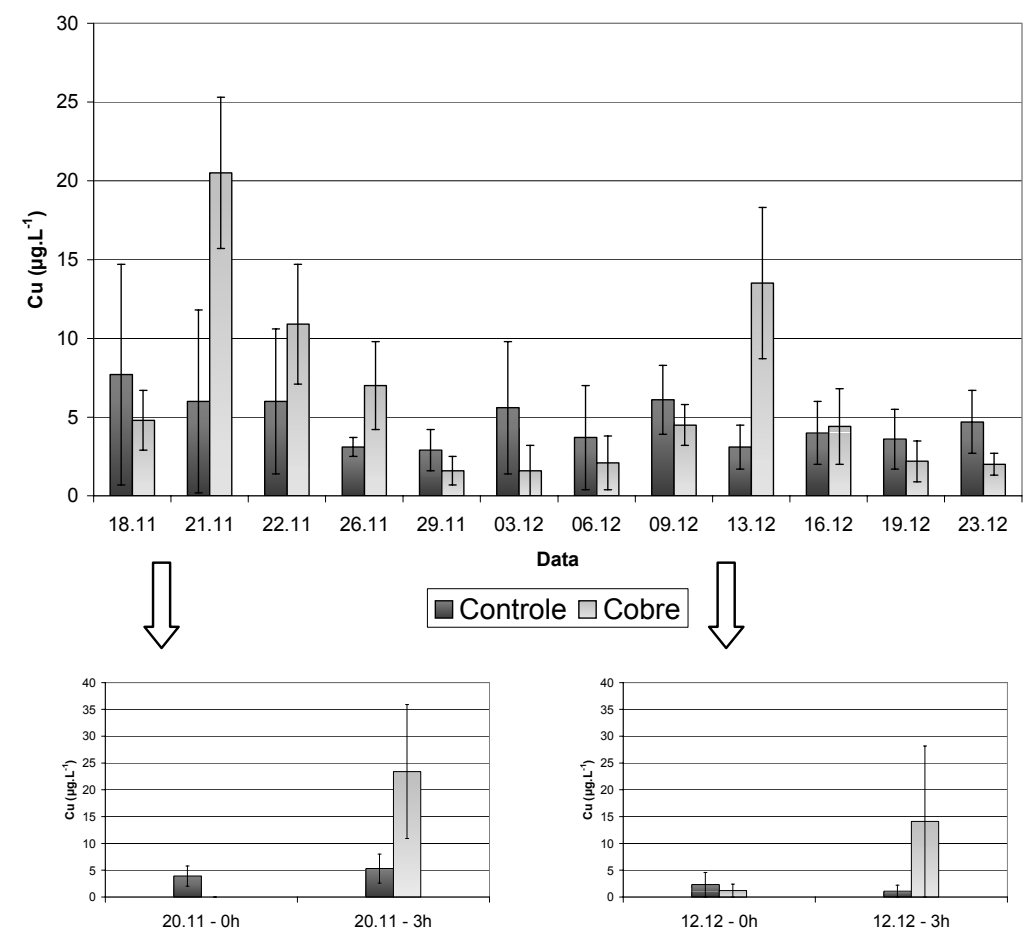

Figura 74: Concentrações médias de $\mathrm{Cu}\left(\mu \mathrm{g} \cdot \mathrm{L}^{-1}\right)$ determinadas nas amostras de água nos controles e nos mesocosmos contaminados com $\mathrm{Cu}$ durante o período de estudo (as barras de erros referem-se ao desvio padrão da média entre as réplicas dos mesocosmos).

\subsubsection{2- Oxigênio dissolvido, condutividade, $\mathrm{pH}$ e temperatura da água}

As variáveis físico-químicas (oxigênio dissolvido, condutividade, $\mathrm{pH}$ e temperatura), determinadas em cada unidade experimental, durante todo o experimento, estão apresentadas em apêndice. Os valores médios obtidos estão apresentados nas Figuras 75 a 78.

$\mathrm{Na}$ análise realizada 3 hs após a primeira contaminação, nos experimentos com $\mathrm{Cu}$ e $\mathrm{Cr}$ verificou-se um pequeno decréscimo nas concentrações de oxigênio, em relação ao controle $\left(6,3 \mathrm{mg} \cdot \mathrm{L}^{-1}\right.$ nas amostras do controle e $5.9 \mathrm{mg} \cdot \mathrm{L}^{-1} \mathrm{em}$ ambos os experimentos). Os tanques contaminados com $\mathrm{Cr}$ apresentaram as menores concentrações de oxigênio dissolvido entre os três tratamentos durante todo o 
experimento, sendo a menor concentração $\left(5,2 \mathrm{mg} \cdot \mathrm{L}^{-1}\right)$ observada no dia seguinte à primeira contaminação. As concentrações de oxigênio dissolvido determinadas nos tanques contaminados com $\mathrm{Cu}$ foram semelhantes às determinadas nos controles (Figura 75).

A condutividade (Figura 76) permaneceu praticamente constante durante o experimento, variando menos de $1 \mu \mathrm{S} . \mathrm{cm}^{-1}$, em todos os tratamentos. Observou-se apenas um pequeno aumento nos valores determinados nos tanques após a contaminação com ambos os metais.

Durante a primeira fase do experimento, antes da inclusão de peixes e macrófitas, os valores de $\mathrm{pH}$ permaneceram praticamente constantes. Após a inclusão dos peixes e macrófitas nos mesocosmos esses valores apresentaram uma grande variação entre as coletas, em todos os tratamentos.

A temperatura da água dos mesocosmos contaminados com $\mathrm{Cr}$ e $\mathrm{Cu}$ foi similar a do controle, não sendo observadas diferenças entre os mesocosmos.

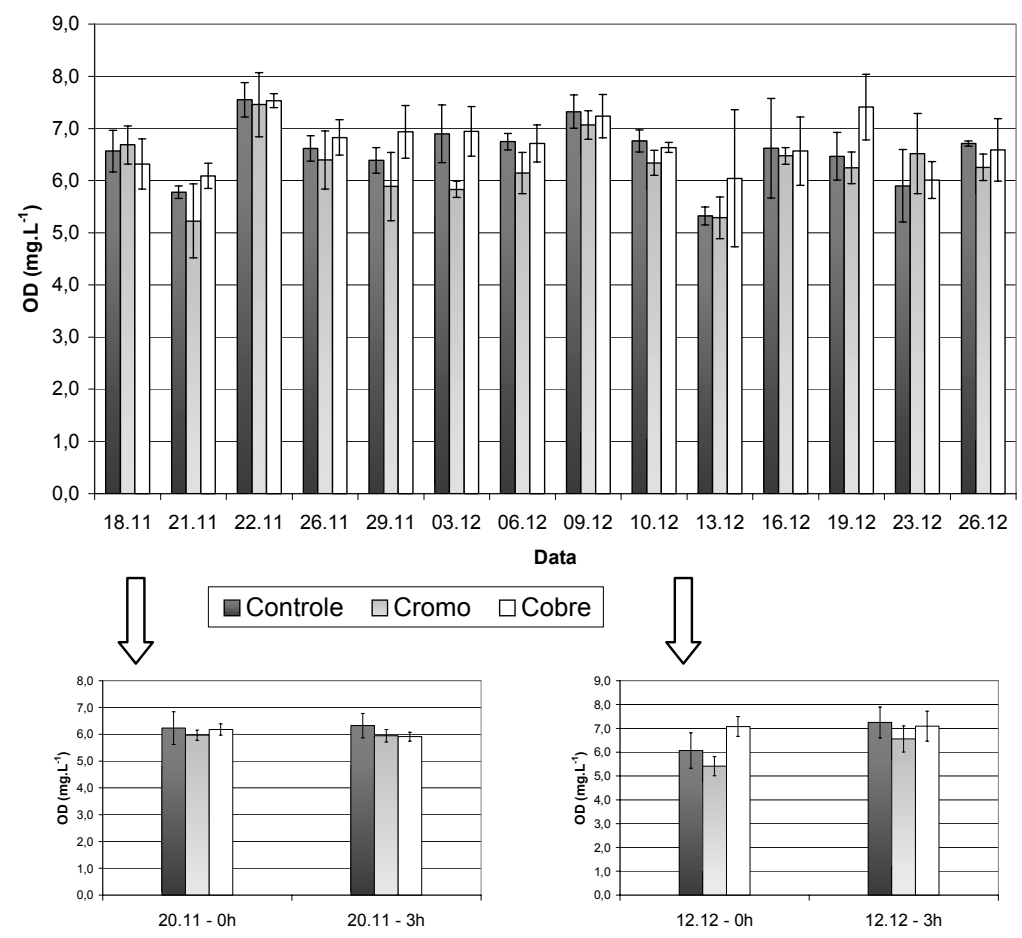

Figura 75: Concentrações médias de oxigênio dissolvido $\left(\mathrm{mg}^{-\mathrm{L}^{-1}}\right)$ determinadas nas amostras de água no controle e nos mesocosmos contaminados com $\mathrm{Cr}$ e $\mathrm{Cu}$ durante o período de estudo (as barras de erros referem-se ao desvio padrão da média entre as réplicas dos mesocosmos). 


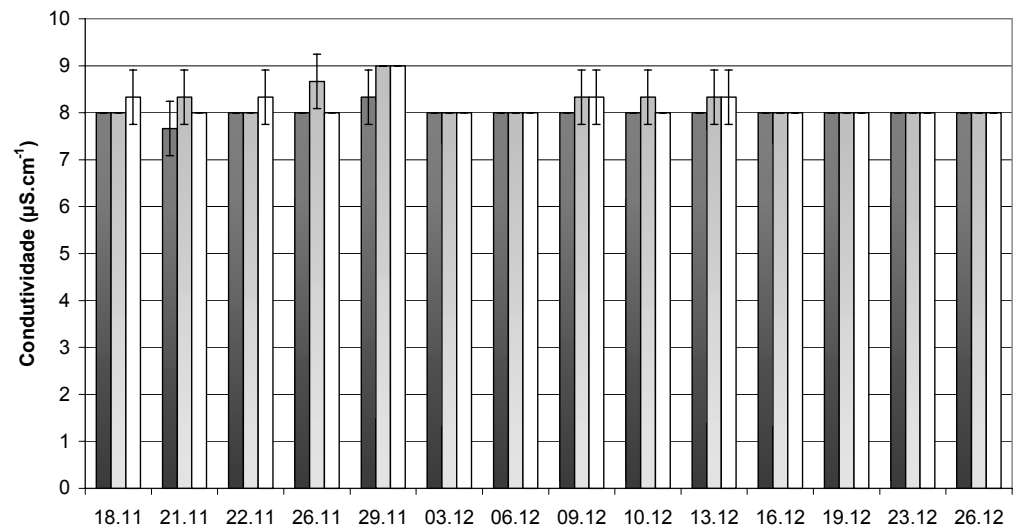

$\sqrt{\square \text { Controle } \square \text { Cromo } \square \text { Cobre }}$
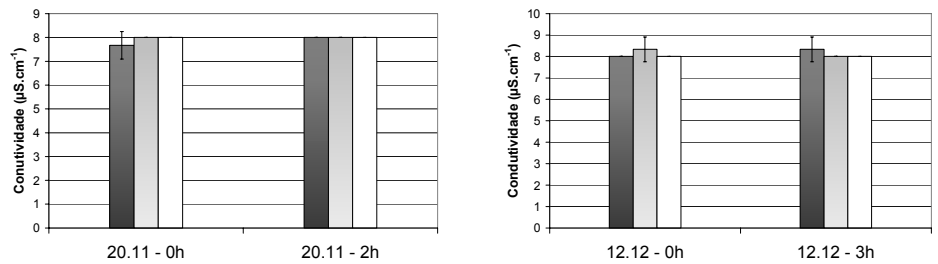

Figura 76: Condutividade média $\left(\mu \mathrm{S} . \mathrm{cm}^{-1}\right)$ determinadas nas amostras de água no controle e nos mesocosmos contaminados com $\mathrm{Cr}$ e Cu durante o período de estudo (as barras de erros referem-se ao desvio padrão da média entre as réplicas dos mesocosmos).
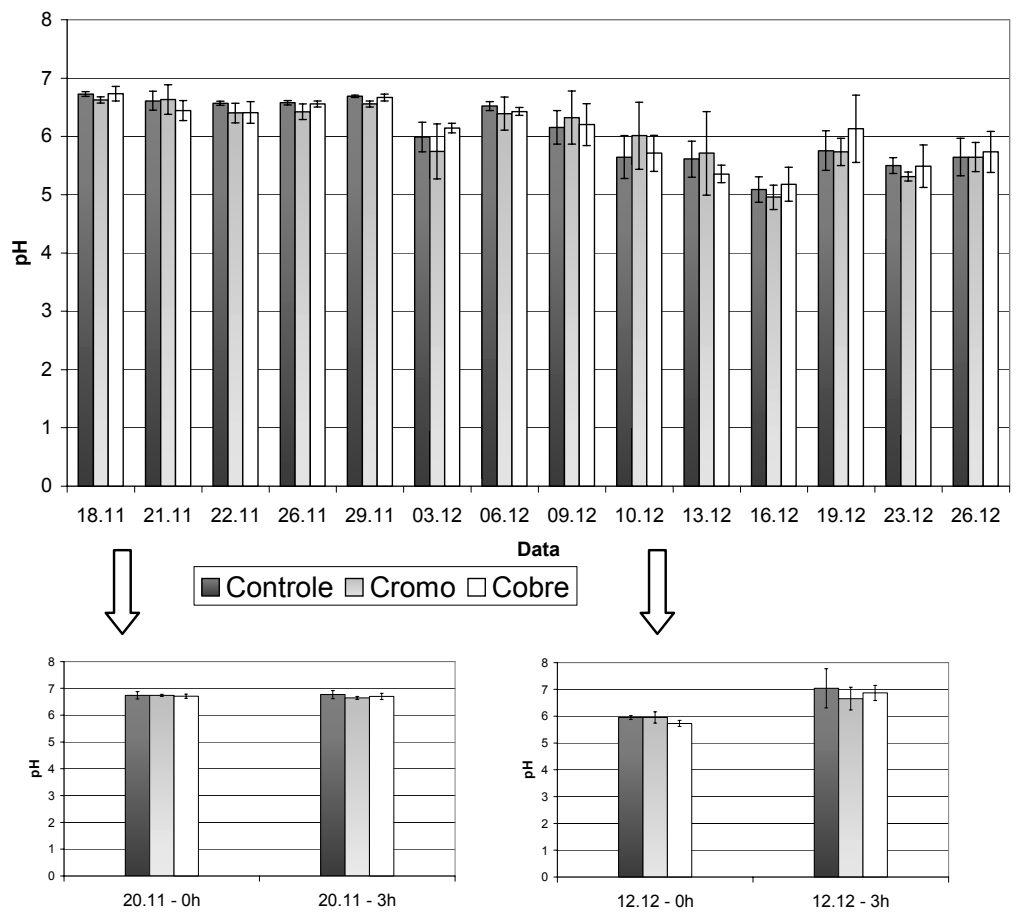

Figura 77: Valores médios de pH determinados nas amostras de água no controle e nos mesocosmos contaminados com $\mathrm{Cr}$ e Cu durante o período de estudo (as barras de erros referem-se ao desvio padrão da média entre as réplicas dos mesocosmos). 

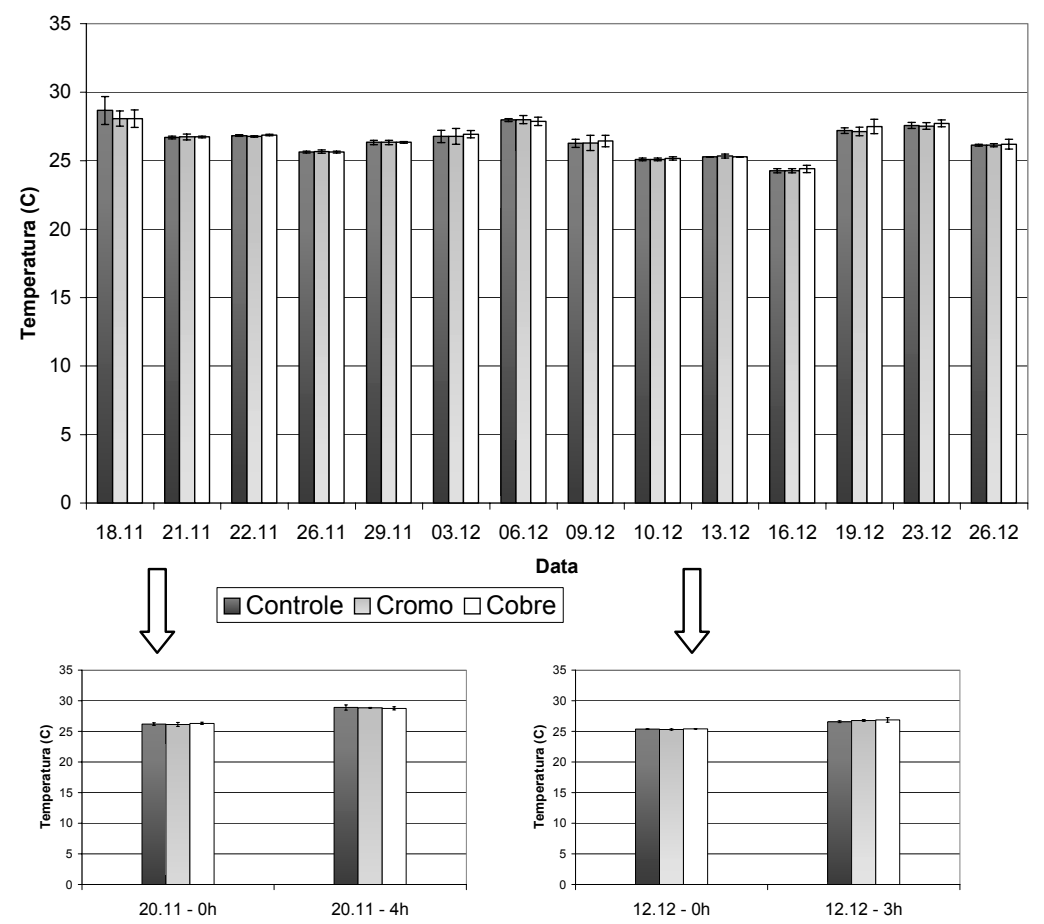

Figura 78: Valores médios de temperatura $\left({ }^{\circ} \mathrm{C}\right)$ determinados nas amostras de água no controle e nos mesocosmos contaminados com $\mathrm{Cr}$ e $\mathrm{Cu}$ durante o período de estudo (as barras de erros referem-se ao desvio padrão da média entre as réplicas dos mesocosmos).

\subsubsection{3- Clorofila}

As concentrações de clorofila determinadas na água de cada unidade experimental, durante o período de estudo estão apresentadas em Apêndice, e as médias das concentrações determinadas estão apresentadas na figura 79 .

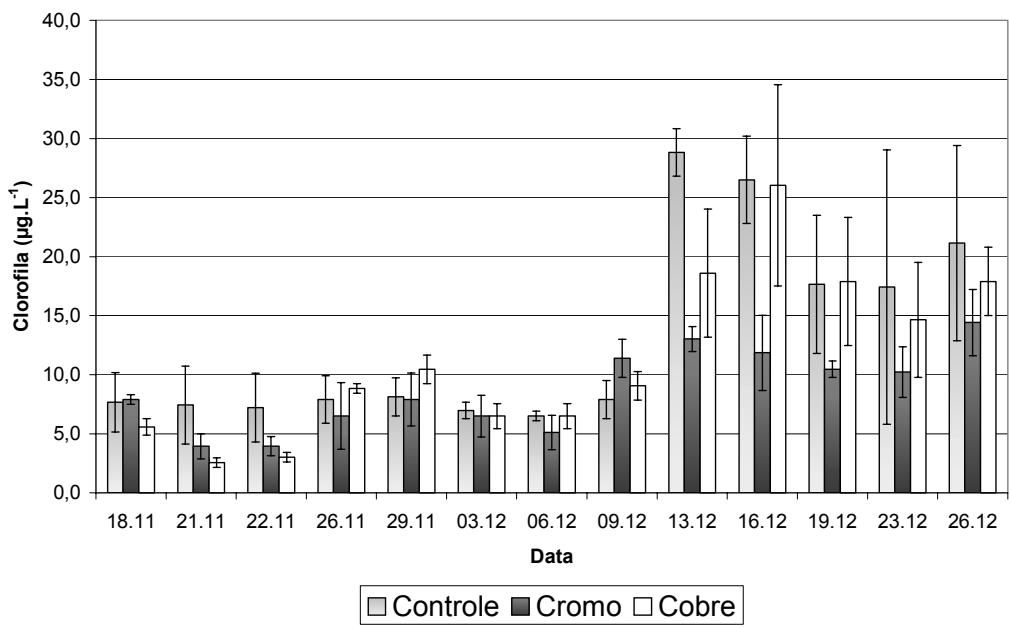

Figura 79: Concentrações $\left(\mu \mathrm{g} \cdot \mathrm{L}^{-1}\right)$ médias de clorofila determinadas nas amostras de água no controle e nos mesocosmos contaminados com $\mathrm{Cr}$ e $\mathrm{Cu}$ durante o período de estudo (as barras de erros referem-se ao desvio padrão da média entre as réplicas dos mesocosmos). 
$\mathrm{Na}$ primeira parte do experimento, as concentrações de clorofila variaram entre 3 e $10 \mu \mathrm{g} \cdot \mathrm{L}^{-1}$, considerando-se todos os tratamentos. Após a introdução dos peixes e macrófitas, a concentração de clorofila aumentou significativamente em todos os mesocosmos, atingindo valor máximo de $29 \mu \mathrm{g} . \mathrm{L}^{-1}$ no controle em 13 de dezembro. $\mathrm{Na}$ primeira fase do experimento, os tanques contaminados com $\mathrm{Cu}$ apresentaram as menores concentrações de clorofila $\left(2,6 \mu \mathrm{g} \cdot \mathrm{L}^{-1}\right)$, sendo que na segunda fase, contando com a presença de peixes e macrófitas, as menores concentrações foram apresentadas pelos tanques contaminados com $\mathrm{Cr}\left(10 \mu \mathrm{g} \cdot \mathrm{L}^{-1}\right)$.

\subsubsection{4- Material em Suspensão}

As concentrações de material em suspensão total, orgânico e inorgânico, determinadas na água de cada unidade experimental durante o período de estudo, estão apresentadas em Apêndice. As concentrações médias para cada tratamento estão apresentadas nas Figuras 80 a 82 . Na coleta seguinte à primeira contaminação, a concentração de material em suspensão total no tratamento com $\mathrm{Cr}\left(3,0 \mathrm{mg} \cdot \mathrm{L}^{-1}\right)$ foi maior que no controle e no tratamento com Cu (2,1 mg. $\mathrm{L}^{-1}$ nos dois casos). As concentrações de material em suspensão total foram maiores ao final do experimento, para todos os tratamentos, sendo que os tanques contaminados com $\mathrm{Cu}$ não apresentaram valores muito diferentes do controle. A concentração média determinada no experimento com $\mathrm{Cr}$ apresentou o menor valor $\left(1,6 \mathrm{mg} \cdot \mathrm{L}^{-1}\right)$ no dia 16 de dezembro, entre todas as datas (Figura 80).

As concentrações de material em suspensão orgânico (Figura 81) apresentaram o mesmo padrão que o material em suspensão total, sendo os maiores valores determinados no dia 13 de dezembro para todos os tratamentos $\left(4,8 \mathrm{mg} \cdot \mathrm{L}^{-1}\right.$ no controle, 3,5 mg. $\mathrm{L}^{-1}$ no tratamento com $\mathrm{Cr}$ e $5,0 \mathrm{mg} \cdot \mathrm{L}^{-1}$ no tratamento com $\mathrm{Cu}$ ). tratamento com $\mathrm{Cr}$ apresentou decréscimo nas concentrações após a primeira contaminação (de 3,0 para $1,9 \mathrm{mg} \cdot \mathrm{L}^{-1}$ ), porém, na segunda contaminação foi observado o contrário (de 2,9 para 3,5 mg. $\mathrm{L}^{-1}$ ). De forma geral, foram observados valores mais altos para o material em suspensão orgânico após a inclusão das peixes e macrófitas nos mesocosmos).

As concentrações de material em suspensão inorgânico determinadas no controle foram superiores às observadas nos outros tanques mesmo antes da contaminação $\left(2,1 \mathrm{mg} \cdot \mathrm{L}^{-1}\right.$ para o controle, $0,5 \mathrm{mg} \cdot \mathrm{L}^{-1}$ para o tratamento com $\mathrm{Cr}$ e 0,1 mg. $\mathrm{L}^{-1}$ para o tratamento com $\mathrm{Cu}$ ), e todos os tratamentos apresentaram um decréscimo logo na segunda coleta (21 de novembro). Em 9 de dezembro foi observado um aumento na concentração do material em suspensão inorgânico para todos os tratamentos. $\mathrm{O}$ tratamento com $\mathrm{Cr}$ apresentou a maior concentração entre 
todos os tratamentos, durante o período de estudo, na última coleta, em 26 de dezembro $\left(2,8 \mathrm{mg} \cdot \mathrm{L}^{-1}\right)$.

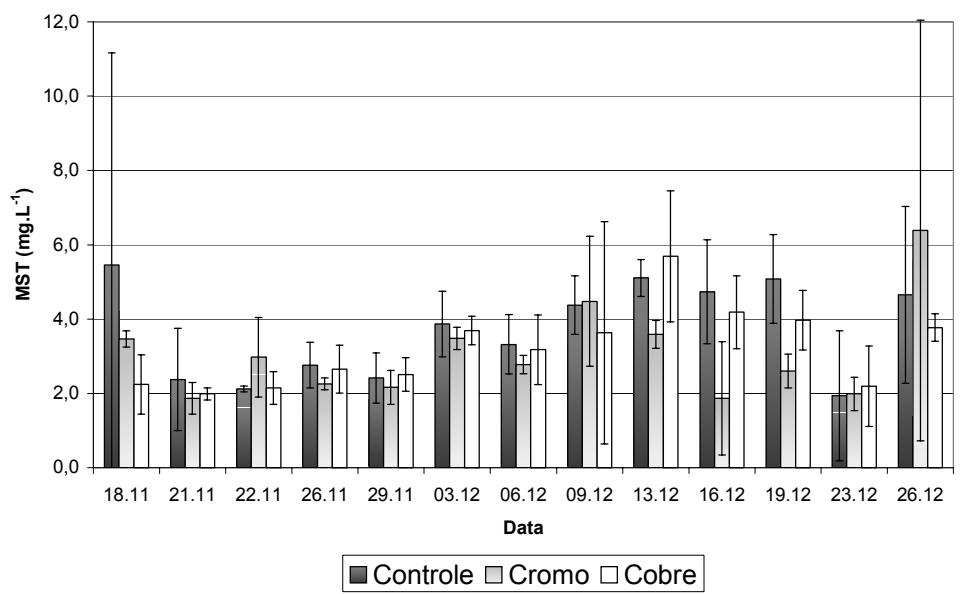

Figura 80: Concentrações médias $\left(\mathrm{mg}^{\mathrm{L}} \mathrm{L}^{-1}\right)$ de material em suspensão total determinadas nas amostras de água no controle e nos mesocosmos contaminados com $\mathrm{Cr}$ e $\mathrm{Cu}$ durante o período de estudo (as barras de erros referem-se ao desvio padrão da média entre as réplicas dos mesocosmos).

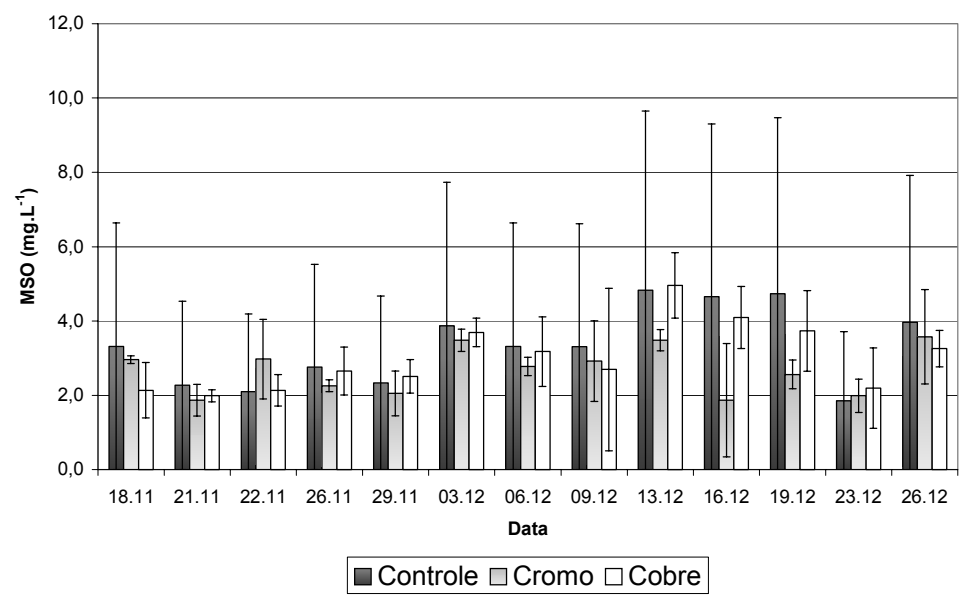

Figura 81: Concentrações médias $\left(\mathrm{mg}^{-\mathrm{L}^{-1}}\right)$ de material em suspensão orgânico determinadas nas amostras de água no controle e nos mesocosmos contaminados com $\mathrm{Cr}$ e $\mathrm{Cu}$ durante o período de estudo (as barras de erros referem-se ao desvio padrão da média entre as réplicas dos mesocosmos). 


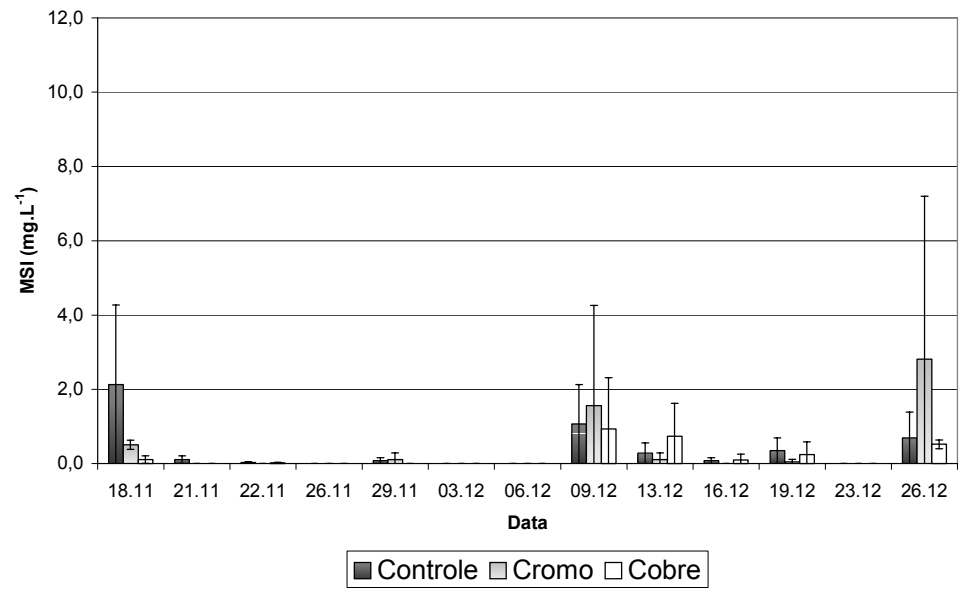

Figura 82: Concentrações médias (mg.L-1) de material em suspensão inorgânico determinadas nas amostras de água no controle e nos mesocosmos contaminados com $\mathrm{Cr}$ e $\mathrm{Cu}$ durante o período de estudo (as barras de erros referem-se ao desvio padrão da média entre as réplicas dos mesocosmos).

\subsubsection{5- Nutrientes nitrogenados, fosfatados e silicato}

As concentrações de silicato dissolvido determinadas na água de cada unidade experimental, durante o período de estudo, estão apresentadas em Apêndice, sendo que as médias das concentrações determinadas estão apresentadas na Figura 83.

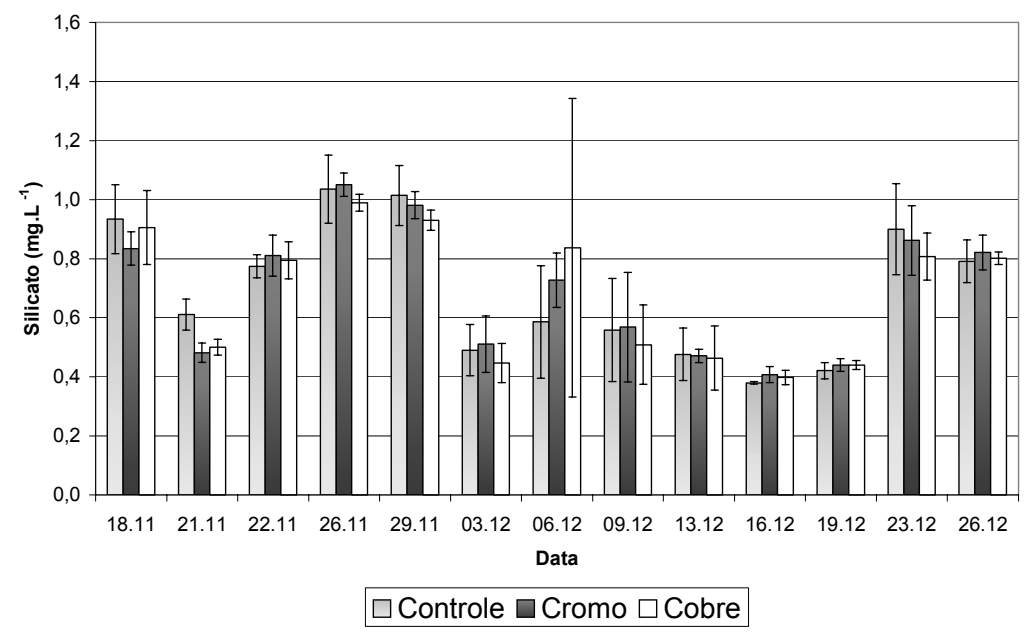

Figura 83: Concentrações médias $\left(\mathrm{mg}^{\mathrm{L}} \mathrm{L}^{-1}\right)$ de silicato dissolvido determinadas nas amostras de água no controle e nos mesocosmos contaminados com $\mathrm{Cr}$ e Cu durante o período de estudo (as barras de erros referem-se ao desvio padrão da média entre as réplicas dos mesocosmos).

As concentrações de silicato não variaram muito entre tratamentos. Apenas no dia 06 de dezembro as amostras dos tanques contaminados com $\mathrm{Cr}$ e com $\mathrm{Cu}$ apresentaram concentrações de silicato dissolvido maiores que as do controle $(0,6$ 
$\mathrm{mg} \cdot \mathrm{L}^{-1}$ para o controle e 0,7 e $0,8 \mathrm{mg} \cdot \mathrm{L}^{-1}$ para os tratamentos com $\mathrm{Cr}$ e $\mathrm{Cu}$, respectivamente).

As concentrações de nitrato, nitrito, amônio e nitrogênio total determinadas na água de cada unidade experimental, durante o período de estudo, estão apresentadas em Apêndice, sendo que as médias das concentrações determinadas estão apresentadas nas Figuras 84 a 87 . Imediatamente após a primeira contaminação, observa-se que as concentrações de nitrato determinadas nas amostras dos mesocosmos com $\mathrm{Cr}$ e $\mathrm{Cu}\left(29 \mu \mathrm{g} \cdot \mathrm{L}^{-1}\right.$ para ambos os tratamentos) foram muito menores (cerca de $50 \%$ ) que as determinadas para o controle $\left(62 \mu \mathrm{g} . \mathrm{L}^{-1}\right)$ na mesma data. $\mathrm{Na}$ segunda fase do experimento, após a inclusão de peixes e macrófitas, os mesocosmos contaminados com $\mathrm{Cr}$ como com $\mathrm{Cu}$ apresentaram concentrações maiores de nitrato que o controle (entre 15 e $39 \mu \mathrm{g} \cdot \mathrm{L}^{-1}$ para o tratamento com Cr; entre 27 e $52 \mu \mathrm{g} \cdot \mathrm{L}^{-1}$ para o tratamento com Cu e entre 10 e $30 \mu \mathrm{g} \cdot \mathrm{L}^{-1}$ para o controle).

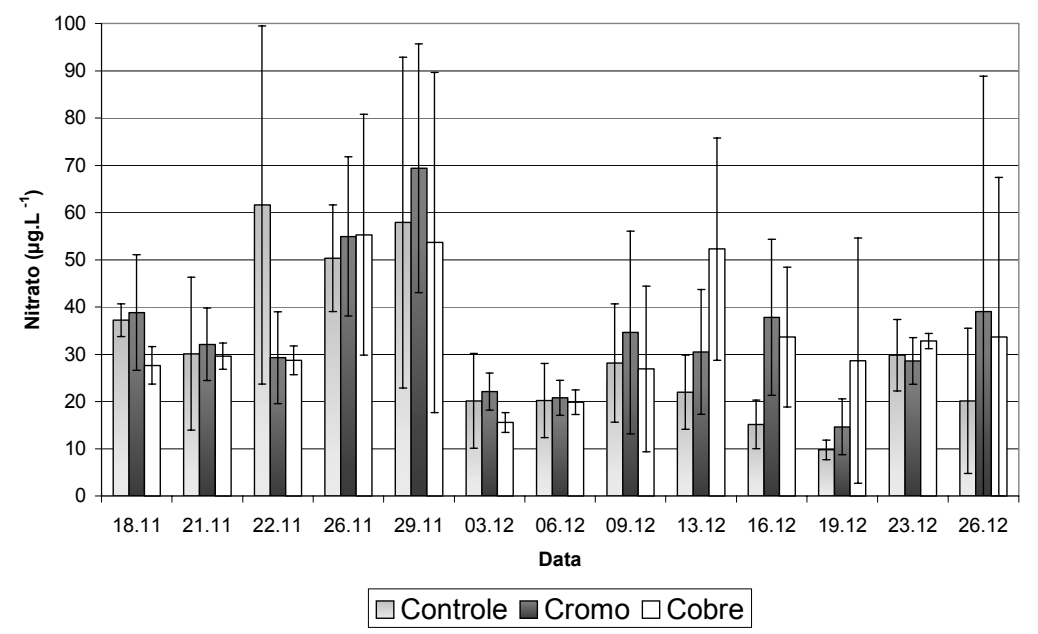

Figura 84: Concentrações médias $\left(\mu \mathrm{g} \cdot \mathrm{L}^{-1}\right)$ de nitrato determinadas nas amostras de água no controle e nos mesocosmos contaminados com $\mathrm{Cr}$ e $\mathrm{Cu}$ durante o período de estudo (as barras de erros referem-se ao desvio padrão da média entre as réplicas dos mesocosmos).

As concentrações de nitrito (Figura 85) determinadas nas amostras dos mesocosmos contaminados com $\mathrm{Cr}$ e $\mathrm{Cu}$ não apresentaram valores muito diferentes do controle. Todos os tratamentos apresentaram um aumento nas concentrações de nitrito no dia 3 de dezembro $\left(4,8 ; 4,9\right.$ e 4,1 $\mu \mathrm{g} \cdot \mathrm{L}^{-1}$ para o controle, o tratamento com $\mathrm{Cr}$ e o tratamento com $\mathrm{Cu}$, respectivamente), seguido de um brusco decréscimo, coincidindo com a introdução dos peixes e macrófitas $\left(1,0 \mu \mathrm{g} \cdot \mathrm{L}^{-1}\right.$ para o controle e o tratamento com $\mathrm{Cr}$ e 1,2 $\mathrm{\mu g} \cdot \mathrm{L}^{-1}$ para o tratamento com $\mathrm{Cu}$, em 9 de dezembro). 


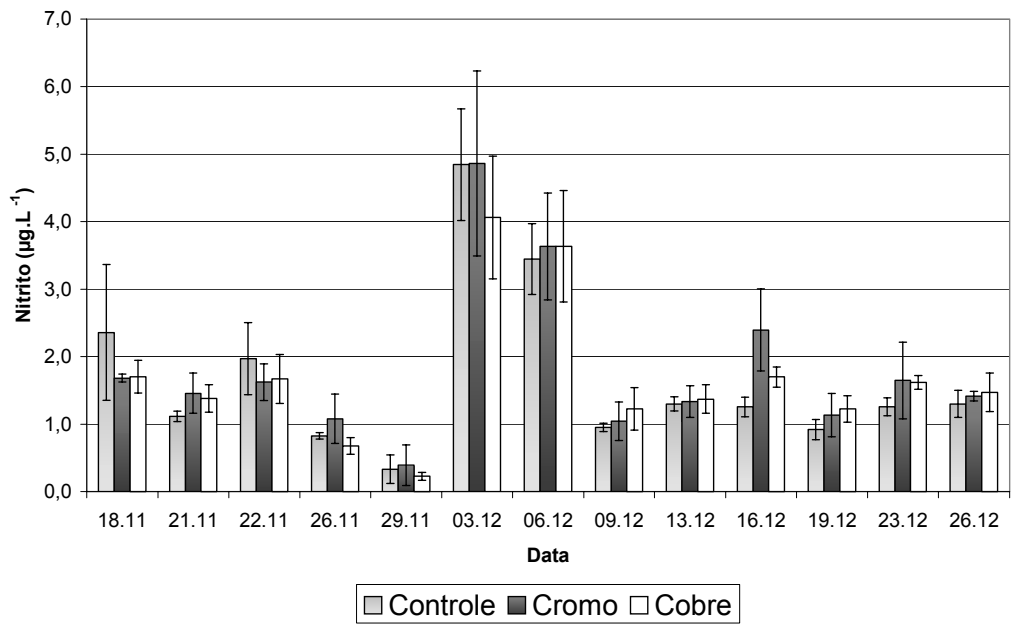

Figura 85: Concentrações médias $\left(\mu \mathrm{g} \cdot \mathrm{L}^{-1}\right)$ de nitrito determinadas nas amostras de água no controle e nos mesocosmos contaminados com $\mathrm{Cr}$ e $\mathrm{Cu}$ durante o período de estudo (as barras de erros referem-se ao desvio padrão da média entre as réplicas dos mesocosmos).

Todos os tratamentos apresentaram variações semelhantes em relação à concentração de amônia, durante todo o experimento, apresentando as maiores concentrações de amônia no início do experimento (523, 470 e $515 \mu \mathrm{g} . \mathrm{L}^{-1}$ em 21 de novembro) e sofrendo um decréscimo significativo a partir do dia 22 de novembro. $O$ menores valores foram determinados na última coleta $\left(6 \mu \mathrm{g} \cdot \mathrm{L}^{-1}\right.$ para o controle e 9 $\mu \mathrm{g} . \mathrm{L}^{-1}$ para os tratamentos com $\mathrm{Cr}$ e Cu (Figura 86).

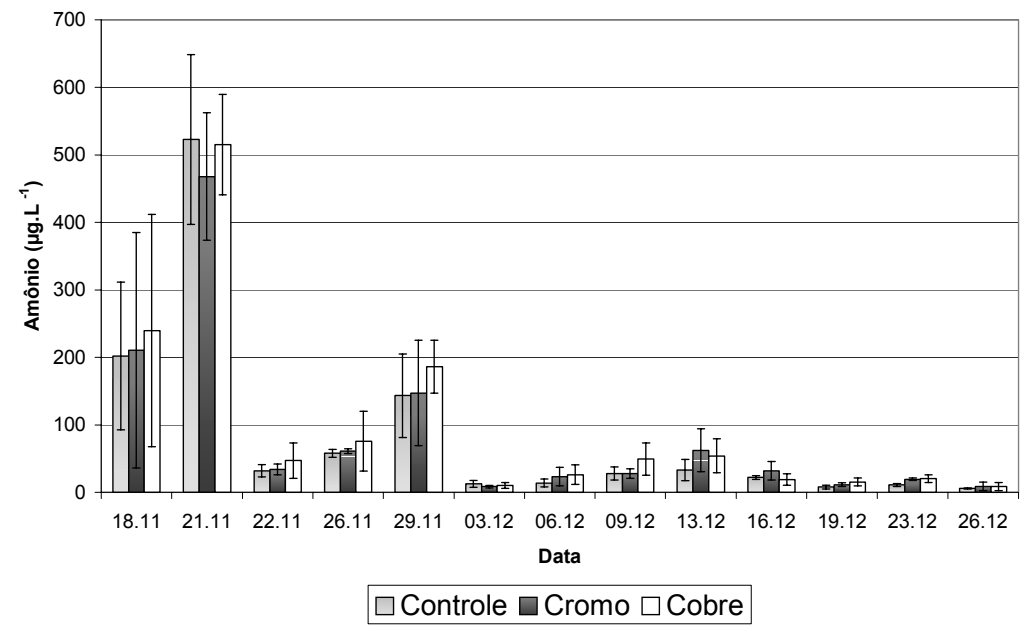

Figura 86: Concentrações médias $\left(\mu \mathrm{g} \cdot \mathrm{L}^{-1}\right)$ de amônio determinadas nas amostras de água no controle e nos mesocosmos contaminados com $\mathrm{Cr}$ e $\mathrm{Cu}$ durante o período de estudo (as barras de erros referem-se ao desvio padrão da média entre as réplicas dos mesocosmos). 
As concentrações de nitrogênio total oscilaram bastante ao longo do tempo nas amostras coletadas em todos os tratamentos. Os desvios padrão obtidos entre as réplicas dos tratamentos foram muito altos em todos os casos. Após a contaminação observou-se um decréscimo nas concentrações de nitrogênio total nas amostras coletadas nos mesocosmos com $\mathrm{Cu}$ (de 0,4 para 0,3 mg. $\mathrm{L}^{-1}$ ) e $\mathrm{Cr}$ (de 1,0 para 0,4 mg. $\mathrm{L}^{-1}$ ). Os mesocosmos contaminados com $\mathrm{Cr}$ apresentaram um aumento nas concentrações de nitrogênio total no dia 03 de dezembro. Porém, todos os tratamentos apresentaram o mesmo comportamento durante o experimento, sendo que após a introdução de peixes e macrófitas (dia 9 de dezembro) ocorreu um aumento nas concentrações de nitrogênio total nas amostras coletadas em todos os tratamentos

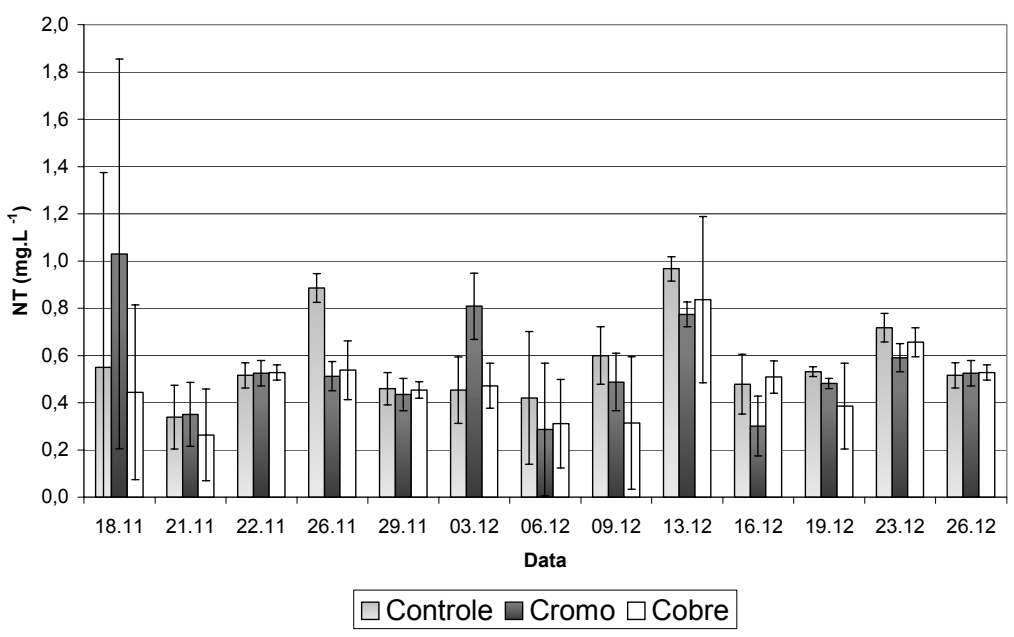

Figura 87: Concentrações médias $\left(\mathrm{mg}^{-1} \mathrm{~L}^{-1}\right)$ de nitrogênio total determinadas nas amostras de água no controle e nos mesocosmos contaminados com $\mathrm{Cr}$ e Cu durante o período de estudo (as barras de erros referem-se ao desvio padrão da média entre as réplicas dos mesocosmos).

As concentrações de fosfato inorgânico, fosfato total dissolvido e fósforo total determinadas na água de cada unidade experimental, durante o período de estudo, estão apresentadas em Apêndice. As médias das concentrações determinadas estão apresentadas nas figuras 88 a 90, respectivamente.

As concentrações de fosfato inorgânico (Figura 88) oscilaram bastante ao longo do tempo nas amostras coletadas em todos os tratamentos, que apresentaram o mesmo comportamento durante o experimento. As maiores concentrações de fosfato inorgânico foram determinadas nas amostras coletadas no dia 19 de dezembro, em todos os casos $\left(8,2 ; 7,3\right.$ e $7,2 \mu \mathrm{g} . \mathrm{L}^{-1}$, para o controle, o tratamento com $\mathrm{Cr}$ e o tratamento com $\mathrm{Cu}$, respectivamente). 


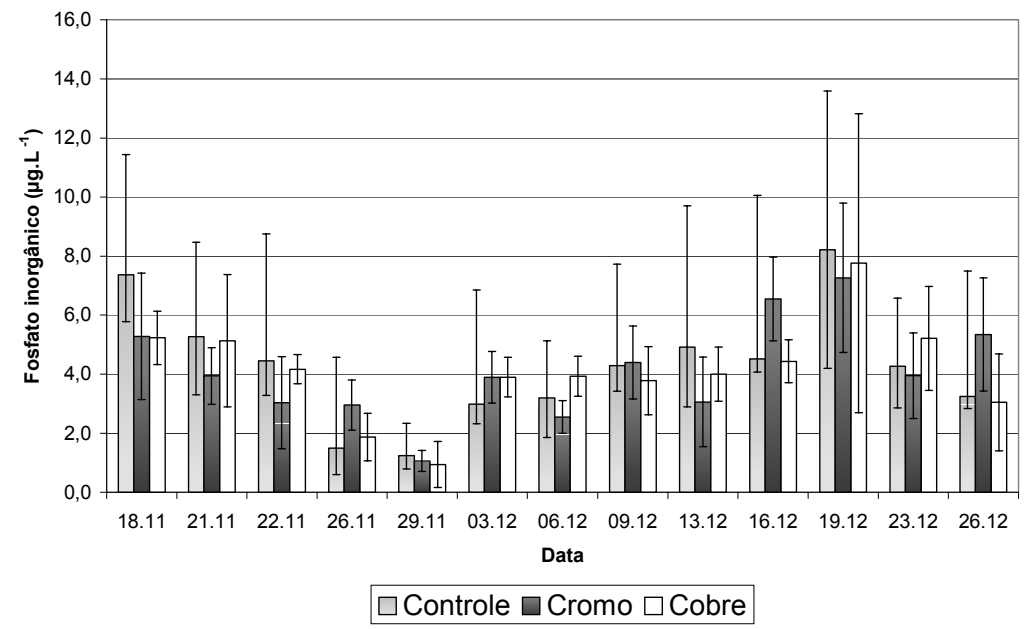

Figura 88: Concentrações médias $\left(\mu \mathrm{g} \cdot \mathrm{L}^{-1}\right)$ de fosfato inorgânico determinadas nas amostras de água no controle e nos mesocosmos contaminados com $\mathrm{Cr}$ e Cu durante o período de estudo (as barras de erros referem-se ao desvio padrão da média entre as réplicas dos mesocosmos).

Da mesma forma, os três tratamentos apresentaram variações semelhantes em relação às concentrações de fósforo total dissolvido. As maiores concentrações foram determinadas na coleta do dia 18 de novembro $\left(18,18\right.$ e $16 \mu \mathrm{g} \cdot \mathrm{L}^{-1}$ para o controle e os tratamentos com $\mathrm{Cr}$ e $\mathrm{Cu}$, respectivamente), antes da contaminação dos tanques, e de forma geral os tanques contaminados com $\mathrm{Cr}$ e $\mathrm{Cu}$ apresentaram concentrações de fósforo total dissolvido ligeiramente menores que o controle (Figura 89).

As concentrações de fósforo total (Figura 90) determinadas nos mesocosmos com $\mathrm{Cr}$ e $\mathrm{Cu}$ e nos controles variaram de forma homogênea durante todo o experimento, sendo observados aumento ou diminuição na concentração nas mesmas datas para os diferentes tratamentos. As maiores concentrações foram observadas no dia 18 de novembro, antes da contaminação dos mesocosmos $\left(113,110\right.$ e $85 \mu \mathrm{g} . \mathrm{L}^{-1}$ para o controle e os tratamentos com $\mathrm{Cr}$ e $\mathrm{Cu}$, respectivamente) e as menores no dia 6 de dezembro ( $23 \mu \mathrm{g} . \mathrm{L}^{-1}$ para todos os tratamentos). 


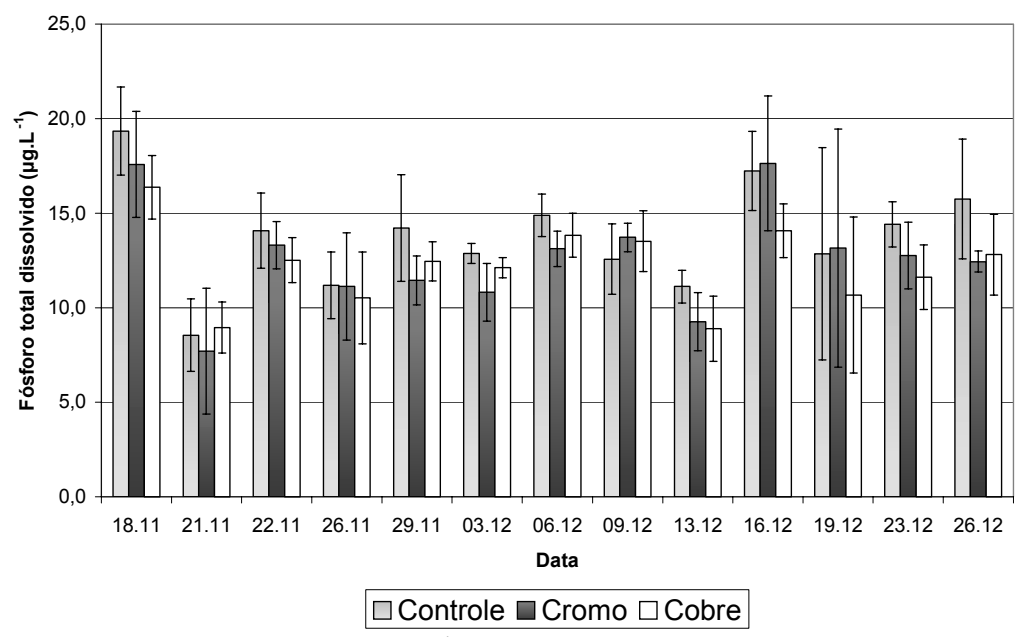

Figura 89: Concentrações médias $\left(\mu \mathrm{g} \cdot \mathrm{L}^{-1}\right)$ de fosfato total dissolvido determinadas nas amostras de água no controle e nos mesocosmos contaminados com $\mathrm{Cr}$ e $\mathrm{Cu}$ durante o período de estudo (as barras de erros referem-se ao desvio padrão da média entre as réplicas dos mesocosmos).

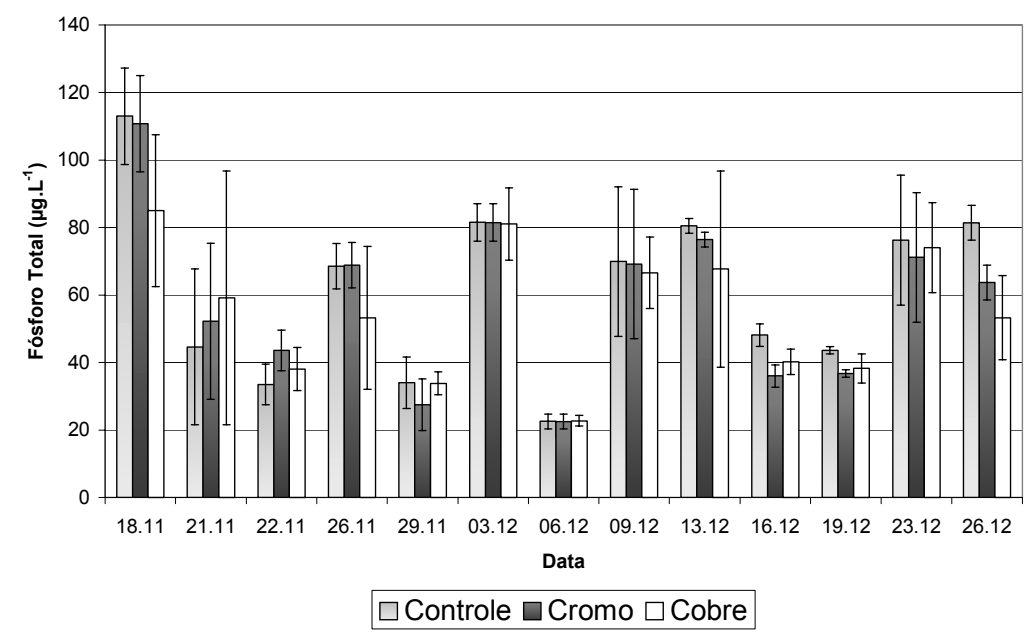

Figura 90: Concentrações médias $\left(\mu \mathrm{g} \cdot \mathrm{L}^{-1}\right)$ de fósforo total determinadas nas amostras de água no controle e nos mesocosmos contaminados com $\mathrm{Cr}$ e $\mathrm{Cu}$ durante o período de estudo (as barras de erros referem-se ao desvio padrão da média entre as réplicas dos mesocosmos).

\subsubsection{6- - Análise Estatística das variáveis físico-químicas, químicas e biológicas (clorofila)da água}

Analisando os dados obtidos nas duas partes do experimento, foi observada uma diferença muito significativa pela análise de variância multivariada (MANOVA) entre cada uma delas, antes e após a inclusão de peixes e macrófitas, gerando valores de $p=0,000$, para os dois tratamentos $(\mathrm{Cr}$ e $\mathrm{Cu}$ ). Assim, na análise estatística do experimento, optou-se pela utilização dos dados obtidos na primeira parte do 
experimento separadamente da segunda parte com o objetivo de comparar os efeitos da adição de metais em níveis tróficos diferentes.

Foram construídas matrizes de Correlação de Pearson, para a avaliação da correlação entre os parâmetros analisados utilizando os valores do controle e de cada tratamento e análise de variância multivariada (MANOVA) e univariada (ANOVA) para a comparação dos valores obtidos no controle com os tratamentos. Os resultados obtidos através das análises estatísticas estão apresentados em Apêndice.

Considerando-se os resultados obtidos antes da inclusão dos peixes e macrófitas, a concentração de $\mathrm{Cr}$ na água dos tanques apresentou correlação inversa com o oxigênio dissolvido ( $r=-0,367 ; p=0,017$ ), fósforo total dissolvido $(r=-0,358$; $p=0,020)$ e, num nível muito significativo, com a concentração de clorofila $(r=-0,538$; $p=0,000)$. As concentrações de $\mathrm{Cr}$ apresentaram ainda uma forte correlação positiva com a amônia $(r=0,385 ; p=0,012)$. O oxigênio dissolvido apresentou correlação significativa inversa com a concentração de amônio ( $r=-0,466 ; p=0,002)$ e positiva com a o fósforo total dissolvido $(r=0,454 ; p=0,003)$. De forma geral, as variáveis físico químicas apresentaram forte influência sobre as concentrações de material em suspensão orgânico e sobre a distribuição das formas nitrogenadas. O material em suspensão orgânico também foi relacionado positivamente com a concentração de nitrito $(r=0,460 ; p=0,002)$ e negativamente as concentrações de amônio ( $r=-0,383$; $p=0,012)$ e nitrato $(r=-0,358 ; p=0,020)$. O material em suspensão total demonstrou influência também a distribuição das formas fosfatadas, apresentando correlação positiva com as concentrações de fósforo total $(r=0,436 ; p=0,004)$, fósforo total dissolvido $(r=0,338 ; p=0,029)$ e, com menor significância, para fosfato dissolvido ( $r=$ $0,280 ; p=0,073)$. A concentração de clorofila também foi relacionada com o material em suspensão total $(r=0,321 ; p=0,038)$ e com silicato $(r=0,324 ; p=0,036)$, além da concentração de Cr.

Após a inclusão dos peixes e macrófitas, a adição de $\mathrm{Cr}$ continuou apresentando correlação positiva com as concentrações de amônio ( $r=0,550$; $p=0,001)$ e negativa com fósforo total dissolvido $(r=-0,366 ; p=0,028)$ e oxigênio dissolvido $(r=-0,455 ; p=0,006)$, porém não foi mais relacionado significativamente com a concentração de clorofila $(r=-0,167 ; p=0,330)$. As variáveis físico-químicas apresentaram correlações bem menos significativas com a distribuição de nutrientes e material em suspensão. A clorofila apresentou correlações positivas com o nitrogênio total $(r=0,405 ; p=0,014)$, material em suspensão total $(r=0,394 ; p=0,017) e$, muito significativamente, com o material em suspensão orgânico $(r=0,609 ; p=0,000)$. Apenas a temperatura apresentou correlação inversa com a clorofila $(r=-0,354 ; p=0,034)$. 
No tratamento com $\mathrm{Cu}$, antes da inclusão dos peixes e macrófitas, as concentrações do metal apresentaram correlação significativa apenas sobre a concentração de amônio $(r=0,513 ; p=0,007)$. A clorofila foi a variável que apresentou correlação significativa com o maior número de outros parâmetros, como temperatura $(r=-0,557 ; p=0,003) ; p H(r=-0,838 ; p=0,000)$; material em suspensão total $(r=0,564$; $p=0,003)$ e orgânico $(r=0,675 ; p=0,000)$. Dentre as variáveis físico-químicas analisadas, o pH apresentou relação com o maior número de variáveis, influenciando negativamente a concentração de material em suspensão total $(r=-, 0482 ; p=0,013)$ e orgânico ( $r=-0,613 ; p=0,001)$, e positivamente o silicato $(p=0,513 ; p=0,007)$; nitrato $(r=0,393 ; p=0,047)$ e amônio $(0,464 ; p=0,017)$.

Após a inclusão dos peixes e macrófitas, a concentração de $\mathrm{Cu}$ pareceu influenciar a distribuição das formas de nitrogênio, apresentando correlação positiva com as concentrações de nitrato $(r=0,432, p=0,008)$ e amônio $(r=0,369 ; p=0,027)$, e menos significativamente a concentração de nitrogênio total $(r=0,311 ; p=0,064)$. A concentração de clorofila apresentou correlações significativas com as mesmas variáeis de antes da inclusão dos peixes, com valores de $p$ da mesma ordem.

Através da análise de variância multivariada (MANOVA), pode-se concluir que a adição de $\mathrm{Cr}$ na primeira parte do experimento (sem a inclusão de peixes e macrófitas), provocou efeitos significativos sobre as variáveis funcionais do sistema, comparando-se com as medidas realizadas no controle, gerando valores de $p=0,028$ para os testes de Wilk's, Lawey-Hotelling, Pillai's e Roys. Os parâmetros que apresentaram diferenças significativas entre o tratamento com $\mathrm{Cr}$ e o controle, de acordo com a análise de variância univariada, estão apresentados na Tabela 39.

Tabela 39: Variáveis que sofreram efeito significativo após a adição de $\mathrm{Cr}$ (antes da inclusão de peixes e macrófitas). (ANOVA, $p<0,05$ ).

\begin{tabular}{lc}
\hline \hline Variável & valor-P \\
\hline Oxigênio Dissolvido & 0,052 \\
Condutividade & 0,025 \\
Clorofila & 0,027 \\
\hline \hline
\end{tabular}

Após a inclusão dos peixes e macrófitas, a adição de $\mathrm{Cr}$ provocou efeito menos pronunciados no sistema, gerando valores de $p$ menos significativos $(p=0,054)$ para os testes de Wilk's, Lawey-Hotelling, Pillai's e Roys (MANOVA). As variáveis afetadas pela adição de $\mathrm{Cr}$, de acordo com a análise de variância, estão apresentadas na Tabela 40. 
Tabela 40: Variáveis que sofreram efeito significativo após a adição de $\mathrm{Cr}$ (após a inclusão de peixes e macrófitas).

\begin{tabular}{lc}
\hline \hline Variável & valor-P \\
\hline Material em suspensão orgânico & 0,052 \\
Clorofila & 0,001 \\
Nitrito & 0,026 \\
\hline \hline
\end{tabular}

A adição de $\mathrm{Cu}$ no sistema não apresentou efeitos sobre o sistema antes e após a inclusão dos peixes e macrófitas $(p=0,613$ e $p=0,165$, respectivamente, para os testes de Wilk's, Lawey-Hotelling, Pillai's e Roys).

De acordo com a análise de variância univariada, o único parâmetro que apresentou diferenças entre o controle e o tratamento com $\mathrm{Cu}$ e o controle, na primeira fase do experimento, foi a condutividade $(p=0,050)$. As variáveis que apresentaram diferenças significativas entre o controle e o tratamento com $\mathrm{Cu}$ na segunda fase do experimento estão apresentados na tabela 41.

Tabela 41: Variáveis que sofreram efeito significativo após a adição de Cu (após a inclusão de peixes e macrófitas).

\begin{tabular}{lc}
\hline Variável & valor-P \\
\hline Fósforo Total Dissolvido & 0,001 \\
Nitrato & 0,015 \\
Nitrito & 0,002 \\
\hline
\end{tabular}

Considerando-se os resultados das análises estatísticas observa-se que a adição de Cr provocou efeitos menos significativos sobre o sistema após a inclusão de peixes e macrófitas, principalmente a respeito de sua influência sobre a concentração de clorofila, que na segunda parte do experimento não apresentou relação com a concentração de $\mathrm{Cr}$, apesar de apresentar diferenças significativas em relação ao controle. Nas duas fases do experimento $\mathrm{Cr}$ relacionou-se positivamente com amônio e negativamente com oxigênio dissolvido, e na segunda fase, apresentou influência sobre a concentração de nitrito.

A adição de Cu não apresentou efeitos significativos em nenhuma das fases do experimento considerando-se todas as variáveis estudadas em conjunto. Porém, comparando-se individualmente as variáveis, após a inclusão dos peixes e macrófitas $\mathrm{Cu}$ apresentou influência sobre a distribuição de nutrientes, principalmente das formas de nitrogênio.

$\mathrm{Na}$ segunda fase do experimento os tratamentos com $\mathrm{Cu}$ e $\mathrm{Cr}$ apresentaram diferenças significativas para a concentração de nitrito em relação ao controle. Em ambos os tratamentos, a concentração de clorofila foi influenciada principalmente pelo fósforo total dissolvido após a inclusão dos peixes e deixou de ser relacionada às 
concentrações de silicato e às variáveis físico-químicas, com exceção da temperatura, no experimento com $\mathrm{Cu}$.

\subsection{2- Análises químicas do sedimento}

\subsubsection{1- Cromo e Cobre}

Os resultados das análises da fração potencialmente disponível ou fracamente ligada de $\mathrm{Cu}$ e $\mathrm{Cr}$ nos sedimentos coletados nos tanques estão apresentados em apêndice. Cromo não foi detectado em nenhuma das amostras da fração potencialmente disponível do sedimento. As concentrações médias de $\mathrm{Cu}$ na fração potencialmente biodisponível ou fracamente ligada dos sedimentos coletados nos tanques estão apresentadas na figura 91.

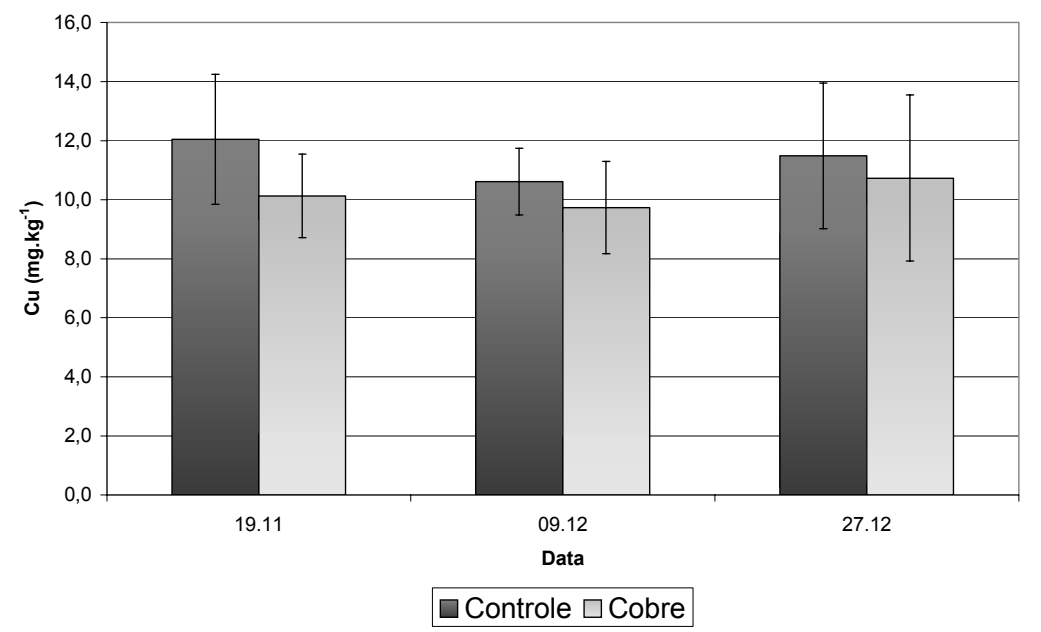

Figura 91: Concentrações médias $\left(\mathrm{mg} \cdot \mathrm{kg}^{-1}\right)$ de Cu na fração fracamente ligada do sedimento dos mesocosmos controle e contaminados com Cu (as barras de erros referem-se ao desvio padrão da média entre as réplicas dos mesocosmos).

As concentrações de Cu determinadas na fração potencialmente disponível dos sedimentos estudados foram muito próximas tanto entre os tratamentos quanto em relação às datas, variando entre 10 e $12 \mathrm{mg} \cdot \mathrm{kg}^{-1}$. Não foram observadas diferenças significativas estatisticamente ente os valores determinados para o controle e para o tratamento com $\mathrm{Cu}$.

As médias das concentrações totais de $\mathrm{Cr}$ nas amostras de sedimento estão apresentadas na Figura 92. As concentrações referentes a cada uma das réplicas estão apresentadas em Apêndice. 


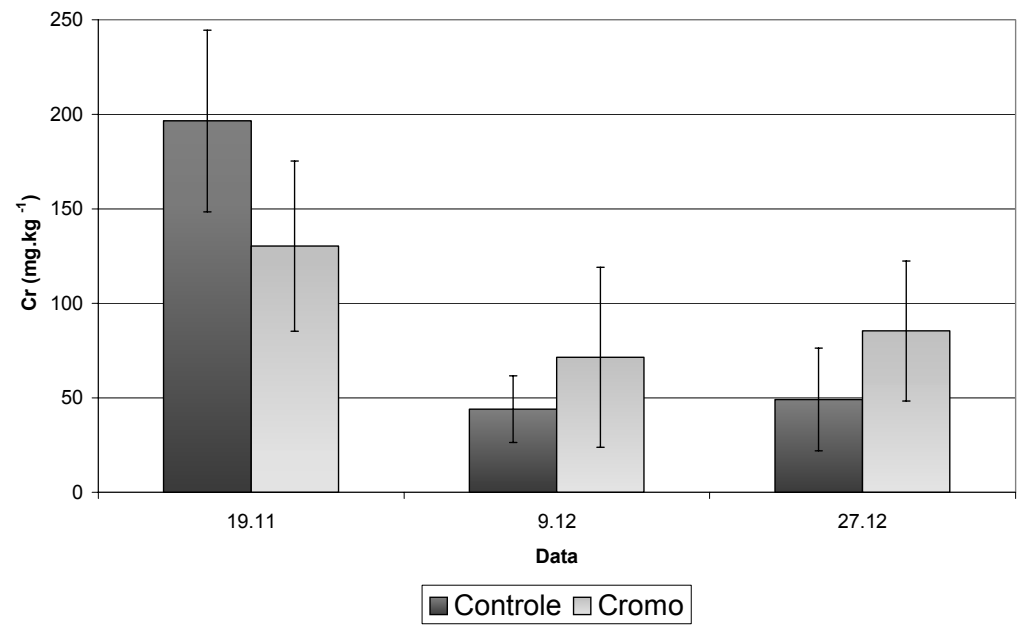

Figura 92: Concentrações totais médias $\left(\mathrm{mg}^{\mathrm{kg}} \mathrm{kg}^{-1}\right) \mathrm{de} \mathrm{Cr}$ no sedimento dos mesocosmos controle e contaminados com $\mathrm{Cr}$ (as barras de erros referem-se ao desvio padrão da média entre as réplicas dos mesocosmos).

As concentrações de $\mathrm{Cr}$ determinadas nas amostras de sedimento dos tanques foram altas em todas as amostras, principalmente na primeira coleta, se comparado com as concentrações determinadas no experimento realizado em abril de 2002, na mesma área. Nas amostras coletadas em 18 de novembro, antes da contaminação dos tanques, o controle apresentou teores de $\mathrm{Cr}$ maiores que os apresentados pelo tratamento com Cr (196 mg. $\mathrm{kg}^{-1}$ para o controle e $130 \mathrm{mg} \cdot \mathrm{kg}^{-1}$ para o tratamento com $\mathrm{Cr}$ ). Nas duas coletas seguintes, após 20 e 16 dias da $1^{\mathrm{a}}$ e $2^{\mathrm{a}}$ contaminação, respectivamente, o controle apresentou concentrações menores que os tanques contaminados (44 e $72 \mathrm{mg} \cdot \mathrm{kg}^{-1}$, respectivamente para o controle e para o tratamento com $\mathrm{Cr}$ no dia 9 de dezembro e 49 e $85 \mathrm{mg} \mathrm{kg}^{-1}$, respectivamente para o controle e para o tratamento com $\mathrm{Cr}$ no dia 27 de dezembro).

As concentrações totais médias de $\mathrm{Cu}$ nas amostras de sedimento coletadas nos mesocosmos controle e nos contaminados com Cu estão apresentadas na Figura 93. As concentrações referentes a cada uma das réplicas estão apresentadas em Apêndice. Em todas as datas, os valores apresentados pelo controle foram semelhantes aos apresentados pelos mesocosmos contaminados com $\mathrm{Cu}$ (75 e 70 mg. $\mathrm{kg}^{-1}$, em 19 de novembro, para o controle e o tratamento com $\mathrm{Cu}$, respectivamente; 52 e $46 \mathrm{mg} \cdot \mathrm{kg}^{-1}$, em 9 de dezembro, para o controle e o tratamento com $\mathrm{Cu}$, respectivamente e 71 e $77 \mathrm{mg} \cdot \mathrm{kg}^{-1}$ em 27 de dezembro, para o controle e o tratamento com $\mathrm{Cu}$, respectivamente).

Os valores médios obtidos para o $\mathrm{Cr}$ na primeira análise estiveram acima dos valores médios para sedimentos, de $72 \mathrm{mg} \cdot \mathrm{kg}^{-1}$ (BOWEN, 1979, apud SALOMONS \& FORSTNER, 1984) e acima do valor estabelecido para o folhelho médio, de $90 \mathrm{mg} \cdot \mathrm{kg}^{-1}$ 
(TUREKIAN \& WEDEPHOL, 1961, apud SALOMONS \& FORSTNER, 1984). Os valores médios obtidos para o $\mathrm{Cu}$ estiveram acima tanto do valor médio para sedimentos (33 mg. $\mathrm{kg}^{-1}$, BOWEN, 1979, apud SALOMONS \& FORSTNER, 1984) como do valor estabelecido para o folhelho médio (45 mg. $\mathrm{kg}^{-1}$, TUREKIAN \& WEDEPHOL, 1961, apud SALOMONS \& FORSTNER, 1984) em todas as amostras analisadas.

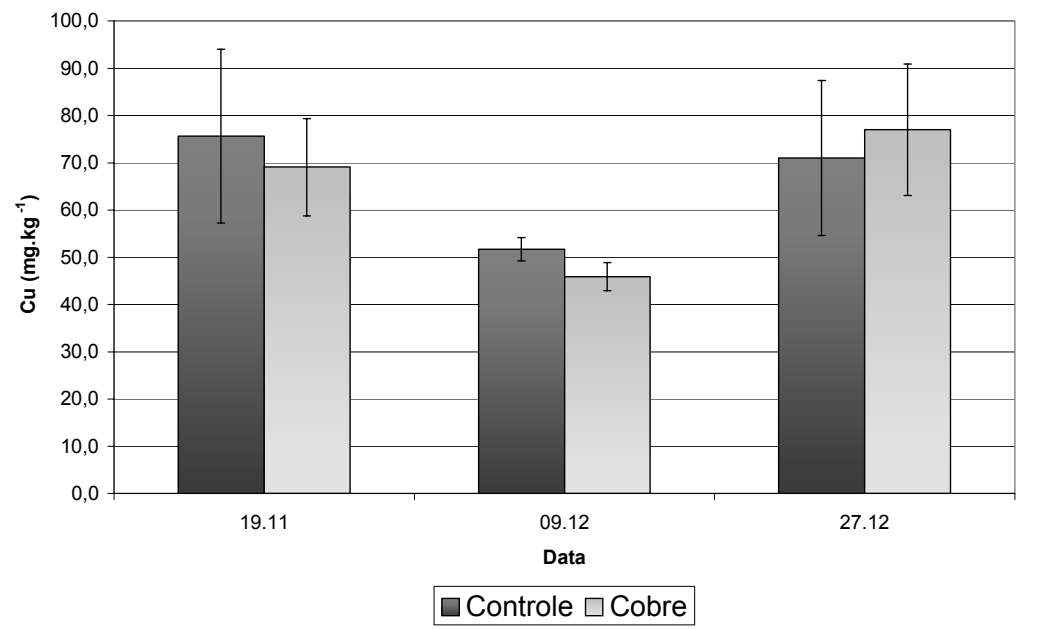

Figura 93: Concentrações totais médias $\left(\mathrm{mg}^{\mathrm{kg}}{ }^{-1}\right)$ de $\mathrm{Cu}$ no sedimento dos mesocosmos controle e contaminados com Cu (as barras de erros referem-se ao desvio padrão da média entre as réplicas dos mesocosmos).

A solubilização das amostras de sedimento para a análise das concentrações totais de $\mathrm{Cr}$ e $\mathrm{Cu}$ foi acompanhada da solubilização de uma amostra de sedimento de lago certificada (IAEA -SL1), com a finalidade de avaliar a eficiência do procedimento de digestão e da técnica analítica. Os valores referentes à recuperação das concentrações de Cr e Cu no sedimento certificado estão apresentados na Tabela 42.

Com base nos resultados referentes a essa análise, observa-se que o valor recuperado apresenta grande desvio padrão para o $\mathrm{Cr}$, e valor inferior ao certificado para $\mathrm{Cu}$, indicando que os procedimentos de digestão e análise podem estar interferindo nos resultados obtidos.

Tabela 42: Concentrações $\left(\mathrm{mg} \cdot \mathrm{kg}^{-1}\right)$ de $\mathrm{Cr}$ e $\mathrm{Cu}$ recuperadas após digestão e análise de sedimento certificado IAEA - SL1

\begin{tabular}{lcc}
\hline & Certificado & Determinado \\
\hline \hline $\mathrm{Cr}\left(\mathrm{mg} \cdot \mathrm{kg}^{-1}\right)$ & $104 \pm 9$ & $110 \pm 30,4$ \\
\hline $\mathrm{Cu}\left(\mathrm{mg} \cdot \mathrm{kg}^{-1}\right)$ & $29,4 \pm 5,6$ & $21,8 \pm 0,7$ \\
\hline \hline
\end{tabular}




\subsubsection{2- Matéria orgânica e nutrientes (fósforo e nitrogênio)}

Os resultados obtidos para o teor de matéria orgânica (\%), determinados pela perda de massa por ignição, nos sedimentos coletados nos tanques, estão apresentados em anexo. As concentrações médias para cada tratamento estão apresentadas na Figura 94.

Os teores de matéria orgânica determinados nos sedimentos variaram entre 14 e $21,9 \%$, não tendo sido observadas grandes diferenças entre os tratamentos, mas sim um pequeno acréscimo ao final do experimento, em todos os tratamentos.

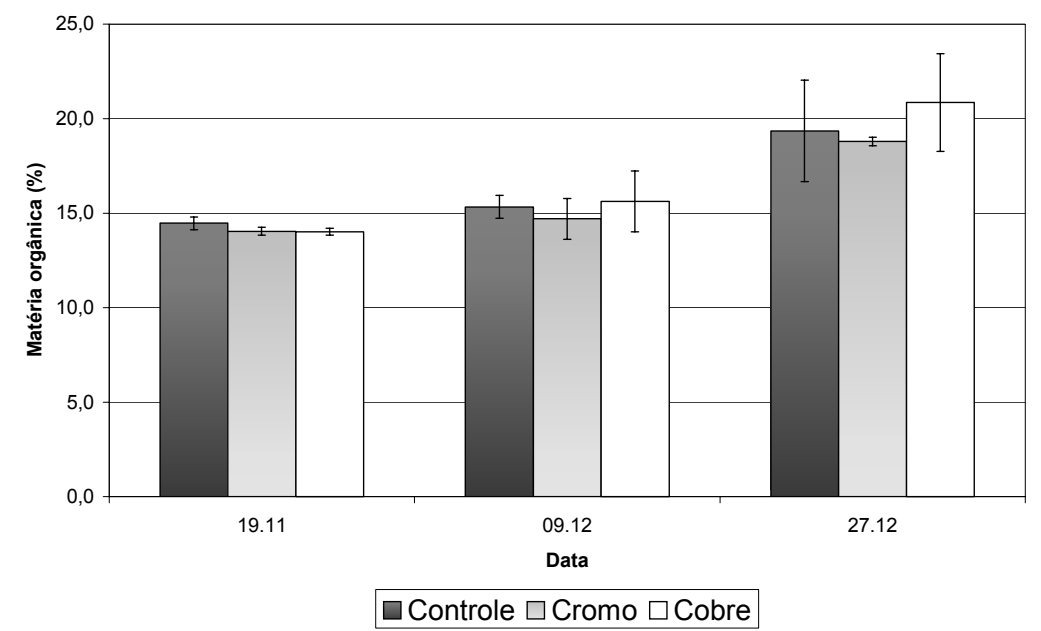

Figura 94: Teores médios de matéria orgânica (\%) determinados nos sedimentos dos mesocosmos controle e contaminados com Cu (as barras de erros referem-se ao desvio padrão da média entre as réplicas dos mesocosmos).

As concentrações médias de nitrogênio determinadas no sedimento dos tanques controle e nos contaminados com cromo e cobre, em cada uma das coletas, estão apresentadas na Figura 95. Os valores determinados para cada uma das amostras estão apresentados em Apêndice.

As concentrações de nitrogênio determinadas nos sedimentos coletados nos tanques apresentaram grande variação, tanto entre as datas como entre os tratamentos. No início do experimento, antes da contaminação, o controle apresentou concentrações bem menores que os outros mesocosmos $(0,04 \%$ para o controle, $0,11 \%$ para o tratamento com $\mathrm{Cr}$ e $0,07 \%$ para o tratamento com $\mathrm{Cu}$ ), sendo observado, porém, um desvio padrão muito alto entre as réplicas. Na coleta realizada dia 27 de dezembro, o controle apresentou concentrações de nitrogênio no sedimento bem inferiores ao outros tratamentos $(0,04 \%$ para o controle; $0,11 \%$ para o tratamento com Cu e $0,10 \%$ para o tratamento com Cr).Valores altos de desvio padrão também foram observados para as amostras coletadas no tratamento com $\mathrm{Cu}$, no dia 18 de 
novembro, para as amostras coletadas no tratamento com $\mathrm{Cr}$ no dia 9 de dezembro e para o controle no dia 27.12

As concentrações médias de fósforo determinadas no sedimento dos mesocosmos, durante o período de estudo, estão apresentadas na Figura 96. Os valores determinados para cada uma das amostras estão apresentados em Apêndice. As concentrações de fósforo nos sedimentos analisados apresentaram-se praticamente constantes em todas as datas (entre 300 e $400 \mathrm{mg} \cdot \mathrm{kg}^{-1}$ ), com exceção do tratamento com $\mathrm{Cr}$, que na segunda coleta apresentou concentrações relativamente menores $\left(240 \mathrm{mg} \cdot \mathrm{kg}^{-1}\right)$.

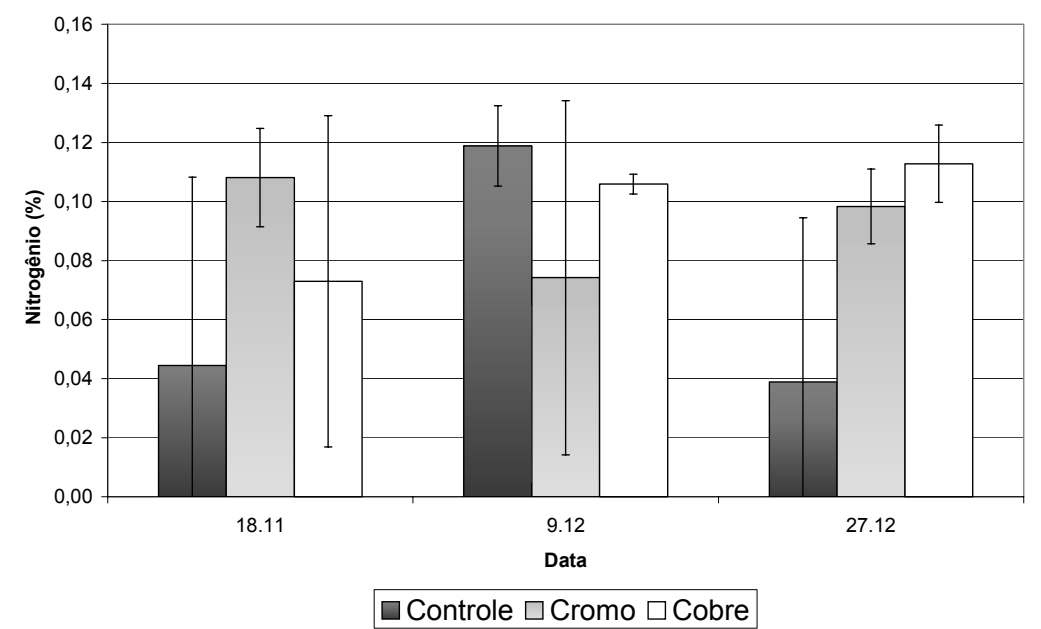

Figura 95: Concentrações médias de nitrogênio (\%) determinadas nos sedimentos coletados nos tanques em cada uma das coletas (as barras de erros referem-se ao desvio padrão da média entre as réplicas dos mesocosmos).

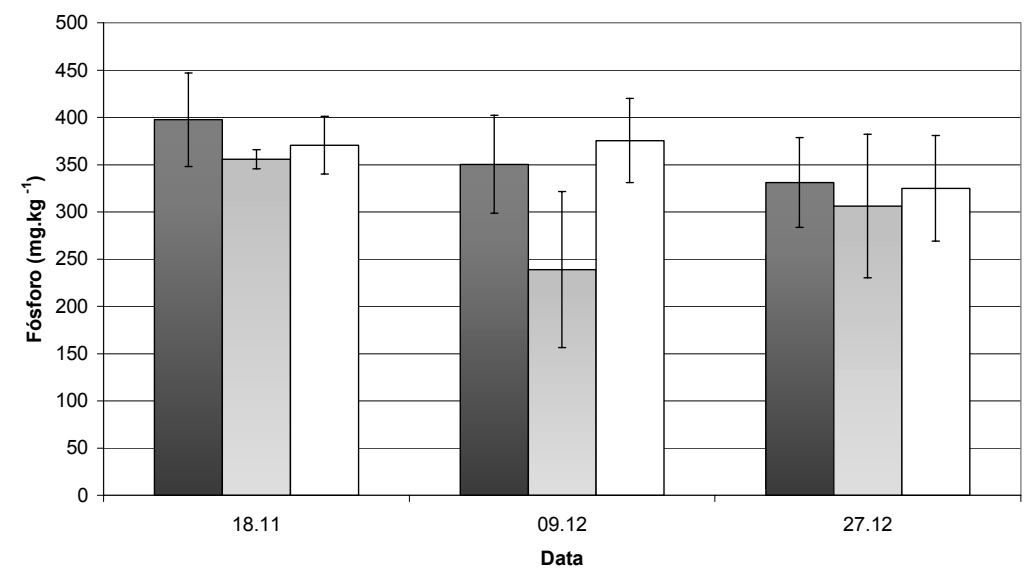

$\square$ Controle $\square$ Cromo $\square$ Cobre

Figura 96: Concentrações médias de fósforo $\left(\mathrm{mg}^{\mathrm{kg}} \mathrm{kg}^{-1}\right)$ determinadas nos sedimentos nos sedimentos dos mesocosmos controle e contaminados com $\mathrm{Cu}$ (as barras de erros referem-se ao desvio padrão da média entre as réplicas dos mesocosmos). 


\subsubsection{3- Água Intersticial}

As concentrações médias de $\mathrm{Cr}$ e $\mathrm{Cu}$ nas amostras de água intersticial estão apresentadas nas Figuras 97 e 98, e todos os valores obtidos estão apresentados em Apêndice.

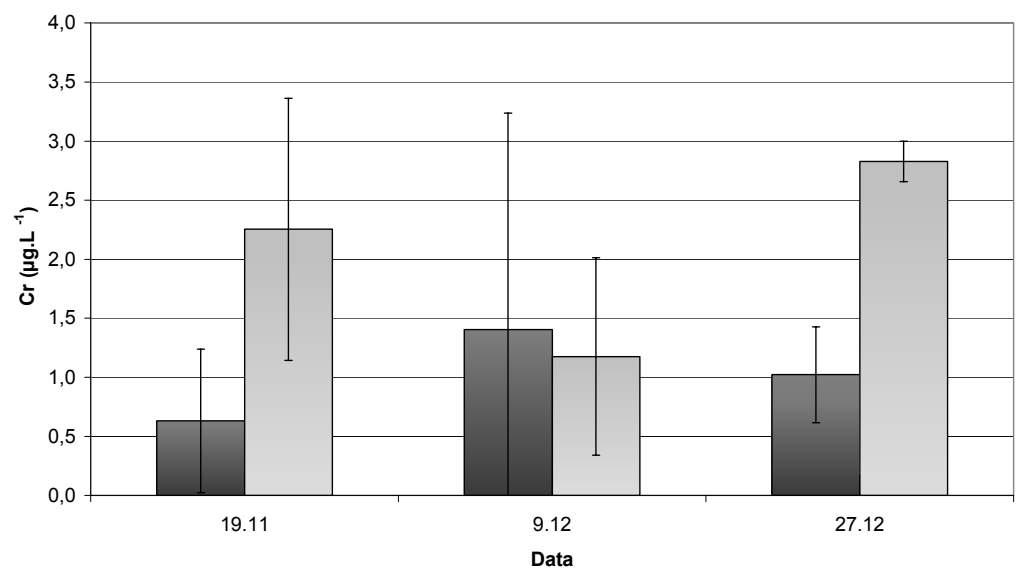

\section{$\square$ Controle $\square$ Cromo}

Figura 97: Concentrações de $\mathrm{Cr}\left(\mu \mathrm{g} \cdot \mathrm{L}^{-1}\right)$ determinadas na água intersticial dos mesocosmos controle e contaminados com $\mathrm{Cr}$ (as barras de erros referem-se ao desvio padrão da média entre as réplicas dos mesocosmos).

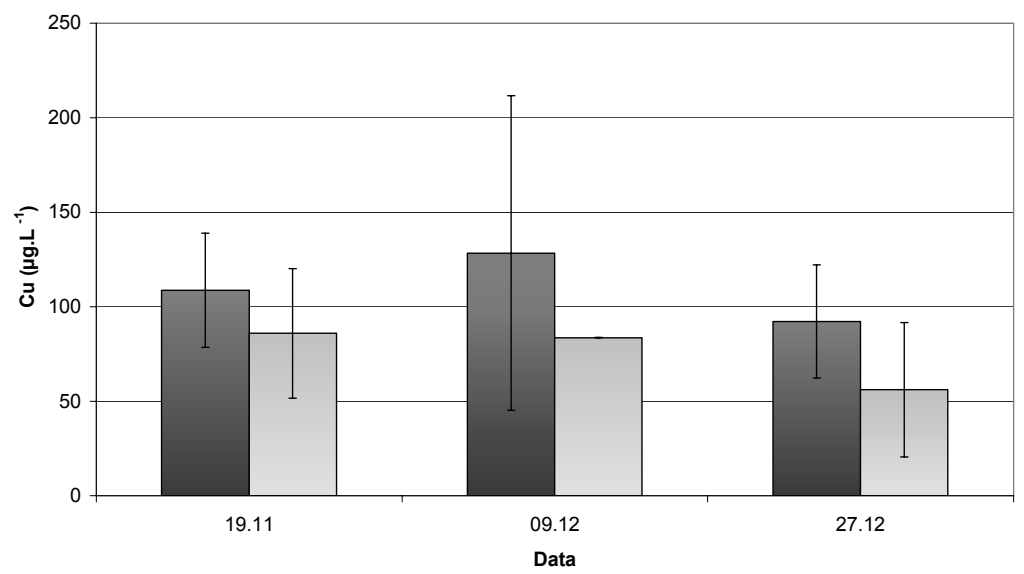

$\square$ Controle $\square$ Cobre

Figura 98: Concentrações de $\mathrm{Cu}\left(\mu \mathrm{g} \cdot \mathrm{L}^{-1}\right)$ determinadas na água intersticial dos mesocosmos controle e contaminados com $\mathrm{Cu}$ (as barras de erros referem-se ao desvio padrão da média entre as réplicas dos mesocosmos).

A maior concentração de $\mathrm{Cr}\left(2,8 \mu \mathrm{g} \cdot \mathrm{L}^{-1}\right)$ foi determinada no tratamento com $\mathrm{Cr}$, no dia 27 de dezembro (15 dias após a segunda contaminação), enquanto que a menor concentração foi determinada para o controle no dia 19 de novembro (antes da contaminação dos tanques).

As concentrações de $\mathrm{Cu}$, determinadas na água intersticial do controle (entre 92 e $128 \mu \mathrm{g} \cdot \mathrm{L}^{-1}$ ), foram maiores que as determinadas para o experimento com $\mathrm{Cu}$ (entre 56 e $86 \mu \mathrm{g} \cdot \mathrm{L}^{-1}$ ), porém essas diferenças não foram significativas 
estatisticamente. Os maiores valores obtidos no tratamento com $\mathrm{Cu}$ são referentes à coleta realizada antes da contaminação dos tanques, o que indica a presença de cobre no sedimento ou na água intersticial da represa do Lobo naturalmente, independente da adição da solução de $\mathrm{CuSO}_{4}$.

\subsubsection{4- Análise Estatística}

No tratamento com $\mathrm{Cr}$ não foi observada correlação significativa entre nenhuma das variáveis estudadas, através da análise de Correlação de Pearson. Considerando-se como nível de significância $p<0,1$; as concentrações de Cu na água intersticial apresentaram correlação positiva com a concentração de fósforo no sedimento $(r=0,450 ; p=0,061)$ e negativa com concentração total de Cu no sedimento $(r=-0,431 ; p=0,074)$. A fração de Cu biodisponível apresentou correlação positiva com o conteúdo de matéria orgânica.

Em relação à análise de variância, a análise Multivariada (MANOVA) não pode ser realizada para o tratamento com $\mathrm{Cr}$, e não apresentou diferenças entre o controle e o tratamento com Cu ( $p=0,271)$ para os testes de Wilk's, Lawey-Hotelling, Pillai's e Roys. Em relação à análise individual de cada variável em relação ao controle, foram observadas diferenças significativas na concentração de $\mathrm{Cr}$ na água intersticial $(p=0,011)$ e, com menor significância, na concentração de fósforo $(p=0,071)$ no tratamento com $\mathrm{Cr}$. No tratamento com $\mathrm{Cu}$ não foram observadas diferenças entre nenhuma das variáveis analisadas.

\subsection{3- Análise de $\mathrm{Cr}$ e Cu nos componentes biológicos}

\subsubsection{1- Plâncton}

A biomassa de plâncton obtida nas coletas variou entre 0,29 e $0,01 \mathrm{~g}$ e foram consideradas para análise amostras com no mínimo $5 \mathrm{mg}$. As concentrações médias de $\mathrm{Cr}$ e $\mathrm{Cu}\left(\mu \mathrm{g} \cdot \mathrm{g}^{-1}\right)$ determinadas nas amostras de plâncton coletadas nos tanques estão apresentadas nas Figuras 99 e 100. As concentrações determinadas em cada réplica estão apresentadas em Apêndice. 


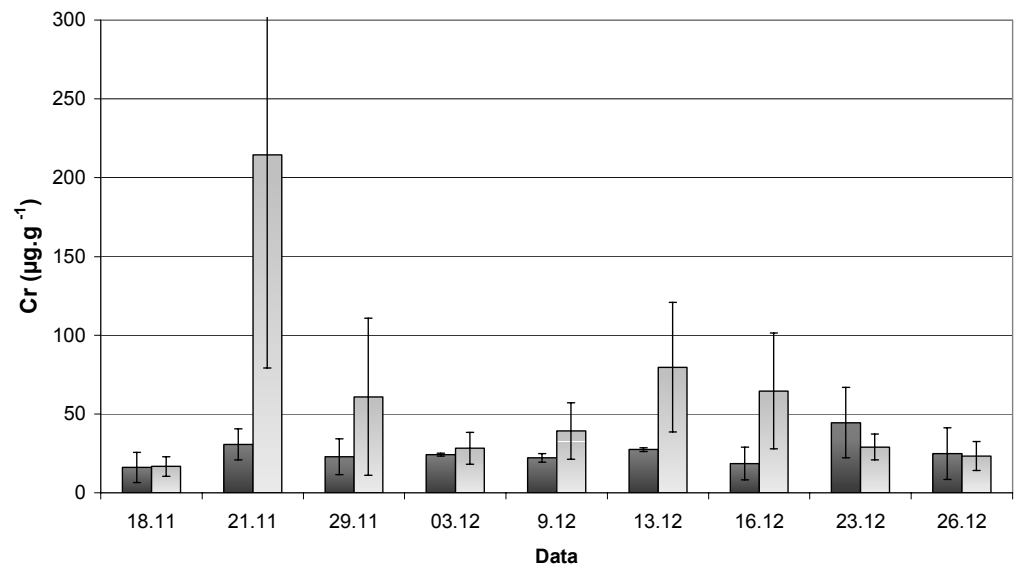

$\square$ Controle $\square$ Cromo

Figura 99: Concentrações médias de $\mathrm{Cr}\left(\mu \mathrm{g} \cdot \mathrm{g}^{-1}\right)$ determinadas nas amostras de plâncton dos mesocosmos controle e contaminados com $\mathrm{Cr}$ (as barras de erros referem-se ao desvio padrão da média entre as réplicas dos mesocosmos).

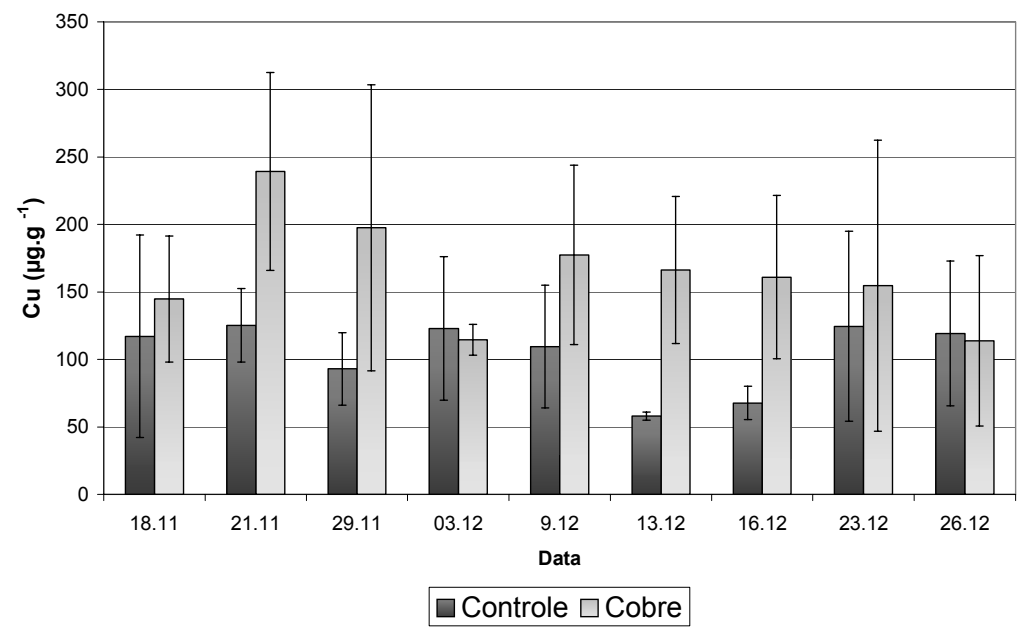

Figura 100: Concentrações médias de $\mathrm{Cu}\left(\mu \mathrm{g} \cdot \mathrm{g}^{-1}\right)$ determinadas nas amostras de plâncton dos mesocosmos controle e contaminados com $\mathrm{Cu}$ (as barras de erros referem-se ao desvio padrão da média entre as réplicas dos mesocosmos).

Nas amostras coletadas no dia seguinte à contaminação dos tanques, em ambas as fases do experimento (21 de novembro e 13 de dezembro, respectivamente), foram obtidas concentrações de $\mathrm{Cu}$ e $\mathrm{Cr}$ maiores do que as determinadas no controle. As amostras coletadas cerca de dez dias após a contaminação já apresentavam concentrações semelhantes às do controle.

As maiores concentrações de $\mathrm{Cr}$ no plâncton foram determinadas nas amostras coletadas no dia 21 de novembro $\left(214 \mu \mathrm{g} \cdot \mathrm{g}^{-1}\right)$. Na segunda fase do experimento, a 
concentração máxima de $\mathrm{Cr}$ determinada nas amostras de plâncton foram menores que aquelas determinadas na primeira fase, antes da inclusão de peixes e macrófitas.

O tratamento com Cu também apresentou a maior concentração deste metal no plâncton nas amostras do dia 21/11 (239 $\left.\mu \mathrm{g} \cdot \mathrm{g}^{-1}\right)$, dia seguinte a primeira contaminação dos tanques, e um aumento menos expressivo na segunda contaminação.

Com base nestes dados e nas concentrações de $\mathrm{Cr}$ e $\mathrm{Cu}$ nas amostras de água, foram calculados os fatores de concentração (Tabela 43).

Tabela 43: Fatores de concentração de Cu e Cr pelo plâncton dos mesocosmos

\begin{tabular}{|c|c|c|c|c|c|c|c|c|c|c|}
\hline \multirow{3}{*}{$\overline{\mathrm{Cu}}$} & & 18.11 & 21.11 & 29.11 & 03.12 & 9.12 & 13.12 & 16.12 & 23.12 & 26.12 \\
\hline & Controle & 15000 & 21000 & 32000 & 22000 & 18000 & 19000 & 17000 & 27000 & 18000 \\
\hline & Cobre & 30000 & 12000 & 123000 & 72000 & 39000 & 12000 & 37000 & 77000 & 34000 \\
\hline$\overline{\mathrm{Cr}}$ & $\begin{array}{l}\text { Controle } \\
\text { Cromo }\end{array}$ & & 7000 & 41000 & & & 3000 & 11000 & 58000 & \\
\hline
\end{tabular}

$\overline{\mathrm{FC}}=\mathrm{ppm}$ no organismo/ ppm na água

Os maiores fatores de concentração foram determinados cerca de 10 dias após a contaminação dos mesocosmos, tanto no tratamento com $\mathrm{Cu}$ quanto com $\mathrm{Cr}$, em ambas as etapas do experimento. Este fato demonstra a capacidade do plâncton refletir condições ambientais anteriores, uma vez que nas datas que ocorreram os maiores fatores de concentração a concentração dos metais na água já havia sido reduzida, e as concentrações no plâncton ainda se mantiveram.

Organismos utilizáveis como biomonitores devem apresentar medidas dos níveis de metais disponíveis no ambiente integradas no tempo, e expressam as quantidades destes elementos que têm relevância ecotoxicológica (RAINBOW \& PHILIPS, 1993; PHILIPS \& SEGAR, 1986). No experimento anterior não foi possível avaliar a capacidade do plâncton dos mesocosmos em integrar as concentrações do meio ao longo do tempo, devido à freqüência de coletas, porém os fatores de concentração obtidos nesta parte do experimento demonstram esta característica, considerando-se um espaço de tempo restrito, de cerca de 10 dias.

A variação da concentração de $\mathrm{Cr}$ e $\mathrm{Cu}$ no plâncton em função das concentrações na água está apresentada nas figuras 101 e 102. 


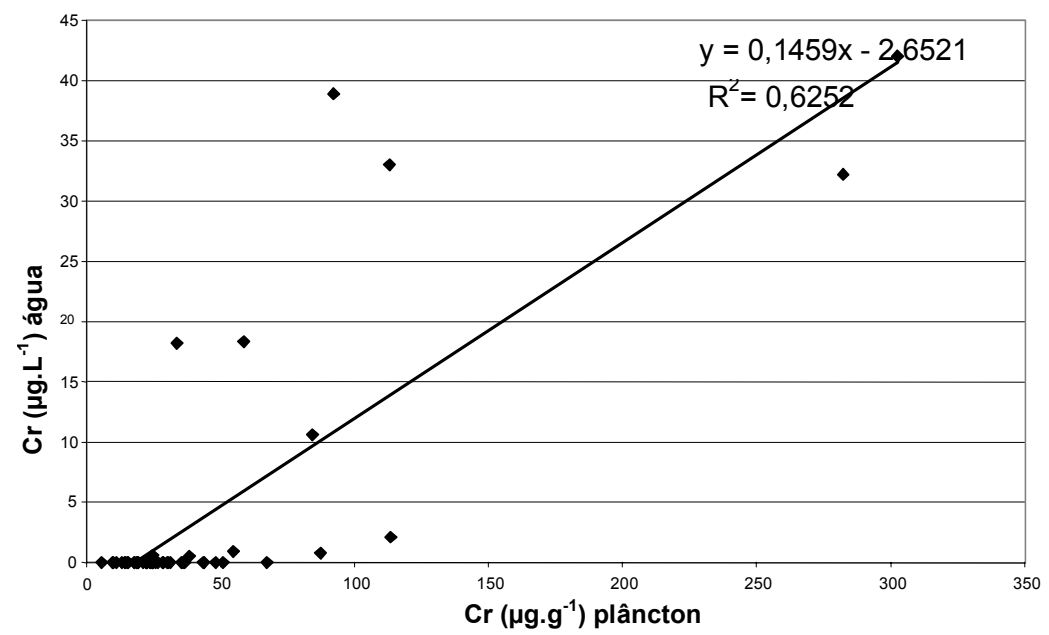

Figura 101: Regressão linear entre as concentrações de $\mathrm{Cr}$ na água e no plâncton dos mesocosmos.

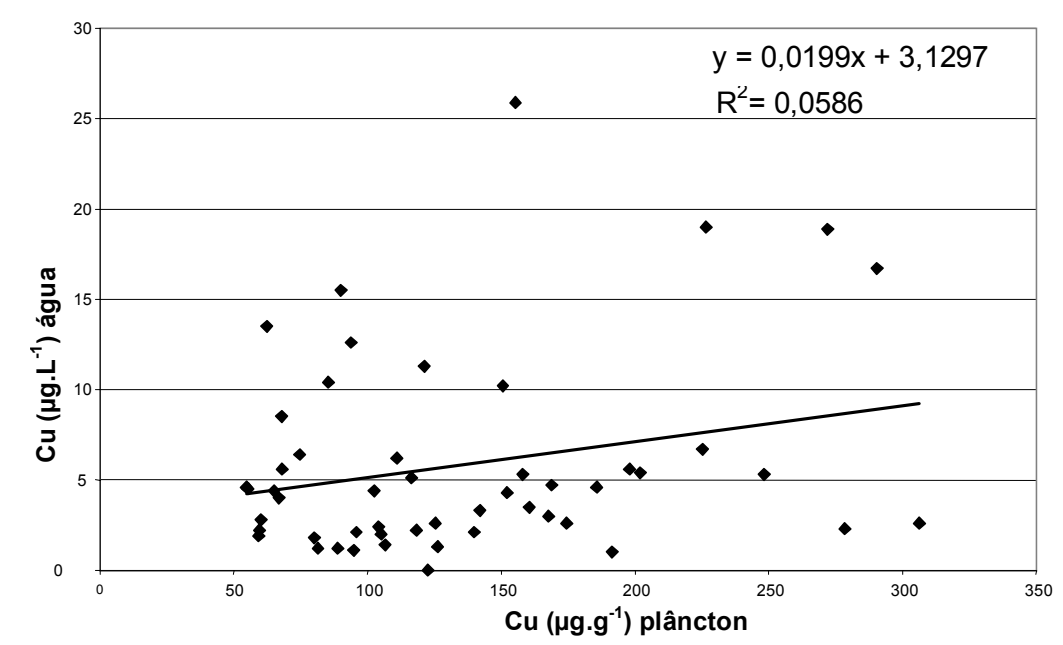

Figura 102: Regressão linear entre as concentrações de $\mathrm{Cu}$ na água e no plâncton dos mesocosmos.

As concentrações de $\mathrm{Cr}$ determinadas no plâncton dos experimentos refletem linearmente as concentrações de $\mathrm{Cr}$ na água, como pode ser visto pela análise de Regressão Linear. A análise de Correlação de Pearson gerou valor de $r=0,791$ e $p=0,000$, sendo esta correlação muito significativa.

Já para o tratamento com $\mathrm{Cu}$, o plâncton não refletiu as concentrações deste metal na água, como pode ser observado pela análise de Regressão Linear. Da mesma forma, a Correlação de Pearson foi muito menos significativa ( $r=0,242$; $\mathrm{p}=0,087$ ). Como $\mathrm{Cu}$ já ocorre naturalmente na água da represa, as comunidades podem apresentar mecanismos de regulação das concentrações deste elemento em 
seus tecidos, além de apresentaram normalmente concentrações razoáveis de Cu, independente da adição do metal ao sistema.

POWELL \& WHITE (1990) demonstraram a capacidade de Semibalanus balanoides concentrarem $\mathrm{Cd}$, $\mathrm{Cu}$ e $\mathrm{Pb}$ linearmente com as concentrações do meio em testes de laboratório, em um período de 50 dias. No entanto, Palaemon elegans, (Decapoda), demonstrou habilidade em regular as concentrações de metais essenciais, especificamente $\mathrm{Cu}$ e $\mathrm{Zn}$, apresentando concentrações constantes em seus tecidos variando-se as concentrações na água, não apresentando tal regulação para Cd (RAINBOW \& WHITE, 1989). Da mesma forma, RAINBOW (1985) observou que Carcinus maenas pode regular as concentrações de $\mathrm{Cu}$ e $\mathrm{Zn}$ em seus tecidos, mas não de Cd.

Poucos trabalhos apresentam concentrações de metais no plâncton de água doce. FARKAS et al. (2003), verificaram uma forte correlação entre as concentrações de $\mathrm{Cd}$, Cu e Zn no zooplâncton do Lago Balaton (Hungria) e as concentrações da água ambiente, analisando dados obtidos num período de 4 anos.

Os valores de $\mathrm{Cr}$ e $\mathrm{Cu}$ obtidos no plâncton dos mesocosmos que sofreram adição dos metais foram comparados com os valores obtidos no controle por análise de variância (ANOVA), considerando-se todos os valores obtidos em todas as datas. Em ambos os casos foram observadas diferenças significativas entre os tratamentos $e$ o controle ( $p=0,016$ e $p=0,000$, para $\mathrm{Cr}$ e Cu, respectivamente).

A influência da inclusão de peixes e macrófitas nos tanques também foi testada pela análise de variância, não tendo sido observada diferença significativa em cada tratamento na concentração do plâncton em cada fase do experimento $(p=0,309$ e $\mathrm{p}=0,260$, para $\mathrm{Cr}$ e $\mathrm{Cu}$, respectivamente), o que permitiu que os dados fossem analisados em conjunto.

\subsubsection{2- Bentos}

A biomassa da comunidade bentônica obtida nas coletas variou entre 2 e 37 $\mathrm{mg}$, sendo que os valores de biomassa para cada tanque estão apresentados em Apêndice. Foram consideradas para análise amostras com no mínimo $5 \mathrm{mg}$, porém essa massa não foi obtida na maioria dos casos.

Apenas na amostra coletada para o controle no dia 9 de dezembro, e nas amostras coletadas nos tanques contaminados com Cu nos dias 19 de novembro e 27 de dezembro obteve-se massa suficiente para a realização das análises. A amostra obtida para o controle apresentou a maior concentração de Cu entre as três amostras (78,7 $\mu \mathrm{g} \cdot \mathrm{g}^{-1}$ no controle no dia 9 de dezembro, véspera da segunda contaminação dos mesocomos, e 15,0 e 19,5 $\mu \mathrm{g}^{-1}{ }^{-1}$ nos tanques contaminados com Cu nos dia 19 de 
novembro, véspera da primeira contaminação, e 27 de dezembro, 15 dias após a segunda contaminação, respectivamente). Cromo não foi detectado em nenhuma das amostras analisadas.

\subsubsection{3 - Peixes}

Os peixes (Oreochromis niloticus) foram incluídos nos mesocosmos no dia 9 de dezembro. Os tanques foram novamente contaminados no dia 12 de dezembro, e o experimento acompanhado até dia 27 de dezembro de 2002. Os indivíduos utilizados no experimento foram mantidos em laboratório, em aquários de 20 litros contendo água da represa do Lobo, por 5 dias, sendo alimentados com ração comercial para peixes até 48 horas antes da inclusão.

Para cada tanque foram selecionados entre 47 e 72 peixes, totalizando uma biomassa de aproximadamente $120 \mathrm{~g}$, correspondendo a uma densidade de $35 \mathrm{~g} / \mathrm{m}^{3}$. Cada grupo de peixes foi mantido em um aquário e os indivíduos mortos ou debilitados foram substituídos por peixes que estavam sendo mantidos em um aquário de 90 litros, nas mesmas condições que os peixes selecionados e provenientes da mesma coleta, justamente para esse fim. Os peixes utilizados no experimento não foram medidos nem pesados individualmente, para evitar o estresse decorrente da manipulação. O peso médio dos peixes utilizados foi de $1,9 \mathrm{~g}$.

Quando da retirada dos tanques-rede para a coleta dos peixes, no dia 27 de dezembro, o Tanque 05, correspondente a um dos controles, foi rasgado e os peixes perdidos. No decorrer do experimento foram observados peixes mortos nos tanques, que foram retirados mas não substituídos. No tratamento com $\mathrm{Cu}$, observou-se o decréscimo do peso médio dos indivíduos ao final do experimento, em média 0,2 g, considerando-se os indivíduos utilizados em todas as réplicas. No tratamento com $\mathrm{Cr}$ e no controle não foi observado decréscimo no peso médio dos peixes.

Do número total de peixes foram formadas 3 amostras compostas para cada tanque. Assim, optou-se pela apresentação dos resultados individuais para cada mesocosmos ao invés de médias. A avaliação biométrica dos peixes está apresentada na tabela 44. 
Tabela 44: Valores médios da biomassa total, peso individual, comprimento e número de indivíduos no início e término do experimento.

\begin{tabular}{|c|c|c|c|c|c|c|}
\hline & \multicolumn{2}{|r|}{ Inicial } & \multicolumn{4}{|c|}{ Final } \\
\hline & $\mathrm{N}$ & $\begin{array}{l}\text { Biomassa Total } \\
(\mathrm{g})\end{array}$ & $\begin{array}{c}\text { Peso } \\
(\mathrm{g}) \\
\end{array}$ & $\begin{array}{c}\text { Comprimento } \\
(\mathrm{cm})\end{array}$ & $\mathrm{N}$ & $\begin{array}{c}\text { Biomassa Total } \\
(\mathrm{g}) \\
\end{array}$ \\
\hline Controle 1 & 47 & 121 & 1,87 & 4,81 & 36 & 67,4 \\
\hline Desvio Padrão & & & 0,70 & 0,64 & & \\
\hline Controle 3 & 61 & 117,9 & 2,58 & 5,28 & 19 & 49,1 \\
\hline Desvio Padrão & & & 1,10 & 0,74 & & \\
\hline Cromo 1 & 61 & 120 & 1,83 & 4,75 & 40 & 73,3 \\
\hline Desvio Padrão & & & 0,93 & 0,64 & & \\
\hline Cromo 2 & 69 & 112,6 & 1,79 & 4,72 & 52 & 93,1 \\
\hline Desvio Padrão & & & 0,71 & 0,60 & & \\
\hline Cromo 3 & 61 & 112,1 & 1,86 & 4,74 & 48 & 89,2 \\
\hline Desvio Padrão & & & 0,76 & 0,59 & & \\
\hline Cobre 1 & 63 & 113,01 & 1,47 & 4,57 & 55 & 82,1 \\
\hline Desvio Padrão & & & 0,43 & 0,44 & & \\
\hline Cobre 2 & 72 & 116,7 & 1,51 & 4,55 & 58 & 87,8 \\
\hline Desvio Padrão & & & 0,65 & 0,58 & & \\
\hline Cobre 3 & 51 & 118,3 & 1,87 & 4,76 & 40 & 67,4 \\
\hline Desvio Padrão & & & 0,56 & 0,52 & & \\
\hline
\end{tabular}

As concentrações médias de $\mathrm{Cr}$ nos organismos analisados estão apresentadas na Figura 103. As concentrações referentes a cada uma das réplicas estão apresentadas em Apêndice. Quando da coleta dos peixes para inclusão nos mesocosmos, foi coletada também uma amostra para avaliação da concentração original de $\mathrm{Cr}$ nos indivíduos, que foi de $0,18 \pm 0,15 \mu \mathrm{g} \cdot \mathrm{g}^{-1} \mathrm{Cr}$.

A concentração média de $\mathrm{Cr}$ nos controles foi igual a $0,4 \mu \mathrm{g} \cdot \mathrm{g}^{-1}$ e nos tanques contaminados com $\mathrm{Cr}$ foi igual a $1,1 \mu \mathrm{g} \cdot \mathrm{g}^{-1}$. Comparando-se as concentrações determinadas nas amostras do controle com as determinadas nas amostras dos tanques contaminados com $\mathrm{Cr}$ foram observadas diferenças significativas estatisticamente, como demonstrado na Tabela 45.

Concentrações de $\mathrm{Cr}$ determinadas em $T$. nilotica no lago Nasser (Egito) são próximas às determinadas no controle, 0,27 $\pm 0,22 \mu \mathrm{g} / \mathrm{g}$ (RASHED, 2001). Neste estudo, os indivíduos apresentaram maiores concentrações de $\mathrm{Cr}$ nas brânquias e na coluna vertebral, e as menores no músculo. 


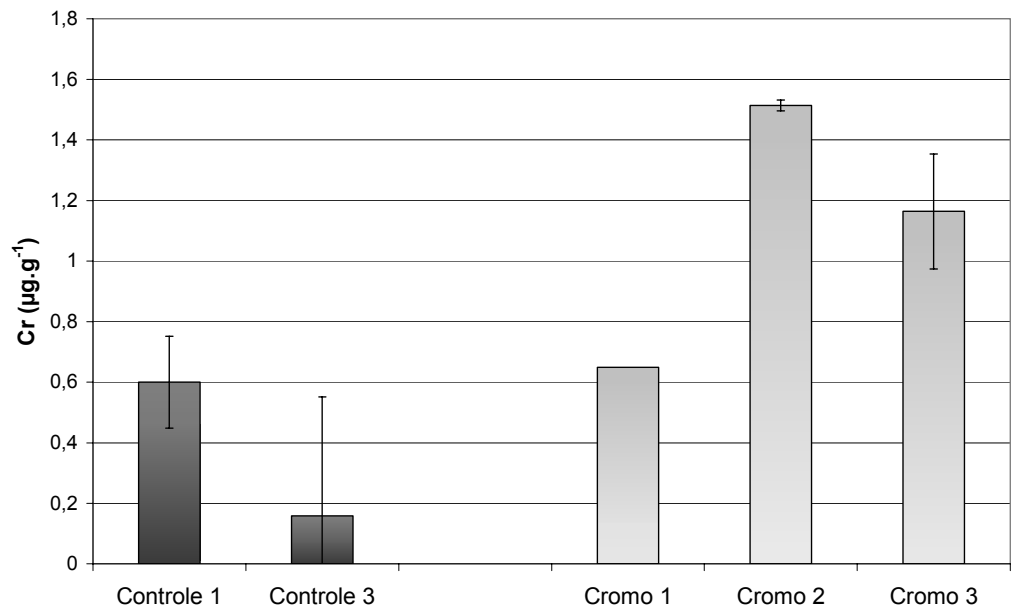

Figura 103: Concentração média $\left(\mu \mathrm{g} \cdot \mathrm{g}^{-1}\right)$ de $\mathrm{Cr}$ determinada nas amostras de peixes coletadas nos tanques controle e contaminados com $\mathrm{Cr}$ ao final do experimento (as barras de erros referem-se ao desvio padrão da média entre as amostras compostas de cada réplica).

Tabela 45: Síntese da análise de variância $(p, 0,05)$ das concentrações de $\mathrm{Cr}$ nas amostras de peixe.

\begin{tabular}{cccc}
\hline \hline & $F$ & valor-P & F crítico \\
\hline 27.12 & 5,744411 & 0,033718 & 4,747221 \\
\hline \hline
\end{tabular}

F> F crítico: significativamente diferente

As concentrações médias de $\mathrm{Cu}$ nos organismos analisados estão apresentadas na Figura 104 e os valores referentes a cada uma das réplicas estão apresentadas em Apêndice. Quando da coleta dos peixes para inclusão nos tanques, foi coletada também uma amostra para avaliação da concentração inicial de Cu nos indivíduos, que foi de $3,9 \pm 0,2 \mu \mathrm{g} \cdot \mathrm{g}^{-1} \mathrm{Cu}$.

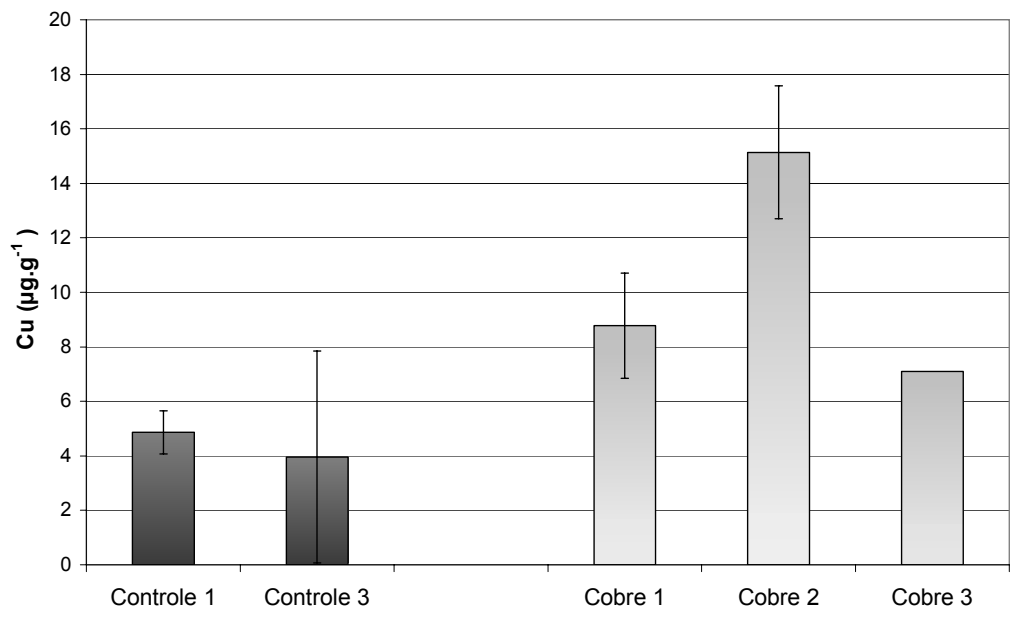

Figura 104: Concentração média $\left(\mu \mathrm{g} \cdot \mathrm{g}^{-1}\right)$ de Cu determinada nas amostras de peixes coletadas nos tanques controle e contaminados com $\mathrm{Cu}$ ao final do experimento (as barras de erros referem-se ao desvio padrão da média entre as amostras compostas de cada réplica). 
As amostras do controle apresentaram uma concentração média de $4,4 \mu \mathrm{g} \cdot \mathrm{g}^{-1}$, enquanto que no tratamento com $\mathrm{Cu}$ esta concentração foi de 10,3 $\mu \mathrm{g} \cdot \mathrm{g}^{-1}$. Comparando-se as concentrações determinadas nas amostras do controle com as determinadas nas amostras dos tanques contaminados com $\mathrm{Cu}$ foram observadas diferenças significativas estatisticamente, como demonstrado na Tabela 46.

Tabela 46: Síntese da análise de variância das concentrações de Cu nas amostras de peixe.

\begin{tabular}{llll}
\hline \hline & $\mathrm{F}$ & valor-P & $\mathrm{F}$ crítico \\
\hline 27.12 & 8,6672 & 0,0134 & 4,8443 \\
\hline \hline
\end{tabular}

F> F crítico: significativamente diferente

Diversos trabalhos reportam concentrações de Cu em peixes, em experimentos de laboratório e sob exposição ambiental. RASHED (2001) determinou concentração média de $0,27 \mu \mathrm{g} \cdot \mathrm{g}^{-1}$ em $T$. nilotica no lago Nasser (Egito), concentração muito inferior às determinadas no controle. $\mathrm{O}$. niloticus pode concentrar $\mathrm{Cu}$ em tecidos proporcionalmente à concentração da água, de acordo com trabalho de ÇOGUN \& KARGUN (2004), que testaram a toxicidade e bioacumulação de $\mathrm{Cu}$ por esta espécies em diferentes valores de $\mathrm{pH}$. Os autores observaram também que em todas as concentrações -teste Cu foi acumulado em maiores concentrações no fígado, seguido pelas brânquias e pelos músculos. MAZON et al. (2000) também observou uma relação direta na concentração de $\mathrm{Cu}$ nos tecidos de $P$. scrofa e as concentrações ambientais de $\mathrm{Cu}$.

Avaliando-se os dados biométricos (peso e comprimento) juntamente com as concentrações de $\mathrm{Cr}$, através de análise de regressão linear, observa-se que estes parâmetros apresentam uma relação inversa, ou seja, que o aumento da concentração de $\mathrm{Cr}$ na água foi inversamente proporcional ao tamanho e peso dos organismos. A mesma relação entre peso e comprimento e concentração do metal foi observada para $\mathrm{Cu}$. As análises de regressão estão apresentadas nas Figuras 105 e 106. 


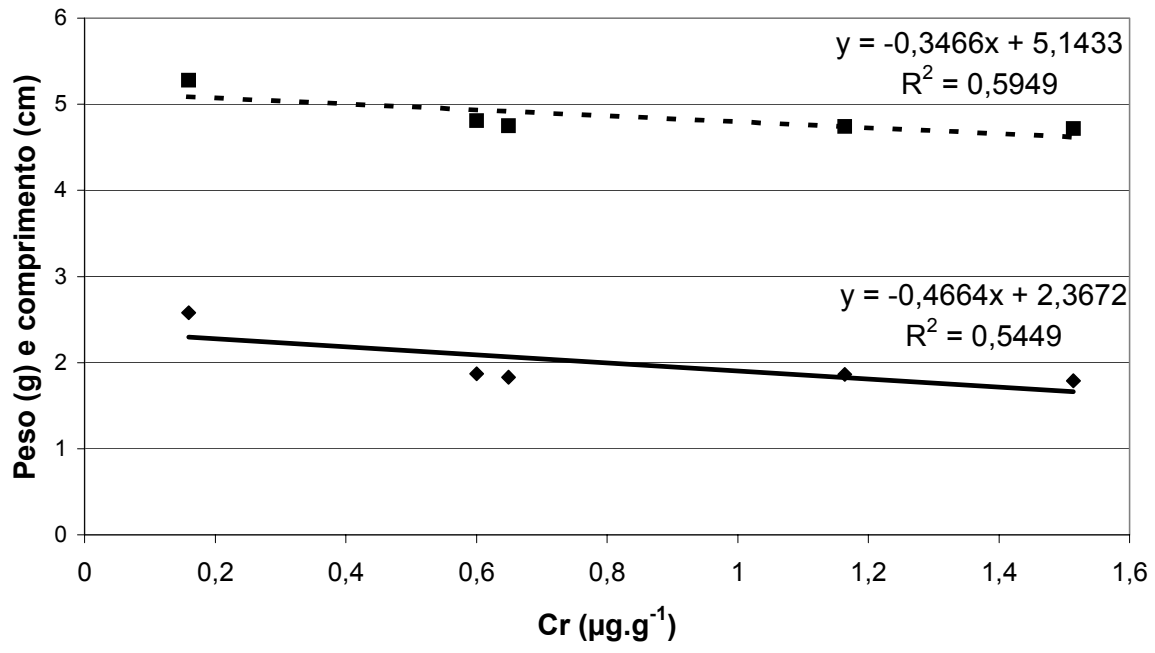

- Peso (g) — Comprimento (cm)

Figura 105: Regressão linear entre as concentrações de $\mathrm{Cr}$ e peso e comprimento dos peixes.

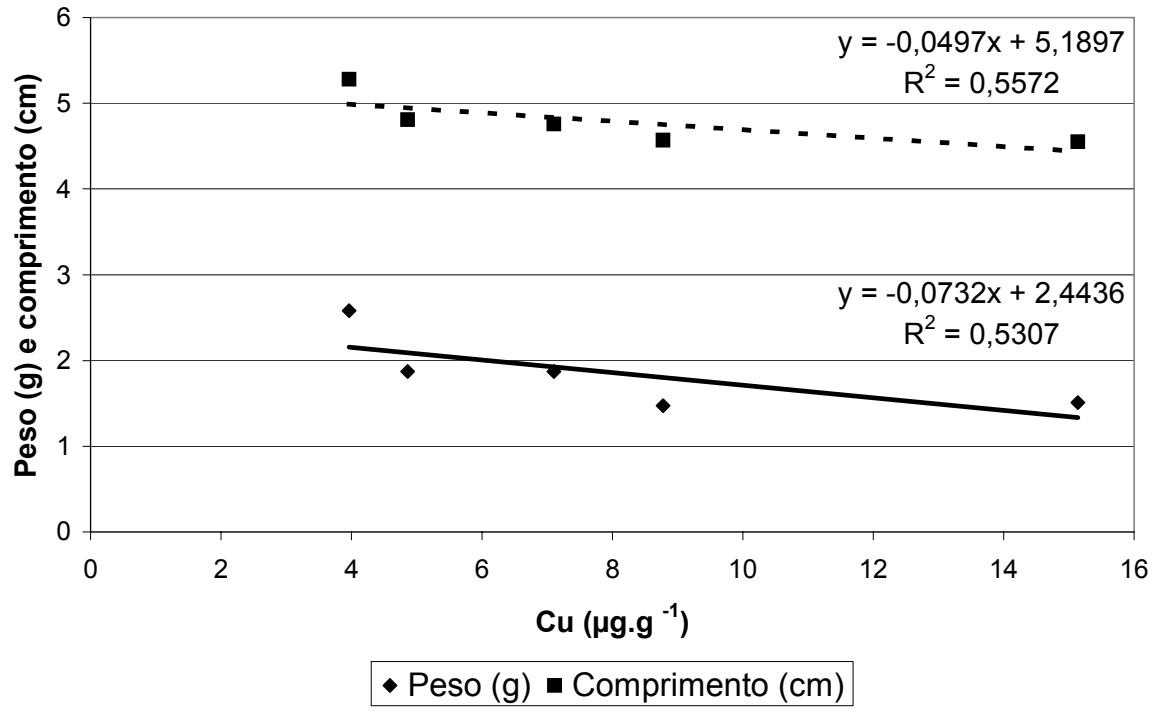

Figura 106: Regressão linear entre as concentrações de Cu e peso e comprimento dos peixes.

\subsubsection{4- Macrófitas}

As macrófitas (Pistia stratiotes) foram incluídas nos mesocosmos no dia 9 de dezembro e estes foram novamente contaminados no dia 12 de dezembro, sendo o experimento acompanhado até dia 27 de dezembro de 2002. Os indivíduos utilizados no experimento foram mantidos em laboratório, em aquários contendo água da represa do Lobo, por 5 dias, com aeração. 
Em cada tanque foram inseridos 6 indivíduos de Pistia stratiotes, constituindo uma biomassa entre 102,6 e 223 g por mesocosmos. A biomassa média dos indivíduos igual a $24,7 \mathrm{~g}$. Antes da inclusão, as macrófitas tiveram todos os brotos removidos. No final do experimento observou-se o crescimento dos brotos e o aumento na biomassa das plantas utilizadas em todos os tratamentos, sendo a biomassa média igual a 52,2 $\mathrm{g}$.

Em relação aos valores médios, não foi observada diferença entre a produção de brotos, a altura e o diâmetro das plantas utilizadas em cada um dos tratamentos. Os parâmetros biométricos avaliados estão apresentados na tabela 47 .

Tabela 47: Avaliação biométrica (valores médios) das macrófitas utilizados no experimento.

\begin{tabular}{|c|c|c|c|c|c|}
\hline & $\begin{array}{l}\text { Biomassa } \\
\text { Inicial }(\mathrm{g})\end{array}$ & $\begin{array}{l}\text { Altura Final } \\
(\mathrm{cm})\end{array}$ & $\begin{array}{l}\text { Diâmetro Final } \\
(\mathrm{cm})\end{array}$ & $\begin{array}{l}\text { Número de } \\
\text { Brotos Final }\end{array}$ & $\begin{array}{c}\text { Biomassa } \\
\text { Final }(\mathrm{g})\end{array}$ \\
\hline Controle 1 & 142,4 & 6,5 & 12,9 & 1,2 & 264,0 \\
\hline Desvio Padrão & & 0,9 & 2,7 & 1,6 & \\
\hline Controle 2 & 115,2 & 6,1 & 12,2 & 2,4 & 298,8 \\
\hline Desvio Padrão & & 1,8 & 3,9 & 1,7 & \\
\hline Controle 3 & 154,3 & 7,1 & 13,2 & 2,0 & 318,7 \\
\hline Desvio Padrão & & 1,1 & 3,7 & 2,3 & \\
\hline Cromo 1 & 102,6 & 6,3 & 14,9 & 2,8 & 336,3 \\
\hline Desvio Padrão & & 1,6 & 3,8 & 1,3 & \\
\hline Cromo 2 & 164,4 & 6,3 & 13,2 & 1,3 & 326,3 \\
\hline Desvio Padrão & & 1,5 & 4,4 & 1,2 & \\
\hline Cromo 3 & 223,0 & 5,7 & 13,9 & 1,3 & 319,7 \\
\hline Desvio Padrão & & 1,7 & 3,3 & 1,8 & \\
\hline Cobre 1 & 136,6 & 5,8 & 12,7 & 0,7 & 264,0 \\
\hline Desvio Padrão & & 1,0 & 5,0 & 1,6 & \\
\hline Cobre 2 & 142,5 & 6,3 & 14,7 & 1,2 & 300,2 \\
\hline Desvio Padrão & & 0,7 & 2,8 & 1,5 & \\
\hline Cobre 3 & 151,0 & 6,6 & 14,8 & 2,2 & 393,1 \\
\hline Desvio Padrão & & 1,6 & 4,1 & 1,3 & \\
\hline
\end{tabular}

As análises da concentração de metais nas plantas foram realizadas separadamente para as partes aéreas (folhas) e submersas (raízes). As concentrações médias de $\mathrm{Cr}$ nas plantas analisadas estão apresentadas na Figura 107. As concentrações referentes a cada uma das réplicas estão apresentadas em anexo. Quando da coleta das plantas para inclusão nos tanques, foi coletada também uma amostra para avaliação da concentração original de $\mathrm{Cr}$ nos indivíduos, que foi de $0,2 \pm 0,4 \mu \mathrm{g} \cdot \mathrm{g}^{-1}$ de $\mathrm{Cr}$, para a parte aérea e $5,4 \pm 0,3 \mu \mathrm{g} \cdot \mathrm{g}^{-1}$ de $\mathrm{Cr}$ para a parte submersa. 


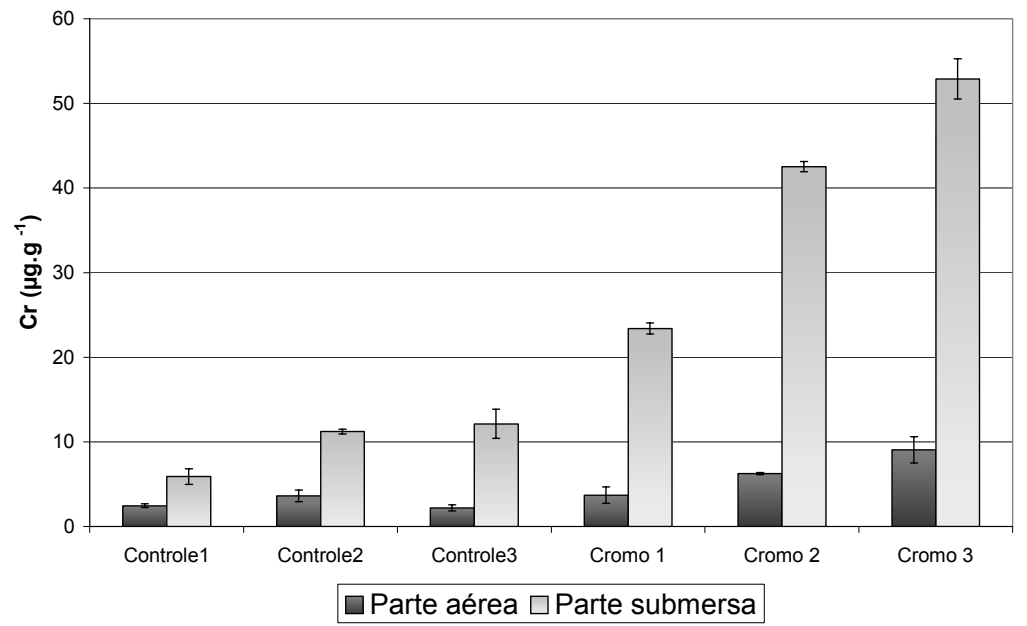

Figura 107: Concentração média $\left(\mu \mathrm{g} \cdot \mathrm{g}^{-1}\right)$ de $\mathrm{Cr}$ determinada nas amostras de macrófitas coletadas nos tanques controle e contaminados com $\mathrm{Cr}$ ao final do experimento (as barras de erros referem-se ao desvio padrão da média entre as amostras compostas de cada réplica).

Foram observadas diferenças significativas estatisticamente entre os tratamentos em relação às análises de $\mathrm{Cr}$ na parte aérea (folhas) e na parte submersa (raízes) das plantas (Tabela 48). Principalmente nas amostras de raízes, o tratamento contaminado com $\mathrm{Cr}$ apresentou concentrações mais altas que o controle, o que sugere que as plantas estejam concentrando o metal estudado a partir da solução adicionada.

Tabela 48: Síntese da análise de variância $(p<0,05)$ das concentrações de $\mathrm{Cr}$ nas amostras de macrófita.

\begin{tabular}{lccc}
\hline \hline & $F$ & valor-P & F crítico \\
\hline Parte Aérea & 10,97463 & 0,007842 & 4,964591 \\
Parte Submersa & 28,12256 & 0,000346 & 4,964591 \\
\hline \hline
\end{tabular}

F> F crítico: significativamente diferente

A capacidade das macrófitas aquáticas concentrarem $\mathrm{Cr}$ é bem documentada (CERVANTES et al, 2001; MAINE et al, 2004). KLUMP et al. (2002) determinaram valores de $\mathrm{Cr}$ entre 1,4 e $3,1 \mu \mathrm{g} . \mathrm{g}^{-1}$ em $P$. stratiotes, considerando a planta toda, em diversos pontos do rio Cachoeira (Bahia, Brasil). Esses valores são bastante inferiores aos determinados para as plantas expostas ao $\mathrm{Cr}$, principalmente considerando a parte submersa.

A acumulação de $\mathrm{Cr}$ em tecidos de $P$. stratiotes ocorre especialmente pelas raízes, o que é comprovado pela observação em microscópio da presença de precipitados, provavelmente de óxidos de cromo hidratados, nas raízes de plantas 
expostas a 6 ppm de $\mathrm{Cr}$ (MAINE et al, 2004). Plantas expostas à concentrações entre 1 e 6 ppm de $\mathrm{Cr}$ apresentaram concentrações entre 0,8 e 6,2 mg. $\mathrm{g}^{-1}$ de $\mathrm{Cr}$ nas raízes e concentrações entre 0,09 e $0,45 \mathrm{mg} \cdot \mathrm{g}^{-1}$ nas partes aéreas, removendo em torno de $90 \%$ das concentrações de $\mathrm{Cr}$ da água, após 31 dias de exposição.

A assimilação de $\mathrm{Cr}$ por $P$. stratiotes é um processo rápido, que ocorre principalmente nas 24 primeiras horas de exposição. Além da assimilação pelas raízes, as plantas podem assimilar $\mathrm{Cr}$ através do contato direto das folhas com o meio, sendo a translocação das raízes para as folhas pouco eficiente, apesar de se tratar de um processo rápido. A rapidez com que se dá a assimilação de $\mathrm{Cr}$ por $P$. stratiotes sugere que a sorção física ou adsorção é um mecanismos importante. A precipitação mediada pelas raízes e os processos biológicos como assimilação intracelular são processos mais lentos na remoção de $\mathrm{Cr}$ do meio (MAINE, op cit.).

As concentrações médias de Cu nas plantas analisadas estão apresentadas na figura 108, sendo que as concentrações referentes a cada uma das réplicas estão apresentadas em Apêndice. A concentração original de Cu nos indivíduos foi de 11,5 \pm $4,3 \mu \mathrm{g} \cdot \mathrm{g}^{-1}$ de $\mathrm{Cu}$, para a parte aérea e $54,9 \pm 1,7 \mu \mathrm{g} \cdot \mathrm{g}^{-1}$ de Cu para a parte submersa.

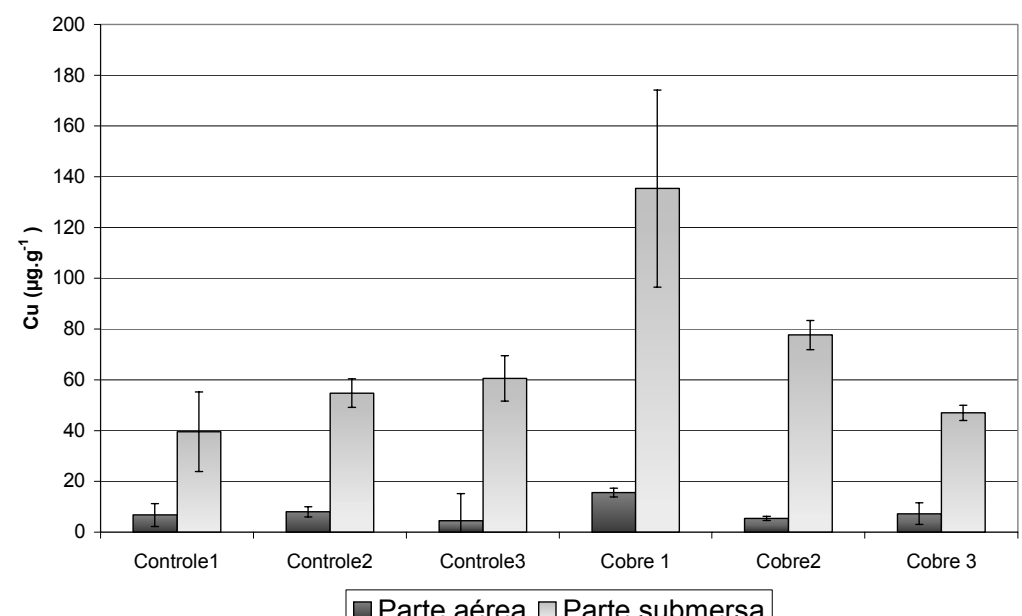

Figura 108: Concentração média $\left(\mu \mathrm{g} \cdot \mathrm{g}^{-1}\right)$ de $\mathrm{Cu}$ determinada nas amostras de macrófitas coletadas nos tanques controle e contaminados com $\mathrm{Cu}$ ao final do experimento (as barras de erros referem-se ao desvio padrão da média entre as amostras compostas de cada réplica).

Apesar das concentrações determinadas nas amostras dos tanques contaminados com $\mathrm{Cu}$ serem maiores que do controle, essas diferenças não foram significativas estatisticamente (ANOVA, $p<0,05$ ). Como a água da represa apresenta naturalmente concentrações de Cu comparáveis com as obtidas nos tanques, a adição desse elemento, na concentração utilizada, não causou efeito sobre as macrófitas. 
Para avaliar a ocorrência de efeitos crônicos pela adição dos metais sobre as características biométricas das plantas foram realizadas análises de regressão entre estas características e as concentrações de metais (Figuras 109 a 112).

As concentrações de $\mathrm{Cr}$ nas raízes e na parte aérea da planta foram relacionadas com a altura dos indivíduos, sugerindo a influência da bioacumulação deste metal sobre a altura. A concentração do Cu na parte aérea foi relacionada com a altura das plantas e na parte submersa foi relacionada tanto com a altura quanto com o número de brotos, sugerindo a influência do metal sobre estes parâmetros.

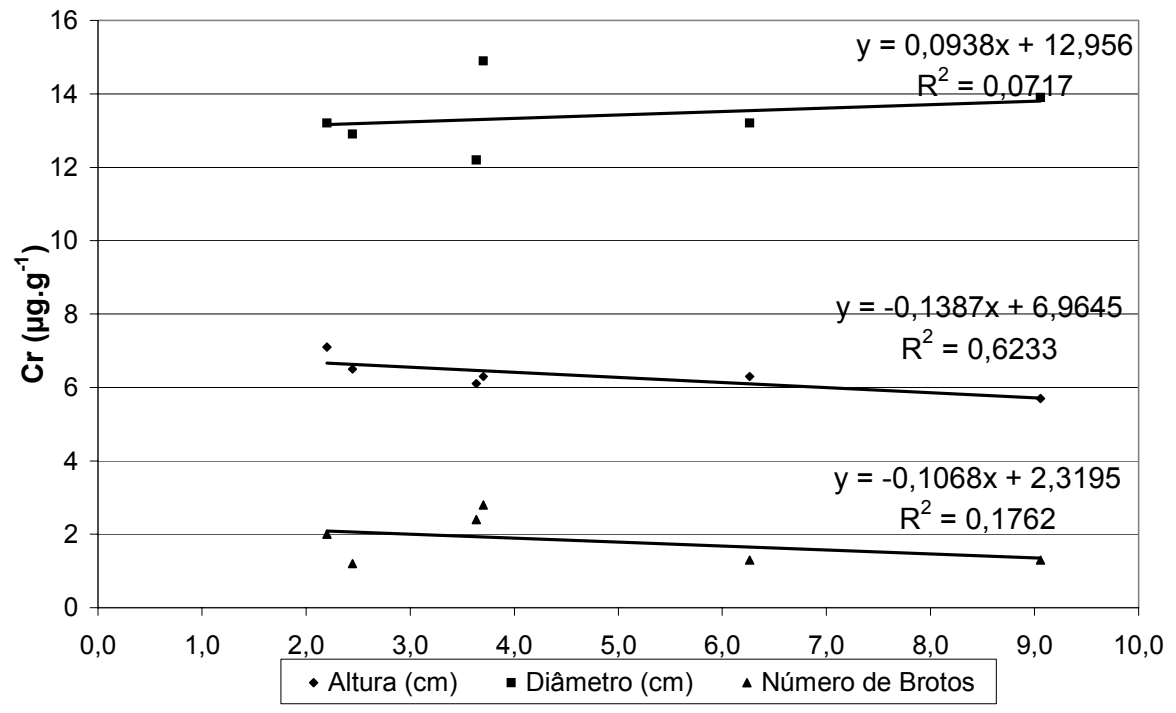

Figura 109: Regressão linear entre as concentrações de $\mathrm{Cr}$ na parte aérea das plantas e parâmetros biométricos

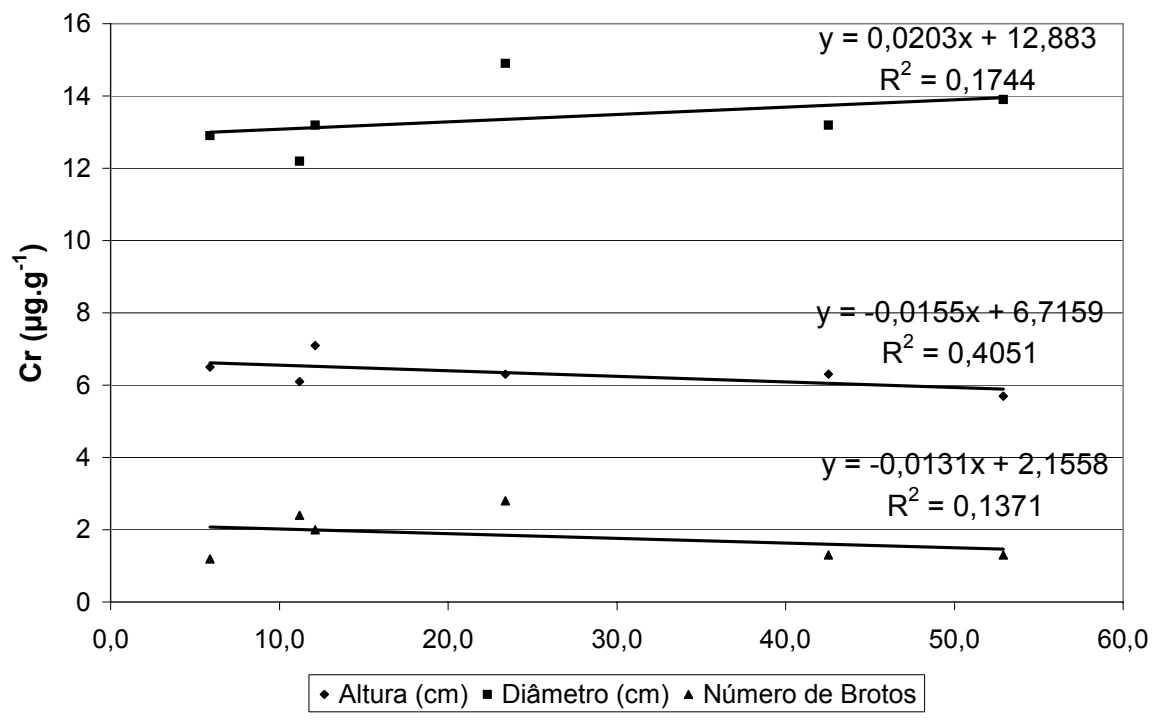

Figura 110: Regressão linear entre as concentrações de Cr na parte submersa das plantas e parâmetros biométricos 


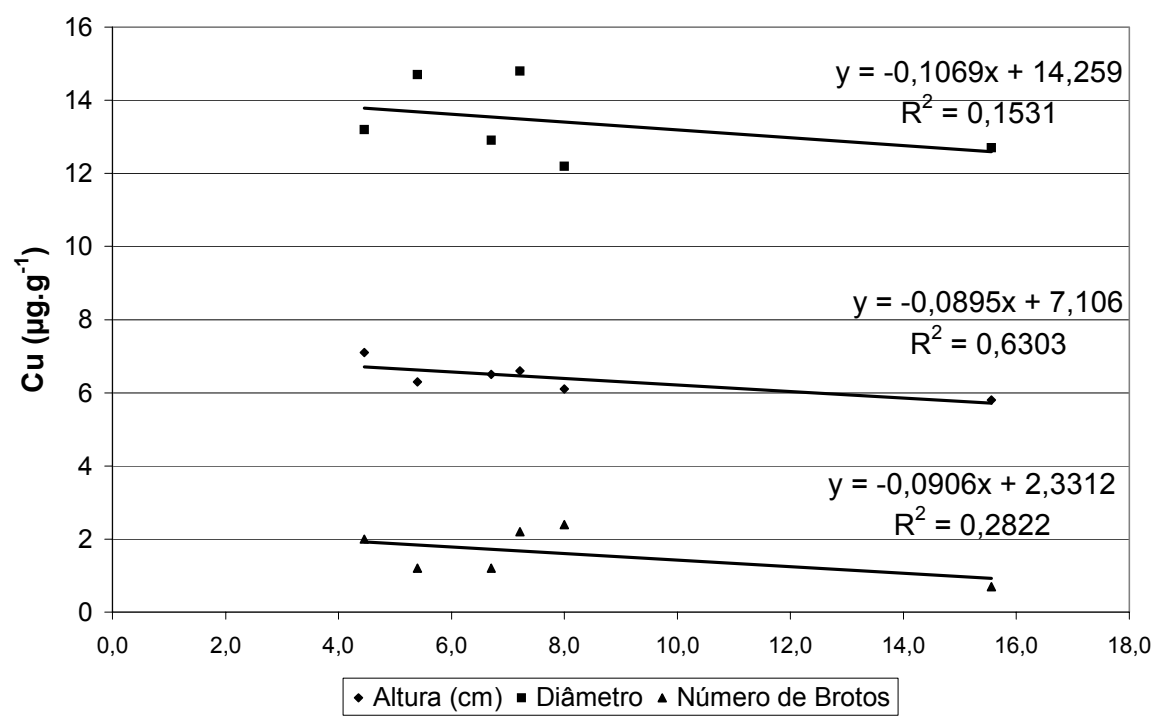

Figura 111: Regressão linear entre as concentrações de Cu na parte aérea das plantas e parâmetros biométricos

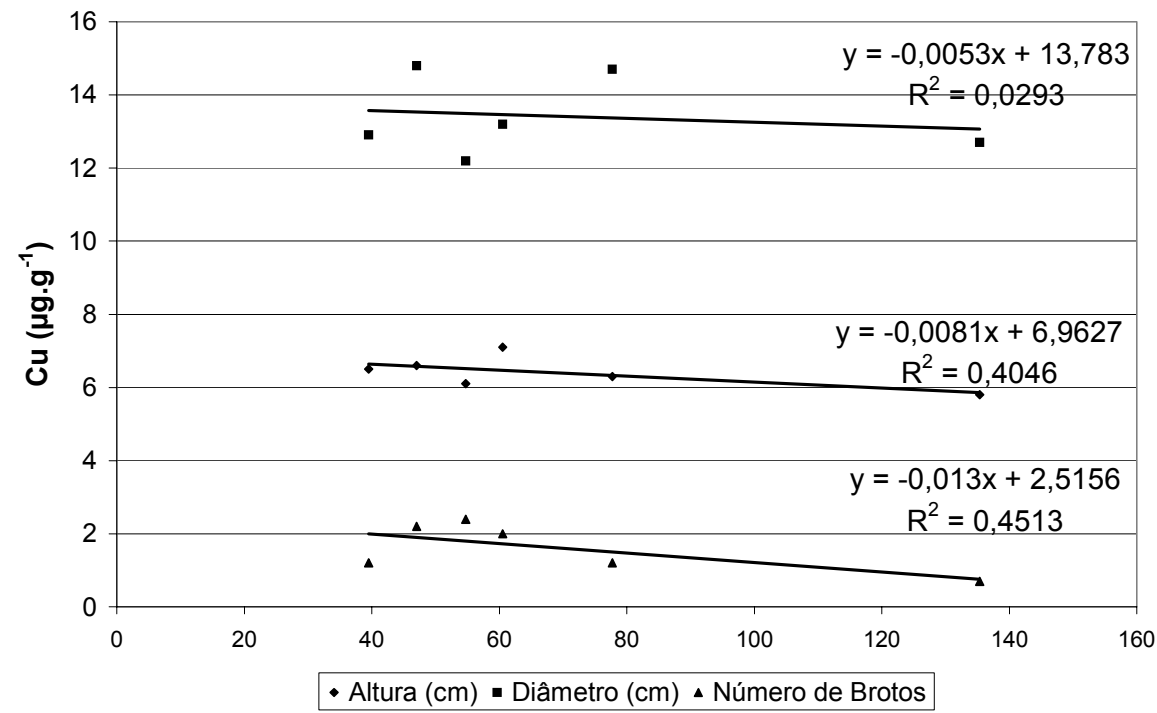

Figura 112: Regressão linear entre as concentrações de Cu na parte submersa das plantas e parâmetros biométricos

A concentração de $\mathrm{Cr}$ na água influencia as taxas de crescimento de $P$. stratiotes, como demonstrado por MAINE et al. (2004), que determinou correlação linear negativa significativa entre as taxas de crescimento da planta e concentrações de $\mathrm{Cr}$ na água, trabalhando porém com concentrações superiores às utilizadas neste trabalho. Os autores apontam ainda um decréscimo no conteúdo de clorofila das macrófitas com o aumento das concentrações de $\mathrm{Cr}$ no meio. Entretanto, mesmo 
quando sofrem efeitos tóxicos devido à bioacumulação, indivíduos de $P$. stratiotes continuam removendo o $\mathrm{Cr}$ da água (MAINE op cit.).

\subsection{2- Produção Primária do Fitoplâncton}

A produção primária do fitoplâncton foi avaliada em quatro experimentos, sendo na véspera da contaminação dos tanques, e depois de 3 hs da contaminação. Foram incubadas amostras em todos os tanques. Os valores de produção primária em termos de oxigênio dissolvido para cada uma das réplicas estão apresentados em apêndice. Os valores médios estão apresentados nas figuras 113 e 114 .

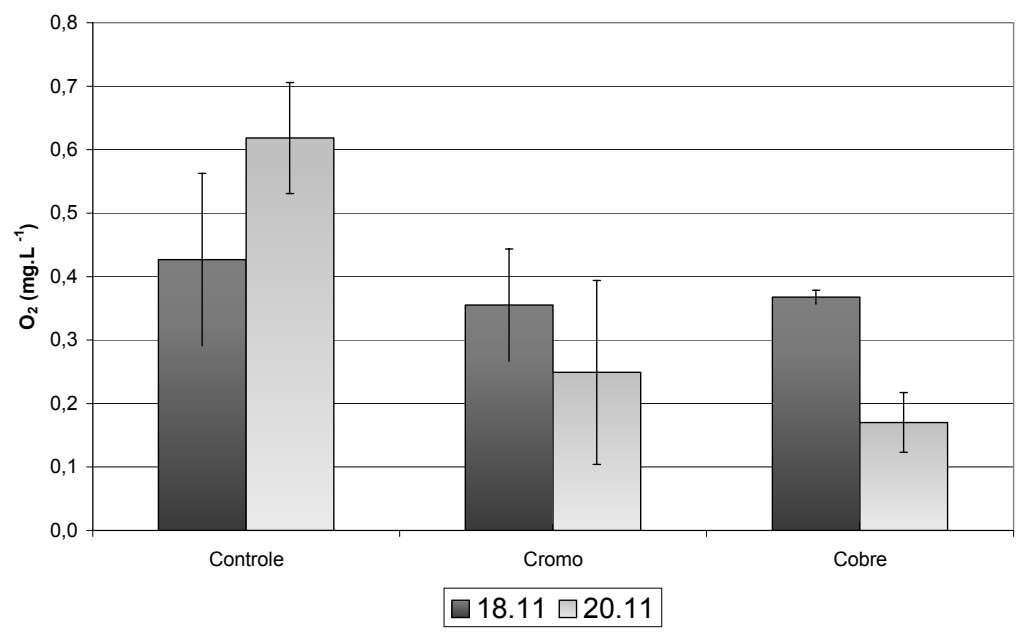

Figura 113: Produção primária média do fitoplâncton $\left(m g \cdot \mathrm{L}^{-1} \mathrm{O}_{2}\right)$ antes e após a contaminação dos tanques na primeira etapa do experimento (18 e 20 de novembro) (as barras de erros referem-se ao desvio padrão da média entre as réplicas dos mesocosmos).

As diferenças observadas nos valores apresentados pelos controles nas diferentes datas são devidas às variações nas condições climáticas no momento da realização do experimento. Na primeira avaliação da produção primária do fitoplâncton, o controle já apresentou concentrações de $\mathrm{O}_{2}$ maiores que os outros tratamentos. Após a contaminação dos tanques, porém, a produção primária média dos tanques contaminados por $\mathrm{Cu}$ e $\mathrm{Cr}$ foi igual a $27 \%$ e $40 \%$ da produção primária dos controles, respectivamente. Neste experimento, $\mathrm{Cu}$ apresentou maior inibição na produção primária do fitoplâncton que $\mathrm{Cr}$, em termos de oxigênio, o contrário do experimento realizado em abril de 2002, utilizando $C^{14}$. 


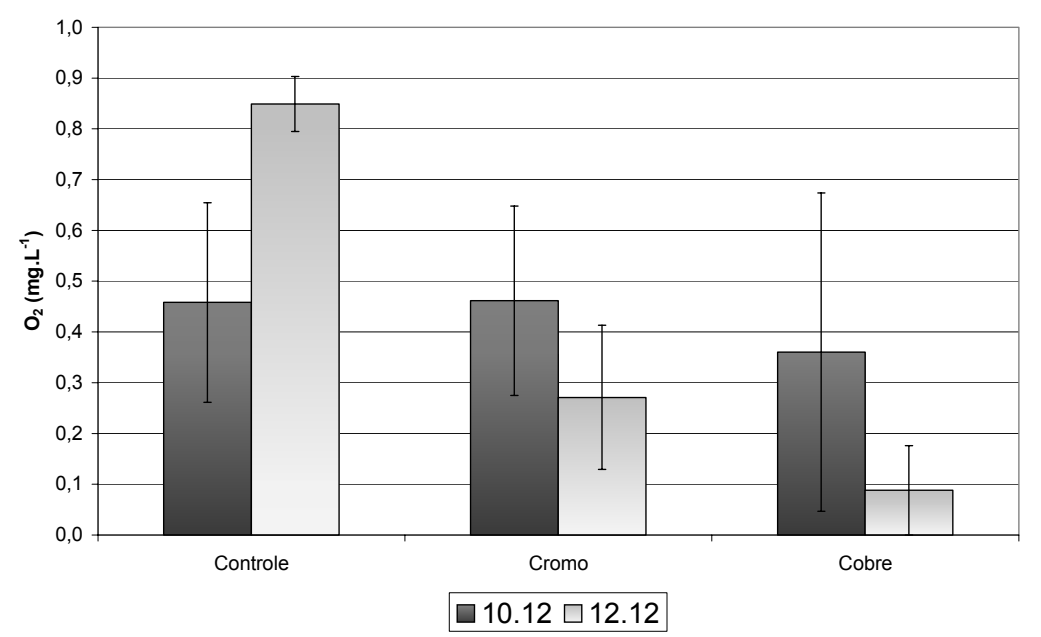

Figura 114: Produção primária média do fitoplâncton $\left(m g \cdot \mathrm{L}^{-1} \mathrm{O}_{2}\right)$ antes e após a contaminação dos tanques na segunda etapa do experimento (10 e 12 de dezembro) (as barras de erros referem-se ao desvio padrão da média entre as réplicas dos mesocosmos).

Novamente, ocorreram diferenças nos valores apresentados pelos controles na véspera e no dia da contaminação, devido à variações nas condições climáticas no momento da realização do experimento. Antes da nova contaminação dos tanques, os valores apresentados pelos experimentos com $\mathrm{Cu}$ já eram menores que os apresentados pelos outros tratamentos. Após a contaminação, porém, esses valores foram reduzidos a $10 \%$ da concentração apresentada pelo controle. Nessa segunda etapa do experimento, ambos os metais testados apresentaram maior inibição sobre a produção primária, em relação à fase anterior.

As diferentes respostas obtidas nos experimentos de produção primária realizados em abril e dezembro de 2002 podem ser devido à alterações nas comunidades fitoplanctônicas, que poderiam responder de forma diferenciada aos metais, ou à alterações nas características climáticas e limnológicas ou a diferentes respostas do sistema ao $\mathrm{C}^{14}$ em relação ao oxigênio dissolvido.

Nas duas avaliações da produção primária após a adição dos metais observouse um pronunciado decréscimo na produção primária após a adição de ambos os metais, indicando os efeitos dos metais sobre a comunidade fitoplanctônica.

\subsection{5- Bioensaios de toxicidade}

Os bioensaios de toxicidade foram desenvolvidos no decorrer dos experimentos, permitindo uma avaliação da toxicidade da água em relação ao tempo. Nenhuma das amostras coletadas antes da contaminação dos mesocosmos 
apresentou toxicidade aguda para $D$. similis. Os resultados de cada teste de toxicidade estão apresentados em apêndice, e os valores médios de mortalidade na figura 115.

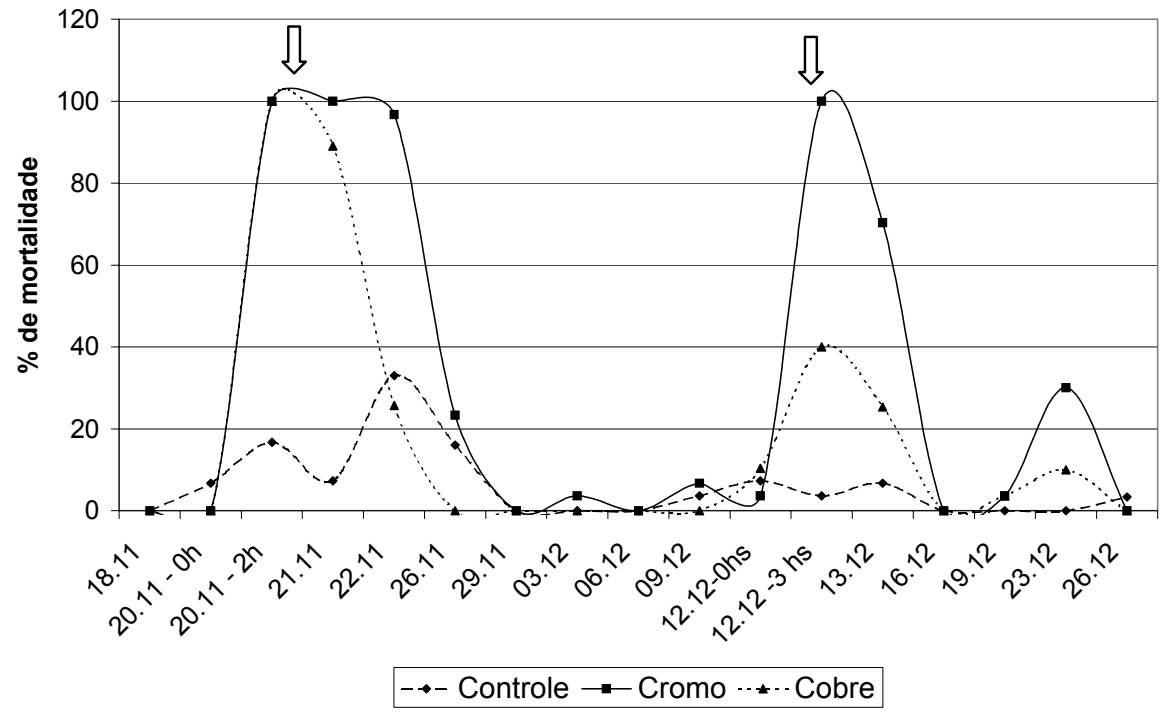

Figura 115: Porcentagem de mortalidade de $D$. similis em amostras de água dos mesocosmos (as setas indicam a data da contaminação dos mesocosmos).

Imediatamente após a contaminação dos tanques, todas as amostras, exceto o controle, apresentaram toxicidade aguda para $D$. similis. As amostras dos tanques contaminados com $\mathrm{Cu}$ perderam a toxicidade mais rápido que os contaminados com $\mathrm{Cr}$ e, na segunda fase do experimento, a toxicidade das amostras dos experimentos contaminados com $\mathrm{Cu}$ foi menor que a toxicidade das amostras geradas na primeira fase do experimento.

A toxicidade das amostras variou linearmente com as concentrações de $\mathrm{Cr}$ e $\mathrm{Cu}$, como pode ser visto nas Figuras 116 e 117.

Os valores de $\mathrm{R}^{2}$ (0,8134 e 0,5695, para $\mathrm{Cr}$ e Cu respectivamente) obtidos para a regressão linear entre as concentrações dos metais e a mortalidade dos indivíduos nos testes demonstram a forte relação, sendo mais significativa para o $\mathrm{Cr}$, entre essas observações.

Através das equações apresentadas nas figuras 115 e 116 foi calculada a concentração que causaria uma mortalidade igual a $50 \%$ da população, ou seja, a CE (50) de $\mathrm{Cr}$ e $\mathrm{Cu}$, exposta aos metais em água natural. Esses valores foram iguais a 19 $\mu \mathrm{g} / \mathrm{L}$ para o $\mathrm{Cr}$ e $22 \mu \mathrm{g} / \mathrm{L}$ para o $\mathrm{Cu}$.

Comparando-se estes valores de CE (50) com os determinados nos testes utilizando soluções preparadas no laboratório e água reconstituída $(22 \mu \mathrm{g} / \mathrm{L}$ para o $\mathrm{Cr}$ e $10 \mu \mathrm{g} / \mathrm{L}$ para o $\mathrm{Cu}$ ), a sensibilidade dos organismos ao $\mathrm{Cr}$ foi praticamente a mesma 
nos dois meios, enquanto para o $\mathrm{Cu}$ os organismos foram menos sensíveis em condições ambientais, demonstrando o decréscimo da toxicidade deste elemento em águas naturais.

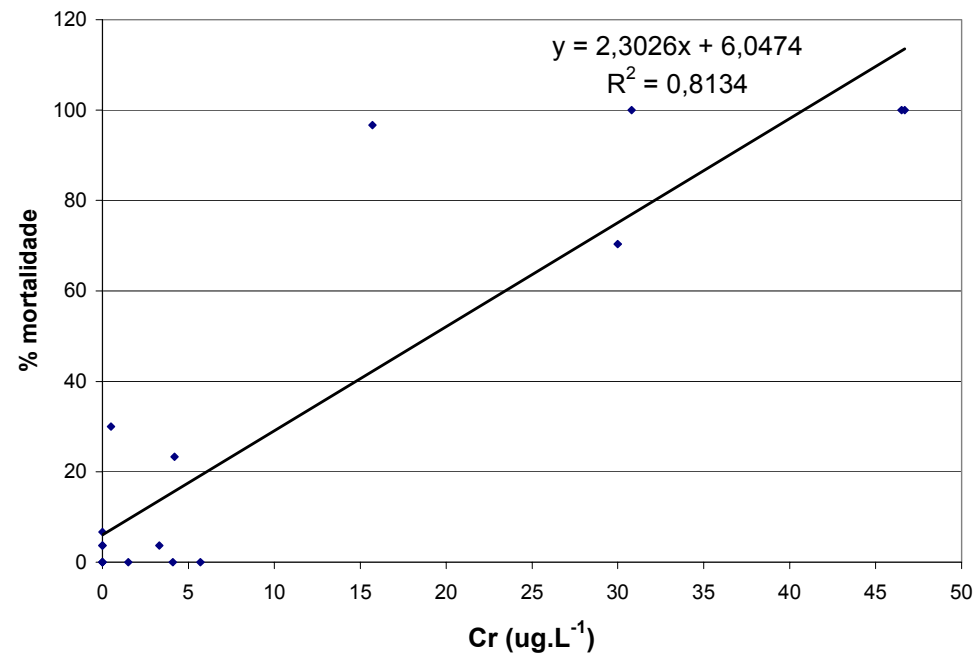

Figura 116: Regressão linear entre as concentrações de $\mathrm{Cr}$ e mortalidade de $D$. similis nas amostras de água dos mesocosmos.

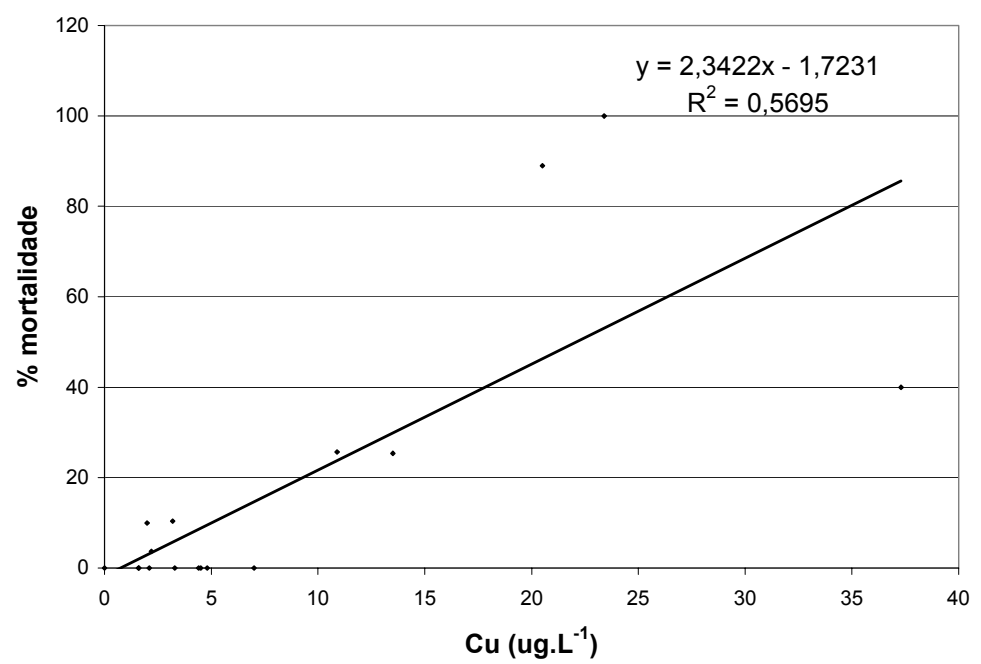

Figura 117: Regressão linear entre as concentrações de $\mathrm{Cu}$ e mortalidade de $D$. similis nas amostras de água dos mesocosmos. 


\subsection{6- - Avaliação da metodologia empregada nos experimentos em mesocosmos (aspectos funcionais e bioacumulação)}

A variabilidade entre cada conjunto de réplicas foi avaliada através de análises estatística multivariadas (MANOVA) e univariadas (ANOVA), com o auxílio do software MINITAB 13.

Em relação às variáveis avaliados na água superficial, não foram observadas diferenças estatística significativas entre nenhum dos conjuntos de réplicas, gerando valores de $\mathrm{p}$ iguais a 0,338; 0,349 e 0,625 para as réplicas controle, $\mathrm{Cr}$ e $\mathrm{Cu}$ respectivamente, para os testes de Wilk's, Lawey-Hotelling, Pillai's e Roys. Avaliandose cada variável individualmente, as réplicas do controle apresentaram diferenças significativas para o material em suspensão total $(p=0,012)$ e orgânico $(p=0,041)$. tratamento com $\mathrm{Cr}$ não apresentou diferenças significativas entre as réplicas para nenhuma das variáveis avaliadas assim como o tratamento com $\mathrm{Cu}$.

As réplicas do controle e dos tratamentos com $\mathrm{Cr}$ e $\mathrm{Cu}$ também não apresentaram diferenças significativas para as variáveis analisados no controle, tanto pela análise multivariada $(p=0,699 ; p=0,991 ; p=0,269$; respectivamente para $o$ controle, $\mathrm{Cr}$ e $\mathrm{Cu}$ ) como univariada considerando-se cada parâmetro individualmente.

A metodologia utilizada nos experimentos foi plenamente satisfatória, não apresentando variabilidade significativa entre as características funcionais do sistema para nenhum dos parâmetros estudados.

A freqüência das determinações dos metais no plâncton e das avaliações de toxicidade nas amostras de água dos mesocosmos foi eficiente para a obtenção de correlações com as concentrações de metais na água, porém a metodologia não foi aplicável à avaliação da bioacumulação pelo bentos. 


\section{5- CONSIDERAÇÕES FINAIS SOBRE OS EXPERIMENTOS EM MICRO E MESOCOSMOS}

\section{1- Experimento em microcosmos}

A adição de $\mathrm{Cr}$ e $\mathrm{Cu}$ aos experimentos em microcosmos, representando a represa do Lobo, causou efeitos significativos sobre um pequeno número de variáveis limnológicas, mais expressivamente sobre a concentração de clorofila, em ambos os casos. A concentração de $\mathrm{Cu}$ na fase dissolvida da água dos microcosmos aparentemente foi controlada pelo material em suspensão orgânico e, indiretamente, pelo $\mathrm{pH}$, o que não foi observado para o $\mathrm{Cr}$.

A comunidade fitoplanctônica foi mais sensível ao $\mathrm{Cr}$, sofrendo maior inibição na densidade total de organismos que quando exposta ao $\mathrm{Cu}$, e uma diminuição significativa na riqueza de espécies. Observando-se os outros índices, diversidade $\left(H^{\prime}\right)$, uniformidade (U') e dominância (D') não foram observados efeitos comparando-se os tratamentos com $\mathrm{Cr}$ e $\mathrm{Cu}$ com o controle, sugerindo que as diferenças entre a composição inicial e a final nos microcosmos foram devidas principalmente ao enclausuramento e às condições climáticas. Nos testes realizados em laboratório com S. capricornutum esta espécies apresentou maior sensibilidade ao $\mathrm{Cu}$ que ao $\mathrm{Cr}$, contrário ao observado pela comunidade fitoplanctônica avaliada nos microcosmos.

A comunidade zooplanctônica total foi mais sensível ao $\mathrm{Cr}$, o que pode ser observado pelos índices de diversidade, uniformidade e dominância. A densidade total foi afetada mais expressivamente pela exposição ao $\mathrm{Cu}$. Considerando-se apenas a comunidade de Cladocera, o $\mathrm{Cu}$ foi mais tóxico que o $\mathrm{Cr}$, como observado nos testes de toxicidade com $D$. similis e $C$. dubia. Uma síntese dos efeitos do $\mathrm{Cr}$ e do $\mathrm{Cu}$ sobre os componentes do sistema estudados estão apresentados nas tabelas 49 e 50.

Tabela 49: Síntese dos efeitos do $\mathrm{Cr}$, em comparação com o controle, nos experimentos em microcosmos. O: observado; NO: não observado.

\begin{tabular}{lll}
\hline \hline Variável & Efeito & Tipo de efeito \\
\hline $\mathrm{pH}$ & $\mathrm{NO}$ & \\
Nutrientes & $\mathrm{NO}$ & \\
Material em Suspensão & $\mathrm{NO}$ & \\
Clorofila & $\mathrm{O}$ & Inibição $(80 \% ; 7$ dias $)$ \\
Fitoplâncton & $\mathrm{O}$ & Densidade $(80 \% ; 72 \mathrm{hs})$ \\
& & Riqueza $(7$ dias $)$ \\
Zooplâncton & $\mathrm{O}$ & Diversidade (7 dias) \\
\hline \hline
\end{tabular}


Tabela 50: Síntese dos efeitos do $\mathrm{Cu}$, em comparação com o controle, nos experimentos em microcosmos. O: observado; NO: não observado.

\begin{tabular}{lll}
\hline \hline Variável & Efeito & Tipo de efeito \\
\hline pH & NO & \\
Nutrientes & NO & \\
Material em Suspensão & NO & \\
Clorofila & $\mathrm{O}$ & Inibição $(50 \%)$ \\
Fitoplâncton & $\mathrm{O}$ & Densidade $(70 \%)$ \\
& & Riqueza \\
Zooplâncton & $\mathrm{O}$ & Densidade (40\%) \\
\hline \hline
\end{tabular}

Apesar dos problemas metodológicos oriundos de experimentos em microcosmos ou mesocosmos, verificou-se uma resposta diferenciada quando os testes com $\mathrm{Cu}$ e $\mathrm{Cr}$ foram feitos em um sistema maior, com uma comunidade mais abrangente (fitoplâncton e zooplâncton) em comparação com os testes de toxicidade com algas e zooplâncton realizados em laboratório. Reconhece-se, ainda, que a simples retirada da água da represa e seu "confinamento" em tanques já representa um fator adicional favorável a reestruturação do "sistema tanque", pois modificações no $\mathrm{pH}$, condutividade, luz e nutrientes (assimilação e sedimentação) contribuem para a reorganização da comunidade. No presente estudo, a comunidade "reorganizada" nos microcosmos foi representativa do sistema que se pretendia reproduzir, assim como as características limnológicas da água.

Apesar das concentrações de $\mathrm{Cr}$ e $\mathrm{Cu}$ relativamente baixas, os efeitos dos metais no sistema foram identificados, nos compartimentos abióticos e nos bióticos, o que ressalta a importância da realização de estudos sobre a toxicidade de contaminantes em concentrações ambientais reais, o que dificilmente é retratado pelos testes de toxicidade agudos ou crônicos de curta duração.

\section{2- Experimentos em mesocosmos 1- Aspectos funcionais e estruturais}

Em relação às características funcionais do sistema, a adição de $\mathrm{Cr}$ e de $\mathrm{Cu}$ provocou efeitos significativos nas variáveis limnológicas da água. A contaminação por $\mathrm{Cr}$ apresentou efeito sobre um maior número de variáveis que a contaminação por $\mathrm{Cu}$, sendo que em todos os casos as condições iniciais demoraram mais para ser restabelecidas, ou não o foram. As principais variáveis afetadas pela adição de $\mathrm{Cr}$ foram o de material em suspensão total, orgânico e inorgânico, oxigênio dissolvido, silicato, amônio, fósforo total e fósforo total dissolvido e clorofila.

As variáveis avaliadas nos sedimentos não apresentaram alterações após a contaminação dos tanques, porém foi observada uma forte correlação entre a concentração de Cu na água intersticial e o conteúdo de matéria orgânica, Eh e 
oxigênio dissolvido no sedimento. A concentração total de $\mathrm{Cr}$ no sedimento também aparenta ser controlada pelo conteúdo de matéria orgânica e pelo oxigênio dissolvido.

Em relação à ocorrência de bioacumulação dos metais estudados pelo plâncton, não foram observadas diferenças entre as concentrações obtidas nos controles e nos tanques expostos ao $\mathrm{Cu}$ em nenhuma das datas, e apenas nas amostras do dia 19/04 para o Cr. Já para os organismos bentônicos foram observadas diferenças para os dois metais nas amostras de 30/04. Desta forma, ficou comprovouse a ocorrência de bioacumulação apenas de $\mathrm{Cr}$ pelo plâncton, e tanto de $\mathrm{Cr}$ como de Cu pelos organismos bentônicos.

O efeito da exposição do fitoplâncton aos metais estudados pode ser observada através das alterações nas concentrações de clorofila em função das concentrações de metais presentes na água, como mostram as figuras 117 e 118 . Entre os metais estudados, $\mathrm{Cr}$ apresentou a maior inibição na produção de clorofila, assim como maior inibição na produção primária do fitoplâncton, sendo determinados valores próximos a zero após à contaminação dos tanques.

Em relação ao zooplâncton, ambos os metais apresentaram efeitos sobre a estrutura da comunidade, comparando-se os índices ecológicos obtidos para os tratamentos com metais com o controle.

Os efeitos dos metais adicionados sobre a estrutura do sistema pode ser vista de forma simplificada nas figuras 117 e 118. Nestas figuras foram consideradas a densidade total do zooplâncton, as concentrações de clorofila e metais e os dados obtidos para o fitoplâncton apenas para Cr (TUCCI, 2004).

Considerando a concentração obtida 2 hs após a contaminação (01.04-2hs) como a concentração inicial de $\mathrm{Cr}$ no tanque $\mathrm{Cr} 1$ (no qual foram analisadas as comunidades fito e zooplanctônicas), e o decréscimo na densidade de organismos em comparação com a densidade obtida antes da contaminação (01/04 - 0hs), pode-se inferir que a esta concentração, igual a 44,9 $\mu \mathrm{g} \cdot \mathrm{L}^{-1}$, representa a CE (43) 4 hs; CE (64) 24 hs; CE (90) 96 hs; CE (86) 8d; CE (80) 15d; CE (66) 29d, para a comunidade zooplanctônica total.

Considerando a concentração obtida 2 hs após a contaminação (01.04-2hs) como a concentração inicial de $\mathrm{Cu}$ no tanque $\mathrm{Cu} 2$ (no qual foi analisada a comunidade zooplanctônica), e o decréscimo na densidade de organismos em comparação com a densidade obtida antes da contaminação (01/04 - 0hs), pode-se inferir que a esta concentração, igual a $20,6 \mu \mathrm{g} \cdot \mathrm{L}^{-1}$, representa a CE (3) 4 hs; CE (16) 24 hs e a CE (26) 96 hs para a comunidade zooplanctônica total, sendo que após esta data as densidades foram superiores às iniciais. 


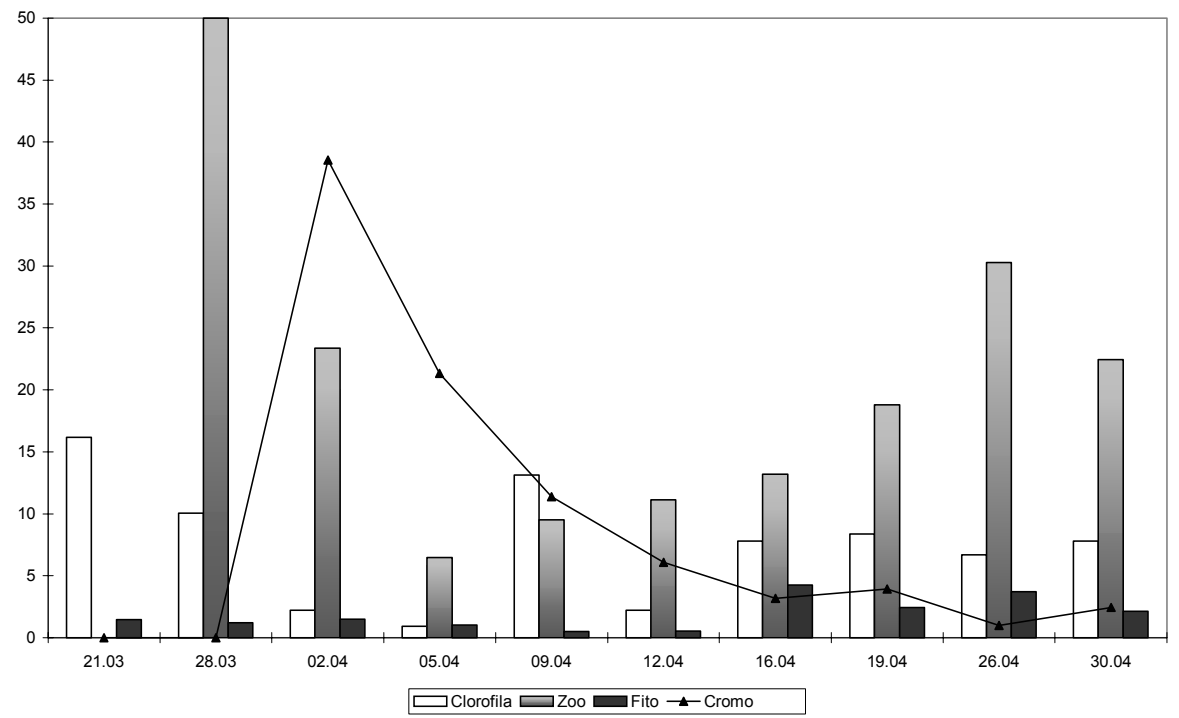

Figura 118: Efeitos do $\mathrm{Cr}$ sobre os compartimentos bióticos dos mesocosmos. Clorofila e Cr: $\mu \mathrm{g} \cdot \mathrm{L}^{-1}$; Fitoplâncton: x 1000 org. $\mathrm{mL}^{-1}$; Zooplâncton: x 10000 org. $\mathrm{L}^{-1}$.

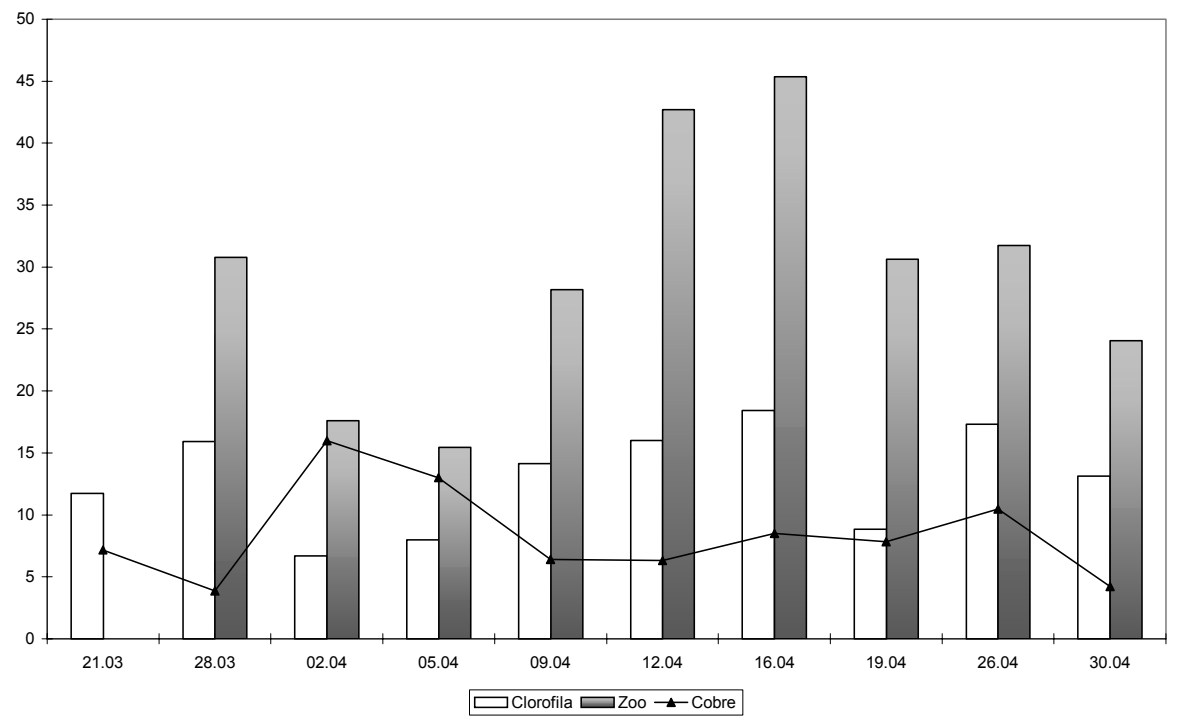

Figura 119: Efeitos do Cu sobre os compartimentos bióticos dos mesocosmos. Clorofila e Cu: $\mu \mathrm{g} \cdot \mathrm{L}^{-1}$; Zooplâncton: $\mathrm{x} 10000$ org. $\mathrm{L}^{-1}$.

De forma geral, $\mathrm{Cr}$ apresentou maior impacto sobre os compartimentos estudados do que $\mathrm{Cu}$, tanto sobre as características funcionais quanto estruturais do sistema, o contrário do que sugeriam os testes de sensibilidade com organismos padronizados com soluções de $\mathrm{Cr}$ e $\mathrm{Cu}$.

Os resultados dos testes de toxicidade aguda para $D$. similis foram comparáveis aos efeitos observados nos experimentos sendo que as amostras que 
apresentaram toxicidade aguda foram as mesmas que indicaram alterações na estrutura das comunidades fito e zooplanctônicas.

A comunidade bentônica também apresentou modificações estruturais nos tanques contaminados com $\mathrm{Cr}$ e $\mathrm{Cu}$, apesar de não terem sido observadas alterações significativas nas características do sedimento, em comparação com o controle.

$\mathrm{Na}$ utilização dos mesocosmos verificou-se maior variabilidade entre as réplicas que os experimentos em menor escala, o que não afetou a análise dos efeitos dos metais sobre o sistema. O tratamento que apresentou a maior variação foi o controle, e o mais estável o tratamento com Cr. As escalas espaciais e temporais foram adequadas para as avaliações propostas, porém a freqüência de coletas e o número de amostras não possibilitou uma melhor avaliação de algumas variáveis. Uma síntese dos efeitos observados neste experimento em mesocosmos está apresentadas nas Tabelas 51 e 52.

Tabela 51: Síntese dos efeitos do $\mathrm{Cr}$, em comparação com o controle, nos experimentos em mesocosmos (aspectos funcionais e estruturais). O: observado; NO: não observado.

\begin{tabular}{llll}
\hline \hline & Variável & Efeito & Tipo de efeito \\
\hline Água & Oxigênio dissolvido & $\mathrm{O}$ & \\
& Condutividade & $\mathrm{O}$ & \\
& pH & $\mathrm{O}$ & \\
& Nutrientes & $\mathrm{O}$ & \\
& Material em Suspensão & $\mathrm{O}$ & \\
& Matéria Orgânica & $\mathrm{NO}$ & \\
& Fósforo & $\mathrm{NO}$ & \\
\hline Sedimento & Nitrogênio & $\mathrm{NO}$ & \\
& Clorofila & $\mathrm{O}$ & Inibição $(35 \% ; 2 \mathrm{hs})$ \\
& Produção primária & $\mathrm{O}$ & Inibição $(90 \% ; 2 \mathrm{hs})$ \\
& fitoplâncton & & \\
& Zooplâncton & $\mathrm{O}$ & Decréscimo na densidade \\
& Plâncton & & (90\%; $96 \mathrm{hs})$ \\
& Toxicidade & $\mathrm{O}$ & Bioacumulação \\
& & $\mathrm{O}$ & Mortalidade (100\%, 2hs) \\
& & $\mathrm{O}$ & Decréscimo na densidade \\
& & & (86\%, 30 dias) \\
& & & Decréscimo na riqueza \\
Bentos & & $\mathrm{O}$ & Bioacumulação \\
& &
\end{tabular}


Tabela 52: Síntese dos efeitos do $\mathrm{Cu}$, em comparação com o controle, nos experimentos em mesocosmos (aspectos estruturais e funcionais). O: observado; NO: não observado.

\begin{tabular}{llll}
\hline \hline & Variável & Efeito & Tipo de efeito \\
\hline Água & Oxigênio dissolvido & NO & \\
& Condutividade & $\mathrm{O}$ & \\
& $\mathrm{pH}$ & $\mathrm{O}$ & \\
& Nutrientes & $\mathrm{NO}$ & \\
& Material em Suspensão & $\mathrm{NO}$ & \\
& Matéria Orgânica & $\mathrm{NO}$ & \\
& Fósforo & $\mathrm{NO}$ & \\
\hline Sedimento & Nitrogênio & $\mathrm{NO}$ & \\
& Clorofila & $\mathrm{O}$ & Inibição $(35 \% ; 2 \mathrm{hs})$ \\
& Produção primária & $\mathrm{O}$ & Inibição $(60 \% ; 2 \mathrm{hs})$ \\
& ditoplâncton & & \\
& Zooplâncton & & Decréscimo na densidade \\
& Plâncton & & (26\%; 96 hs) \\
& Toxicidade & $\mathrm{NO}$ & Bioacumulação \\
& & $\mathrm{O}$ & Mortalidade (100\%, 2hs) \\
& & $\mathrm{O}$ & Decréscimo na densidade \\
& & & (79\%; 30 dias) \\
& & $\mathrm{O}$ & Decréscimo na riqueza \\
& & Bioacumulação \\
\hline Bentos & &
\end{tabular}

\section{3- Experimentos em Mesocosmos 2- Aspectos Funcionais e Bioacumulação}

A adição de $\mathrm{Cr}$ e Cu causaram efeitos significativos nas variáveis limnológicas da água. A contaminação por $\mathrm{Cr}$ apresentou efeito sobre um maior número de variáveis que a contaminação por $\mathrm{Cu}$, sendo que em todos os casos as condições iniciais demoraram mais para serem restabelecidas, ou não o foram.

Ao contrário do observado no experimento realizado anteriormente, a adição de Cu causou uma maior inibição na produção primária do fitoplâncton que a adição de Cr. O efeito da exposição do fitoplâncton dos metais estudados pode ser observado através das alterações nas concentrações de clorofila em função das concentrações de metais presentes na água, como mostram as figuras 119 e 120, verificando-se ainda a toxicidade destes metais para $D$. similis. 


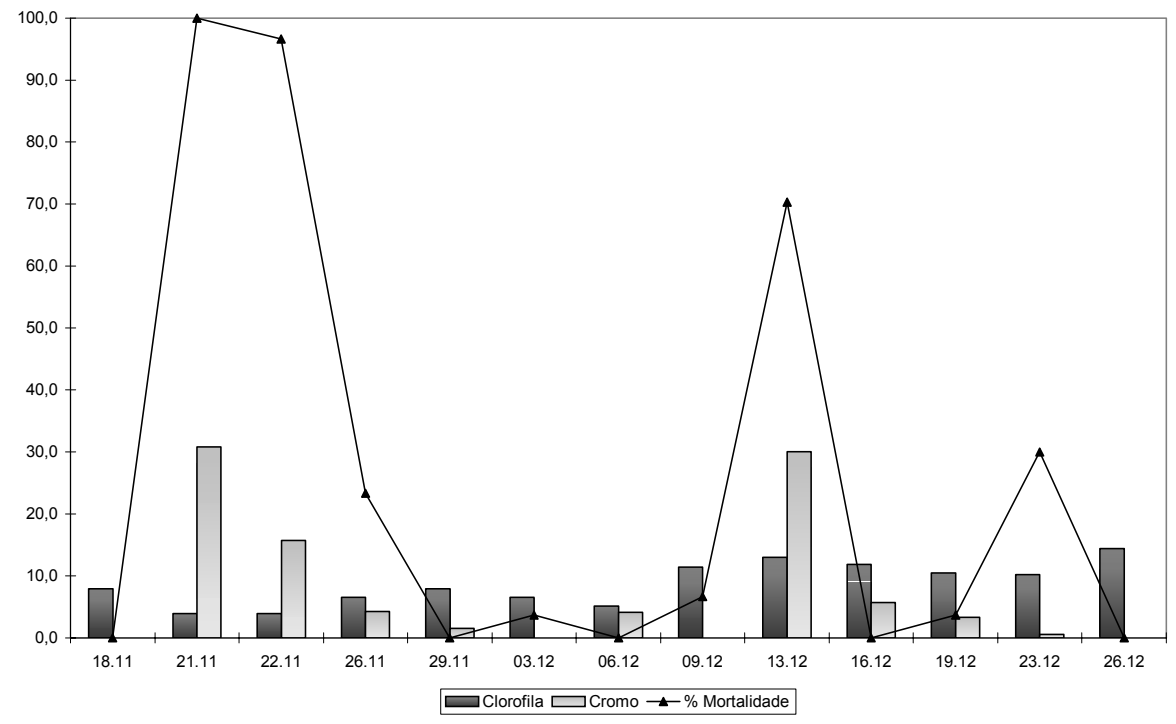

Figura 120: Influência da adição de $\mathrm{Cr}$ na concentração de clorofila e na toxicidade para D. similis.

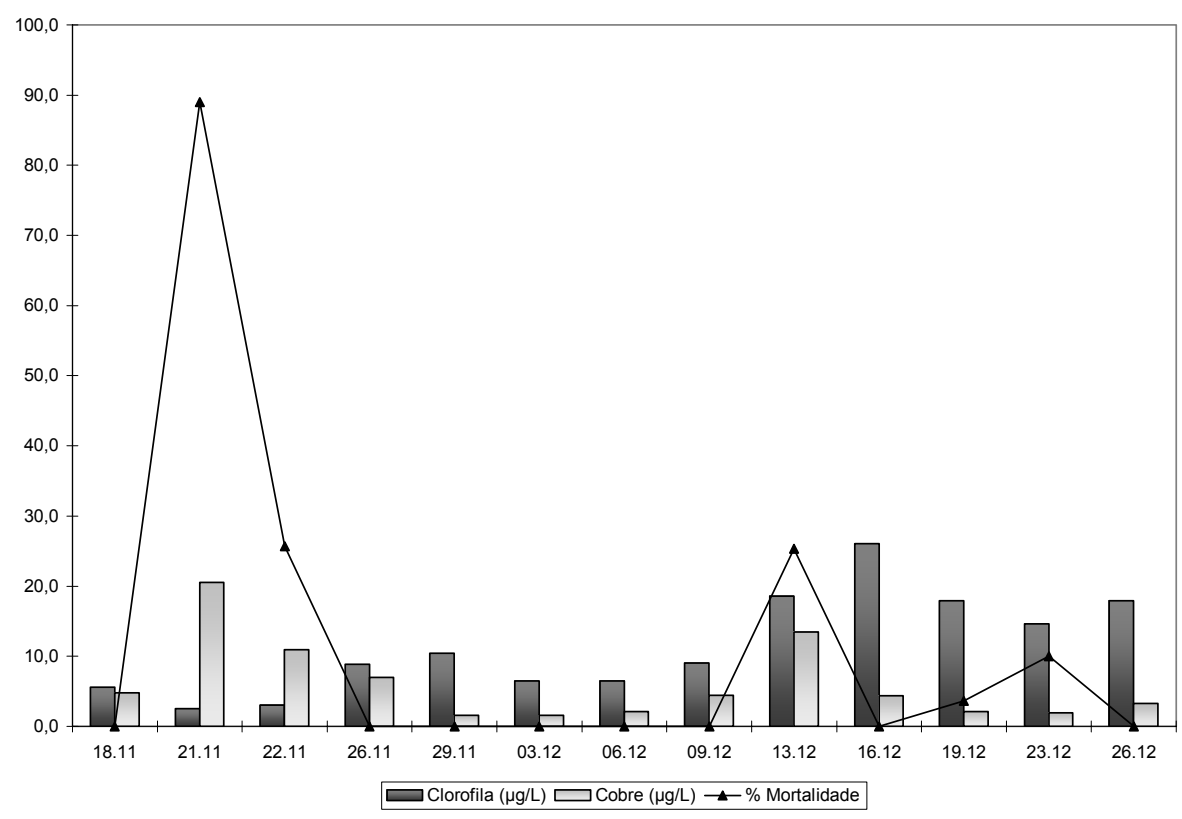

Figura 121: Influência da adição de Cu na concentração de clorofila e na toxicidade para $D$. similis.

$\mathrm{Na}$ primeira contaminação dos tanques, as concentrações de clorofila, determinadas nos tanques contaminados com $\mathrm{Cr}$ e $\mathrm{Cu}$, foram semelhantes. Já na segunda fase, a contaminação por $\mathrm{Cr}$ causou uma redução na concentração de clorofila muito maior que a contaminação por $\mathrm{Cu}$. Após a inclusão dos peixes e macrófitas a toxicidade da água dos mesocosmos foi perdida mais rapidamente do que na fase anterior, assim como as concentrações de clorofila foram restauradas mais rápido. Os efeitos do $\mathrm{Cr}$ e $\mathrm{Cu}$ sobre o sistema foram bastante diferentes com e 
sem a inclusão dos peixes e macrófitas. As amostras de plâncton analisadas apresentaram concentrações diretamente proporcionais às observadas na água superficial, indicando a aplicabilidade destas análises no monitoramento da contaminação de metais.

Apesar da freqüência de coletas não haver possibilitado a avaliação dessa relação com os peixes e macrófitas, ambos os organismos apresentaram concentrações mais altas dos metais em seus tecidos com a adição de $\mathrm{Cr}$ e $\mathrm{Cu}$, em comparação com o controle, indicando sua capacidade de acumular estes elementos do meio. A bioacumulação de $\mathrm{Cr}$ e $\mathrm{Cu}$ pelo bentos não pode ser avaliada, uma vez que não foi obtida a massa necessária para a realização destas análises.

Da mesma forma que no experimento anterior, o sedimento não foi influenciado pela adição dos metais estudados. A síntese dos efeitos dos metais $\mathrm{Cr}$ e $\mathrm{Cu}$ sobre os componentes estudados está apresentada nas Tabelas 53 e 54.

Tabela 53: Síntese dos efeitos do $\mathrm{Cr}$, em comparação com o controle, nos experimentos em mesocosmos (aspectos funcionais e bioacumulação). O: observado; NO: não observado.

\begin{tabular}{|c|c|c|c|}
\hline \multicolumn{4}{|c|}{ Fase 01 (antes da inclusão de peixes e macrófitas) } \\
\hline (2. & Variável & Efeito & Tipo de efeito \\
\hline \multirow[t]{5}{*}{ Água } & Oxigênio dissolvido & $\mathrm{O}$ & \\
\hline & Condutividade & 0 & \\
\hline & $\mathrm{pH}$ & NO & \\
\hline & Nutrientes & NO & \\
\hline & Material em Suspensão & NO & \\
\hline \multirow[t]{3}{*}{ Sedimento } & Matéria Orgânica & NO & \\
\hline & Fósforo & NO & \\
\hline & Nitrogênio & NO & \\
\hline Componentes & Clorofila & $\mathrm{O}$ & Inibição (50\%; 24hs) \\
\hline \multirow[t]{3}{*}{ Bióticos } & $\begin{array}{l}\text { Produção primária do } \\
\text { fitoplâncton }\end{array}$ & $\mathrm{O}$ & Inibição (90\%; 2hs) \\
\hline & Plâncton & O & Bioacumulação \\
\hline & Toxicidade & O & Mortalidade $(100 \%, 2 \mathrm{hs})$ \\
\hline \multicolumn{4}{|c|}{ Fase 02 (após a inclusão de peixes e macrófitas) } \\
\hline & Variável & Efeito & Tipo de efeito \\
\hline \multirow{5}{*}{ Água } & Oxigênio dissolvido & NO & \\
\hline & Condutividade & NO & \\
\hline & & NO & \\
\hline & Nutrientes & 0 & \\
\hline & Material em Suspensão & $\mathrm{O}$ & \\
\hline \multirow[t]{3}{*}{ Sedimento } & Matéria Orgânica & NO & \\
\hline & Fósforo & NO & \\
\hline & Nitrogênio & NO & \\
\hline Componentes & Clorofila & $\mathrm{O}$ & Inibição (35\%; 2hs) \\
\hline \multirow[t]{5}{*}{ Bióticos } & $\begin{array}{l}\text { Produção primária do } \\
\text { fitoplâncton }\end{array}$ & $\mathrm{O}$ & Inibição (90\%; 2hs) \\
\hline & Plâncton & $\mathrm{O}$ & Bioacumulação \\
\hline & Peixes & 0 & Bioacumulação \\
\hline & Macrófitas & 0 & Bioacumulação \\
\hline & Toxicidade & $\mathrm{O}$ & Mortalidade $(100 \%, 2 \mathrm{hs})$ \\
\hline
\end{tabular}


Tabela 54: Síntese dos efeitos do $\mathrm{Cu}$, em comparação com o controle, nos experimentos em mesocosmos (aspectos funcionais e bioacumulação). O: observado; NO: não observado.

\begin{tabular}{|c|c|c|c|}
\hline \multicolumn{4}{|c|}{ Fase 01 (antes da inclusão de peixes e macrófitas) } \\
\hline & Variável & Efeito & Tipo de efeito \\
\hline \multirow[t]{5}{*}{ Água } & Oxigênio dissolvido & $\mathrm{NO}$ & \\
\hline & Condutividade & $\mathrm{O}$ & \\
\hline & & NO & \\
\hline & Nutrientes & NO & \\
\hline & Material em Suspensão & NO & \\
\hline \multirow[t]{3}{*}{ Sedimento } & Matéria Orgânica & NO & \\
\hline & Fósforo & NO & \\
\hline & Nitrogênio & NO & \\
\hline Componentes & Clorofila & $\mathrm{O}$ & Inibição (50\%; 24hs) \\
\hline \multirow[t]{3}{*}{ Bióticos } & $\begin{array}{l}\text { Produção primária do } \\
\text { fitoplâncton }\end{array}$ & $\mathrm{O}$ & Inibição (90\%; 2hs) \\
\hline & Plâncton & $\mathrm{O}$ & Bioacumulação \\
\hline & Toxicidade & $\mathrm{O}$ & Mortalidade $(100 \%, 2 \mathrm{hs})$ \\
\hline \multicolumn{4}{|c|}{ Fase 02 (após a inclusão de peixes e macrófitas) } \\
\hline & Variável & Efeito & Tipo de efeito \\
\hline \multirow{5}{*}{ Água } & Oxigênio dissolvido & NO & \\
\hline & Condutividade & NO & \\
\hline & & NO & \\
\hline & Nutrientes & $\mathrm{O}$ & \\
\hline & Material em Suspensão & NO & \\
\hline \multirow[t]{3}{*}{ Sedimento } & Matéria Orgânica & NO & \\
\hline & Fósforo & NO & \\
\hline & Nitrogênio & NO & \\
\hline Componentes & Clorofila & NO & \\
\hline \multirow[t]{5}{*}{ Bióticos } & $\begin{array}{l}\text { Produção primária do } \\
\text { fitoplâncton }\end{array}$ & $\mathrm{O}$ & Inibição (90\%; 2hs) \\
\hline & Plâncton & $\mathrm{O}$ & Bioacumulação \\
\hline & Peixes & 0 & Bioacumulação \\
\hline & Macrófitas & NO & \\
\hline & Toxicidade & $\mathrm{O}$ & Mortalidade $(100 \%, 2 \mathrm{hs})$ \\
\hline
\end{tabular}

\section{6- REFERÊNCIAS BIBLIOGRÁFICAS}

ANDERSEN, J. M. (1976).An ignition method for determination of total phosphorus in lake sediments. Wat. Res., 10:329-331.

ANDREW, R. W.; BIESINGER, K. E. GLASS, G. E. (1977). Effects of inorganic complexing on the toxicity of copper to Daphnia magna. Water Research, 11: 309-315.

ARGENTON, E. C. (2004). "Limnologia, balneabilidade e impactos ambientais: uma análise temporal e espacial na represa do Lobo (Broa), Itirapina/ Brotas - SP". Dissertação (Mestrado) - Escola de Engenharia de São Carlos - Universidade de São Paulo. São Carlos. 
BARRETO, A. S. (1994). "Assimilação de cromo trivalente nas biomassas nanoplanctônicas e microplanctônicas e sua quantificação no sedimento e sobrenadante: experimento em microcosmos" (Mestrado) - Escola de Engenharia de São Carlos - Universidade de São Paulo. São Carlos

BOWEN, H. J. M. (1966). "Trace metals in biochemistry". Academic Press. 241p. London.

BRAY, G. A. (1969). "A simple efficient liquid scintillation method for counting aqueous solutions in a liquid scintillation counter". Analyt. Biochem. 1, 279-285.

BROCK, T.C. M.; LAHR, J.; VAN DER BRINK, P. J. (2000). Ecological risks of pesticides in freshwater ecosystems. Part 1: Herbicides. Alterra, Green World Research, 129 p. Wageningen.

CAIRNS JR, J.; NIEDERLEHNER, B. R.; BIDWELL, J. R. (1998). "Ecological toxicity testing”. In: Encyclopedia of Environmental Analysis and Remediation. Meyers, R. A. (ed). John Wiley \& Sons, Inc.

CAIRNS JR, J. (1988) Putting the eco in ecotoxicology. Reg. Toxicol. Pharm. 8: 226238.

CALIJURI, M. C. (1985). "Curvas de luz-fotossíntese e fatores ecológicos em ecossistema artificial e não estratificado - Represa do broa (Lobo) São Carlos - SP". Dissertação de mestrado, PPG -ERN, UFSCar. São Carlos.

CAMARGO, A. F. M. (1984). "Aspectos ecológicos de três espécies de macrófitas aquáticas da represa do Lobo, SP: Interações com invertebrados e decomposição". (Mestrado) - PPGRN - Departamento de Ciências Biológicas - Unversidade Federal de São Carlos. 134p. São Carlos.

CAMPBELL, P. G. C.; LEWIS, A. G.; CHAPMAN, P. M.; CROWDER, A. A.; FLETCHER, W. K.; IMBER, B.; LUOMA, S. N.; STROKES, P. M.; WINFREY, M. (1988). "Biologically available metals in sediments". Publication No. NRCC 27694. 298p. NRCC/CNRC. Otawa, Canada. 
CAQUET, T.; LAGADIC, L.; JONOT, O.; BATURO, W.; KILANDA, M.; SIMON, P.; LE BRAS, S.; ECHAUBARD, M.; RAMADE, F. (1996). Outdoor experimental ponds (mesocosms) designed for long-term ecotoxicological studies in aquatic environments. Ecotoxicology and Environmental Safety, 34: 125- 133.

CARVALHO, D. P. (2002). "Distribuição espacial e mudanças temporais da comunidade fitoplanctônica no reservatório do Lobo (Itirapina, SP)". Dissertação (mestrado). Escola de Engenharia de São Carlos- Universidade de são Paulo.

CERVANTES, C.; CAMPOS-GARCÍA, J.; DEVARS, S.; GUITIÉRREZ-CORONA, F.; LOZA-TAVERA, H.; TORRES-GUZMÁN, J.; MORENO-SANCHÉZ, R. (2001). Interactions of chromium with microoganisms and plants. FEMS Microbiology reviews $25,335-347$.

CETESB. (1992). "Água - Métodos de avaliação da toxicidade de poluentes a organismos aquáticos. v1 (série didática)". São Paulo.

CHASIN, A. M.; PEDROSO, M. F. M. (2003).O estudo da toxicologia. In: AZEVEDO, F. A.; CHASIN, A. M. As bases toxicológicas da ecotoxicologia. Eds Rima/ Intertox. pp. 126. São Carlos.

CHAPMAN, P. M. (1995). Ecotoxicology and pollution key issues. Marine polluion Bulletin, 31: 167-177.

CIENFUEGOS, F.; VAITSMAN, D. (2000) Análise Instrumental. Editora Interciência, 606 p. Rio de Janeiro.

CLINE, J. M.; EAST, T. L.; THERLKELD, S. T. (1994). "Fish interactions with the sediment water interface" Hydrobiologia, 275-276: 301- 311.

CONAMA (1986). CONSELHO NACIONAL DO MEIO AMBIENTE. Resolução $\mathrm{n}^{\circ}$ 020/86. 24 p.

ÇOGUN, H. Y.; KARGM, F. (2004). Effects of pH on the mortality and accumulation of copper in tissues of Oreochromis niloticus. Chemosphere, 55:277-282. 
CROSSLAND, N. O. (1994). Extrapolating from mesocosms to the real world .Toxicol. Ecotoxicol. News 1: 15-22.

DASKALAKIS, K. D.; O' CONNOR, T. P. (1995). "Normalization and elemental sediment contamination in the Coastal United States". Environ. Sci. Techol. (20), 2, 470-477. United States.

DORNFELD, C. B., MASUTTI, M. B., ANDRADE, C. A., ALMEIDA, C. A., SILVÉRIO, P. F. Caracterização ecotoxicológica do sedimento da represa do Lobo (Itirapina Brotas, SP) e seus tributários. IN: PPG EM CIÊNCIAS DA ENGENHARIA AMBIENTAL, USP, CRHEA - SHS - EESC-.Série - Ciências da Engenharia Ambiental. São Carlos, 2002, v.01, p.75-90.

DOWING, J. A.; RIGLER, F. H. (1984)."A manual on methods for the assessment of secondary productivity in fresh waters". 2 ed., Oxford, USA. Blackwell Scient. 501 p.

ELMOOR-LOUREIRO, L. M. A. (1997). "Manual de Identificação de cladóceros límnicos do Brasil". Editora da Universidade Católica de Brasília, 155p.

FARKAS, A.; SALÁNKI, J.; VARANKA, I. (2003). Crustaceans as biological indicators of heavy metal pollution in Lake Balaton (Hungary). Hidrobiologia, 506-509: 259-364.

GEORGE MICHAEL, R.; SHARMA, B. K. (1988). "Fauna of indica and adjacent countries: Indian Cladocera (Crustacea: Branchiopoda: Cladocera)". Kolkata, Zoologycal Survey of India. Calcuta, 262 p.

GIESY, J. P.; HOKE, R. A.; (1989). "Freshwater sediment quality criteria: Toxicity Bioassessment". In: Baudo et al. (ed). Sediments: chemistry and toxicity of in-place pollutants. Lewis Publishers. pp. 265-348.

GOLTERMAN, H. L.; CLYMO, R. S. 1969. "Methods for chemical analysis of freshwaters". IBP Handbook $n^{0} 8$ Blackell Scientific Publications, 171p. Oxford.

GRANEY, R. L.; GIESY, J. P. \& CLARCK, J. R. (1995). "Field Studies”. In: RAND, G. M. Fundamentals of Aquatic Toxicology. Effects, Environmental Fate and Risk Assessment. Taylor \& Francis, Washington, USA. P. $257-305$. 
GUSMÃO, L. F. M. (2004). "Efeitos do cobre e cromo na comunidade zooplanctônica: um estudo experimental em mesocosmos". Dissertação (Mestrado). Escola de engenharia de São Carlos. Universidade de São Paulo, 269 p. São Carlos.

HALFFMAN, W. (1995). ."The bondary between ecology and toxicology: a sociologist's perspective". In: CAIRNS, J.; NIEDERLEHNER, B. R. Ecological toxicity testing scale, complexity an relevance. Lewis publishers, pp. 12-34. Boca Raton,

HAVENS, K. E. (1992). Acidification effects on the plankton size spectrum: an in situ mesocosm experiment . J. of Plankton Research, 14 (12): 1687-1696.

HENRY, R., NUNES, M. A., MITSUKA, P. M., LIMA, N. DE CASANOVA, S. M. C. (1998). Variação espacial e temporal da produtividade primária pelo fitoplâncton na represa de Jurumirim (rio Paranapanema, SP). Rev. Brasil. Biol., 58(4): 571-590.

JAK, R. G.; MAAS, J. L.; SCHOLTEN, M. C. T. (1996). Evaluation of laboratory derived toxic effect concentrations of a mixture of metals by testing fresh water plankton communities in enclosures. Water Research, 30 (5) 1215-1227.

KEMP, W. M.; PETERSEN, J. E.; GARDNER, R. H. (2001). "Scale dependence and the problem of extrapolation". In: Gardner, R. H.; Kemp, W. M.; Kennedy, V. S. \& Petersen, j. E. (eds) Scalling relations in experimental ecology. Columbia University Press, New York, p. 3- 57.

KENNEDY, J. H.; JOHNSON, P. C.; JOHNSON, Z. B. (1995). "The use of constructed or artificial ponds in simulated field studies". In: CAIRNS, J. \& NIEDERLEHNER, B. R. (eds). Ecological toxicity testing: scale, complexity and relevance. Lewis Publishers, Boca Raton. 1995.

KLUMPP, A.; BAUER, K.; FRANZ-GERSTEIN, C.; MENEZES, M. (2002). Variation of nutrient and metal conetrations in aquatic macrophytes along the Rio Cachoeira in Bahia (Brazil). Environmental International, 28: 165 - 171.

KOROLEFF, F. (1976). "Determination of nutrients. In: GRASSOHOF, K. (ed). Methods of seawater analysis. Verlag. Chemie. Weinhein. P. 117-181. 
KOSTE, W.; TERLUTTER, H. (2001). Die Rotatorienfauna einiger Gewsser des Naturschutzgebietes "Heiliges Meer" im Kreisn Steinfurt. Osnabrucker Naturwissenschaftliche Mitteilungen 27: 113 - 177.

KOSTE, W. (1978). Rotatoria. Die Radertiere Mittleuropas. Bestimmungswerk begrundet von Max Voit, Uberordnung Monogononta, vol 1-2; $643+234$.

KRANTZBERG, G. (1989). Metal accumulation by chironomid larvae: the effects of age and body weight on metal body burdens. Hydrobiologia, 188/189:497 - 506.

LA POINT, T. W.; FAIRCHILD, J. F.; LITTLE, E. E.; FINGER, S. E. (1989). "Laboratory and field techniques in ecotoxicological research: strengths and limitations". In: Boudou, A.; Ribeyre, F. ed Aquatic Toxicology: Fundamentals, Concepts and Methodolgies. Volume II. CRC Press, Boca Raton, USA. P.239- 255.

LALLI, C. M. (1990). "Enclosed experimental ecosystems: a review and recommendations". Springer-Verlag, New York, 218p.

LEENDERTSE, P. C.; SCHOLTEN, M. C. T.; VAN DER WAL, J. T. (1996). "Fate and effects of nutrients and hevy metals in experimental salt marsh ecosystems". Environ. Poll. 94 (1) : $19-29$.

LLOYD, M. \& GHELARDI, R.J. (1964). A table for calculating the equitability component of species diversity. Journal An. Ecology 33:217-225.

LUND, J.W.G.; KIPLING, C. \& LECREN, E.D. (1958). The invert microscope method of estimating algal numbers and the statistical basis of estimations by counting. Hydrobiologia. 11:143-170.

MACKERETH, S. J. H.; HERON, J.; TALLING, J. S. (1978). "Water ana;ysis: some revised methods for limnology”. Kendal, Freshwater Biol. Assoc. Sci. Publ. 36., Wilson \& Sons, $117 p$.

MAINE, M. A. SUÑE, N. L.; LAGGER, S.C. (2004) Chromium bioaccumulation: comparison of the capacity of two floating aquatic macrophytes. Water Research, in press. 
MARINELLI, C. E. (2002). "Introdução de espécies, estrutura das habitats e padrões de diversidade da ictiofauna em ecótonos do reservatório do Broa, SP". Dissertação (Mestrado). Escola de Engenharia de São Carlos, Universidade de São Paulo, 225 p.. Sã Carlos.

MATSUMURA-TUNDISI, T. (1986). Latitudinal distribution of Calanoida copepods in freshwater aquatic systems of Brazil. Rev. Bras. Biol. 46 (3):527:553.

MATSUMURA TUNDISI, T. \& TUNDISI, J. G. (1976). Plankton studies in a lacustrine environment. Preliminary data on zooplankton eclogy of Broa Reservoir. Oecologia, 25: $265-270$.

MERRITT, R. W.; CUMMINS, K. W. (1984). "An introduction to the aquatic insects of North America". Kendall/Hunt Publishing Co., 772p. Dubuque.

MINITAB INC. (2000). MINITAB ${ }^{\text {TM }}$ Statistical Software Release 13.30.

MORAES, E. M. (1978). "Ciclo sazonal, distribuições horizontal e vertical e interrelação ecológicas de nutrientes na Represa do Lobo (Brotas-Itirapina-SP) “.Dissertação (Mestrado), 153 p.. I. B. São Paulo.

MORALES, E. S., REID, J. K.; LLIFFE, T. M.; FIERS, F. (1996)."Catálogo de los Copepodos (Crustacea) continentals de la península de Yucatán, México". CONABIO - ECOSUR, México, D. F. 296 p.

MONTÚ, M. A.; GLOEDEN, I. M. (1986). Atlas dos Cladocera e Copepoda (Crustacea) do estuário da Lagoa dos Patos (Rio Grande, Brasil). Neritica, 1 (2): 1-134.

MUNGER, C.; HARE, LANDIS, TESSIER, A. (1999). Cadmium sources and exchange rates for Chaoborus larvae in nature. Limnol. Oceanogr. 44 (7) : 1763-1771.

$\mathrm{NUSCH}$, E. A. (1980). Comparison of methods for chlorophyll and phaeopigments determination. Arch. fur Hydrobiol., 14: 14 - 36.

ODUM, E. P. (1984). The Mesocosm. BioScience, 34: 558-562. 
OECD. (2004). Draft Guidance Document on Simulated Freshwater Lentic Field Tests (Outdoor Microcosms and Mesocosms). 26 p.

OLIVEIRA, M. D. (1993). "Produção primária e estrutura da comunidade fitoplanctônica no reservatório do Lobo (SP): uma comparação entre fatores ecológicos na represa e seus principais tributários". Tese de doutorado. EESC. USP.

OISHI, M.K. (1990). "Determinação do potencial trófico das águas dos componentes da bacia hidrográfica da represa do Lobo (Brotas-Itirapina-SP) através de ensaio algal”. Dissertação (Mestrado) - Escola de Engenharia de São Carlos - Universidade de São Paulo. São Carlos.

OLIVEIRA - NETO, A. L. (2000). "Toxicidade de alguns metais pesados (Cd, Cr,Pb) em organismos planctônicos lacustres de região tropical". Tese (Doutorado) - Escola de Engenharia de São Carlos - USP, 91p. São Carlos.

OLIVEIRA-NETO, A. L. (1993). "Estudo da variação da comunidade zooplanctônica, com ênfase na comunidade de rotíferos, em curtos intervalos de tempo (variações diárias e nictimerais) na represa do Lobo (Broa) - Itirapina, SP”. Dissertação (mestrado) IB/ Universidade de São Paulo, 74 p. São Paulo.

OLIVEIRA, M. D. (1993). "Produção primária e estrutura da comunidade fitoplanctônica do reservatório do Lobo (SP): uma comparação entre fatores ecológicos na represa e seus principais tributários". Dissertação (Mestrado) 178 p. - Escola de Engenharia de São Carlos - Universidade de São Paulo. São Carlos.

PENNAK, R. W. (1989). "Fresh-water invertebrates of the United States: protozoa to mollusca." $3^{\circ}$ ed. John Wiley \& Sons, Inc. New York.

PHILLIPS, D. J. H.; SEGAR, D. A. (1986). Use of bio-indicators in monitoring conservative contaminants: programme design imperatives. Marine Pollution Bulletin, 17: 10-17.

POWELL, M. I.; WHITE, K. N. (1990). Heavy metal accumulation by Barnacles and its implications for their use as biological monitors. Marine Environmental Research 30: 91118. 
QUEIRÓZ, O. T. M. M. (2000). "Impactos das atividades turísticas em área de reservatório: uma avaliação sócio-ambiental do uso e ocupação na área da represa do Lobo, município de Itirapina, SP". Tese (Doutorado) - Escola de Engenharia de São Carlos - Universidade de São Paulo. São Carlos.

QUINN, M, R,; FENG, X.; FOLT, C. L.; CHAMBERLEIN, C. P. (2003). Analyzing trophic transfer of metals in stream food webs using nitrogen isotopes. The Science of Total Environmental, 317: 73-89.

RAINBOW, P. S. ; PHILIPS, D. J. H. (1993) Cosmopolitan Biomonitors Of Trace Metals. Marine Pollution Bulletin 26(11): 593-601.

RAINBOW, P. S. (1985). Accumulation of $\mathrm{Zn}, \mathrm{Cu}$ and $\mathrm{Cd}$ by crabs and barnacles. Estuarine, Coastal and Shelf Science, 21, pp. 669-689.

RAINBOW, P. S.; WHITE, S. L. (1989). Comparative strategies of heavy metal accumulation by crustaceans: zinc, copper and cadmium in a decapod, an amphipod and a barnacle. Hydrobiologia, 174, pp. 245-262.

RASHED, M. N. (2001). Monitoring of environmental heavy metals in fish from Nasser lake. Environment International 27: 27:33.

REID, J. W. (1985). "Chave de identificação e lista de referências bibliográficas para as espécies continentais de vida livre da ordem Ciclopoida (Crustacea-Copepoda). Bol. Zool. 9:17-143.

REIS FILHO, R. W. (2004). "Avaliação ecotoxicológica do sedimento da represa do Lobo (SP) em mesocosmos submetidos aos metais cobre e cromo". Dissertação (Mestrado). Escola de Engenharia de São Carlos. Universidade de São Paulo, 114 p. São Carlos.

RIETZLER, A. C. (1991). "Estudo da dinâmica de populações de copépoda-calanoida na represa do Lobo (Broa)". Dissertação (Mestrado), 196 p. - Escola de Engenharia de São Carlos - Universidade de São Paulo. São Carlos. 
ROCHA, O.; MATSUMURA - TUNDISI, T. (1976). "Atlas do zooplâncton (Represa do Broa, São Carlos) Vol. 1- Copepoda". Editora da Universidade Federal de São Carlos, 68 p. São Carlos.

ROCHA, O.; MATUSUMURA-TUNDISI, T. (1984). Biomass and productions of Argyrodiaptomus furcatus, a tropical calanoid copepod in Broa reservoir, southern Brazil. Hydrobiologia, 113: 307-311.

RODRÍGUEZ, M. P.; MATSUMURA-TUNDISI, T. (2000). Variation of density, species composition and dominance of rotifers at a shallow tropical reservoir (Broa Reservoir, SP, Brazil) in a short scale time. Rev. Bras. Biol. 60 (1):1-9.

SALOMONS, W.; FOSTNER, U. (1984). "Metals in the hydrocycle" . Springer-Verlag Berlin Heidelberg New York Tokyo, 349.

SEGERS, H. (1995). Rotifera Volume 2: the Lecanidae (Monogononta). Guides to the identification of the microinvertebrates of the continental waters of the world, vol 6. SPB Academic Publishing, 223p.

SEGERS, H.; DUMONT, H. J. (1995). 102 + rotifer species (Rotifera: Monogononta) in Broa reservoir (SP, Brazil) on 26 August 1994, with description of three new species. Hydrobiologia, 316: 183-197.

SEIXAS, M. H. (1981). "Aspectos ecológicos das populações de Cladocera (Crustácea) na represa do Lobo (Broa)". Dissertação (Mestrado) 156 . UFSCar, São Carlos.

SHANNON, C.E. \& WEAVER, W. (1963)."The mathematical theory of communication". Urbana: University of Illianois Press, 173p.

SIBLEY, T. H.; SHOTT, G.; CHANG, C. (1994). Distrubution and toxicity of copper in freshwater microcosms. Verh. Interant. Verin. Limnol. 25:2013 - 2015.

SILVÉRIO, P. F.(2003) "Bases técnico-científicas para a derivação de valores-guias de qualidade de sedimentos para metais: experimentos de campo e laboratório". Tese 
(Doutorado). Escola de Engenharia de São Carlos. Universidade de São Paulo, 132 p. São Carlos.

SIMPSON, E.H. (1949). Measurement of diversity. Nature , v.163, p.688.

STRICKLAND, J. D. H.; PARSONS, T. R. (1960). "A manual of sea water analusis". Bull. Fish. Res. Bd. Canada 125, 1-185.

STUMM, W.; MORGAN, J.J. (1981). "Aquatic Chemistry". Ed John Wiley \& Sons, 780p. New York.

TEIXEIRA, C. (1973). "Introdução aos métodos para medir a produção primária do fitoplâncton marinho". Inst. Oceanogr. USP 22(335) 59-92.

TODD, J.; JOSEPHSON, B. (1996). "The design of living technologies for waste treatment" Ecological Engineering, 6: 109-136

TRINDADE, M. (1980). "Nutrientes em sedimentos da represa do Lobo (Brotas Itirapina, SP)". Dissertação (Mestrado) 216p. UFSCar. São Carlos.

TRIVINHO-STRIXINO, S.; STRIXINO, G. "Estrutura da comunidade de insetos aquáticos associados à Pontederia lanceolata Nuttal” Ver. Brasil. Biol., 53 (1): 103111.1

TUCCI, A. (2002). "Sucessão da comunidade fitoplanctônica de um reservatório urbano e eutrófico, São Paulo, SP.: Variação semanal." Tese de doutorado em Ciências Biológicas - Área de Biologia Vegetal. Universidade Estadual Paulista Campus de Rio Claro, SP. 274.p.

TUNDISI, J. G. (1977). "Produção Primária, standing stock, fracionamento do fitoplâncton e fatores ecológicos em ecossistema lacustre artifical (Represa do Broa, São Carlos)". Tese (Livre Docência) 409 p.- I. B. USP. Ribeirão Preto.

TUNDISI, J. G.; MATUSUMURA TUNDISI, T. (1995). "The Lobo-Broa ecosystem research". In: Tundisi, J. G.; Bicudo, C. E. M.; Matusumura Tundisi, T. (eds). Limnology in Brazil. Rio de Janeiro: Brazilian Academy of Sciences and Brazilian Limnological Society, p. 219-243. 
UTERMÖHL, H. (1958). Zur Vervolkomnung der quantitativen phytoplankton: methodik. Mitteilungen Internationale Vereinigung fur Theoretische und Angewandte Limnologie, 9:1-38.

VALDERRAMA, J.C. (1981). The simultaneous analysis of total nitrogen and total phosphorus in natural waters. Marine Chem. 10:109-122.

WATANABE, T. (1981). "Flutuação sazonal e distribuição espacial do nano e microfitoplâncton na Represa do Lobo (broa), São Carlos, SP”. Dissertação (Mestrado), 160p.

WEBER, C.I. (1973). Plankton. In: National Environmental Research Center Office of Research and Development U.S. Environmental Protection Agency Cincinnati (Ed.). Biological field and laboratory methods for measuring the quality of surface water and effluents. p.1-17.

WETZEL; W. G.; LIKENS; G. E. (1991). "Limnological Analyses”. Ed. Springer-Verlag, $2^{\circ}$ edição. 391 p. USA. 
CAPÍTULO 4: CONCLUSÕES 
Os testes de sensibilidade ao $\mathrm{Cr}$ e ao $\mathrm{Cu}$, por diferentes organismos de diferentes níveis tróficos, apresentam valores de CE 50 variando em muitas ordens de grandeza. Os organismos zooplanctônicos foram os mais sensíveis, com valores de CE (50) muito semelhantes aos estabelecidos como limites para corpos d'água classe 2 pelo CONAMA (resolução $n^{0} 20$ de 1986). As macrófitas e peixes mostraram-se como os organismos mais resistentes, e as algas e organismos bentônicos apresentaram sensibilidade intermediária. Todos os organismos estudados foram mais sensíveis ao $\mathrm{Cu}$ que ao $\mathrm{Cr}$.

A sensibilidade de Daphnia similis e Ceriodaphnia dubia aos contaminantes testados refletiu as respostas observadas sobre a comunidade zooplanctônica natural da represa. O decréscimo mais significativo na densidade de organismos e na riqueza de espécies após a adição dos metais ocorreu com concentrações ambientais da mesma ordem dos valores de CE (50) determinados em laboratório.

Da mesma forma, quando da exposição destes organismos testes à amostras de água dos tanques contaminados, a mortalidade dos organismos foi relacionada linearmente às concentrações dos metais na amostra. Quando as concentrações das amostras dos tanques atingiram os valores determinados para a CE (50) nos testes com água reconstituída foi observada também uma mortalidade de organismos próxima a $50 \%$, demonstrando a validação dos resultados obtidos com soluções preparadas em laboratório com os resultados obtidos com matrizes ambientais, considerando-se o mesmo contaminante.

Apesar da menor sensibilidade dos outros organismos testados em relação ao zooplâncton, estes testes trazem informações importantes a respeito dos efeitos dos metais estudados sobre estes organismos. Chironomus xanthus, Oreochromis niloticus e Pistia stratiotes estão presentes normalmente em ambientes contaminados e sua sensibilidade a potenciais contaminantes pode ser um indicativo da qualidade dos sistemas. $P$. stratiotes e $O$. niloticus também são utilizados em sistemas de tratamento de efluentes, e informações a respeito de sua sensibilidade aos metais são escassas.

Nos experimentos em microcosmos realizados em dezembro de 2001, contando com a água da represa e os organismos fito e zooplanctônicos de origem natural, a adição de Cu não causou efeitos sobre as variáveis limnológicas ou sobre a concentração de clorofila, enquanto $\mathrm{Cr}$ provocou efeitos apenas sobre as concentrações de clorofila e silicato.

Apesar dos poucos efeitos sobre as variáveis químicas da água, foram observados efeitos na comunidade fitoplanctônica e zooplanctônica. Em relação ao fitoplâncton foi observada a redução na densidade de organismos nas 24 horas após a adição de ambos os contaminantes, assim como um menor número de taxa ao final do 
experimento. A comunidade fitoplanctônica foi afetada mais significativamente pela adição de $\mathrm{Cr}$ que pela adição de $\mathrm{Cu}$, o contrário do observado nos testes em laboratório realizados com $S$. capricornutum. Esta observação pode estar relacionada às concentrações de $\mathrm{Cu}$ naturalmente elevadas na represa do Lobo, o que proporcionaria o estabelecimento de espécies naturalmente adaptadas a presença deste metal.

Entre os organismos zooplanctônicos, Cladocera apresentou a maior sensibilidade, com redução da população a $6 \%$ da inicial após a exposição ao $\mathrm{Cr}$ e a $1 \%$ da inicial após exposição ao $\mathrm{Cu}$.

Nos experimentos em mesocosmos os efeitos sobre as características funcionais foram mais evidentes que nos experimentos em microcosmos e, novamente, a adição de $\mathrm{Cr}$ provocou efeitos mais significativos, tanto em relação ao número de variáveis afetadas quanto em relação ao tempo de restauração do sistema.

As principais variáveis afetadas pela adição de $\mathrm{Cr}$ foram material em suspensão total, orgânico e inorgânico, oxigênio dissolvido, silicato, amônio, fósforo total e fósforo total dissolvido e clorofila. O cobre causou alterações no $\mathrm{pH}$, oxigênio dissolvido, amônia, concentração de clorofila, fósforo total dissolvido, nitrato e nitrito.

Os sedimentos não apresentaram alterações em nenhuma das características estudadas, inclusive quanto às concentrações dos metais adicionados aos sistemas, após a adição de metais.

Os resultados referentes às alterações na estrutura da comunidade do zooplâncton foram semelhantes aos obtidos nos experimentos em microcosmos. Da mesma forma que nos experimentos em microcosmos, no zooplâncton da represa, o grupo Cladocera apresentou a maior sensibilidade aos metais estudados, enquanto Copepoda Calanoida foi dominante nos experimentos com Cr.

Apesar de não terem sido observadas alterações nas características do sedimento, a comunidade bentônica parece ter sido afetada após a contaminação dos mesocosmos. Todos os grupos de organismos bentônicos identificados no início do experimento apresentaram densidade de indivíduos bastante reduzida ao final do experimento, após 30 dias de exposição, sendo a maior redução observada nos mesocosmos contaminados com $\mathrm{Cu}$.

Ambos os metais estudados causaram efeitos muito significativos sobre a produção primária do fitoplâncton. A maior inibição na produção primária foi observada após a contaminação com $\mathrm{Cr}$, no experimento realizado em abril de 2002 e após a contaminação com Cu, no experimento realizado em novembro/dezembro de 2002. Esta observação pode estar relacionada com a utilização de diferentes metodologias 
em cada campanha e com alterações nas comunidades fitoplanctônicas presentes em cada data.

Com o aumento da complexidade trófica do sistema, com a inclusão de peixes e macrófitas, foi observado um decréscimo na toxicidade dos metais estudados, principalmente para o $\mathrm{Cu}$.

Foi observada a ocorrência de bioacumulação por todos os organismos analisados. As concentrações de $\mathrm{Cr}$ e $\mathrm{Cu}$ nos organismos analisados seguiram a sequência: plâncton $\approx$ bentos> macrófitas> peixes. Em relação aos peixes, foi verificada a ocorrência de bioconcentração dos dois metais estudados, em comparação com o controle, enquanto para as macrófitas foi observado apenas a bioconcentração de $\mathrm{Cr}$, pelas folhas e pelas raízes.

As concentrações de $\mathrm{Cr}$ e $\mathrm{Cu}$ no plâncton variaram linearmente com as concentrações destes metais na água, demonstrando a capacidade destes organismos refletir as concentrações ambientais dos metais e sua utilidade como bioindicadores.

As metodologias utilizadas nos experimentos em mesocosmos mostraram-se ferramentas eficientes na avaliação da toxicidade de metais em ecossistemas aquáticos. Muitas respostas observadas nos experimentos em microcosmos puderam ser comprovadas e analisadas mais minuciosamente nos experimentos em mesocosmos, principalmente a respeito do fito e zooplâncton.

A metodologia não foi eficiente, porém, para a observação e avaliação de efeitos sobre os sedimentos, e as comunidades aí estabelecidas, pois possibilitou a coleta de um número e quantidade de amostras insuficientes para a avaliação mais precisa da ocorrência de bioconcentração e para a avaliação da comunidade bentônica (composição, densidade).

A literatura reporta grande variabilidade entre as réplicas para experimento em campo, mas, neste trabalho, esta variabilidade não foi significativa estatisticamente (ANOVA e MANOVA) comparando-se as réplica de cada tratamento, mesmo no experimento com maior complexidade trófica, que incluía peixes e macrófitas, validando assim os sistemas utilizados neste trabalho para a avaliação de riscos potenciais de metais nos ecossistemas aquáticos.

Apesar das baixas concentrações de $\mathrm{Cr}$ e Cu utilizadas no experimento, muitos efeitos puderam ser observados em nível biológico, tanto na sensibilidade das espécies naturais da represa do Lobo aos contaminantes como na ocorrência de bioacumulação por esses organismos.

As diferenças observadas entre os resultados obtidos com os testes de laboratório e os experimentos de campo indicam a necessidade de estudos de 
toxicidade serem realizados em campo, em condições mais realísticas, contando com a presença de organismos nativos e com concentrações de contaminantes não necessariamente altas, avaliando o efeito das tóxicos sobre a comunidade local. 
APÊNDICES 
288 


\section{CAPÍTULO 2}

Tabela 01: Características dos indivíduos (valores médios) de $P$. stratiotes no início e final do teste com $\mathrm{Cr}(168 \mathrm{hs}) \mathrm{n}^{\circ} 01$

\begin{tabular}{|c|c|c|c|c|}
\hline \multicolumn{5}{|l|}{ Inicial } \\
\hline & Altura (cm) & Diâmetro (cm) & Número de Folhas & \\
\hline Controle & 6,2 & 5,7 & 5,2 & \\
\hline $1 \mathrm{mg} / \mathrm{l}$ & 6,9 & 5,4 & 3,5 & \\
\hline $5 \mathrm{mg} / \mathrm{l}$ & 5,8 & 5,2 & 4,5 & \\
\hline $10 \mathrm{mg} / \mathrm{l}$ & 6,0 & 4,6 & 4 & \\
\hline \multicolumn{5}{|l|}{ Final } \\
\hline & Altura $(\mathrm{cm})$ & Diâmetro $(\mathrm{cm})$ & Número de Folhas & Número de raízes \\
\hline Controle & 5,6 & 6,3 & 6,2 & $\overline{6,2}$ \\
\hline $1 \mathrm{mg} / \mathrm{l}$ & 6,6 & 4,8 & 3,5 & 4,2 \\
\hline $5 \mathrm{mg} / \mathrm{l}$ & 5,6 & 4,3 & 4,5 & 7,2 \\
\hline $10 \mathrm{mg} / \mathrm{l}$ & 6,0 & 3,8 & 3,5 & 7,2 \\
\hline
\end{tabular}

Tabela 02: Características dos indivíduos (valores médios) de $P$. stratiotes no início e final do teste com $\mathrm{Cr}(168 \mathrm{hs}) \mathrm{n}^{\circ} 02$

\begin{tabular}{lcccc}
\hline \hline Inicial & \multicolumn{5}{l}{} \\
\hline & Altura $(\mathrm{cm})$ & Diâmetro $(\mathrm{cm})$ & Número de Folhas & \\
\hline \hline Controle & 5,2 & 9,6 & 3,5 & \\
$5 \mathrm{mg} / \mathrm{l}$ & 5,9 & 10,2 & 3,2 & \\
$10 \mathrm{mg} / \mathrm{l}$ & 4,9 & 9,0 & 2,9 & \\
$15 \mathrm{mg} / \mathrm{l}$ & 4,9 & 9,4 & 3,4 & \\
\hline \hline Final & \multicolumn{5}{c}{} & \\
\hline \multicolumn{5}{c}{} \\
\hline \hline Controle & Altura $(\mathrm{cm})$ & Diâmetro $(\mathrm{cm})$ & Número de Folhas & Número de raízes \\
$5 \mathrm{mg} / \mathrm{l}$ & 3,9 & 9,6 & 2,9 & 2,2 \\
$10 \mathrm{mg} / \mathrm{l}$ & 4,9 & 11,1 & 3,2 & 3,2 \\
$15 \mathrm{mg} / \mathrm{l}$ & 4,4 & 9,3 & 2,8 & 3,1 \\
\hline \hline
\end{tabular}

Tabela 03: Características dos indivíduos (valores médios) de $P$. stratiotes no início e final do teste com $\mathrm{Cr}(168 \mathrm{hs}) \mathrm{n}^{\circ} 03$

\begin{tabular}{lcccc}
\hline \hline Inicial & \multicolumn{5}{l}{} \\
\hline \hline Controle & Altura $(\mathrm{cm})$ & Diâmetro $(\mathrm{cm})$ & Número de Folhas & \\
$10 \mathrm{mg} / \mathrm{l}$ & 5,4 & 5,6 & 3,8 & \\
$50 \mathrm{mg} / \mathrm{l}$ & 5,6 & 6,6 & 3,2 & \\
$100 \mathrm{mg} / \mathrm{l}$ & 5,8 & 4,9 & 3,5 & \\
\hline \hline Final & 5,9 & 7,3 & 3,8 & \\
\hline \multicolumn{5}{c}{} \\
\hline \hline Controle & Altura $(\mathrm{cm})$ & Diâmetro $(\mathrm{cm})$ & Número de Folhas & Número de raízes \\
$10 \mathrm{mg} / \mathrm{l}$ & 4,3 & 7,8 & 4,2 & 5,5 \\
$50 \mathrm{mg} / \mathrm{l}$ & 5,2 & 7,4 & 3,6 & 1,5 \\
$100 \mathrm{mg} / \mathrm{l}$ & 5,2 & 6,7 & 3,6 & 0,5 \\
\hline \hline
\end{tabular}


Tabela 04: Características dos indivíduos (valores médios) de $P$. stratiotes no início e final do teste com $\mathrm{Cr}(168 \mathrm{hs}) \mathrm{n}^{\circ} 04$

\begin{tabular}{|c|c|c|c|c|}
\hline \multicolumn{5}{|l|}{ Inicial } \\
\hline & Altura $(\mathrm{cm})$ & Diâmetro $(\mathrm{cm})$ & Número de Folhas & \\
\hline Controle & 7,6 & 4,4 & 2,9 & \\
\hline $10 \mathrm{mg} / \mathrm{l}$ & 8,0 & 5,1 & 2,9 & \\
\hline $50 \mathrm{mg} / \mathrm{l}$ & 7,2 & 6,2 & 3,6 & \\
\hline $100 \mathrm{mg} / \mathrm{l}$ & 8,0 & 6,4 & 3,4 & \\
\hline \multicolumn{5}{|l|}{$\overline{\text { Final }}$} \\
\hline & Altura (cm) & Diâmetro $(\mathrm{cm})$ & Número de Folhas & Número de raízes \\
\hline Controle & $\overline{6,1}$ & $\overline{10,3}$ & $\overline{3,2}$ & 3 \\
\hline $10 \mathrm{mg} / \mathrm{l}$ & 7,1 & 8,3 & 3,6 & 3,8 \\
\hline $50 \mathrm{mg} / \mathrm{l}$ & 6,6 & 7,2 & 3,5 & 1,6 \\
\hline $100 \mathrm{mg} / \mathrm{l}$ & 6,3 & 9,4 & 2,8 & 0,9 \\
\hline
\end{tabular}

Tabela 05: Características dos indivíduos (valores médios) de $P$. stratiotes no início e final do teste com Cu (168 hs) $n^{\circ} 1$.

\begin{tabular}{|c|c|c|c|c|}
\hline Inicial & & & & \\
\hline & Altura $(\mathrm{cm})$ & Diâmetro $(\mathrm{cm})$ & Número de Folhas & \\
\hline Controle & 6,36 & 3,87 & 3,8 & \\
\hline $1 \mathrm{mg} / \mathrm{l}$ & 6,43 & 4,31 & 3,5 & \\
\hline $5 \mathrm{mg} / \mathrm{l}$ & 6,24 & 3,84 & 3,4 & \\
\hline $10 \mathrm{mg} / \mathrm{l}$ & 5,89 & 4,02 & 3,8 & \\
\hline$\overline{\text { Final }}$ & & & & \\
\hline & Altura $(\mathrm{cm})$ & Diâmetro $(\mathrm{cm})$ & Número de Folhas & Número de raízes \\
\hline Controle & $\overline{6,36}$ & $\overline{6,26}$ & $\overline{5,6}$ & $\overline{5,1}$ \\
\hline $1 \mathrm{mg} / \mathrm{l}$ & 6,78 & 5,84 & 5,3 & 1,9 \\
\hline $5 \mathrm{mg} / \mathrm{l}$ & 4,825 & 9,0875 & 4,375 & 0 \\
\hline
\end{tabular}

Tabela 06: Características dos indivíduos (valores médios) de $P$. stratiotes no início e final do teste com $\mathrm{Cu}(168 \mathrm{hs}) \mathrm{n}^{\circ} 2$.

\begin{tabular}{lcccc}
\hline \hline Inicial & \multicolumn{5}{l}{} \\
\hline \hline Controle & Altura $(\mathrm{cm})$ & Diâmetro $(\mathrm{cm})$ & Número de Folhas & \\
$1 \mathrm{mg} / \mathrm{l}$ & 5,5 & 3,4 & 3,3 & \\
$5 \mathrm{mg} / \mathrm{l}$ & 5,7 & 3,2 & 3,3 & \\
$10 \mathrm{mg} / \mathrm{l}$ & 6,0 & 3,6 & 3,3 & \\
\hline \hline Final & 5,7 & 3,2 & 3,3 & \\
\hline \multicolumn{5}{c}{} \\
\hline \hline Controle & Altura $(\mathrm{cm})$ & Diâmetro $(\mathrm{cm})$ & Número de Folhas & Número de raízes \\
$1 \mathrm{mg} / \mathrm{l}$ & 5,8 & 4,4 & 4,9 & 7,3 \\
$5 \mathrm{mg} / \mathrm{l}$ & 5,7 & 4,6 & 3,8 & 5,0 \\
\hline \hline
\end{tabular}


Tabela 07: Características dos indivíduos (valores médios) de $P$. stratiotes no início e final do teste com Cu (168 hs) $\mathrm{n}^{\circ} 3$.

\begin{tabular}{|c|c|c|c|c|}
\hline \multicolumn{5}{|l|}{ Inicial } \\
\hline & Altura $(\mathrm{cm})$ & Diâmetro $(\mathrm{cm})$ & Número de Folhas & \\
\hline Controle & 6,6 & 6,5 & 4,3 & \\
\hline $0,1 \mathrm{mg} / \mathrm{l}$ & 5,9 & 6,0 & 3,6 & \\
\hline $0,5 \mathrm{mg} / \mathrm{l}$ & 5,6 & 5,2 & 3,5 & \\
\hline $1,0 \mathrm{mg} / \mathrm{l}$ & 5,2 & 6,3 & 3,9 & \\
\hline \multicolumn{5}{|l|}{ Final } \\
\hline & Altura $(\mathrm{cm})$ & Diâmetro $(\mathrm{cm})$ & Número de Folhas & Número de raízes \\
\hline Controle & 5,2 & 9,7 & 4,9 & 5,5 \\
\hline $0,1 \mathrm{mg} / \mathrm{l}$ & 5,3 & 7,8 & 4,9 & 4,1 \\
\hline $0,5 \mathrm{mg} / \mathrm{l}$ & 5,3 & 8,1 & 4,0 & 0,6 \\
\hline $1,0 \mathrm{mg} / \mathrm{l}$ & 4,5 & 8,5 & 4,6 & 0,0 \\
\hline
\end{tabular}

Tabela 08: Características dos indivíduos (valores médios) de $P$. stratiotes no início e final do teste com Cu (168 hs) $\mathrm{n}^{\circ} 4$.

\begin{tabular}{|c|c|c|c|c|}
\hline \multicolumn{5}{|l|}{ Inicial } \\
\hline & Altura $(\mathrm{cm})$ & Diâmetro (cm) & Número de Folhas & \\
\hline Controle & 7,6 & 4,4 & 2,9 & \\
\hline $0,1 \mathrm{mg} / \mathrm{l}$ & 8,0 & 5,4 & 3,4 & \\
\hline $0,5 \mathrm{mg} / \mathrm{l}$ & 8,2 & 5,8 & 2,8 & \\
\hline $1,0 \mathrm{mg} / \mathrm{l}$ & 7,0 & 5,9 & 3,9 & \\
\hline \multicolumn{5}{|l|}{ Final } \\
\hline & Altura (cm) & Diâmetro $(\mathrm{cm})$ & Número de Folhas & Número de raízes \\
\hline Controle & 6,1 & 10,3 & 3,3 & 3,1 \\
\hline $0,1 \mathrm{mg} / \mathrm{l}$ & 7,0 & 10,5 & 3,5 & 8,3 \\
\hline $0,5 \mathrm{mg} / \mathrm{l}$ & 7,4 & 10,3 & 3,4 & 2,3 \\
\hline $1,0 \mathrm{mg} / \mathrm{l}$ & 6,8 & 8,9 & 4,0 & 0,6 \\
\hline
\end{tabular}


Tabela 09: Características dos indivíduos (valores médios) de $P$. stratiotes no início e final do teste com $\mathrm{Cr}$ (14 dias).

\begin{tabular}{|c|c|c|c|c|c|}
\hline$\overline{\text { Inicial }}$ & & & & & \\
\hline & Altura $(\mathrm{cm})$ & Diâmetro (cm) & $\begin{array}{l}\text { Número de } \\
\text { Folhas }\end{array}$ & & \\
\hline Controle & 8,725 & 6,8625 & 2,875 & & \\
\hline 10 & 8,4625 & 7,3 & 2,75 & & \\
\hline 20 & 8,6375 & 6,8 & 3,125 & & \\
\hline 40 & 7,675 & 6,8875 & 3,625 & & \\
\hline 60 & 8,6125 & 7,5875 & 3 & & \\
\hline 80 & 8,2125 & 8,275 & 2,875 & & \\
\hline$\overline{\text { Final }}$ & & & & & \\
\hline & Altura $(\mathrm{cm})$ & Diâmetro $(\mathrm{cm})$ & $\begin{array}{l}\text { Número de } \\
\text { Folhas }\end{array}$ & $\begin{array}{l}\text { Número de } \\
\text { raízes }\end{array}$ & $\begin{array}{c}\text { Comprimento } \\
\text { Raízes }\end{array}$ \\
\hline Controle & $\overline{5,8}$ & 13,5 & 3,4 & $\overline{4,4}$ & $\overline{1,3}$ \\
\hline 10 & 5,6 & 11,5 & 3,3 & 2,8 & 1,3 \\
\hline 20 & 5,2 & 10,3 & 3,6 & 7,8 & 1,1 \\
\hline 40 & 5,0 & 6,7 & 3,6 & 1,3 & 0,4 \\
\hline 60 & & & & & \\
\hline 80 & & & & & \\
\hline
\end{tabular}

Tabela 10: Características dos indivíduos (valores médios) de $P$. stratiotes no início e final do teste com Cu (14 dias).

\begin{tabular}{|c|c|c|c|c|c|}
\hline \multicolumn{6}{|l|}{$\overline{\text { Inicial }}$} \\
\hline & Altura (cm) & Diâmetro (cm) & $\begin{array}{l}\text { Número de } \\
\text { Folhas }\end{array}$ & & \\
\hline Controle & 7,8 & 6,3 & 3,6 & & \\
\hline 0,2 & 8,5 & 6,9 & 3,5 & & \\
\hline 0,4 & 7,8 & 6,8 & 4,1 & & \\
\hline 0,6 & 7,9 & 6,7 & 3,4 & & \\
\hline 0,8 & 8,9 & 6,5 & 2,9 & & \\
\hline 1 & 8,5 & 7,3 & 2,8 & & \\
\hline \multicolumn{6}{|l|}{$\begin{array}{l}\text { Final } \\
\end{array}$} \\
\hline & Altura (cm) & Diâmetro (cm) & $\begin{array}{l}\text { Número de } \\
\text { Folhas }\end{array}$ & $\begin{array}{l}\text { Número de } \\
\text { raízes }\end{array}$ & $\begin{array}{l}\text { Comprimento } \\
\text { Raízes }\end{array}$ \\
\hline Controle & $\overline{6,4}$ & $\overline{11,4}$ & 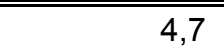 & $\overline{7,3}$ & $\overline{11,8}$ \\
\hline 0,2 & 7,8 & 12,4 & 3,4 & 8,0 & 3,5 \\
\hline 0,4 & 5,5 & 9,7 & 4,5 & 5,8 & 2,1 \\
\hline 0,6 & 6,3 & 9,6 & 3,1 & 6,1 & 1,1 \\
\hline 0,8 & 7,9 & 11,1 & 2,9 & 2,9 & 0,7 \\
\hline 1 & 6,9 & 11,2 & 3,1 & 1,5 & 0,5 \\
\hline
\end{tabular}




\section{CAPÍTULO 3}

\section{Experimentos em Microcosmos}

Tabela 01: Valores de $\mathrm{pH}$ determinados na água coleta em cada unidade experimental a $0,2,3,24,48,72,96,120,144$ e 168 hs do início do experimento.

\begin{tabular}{|c|c|c|c|c|c|c|c|c|c|c|c|}
\hline & & Ohs & $2 \mathrm{hs}$ & $3 \mathrm{hs}$ & $24 \mathrm{hs}$ & $48 \mathrm{hs}$ & $\overline{72 \mathrm{hs}}$ & $96 \mathrm{hs}$ & 120 & 144 & 168 \\
\hline & & & & & & & & & hs & hs & hs \\
\hline \multirow[t]{5}{*}{ Controle } & $\mathrm{C} 1$ & 6,0 & 6,4 & 7,7 & 5,3 & 7,5 & 7,0 & 6,5 & 6,8 & 6,7 & 7,2 \\
\hline & $\mathrm{C} 2$ & 5,4 & 7,3 & 7,4 & 6,9 & 7,1 & 7,0 & 6,3 & 6,9 & 6,6 & 6,9 \\
\hline & $\mathrm{C} 3$ & 5,5 & 7,5 & 7,5 & 7,1 & 7,3 & 6,3 & 6,4 & 6,6 & 6,8 & 6,8 \\
\hline & Média & 5,6 & 7,1 & 7,5 & $\overline{6,4}$ & 7,3 & 6,8 & 6,4 & 6,8 & 6,7 & 7,0 \\
\hline & Desvio Padrão & 0,3 & 0,6 & 0,1 & 1,0 & 0,2 & 0,4 & 0,1 & 0,2 & 0,1 & 0,2 \\
\hline \multirow[t]{5}{*}{ Cromo } & Cr1 & 5,6 & 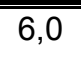 & 7,3 & $\overline{5,2}$ & 7,1 & 6,9 & 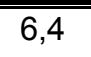 & $\overline{~ 6,6}$ & 6,6 & 6,6 \\
\hline & $\mathrm{Cr} 2$ & 5,3 & 6,8 & 6,8 & 7,0 & 7,1 & 6,7 & 6,3 & 6,6 & 6,7 & 6,5 \\
\hline & Cr3 & 5,4 & 7,0 & 7,3 & 7,2 & 7,0 & 6,9 & 6,3 & 6,6 & 6,5 & 6,4 \\
\hline & Média & 5,4 & 6,6 & 7,1 & $\overline{6,5}$ & $\overline{7,1}$ & 6,8 & 6,3 & 6,6 & 6,6 & 6,5 \\
\hline & Desvio Padrão & 0,2 & 0,5 & 0,3 & 1,1 & 0,0 & 0,1 & 0,1 & 0,0 & 0,1 & 0,1 \\
\hline \multirow[t]{5}{*}{ Cobre } & Cu1 & $\bar{~} 5,3$ & 7,2 & $7,7,3$ & $\overline{5,5}$ & 7,3 & $6,6,6$ & $\bar{~} 6,5$ & 76,9 & $\bar{~} 6,8$ & 6,6 \\
\hline & Cu2 & 5,5 & 7,2 & 7,5 & 7,0 & 7,0 & 6,9 & 6,5 & 6,5 & 6,6 & 6,5 \\
\hline & Cu3 & 5,6 & 7,5 & 7,3 & 7,2 & 7,2 & 6,9 & 6,5 & 6,8 & 6,7 & 6,6 \\
\hline & Média & 5,5 & 7,3 & 7,3 & 6,6 & 7,2 & 6,8 & 6,5 & 6,7 & 6,7 & 6,6 \\
\hline & Desvio Padrão & 0,1 & 0,2 & 0,1 & 0,9 & 0,1 & 0,2 & $\overline{0,0}$ & 0,2 & 0,1 & 0,1 \\
\hline
\end{tabular}


Tabela 02: Concentrações de clorofila $\left(\mathrm{mg}^{-1} \mathrm{~L}^{-1}\right)$ determinadas na água coleta em cada unidade experimental a 48, 96 e 144 hs do início do experimento.

\begin{tabular}{ccccc}
\hline \hline Clorofila $\left(\mathrm{mg}^{-1} \mathrm{~L}^{-1}\right)$ & Amostra & $48 \mathrm{hs}$ & $96 \mathrm{hs}$ & $144 \mathrm{hs}$ \\
\hline \hline Controle & $\mathrm{C} 1$ & 21,6 & 10,5 & 13,3 \\
& $\mathrm{C} 2$ & 14,0 & 7,7 & 14,6 \\
& $\mathrm{C} 3$ & 15,3 & 10,5 & 20,9 \\
\cline { 2 - 5 } & Média & 17,0 & 9,5 & 16,3 \\
\cline { 2 - 5 } & Desvio Padrão & 3,3 & 1,3 & 3,3 \\
\hline \hline Cromo & Cr 1 & 7,7 & 2,8 & 4,2 \\
& Cr 2 & 9,1 & 3,5 & 2,8 \\
& Cr 3 & 5,6 & 3,5 & 2,8 \\
\cline { 2 - 5 } & Média & 7,4 & 3,3 & 3,3 \\
\cline { 2 - 5 } & Desvio Padrão & 1,4 & 0,3 & 0,7 \\
\hline \hline \multirow{2}{*}{ Cobre } & Cu1 & 6,3 & 7,0 & 4,2 \\
& Cu2 & 11,9 & 8,4 & 9,8 \\
& Cu3 & 12,6 & 7,0 & 6,3 \\
\cline { 2 - 5 } & Média & 10,2 & 7,4 & 6,7 \\
\cline { 2 - 5 } & Desvio Padrão & 2,8 & 0,7 & 2,3 \\
\hline \hline
\end{tabular}

Tabela 03: Concentrações $\left(\mathrm{mg} \cdot \mathrm{L}^{-1}\right)$ de material em suspensão total, orgânico e inorgânico determinadas em cada unidade experimental a 48, 96 e 144 hs.

\begin{tabular}{|c|c|c|c|c|c|c|c|c|c|c|}
\hline & \multirow[t]{2}{*}{ Amostra } & \multicolumn{3}{|c|}{$48 \mathrm{hs}$} & \multicolumn{3}{|c|}{$96 \mathrm{hs}$} & \multicolumn{3}{|c|}{$144 \mathrm{hs}$} \\
\hline & & MT & MI & MO & MT & MI & $\mathrm{MO}$ & MT & MI & MO \\
\hline \multirow[t]{5}{*}{$\overline{\text { Controle }}$} & $\overline{\mathrm{C} 1}$ & $\overline{4,8}$ & 0 , & $\overline{4,5}$ & 2,56 & 0,48 & $\overline{22,08}$ & 2,04 & & $\begin{array}{ll}0 \quad 2,04 \\
\end{array}$ \\
\hline & $\mathrm{C} 2$ & 5,2 & 0 , & 5,0 & 2,68 & 0,36 & 2,32 & 2,08 & & $0 \quad 2,08$ \\
\hline & C3 & 5,2 & 0 , & 4,5 & 6,36 & 3,8 & 32,56 & 4,2 & & 4,2 \\
\hline & Média & $\overline{5,1}$ & 0 , & $4 \quad 4,7$ & $\overline{3,9}$ & 1,5 & $5 \quad 2,3$ & 2,8 & $\overline{0}$ & $\overline{2,8}$ \\
\hline & Desvio Padrão & 0,2 & $\overline{0}$ & $2 \quad 0,3$ & $\overline{1,8}$ & 1,6 & 00,2 & $\overline{1,0}$ & $\overline{0}$ & $\overline{1,0}$ \\
\hline \multirow[t]{5}{*}{ Cromo } & Cr 1 & 3,6 & 0 , & 3,6 & 3,12 & 1,04 & $4 \quad 2,08$ & 3,04 & 0,4 & $4 \quad 2,64$ \\
\hline & $\mathrm{Cr} 2$ & 4,5 & 0 , & 3,9 & 4,24 & 1,92 & 2,32 & 2,48 & 0,24 & $4 \quad 2,24$ \\
\hline & Cr 3 & 4,1 & 0 , & 3,5 & 3,04 & 0,52 & 2,52 & 2,48 & & $\begin{array}{ll}0 & 2,48\end{array}$ \\
\hline & Média & 4,0 & 0 , & $4 \quad 3,7$ & 3,5 & 1,2 & $2 \quad 2,3$ & 2,7 & 0,2 & $2 \quad 2,5$ \\
\hline & Desvio Padrão & 0,4 & 0 , & 0,2 & 0,5 & 0,6 & 0,2 & 0,3 & 0,2 & 0,2 \\
\hline \multirow[t]{5}{*}{ Cobre } & Cu1 & $\overline{44,2}$ & $\overline{1}$, & $\overline{3,2}$ & 3,28 & 0,36 & $2,2,92$ & $\overline{3,6}$ & 0,92 & 22,68 \\
\hline & Cu2 & 4,5 & 0 , & 4,5 & 3,72 & 0,6 & 3,12 & 3,56 & 0,36 & 3,2 \\
\hline & Cu3 & 4,8 & 0 , & 4,5 & 3,6 & 0,56 & 3,04 & 3,44 & 0,16 & $\begin{array}{ll}5 & 3,28\end{array}$ \\
\hline & Média & 4,5 & 0 , & $5 \quad 4,1$ & 3,5 & 0,5 & $5 \quad 3,0$ & 3,5 & 0,5 & $5 \quad 3,1$ \\
\hline & Desvio Padrão & 0,2 & 0 , & 0,6 & 0,2 & 0,1 & 0,1 & 0,1 & 0,3 & 0,3 \\
\hline
\end{tabular}


Tabela 04: Concentrações de silicato $\left(\mathrm{mg}^{\mathrm{L}} \mathrm{L}^{-1}\right)$ determinadas na água coleta em cada unidade experimental a 48, 96 e 144 hs.

\begin{tabular}{ccccc}
\hline \hline Silicato $\left(\mathrm{mg} \cdot \mathrm{L}^{-1}\right)$ & Amostra & $48 \mathrm{hs}$ & $96 \mathrm{hs}$ & $144 \mathrm{hs}$ \\
\hline \hline Controle & $\mathrm{C} 1$ & 0,45 & 0,26 & 0,28 \\
& $\mathrm{C} 2$ & 0,54 & 0,49 & 0,22 \\
& $\mathrm{C} 3$ & 0,46 & 0,33 & 0,32 \\
\cline { 2 - 5 } & Média & 0,48 & 0,36 & 0,27 \\
\cline { 2 - 5 } & Desvio Padrão & 0,05 & 0,12 & 0,05 \\
\hline \hline Cromo & Cr 1 & 0,02 & 0,34 & 0,23 \\
& Cr 2 & 0,31 & 0,30 & 0,25 \\
& Cr 3 & 0,29 & 0,32 & 0,25 \\
\cline { 2 - 5 } & Média & 0,20 & 0,32 & 0,24 \\
\cline { 2 - 5 } & Desvio Padrão & 0,16 & 0,02 & 0,01 \\
\hline \hline Cobre & Cu1 & 0,33 & 0,35 & 0,29 \\
& Cu2 & 0,58 & 0,37 & 0,30 \\
& Cu3 & 0,32 & 0,32 & 0,53 \\
& Média & 0,41 & 0,35 & 0,37 \\
\cline { 2 - 5 } & Desvio Padrão & 0,15 & 0,03 & 0,14 \\
\cline { 2 - 5 } & & & \\
\cline { 2 - 5 } & & & 0
\end{tabular}

Tabela 05: Concentrações de nitrato, nitrito, amônio $\left(\mu \mathrm{g} \cdot \mathrm{L}^{-1}\right)$ e nitrogênio total $\left(\mathrm{mg}^{\mathrm{L}} \mathrm{L}^{-1}\right)$ determinadas em cada unidade experimental a 48, 96 e $144 \mathrm{hs}$.

\begin{tabular}{|c|c|c|c|c|c|c|c|c|c|c|c|c|c|}
\hline & \multirow[t]{2}{*}{ Amostra } & \multicolumn{4}{|c|}{$48 \mathrm{hs}$} & \multicolumn{4}{|c|}{$96 \mathrm{hs}$} & \multicolumn{4}{|c|}{$144 \mathrm{hs}$} \\
\hline & & $\mathrm{NO}_{3}{ }^{2-}$ & $\mathrm{NO}_{3}^{-}$ & $\mathrm{NH}_{4}^{-}$ & NT & $\mathrm{NO}_{3}{ }^{2-}$ & $\mathrm{NO}_{3}$ & $\mathrm{NH}_{4}^{-}$ & NT & $\mathrm{NO}_{3}{ }^{2-}$ & $\mathrm{NO}_{3}^{-}$ & $\mathrm{NH}_{4}^{-}$ & NT \\
\hline \multirow[t]{5}{*}{ Controle } & $\overline{\mathrm{C} 1}$ & 477,1 & 2,0 & 76,8 & $\overline{0,1}$ & 99,7 & $\overline{2,0}$ & 33,1 & 0,6 & 115,3 & 2,5 & 35,0 & 0,2 \\
\hline & $\mathrm{C} 2$ & 266,2 & 1,8 & 33,0 & 0,2 & 287,1 & 4,8 & 109,3 & 0,5 & 322,6 & 6,8 & 28,9 & 0,5 \\
\hline & C3 & 78,4 & 1,1 & 15,2 & 0,3 & 52,0 & 1,9 & 129,6 & 0,5 & 108,0 & 1,9 & 164,4 & 0,7 \\
\hline & Média & 273,9 & 1,6 & 41,7 & 0,2 & 146,3 & $\overline{2,9}$ & 90,7 & 0,5 & 181,9 & $\overline{3,8}$ & 76,1 & 0,5 \\
\hline & Desvio Padrão & 199,5 & $\overline{0,5}$ & 31,7 & 0,1 & 124,3 & $\overline{1,6}$ & 50,9 & 0,1 & 121,8 & $\overline{2,6}$ & 76,6 & 0,2 \\
\hline \multirow[t]{5}{*}{ Cromo } & $\mathrm{Cr} 1$ & 222,3 & 1,6 & 19,3 & 0,8 & 289,0 & 2,3 & 105,0 & 0,4 & 411,8 & 2,8 & 129,2 & 0,6 \\
\hline & $\mathrm{Cr} 2$ & 89,6 & 1,2 & 20,6 & 0,1 & 219,0 & 3,8 & 52,0 & 0,3 & 192,1 & 1,9 & 121,0 & 0,6 \\
\hline & $\mathrm{Cr} 3$ & 131,6 & 1,0 & 14,2 & 0,1 & 169,3 & 2,4 & 114,2 & 0,8 & 231,1 & 2,8 & 39,9 & 0,7 \\
\hline & Média & 147,8 & $\overline{1,3}$ & $\overline{18,0}$ & $\overline{0,3}$ & 225,8 & $\overline{2,8}$ & 90,4 & 0,5 & 278,3 & $\overline{2,5}$ & 96,7 & 0,7 \\
\hline & Desvio Padrão & 67 & $\overline{0,3}$ & $\overline{3,4}$ & $\overline{0,4}$ & $\overline{60,1}$ & $\overline{0,8}$ & $\overline{33,6}$ & 0,2 & 117,2 & $\overline{0,5}$ & 49,4 & $\overline{0,0}$ \\
\hline \multirow[t]{5}{*}{ Cobre } & Cu1 & 138,7 & 1,6 & 21,6 & 0,2 & 229,9 & 4,0 & 110,4 & 0,6 & 157,7 & 5,4 & 69,9 & 0,2 \\
\hline & Cu2 & 53,4 & 1,6 & 32,8 & 0,2 & 89,5 & 2,3 & 24,8 & 0,3 & 271,9 & 3,0 & 112,8 & 0,5 \\
\hline & Cu3 & 238,3 & 2,0 & 44,6 & 0,3 & 273,8 & 3,1 & 164,5 & 0,5 & 266,5 & 3,5 & 109,4 & 0,2 \\
\hline & Média & 143,5 & $\overline{1,7}$ & 33,0 & $\overline{0,2}$ & 197,7 & $\overline{3,1}$ & 99,9 & 0,5 & 232,0 & $\overline{4,0}$ & $\overline{97,4}$ & 0,3 \\
\hline & Desvio Padrão & 92,5 & $\overline{0,2}$ & $\overline{11,5}$ & $\overline{0,0}$ & 96,3 & $\overline{0,9}$ & 70,5 & & 64,4 & $\overline{1,3}$ & 23,8 & 0,2 \\
\hline
\end{tabular}


Tabela 06: Concentrações de fosfato inorgânico, fosfato total dissolvido e fósforo total $\left(\mu \mathrm{g} . \mathrm{L}^{-1}\right)$ determinadas em cada unidade experimental a 48,96 e 144 hs do início do experimento.

\begin{tabular}{|c|c|c|c|c|c|c|c|c|c|c|}
\hline & \multirow[t]{2}{*}{ Amostra } & \multicolumn{3}{|c|}{$48 \mathrm{hs}$} & \multicolumn{3}{|c|}{96 hs } & \multicolumn{3}{|c|}{$144 \mathrm{hs}$} \\
\hline & & \multicolumn{3}{|c|}{$\begin{array}{c}\mathrm{PO}_{4}{ }^{3-} \mathrm{I} \mathrm{PO}_{4}{ }^{3-} \\
\mathrm{D}\end{array}$} & \multicolumn{3}{|c|}{$\begin{array}{c}\mathrm{PO}_{4}^{3-} \mathrm{IOO}_{4}^{3-} \quad \mathrm{PT} \\
\mathrm{D}\end{array}$} & \multicolumn{3}{|c|}{$\begin{array}{c}\mathrm{PO}_{4}^{3-} \mathrm{I} \mathrm{PO}_{4}^{3-} \quad \mathrm{PT} \\
\mathrm{D}\end{array}$} \\
\hline \multirow[t]{5}{*}{ Controle } & C1 & 12,3 & 10,7 & $\overline{17,4}$ & 0,5 & 44,2 & 23,2 & 2,1 & $\overline{7,5}$ & $\overline{19,0}$ \\
\hline & $\mathrm{C} 2$ & 2,5 & 6,0 & 26,7 & 3,2 & 2,8 & 15,2 & 1,6 & 5,9 & 19,7 \\
\hline & C3 & 4,3 & 5,6 & 24,6 & 3,2 & 6,2 & 26,8 & 0,1 & 3,5 & 21,8 \\
\hline & Média & 6,4 & $\overline{7,4}$ & 22,9 & 2,3 & 4,4 & 21,7 & 1,3 & 5,7 & 20,2 \\
\hline & Desvio Padrão & 5,2 & 2,8 & 4,9 & 1,5 & 1,7 & 5,9 & 1,0 & 2,0 & 1,5 \\
\hline \multirow[t]{5}{*}{ Cromo } & $\mathrm{Cr} 1$ & 1,2 & 4,7 & 39,2 & 1,4 & 4,3 & 14,9 & 0,3 & 1,8 & 19,0 \\
\hline & $\mathrm{Cr} 2$ & 5,0 & 14,2 & 26,6 & 6,4 & 8,9 & 18,9 & 1,2 & 5,0 & 21,7 \\
\hline & Cr 3 & 2,3 & 8,1 & 27,3 & 2,1 & 3,3 & 17,6 & 1,3 & 4,8 & 21,1 \\
\hline & Média & 2,8 & 9,0 & 31,0 & 3,3 & 5,5 & 17,1 & 1,0 & 3,9 & 20,6 \\
\hline & Desvio Padrão & 2,0 & 4,8 & $\overline{7,1}$ & 2,7 & 3,0 & 2,0 & 0,5 & 1,8 & $\overline{1,4}$ \\
\hline \multirow[t]{5}{*}{ Cobre } & Cu1 & 3,6 & 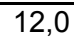 & 21,1 & 2,2 & 4,3 & $\overline{17,3}$ & 2,9 & 7,8 & $\overline{17,2}$ \\
\hline & Cu2 & 3,4 & 8,8 & 24,7 & 0,7 & 4,0 & 22,3 & 1,8 & 3,5 & 24,3 \\
\hline & Cu3 & 3,2 & 9,0 & 31,8 & 3,0 & 5,2 & 18,3 & 3,6 & 14,1 & 22,7 \\
\hline & Média & 3,4 & 9,9 & 25,9 & 2,0 & 4,5 & 19,3 & 2,8 & 8,4 & 21,4 \\
\hline & Desvio Padrão & 0,2 & 1,8 & $\overline{5,4}$ & 1,2 & 0,6 & 2,6 & 0,9 & 5,3 & 3,7 \\
\hline
\end{tabular}


Tabela 07: Concentrações $\left(\mu \mathrm{g} \cdot \mathrm{L}^{-1}\right)$ de $\mathrm{Cu}$ determinados na água coleta em cada unidade experimental a $0,2,3,24,48,72,96,120,144$ e 168 hs do início do experimento.

\begin{tabular}{lrrrrrrrr}
\hline \hline & $3 \mathrm{hs}$ & $24 \mathrm{hs}$ & $48 \mathrm{hs}$ & $72 \mathrm{hs}$ & $96 \mathrm{hs}$ & $120 \mathrm{hs}$ & $144 \mathrm{hs}$ & $168 \mathrm{hs}$ \\
\hline \hline C1 & 16,3 & 12,6 & 4,5 & 4,3 & 6,5 & 3,2 & 16,6 & 5,5 \\
C2 & 4,2 & 6,0 & 3,4 & 3,4 & 7,0 & 4,4 & 8,1 & 13,1 \\
C3 & 4,2 & 4,7 & 5,3 & 7,5 & 3,9 & 5,1 & 11,2 & 14,8 \\
\hline Média & 8,2 & 7,8 & 4,4 & 5,1 & 5,8 & 4,2 & 12,0 & 11,1 \\
\hline Desvio Padrão & 7,0 & 4,3 & 0,9 & 2,2 & 1,6 & 1,0 & 4,3 & 5,0 \\
\hline \hline Cu1 & 10,6 & 32,5 & 11,5 & 12,3 & 14,7 & 10,1 & 10,5 & 10,7 \\
Cu2 & 13,2 & 23,9 & 9,7 & 22,0 & 12,8 & 6,3 & 14,4 & 8,8 \\
Cu3 & 20,3 & 8,8 & 10,2 & 8,8 & 8,9 & 13,8 & 15,5 & 12,1 \\
\hline Média & 14,7 & 21,7 & 10,5 & 14,4 & 12,1 & 10,1 & 13,5 & 10,6 \\
\hline Desvio Padrão & 5,0 & 12,0 & 0,9 & 6,8 & 2,9 & 3,8 & 2,6 & 1,7 \\
\hline \hline
\end{tabular}

Tabela 08: Concentrações $\left(\mu \mathrm{g} \cdot \mathrm{L}^{-1}\right)$ de $\mathrm{Cr}$ determinados na água coleta em cada unidade experimental a $0,2,3,24,48,72,96,120,144$ e 168 hs do início do experimento. $\mathrm{Cr}$ não foi detectado em nenhum dos controles.

\begin{tabular}{lrrrrrrrr}
\hline \hline & $3 \mathrm{hs}$ & $24 \mathrm{hs}$ & $48 \mathrm{hs}$ & $72 \mathrm{hs}$ & $96 \mathrm{hs}$ & $120 \mathrm{hs}$ & $144 \mathrm{hs}$ & $168 \mathrm{hs}$ \\
\hline \hline Cr1 & 21,4 & 18,7 & 18,1 & 16,6 & 16,9 & 15,5 & 16,9 & 15,0 \\
Cr2 & 18,9 & 17,1 & 18,3 & 18,5 & 19,1 & 18,2 & 17,4 & 15,6 \\
Cr3 & 22,7 & 17,7 & 18,4 & 16,2 & 19,5 & 18,7 & 17,5 & 16,4 \\
\hline Média & 21,0 & 17,8 & 18,3 & 17,1 & 18,5 & 17,5 & 17,3 & 15,7 \\
\hline Desvio Padrão & 1,9 & 0,8 & 0,1 & 1,3 & 1,4 & 1,7 & 0,3 & 0,7 \\
\hline \hline
\end{tabular}


Tabela 09: Análise quantitativa da comunidade fitoplanctônica dos experimentos realizados em microcosmos em dezembro de 2001, 3 horas após o início do experimento .

\begin{tabular}{|c|c|c|c|c|c|c|c|c|}
\hline \multicolumn{3}{|c|}{ Controle } & \multicolumn{3}{|c|}{ Cromo } & \multicolumn{3}{|c|}{ Cobre } \\
\hline Espécies & Ind/mL & & Espécies & $\operatorname{lnd} / \mathrm{mL}$ & & Espécies & $\operatorname{lnd} / \mathrm{mL}$ & \\
\hline $\begin{array}{l}\text { Aulacoseira } \\
\text { granulata }\end{array}$ & 205,8 & 17,0 & $\begin{array}{l}\text { Aulacoseira } \\
\text { granulata }\end{array}$ & 803,4 & 33,7 & $\begin{array}{l}\text { Coelastrum } \\
\text { reticulatum }\end{array}$ & 169,8 & 9,4 \\
\hline $\begin{array}{l}\text { Chlamydomonas } \\
\text { sp }\end{array}$ & 51,4 & 4,2 & $\begin{array}{l}\text { Chlamydomonas } \\
\text { sp }\end{array}$ & 35,4 & 1,5 & $\begin{array}{l}\text { Chlamydomonas } \\
\text { sp }\end{array}$ & 339,5 & 18,8 \\
\hline Chlorella $s p$ & 8,6 & 0,7 & Chlorella $s p$ & 5,1 & 0,2 & Radiococcus sp. & 141,5 & 7,8 \\
\hline $\begin{array}{l}\text { Coelastrum } \\
\text { sphaericum }\end{array}$ & 128,6 & 10,6 & $\begin{array}{l}\text { Coelastrum } \\
\text { reticulatum }\end{array}$ & 156,6 & 6,6 & cryptomonas sp. & 42,4 & 2,3 \\
\hline Cosmarium sp & 4,3 & 0,4 & Cosmarium sp & 15,2 & 0,6 & $\begin{array}{l}\text { Golenkinia } \\
\text { radiata }\end{array}$ & 14,1 & 0,8 \\
\hline Cryptomonas sp & 4,3 & 0,4 & Didimocystis fina & 40,4 & 1,7 & Didimocystis fina & 56,6 & 3,1 \\
\hline Didimocystis fina & 68,6 & 5,7 & $\begin{array}{l}\text { Elakatotrix } \\
\text { gelatinosa }\end{array}$ & 5,1 & 0,2 & $\begin{array}{l}\text { Sphaerocystis } \\
\text { schoeterie }\end{array}$ & 481,0 & 26,6 \\
\hline Euglena sp & 47,2 & 3,9 & $\begin{array}{l}\text { Monoraphydium } \\
\text { arcuatum }\end{array}$ & 30,3 & 1,3 & Quadrigula sp.p & 382,0 & 21,1 \\
\hline Eunotia $s p$ & 17,1 & 1,4 & $\begin{array}{l}\text { Oocysstis } \\
\text { lacustrres }\end{array}$ & 5,1 & 0,2 & $\begin{array}{l}\text { Oocysstis } \\
\text { lacustrres }\end{array}$ & 56,6 & 3,1 \\
\hline $\begin{array}{l}\text { Monoraphydium } \\
\text { circinale }\end{array}$ & 60,0 & 4,9 & $\begin{array}{l}\text { Pediastrum } \\
\text { duplex }\end{array}$ & 10,1 & 0,4 & Staurastrum sp. & 14,1 & 0,8 \\
\hline Quadrigula sp.p & 120,0 & 9,9 & Quadrigula sp.p & 389,0 & 16,3 & $\begin{array}{l}\text { Aulacoseira } \\
\text { granulata }\end{array}$ & 14,1 & 0,8 \\
\hline Radiococcus sp & 411,6 & 33,9 & Radiococcus sp. & 661,9 & 27,8 & $\begin{array}{l}\text { Monoraphydium } \\
\text { arcuatum }\end{array}$ & 14,1 & 0,8 \\
\hline $\begin{array}{l}\text { Rizosolenia } \\
\text { longiseta }\end{array}$ & 4,3 & 0,4 & $\begin{array}{l}\text { Scenedesmus } \\
\text { sp. }\end{array}$ & 30,3 & 1,3 & Cosmarium sp. & 28,3 & 1,6 \\
\hline $\begin{array}{l}\text { Sphaerocystis } \\
\text { schoeterie }\end{array}$ & 77,2 & 6,4 & $\begin{array}{l}\text { Sphaerocystis } \\
\text { schoeterie }\end{array}$ & 65,7 & 2,8 & $\begin{array}{l}\text { Aulacoseira } \\
\text { italica }\end{array}$ & 56,6 & 3,1 \\
\hline $\begin{array}{l}\text { Staurastrum cf. } \\
\text { incus }\end{array}$ & 4,3 & 0,4 & $\begin{array}{l}\text { Staurastrum cf. } \\
\text { incus } \\
\text { Trachelomonas } \\
\text { volvocina }\end{array}$ & $\begin{array}{r}101,1 \\
30,3\end{array}$ & $\begin{array}{l}4,2 \\
1,3\end{array}$ & & & \\
\hline Total & 1213,2 & 100,0 & Total & 2384,8 & 100,0 & & 810,8 & 100,0 \\
\hline
\end{tabular}


Tabela 10: Análise quantitativa da comunidade fitoplanctônica dos experimentos realizados em microcosmos em dezembro de 2001, 24 horas após o início do experimento .

\begin{tabular}{|c|c|c|c|c|c|c|c|c|}
\hline \multicolumn{3}{|c|}{ Controle } & \multicolumn{3}{|c|}{ Cromo } & \multicolumn{3}{|c|}{ Cobre } \\
\hline Espécies & Ind $/ \mathrm{mL}$ & & Espécies & Ind/mL & & Espécies & Ind/mL $\%$ & \\
\hline $\begin{array}{l}\text { Coelastrum } \\
\text { reticulatum }\end{array}$ & 141,5 & 7,7 & Asterococcus sp. & 183,9 & 21,3 & $\begin{array}{l}\text { Monoraphydium } \\
\text { circinale }\end{array}$ & 240,5 & 15,2 \\
\hline $\begin{array}{l}\text { Coelastrum } \\
\text { sphaericum }\end{array}$ & 14,1 & 0,8 & Chlorella sp. & 169,8 & 19,7 & cryptomonas sp & 56,6 & 3,6 \\
\hline cryptomonas sp. & 14,1 & 0,8 & $\begin{array}{l}\text { Coelastrum } \\
\text { reticulatum }\end{array}$ & 28,3 & 3,3 & Didimocystis fina & 84,9 & 5,4 \\
\hline $\begin{array}{l}\text { Kirchneriella } \\
\text { lunaris }\end{array}$ & 70,7 & 3,8 & $\begin{array}{l}\text { Monoraphydium } \\
\text { circinale }\end{array}$ & 28,3 & 3,3 & $\begin{array}{l}\text { Chlamydomonas } \\
\text { sp }\end{array}$ & 183,9 & 11,6 \\
\hline $\begin{array}{l}\text { Monoraphydium } \\
\text { circinale }\end{array}$ & 1160,1 & 63,1 & $\begin{array}{l}\text { Oocystis } \\
\text { lacustres }\end{array}$ & 14,1 & 1,6 & $\begin{array}{l}\text { Coelastrum } \\
\text { reticulatum }\end{array}$ & 113,2 & 7,1 \\
\hline $\begin{array}{l}\text { Oocystis } \\
\text { lacustres }\end{array}$ & 28,3 & 1,5 & Quadrigula sp. & 254,6 & 29,5 & Radiococcus sp & 226,4 & 14,3 \\
\hline $\begin{array}{l}\text { Pediastrum } \\
\text { duplex }\end{array}$ & 14,1 & 0,8 & Radiococcus sp & 169,8 & 19,7 & $\begin{array}{l}\text { Oocystis } \\
\text { lacustres }\end{array}$ & 14,1 & 0,9 \\
\hline Quadrigula sp & 56,6 & 3,1 & $\begin{array}{l}\text { Staurastrum } \\
\text { sebaldi }\end{array}$ & 14,1 & 1,6 & $\begin{array}{l}\text { Sphaerocystis } \\
\text { schoeterie }\end{array}$ & 452,7 & 28,6 \\
\hline $\begin{array}{l}\text { Scenedesmus } \\
\text { sp. }\end{array}$ & 14,1 & 0,8 & & & & Quadrigula sp. & 212,2 & 13,4 \\
\hline $\begin{array}{l}\text { Sphaerocystis } \\
\text { schoeterie }\end{array}$ & 226,4 & 12,3 & & & & & & \\
\hline Staurastrum $s p$ & 42,4 & 2,3 & & & & & & \\
\hline Synedra sp & 56,6 & 3,1 & & & & & & \\
\hline Total & 1839,1 & 100,0 & Total & 863,0 & 100,0 & Total & 1584,51 & 100,0 \\
\hline
\end{tabular}


Tabela 11: Análise quantitativa da comunidade fitoplanctônica dos experimentos realizados em microcosmos em dezembro de 2001, 48 horas após o início do experimento .

\begin{tabular}{|c|c|c|c|c|c|c|c|c|}
\hline \multicolumn{3}{|c|}{ Controle } & \multicolumn{3}{|c|}{ Cromo } & \multicolumn{3}{|c|}{ Cobre } \\
\hline $\begin{array}{l}\text { Espécies } \\
\text { Chlamydomonas }\end{array}$ & \multicolumn{2}{|c|}{ Ind/mL \% } & \multirow{2}{*}{$\begin{array}{l}\text { Espécies } \\
\text { Chlamydomonas } \\
\text { sp. }\end{array}$} & \multicolumn{2}{|c|}{ Ind/mL \% } & \multirow{2}{*}{\begin{tabular}{|l|} 
Espécies \\
Oocystis sp
\end{tabular}} & \multicolumn{2}{|c|}{ Ind/mL \% } \\
\hline $\begin{array}{l}\text { Chlamydomonas } \\
\text { sp. }\end{array}$ & 294,3 & 10,9 & & 147,1 & 21,3 & & 34,0 & 4,1 \\
\hline Chlorella sp. & 22,6 & 0,8 & Chlorella sp. & 45,3 & 6,6 & $\begin{array}{l}\text { Elakatotrix } \\
\text { gelatinosa }\end{array}$ & 22,6 & 2,7 \\
\hline $\begin{array}{l}\text { Coelastrum } \\
\text { reticulatum }\end{array}$ & 90,5 & 3,4 & $\begin{array}{l}\text { Coelastrtum } \\
\text { reticulatum }\end{array}$ & 22,6 & 3,3 & $\begin{array}{l}\text { Chlamydomonas } \\
\text { sp. }\end{array}$ & 181,1 & 21,9 \\
\hline Cosmarium sp. & 22,6 & 0,8 & $\begin{array}{l}\text { Crucigenia } \\
\text { tetrapedia }\end{array}$ & 11,3 & 1,6 & Quadrigula sp. & 113,2 & 13,7 \\
\hline cryptomonas sp & 22,6 & 0,8 & $\begin{array}{l}\text { Elakatotrix } \\
\text { gelatinosa }\end{array}$ & 11,3 & 1,6 & Cyclotela sp & 11,3 & 1,4 \\
\hline Didimocystis fina & 135,8 & 5,0 & $\begin{array}{l}\text { Monoraphydium } \\
\text { cf. kormakovae }\end{array}$ & 11,3 & 1,6 & $\begin{array}{l}\text { Coelastrtum } \\
\text { reticulatum }\end{array}$ & 124,5 & 15,1 \\
\hline Elakatotrix sp. & 22,6 & 0,8 & Quadrigula sp. & 203,7 & 29,5 & $\begin{array}{l}\text { Monoraphydium } \\
\text { circinale }\end{array}$ & 22,6 & 2,7 \\
\hline $\begin{array}{l}\text { Monoraphydium } \\
\text { cf. kormakovae }\end{array}$ & 22,6 & 0,8 & Radiococcus sp. & 11,3 & 1,6 & Radiococcus sp. & 181,1 & 21,9 \\
\hline $\begin{array}{l}\text { Monoraphydium } \\
\text { circinale }\end{array}$ & 135,8 & 5,0 & $\begin{array}{l}\text { Sphaerocystis } \\
\text { schoeterie }\end{array}$ & 226,4 & 32,8 & $\begin{array}{l}\text { Scenedesmus } \\
s p .\end{array}$ & 45,3 & 5,5 \\
\hline $\begin{array}{l}\text { Oocystis } \\
\text { lacustres }\end{array}$ & 90,5 & 3,4 & & & & $\begin{array}{l}\text { Sphaerocystis } \\
\text { schoeterie }\end{array}$ & 90,5 & 11,0 \\
\hline Quadrigula sp. & 747,0 & 27,7 & & & & & & \\
\hline Radiococcus sp. & 271,6 & 10,1 & & & & & & \\
\hline $\begin{array}{l}\text { Sphaerocystis } \\
\text { schoeterie }\end{array}$ & 792,2 & 29,4 & & & & & & \\
\hline $\begin{array}{l}\text { Staurastrum cf. } \\
\text { incus }\end{array}$ & 22,6 & 0,8 & & & & & & \\
\hline Total & 2693,6 & 100,0 & Total & 690,4 & 100,0 & Total & 826,21 & 100,0 \\
\hline
\end{tabular}


Tabela 12: Análise quantitativa da comunidade fitoplanctônica dos experimentos realizados em microcosmos em dezembro de 2001, 72 horas após o início do experimento .

\begin{tabular}{|c|c|c|c|c|c|c|c|c|}
\hline \multicolumn{3}{|c|}{ Controle } & \multicolumn{3}{|c|}{ Cromo } & \multicolumn{3}{|c|}{ Cobre } \\
\hline $\begin{array}{l}\text { Espécies } \\
\text { Chlamydomonas }\end{array}$ & \multicolumn{2}{|c|}{ Ind/mL \% } & Espécies & \multicolumn{2}{|c|}{ Ind/mL \% } & Espécies & \multicolumn{2}{|c|}{ Ind/mL \% } \\
\hline $\begin{array}{l}\text { Chlamydomonas } \\
\text { sp. }\end{array}$ & 34,0 & 4,2 & $\begin{array}{l}\text { Chlamydomonas } \\
\text { sp. }\end{array}$ & 34,0 & & Oocystis sp & 67,9 & 4,1 \\
\hline $\begin{array}{l}\text { Coelastrum } \\
\text { reticulatum }\end{array}$ & 113,2 & 14,1 & $\begin{array}{l}\text { Coelastrum } \\
\text { reticulatum }\end{array}$ & 67,9 & 13,3 & $\begin{array}{l}\text { Coelastrum } \\
\text { reticulatum }\end{array}$ & 158,4 & 9,5 \\
\hline Cosmarium sp. & 22,6 & 2,8 & Coenocloris sp. & 181,1 & 35,6 & Chlorella $s p$ & 181,1 & 10,8 \\
\hline cryptomonas sp. & 22,6 & 2,8 & Didimocystis fina & 22,6 & 4,4 & $\begin{array}{l}\text { Chlamydomonas } \\
\text { sp. }\end{array}$ & 22,6 & 1,4 \\
\hline $\begin{array}{l}\text { Crucigenia } \\
\text { tetrapedia }\end{array}$ & 11,3 & 1,4 & $\begin{array}{l}\text { Monoraphydium } \\
\text { circinale }\end{array}$ & 11,3 & 2,2 & Didimocystis fina & 135,8 & 8,1 \\
\hline didimocystis fina & 45,3 & 5,6 & $\begin{array}{l}\text { Oocystis } \\
\text { lacustres }\end{array}$ & 56,6 & 11,1 & Quadrigula sp. & 158,4 & 9,5 \\
\hline Quadrigula sp. & 101,9 & 12,7 & Quadrigula sp. & 90,5 & 17,8 & Radiococcus sp. & 814,9 & 48,6 \\
\hline Radiococcus sp. & 181,1 & 22,5 & Radiococcus sp. & 45,3 & 8,9 & Cosmarium sp & 22,6 & 1,4 \\
\hline $\begin{array}{l}\text { Sphaerocystis } \\
\text { schoeterie }\end{array}$ & 271,6 & 33,8 & & & & $\begin{array}{l}\text { Dictyosphaerium } \\
\text { pulchellum }\end{array}$ & 90,5 & 5,4 \\
\hline & & & & & & Mallomonas sp & 22,6 & 1,4 \\
\hline & & & & & & $\begin{array}{l}\text { Monoraphydium } \\
\text { arcuatum }\end{array}$ & 22,6 & 1,4 \\
\hline Total & 803,6 & 100,0 & Total & 509,3 & 100,0 & Total & 1675,0 & $\overline{100,0}$ \\
\hline
\end{tabular}


Tabela 13: Análise quantitativa da comunidade fitoplanctônica dos experimentos realizados em microcosmos em dezembro de 2001, 96 horas após o início do experimento .

\begin{tabular}{|c|c|c|c|c|c|c|c|c|}
\hline \multicolumn{3}{|c|}{ Controle } & \multicolumn{3}{|c|}{ Cromo } & \multicolumn{3}{|c|}{ Cobre } \\
\hline Espécies & \multicolumn{2}{|c|}{ Ind/mL \% } & Espécies & \multicolumn{2}{|c|}{ Ind/mL \% } & Espécies & \multicolumn{2}{|c|}{ Ind $/ \mathrm{mL} \%$} \\
\hline $\begin{array}{l}\text { Chlamydomonas } \\
\text { sp }\end{array}$ & 11,3 & 3,0 & Asterococcus sp. & 22,6 & 4,4 & Chlorella sp. & 249,0 & 46,8 \\
\hline Chlorella sp. & 11,3 & 3,0 & Chlorella sp. & 90,5 & 17,8 & $\begin{array}{l}\text { Chlamydomonas } \\
\text { sp }\end{array}$ & 34,0 & 6,4 \\
\hline $\begin{array}{l}\text { Coelastrum } \\
\text { reticulatum }\end{array}$ & 79,2 & 21,2 & $\begin{array}{l}\text { Coelastrum } \\
\text { reticulatum }\end{array}$ & 11,3 & 2,2 & Cosmarium sp. & 22,6 & 4,3 \\
\hline cryptomonas sp. & 11,3 & 3,0 & cryptomonas sp. & 11,3 & 2,2 & $\begin{array}{l}\text { Dictyosphaerium } \\
\text { pulchellum }\end{array}$ & 67,9 & 12,8 \\
\hline Didimocystis fina & 22,6 & 6,1 & Didimocystis fina & 45,3 & 8,9 & Didimocystis fina & 11,3 & 2,1 \\
\hline $\begin{array}{l}\text { Monoraphydium } \\
\text { cf. kormakovae }\end{array}$ & 11,3 & 3,0 & $\begin{array}{l}\text { Monoraphydium } \\
\text { arcuatum }\end{array}$ & 22,6 & 4,4 & $\begin{array}{l}\text { Aulacoseira } \\
\text { granulata }\end{array}$ & 11,3 & 2,1 \\
\hline Oocystis lacustris & 11,3 & 3,0 & $\begin{array}{l}\text { pediastrum } \\
\text { duplex }\end{array}$ & 11,3 & 2,2 & $\begin{array}{l}\text { Coelastrum } \\
\text { reticulatum }\end{array}$ & 34,0 & 6,4 \\
\hline Quadrigula sp. & 56,6 & 15,2 & Quadrigula sp. & 101,9 & 20,0 & Radiococcus sp. & 34,0 & 6,4 \\
\hline Radiococcus sp & 56,6 & 15,2 & $\begin{array}{l}\text { Sphaerocystis } \\
\text { schoeterie }\end{array}$ & 181,1 & 35,6 & Cryptomonas sp. & 11,3 & 2,1 \\
\hline $\begin{array}{l}\text { Sphaerocystis } \\
\text { schoeterie }\end{array}$ & 90,5 & 24,2 & Synedra sp. & 11,3 & 2,2 & Quadrigula sp. & 11,3 & 2,1 \\
\hline $\begin{array}{l}\text { Staurastrum cf. } \\
\text { incus }\end{array}$ & 11,3 & 3,0 & & & 0,0 & $\begin{array}{l}\text { Sphaerocystis } \\
\text { schoeterie }\end{array}$ & 34,0 & 6,4 \\
\hline & & & & & 0,0 & $\begin{array}{l}\text { Monoraphydium } \\
\text { circinale }\end{array}$ & 11,3 & 2,1 \\
\hline Total & 373,5 & 100,0 & Total & 509,3 & 100,0 & Total & 531,9 & 100,0 \\
\hline
\end{tabular}


Tabela 14: Análise quantitativa da comunidade fitoplanctônica dos experimentos realizados em microcosmos em dezembro de 2001, 120 horas após o início do experimento .

\begin{tabular}{|c|c|c|c|c|c|c|c|c|}
\hline \multicolumn{3}{|c|}{ Controle } & \multicolumn{3}{|c|}{ Cromo } & \multicolumn{3}{|c|}{ Cobre } \\
\hline Espécies & $\operatorname{lnd} / \mathrm{mL}$ & & Espécies & Ind/mL & & Espécies & $\operatorname{lnd} / \mathrm{mL}$ & \\
\hline Chlorella $s p$ & 11,3 & 1,5 & Asterococcus sp. & 45,3 & 6,7 & Asterococcus sp. & 45,3 & 8,5 \\
\hline $\begin{array}{l}\text { coelastrum } \\
\text { reticulatum }\end{array}$ & 15,8 & 2,1 & Chlorella sp & 249,0 & 36,7 & Radiococcus sp. & 67,9 & 12,8 \\
\hline cryptomonas sp & 2,3 & 0,3 & $\begin{array}{l}\text { Coelastrum } \\
\text { reticulatum }\end{array}$ & 22,6 & 3,3 & Coenocloris sp. & 305,6 & 57,4 \\
\hline $\begin{array}{l}\text { Crucigenia } \\
\text { fenestrada }\end{array}$ & 2,3 & 0,3 & Didimocystis fina & 135,8 & 20,0 & $\begin{array}{l}\text { Eutetramorus } \\
\text { fottii }\end{array}$ & 11,3 & 2,1 \\
\hline Didimocystis fina & 6,8 & 0,9 & $\begin{array}{l}\text { Monoraphydium } \\
\text { circinale }\end{array}$ & 135,8 & 20,0 & $\begin{array}{l}\text { Coelastrum } \\
\text { reticulatum }\end{array}$ & 11,3 & 2,1 \\
\hline $\begin{array}{l}\text { Elakatotrix } \\
\text { gelatinosa }\end{array}$ & 4,5 & 0,6 & Quadrigula sp. & 45,3 & 6,7 & $\begin{array}{l}\text { Monoraphydium } \\
\text { circinale }\end{array}$ & 34,0 & 6,4 \\
\hline $\begin{array}{l}\text { Monoraphydium } \\
\text { circinale }\end{array}$ & 674,5 & 91,1 & Radiococcus sp. & 45,3 & 6,7 & Cosmarium sp & 22,6 & 4,3 \\
\hline Oocystis $s p$ & 4,5 & 0,6 & & & & Didimocystis fina & 11,3 & 2,1 \\
\hline Quadrigula sp. & 15,8 & 2,1 & & & & Chlorella sp & 22,6 & 4,3 \\
\hline $\begin{array}{l}\text { Tetraedron } \\
\text { caudatum }\end{array}$ & 2,3 & 0,3 & & & & & & \\
\hline 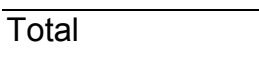 & 740,2 & 100,0 & Total & 679,1 & 100,0 & Total & 531,9 & 100,0 \\
\hline
\end{tabular}


Tabela 15: Análise quantitativa da comunidade fitoplanctônica dos experimentos realizados em microcosmos em dezembro de 2001, 144 horas após o início do experimento .

\begin{tabular}{|c|c|c|c|c|c|c|c|c|}
\hline \multicolumn{3}{|c|}{ Controle } & \multicolumn{3}{|c|}{ Cromo } & \multicolumn{3}{|c|}{ Cobre } \\
\hline \multirow{2}{*}{$\begin{array}{l}\text { Espécies } \\
\text { Asterococcus sp. }\end{array}$} & \multicolumn{2}{|c|}{ Ind/mL \% } & \multirow{2}{*}{\begin{tabular}{|l} 
Espécies \\
Chlorella sp.
\end{tabular}} & \multicolumn{2}{|c|}{ Ind/mL \% } & \multirow{2}{*}{$\begin{array}{l}\text { Espécies } \\
\text { Monoraphydium } \\
\text { circinale }\end{array}$} & \multicolumn{2}{|c|}{ Ind/mL \% } \\
\hline & 42,4 & 6,5 & & 67,9 & 37,5 & & 22,6 & 1,5 \\
\hline $\begin{array}{l}\text { Chlamydomonas } \\
\text { sp. }\end{array}$ & 14,1 & 2,2 & cryptomonas sp. & 22,6 & 12,5 & Mallomonas $s p$ & 113,2 & 7,5 \\
\hline $\begin{array}{l}\text { coelastrum } \\
\text { reticulatum }\end{array}$ & 14,1 & 2,2 & Didimocystis fina & 34,0 & 18,8 & Chlorella sp & 407,4 & 26,9 \\
\hline Coenocloris $s p$ & 198,1 & 30,4 & $\begin{array}{l}\text { Monoraphydium } \\
\text { circinale }\end{array}$ & 11,3 & 6,3 & Coenocloris sp & 543,2 & 35,8 \\
\hline cryptomonas sp & 28,3 & 4,3 & $\begin{array}{l}\text { Sphaerocystis } \\
\text { schoeterie }\end{array}$ & 45,3 & 25,0 & $\begin{array}{l}\text { Dictyosphaerium } \\
\text { pulchellum }\end{array}$ & 90,5 & 6,0 \\
\hline Didimocystis fina & 28,3 & 4,3 & & & & peridinium $s p$ & 22,6 & 1,5 \\
\hline $\begin{array}{l}\text { Elakatotrix } \\
\text { gelatinosa }\end{array}$ & 56,6 & 8,7 & & & & $\begin{array}{l}\text { Coelastrum } \\
\text { reticulatum }\end{array}$ & 203,7 & 13,4 \\
\hline $\begin{array}{l}\text { Eutetramorus } \\
\text { fottii }\end{array}$ & 14,1 & 2,2 & & & & Oocystis sp. & 22,6 & 1,5 \\
\hline Mallomonas sp. & 14,1 & 2,2 & & & & Carteria sp. & 22,6 & 1,5 \\
\hline $\begin{array}{l}\text { Monoraphydium } \\
\text { circinale }\end{array}$ & 42,4 & 6,5 & & & & Quadrigula sp. & 22,6 & 1,5 \\
\hline Peridinium sp. & 14,1 & 2,2 & & & & $\begin{array}{l}\text { Monoraphydium } \\
\text { kormakovae }\end{array}$ & 22,6 & 1,5 \\
\hline Quadrigula sp. & 84,9 & 13,0 & & & & $\begin{array}{l}\text { Trachelomonas } \\
\text { volvocina }\end{array}$ & 22,6 & 1,5 \\
\hline Radiococcus sp & 42,4 & 6,5 & & & & & & \\
\hline $\begin{array}{l}\text { Staurastrum cf. } \\
\text { incus }\end{array}$ & 28,3 & & & & & & & \\
\hline $\begin{array}{l}\text { Trachelomonas } \\
\text { volvocina }\end{array}$ & 28,3 & & & & & & & \\
\hline Total & 650,8 & 100,0 & 0 & 181,1 & 100,0 & & 1516,6 & 100,0 \\
\hline
\end{tabular}


Tabela 16: Análise quantitativa da comunidade fitoplanctônica dos experimentos realizados em microcosmos em dezembro de 2001, 168 horas após o início do experimento .

\begin{tabular}{|c|c|c|c|c|c|c|c|c|}
\hline \multicolumn{3}{|c|}{ Controle } & \multicolumn{3}{|c|}{ Cromo } & \multicolumn{3}{|c|}{ Cobre } \\
\hline Espécies & Ind/mL & & Espécies & Ind/mL & & Espécies & Ind/mL & \\
\hline Chlorella sp. & 67,9 & 2,3 & $\begin{array}{l}\text { Dictyosphaerium } \\
\text { pulchellum }\end{array}$ & 90,5 & 22,2 & Radiococcus sp. & 271,6 & 23,1 \\
\hline $\begin{array}{l}\text { Coelastrum } \\
\text { reticulatum }\end{array}$ & 22,6 & 0,8 & $\begin{array}{l}\text { Chlamydomonas } \\
\text { sp. }\end{array}$ & 22,6 & 5,6 & Coenocloris sp. & 565,9 & 48,1 \\
\hline Coenocloris sp. & 56,6 & 2,0 & Chlorella sp. & 90,5 & 22,2 & $\begin{array}{l}\text { Coelastrum } \\
\text { reticulatum }\end{array}$ & 22,6 & 1,9 \\
\hline Didimocystis fina & 22,6 & 0,8 & $\begin{array}{l}\text { Coelastrum } \\
\text { reticulatum }\end{array}$ & 22,6 & 5,6 & Peridinium sp. & 22,6 & 1,9 \\
\hline $\begin{array}{l}\text { Elakatothrix } \\
\text { gelatinosa }\end{array}$ & 11,3 & 0,4 & Coenocloris sp. & 67,9 & 16,7 & Oocystis sp. & 67,9 & 5,8 \\
\hline $\begin{array}{l}\text { Monoraphydium } \\
\text { circinale }\end{array}$ & 2410,7 & 83,2 & Cryptomonas sp & 22,6 & 5,6 & Chlorella sp. & 67,9 & 5,8 \\
\hline $\begin{array}{l}\text { Oocystis } \\
\text { lacustres }\end{array}$ & 56,6 & 2,0 & Didimocystis fina & 67,9 & 16,7 & $\begin{array}{l}\text { Micractinium } \\
\text { pussilum }\end{array}$ & 90,5 & 7,7 \\
\hline Peridinium sp. & 11,3 & 0,4 & $\begin{array}{l}\text { Monoraphydium } \\
\text { circinale }\end{array}$ & 22,6 & 5,6 & $\begin{array}{l}\text { Chlamydomonas } \\
\text { sp }\end{array}$ & 22,6 & 1,9 \\
\hline Quadrigula sp. & 22,6 & 0,8 & & & & Cryptomonas sp & 22,6 & 1,9 \\
\hline Radiococcus sp. & 181,1 & 6,3 & & & & Mallomonas sp. & 22,6 & 1,9 \\
\hline Synedra sp. & 11,3 & 0,4 & & & & & & \\
\hline $\begin{array}{l}\text { Tetrastrum } \\
\text { heteracanthum }\end{array}$ & 11,3 & 0,4 & & & & & & \\
\hline $\begin{array}{l}\text { Trachelomonas } \\
\text { volvocina }\end{array}$ & 11,3 & 0,4 & & & & & & \\
\hline Total & 2897,3 & 100,0 & Total & 407,4 & 100,0 & Total & 1177,0 & 100,0 \\
\hline
\end{tabular}


Tabela 17: Matriz de correlação de Pearson entre pH, material em suspensão total, orgânico e inorgânico, silicato, nitrato, nitrito, amônio, nitrogênio total, ortofosfato dissolvido, fósforo total dissolvido, fósforo total e clorofila utilizando-se os valores determinados no controle e no experimento com $\mathrm{Cr}$ em todas as datas (primeira linha: r; segunda linha:p).

\begin{tabular}{|c|c|c|c|c|c|c|c|c|c|c|c|c|c|}
\hline & $\mathrm{pH}$ & MST & MSO & $\mathrm{MSI}$ & Silicato & Nitrato & Nitrito & Amônio & NT & Ortofosfato & PTD & PT & Clorofila \\
\hline \multirow[t]{2}{*}{ MST } & 0,421 & & & & & & & & & & & & \\
\hline & 0,082 & & & & & & & & & & & & \\
\hline \multirow[t]{2}{*}{ MSO } & 0,837 & 0,681 & & & & & & & & & & & \\
\hline & 0 & 0,002 & & & & & & & & & & & \\
\hline \multirow[t]{2}{*}{$\mathrm{MSI}$} & $-0,348$ & 0,6 & $-0,177$ & & & & & & & & & & \\
\hline & 0,157 & 0,008 & 0,483 & & & & & & & & & & \\
\hline \multirow[t]{2}{*}{ Silicato } & 0,146 & 0,431 & 0,42 & 0,121 & & & & & & & & & \\
\hline & 0,563 & 0,074 & 0,083 & 0,632 & & & & & & & & & \\
\hline \multirow[t]{2}{*}{ Nitrato } & 0,142 & $\begin{array}{l}-0,22 \\
\end{array}$ & 0,018 & $-0,315$ & 0,093 & & & & & & & & \\
\hline & 0,573 & 0,38 & 0,944 & 0,202 & 0,714 & & & & & & & & \\
\hline \multirow[t]{2}{*}{ Nitrito } & $-0,483$ & $-0,495$ & $-0,518$ & $-0,1$ & $-0,049$ & 0,425 & & & & & & & \\
\hline & 0,042 & 0,037 & 0,028 & 0,694 & 0,845 & 0,079 & & & & & & & \\
\hline \multirow[t]{2}{*}{ Amônio } & $-0,42$ & 0,02 & $-0,199$ & 0,245 & 0,113 & 0,147 & 0,067 & & & & & & \\
\hline & 0,083 & 0,936 & 0,428 & 0,327 & 0,654 & 0,56 & 0,793 & & & & & & \\
\hline \multirow[t]{2}{*}{ NT } & $-0,201$ & $-0,245$ & $-0,163$ & $-0,152$ & $-0,486$ & $-0,437$ & $-0,031$ & 0,038 & & & & & \\
\hline & 0,424 & 0,327 & 0,518 & 0,548 & 0,041 & 0,07 & 0,902 & 0,88 & & & & & \\
\hline \multirow[t]{2}{*}{ Ortofosfato } & 0,432 & 0,455 & 0,386 & 0,19 & 0,442 & 0,337 & $-0,058$ & $-0,16$ & $-0,434$ & & & & \\
\hline & 0,073 & 0,058 & 0,114 & 0,45 & 0,067 & 0,171 & 0,82 & 0,527 & 0,072 & & & & \\
\hline \multirow[t]{2}{*}{ PTD } & 0,465 & 0,374 & 0,324 & 0,149 & 0,094 & $-0,16$ & $-0,233$ & $-0,511$ & $-0,16$ & 0,676 & & & \\
\hline & 0,052 & 0,126 & 0,189 & 0,556 & 0,712 & 0,525 & 0,353 & 0,03 & 0,527 & 0,002 & & & \\
\hline \multirow[t]{2}{*}{ PT } & 0,464 & 0,372 & 0,42 & 0,041 & $-0,438$ & $-0,384$ & $-0,473$ & $-0,44$ & 0,407 & $-0,175$ & 0,173 & & \\
\hline & 0,052 & 0,129 & 0,083 & 0,872 & 0,069 & 0,116 & 0,047 & 0,068 & 0,093 & 0,488 & 0,493 & & \\
\hline \multirow[t]{2}{*}{ Clorofila } & 0,561 & 0,368 & 0,6 & $-0,16$ & 0,374 & 0,026 & $-0,026$ & $-0,05$ & $-0,196$ & 0,365 & 0,227 & 0,066 & \\
\hline & 0,015 & 0,132 & 0,008 & 0,525 & 0,126 & 0,919 & 0,918 & 0,843 & 0,437 & 0,136 & 0,366 & 0,796 & \\
\hline \multirow[t]{2}{*}{$\mathrm{Cr}$} & $-0,155$ & $-0,201$ & $-0,221$ & $-0,029$ & $-0,497$ & 0,049 & $-0,204$ & $-0,026$ & 0,198 & $-0,148$ & 0,07 & 0,124 & $-0,808$ \\
\hline & 0,539 & 0,424 & 0,379 & 0,908 & 0,036 & 0,846 & 0,417 & 0,919 & 0,431 & 0,557 & 0,782 & 0,623 & 0 \\
\hline
\end{tabular}


Tabela 18: Matriz de correlação de Pearson entre pH, material em suspensão total, orgânico e inorgânico, silicato, nitrato, nitrito, amônio, nitrogênio total, ortofosfato dissolvido, fósforo total dissolvido, fósforo total e clorofila utilizando-se os valores determinados no controle e no experimento com Cu em todas as datas (primeira linha: $r$; segunda linha:p).

\begin{tabular}{|c|c|c|c|c|c|c|c|c|c|c|c|c|c|}
\hline & $\mathrm{pH}$ & MST & MSO & $\mathrm{MSI}$ & Silicato & Nitrato & Nitrito & Amônio & NT & Ortofosfato & PTD & $\overline{P T}$ & Clorofila \\
\hline \multirow[t]{2}{*}{ MST } & 0,474 & & & & & & & & & & & & \\
\hline & 0,047 & & & & & & & & & & & & \\
\hline \multirow[t]{2}{*}{ MSO } & 0,763 & 0,686 & & & & & & & & & & & \\
\hline & 0 & 0,002 & & & & & & & & & & & \\
\hline \multirow[t]{2}{*}{$\mathrm{MSI}$} & $-0,227$ & 0,567 & $-0,21$ & & & & & & & & & & \\
\hline & 0,366 & 0,014 & 0,404 & & & & & & & & & & \\
\hline \multirow[t]{2}{*}{ Silicato } & 0,341 & 0,389 & 0,604 & $-0,16$ & & & & & & & & & \\
\hline & 0,166 & 0,11 & 0,008 & 0,526 & & & & & & & & & \\
\hline \multirow[t]{2}{*}{ Nitrato } & 0,195 & $-0,172$ & 0,113 & $-0,359$ & 0,09 & & & & & & & & \\
\hline & 0,439 & 0,495 & 0,655 & 0,143 & 0,724 & & & & & & & & \\
\hline \multirow[t]{2}{*}{ Nitrito } & 0,18 & 0,577 & 0,113 & 0,647 & 0,098 & $-0,048$ & & & & & & & \\
\hline & 0,474 & 0,012 & 0,654 & 0,004 & 0,699 & 0,851 & & & & & & & \\
\hline \multirow[t]{2}{*}{ Amônio } & $-0,429$ & 0,061 & $-0,105$ & 0,202 & $-0,072$ & 0,207 & 0,071 & & & & & & \\
\hline & 0,075 & 0,81 & 0,677 & 0,423 & 0,777 & 0,41 & 0,78 & & & & & & \\
\hline \multirow[t]{2}{*}{ NT } & $-0,646$ & $-0,271$ & $-0,41$ & 0,1 & $-0,48$ & $-0,128$ & $-0,217$ & 0,503 & & & & & \\
\hline & 0,004 & 0,276 & 0,091 & 0,694 & 0,044 & 0,613 & 0,388 & 0,034 & & & & & \\
\hline \multirow[t]{2}{*}{ Ortofosfato } & 0,61 & 0,354 & 0,384 & 0,042 & 0,375 & 0,575 & 0,299 & $-0,003$ & $-0,542$ & & & & \\
\hline & 0,007 & 0,149 & 0,116 & 0,869 & 0,125 & 0,0013 & 0,227 & 0,905 & 0,02 & & & & \\
\hline \multirow[t]{2}{*}{ PTD } & 0,443 & 0,081 & 0,059 & 0,042 & 0,074 & 0,244 & 0,333 & $-0,151$ & $-0,478$ & 0,461 & & & \\
\hline & 0,066 & 0,749 & 0,817 & 0,868 & 0,771 & 0,329 & 0,177 & 0,55 & 0,045 & 0,054 & & & \\
\hline \multirow[t]{2}{*}{$\mathrm{PT}$} & 0,274 & 0,583 & 0,484 & 0,236 & 0,111 & $-0,331$ & $-0,039$ & $-0,255$ & $-0,128$ & $-0,187$ & $-0,043$ & & \\
\hline & 0,271 & 0,011 & 0,042 & 0,345 & 0,662 & 0,18 & 0,878 & 0,308 & 0,612 & 0,456 & 0,866 & & \\
\hline \multirow[t]{2}{*}{ Clorofila } & 0,479 & 0,26 & 0,504 & $-0,22$ & 0,085 & 0,193 & $-0,22$ & $-0,061$ & 0,055 & 0,341 & $-0,183$ & 0,181 & \\
\hline & 0,044 & 0,297 & 0,033 & 0,379 & 0,737 & 0,442 & 0,381 & 0,811 & 0,828 & 0,166 & 0,468 & 0,472 & \\
\hline \multirow[t]{2}{*}{$\mathrm{Cu}$} & $-0,24$ & $-0,519$ & $-0,291$ & $-0,368$ & $-0,224$ & $-0,121$ & $-0,336$ & 0,112 & $-0,011$ & $-0,363$ & 0,224 & $-0,176$ & $-0,382$ \\
\hline & 0,337 & 0,027 & 0,242 & 0,133 & 0,372 & 0,631 & 0,173 & 0,658 & 0,967 & 0,139 & 0,371 & 0,484 & 0,118 \\
\hline
\end{tabular}


Tabela 19: Comparação entre os índices calculados para o controle e os experimentos com $\mathrm{Cr}$ e $\mathrm{Cu}$, considerando a comunidade zooplanctônica total através de análise de variância (ANOVA).

\begin{tabular}{lccc|ccc}
\hline \hline & \multicolumn{3}{c|}{ CxCr } & \multicolumn{3}{c}{ CxCu } \\
\cline { 2 - 7 } & $F$ & valor-P & F crítico & $F$ & valor-P & F crítico \\
\cline { 2 - 7 } Shannon H' Log Base 2. & 207,68 & 0,000 & 7,71 & 11,36 & 0,028 & 7,71 \\
Shannon J' (Uniformidade & 66,25 & 0,001 & 7,71 & 2,18 & 0,214 & 7,71 \\
$\begin{array}{l}\text { de Pielou) } \\
\text { Índice de Simpson (D) }\end{array}$ & 92,75 & 0,001 & 7,71 & 1,00 & 0,373 & 7,71 \\
(Dominância de Simpson) & & & & & & \\
N & 1,16 & 0,343 & 7,71 & 20,82 & 0,010 & 7,71 \\
S & 0,21 & 0,670 & 7,71 & 0,18 & 0,696 & 7,71 \\
\hline \hline
\end{tabular}

Tabela 20: Comparação entre os índices calculados para o controle e os experimentos com $\mathrm{Cr}$ e $\mathrm{Cu}$, considerando a comunidade de microcrustáceos através de análise de variância (ANOVA).

\begin{tabular}{lrrr|rrr}
\hline \hline & \multicolumn{3}{c}{ CxCr } & \multicolumn{3}{c}{ CxCu } \\
\cline { 2 - 8 } & \multicolumn{1}{c}{ valor-P } & F crítico & \multicolumn{1}{c}{$F$} & valor-P & F crítico \\
\cline { 2 - 8 } Shannon H' Log Base 2. & 0,115 & 0,751 & 7,709 & 0,370 & 0,576 & 7,709 \\
Shannon J' (Uniformidade & 0,110 & 0,757 & 7,709 & 0,104 & 0,763 & 7,709 \\
$\begin{array}{l}\text { de Pielou) } \\
\text { Índice de Simpson (D) }\end{array}$ & 0,693 & 0,452 & 7,709 & 0,139 & 0,728 & 7,709 \\
$\begin{array}{l}\text { (Dominância de Simpson) } \\
\text { N }\end{array}$ & 4,012 & 0,116 & 7,709 & 5,909 & 0,072 & 7,709 \\
S & 3,571 & 0,132 & 7,709 & 1,125 & 0,349 & 7,709 \\
\hline \hline
\end{tabular}

Tabela 21: Comparação entre os índices calculados para o controle e os experimentos com $\mathrm{Cr}$ e $\mathrm{Cu}$, considerando a comunidade de rotíferos através de análise de variância (ANOVA).

\begin{tabular}{lrrr|rrr}
\hline \hline & \multicolumn{3}{c|}{ CxCr } & \multicolumn{3}{c}{ CxCu } \\
\cline { 2 - 8 } & \multicolumn{1}{c}{ valor-P } & F crítico & \multicolumn{1}{c}{$F$} & valor-P & F crítico \\
\cline { 2 - 8 } Shannon H' Log Base 2. & 42,631 & 0,003 & 7,709 & 7,197 & 0,055 & 7,709 \\
Shannon J' (Uniformidade & 75,748 & 0,001 & 7,709 & 0,548 & 0,500 & 7,709 \\
de Pielou) & & & & & & \\
Índice de Simpson (D) & 54,850 & 0,002 & 7,709 & 0,472 & 0,530 & 7,709 \\
$\begin{array}{l}\text { (Dominância de Simpson) } \\
\text { N }\end{array}$ & 3,011 & 0,158 & 7,709 & 20,077 & 0,011 & 7,709 \\
S & 0,286 & 0,621 & 7,709 & 1,441 & 0,296 & 7,709 \\
\hline \hline
\end{tabular}

Tabela 22: Comparação entre os índices calculados para o controle e os experimentos com $\mathrm{Cr}$ e $\mathrm{Cu}$, para a comunidade de fitoplâncton através de análise de variância (ANOVA).

\begin{tabular}{lrrr|rrr}
\hline \hline & \multicolumn{3}{c|}{ CxCr } & \multicolumn{3}{c}{ CxCu } \\
\cline { 2 - 7 } & \multicolumn{1}{c}{ valor-P } & F crítico & \multicolumn{1}{c}{$F$} & valor-P & F crítico \\
\cline { 2 - 7 } DT & 2,22 & 0,16 & 4,60 & 0,244 & 0,629 & 4,600 \\
R & 6,31 & 0,02 & 4,60 & 2,220 & 0,158 & 4,600 \\
H $^{\prime}$ & 0,19 & 0,67 & 4,60 & 1,494 & 0,242 & 4,600 \\
U $^{\prime}$ & 2,59 & 0,13 & 4,60 & 2,727 & 0,121 & 4,600 \\
D' $^{\prime}$ & 1,98 & 0,18 & 4,60 & 1,348 & 0,265 & 4,600 \\
\hline \hline
\end{tabular}


Tabela 23: Comparação dos valores obtidos para as análises químicas e físico químicas entre as réplicas para todas as datas através de análise de variância (ANOVA).

\begin{tabular}{|c|c|c|c|c|}
\hline & & $F$ & valor- $P$ & F crítico \\
\hline & Controle & 0,053 & 0,949 & 3,354 \\
\hline \multirow[t]{3}{*}{$\mathrm{pH}$} & Cromo & 0,354 & 0,705 & 3,354 \\
\hline & Cobre & 0,384 & 0,685 & 3,354 \\
\hline & Controle & 0,519 & 0,612 & 4,256 \\
\hline \multirow[t]{3}{*}{ MST } & Cromo & 0,411 & 0,680 & 5,143 \\
\hline & Cobre & 0,156 & 0,859 & 5,143 \\
\hline & Controle & 0,106 & 0,901 & 4,256 \\
\hline \multirow[t]{3}{*}{ MO } & Cromo & 0,009 & 0,991 & 5,143 \\
\hline & Cobre & 1,019 & 0,416 & 5,143 \\
\hline & Controle & 0,822 & 0,470 & 4,256 \\
\hline \multirow[t]{3}{*}{ MI } & Cromo & 0,636 & 0,562 & 5,143 \\
\hline & Cobre & 2,108 & 0,203 & 5,143 \\
\hline & Controle & 0,401 & 0,686 & 5,143 \\
\hline \multirow[t]{3}{*}{ PO4 } & Cromo & 3,166 & 0,115 & 5,143 \\
\hline & Cobre & 1,764 & 0,250 & 5,143 \\
\hline & Controle & 1,159 & 0,375 & 5,143 \\
\hline \multirow[t]{3}{*}{ PTD } & Cromo & 2,626 & 0,152 & 5,143 \\
\hline & Cobre & 0,842 & 0,476 & 5,143 \\
\hline & Controle & 1,098 & 0,392 & 5,143 \\
\hline \multirow[t]{3}{*}{ PT } & Cromo & 0,071 & 0,933 & 5,143 \\
\hline & Cobre & 1,657 & 0,267 & 5,143 \\
\hline & Controle & 0,889 & 0,459 & 5,143 \\
\hline \multirow[t]{3}{*}{$\mathrm{NH} 4$} & Cromo & 0,221 & 0,808 & 5,143 \\
\hline & Cobre & 0,766 & 0,506 & 5,143 \\
\hline & Controle & 2,165 & 0,196 & 5,143 \\
\hline \multirow[t]{3}{*}{ NO3 2- } & Cromo & 3,886 & 0,083 & 5,143 \\
\hline & Cobre & 2,327 & 0,179 & 5,143 \\
\hline & Controle & 3,225 & 0,112 & 5,143 \\
\hline \multirow[t]{3}{*}{ No3- } & Cromo & 0,061 & 0,941 & 5,143 \\
\hline & Cobre & 1,036 & 0,411 & 5,143 \\
\hline & Controle & 0,406 & 0,683 & 5,143 \\
\hline \multirow[t]{3}{*}{ NT } & Cromo & 0,727 & 0,521 & 5,143 \\
\hline & Cobre & 0,012 & 0,988 & 5,143 \\
\hline & Controle & 0,359 & 0,712 & 5,143 \\
\hline \multirow[t]{3}{*}{ Silicato } & Cromo & 0,878 & 0,463 & 5,143 \\
\hline & Cobre & 0,533 & 0,612 & 5,143 \\
\hline & Controle & 0,361 & 0,711 & 5,143 \\
\hline \multirow[t]{2}{*}{ Clorofila } & Cromo & 0,168 & 0,849 & 5,143 \\
\hline & Cobre & 2,400 & 0,171 & 5,143 \\
\hline Cromo & Cromo & 0,595 & 0,561 & 3,467 \\
\hline \multirow[t]{2}{*}{ Cobre } & Cobre & 1,032 & 0,372 & 3,403 \\
\hline & Controle & 0,201 & 0,819 & 3,467 \\
\hline
\end{tabular}




\section{Experimentos em Mesocosmos (1)}

Tabela 24: Concentrações de oxigênio dissolvido $\left(\mathrm{mg}_{\mathrm{L}} \mathrm{L}^{-1}\right)$ determinados na água coleta em cada unidade experimental

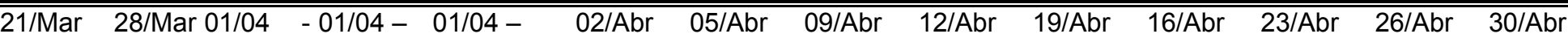

Oh $\quad 2$ hs $\quad 4$ hs

\begin{tabular}{|c|c|c|c|c|c|c|c|c|c|c|c|c|c|c|}
\hline Controle 1 & 6,5 & 7,2 & 5,9 & 8,7 & 8,6 & 8,6 & 6,9 & 7,1 & 6,3 & 5,6 & 6,6 & 6,4 & 6,2 & 7,5 \\
\hline Controle 2 & 3,9 & 3,9 & 4,9 & 5,3 & 5,5 & 5,6 & 5,1 & 4,8 & 4,5 & 5,1 & 4,5 & 5,6 & 4,7 & 4,6 \\
\hline Controle 3 & 7,2 & 5,8 & 5,5 & 6,1 & 6,0 & 6,7 & 5,2 & 6,1 & 5,8 & 4,2 & 4,9 & 5,5 & 5,4 & 6,1 \\
\hline Média & 5,9 & 5,6 & 5,5 & 6,7 & 6,7 & 7,0 & 5,7 & 6,0 & 5,5 & 5,0 & 5,3 & 5,8 & 5,4 & $\overline{6,1}$ \\
\hline Desvio Padrão & 1,7 & 1,7 & 0,5 & 1,8 & 1,7 & 1,5 & 1,0 & 1,2 & 0,9 & 0,7 & 1,1 & 0,5 & 0,8 & $\overline{1,4}$ \\
\hline Cromo 1 & 5,1 & 4,9 & 4,6 & 5,1 & 5,7 & 4,5 & 3,6 & 3,2 & 3,2 & 2,7 & 3,0 & 4,6 & 4,1 & $\overline{4,9}$ \\
\hline Cromo 2 & 6,3 & 5,1 & 5,0 & 5,5 & 5,8 & 5,6 & 3,8 & 2,4 & 2,2 & 2,8 & 3,1 & 3,6 & 3,1 & 4,1 \\
\hline Cromo3 & 6,1 & 6,1 & 4,9 & 6,5 & 6,2 & 6,2 & 3,7 & 3,4 & 3,5 & 4,0 & 3,6 & 3,9 & 3,6 & 3,9 \\
\hline Média & 5,8 & 5,4 & 4,8 & 5,7 & 5,9 & 5,4 & 3,7 & 3,0 & 2,9 & 3,2 & 3,2 & 4,0 & 3,6 & 4,3 \\
\hline Desvio Padrão & 0,6 & 0,7 & 0,2 & 0,7 & 0,2 & 0,9 & 0,1 & 0,5 & 0,7 & 0,7 & 0,3 & 0,5 & 0,5 & 0,5 \\
\hline Cobre 1 & 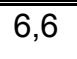 & 5,8 & 5,2 & 5,6 & 5,9 & 5,9 & 4,7 & 4,4 & 4,0 & 5,0 & 4,6 & 4,9 & 5,3 & $\overline{6,0}$ \\
\hline Cobre 2 & 5,7 & 5,6 & 5,0 & 6,4 & 5,8 & 6,3 & 5,8 & 5,4 & 6,1 & 4,6 & 6,3 & 6,1 & 6,3 & 6,3 \\
\hline Cobre 3 & 6,3 & 6,4 & 5,8 & 7,0 & 7,0 & 6,7 & 5,4 & 6,2 & 6,4 & 6,4 & 6,5 & 5,8 & 5,8 & 6,1 \\
\hline Média & 6,2 & 5,9 & 5,4 & 6,3 & 6,3 & 6,3 & 5,3 & 5,3 & 5,5 & 5,3 & 5,8 & 5,6 & 5,8 & $\overline{6,1}$ \\
\hline Desvio Padrão & 0,5 & 0,4 & 0,4 & 0,7 & 0,6 & 0,4 & 0,5 & 0,9 & 1,3 & 0,9 & 1,0 & 0,6 & 0,5 & $\overline{0,1}$ \\
\hline
\end{tabular}


Tabela 25: Valores de condutividade determinados na água coleta em cada unidade experimental

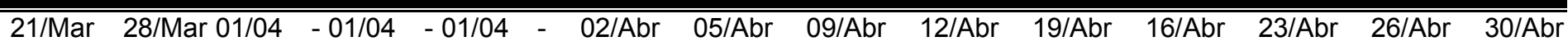

Oh $\quad 2$ hs $\quad 4 \mathrm{hs}$

\begin{tabular}{|c|c|c|c|c|c|c|c|c|c|c|c|c|c|c|}
\hline Controle 1 & 18,0 & 15,0 & 15,0 & 16,0 & 16,0 & 16,0 & 15,0 & 13,0 & 12,0 & 10,0 & 10,0 & 9,0 & 9,0 & 9,0 \\
\hline Controle 2 & 15,0 & 13,0 & 9,0 & 9,0 & 9,0 & 9,0 & 9,0 & 8,0 & 8,0 & 8,0 & 8,0 & 8,0 & 7,0 & 8,0 \\
\hline Controle 3 & 10,0 & 8,0 & 8,0 & 8,0 & 8,0 & 8,0 & 8,0 & 8,0 & 8,0 & 8,0 & 8,0 & 7,0 & 7,0 & 7,0 \\
\hline Média & 14,3 & 12,0 & 10,7 & 11,0 & 11,0 & 11,0 & 10,7 & 9,7 & 9,3 & 8,7 & 8,7 & 8,0 & 7,7 & 8,0 \\
\hline Desvio Padrão & 4,0 & 3,6 & 3,8 & 4,4 & 4,4 & 4,4 & 3,8 & 2,9 & 2,3 & 1,2 & 1,2 & 1,0 & 1,2 & 1,0 \\
\hline Cromo 1 & 14,0 & 15,0 & 13,0 & 13,0 & 13,0 & 14,0 & 15,0 & 15,0 & 14,0 & 15,0 & 14,0 & 13,0 & 13,0 & $\overline{16,0}$ \\
\hline Cromo 2 & 13,0 & 1,0 & 12,0 & 13,0 & 12,0 & 13,0 & 13,0 & 13,0 & 13,0 & 13,0 & 12,0 & 11,0 & 11,0 & 10,0 \\
\hline Cromo3 & 9,0 & 9,0 & 10,0 & 10,0 & 10,0 & 10,0 & 10,0 & 10,0 & 11,0 & 10,0 & 11,0 & 10,0 & 10,0 & 10,0 \\
\hline Média & 12,0 & 8,3 & 11,7 & 12,0 & 11,7 & 12,3 & 12,7 & 12,7 & 12,7 & 12,7 & 12,3 & 11,3 & 11,3 & 12,0 \\
\hline Desvio Padrão & 2,6 & 7,0 & 1,5 & 1,7 & 1,5 & 2,1 & 2,5 & 2,5 & 1,5 & 2,5 & 1,5 & 1,5 & 1,5 & 3,5 \\
\hline Cobre 1 & 11,0 & 10,0 & 10,0 & 10,0 & 10,0 & 10,0 & 10,0 & 10,0 & 10,0 & 9,0 & 9,0 & 9,0 & 9,0 & $\overline{9,0}$ \\
\hline Cobre 2 & 11,0 & 10,0 & 9,0 & 9,0 & 9,0 & 9,0 & 9,0 & 8,0 & 8,0 & 8,0 & 8,0 & 8,0 & 8,0 & 8,0 \\
\hline Cobre 3 & 8,0 & 8,0 & 7,0 & 7,0 & 8,0 & 7,0 & 7,0 & 7,0 & 7,0 & 6,0 & 6,0 & 6,0 & 6,0 & 6,0 \\
\hline Média & 10,0 & 9,3 & 8,7 & 8,7 & 9,0 & 8,7 & 8,7 & 8,3 & 8,3 & 7,7 & 7,7 & 7,7 & 7,7 & 7,7 \\
\hline Desvio Padrão & 1,7 & 1,2 & 1,5 & 1,5 & 1,0 & 1,5 & 1,5 & 1,5 & 1,5 & 1,5 & 1,5 & 1,5 & 1,5 & 1,5 \\
\hline
\end{tabular}


Tabela 26: Valores de $\mathrm{pH}$ determinados na água coleta em cada unidade experimental

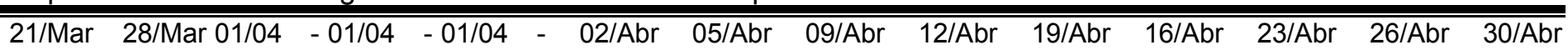
Oh $\quad 2 \mathrm{hs} \quad 4 \mathrm{hs}$

\begin{tabular}{|c|c|c|c|c|c|c|c|c|c|c|c|c|c|c|}
\hline Controle 1 & 6,8 & 7,6 & 7,5 & 7,8 & 8,3 & 8,5 & 7,8 & 7,6 & 7,7 & 6,9 & 7,5 & 7,6 & 7,0 & 7,7 \\
\hline Controle 2 & 6,6 & 7,1 & 6,0 & 6,4 & 6,7 & 7,2 & 6,3 & 6,5 & 6,3 & 6,2 & 6,6 & 6,8 & 6,2 & 7,7 \\
\hline Controle 3 & 6,7 & 6,8 & 5,2 & 6,3 & 6,6 & 6,5 & 6,0 & 6,0 & 5,1 & 5,4 & 6,1 & 6,6 & 5,4 & 6,9 \\
\hline Média & 6,7 & 7,2 & 6,2 & 6,8 & 7,2 & 7,4 & 6,7 & 6,7 & 6,4 & 6,2 & 6,7 & 7,0 & 6,2 & $\overline{7,4}$ \\
\hline Desvio Padrão & 0,1 & 0,4 & 1,2 & 0,8 & 1,0 & 1,0 & 1,0 & 0,8 & 1,3 & 0,8 & 0,7 & 0,5 & 0,8 & $\overline{0,5}$ \\
\hline Cromo 1 & 7,3 & 7,7 & 6,5 & 6,0 & 7,1 & 6,8 & 6,7 & 6,5 & 6,1 & 6,8 & 6,6 & 6,3 & $\overline{6,7}$ & $\overline{7,3}$ \\
\hline Cromo 2 & 6,8 & 6,8 & 5,7 & 6,0 & 6,3 & 6,9 & 5,7 & 5,7 & 5,7 & 5,3 & 6,1 & 6,7 & 5,6 & 7,0 \\
\hline Cromo3 & 6,6 & 6,8 & 5,2 & 5,8 & 5,9 & 6,7 & 5,6 & 5,7 & 5,0 & 5,3 & 6,7 & 6,7 & 5,7 & 6,8 \\
\hline Média & 6,9 & 7,1 & 5,8 & 5,9 & 6,4 & 6,8 & 6,0 & 6,0 & 5,6 & 5,8 & 6,4 & 6,5 & 6,0 & 7,0 \\
\hline Desvio Padrão & 0,4 & 0,5 & 0,7 & 0,1 & 0,6 & 0,1 & 0,6 & 0,5 & 0,5 & 0,8 & 0,3 & 0,2 & 0,6 & 0,3 \\
\hline Cobre 1 & 6,5 & 7,0 & 5,9 & 6,0 & 6,4 & 6,7 & 6,1 & 5,7 & 5,8 & 5,6 & 6,3 & 6,8 & 5,9 & $\overline{7,1}$ \\
\hline Cobre 2 & 6,4 & 6,7 & 5,5 & 5,9 & 6,0 & 6,6 & 5,7 & 5,8 & 5,4 & 5,4 & 6,5 & 6,9 & 5,9 & 7,0 \\
\hline Cobre 3 & 6,6 & 6,7 & 5,2 & 6,1 & 6,4 & 6,8 & 5,7 & 6,5 & 5,9 & 6,3 & 7,6 & 6,8 & 5,5 & 7,1 \\
\hline Média & 6,5 & 6,8 & 5,5 & 6,0 & 6,2 & 6,7 & 5,8 & 6,0 & 5,7 & 5,8 & 6,8 & 6,8 & 5,8 & 7,1 \\
\hline Desvio Padrão & 0,1 & 0,2 & 0,4 & 0,1 & 0,2 & 0,1 & 0,2 & 0,4 & 0,3 & 0,4 & 0,7 & 0,1 & 0,2 & 0,1 \\
\hline
\end{tabular}


Tabela 27: Valores de temperatura $\left({ }^{\circ} \mathrm{C}\right)$ determinados na água coleta em cada unidade experimental

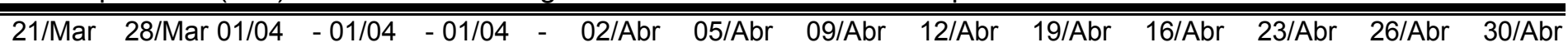
Oh $\quad 2$ hs $\quad 4$ hs

\begin{tabular}{|c|c|c|c|c|c|c|c|c|c|c|c|c|c|c|}
\hline Controle 1 & 27,2 & 25,4 & 25,4 & 25,9 & 27,3 & 25,6 & 26,5 & 26,2 & 25 & 26,8 & 26,2 & 25,7 & 24,4 & 24,4 \\
\hline Controle 2 & 27,2 & 25,7 & 25,5 & 26,5 & 26,6 & 25,6 & 26,4 & 26,3 & 25 & 26,8 & 26,2 & 25,8 & 24,5 & 24,5 \\
\hline Controle 3 & 27,7 & 25,8 & 25,5 & 26,6 & 27,3 & 25,6 & 26,6 & 26,5 & 25,1 & 27,4 & 26,3 & 25,8 & 24,6 & 24,7 \\
\hline Média & 27,4 & 25,6 & 25,5 & 26,3 & 27,1 & 25,6 & 26,5 & 26,3 & 25,0 & 27,0 & 26,2 & 25,8 & 24,5 & 24,5 \\
\hline Desvio Padrão & 0,3 & 0,2 & 0,1 & 0,4 & 0,4 & 0,0 & 0,1 & 0,2 & 0,1 & 0,3 & 0,1 & 0,1 & 0,1 & 0,2 \\
\hline$\overline{\text { Cromo } 1}$ & 27,0 & 25,5 & 25,5 & 26,3 & 27,3 & 25,6 & 26,3 & 26,0 & 24,9 & 26,8 & 26,1 & 25,6 & 24,5 & 24,3 \\
\hline Cromo 2 & 28,0 & 25,6 & 25,5 & 26,8 & 27,2 & 25,7 & 26,4 & 26,6 & 25,1 & 27,2 & 26,3 & 25,8 & 24,6 & 24,6 \\
\hline Cromo3 & 27,7 & 25,8 & 25,5 & 26,7 & 27,2 & 25,7 & 26,6 & 26,5 & 25,1 & 27,3 & 26,3 & 26,0 & 24,6 & 24,8 \\
\hline Média & 27,6 & 25,6 & 25,5 & 26,6 & 27,2 & 25,7 & 26,4 & 26,4 & 25,0 & 27,1 & 26,2 & 25,8 & 24,6 & 24,6 \\
\hline Desvio Padrão & 0,5 & 0,2 & 0,0 & 0,3 & 0,1 & 0,1 & 0,2 & 0,3 & 0,1 & 0,3 & 0,1 & 0,2 & 0,1 & 0,3 \\
\hline Cobre 1 & 27,1 & 25,5 & 25,5 & 26,5 & 27,1 & 25,7 & 26,5 & 26,4 & 24,9 & 27,3 & 26,2 & 25,7 & 24,5 & 24,5 \\
\hline Cobre 2 & 27,9 & 25,9 & 25,5 & 26,7 & 26,9 & 25,6 & 26,5 & 26,5 & 25,0 & 27,5 & 26,3 & 25,8 & 24,6 & 24,6 \\
\hline Cobre 3 & 27,7 & 25,8 & 25,5 & 26,6 & 27,3 & 25,6 & 26,6 & 26,5 & 25,1 & 27,4 & 26,3 & 25,8 & 24,6 & 24,7 \\
\hline Média & 27,6 & 25,7 & 25,5 & 26,6 & 27,1 & 25,6 & 26,5 & 26,5 & 25,0 & 27,4 & 26,3 & 25,8 & 24,6 & 24,6 \\
\hline Desvio Padrão & 0,4 & 0,2 & 0,0 & 0,1 & 0,2 & 0,1 & 0,1 & 0,1 & 0,1 & 0,1 & 0,1 & 0,1 & 0,1 & 0,1 \\
\hline
\end{tabular}


Tabela 28: Valores de clorofila $\left(\mathrm{mg} \cdot \mathrm{L}^{-1}\right)$ determinados na água coleta em cada unidade experimental

\begin{tabular}{lrrrrrrrrrrr}
\hline \hline & 21/Mar & 28/Mar & 02/Abr & 05/Abr & 09/Abr & 12/Abr & 19/Abr & 16/Abr & 23/Abr & 26/Abr & 30/Abr \\
\hline \hline Controle 1 & 39,3 & 67,8 & 97,1 & 36,8 & 56,4 & 36,8 & 70,3 & 29,0 & 27,3 & 33,5 & 39,3 \\
Controle 2 & 11,7 & 5,9 & 14,2 & 7,8 & 6,7 & 10,0 & 8,4 & 12,6 & 6,7 & 16,7 & 12,6 \\
Controle 3 & 19,3 & 21,8 & 25,1 & 22,9 & 3,9 & 12,8 & 13,4 & 18,4 & 6,7 & 5,0 & 10,0 \\
\hline Média & 14,3 & 32,2 & 45,0 & 14,5 & 29,5 & 14,7 & 34,4 & 8,3 & 11,9 & 14,3 & 16,2 \\
\hline Desvio Padrão & 23,4 & 31,8 & 45,5 & 22,5 & 22,3 & 19,9 & 30,7 & 20,0 & 13,6 & 18,4 & 20,6 \\
\hline \hline Cromo 1 & 18,4 & 9,2 & 1,7 & 1,1 & 7,5 & 1,7 & 5,0 & 7,5 & 10,9 & 9,2 & 12,6 \\
Cromo 2 & 14,2 & 10,9 & 3,3 & 1,1 & 18,4 & 2,5 & 5,9 & 8,4 & 5,9 & 6,7 & 5,9 \\
Cromo3 & 15,9 & 10,0 & 1,7 & 0,6 & 13,4 & 2,5 & 12,6 & 9,2 & 7,5 & 4,2 & 5,0 \\
\hline Média & 16,2 & 10,0 & 2,2 & 0,9 & 13,1 & 2,2 & 7,8 & 8,4 & 8,1 & 6,7 & 7,8 \\
\hline Desvio Padrão & 1,1 & 0,5 & 0,9 & 0,3 & 3,0 & 0,2 & 3,4 & 0,5 & 1,2 & 1,4 & 1,4 \\
\hline \hline Cobre 1 & 7,5 & 13,4 & 4,2 & 2,2 & 38,5 & 4,2 & 1,7 & 6,7 & 4,2 & 9,2 & 12,6 \\
Cobre 2 & 9,2 & 10,0 & 1,7 & 5,6 & 1,7 & 10,9 & 9,2 & 10,9 & 14,2 & 14,2 & 13,4 \\
Cobre 3 & 18,4 & 24,3 & 14,2 & 16,2 & 2,2 & 32,9 & 44,4 & 8,9 & 9,5 & 28,5 & 13,4 \\
\hline Média & 11,7 & 15,9 & 6,7 & 8,0 & 14,1 & 16,0 & 18,4 & 8,8 & 9,3 & 17,3 & 13,1 \\
\hline Desvio Padrão & 4,8 & 7,2 & 6,3 & 5,6 & 7,0 & 11,5 & 18,2 & 1,2 & 2,8 & 7,5 & 0,2 \\
\hline \hline
\end{tabular}


Tabela 29: Valores de material em suspensão total $\left(\mathrm{mg}_{\mathrm{L}} \mathrm{L}^{-1}\right)$ determinados na água coleta em cada unidade experimental

\begin{tabular}{lrrrrrrrrrrr}
\hline & 21/Mar & 28/Mar & 02/Abr & 05/Abr & 09/Abr & 12/Abr & 19/Abr & 16/Abr & 23/Abr & 26/Abr & $30 / \mathrm{Abr}$ \\
\hline \hline Controle 1 & 6,0 & 2,4 & 12,6 & 13,1 & 10,0 & 12,0 & 2,7 & 6,3 & 2,3 & 3,5 & 5,5 \\
Controle 2 & 3,6 & 2,4 & 5,4 & 3,3 & 2,5 & 2,6 & 1,6 & 1,3 & 0,1 & 0,2 & 1,8 \\
Controle 3 & 5,7 & 5,0 & 5,7 & 6,0 & 7,7 & 5,0 & 5,3 & 3,6 & 1,3 & 0,7 & 1,9 \\
\hline Média & 5,1 & 3,2 & 7,9 & 7,5 & 6,7 & 6,5 & 3,2 & 3,7 & 1,2 & 1,5 & 3,1 \\
\hline Desvio Padrão & 1,1 & 1,2 & 3,3 & 4,1 & 3,2 & 4,0 & 1,5 & 2,1 & 0,9 & 1,5 & 1,7 \\
\hline \hline Cromo 1 & 4,6 & 2,8 & 2,1 & 1,7 & 1,3 & 1,7 & 1,1 & 0,7 & 1,5 & 0,9 & 1,9 \\
Cromo 2 & 4,2 & 2,6 & 2,8 & 2,8 & 3,0 & 2,8 & 1,5 & 2,3 & 1,6 & 0,0 & 0,6 \\
Cromo3 & 4,5 & 4,1 & 2,6 & 1,6 & 1,5 & 0,7 & 1,1 & 1,0 & 1,8 & 0,0 & 0,3 \\
\hline Média & 4,4 & 3,2 & 2,5 & 2,1 & 1,9 & 1,7 & 1,2 & 1,3 & 1,6 & 0,3 & 0,9 \\
\hline Desvio Padrão & 0,2 & 0,7 & 0,3 & 0,6 & 0,7 & 0,8 & 0,2 & 0,7 & 0,1 & 0,4 & 0,7 \\
\hline \hline Cobre 1 & 2,3 & 3,1 & 2,8 & 2,4 & 1,8 & 1,8 & 0,3 & 0,7 & 1,4 & 0,1 & 0,8 \\
Cobre 2 & 2,2 & 2,8 & 3,0 & 2,2 & 2,6 & 3,4 & 1,5 & 1,8 & 2,2 & 0,8 & 1,9 \\
Cobre 3 & 5,0 & 6,0 & 6,7 & 7,9 & 15,1 & 8,4 & 2,2 & 8,6 & 2,7 & 3,6 & 5,6 \\
\hline Média & 3,2 & 3,9 & 4,2 & 4,2 & 6,5 & 4,5 & 1,3 & 3,7 & 2,1 & 1,5 & 2,8 \\
\hline Desvio Padrão & 1,3 & 1,4 & 1,8 & 2,6 & 6,1 & 2,8 & 0,8 & 3,5 & 0,5 & 1,5 & 2,1 \\
\hline \hline
\end{tabular}


Tabela 30: Valores de material em suspensão orgânico $\left(\mathrm{mg}^{\mathrm{L}} \mathrm{L}^{-1}\right)$ determinados na água coleta em cada unidade experimental

\begin{tabular}{lrrrrrrrrrrr}
\hline \hline & $21 / \mathrm{Mar}$ & 28/Mar & 02/Abr & 05/Abr & 09/Abr & $12 / \mathrm{Abr}$ & $19 / \mathrm{Abr}$ & $16 / \mathrm{Abr}$ & $23 / \mathrm{Abr}$ & $26 / \mathrm{Abr}$ & $30 / \mathrm{Abr}$ \\
\hline \hline Controle 1 & 6,0 & 2,4 & 12,6 & 13,1 & 10,0 & 11,8 & 2,7 & 4,8 & 2,3 & 3,5 & 5,5 \\
Controle 2 & 3,3 & 2,3 & 3,8 & 3,2 & 2,4 & 2,3 & 1,6 & 1,2 & 0,1 & 0,2 & 1,8 \\
Controle 3 & 5,0 & 4,9 & 5,5 & 6,0 & 7,0 & 4,6 & 5,3 & 2,4 & 1,3 & 0,7 & 1,9 \\
\hline Média & 4,8 & 3,2 & 7,3 & 7,4 & 6,4 & 6,2 & 3,2 & 2,8 & 1,2 & 1,5 & 3,1 \\
\hline Desvio Padrão & 1,1 & 1,2 & 3,8 & 4,1 & 3,1 & 4,0 & 1,5 & 1,5 & 0,9 & 1,5 & 1,7 \\
\hline \hline Cromo 1 & 4,5 & 2,8 & 2,1 & 1,7 & 1,3 & 1,7 & 1,1 & 0,7 & 1,2 & 0,9 & 1,9 \\
Cromo 2 & 3,6 & 2,6 & 2,2 & 2,3 & 2,3 & 1,9 & 1,5 & 1,4 & 1,6 & 0,0 & 0,6 \\
Cromo 3 & 3,1 & 4,1 & 2,6 & 1,6 & 1,5 & 0,7 & 1,1 & 1,0 & 1,8 & 0,0 & 0,3 \\
\hline Média & 3,7 & 3,2 & 2,3 & 1,9 & 1,7 & 1,4 & 1,2 & 1,0 & 1,5 & 0,3 & 0,9 \\
\hline Desvio Padrão & 0,6 & 0,7 & 0,2 & 0,3 & 0,4 & 0,5 & 0,2 & 0,3 & 0,2 & 0,4 & 0,7 \\
\hline \hline Cobre 1 & 2,3 & 3,1 & 2,8 & 2,2 & 1,8 & 1,6 & 0,3 & 0,7 & 1,4 & 0,1 & 0,8 \\
Cobre 2 & 2,2 & 2,7 & 2,6 & 2,2 & 2,6 & 3,0 & 1,5 & 0,8 & 1,9 & 0,8 & 1,9 \\
Cobre 3 & 3,1 & 5,3 & 6,5 & 6,9 & 13,6 & 8,4 & 0,8 & 6,8 & 2,6 & 3,6 & 5,6 \\
\hline Média & 2,5 & 3,7 & 4,0 & 3,8 & 6,0 & 4,3 & 0,8 & 2,8 & 2,0 & 1,5 & 2,8 \\
\hline Desvio Padrão & 0,4 & 1,1 & 1,8 & 2,2 & 5,4 & 3,0 & 0,5 & 2,9 & 0,5 & 1,5 & 2,1 \\
\hline
\end{tabular}


Tabela 31: Valores de material em suspensão inorgânico $\left(m g \cdot \mathrm{L}^{-1}\right)$ determinados na água coleta em cada unidade experimental

\begin{tabular}{lccccccccccc}
\hline & $21 / \mathrm{Mar}$ & $28 / \mathrm{Mar}$ & 02/Abr & 05/Abr & 09/Abr & 12/Abr & 19/Abr & 16/Abr & 23/Abr & 26/Abr & $30 / \mathrm{Abr}$ \\
\hline \hline Controle 1 & 0,3 & 0,0 & 1,6 & 0,1 & 0,1 & 0,3 & 0,0 & 0,1 & 0,0 & 0,0 & 0,0 \\
Controle 2 & 0,7 & 0,1 & 0,2 & 0,1 & 0,8 & 0,5 & 0,0 & 1,1 & 0,0 & 0,0 & 0,0 \\
Controle 3 & 0,3 & 0,1 & 0,6 & 0,1 & 0,3 & 0,3 & 0,0 & 0,9 & 0,0 & 0,0 & 0,0 \\
\hline Média & 0,2 & 0,1 & 0,7 & 0,0 & 0,4 & 0,1 & 0,0 & 0,5 & 0,0 & 0,0 & 0,0 \\
\hline Desvio Padrão & 0,1 & 0,0 & 0,0 & 0,0 & 0,0 & 0,0 & 0,0 & 0,0 & 0,3 & 0,0 & 0,0 \\
\hline \hline Cromo 1 & 0,6 & 0,0 & 0,6 & 0,5 & 0,7 & 0,9 & 0,0 & 0,9 & 0,0 & 0,0 & 0,0 \\
Cromo 2 & 1,4 & 0,0 & 0,0 & 0,0 & 0,0 & 0,0 & 0,0 & 0,0 & 0,0 & 0,0 & 0,0 \\
Cromo3 & 0,7 & 0,0 & 0,2 & 0,2 & 0,2 & 0,3 & 0,0 & 0,3 & 0,1 & 0,0 & 0,0 \\
\hline Média & 0,4 & 0,0 & 0,3 & 0,3 & 0,3 & 0,5 & 0,0 & 0,5 & 0,1 & 0,0 & 0,0 \\
\hline Desvio Padrão & 0,0 & 0,0 & 0,0 & 0,2 & 0,0 & 0,2 & 0,0 & 0,0 & 0,1 & 0,0 & 0,0 \\
\hline \hline Cobre 1 & 0,0 & 0,1 & 0,4 & 0,0 & 0,0 & 0,4 & 0,0 & 0,9 & 0,3 & 0,0 & 0,0 \\
Cobre 2 & 1,9 & 0,7 & 0,2 & 1,0 & 1,5 & 0,0 & 1,4 & 1,8 & 0,0 & 0,0 & 0,0 \\
Cobre 3 & 0,6 & 0,3 & 0,2 & 0,4 & 0,5 & 0,2 & 0,5 & 0,9 & 0,1 & 0,0 & 0,0 \\
\hline Média & 1,0 & 0,3 & 0,1 & 0,5 & 0,8 & 0,2 & 0,7 & 0,5 & 0,1 & 0,0 & 0,0 \\
\hline Desvio Padrão & 0,4 & 1,1 & 1,8 & 2,2 & 5,4 & 3,0 & 0,5 & 2,9 & 0,5 & 1,5 & 2,1 \\
\hline \hline
\end{tabular}


Tabela 32: Concentrações de silicatos dissolvidos $\left(\mathrm{mg}_{\mathrm{L}} \mathrm{L}^{-1}\right)$ determinados na água coleta em cada unidade experimental

\begin{tabular}{lrrrrrrrrrrr}
\hline \hline & 21/Mar & 28/Mar & 02/Abr & 05/Abr & 09/Abr & 12/Abr & 19/Abr & 16/Abr & 23/Abr & 26/Abr & 30/Abr \\
\hline \hline Controle 1 & 4,39 & 5,51 & 3,74 & 5,27 & 5,62 & 3,72 & 3,53 & 5,62 & 2,57 & 3,83 & 7,06 \\
Controle 2 & 2,62 & 3,97 & 3,18 & 3,13 & 2,75 & 2,99 & 3,13 & 2,78 & 2,45 & 3,78 & 2,46 \\
Controle 3 & 3,27 & 1,99 & 2,95 & 1,64 & 1,58 & 2,68 & 1,75 & 1,90 & 1,82 & 2,18 & 1,83 \\
\hline Média & 3,43 & 3,83 & 3,29 & 3,35 & 3,32 & 3,13 & 2,80 & 3,43 & 2,28 & 3,26 & 3,78 \\
\hline Desvio Padrão & 0,89 & 1,76 & 0,41 & 1,82 & 2,08 & 0,54 & 0,94 & 1,94 & 0,40 & 0,94 & 2,85 \\
\hline \hline Cromo 1 & 5,75 & 4,78 & 3,84 & 3,34 & 4,68 & 3,78 & 4,12 & 4,21 & 2,41 & 5,00 & 7,08 \\
Cromo 2 & 5,48 & 3,77 & 3,59 & 3,26 & 4,60 & 3,35 & 2,58 & 3,91 & 4,42 & 3,22 & 4,21 \\
Cromo3 & 4,67 & 3,51 & 3,43 & 2,93 & 2,95 & 3,45 & 2,62 & 3,60 & 2,41 & 3,80 & 3,63 \\
\hline Média & 5,30 & 4,02 & 3,62 & 3,18 & 4,08 & 3,53 & 3,11 & 3,91 & 3,08 & 4,01 & 4,97 \\
\hline Desvio Padrão & 0,56 & 0,67 & 0,21 & 0,22 & 0,98 & 0,23 & 0,88 & 0,30 & 1,16 & 0,91 & 1,84 \\
\hline \hline Cobre 1 & 4,71 & 5,55 & 3,63 & 3,27 & 3,42 & 3,10 & 3,18 & 2,95 & 2,26 & 4,31 & 3,71 \\
Cobre 2 & 4,57 & 3,25 & 3,58 & 8,30 & 3,09 & 3,26 & 2,69 & 3,92 & 2,36 & 3,31 & 3,64 \\
Cobre 3 & 3,20 & 2,11 & 2,70 & 1,98 & 1,91 & 3,05 & 2,00 & 3,00 & 2,13 & 2,14 & 2,76 \\
\hline Média & 4,16 & 3,64 & 3,30 & 4,52 & 2,80 & 3,14 & 2,62 & 3,29 & 2,25 & 3,25 & 3,37 \\
\hline Desvio Padrão & 0,83 & 1,75 & 0,53 & 3,33 & 0,79 & 0,11 & 0,59 & 0,54 & 0,11 & 1,09 & 0,53 \\
\hline \hline
\end{tabular}


Tabela 33: Concentrações de nitrato $\left(\mu \mathrm{g} \cdot \mathrm{L}^{-1}\right)$ determinados na água coleta em cada unidade experimental

\begin{tabular}{lrrrrrrrrrrr}
\hline \hline & 21/Mar & 28/Mar & 02/Abr & 05/Abr & 09/Abr & 12/Abr & 19/Abr & 16/Abr & 23/Abr & 26/Abr & $30 / \mathrm{Abr}$ \\
\hline Controle 1 & 9,6 & 11,2 & 17,6 & 24,1 & 20,4 & 17,4 & 22,8 & 11,0 & 8,7 & 33,0 & 7,5 \\
Controle 2 & 10,7 & 15,0 & 22,4 & 9,1 & 17,2 & 16,9 & 5,9 & 14,7 & 8,0 & 13,0 & 23,1 \\
Controle 3 & 15,9 & 52,5 & 23,1 & 11,5 & 55,8 & 24,7 & 16,6 & 14,5 & 13,8 & 31,4 & 18,8 \\
\hline Média & 12,1 & 26,2 & 21,1 & 14,9 & 31,2 & 19,7 & 15,1 & 13,4 & 10,1 & 25,8 & 16,5 \\
\hline Desvio Padrão & 3,4 & 22,8 & 3,0 & 8,1 & 21,4 & 4,4 & 8,5 & 2,1 & 3,2 & 11,1 & 8,1 \\
\hline \hline Cromo 1 & 12,1 & 26,2 & 21,1 & 14,9 & 31,2 & 19,7 & 15,1 & 13,4 & 10,1 & 25,8 & 16,5 \\
Cromo 2 & 22,7 & 13,2 & 56,5 & 22,8 & 41,9 & 15,0 & 33,3 & 17,8 & 7,1 & 20,0 & 15,6 \\
Cromo3 & 9,4 & 12,6 & 26,9 & 9,1 & 27,7 & 24,9 & 31,4 & 24,2 & 6,1 & 32,6 & 16,8 \\
\hline Média & 40,3 & 14,2 & 18,5 & 9,6 & 27,7 & 20,6 & 17,7 & 26,4 & 12,1 & 41,3 & 17,1 \\
\hline Desvio Padrão & 24,1 & 13,3 & 34,0 & 13,8 & 32,4 & 20,2 & 27,5 & 22,8 & 8,5 & 31,3 & 16,5 \\
\hline \hline Cobre 1 & 15,5 & 0,8 & 20,0 & 7,8 & 8,2 & 4,9 & 8,5 & 4,5 & 3,2 & 10,7 & 0,8 \\
Cobre 2 & 10,8 & 16,3 & 18,9 & 7,5 & 25,6 & 14,3 & 71,5 & 53,7 & 3,9 & 23,7 & 15,7 \\
Cobre 3 & 15,2 & 16,6 & 26,2 & 10,8 & 32,8 & 100,6 & 48,7 & 12,0 & 4,2 & 21,7 & 15,8 \\
\hline Média & 21,3 & 15,4 & 18,5 & 12,7 & 59,5 & 24,0 & 14,1 & 18,0 & 11,2 & 20,7 & 14,4 \\
\hline Desvio Padrão & 15,8 & 16,1 & 21,2 & 10,3 & 39,3 & 46,3 & 44,8 & 27,9 & 6,5 & 22,0 & 15,3 \\
\hline \hline
\end{tabular}


Tabela 34: Concentrações de nitrito $\left(\mu \mathrm{g} \cdot \mathrm{L}^{-1}\right)$ determinados na água coleta em cada unidade experimental

\begin{tabular}{lccccccccccc}
\hline \hline & 21/Mar & 28/Mar & 02/Abr & 05/Abr & 09/Abr & $12 / \mathrm{Abr}$ & $19 / \mathrm{Abr}$ & $16 / \mathrm{Abr}$ & 23/Abr & 26/Abr & 30/Abr \\
\hline \hline Controle 1 & 3,60 & 1,01 & 2,09 & 0,78 & 1,36 & 2,43 & 1,19 & 3,26 & 1,47 & 1,44 & 1,67 \\
Controle 2 & 1,32 & 3,02 & 3,03 & 1,85 & 2,62 & 3,34 & 1,87 & 2,27 & 1,87 & 1,61 & 3,99 \\
Controle 3 & 1,74 & 0,79 & 1,09 & 1,56 & 0,85 & 1,24 & 1,16 & 1,54 & 1,29 & 2,34 & 2,54 \\
\hline Média & 2,22 & 1,61 & 2,07 & 1,39 & 1,61 & 2,34 & 1,40 & 2,36 & 1,54 & 1,80 & 2,73 \\
\hline Desvio Padrão & 1,22 & 1,23 & 0,97 & 0,55 & 0,91 & 1,05 & 0,40 & 0,86 & 0,30 & 0,48 & 1,17 \\
\hline \hline Cromo 1 & 1,53 & 1,14 & 2,59 & 1,36 & 1,30 & 2,75 & 1,31 & 1,35 & 1,33 & 1,52 & 0,89 \\
Cromo 2 & 1,83 & 2,33 & 3,09 & 1,02 & 0,64 & 1,80 & 0,95 & 1,22 & 1,11 & 1,45 & 1,61 \\
Cromo3 & 2,68 & 1,15 & 2,54 & 0,86 & 0,70 & 3,80 & 1,18 & 1,56 & 0,97 & 1,57 & 1,52 \\
\hline Média & 2,01 & 1,54 & 2,74 & 1,08 & 0,88 & 2,78 & 1,15 & 1,38 & 1,14 & 1,51 & 1,34 \\
\hline Desvio Padrão & 0,60 & 0,69 & 0,30 & 0,26 & 0,36 & 1,00 & 0,18 & 0,17 & 0,18 & 0,06 & 0,39 \\
\hline \hline Cobre 1 & 0,69 & 0,76 & 3,17 & 2,01 & 1,99 & 2,61 & 2,15 & 2,96 & 1,95 & 2,17 & 2,31 \\
Cobre 2 & 1,28 & 2,27 & 3,44 & 1,48 & 1,39 & 2,44 & 1,67 & 2,24 & 1,74 & 2,62 & 2,29 \\
Cobre 3 & 1,33 & 1,46 & 1,98 & 0,78 & 0,35 & 1,20 & 0,79 & 2,64 & 2,94 & 0,81 & 2,36 \\
\hline Média & 1,10 & 1,50 & 2,87 & 1,42 & 1,24 & 2,08 & 1,54 & 2,62 & 2,21 & 1,87 & 2,32 \\
\hline Desvio Padrão & 0,36 & 0,75 & 0,77 & 0,62 & 0,83 & 0,77 & 0,69 & 0,36 & 0,64 & 0,94 & 0,04 \\
\hline \hline
\end{tabular}


Tabela 35: Concentrações de amônia $\left(\mu \mathrm{g} \cdot \mathrm{L}^{-1}\right)$ determinados na água coleta em cada unidade experimental

\begin{tabular}{lrrrrrrrrrrr}
\hline \hline & 21/Mar & 28/Mar & 02/Abr & 05/Abr & 09/Abr & 12/Abr & 19/Abr & 16/Abr & 23/Abr & 26/Abr & $30 / \mathrm{Abr}$ \\
\hline Controle 1 & 53,8 & 2,3 & 2,9 & 5,1 & 12,7 & 6,0 & 55,6 & 10,7 & 16,7 & 3,5 & 4,0 \\
Controle 2 & 11,0 & 27,1 & 20,5 & 5,6 & 16,0 & 6,1 & 35,4 & 32,6 & 17,7 & 4,8 & 81,3 \\
Controle 3 & 8,3 & 1,7 & 1,8 & 63,8 & 24,2 & 6,7 & 41,2 & 12,3 & 36,5 & 10,9 & 9,8 \\
\hline Média & 24,3 & 10,4 & 8,4 & 24,8 & 17,6 & 6,2 & 44,0 & 18,5 & 23,7 & 6,4 & 31,7 \\
\hline Desvio Padrão & 25,5 & 14,5 & 10,5 & 33,8 & 5,9 & 0,4 & 10,4 & 12,2 & 11,1 & 3,9 & 43,0 \\
\hline \hline Cromo 1 & 54,2 & 14,1 & 120,2 & 103,2 & 71,8 & 39,7 & 57,4 & 49,1 & 34,0 & 40,1 & 12,0 \\
Cromo 2 & 7,5 & 4,2 & 30,2 & 29,0 & 16,9 & 17,4 & 47,7 & 10,3 & 15,2 & 2,7 & 57,7 \\
Cromo 3 & 57,2 & 2,3 & 15,0 & 22,2 & 17,8 & 39,6 & 48,5 & 11,6 & 19,2 & 11,4 & 11,3 \\
\hline Média & 39,6 & 6,9 & 55,1 & 51,4 & 35,5 & 32,2 & 51,2 & 23,7 & 22,8 & 18,1 & 27,0 \\
\hline Desvio Padrão & 27,9 & 6,3 & 56,8 & 44,9 & 31,5 & 12,9 & 5,4 & 22,0 & 9,9 & 19,5 & 26,6 \\
\hline \hline Cobre 1 & 6,3 & 6,7 & 5,5 & 4,5 & 4,1 & 10,9 & 49,4 & 22,9 & 37,0 & 34,3 & 12,2 \\
Cobre 2 & 11,2 & 0,3 & 4,3 & 9,1 & 41,5 & 3,7 & 38,6 & 18,3 & 48,8 & 7,2 & 8,3 \\
Cobre 3 & 8,1 & 4,5 & 17,8 & 10,0 & 3,7 & 1,9 & 19,8 & 21,6 & 33,1 & 15,6 & 11,6 \\
\hline Média & 8,5 & 3,8 & 9,2 & 7,8 & 16,4 & 5,5 & 35,9 & 20,9 & 39,6 & 19,0 & 10,7 \\
\hline Desvio Padrão & 2,5 & 3,2 & 7,5 & 2,9 & 21,7 & 4,8 & 15,0 & 2,4 & 8,1 & 13,9 & 2,1 \\
\hline \hline
\end{tabular}


Tabela 36: Concentrações de nitrogênio total $\left(\mathrm{mg} \cdot \mathrm{L}^{-1}\right)$ determinados na água coleta em cada unidade experimental

\begin{tabular}{lccccccccccc}
\hline \hline & 21/Mar & 28/Mar & 02/Abr & 05/Abr & 09/Abr & 12/Abr & 19/Abr & 16/Abr & 23/Abr & 26/Abr & 30/Abr \\
\hline \hline Controle 1 & 0,51 & 0,65 & 1,12 & 0,84 & 1,07 & 0,89 & 0,37 & 1,07 & 0,47 & 0,70 & 0,61 \\
Controle 2 & 0,37 & 0,37 & 0,89 & 0,33 & 1,03 & 0,84 & 0,09 & 0,65 & 0,33 & 0,84 & 0,37 \\
Controle 3 & 0,33 & 0,23 & 0,65 & 0,84 & 0,89 & 1,59 & 0,61 & 0,61 & 0,84 & 0,89 & 0,65 \\
\hline Média & 0,40 & 0,42 & 0,89 & 0,67 & 1,00 & 1,10 & 0,36 & 0,78 & 0,54 & 0,81 & 0,54 \\
\hline Desvio Padrão & 0,10 & 0,21 & 0,23 & 0,30 & 0,10 & 0,42 & 0,26 & 0,26 & 0,27 & 0,10 & 0,15 \\
\hline \hline Cromo 1 & 0,37 & 0,47 & 1,59 & 0,33 & 0,70 & 0,51 & 0,33 & 0,65 & 0,47 & 0,61 & 0,65 \\
Cromo 2 & 0,51 & 0,61 & 0,75 & 0,33 & 0,65 & 0,79 & 0,05 & 0,93 & 0,47 & 0,70 & 0,93 \\
Cromo3 & 0,33 & 0,28 & 0,89 & 1,17 & 0,89 & 0,61 & 0,19 & 1,21 & 0,56 & 1,12 & 0,79 \\
\hline Média & 0,40 & 0,45 & 1,07 & 0,61 & 0,75 & 0,64 & 0,19 & 0,93 & 0,50 & 0,81 & 0,79 \\
\hline Desvio Padrão & 0,10 & 0,16 & 0,45 & 0,48 & 0,12 & 0,14 & 0,14 & 0,28 & 0,05 & 0,27 & 0,14 \\
\hline \hline Cobre 1 & 0,61 & 0,23 & 0,56 & 0,37 & 1,07 & 0,65 & 0,09 & 0,98 & 0,56 & 0,33 & 0,61 \\
Cobre 2 & 0,28 & 0,23 & 0,42 & 0,37 & 0,70 & 1,82 & 0,14 & 0,70 & 0,33 & 0,47 & 0,61 \\
Cobre 3 & 0,61 & 0,47 & 0,84 & 0,56 & 0,70 & 1,17 & 0,33 & 0,70 & 0,51 & 0,98 & 0,61 \\
\hline Média & 0,50 & 0,31 & 0,61 & 0,44 & 0,82 & 1,21 & 0,19 & 0,79 & 0,47 & 0,59 & 0,61 \\
\hline Desvio Padrão & 0,19 & 0,13 & 0,21 & 0,11 & 0,22 & 0,58 & 0,12 & 0,16 & 0,12 & 0,34 & 0,00 \\
\hline \hline
\end{tabular}


Tabela 37: Concentrações de fosfato inorgânico $\left(\mu \mathrm{g} \cdot \mathrm{L}^{-1}\right)$ determinados na água coleta em cada unidade experimental

\begin{tabular}{lrrrrrrrrrrr}
\hline \hline & 21/Mar & 28/Mar & 02/Abr & 05/Abr & 09/Abr & $12 / \mathrm{Abr}$ & $19 / \mathrm{Abr}$ & $16 / \mathrm{Abr}$ & 23/Abr & 26/Abr & 30/Abr \\
\hline Controle 1 & 6,9 & 3,5 & 6,2 & 3,7 & 5,8 & 7,4 & 5,5 & 11,3 & 4,6 & 4,6 & 7,8 \\
Controle 2 & 4,5 & 5,3 & 8,1 & 5,5 & 8,2 & 8,2 & 6,8 & 8,7 & 7,2 & 4,9 & 4,9 \\
Controle 3 & 5,5 & 3,1 & 5,7 & 7,4 & 4,0 & 5,2 & 5,2 & 6,6 & 5,4 & 6,9 & 8,6 \\
\hline Média & 5,6 & 4,0 & 6,6 & 5,5 & 6,0 & 6,9 & 5,8 & 8,8 & 5,7 & 5,5 & 7,1 \\
\hline Desvio Padrão & 1,2 & 1,2 & 1,3 & 1,8 & 2,1 & 1,5 & 0,9 & 2,4 & 1,3 & 1,2 & 2,0 \\
\hline \hline Cromo 1 & 5,1 & 4,5 & 7,1 & 5,2 & 4,7 & 7,8 & 4,8 & 8,4 & 4,6 & 6,6 & 6,2 \\
Cromo 2 & 6,1 & 4,7 & 7,0 & 4,4 & 4,4 & 6,3 & 4,4 & 7,1 & 7,7 & 6,0 & 5,9 \\
Cromo3 & 4,9 & 3,2 & 8,7 & 5,3 & 6,5 & 8,9 & 3,9 & 4,8 & 2,7 & 4,6 & 6,3 \\
\hline Média & 5,4 & 4,2 & 7,6 & 5,0 & 5,2 & 7,7 & 4,4 & 6,8 & 5,0 & 5,7 & 6,1 \\
\hline Desvio Padrão & 0,7 & 0,8 & 1,0 & 0,5 & 1,1 & 1,3 & 0,4 & 1,8 & 2,5 & 1,0 & 0,2 \\
\hline \hline Cobre 1 & 5,5 & 3,5 & 7,7 & 4,9 & 6,2 & 7,5 & 6,2 & 8,5 & 6,0 & 5,6 & 6,6 \\
Cobre 2 & 1,9 & 5,8 & 9,2 & 12,6 & 6,8 & 6,1 & 4,8 & 6,4 & 6,4 & 5,2 & 6,4 \\
Cobre 3 & 17,6 & 4,6 & 5,8 & 4,7 & 4,1 & 6,3 & 4,9 & 5,6 & 10,3 & 3,6 & 10,3 \\
\hline Média & 8,3 & 4,6 & 7,6 & 7,4 & 5,7 & 6,6 & 5,3 & 6,8 & 7,6 & 4,8 & 7,7 \\
\hline Desvio Padrão & 8,2 & 1,1 & 1,7 & 4,5 & 1,4 & 0,8 & 0,8 & 1,5 & 2,4 & 1,1 & 2,2 \\
\hline \hline
\end{tabular}


Tabela 38: Concentrações de fósforo total dissolvido $\left(\mu \mathrm{g} \cdot \mathrm{L}^{-1}\right)$ determinados na água coleta em cada unidade experimental

\begin{tabular}{lrrrrrrrrrrr}
\hline \hline & 21/Mar & 28/Mar & 02/Abr & 05/Abr & 09/Abr & 12/Abr & 19/Abr & 16/Abr & 23/Abr & 26/Abr & 30/Abr \\
\hline \hline Controle 1 & 5,77 & 2,74 & 1,13 & 3,37 & 5,12 & 2,45 & 6,53 & 21,06 & 8,38 & 7,58 & 10,09 \\
Controle 2 & 3,05 & 4,65 & 4,49 & 3,89 & 6,24 & 3,07 & 7,71 & 14,02 & 10,92 & 8,86 & 5,79 \\
Controle 3 & 1,11 & 1,24 & 1,04 & 6,39 & 6,46 & 0,20 & 11,42 & 16,71 & 14,71 & 16,04 & 16,54 \\
\hline Média & 3,31 & 2,88 & 2,22 & 4,55 & 5,94 & 1,90 & 8,56 & 17,26 & 11,34 & 10,83 & 10,81 \\
\hline Desvio Padrão & 2,34 & 1,71 & 1,97 & 1,61 & 0,72 & 1,51 & 2,55 & 3,56 & 3,18 & 4,56 & 5,41 \\
\hline \hline Cromo 1 & 0,38 & 0,41 & 2,73 & 4,45 & 2,83 & 2,71 & 6,18 & 11,11 & 8,60 & 12,29 & 7,24 \\
Cromo 2 & 2,20 & 3,09 & 2,32 & 3,88 & 4,09 & 3,32 & 6,94 & 11,57 & 14,30 & 10,10 & 8,25 \\
Cromo3 & 2,20 & 1,22 & 2,91 & 5,92 & 4,14 & 6,17 & 7,26 & 10,64 & 10,89 & 9,63 & 8,29 \\
\hline Média & 1,59 & 1,57 & 2,65 & 4,75 & 3,69 & 4,07 & 6,79 & 11,11 & 11,26 & 10,67 & 7,93 \\
\hline Desvio Padrão & 1,05 & 1,37 & 0,30 & 1,05 & 0,74 & 1,85 & 0,56 & 0,47 & 2,87 & 1,42 & 0,59 \\
\hline \hline Cobre 1 & 0,63 & 0,61 & 3,16 & 4,76 & 4,48 & 2,51 & 7,56 & 13,32 & 11,52 & 9,92 & 8,92 \\
Cobre 2 & 0,73 & 1,65 & 4,44 & 12,39 & 8,72 & 1,58 & 7,67 & 12,48 & 11,91 & 6,95 & 6,90 \\
Cobre 3 & 8,51 & 1,76 & 1,19 & 6,40 & 2,72 & 1,82 & 7,41 & 10,96 & 18,25 & 9,75 & 10,25 \\
\hline Média & 3,29 & 1,34 & 2,93 & 7,85 & 5,31 & 1,97 & 7,54 & 12,26 & 13,90 & 8,87 & 8,69 \\
Desvio Padrão & 4,52 & 0,64 & 1,64 & 4,02 & 3,08 & 0,48 & 0,13 & 1,20 & 3,78 & 1,67 & 1,69 \\
\hline \hline
\end{tabular}


Tabela 39: Concentrações de fósforo total $\left(\mu \mathrm{g} \cdot \mathrm{L}^{-1}\right)$ determinados na água coleta em cada unidade experimental

\begin{tabular}{|c|c|c|c|c|c|c|c|c|c|c|c|}
\hline & 21/Mar & 28/Mar & 02/Abr & 05/Abr & 09/Abr & $12 / \mathrm{Abr}$ & 19/Abr & 16/Abr & 23/Abr & $26 / \mathrm{Abr}$ & $30 / \mathrm{Abr}$ \\
\hline Controle 1 & 29,87 & 39,84 & 28,92 & 36,87 & 32,90 & 21,52 & 34,95 & 25,69 & 28,30 & 27,59 & 39,66 \\
\hline Controle 2 & 31,71 & 27,23 & 24,23 & 25,57 & 25,69 & 10,88 & 28,36 & 17,80 & 35,72 & 31,53 & 27,82 \\
\hline Controle 3 & 48,77 & 40,91 & 34,41 & 37,50 & 41,92 & 13,02 & 42,81 & 30,26 & 43,04 & 37,23 & 39,54 \\
\hline Média & 36,78 & 35,99 & 29,19 & 33,31 & 33,50 & 15,14 & 35,37 & 24,58 & 35,69 & 32,12 & 35,68 \\
\hline Desvio Padrão & 10,42 & 7,61 & 5,10 & 6,71 & 8,13 & 5,63 & 7,23 & 6,30 & 7,37 & 4,85 & 6,80 \\
\hline Cromo 1 & 37,11 & 27,79 & 18,78 & 22,04 & 25,96 & 10,05 & 21,68 & 13,43 & 23,82 & 29,34 & 39,01 \\
\hline Cromo 2 & 32,01 & 27,71 & 19,07 & 26,96 & 25,78 & 14,29 & 30,67 & 17,32 & 17,56 & 19,84 & 31,68 \\
\hline Cromo3 & 35,12 & 28,74 & 18,69 & 23,28 & 25,57 & 10,47 & 26,93 & 14,21 & 35,45 & 24,35 & 41,24 \\
\hline Média & 34,75 & 28,08 & 18,84 & 24,10 & 25,77 & 11,60 & 26,43 & 14,99 & 25,61 & 24,51 & 37,31 \\
\hline Desvio Padrão & 2,57 & 0,58 & 0,20 & 2,56 & 0,19 & 2,34 & 4,52 & 2,06 & 9,08 & 4,75 & 5,00 \\
\hline Cobre 1 & 33,46 & 28,36 & 20,79 & 21,80 & 29,16 & 10,32 & 21,68 & 77,86 & 20,26 & 26,13 & $\overline{29,34}$ \\
\hline Cobre 2 & 28,36 & 29,72 & 19,75 & 24,71 & 22,01 & 9,31 & 25,39 & 13,94 & 38,95 & 21,65 & 31,33 \\
\hline Cobre 3 & 44,77 & 42,81 & 42,33 & 46,01 & 49,78 & 32,87 & 46,46 & 27,08 & 45,36 & 39,22 & 44,88 \\
\hline Média & 35,53 & 33,63 & 27,63 & 30,84 & 33,65 & 17,50 & 31,18 & 16,29 & 34,86 & 29,00 & 35,18 \\
\hline Desvio Padrão & 8,40 & 7,98 & 12,75 & 13,22 & 14,42 & 13,32 & 13,36 & 9,83 & 13,04 & 9,13 & 8,46 \\
\hline
\end{tabular}


Tabela 40: Concentrações de cobre $\left(\mu \mathrm{g} \cdot \mathrm{L}^{-1}\right)$ determinados na água coleta em cada unidade experimental

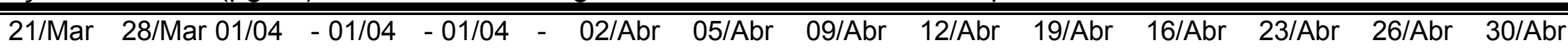
Oh $\quad 2$ hs $\quad 4$ hs

\begin{tabular}{lrrrrrrrrrrrrrr}
\hline Controle 1 & 12,9 & 19,3 & 9,2 & 6,6 & 10,9 & 10,3 & 8,1 & 7,4 & 7,8 & 8,3 & 8,2 & 5,8 & 7,0 & 4,1 \\
Controle 2 & 9,1 & 11,0 & 8,6 & 11,0 & 11,7 & 8,9 & 9,7 & 5,7 & 7,7 & 5,7 & 7,7 & 5,5 & 2,9 & 3,4 \\
Controle 3 & 16,9 & 7,3 & 7,6 & 3,6 & 11,9 & 10,3 & 10,5 & 9,0 & 9,5 & 6,9 & 8,3 & 3,8 & 2,7 & 2,9 \\
\hline Média & 13,0 & 12,5 & 8,5 & 7,1 & 11,5 & 9,8 & 9,4 & 7,4 & 8,3 & 7,0 & 8,0 & 5,0 & 4,2 & 3,5 \\
\hline Desvio Padrão & 3,9 & 6,2 & 0,8 & 3,7 & 0,5 & 0,8 & 1,2 & 1,7 & 1,0 & 1,3 & 0,3 & 1,1 & 2,4 & 0,6 \\
\hline \hline Cobre 1 & 5,8 & 4,4 & 6,3 & 13,6 & 17,8 & 15,5 & 13,5 & 6,3 & 9,3 & 11,2 & 6,8 & 4,1 & 19,6 & 4,9 \\
Cobre 2 & 6,1 & 2,5 & 2,9 & 15,8 & 20,6 & 14,4 & 11,0 & 7,0 & 3,1 & 4,6 & 8,3 & 3,0 & 6,8 & 2,3 \\
Cobre 3 & 9,6 & 4,7 & 3,2 & 17,2 & 24,7 & 18,0 & 14,5 & 5,9 & 6,6 & 9,7 & 8,4 & 4,7 & 5,0 & 5,5 \\
\hline Média & 7,2 & 3,9 & 4,2 & 15,5 & 21,0 & 16,0 & 13,0 & 6,4 & 6,3 & 8,5 & 7,8 & 3,9 & 10,5 & 4,2 \\
\hline Desvio Padrão & 2,1 & 1,2 & 1,9 & 1,8 & 3,5 & 1,8 & 1,8 & 0,6 & 3,1 & 3,5 & 0,9 & 0,9 & 7,9 & 1,7 \\
\hline \hline
\end{tabular}

Tabela 41: Concentrações de cromo $\left(\mu \mathrm{g} \cdot \mathrm{L}^{-1}\right)$ determinados na água coleta em cada unidade experimental

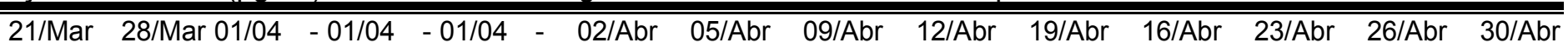
Oh $\quad 2 \mathrm{hs} \quad 4 \mathrm{hs}$

\begin{tabular}{|c|c|c|c|c|c|c|c|c|c|c|c|c|c|c|}
\hline Cromo 1 & ND & ND & ND & 44,9 & 40,2 & 32,2 & 18,1 & 7,7 & 2,0 & 2,8 & $3,8<\mathrm{LQ}$ & & $<L Q$ & 5,2 \\
\hline Cromo 2 & ND & ND & ND & 48,5 & 36,7 & 41,1 & 16,4 & 6,6 & $1,4<L Q$ & $<L Q$ & $<L Q$ & & $<L Q$ & $<L Q$ \\
\hline Cromo3 & ND & ND & ND & 50,1 & 45,6 & 42,4 & 29,5 & 19,8 & 14,9 & 6,6 & 7,5 & 2,6 & 2,4 & 1,9 \\
\hline Média & ND & ND & ND & 47,9 & 40,8 & 38,6 & 21,3 & 11,4 & 6,1 & 4,7 & 5,7 & 2,6 & 2,4 & 3,6 \\
\hline Desvio Padrão & ND & ND & ND & 2,7 & 4,5 & 5,6 & 7,2 & 7,3 & 7,6 & 2,7 & 2,6 & & & $\overline{2,3}$ \\
\hline
\end{tabular}


Tabela 42: Concentrações de $\mathrm{Cr}\left(\mathrm{mg}^{\mathrm{kg}}{ }^{-1}\right)$ determinadas na fração fracamente ligada do sedimento coletadas nos controles e nos tanques contaminados com cobre.

\begin{tabular}{lcccc}
\hline \hline & 21.03 & 09.04 & 19.04 & 30.04 \\
\hline \hline Controle 1 & 1,0 & ND & ND & ND \\
Controle 2 & 2,0 & ND & 0,4 & ND \\
Controle 3 & ND & ND & ND & ND \\
\hline Média & 1,5 & & 0,4 & \\
\hline Desvio Padrão & 1,0 & & & ND \\
\hline \hline Cromo 1 & 0,5 & ND & 1,3 & ND \\
Cromo 2 & 0,2 & ND & ND & \\
Cromo 3 & ND & ND & 1,2 & \\
\hline Média & 0,4 & & 1,3 & \\
\hline Desvio Padrão & 0,2 & & 0,1 & \\
\hline \hline
\end{tabular}

Tabela 43: Concentrações de $\mathrm{Cu}\left(\mathrm{mg} \cdot \mathrm{kg}^{-1}\right)$ determinadas na fração fracamente ligada do sedimento coletadas nos controles e nos tanques contaminados com cobre.

\begin{tabular}{lrrrr}
\hline \hline & 21.03 & 09.04 & 19.04 & 30.04 \\
\hline \hline Controle 1 & 14,9 & 14,2 & 14,0 & 13,0 \\
Controle 2 & 17,0 & 13,9 & 13,9 & 14,6 \\
Controle 3 & 11,8 & 14,3 & 11,4 & 11,1 \\
\hline Média & 14,6 & 14,1 & 13,1 & 12,9 \\
\hline Desvio Padrão & 2,6 & 0,2 & 1,5 & 1,8 \\
\hline \hline Cobre 1 & 10,8 & 13,0 & 13,8 & 14,1 \\
Cobre 2 & 11,9 & 13,7 & 13,2 & 14,1 \\
Cobre 3 & 9,6 & 10,9 & 11,4 & 10,2 \\
\hline Média & 10,8 & 12,5 & 12,8 & 12,8 \\
\hline Desvio Padrão & 1,2 & 1,5 & 1,2 & 2,3 \\
\hline \hline
\end{tabular}


Tabela 44: Concentrações totais de $\mathrm{Cr}\left(\mathrm{mg} \mathrm{kg}^{-1}\right)$ determinadas no sedimento coletado nos controles e nos tanques contaminados com cromo

\begin{tabular}{lcccc}
\hline \hline & 21.03 & 09.04 & 19.04 & 30.04 \\
\hline \hline Controle 1 & 37,2 & 33,3 & 8,6 & 28,5 \\
Controle 2 & 24,9 & 39,0 & 19,8 & 8,9 \\
Controle 3 & 28,3 & 39,4 & 8,5 & 22,9 \\
\hline Média & 30,1 & 37,2 & 12,3 & 20,1 \\
\hline Desvio Padrão & 6,4 & 3,4 & 6,5 & 10,1 \\
\hline \hline Cobre 1 & 22,9 & 36,4 & 15,7 & 36,8 \\
Cobre 2 & 37,2 & 26,1 & 13,3 & 39,3 \\
Cobre 3 & 14,7 & 42,4 & 48,0 & 42,2 \\
\hline Média & 24,9 & 35,0 & 25,7 & 39,4 \\
\hline Desvio Padrão & 11,4 & 8,2 & 19,4 & 2,7 \\
\hline \hline
\end{tabular}

Tabela 45: Concentrações totais de $\mathrm{Cu}\left(\mathrm{mg} \cdot \mathrm{k}^{-1}\right)$ determinadas no sedimento coletado nos controles e nos tanques contaminados com cobre.

\begin{tabular}{ccccc}
\hline \hline & 21.03 & 09.04 & 19.04 & 30.04 \\
\hline \hline Controle 1 & 65,5 & 65,7 & 42,7 & 67,7 \\
Controle 2 & 56,4 & 67,3 & 26 & 21,8 \\
Controle 3 & 54,1 & 57,4 & 36,2 & 32,6 \\
\hline Média & 58,7 & 63,5 & 35,0 & 40,7 \\
\hline Desvio Padrão & 6,0 & 5,3 & 8,4 & 24,0 \\
\hline \hline Cobre 1 & 68 & 44,8 & 40,8 & 43,7 \\
Cobre 2 & 50,8 & 11,4 & 60,9 & 72,5 \\
Cobre 3 & 52,1 & 41 & 61,7 & 53,6 \\
\hline Média & 57,0 & 32,4 & 54,5 & 56,6 \\
\hline Desvio Padrão & 9,6 & 18,3 & 11,8 & 14,6 \\
\hline \hline
\end{tabular}


Tabela 46: Concentrações de fósforo $\left(\mathrm{mg}^{\mathrm{kg}} \mathrm{kg}^{-1}\right)$ determinados nas amostras de sedimento coletadas nos tanques.

\begin{tabular}{ccccc}
\hline \hline & 21.03 & 09.04 & 19.04 & 30.04 \\
\hline Controle 1 & 163,45 & 203,95 & 307,8 & 335,05 \\
Controle 2 & 256 & 252,75 & 298,2 & 344,25 \\
Controle 3 & 267,05 & 272,6 & 304,95 & 321,75 \\
\hline Média & 228,8 & 243,1 & 303,7 & 333,7 \\
\hline Desvio Padrão & 56,9 & 35,3 & 4,9 & 11,3 \\
\hline \hline Cromo 1 & 178,5 & 172,95 & 286,35 & 310,3 \\
Cromo 2 & 190,5 & 128,15 & 310,4 & 292,65 \\
Cromo 3 & 216,95 & 228,75 & 366,2 & 350,6 \\
\hline Média & 195,3 & 176,6 & 321,0 & 317,9 \\
\hline Desvio Padrão & 19,7 & 50,4 & 41,0 & 29,7 \\
\hline \hline Cobre 1 & 258,25 & 141,05 & 294,4 & 306,2 \\
Cobre 2 & 222,9 & 153,85 & 295,55 & 301,5 \\
Cobre 3 & 198,4 & 186,7 & 177,45 & 296,85 \\
\hline Média & 226,5 & 160,5 & 255,8 & 301,5 \\
\hline Desvio Padrão & 30,1 & 23,5 & 67,9 & 4,7 \\
\hline
\end{tabular}

Tabela 47: Concentrações de matéria orgânica (\%) determinados nas amostras de sedimento coletadas nos tanques.

\begin{tabular}{ccccc}
\hline \hline & 21.03 & 09.04 & 19.04 & 30.04 \\
\hline Controle 1 & 17,0 & 15,8 & 14,1 & 14,5 \\
Controle 2 & 17,0 & 15,7 & 13,7 & 14,1 \\
Controle 3 & 14,9 & 14,8 & 12,6 & 13,3 \\
\hline Média & 16,3 & 15,4 & 13,5 & 14,0 \\
\hline Desvio Padrão & 1,2 & 0,6 & 0,8 & 0,6 \\
\hline \hline Cromo 1 & 17,6 & 16,2 & 14,1 & 14,1 \\
Cromo 2 & 15,5 & 15,5 & 13,5 & 14,0 \\
Cromo 3 & 17,2 & 15,4 & 13,5 & 13,6 \\
\hline Média & 16,8 & 15,7 & 13,7 & 13,9 \\
\hline Desvio Padrão & 1,1 & 0,5 & 0,3 & 0,3 \\
\hline \hline Cobre 1 & 18,6 & 15,0 & 14,1 & 14,2 \\
Cobre 2 & 17,8 & 15,6 & 14,4 & 13,9 \\
Cobre 3 & 14,3 & 13,6 & 12,1 & 12,9 \\
\hline Média & 16,9 & 14,7 & 13,5 & 13,7 \\
\hline Desvio Padrão & 2,3 & 1,0 & 1,2 & 0,7 \\
\hline \hline
\end{tabular}


Tabela 48: Concentrações de $\mathrm{Cu}\left(\mathrm{mg}^{\mathrm{L}} \mathrm{L}^{-1}\right)$ determinadas nas amostras de água intersticial coletadas nos controles e nos tanques contaminados com cobre.

\begin{tabular}{lllll}
\hline \hline & 21.03 & 09.04 & 19.04 & 30.04 \\
\hline \hline Controle 1 & nd & nd & 0,20 & 0,32 \\
Controle 2 & nd & nd & 0,33 & 0,38 \\
Controle 3 & nd & nd & 0,34 & 0,31 \\
\hline Média & & & 0,29 & 0,34 \\
\hline Desvio Padrão & & nd & 0,08 & 0,04 \\
\hline \hline Cobre 1 & nd & nd & 0,22 & 0,27 \\
Cobre 2 & nd & nd & 0,33 & 0,31 \\
Cobre 3 & nd & & 0,33 & 0,28 \\
\hline Média & & & 0,10 & 0,29 \\
\hline Desvio Padrão & & & & 0,02 \\
\hline \hline
\end{tabular}


Tabela 49: Massa (mg) das amostras de plâncton para análise de metais determinada em cada coleta.

\begin{tabular}{lccc}
\hline \hline & 28/Mar & 19/Abr & 30/Abr \\
\hline \hline Controle 1 & 3,6 & 10,0 & \\
Controle 2 & 23,9 & 35,1 & 38,2 \\
Controle 3 & 26,8 & 20,3 & 23,1 \\
\hline \hline Cromo 1 & 15,9 & & 10,0 \\
Cromo 2 & 23,2 & 12,5 & 67,1 \\
Cromo 3 & 23,4 & & 125,4 \\
\hline \hline Cobre 1 & & 20,4 & 71,4 \\
Cobre 2 & 25,6 & 15,9 & 32,7 \\
Cobre 3 & 21,5 & 154,8 & 20,6 \\
\hline \hline
\end{tabular}

Tabela 50: Massa das $(\mathrm{mg})$ amostras de bentos para análise de metais determinada em cada coleta.

\begin{tabular}{lcc}
\hline \hline & 28/Mar & 30/Abr \\
\hline \hline Controle 1 & $41,19^{*}$ & 14,17 \\
Controle 2 & & 10,2 \\
Controle 3 & & \\
\hline \hline Cromo 1 & $44,53^{*}$ & 11,3 \\
Cromo 2 & & 27,1 \\
Cromo 3 & & 5,44 \\
\hline \hline Cobre 1 & $62,96^{*}$ & 14,6 \\
Cobre 2 & & \\
Cobre 3 & & 10,4 \\
\hline \hline
\end{tabular}

* Valores referentes as amostras compostas com o material coletado nos três tanques de cada tratamento 
Tabela 51: Matriz de correlação de Pearson entre $\mathrm{pH}$, condutividade, oxigênio dissolvido, temperatura, material em suspensão total, orgânico e inorgânico, silicato, nitrato, nitrito, amônio, nitrogênio total, ortofosfato dissolvido, fósforo total dissolvido, fósforo total e clorofila utilizando-se os valores determinados na água superficial no controle e no experimento com $\mathrm{Cr}$ em todas as datas (primeira linha: $r$; segunda linha:p).

\begin{tabular}{|c|c|c|c|c|c|c|c|c|c|c|c|c|c|c|c|c|}
\hline & OD & Cond & Temp & $\mathrm{pH}$ & MST & MSO & MSI & Silicato & Nitrato & Nitrito & Amônio & NT & Ortofosf & $\begin{array}{l}\text { PT } \\
\end{array}$ & PTD & Clorofil \\
\hline Cond & $\begin{array}{r}-0,145 \\
0,246 \\
\end{array}$ & - & & & & & & & & & & & & & & \\
\hline Temp & $\begin{array}{l}0,011 \\
0,929 \\
\end{array}$ & $\begin{array}{l}0,155 \\
0,213 \\
\end{array}$ & & & & & & & & & & & & & & \\
\hline $\mathrm{pH}$ & $\begin{array}{l}0,591 \\
0,000 \\
\end{array}$ & $\begin{array}{l}0,245 \\
0,048 \\
\end{array}$ & $\begin{array}{r}-0,159 \\
0,204 \\
\end{array}$ & & & & & & & & & & & & & \\
\hline MST & $\begin{array}{l}0,656 \\
0,000 \\
\end{array}$ & $\begin{array}{l}0,160 \\
0,199 \\
\end{array}$ & $\begin{array}{l}0,216 \\
0,082 \\
\end{array}$ & $\begin{array}{l}0,453 \\
0,000 \\
\end{array}$ & & & & & & & & & & & & \\
\hline MSO & $\begin{array}{l}0,659 \\
0,000 \\
\end{array}$ & $\begin{array}{l}0,173 \\
0,164 \\
\end{array}$ & $\begin{array}{l}0,185 \\
0,138 \\
\end{array}$ & $\begin{array}{l}0,470 \\
0,000 \\
\end{array}$ & $\begin{array}{l}0,991 \\
0,000 \\
\end{array}$ & & & & & & & & & & & \\
\hline $\mathrm{MSI}$ & $\begin{array}{l}0,091 \\
0,468\end{array}$ & $\begin{array}{r}-0,080 \\
0,521 \\
\end{array}$ & $\begin{array}{l}0,259 \\
0,036 \\
\end{array}$ & $\begin{array}{r}-0,065 \\
0,602 \\
\end{array}$ & $\begin{array}{l}0,230 \\
0,063 \\
\end{array}$ & $\begin{array}{l}0,095 \\
0,446 \\
\end{array}$ & & & & & & & & & & \\
\hline Silicato & $\begin{array}{l}0,161 \\
0,198\end{array}$ & $\begin{array}{l}0,505 \\
0,000 \\
\end{array}$ & $\begin{array}{r}-0,103 \\
0,409 \\
\end{array}$ & $\begin{array}{l}0,484 \\
0,000 \\
\end{array}$ & $\begin{array}{l}0,170 \\
0,173 \\
\end{array}$ & $\begin{array}{l}0,170 \\
0,172 \\
\end{array}$ & $\begin{array}{l}0,013 \\
0,918 \\
\end{array}$ & & & & & & & & & \\
\hline Nitrato & $\begin{array}{r}-0,142 \\
0,255 \\
\end{array}$ & $\begin{array}{l}0,035 \\
0,778 \\
\end{array}$ & $\begin{array}{r}-0,044 \\
0,723 \\
\end{array}$ & $\begin{array}{r}-0,167 \\
0,181 \\
\end{array}$ & $\begin{array}{l}0,029 \\
0,816 \\
\end{array}$ & $\begin{array}{l}0,016 \\
0,901 \\
\end{array}$ & $\begin{array}{l}0,116 \\
0,354 \\
\end{array}$ & $\begin{array}{r}-0,104 \\
0,404 \\
\end{array}$ & & & & & & & & \\
\hline Nitrito & $\begin{array}{l}0,148 \\
0,237\end{array}$ & $\begin{array}{r}-0,106 \\
0,397 \\
\end{array}$ & $\begin{array}{r}-0,195 \\
0,116 \\
\end{array}$ & $\begin{array}{l}0,162 \\
0,193 \\
\end{array}$ & $\begin{array}{l}0,006 \\
0,961\end{array}$ & $\begin{array}{r}-0,022 \\
0,863 \\
\end{array}$ & $\begin{array}{l}0,185 \\
0,138 \\
\end{array}$ & $\begin{array}{r}-0,012 \\
0,923 \\
\end{array}$ & $\begin{array}{r}-0,079 \\
0,527 \\
\end{array}$ & & & & & & & \\
\hline Amônio & $\begin{array}{r}-0,332 \\
0,006 \\
\end{array}$ & $\begin{array}{l}0,318 \\
0,009 \\
\end{array}$ & $\begin{array}{l}0,286 \\
0,020 \\
\end{array}$ & $\begin{array}{r}-0,146 \\
0,241 \\
\end{array}$ & $\begin{array}{r}-0,221 \\
0,074 \\
\end{array}$ & $\begin{array}{r}-0,210 \\
0,090 \\
\end{array}$ & $\begin{array}{r}-0,107 \\
0,394 \\
\end{array}$ & $\begin{array}{r}-0,017 \\
0,890 \\
\end{array}$ & $\begin{array}{l}0,274 \\
0,026 \\
\end{array}$ & $\begin{array}{l}0,064 \\
0,610 \\
\end{array}$ & & & & & & \\
\hline NT & $\begin{array}{l}0,102 \\
0,416 \\
\end{array}$ & $\begin{array}{r}-0,061 \\
0,629 \\
\end{array}$ & $\begin{array}{r}-0,329 \\
0,007 \\
\end{array}$ & $\begin{array}{r}-0,009 \\
0,942 \\
\end{array}$ & $\begin{array}{l}0,192 \\
0,123 \\
\end{array}$ & $\begin{array}{l}0,184 \\
0,138 \\
\end{array}$ & $\begin{array}{l}0,104 \\
0,406 \\
\end{array}$ & $\begin{array}{l}0,049 \\
0,698 \\
\end{array}$ & $\begin{array}{l}0,252 \\
0,041 \\
\end{array}$ & $\begin{array}{l}0,092 \\
0,462 \\
\end{array}$ & $\begin{array}{r}-0,068 \\
0,590 \\
\end{array}$ & & & & & \\
\hline Ortofosf & $\begin{array}{l}0,046 \\
0,714 \\
\end{array}$ & $\begin{array}{r}-0,087 \\
0,487 \\
\end{array}$ & $\begin{array}{r}-0,185 \\
0,136 \\
\end{array}$ & $\begin{array}{l}0,029 \\
0,820 \\
\end{array}$ & $\begin{array}{l}0,023 \\
0,855 \\
\end{array}$ & $\begin{array}{r}-0,054 \\
0,667 \\
\end{array}$ & $\begin{array}{l}0,213 \\
0,086 \\
\end{array}$ & $\begin{array}{l}0,100 \\
0,424 \\
\end{array}$ & $\begin{array}{r}-0,228 \\
0,066 \\
\end{array}$ & $\begin{array}{l}0,591 \\
0,000 \\
\end{array}$ & $\begin{array}{l}0,044 \\
0,726 \\
\end{array}$ & $\begin{array}{l}0,292 \\
0,017 \\
\end{array}$ & & & & \\
\hline PT & $\begin{array}{l}0,483 \\
0,000 \\
\end{array}$ & $\begin{array}{r}-0,177 \\
0,155 \\
\end{array}$ & $\begin{array}{l}0,185 \\
0,137 \\
\end{array}$ & $\begin{array}{l}0,259 \\
0,035 \\
\end{array}$ & $\begin{array}{l}0,248 \\
0,045 \\
\end{array}$ & $\begin{array}{l}0,261 \\
0,035 \\
\end{array}$ & $\begin{array}{r}-0,049 \\
0,696 \\
\end{array}$ & $\begin{array}{r}-0,010 \\
0,935 \\
\end{array}$ & $\begin{array}{r}-0,022 \\
0,858 \\
\end{array}$ & $\begin{array}{r}-0,321 \\
0,009 \\
\end{array}$ & $\begin{array}{r}-0,123 \\
0,327 \\
\end{array}$ & $\begin{array}{r}-0,265 \\
0,031 \\
\end{array}$ & $\begin{array}{r}-0,355 \\
0,003 \\
\end{array}$ & & & \\
\hline PTD & $\begin{array}{r}-0,144 \\
0,248 \\
\end{array}$ & $\begin{array}{r}-0,295 \\
0,016 \\
\end{array}$ & $\begin{array}{r}-0,179 \\
0,151 \\
\end{array}$ & $\begin{array}{r}-0,125 \\
0,318 \\
\end{array}$ & $\begin{array}{r}-0,324 \\
0,008 \\
\end{array}$ & $\begin{array}{l}0,338 \\
0,006 \\
\end{array}$ & $\begin{array}{l}0,042 \\
0,736 \\
\end{array}$ & $\begin{array}{r}-0,153 \\
0,220 \\
\end{array}$ & $\begin{array}{r}-0,190 \\
0,127 \\
\end{array}$ & $\begin{array}{l}0,030 \\
0,808 \\
\end{array}$ & $\begin{array}{r}-0,051 \\
0,687 \\
\end{array}$ & $\begin{array}{l}0,080 \\
0,524 \\
\end{array}$ & $\begin{array}{l}0,387 \\
0,001\end{array}$ & $\begin{array}{l}0,075 \\
0,550\end{array}$ & & \\
\hline Clorofil & $\begin{array}{l}0,645 \\
0,000 \\
\end{array}$ & $\begin{array}{l}0,191 \\
0,124 \\
\end{array}$ & $\begin{array}{r}-0,005 \\
0,969 \\
\end{array}$ & $\begin{array}{l}0,558 \\
0,000 \\
\end{array}$ & $\begin{array}{l}0,638 \\
0,000 \\
\end{array}$ & $\begin{array}{l}0,656 \\
0,000 \\
\end{array}$ & $\begin{array}{r}-0,034 \\
0,785 \\
\end{array}$ & $\begin{array}{l}0,246 \\
0,047 \\
\end{array}$ & $\begin{array}{r}-0,126 \\
0,312 \\
\end{array}$ & $\begin{array}{l}0,025 \\
0,843 \\
\end{array}$ & $\begin{array}{r}-0,206 \\
0,098 \\
\end{array}$ & $\begin{array}{l}0,055 \\
0,663 \\
\end{array}$ & $\begin{array}{r}-0,021 \\
0,870 \\
\end{array}$ & $\begin{array}{l}0,261 \\
0,034 \\
\end{array}$ & $\begin{array}{r}-0,138 \\
0,268 \\
\end{array}$ & \\
\hline $\mathrm{Cr}$ & $\begin{array}{r}-0,158 \\
0,206 \\
\end{array}$ & $\begin{array}{l}0,174 \\
0,162\end{array}$ & $\begin{array}{l}0,031 \\
0,806\end{array}$ & $\begin{array}{r}-0,164 \\
0,134\end{array}$ & $\begin{array}{r}-0,186 \\
0,134 \\
\end{array}$ & $\begin{array}{l}0,181 \\
0,145\end{array}$ & $\begin{array}{r}-0,066 \\
0,600 \\
\end{array}$ & $\begin{array}{r}-0,014 \\
0,911\end{array}$ & $\begin{array}{l}0,182 \\
0,143\end{array}$ & $\begin{array}{l}0,109 \\
0,386\end{array}$ & $\begin{array}{l}0,316 \\
0,036\end{array}$ & $\begin{array}{l}0,259 \\
0,036\end{array}$ & $\begin{array}{l}0,152 \\
0,224\end{array}$ & $\begin{array}{r}-0,337 \\
0,006\end{array}$ & $\begin{array}{r}-0,209 \\
0,092\end{array}$ & $\begin{array}{r}-0,304 \\
0,013\end{array}$ \\
\hline
\end{tabular}

Cell Contents: Pearson correlation

$$
p \text { - Value }
$$


Tabela 52: Matriz de correlação de Pearson entre pH, condutividade, oxigênio dissolvido, temperatura, material em suspensão total, orgânico e inorgânico, silicato, nitrato, nitrito, amônio, nitrogênio total, ortofosfato dissolvido, fósforo total dissolvido, fósforo total e clorofila utilizando-se os valores determinados na água superficial no controle e no experimento com $\mathrm{Cu}$ em todas as datas (primeira linha: $r$; segunda linha: $p$ ).

\begin{tabular}{|c|c|c|c|c|c|c|c|c|c|c|c|c|c|c|c|c|}
\hline & $\overline{\mathrm{DD}}$ & Cond & Temp & $\mathrm{pH}$ & MST & MSO & $\mathrm{MSI}$ & Silicato & Nitrato & Nitrito & Amônio & $\overline{N T}$ & Ortofosf & $\begin{array}{l}\text { PT } \\
\end{array}$ & $\begin{array}{l}\text { PTD } \\
\end{array}$ & Clorofil \\
\hline Cond & $\begin{array}{l}0,285 \\
0,198\end{array}$ & & & & & & & & & & & & & & & \\
\hline Temp & \begin{tabular}{r|}
$-0,189$ \\
0,400
\end{tabular} & $\begin{array}{l}0,390 \\
0,073\end{array}$ & & & & & & & & & & & & & & \\
\hline$\overline{\mathrm{pH}}$ & $\begin{array}{l}0,635 \\
0,001\end{array}$ & $\begin{array}{l}0,313 \\
0,156\end{array}$ & $\begin{array}{r}-0,193 \\
0,391\end{array}$ & & & & & & & & & & & & & \\
\hline$\overline{M S T}$ & $\begin{array}{l}0,297 \\
0,179\end{array}$ & $\begin{array}{l}0,500 \\
0,018\end{array}$ & $\begin{array}{l}0,157 \\
0,487\end{array}$ & $\begin{array}{l}0,155 \\
0,490\end{array}$ & & & & & & & & & & & & \\
\hline$\overline{M S O}$ & $\begin{array}{l}0,295 \\
0,183\end{array}$ & $\begin{array}{l}0,508 \\
0,016\end{array}$ & $\begin{array}{l}0,086 \\
0,702\end{array}$ & $\begin{array}{l}0,170 \\
0,449\end{array}$ & $\begin{array}{l}0,990 \\
0,000\end{array}$ & & & & & & & & & & & \\
\hline$\overline{\mathrm{MSI}}$ & \begin{tabular}{l|}
0,066 \\
0,769
\end{tabular} & $\begin{array}{l}0,082 \\
0,716\end{array}$ & $\begin{array}{l}0,480 \\
0,024\end{array}$ & $\begin{array}{r}-0,036 \\
0,893\end{array}$ & $\begin{array}{l}0,297 \\
0,179\end{array}$ & $\begin{array}{l}0,158 \\
0,484\end{array}$ & & & & & & & & & & \\
\hline Silicato & $\begin{array}{l}0,228 \\
0,308\end{array}$ & $\begin{array}{l}0,082 \\
0,716\end{array}$ & $\begin{array}{l}0,006 \\
0,979\end{array}$ & $\begin{array}{l}0,072 \\
0,751\end{array}$ & $\begin{array}{l}0,172 \\
0,444\end{array}$ & $\begin{array}{l}0,150 \\
0,506\end{array}$ & $\begin{array}{l}0,192 \\
0,393\end{array}$ & & & & & & & & & \\
\hline Nitrato & \begin{tabular}{r|}
$-0,174$ \\
0,440
\end{tabular} & $\begin{array}{l}0,313 \\
0,155\end{array}$ & $\begin{array}{r}-0,007 \\
0,974\end{array}$ & $\begin{array}{r}-0,461 \\
0,031\end{array}$ & $\begin{array}{l}0,099 \\
0,660\end{array}$ & $\begin{array}{l}0,076 \\
0,737\end{array}$ & $\begin{array}{l}0,193 \\
0,391\end{array}$ & $\begin{array}{r}-0,173 \\
0,441\end{array}$ & & & & & & & & \\
\hline Nitrito & $\begin{array}{l}0,329 \\
0,134\end{array}$ & $\begin{array}{r}-0,187 \\
0,406\end{array}$ & $\begin{array}{r}-0,483 \\
0,023\end{array}$ & $\begin{array}{l}0,372 \\
0,088\end{array}$ & $\begin{array}{r}-0,017 \\
0,941\end{array}$ & $\begin{array}{r}-0,026 \\
0,909\end{array}$ & $\begin{array}{l}0,062 \\
0,783\end{array}$ & $\begin{array}{r}-0,042 \\
0,854\end{array}$ & $\begin{array}{r}-0,108 \\
0,632\end{array}$ & & & & & & & \\
\hline Amônio & $\begin{array}{r}-0,317 \\
0,151\end{array}$ & $\begin{array}{r}-0,118 \\
0,600\end{array}$ & $\begin{array}{l}0,347 \\
0,114\end{array}$ & $\begin{array}{l}0,020 \\
0,930\end{array}$ & $\begin{array}{r}-0,285 \\
0,199\end{array}$ & $\begin{array}{r}-0,272 \\
0,221\end{array}$ & $\begin{array}{r}-0,170 \\
0,450\end{array}$ & $\begin{array}{r}-0,537 \\
0,010\end{array}$ & $\begin{array}{r}-0,151 \\
0,502\end{array}$ & $\begin{array}{r}-0,016 \\
0,943\end{array}$ & & & & & & \\
\hline NT & $\begin{array}{l}0,166 \\
0,461\end{array}$ & $\begin{array}{r}-0,160 \\
0,477\end{array}$ & $\begin{array}{r}-0,465 \\
0,029\end{array}$ & $\begin{array}{r}-0,248 \\
0,266\end{array}$ & $\begin{array}{l}0,422 \\
0,051\end{array}$ & $\begin{array}{l}0,416 \\
0,054\end{array}$ & $\begin{array}{l}0,106 \\
0,638\end{array}$ & $\begin{array}{l}0,040 \\
0,861\end{array}$ & $\begin{array}{l}0,318 \\
0,150\end{array}$ & $\begin{array}{l}0,260 \\
0,243\end{array}$ & $\begin{array}{r}-0,527 \\
0,012\end{array}$ & & & & & \\
\hline Ortofosf & $\begin{array}{l}0,171 \\
0,447\end{array}$ & $\begin{array}{r}-0,256 \\
0,250\end{array}$ & $\begin{array}{l}0,029 \\
0,896\end{array}$ & $\begin{array}{l}0,121 \\
0,592\end{array}$ & $\begin{array}{l}0,050 \\
0,825\end{array}$ & $\begin{array}{r}-0,017 \\
0,941\end{array}$ & $\begin{array}{l}0,389 \\
0,074\end{array}$ & $\begin{array}{l}0,174 \\
0,440\end{array}$ & $\begin{array}{r}-0,309 \\
0,162\end{array}$ & $\begin{array}{l}0,430 \\
0,046\end{array}$ & $\begin{array}{r}-0,057 \\
0,802\end{array}$ & $\begin{array}{l}0,198 \\
0,376\end{array}$ & & & & \\
\hline PTD & $\begin{array}{r}-0,335 \\
0,127\end{array}$ & $\begin{array}{l}0,546 \\
0,009\end{array}$ & $\begin{array}{r}-0,099 \\
0,661\end{array}$ & $\begin{array}{l}0,055 \\
0,808\end{array}$ & $\begin{array}{l}0,533 \\
0,011\end{array}$ & $\begin{array}{r}-0,567 \\
0,006\end{array}$ & $\begin{array}{l}0,090 \\
0,692\end{array}$ & $\begin{array}{r}-0,268 \\
0,227\end{array}$ & $\begin{array}{r}-0,285 \\
0,199\end{array}$ & $\begin{array}{l}0,233 \\
0,296\end{array}$ & $\begin{array}{l}0,500 \\
0,018\end{array}$ & $\begin{array}{r}-0,189 \\
0,400\end{array}$ & $\begin{array}{l}0,346 \\
0,114\end{array}$ & & & \\
\hline$\overline{\mathrm{PT}}$ & $\begin{array}{l}0,101 \\
0,653\end{array}$ & $\begin{array}{l}0,253 \\
0,256\end{array}$ & $\begin{array}{l}0,240 \\
0,283\end{array}$ & $\begin{array}{l}0,281 \\
0,206\end{array}$ & $\begin{array}{r}-0,217 \\
0,333\end{array}$ & $\begin{array}{r}-0,158 \\
0,481\end{array}$ & $\begin{array}{r}-0,440 \\
0,040\end{array}$ & $\begin{array}{l}0,038 \\
0,867\end{array}$ & $\begin{array}{r}-0,360 \\
0,100\end{array}$ & \begin{tabular}{r|}
$-0,453$ \\
0,034
\end{tabular} & $\begin{array}{l}0,331 \\
0,133\end{array}$ & $\begin{array}{r}-0,677 \\
0,001\end{array}$ & $\begin{array}{r}-0,263 \\
0,238\end{array}$ & $\begin{array}{l}0,033 \\
0,885\end{array}$ & & \\
\hline Clorofil & $\begin{array}{l}0,241 \\
0,280\end{array}$ & $\begin{array}{l}0,527 \\
0,012\end{array}$ & $\begin{array}{l}0,004 \\
0,985\end{array}$ & $\begin{array}{l}0,333 \\
0,130\end{array}$ & $\begin{array}{l}0,395 \\
0,069\end{array}$ & $\begin{array}{l}0,418 \\
0,053\end{array}$ & $\begin{array}{r}-0,034 \\
0,881\end{array}$ & $\begin{array}{r}-0,003 \\
0,991\end{array}$ & $\begin{array}{l}0,053 \\
0,815\end{array}$ & $\begin{array}{r}-0,110 \\
0,627\end{array}$ & $\begin{array}{l}0,073 \\
0,748\end{array}$ & \begin{tabular}{l|}
0,013 \\
0,956
\end{tabular} & $\begin{array}{r}-0,359 \\
0,101\end{array}$ & $\begin{array}{r}-0,273 \\
0,219\end{array}$ & $\begin{array}{l}0,152 \\
0,500\end{array}$ & \\
\hline $\mathrm{Cu}$ & $\begin{array}{l}0,122 \\
0,587\end{array}$ & $\begin{array}{l}0,511 \\
0,015\end{array}$ & $\begin{array}{l}0,293 \\
0,186\end{array}$ & $\begin{array}{r}-0,130 \\
0,564\end{array}$ & $\begin{array}{l}0,273 \\
0,219\end{array}$ & $\begin{array}{l}0,258 \\
0,247\end{array}$ & $\begin{array}{l}0,175 \\
0,935\end{array}$ & $\begin{array}{l}0,333 \\
0,130\end{array}$ & $\begin{array}{r}-0,001 \\
0,995\end{array}$ & $\begin{array}{l}0,110 \\
0,625\end{array}$ & $\begin{array}{r}-0,186 \\
0,408\end{array}$ & $\begin{array}{l}0,055 \\
0,809\end{array}$ & $\begin{array}{r}-0,063 \\
0,781\end{array}$ & $\begin{array}{r}-0,369 \\
0,091\end{array}$ & $\begin{array}{r}-0,119 \\
0,597\end{array}$ & $\begin{array}{l}0,106 \\
0,640\end{array}$ \\
\hline
\end{tabular}

Cell Contents: Pearson correlation

$$
p \text { - Value }
$$


Tabela 53: Matriz de correlação de Pearson entre matéria orgânica, fósforo, nitrogênio, cromo na fração fracamente ligada, cromo total, pH, Eh e condutividade utilizando-se os valores determinados no sedimento no controle e no experimento com $\mathrm{Cr}$ em todas as datas (primeira linha: $\mathrm{r}$; segunda linha:p).

\begin{tabular}{|c|c|c|c|c|c|c|c|c|}
\hline & $\mathrm{MO}$ & 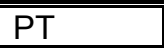 & $\overline{\mathrm{NT}}$ & Cr Bio & Cr Tot & $\mathrm{pH}$ & Eh & COND \\
\hline PT & $\begin{array}{r}-0,787 \\
0,000 \\
\end{array}$ & & & & & & & \\
\hline NT & $\begin{array}{r}-0,580 \\
0,003\end{array}$ & $\begin{array}{l}0,457 \\
0,025\end{array}$ & & & & & & \\
\hline Cr Bio & $\begin{array}{l}0,263 \\
0,214\end{array}$ & $\begin{array}{r}-0,019 \\
0,931\end{array}$ & $\begin{array}{l}0,045 \\
0,836\end{array}$ & & & & & \\
\hline Cr Tot & $\begin{array}{l}0,458 \\
0,024\end{array}$ & $\begin{array}{r}-0,365 \\
0,080 \\
\end{array}$ & $\begin{array}{r}-0,155 \\
0,468\end{array}$ & $\begin{array}{l}0,066 \\
0,759\end{array}$ & & & & \\
\hline $\mathrm{PH}$ & $\begin{array}{r}-0,112 \\
0,604\end{array}$ & $\begin{array}{r}-0,096 \\
0,655\end{array}$ & $\begin{array}{l}0,401 \\
0,052\end{array}$ & $\begin{array}{r}-0,303 \\
0,150\end{array}$ & $\begin{array}{l}0,256 \\
0,228\end{array}$ & & & \\
\hline Eh $(m \mathrm{~V})$ & $\begin{array}{l}0,644 \\
0,001\end{array}$ & $\begin{array}{r}-0,660 \\
0,000\end{array}$ & $\begin{array}{r}-0,493 \\
0,014\end{array}$ & $\begin{array}{l}0,036 \\
0,868\end{array}$ & $\begin{array}{l}0,428 \\
0,037\end{array}$ & $\begin{array}{r}-0,205 \\
0,336\end{array}$ & & \\
\hline COND (uS) & $\begin{array}{l}0,191 \\
0,373\end{array}$ & $\begin{array}{r}-0,011 \\
0,961\end{array}$ & $\begin{array}{r}-0,242 \\
0,255\end{array}$ & $\begin{array}{r}-0,053 \\
0,805\end{array}$ & $\begin{array}{r}-0,103 \\
0,634\end{array}$ & $\begin{array}{r}-0,064 \\
0,768\end{array}$ & $\begin{array}{l}0,003 \\
0,988\end{array}$ & \\
\hline $\mathrm{OD}(\mathrm{mg} / 1)$ & $\begin{array}{l}0,633 \\
0,001\end{array}$ & $\begin{array}{r}-0,485 \\
0,016\end{array}$ & $\begin{array}{r}-0,687 \\
0,000\end{array}$ & $\begin{array}{l}0,175 \\
0,412\end{array}$ & $\begin{array}{l}0,318 \\
0,130\end{array}$ & $\begin{array}{r}-0,134 \\
0,532\end{array}$ & $\begin{array}{l}0,436 \\
0,033\end{array}$ & $\begin{array}{l}0,154 \\
0,472\end{array}$ \\
\hline
\end{tabular}

Cell Contents: Pearson correlation

$$
p-\text { Value }
$$


Tabela 54: Matriz de correlação de Pearson entre matéria orgânica, fósforo, nitrogênio, cobre na água intersticial, cobre na fração fracamente ligada, cobre total, $\mathrm{pH}$, Eh e condutividade utilizando-se os valores determinados no sedimento no controle e no experimento com Cu em todas as datas (primeira linha: $r$; segunda linha:p).

\begin{tabular}{|c|c|c|c|c|c|c|c|c|c|}
\hline & $\mathrm{MO}$ & $\overline{\mathrm{PT}}$ & NT & $\mathrm{Cu} \mathrm{Ai}$ & Cu Bio & Cu Tot & $\overline{\mathrm{pH}}$ & $\overline{E \text { Eh }}$ & COND \\
\hline$\overline{\mathrm{PT}}$ & $\begin{array}{l}-0,309 \\
0,142\end{array}$ & & & & & & & & \\
\hline NT & $\begin{array}{l}0,192 \\
0,369\end{array}$ & $\begin{array}{l}-0,187 \\
0,382\end{array}$ & & & & & & & \\
\hline $\mathrm{Cu} \mathrm{Ai}$ & $\begin{array}{l}-0,675 \\
0,000\end{array}$ & $\begin{array}{l}0,680 \\
0,000\end{array}$ & $\begin{array}{l}-0,342 \\
0,102\end{array}$ & & & & & & \\
\hline $\mathrm{Cu}$ Bio & $\begin{array}{l}0,289 \\
0,170\end{array}$ & $\begin{array}{l}0,102 \\
0,635\end{array}$ & $\begin{array}{l}-0,190 \\
0,373\end{array}$ & $\begin{array}{l}-0,039 \\
0,858\end{array}$ & & & & & \\
\hline Cu Tot & $\begin{array}{l}0,299 \\
0,170\end{array}$ & $\begin{array}{l}0,061 \\
0,778\end{array}$ & $\begin{array}{l}-0,280 \\
0,185\end{array}$ & $\begin{array}{l}-0,182 \\
0,395\end{array}$ & $\begin{array}{l}0,005 \\
0,982\end{array}$ & & & & \\
\hline $\mathrm{pH}$ & \begin{tabular}{|l}
$-0,184$ \\
0,389
\end{tabular} & $\begin{array}{l}0,001 \\
0,995\end{array}$ & $\begin{array}{l}0,198 \\
0,354\end{array}$ & $\begin{array}{l}0,166 \\
0,439\end{array}$ & $\begin{array}{l}-0,267 \\
0,206\end{array}$ & $\begin{array}{l}0,137 \\
0,522\end{array}$ & & & \\
\hline Eh (mV) & $\begin{array}{l}0,381 \\
0,066\end{array}$ & $\begin{array}{l}-0,674 \\
0,000\end{array}$ & $\begin{array}{l}0,128 \\
0,551\end{array}$ & $\begin{array}{l}-0,769 \\
0,000\end{array}$ & $\begin{array}{l}-0,076 \\
0,723\end{array}$ & $\begin{array}{l}0,151 \\
0,481\end{array}$ & $\begin{array}{l}-0,097 \\
0,651\end{array}$ & & \\
\hline COND (uS) & \begin{tabular}{|l|}
0,248 \\
0,242
\end{tabular} & $\begin{array}{l}0,409 \\
0,047\end{array}$ & $\begin{array}{l}-0,244 \\
0,250\end{array}$ & $\begin{array}{l}0,357 \\
0,086\end{array}$ & $\begin{array}{l}0,072 \\
0,739\end{array}$ & $\begin{array}{l}-0,273 \\
0,196\end{array}$ & $\begin{array}{l}0,248 \\
0,243\end{array}$ & $\begin{array}{c}-0,270 \\
0,202\end{array}$ & \\
\hline OD (mg/a) & $\begin{array}{l}0,641 \\
0,001\end{array}$ & $\begin{array}{l}-0,376 \\
0,070\end{array}$ & $\begin{array}{l}0,364 \\
0,081\end{array}$ & $\begin{array}{l}-0,619 \\
0,001\end{array}$ & $\begin{array}{l}-0,092 \\
0,669\end{array}$ & $\begin{array}{l}0,169 \\
0,429\end{array}$ & $\begin{array}{l}0,154 \\
0,474\end{array}$ & $\begin{array}{l}0,489 \\
0,015\end{array}$ & $\begin{array}{l}0,062 \\
0,773\end{array}$ \\
\hline
\end{tabular}

Cell Contents : Pearson correlation

p - Value 
Tabela 55: Comparação entre os índices calculados para o controle e os experimentos com $\mathrm{Cr}$ e $\mathrm{Cu}$, considerando a comunidade zooplanctônica total através de análise de variância (ANOVA).

\begin{tabular}{|c|c|c|c|c|}
\hline & & $\mathrm{CxCr}$ & & $\mathrm{CxCu}$ \\
\hline & $F$ & valor-P & $F$ & valor-P \\
\hline Shannon H' Log Base 2. & 5,36 & 0,031 & 29,02 & 0,000 \\
\hline $\begin{array}{l}\text { Shannon } \\
\text { (Uniformidade } \\
\text { Pielou) }\end{array}$ & 2,02 & 0,170 & 14,38 & 0,001 \\
\hline $\begin{array}{ll}\text { Índice de Simpson } & \text { (D) } \\
\text { (Dominância } & \text { de } \\
\text { Simpson) } & \end{array}$ & 5,00 & 0,037 & 7,10 & 0,015 \\
\hline $\mathrm{N}$ & 0,61 & 0,444 & 14,20 & 0,001 \\
\hline S & 23,98 & 0,000 & 36,06 & 0,000 \\
\hline
\end{tabular}


Tabela 56: Comparação dos valores obtidos para as análises químicas e físico químicas entre as réplicas para todas as datas através de análise de variância.

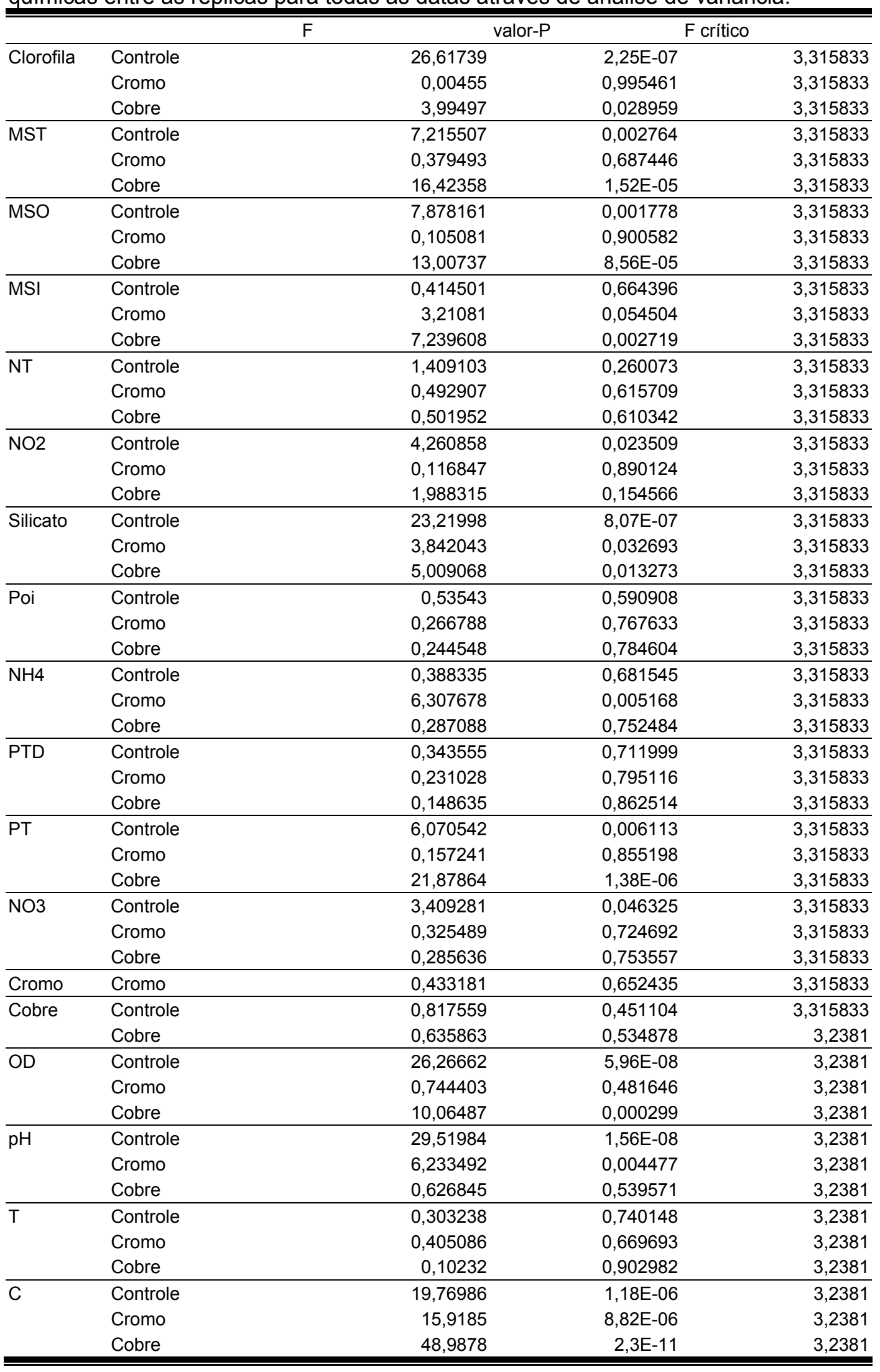


3. Experimentos em Mesocosmos (2)

Tabela 57: Concentrações de oxigênio dissolvido $\left(\mathrm{mg}_{\mathrm{L}} \mathrm{L}^{-1}\right)$ determinados na água coleta em cada unidade experimental

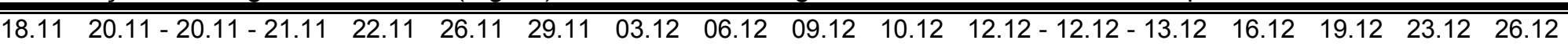
Oh $3 \mathrm{~h} \quad$ Oh $3 \mathrm{~h}$

\begin{tabular}{|c|c|c|c|c|c|c|c|c|c|c|c|c|c|c|c|c|c|c|}
\hline Controle 1 & 6,8 & 5,6 & 6,0 & 5,7 & 7,4 & 6,9 & 6,2 & 6,7 & 6,6 & 7,0 & 6,5 & 6,9 & 6,5 & 5,4 & 5,5 & 6,9 & 6,3 & 6,8 \\
\hline Controle 2 & 6,1 & 6,3 & 6,8 & 5,9 & 7,4 & 6,5 & 6,3 & 6,5 & 6,9 & 7,3 & 6,8 & 5,4 & 7,5 & 5,5 & 7,0 & 6,0 & 5,1 & 6,7 \\
\hline Controle 3 & 6,8 & 6,8 & 6,2 & 5,8 & 7,9 & 6,5 & 6,7 & 7,5 & 6,8 & 7,7 & 7,0 & 5,9 & 7,7 & 5,1 & 7,3 & 6,6 & 6,3 & 6,7 \\
\hline Média & 6,6 & 6,2 & 6,3 & 5,8 & 7,6 & 6,6 & 6,4 & 6,9 & 6,7 & 7,3 & 6,8 & 6,1 & 7,2 & 5,3 & 6,6 & 6,5 & 5,9 & 6,7 \\
\hline Desvio Padrão & 0,4 & 0,6 & 0,5 & 0,1 & 0,3 & 0,2 & 0,2 & 0,6 & 0,2 & 0,3 & 0,2 & 0,7 & 0,7 & 0,2 & 1,0 & 0,5 & 0,7 & 0,1 \\
\hline Cromo 1 & $6,6,3$ & 6,1 & 6,0 & 5,7 & 8,2 & 7,0 & 6,6 & 6,0 & 6,6 & 7,1 & 6,4 & 5,8 & 7,0 & 5,5 & 6,3 & 5,9 & $7,7,2$ & 6,0 \\
\hline Cromo 2 & 6,9 & 5,8 & 5,7 & 4,4 & 7,1 & 6,0 & 5,4 & 5,8 & 5,9 & 6,8 & 6,5 & 5,4 & 5,9 & 4,8 & 6,6 & 6,5 & 5,7 & 6,4 \\
\hline Cromo3 & 6,9 & 6,0 & 6,2 & 5,6 & 7,1 & 6,1 & 5,6 & 5,7 & 5,9 & 7,3 & 6,1 & 5,0 & 6,8 & 5,6 & 6,5 & 6,4 & 6,6 & 6,4 \\
\hline Média & 6,7 & 6,0 & 5,9 & 5,2 & 7,5 & 6,4 & 5,9 & 5,8 & 6,1 & 7,1 & 6,3 & 5,4 & 6,6 & 5,3 & 6,5 & 6,2 & 6,5 & 6,3 \\
\hline Desvio Padrão & 0,4 & 0,2 & 0,2 & 0,7 & 0,6 & 0,6 & 0,7 & 0,2 & 0,4 & 0,3 & 0,2 & 0,4 & 0,5 & 0,4 & 0,2 & 0,3 & 0,8 & 0,3 \\
\hline Cobre 1 & 6,9 & 5,9 & 5,7 & 6,4 & 7,7 & 7,1 & 6,9 & 6,4 & 6,4 & 6,8 & 6,5 & 6,6 & 6,4 & 4,5 & 6,0 & 6,7 & 5,6 & 5,9 \\
\hline Cobre 2 & 6,2 & 6,3 & 6,1 & 6,0 & 7,5 & 6,9 & 6,4 & 7,0 & 7,1 & 7,4 & 6,7 & 7,3 & 7,5 & 6,7 & 6,4 & 7,9 & 6,1 & 7,0 \\
\hline Cobre3 & 5,9 & 6,3 & 5,9 & 5,9 & 7,4 & 6,5 & 7,4 & 7,4 & 6,6 & 7,6 & 6,6 & 7,4 & 7,4 & 6,9 & 7,3 & 7,6 & 6,3 & 6,9 \\
\hline Média & 6,3 & 6,2 & 5,9 & 6,1 & 7,5 & 6,8 & 6,9 & 6,9 & 6,7 & 7,2 & 6,6 & 7,1 & 7,1 & 6,0 & 6,6 & 7,4 & 6,0 & 6,6 \\
\hline Desvio Padrão & 0,5 & 0,2 & 0,2 & 0,2 & 0,1 & 0,3 & 0,5 & 0,5 & 0,4 & 0,4 & 0,1 & 0,4 & 0,6 & 1,3 & 0,7 & 0,6 & 0,4 & 0,6 \\
\hline
\end{tabular}


Tabela 58: Valores de condutividade determinados na água coleta em cada unidade experimental

$\begin{array}{llllllllllllll}18.11 & 20.11-20.11-21.11 & 22.11 & 26.11 & 29.11 & 03.12 & 06.12 & 09.12 & 10.12 & 12.12-12.12-13.12 & 16.12 & 19.12 & 23.12 & 26.12\end{array}$

Oh $3 \mathrm{~h}$

Oh $3 \mathrm{~h}$

\begin{tabular}{|c|c|c|c|c|c|c|c|c|c|c|c|c|c|c|c|c|c|c|}
\hline Controle 1 & 8,0 & 7,0 & 8,0 & 7,0 & 8,0 & 8,0 & 8,0 & 8,0 & 8,0 & 8,0 & 8,0 & 8,0 & 8,0 & 8,0 & $\overline{8,0}$ & 8,0 & 8,0 & 8,0 \\
\hline Controle 2 & 8,0 & 8,0 & 8,0 & 8,0 & 8,0 & 8,0 & 8,0 & 8,0 & 8,0 & 8,0 & 8,0 & 8,0 & 8,0 & 8,0 & 8,0 & 8,0 & 8,0 & 8,0 \\
\hline Controle 3 & 8,0 & 8,0 & 8,0 & 8,0 & 8,0 & 8,0 & 9,0 & 8,0 & 8,0 & 8,0 & 8,0 & 8,0 & 9,0 & 8,0 & 8,0 & 8,0 & 8,0 & 8,0 \\
\hline Média & 8,0 & 7,7 & 8,0 & 7,7 & 8,0 & 8,0 & 8,3 & 8,0 & 8,0 & 8,0 & 8,0 & 8,0 & 8,3 & 8,0 & 8,0 & 8,0 & 8,0 & 8,0 \\
\hline Desvio Padrão & 0,0 & 0,6 & 0,0 & 0,6 & 0,0 & 0,0 & 0,6 & 0,0 & 0,0 & 0,0 & 0,0 & 0,0 & 0,6 & 0,0 & 0,0 & 0,0 & 0,0 & $\overline{0,0}$ \\
\hline Cromo 1 & 8,0 & 8,0 & 8,0 & $\overline{99,0}$ & 8,0 & 99 & 9,0 & 8,0 & 8,0 & 99 & 99 & 99 & 8,0 & 99 & $\overline{8,0}$ & 8,0 & 8,0 & $\overline{8,0}$ \\
\hline Cromo 2 & 8,0 & 8,0 & 8,0 & 8,0 & 8,0 & 8,0 & 9,0 & 8,0 & 8,0 & 8,0 & 8,0 & 8,0 & 8,0 & 8,0 & 8,0 & 8,0 & 8,0 & 8,0 \\
\hline Cromo3 & 8,0 & 8,0 & 8,0 & 8,0 & 8,0 & 9,0 & 9,0 & 8,0 & 8,0 & 8,0 & 8,0 & 8,0 & 8,0 & 8,0 & 8,0 & 8,0 & 8,0 & 8,0 \\
\hline Média & 8,0 & 8,0 & 8,0 & 8,3 & 8,0 & 8,7 & 9,0 & 8,0 & 8,0 & 8,3 & 8,3 & 8,3 & 8,0 & 8,3 & 8,0 & 8,0 & 8,0 & $\overline{8,0}$ \\
\hline Desvio Padrão & 0,0 & 0,0 & 0,0 & 0,6 & 0,0 & 0,6 & 0,0 & 0,0 & 0,0 & 0,6 & 0,6 & 0,6 & 0,0 & 0,6 & 0,0 & 0,0 & 0,0 & $\overline{0,0}$ \\
\hline Cobre 1 & 9,0 & 8,0 & 8,0 & $\overline{8,0}$ & 8,0 & 8,0 & 9,0 & 8,0 & 8,0 & 9,0 & 8,0 & 8,0 & 8,0 & 8,0 & $\overline{8,0}$ & 8,0 & 8,0 & $\overline{8,0}$ \\
\hline Cobre 2 & 8,0 & 8,0 & 8,0 & 8,0 & 8,0 & 8,0 & 9,0 & 8,0 & 8,0 & 8,0 & 8,0 & 8,0 & 8,0 & 8,0 & 8,0 & 8,0 & 8,0 & 8,0 \\
\hline Cobre3 & 8,0 & 8,0 & 8,0 & 8,0 & 9,0 & 8,0 & 9,0 & 8,0 & 8,0 & 8,0 & 8,0 & 8,0 & 8,0 & 9,0 & 8,0 & 8,0 & 8,0 & 8,0 \\
\hline Média & 8,3 & 8,0 & 8,0 & 8,0 & 8,3 & 8,0 & 9,0 & 8,0 & 8,0 & 8,3 & 8,0 & 8,0 & 8,0 & 8,3 & 8,0 & 8,0 & 8,0 & $\overline{8,0}$ \\
\hline Desvio Padrão & 0,6 & 0,0 & 0,0 & 0,0 & 0,6 & 0,0 & 0,0 & 0,0 & 0,0 & 0,6 & 0,0 & 0,0 & 0,0 & 0,6 & 0,0 & 0,0 & 0,0 & $\overline{0,0}$ \\
\hline
\end{tabular}


Tabela 59: Valores de $\mathrm{pH}$ determinados na água coleta em cada unidade experimental $\begin{array}{llllllllllllll}18.11 & 20.11-20.11-21.11 & 22.11 & 26.11 & 29.11 & 03.12 & 06.12 & 09.12 & 10.12 & 12.12-12.12-13.12 & 16.12 & 19.12 & 23.12 & 26.12\end{array}$
$0 \mathrm{~h} \quad 3 \mathrm{~h}$
Oh $\quad 3 h$

\begin{tabular}{|c|c|c|c|c|c|c|c|c|c|c|c|c|c|c|c|c|c|c|}
\hline Controle 1 & 6,8 & 6,9 & 6,9 & 6,8 & 6,6 & 6,5 & 6,7 & 5,7 & 6,6 & 5,9 & 6,1 & 5,9 & 6,2 & 6,0 & 4,9 & 5,4 & 5,6 & 5,3 \\
\hline Controle 2 & 6,7 & 6,6 & 6,6 & 6,5 & 6,6 & 6,6 & 6,7 & 6,2 & 6,6 & 6,1 & 5,5 & 6,0 & 7,5 & 5,5 & 5,1 & 5,9 & 5,4 & 5,7 \\
\hline Controle 3 & 6,7 & 6,8 & 6,8 & 6,5 & 6,5 & 6,6 & 6,7 & 6,1 & 6,4 & 6,5 & 5,4 & & 7,5 & 5,4 & 5,3 & 6,0 & 5,5 & 5,9 \\
\hline Média & 6,7 & 6,7 & 6,8 & 6,6 & 6,6 & 6,6 & 6,7 & 6,0 & 6,5 & 6,2 & 5,6 & 6,0 & 7,0 & 5,6 & 5,1 & 5,8 & 5,5 & 5,6 \\
\hline Desvio Padrão & 0,0 & 0,1 & 0,2 & 0,2 & 0,0 & 0,0 & 0,0 & 0,3 & 0,1 & 0,3 & 0,4 & 0,1 & 0,7 & 0,3 & 0,2 & 0,3 & 0,1 & $\overline{0,3}$ \\
\hline Cromo 1 & $\overline{6,6}$ & 6,8 & $\overline{6,6}$ & 6,9 & $\overline{6,6}$ & 6,3 & $\overline{6,6}$ & $\overline{5,2}$ & $\overline{6,6}$ & $\overline{~ 6,7}$ & $\overline{66,6}$ & $\overline{6,2}$ & 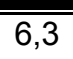 & $\overline{6,5}$ & $\overline{44,8}$ & $\overline{5,6}$ & $\overline{5,3}$ & $\overline{5,5}$ \\
\hline Cromo 2 & 6,7 & 6,8 & 6,6 & 6,6 & 6,4 & 6,5 & 6,6 & 6,0 & 6,5 & 5,8 & 5,9 & 5,8 & 7,1 & 5,4 & 4,8 & 5,6 & 5,3 & 5,5 \\
\hline Cromo3 & 6,6 & 6,7 & 6,7 & 6,4 & 6,2 & 6,5 & 6,5 & 6,0 & 6,1 & 6,4 & 5,5 & 5,8 & 6,5 & 5,2 & 5,2 & 6,0 & 5,4 & 5,9 \\
\hline Média & 6,6 & 6,7 & 6,6 & 6,6 & 6,4 & 6,4 & 6,6 & 5,7 & 6,4 & 6,3 & 6,0 & 6,0 & 6,7 & 5,7 & 5,0 & 5,7 & 5,3 & 5,6 \\
\hline Desvio Padrão & 0,1 & 0,0 & 0,1 & 0,3 & 0,2 & 0,1 & 0,1 & 0,5 & 0,3 & 0,5 & 0,6 & 0,2 & 0,4 & 0,7 & 0,2 & 0,2 & 0,1 & 0,3 \\
\hline Cobre 1 & 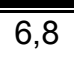 & 6,8 & 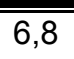 & $6,6,6$ & $6,6,5$ & 6,6 & $\overline{6,6}$ & $\overline{6,2}$ & 6,6 & 25,8 & 6,6 & 5,8 & 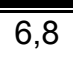 & $\overline{5,5}$ & 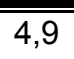 & 5,8 & $\overline{5,2}$ & $\overline{5,4}$ \\
\hline Cobre 2 & 6,6 & 6,7 & 6,6 & 6,3 & 6,5 & 6,6 & 6,7 & 6,1 & 6,5 & 6,3 & 5,5 & 5,6 & 7,2 & 5,2 & 5,1 & 5,8 & 5,4 & 5,7 \\
\hline Cobre3 & 6,8 & 6,7 & 6,7 & 6,4 & 6,2 & 6,5 & 6,7 & 6,1 & 6,4 & 6,5 & 5,6 & 5,8 & 6,6 & 5,4 & 5,5 & 6,8 & 5,9 & 6,1 \\
\hline Média & 6,7 & 6,7 & 6,7 & 6,4 & 6,4 & 6,6 & 6,7 & 6,1 & 6,4 & 6,2 & 5,7 & 5,7 & 6,9 & 5,4 & 5,2 & 6,1 & 5,5 & 5,7 \\
\hline Desvio Padrão & 0,1 & 0,1 & 0,1 & 0,2 & 0,2 & 0,1 & 0,1 & 0,1 & 0,1 & 0,4 & 0,3 & 0,1 & 0,3 & 0,2 & 0,3 & 0,6 & 0,4 & $\overline{0,4}$ \\
\hline
\end{tabular}


Tabela 60: Valores de temperatura $\left({ }^{\circ} \mathrm{C}\right)$ determinados na água coleta em cada unidade experimental

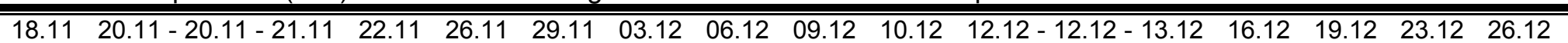
Oh $3 \mathrm{~h}$

Oh $3 \mathrm{~h}$

\begin{tabular}{|c|c|c|c|c|c|c|c|c|c|c|c|c|c|c|c|c|c|c|}
\hline 1 &, 6 & 26,1 & 9,4 & 6,8 & 8 & 25,7 & 5,5 & 3 & 1 & 6 & 25 & ,4 & 26,4 & 25,3 & 24,1 & 27 & 3 & \\
\hline $\mathrm{Cc}$ &, 8 & 26 & 8,7 & 6,6 & 6,8 & 5,6 & 6,3 & 8 & 7,9 & 6,2 & 5,1 & 25,3 & 26,7 & 5,3 & 4,3 & 7,2 & 27,7 & 6 \\
\hline & 6 & 6,4 & 8,6 & 6,7 & $y$ & 5,6 & 0,2 & ,2 & $y$ &, 6 & 5,2 & ,4 &, 6 &, 3 & 4 & 7,4 & 7,7 & , \\
\hline lédia & 7 & 6,2 & 8,9 & 6,7 & 6,8 & 5,6 & 6,3 & 6,8 & 28,0 & 26,3 & 5,1 & 25,4 & 26,6 & 25,3 & 24,3 & 27,2 & 27,6 & 26 , \\
\hline svic & 0 & 0,2 & 0,4 & 0,1 & 0,1 & 0,1 & 0,2 & 0,5 & 0,1 & 0,3 & 0,1 & 0, & 0,2 & 0,0 & 0,2 & 0,2 & 0,2 & 0, \\
\hline & , & 25,9 & 28,8 & $20, \overline{ }$ & 26,8 & 25,8 & 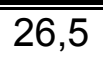 & $20, v$ & 28,3 & 0 & 1 & $2 v, 2$ & $20, v$ &, 5 & ד & 26,9 & 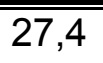 & \\
\hline &, 7 & 26 & 8,8 & 6,5 & 26,7 & 5,6 & 6,3 & 66 & 28 & 26,2 & 25 & 5,3 & 26,8 & 5,2 & 24,1 & 27 & 74 & 6 \\
\hline & 27,7 & 26,5 & 28,9 & 26,8 & 26,8 & 25,6 & 26,2 & 27,4 & 27,7 & 26,9 & 25,2 & 25,4 & 26,6 & 25,3 & 24,3 & 27,5 & 27,8 & 26 , \\
\hline & 1 &, 1 & 3,8 & 6,7 & 6,8 & 5,7 & 6,3 & 6,8 & 8,0 & 6,3 &, 1 & ,3 & 8 & 5,3 & 3 & 7,1 & 27,5 & 26, \\
\hline S & 6 & 0,3 & 0,1 & 0,2 & 0,1 & 0,1 & 0,2 & 0,6 & 0,3 & 0,6 & 0,1 & 0, & 0,2 & 0,2 & 0,2 & 0,3 & 0,2 & \\
\hline &, 8 & 26,1 & $\overline{8,5}$ & 6,8 &, 9 & 25,7 & 26,4 & ,7 & 28,2 & 26,1 & 5,1 & 25,4 & 27,3 & 25,3 & 4,0 & $1, \angle$ & 27,5 & -5, \\
\hline Cobre 2 & ,8 & 26,3 & 7 & 7 & 8 & 25,6 & 3 & 9 & 8 & 3 & 1 & 24 & 7 & 3 & 24,2 & 7,2 & 27,7 & 20, \\
\hline Cobre3 & 6 & 5 & 29 & 7 & 26,9 & 6 & 3 & 7,2 & 6 & 26,9 & 3 & 25,4 & 26,6 & 25,3 & 24,7 & 8,1 & 28 & 26 , \\
\hline ivedia & 3,1 & 6,3 & 8,7 & 6,7 & 6,9 & 25,6 & 6,3 & 6,9 & 27,9 & 26,4 & 5,2 & 25,4 & 26,9 & 25,3 & 24,4 & 27,5 & 27,7 & 26,2 \\
\hline S & 6 & & 0,3 & 0,1 & 0,1 & 0,1 & 0,1 & $0_{1}$ & 0 & 0,4 & 0,1 & 0 . & 0,4 & 00 & 03 & 0 , & 0,3 & U, \\
\hline
\end{tabular}


Tabela 61: Valores de clorofila $\left(\mu \mathrm{g} \cdot \mathrm{L}^{-1}\right)$ determinados na água coleta em cada unidade experimental

\begin{tabular}{|c|c|c|c|c|c|c|c|c|c|c|c|c|c|}
\hline & 18.11 & 21.11 & 22.11 & 26.11 & 29.11 & 03.12 & 06.12 & 09.12 & 13.12 & 16.12 & 19.12 & 23.12 & 26.12 \\
\hline Controle 1 & 9,77 & 11,16 & 10,46 & 9,07 & 9,07 & 6,98 & 6,28 & 6,98 & 26,51 & 30,69 & 24,41 & 30,69 & 30,69 \\
\hline Controle 2 & 4,88 & 6,28 & 4,88 & 5,58 & 6,28 & 6,28 & 6,98 & 9,77 & 29,99 & 23,72 & 13,95 & 12,56 & 16,74 \\
\hline Controle 3 & 8,37 & 4,88 & 6,28 & 9,07 & 9,07 & 7,67 & 6,28 & 6,98 & 29,99 & 25,11 & 14,65 & 9,07 & 16,04 \\
\hline Média & 7,67 & 7,44 & 7,21 & 7,91 & 8,14 & 6,98 & 6,51 & 7,91 & 28,83 & 26,51 & 17,67 & 17,44 & 21,16 \\
\hline Desvio Padrão & 2,51 & 3,30 & 2,90 & 2,01 & 1,61 & 0,70 & 0,40 & 1,61 & 2,01 & 3,69 & 5,85 & 11,61 & 8,26 \\
\hline Cromo 1 & 7,67 & 4,88 & 4,88 & 9,77 & 10,46 & 8,37 & 3,49 & 13,25 & 13,95 & 15,35 & 11,16 & 12,56 & 17,44 \\
\hline Cromo 2 & 7,67 & 4,19 & 3,49 & 4,88 & 6,28 & 4,88 & 5,58 & 10,46 & 13,25 & 11,16 & 10,46 & 9,77 & 13,95 \\
\hline Cromo3 & 8,37 & 2,79 & 3,49 & 4,88 & 6,98 & 6,28 & 6,28 & 10,46 & 11,86 & 9,07 & 9,77 & 8,37 & 11,86 \\
\hline Média & 7,91 & 3,95 & 3,95 & 6,51 & 7,91 & 6,51 & 5,12 & 11,39 & 13,02 & 11,86 & 10,46 & 10,23 & 14,42 \\
\hline Desvio Padrão & 0,40 & 1,07 & 0,81 & 2,82 & 2,24 & 1,76 & 1,45 & 1,61 & 1,07 & 3,20 & 0,70 & 2,13 & 2,82 \\
\hline Cobre 1 & $\overline{5,58}$ & 2,79 & 3,49 & 9,07 & 9,77 & 5,58 & 5,58 & $\overline{7,67}$ & 12,56 & 27,90 & 19,53 & 16,74 & 18,83 \\
\hline Cobre 2 & 6,28 & 2,09 & 2,79 & 8,37 & 9,77 & 7,67 & 7,67 & 9,77 & 20,23 & 33,48 & 22,32 & 18,14 & 20,23 \\
\hline Cobre3 & 4,88 & 2,79 & 2,79 & 9,07 & 11,86 & 6,28 & 6,28 & 9,77 & 23,02 & 16,74 & 11,86 & 9,07 & 14,65 \\
\hline Média & 5,58 & 2,56 & 3,02 & 8,84 & 10,46 & 6,51 & 6,51 & 9,07 & 18,60 & 26,04 & 17,90 & 14,65 & 17,90 \\
\hline Desvio Padrão & 0,70 & 0,40 & 0,40 & 0,40 & 1,21 & 1,07 & 1,07 & 1,21 & 5,42 & 8,52 & 5,42 & 4,88 & 2,90 \\
\hline
\end{tabular}


Tabela 62: Valores de material em suspensão total $\left(\mathrm{mg}^{\mathrm{L}} \mathrm{L}^{-1}\right)$ determinados na água coleta em cada unidade experimental

\begin{tabular}{cccccccccccccc}
\hline & 18.11 & 21.11 & 22.11 & 26.11 & 29.11 & 03.12 & 06.12 & 09.12 & 13.12 & 16.12 & 19.12 & 23.12 & 26.12 \\
\hline \hline Controle 1 & 12,0 & 4,0 & 2,2 & 3,4 & 3,2 & 4,9 & 4,0 & 4 & 5,6 & 6,1 & 6,2 & 2,4 & 7,4 \\
Controle 2 & 2,1 & 1,7 & 2,1 & 2,2 & 1,8 & 3,4 & 3,5 & 5,28 & 4,6 & 4,8 & 3,8 & 0,0 & 3,4 \\
Controle 3 & 2,2 & 1,4 & 2,0 & 2,6 & 2,2 & 3,3 & 2,4 & 3,84 & 5,1 & 3,3 & 5,3 & 3,4 & 3,2 \\
\hline Média & 5,5 & 2,4 & 2,1 & 2,8 & 2,4 & 3,9 & 3,3 & 4,4 & 5,1 & 4,7 & 5,1 & 1,9 & 4,7 \\
\hline Desvio Padrão & 5,7 & 1,4 & 0,1 & 0,6 & 0,7 & 0,9 & 0,8 & 0,8 & 0,5 & 1,4 & 1,2 & 1,7 & 2,4 \\
\hline \hline Cromo 1 & 3,5 & 1,4 & 2,2 & 2,4 & 2,7 & 3,8 & 3,0 & 3,92 & 3,7 & 3,0 & 3,1 & 2,5 & 12,9 \\
Cromo 2 & 3,7 & 2,2 & 2,5 & 2,1 & 1,8 & 3,5 & 2,7 & 6,44 & 3,2 & 2,5 & 2,4 & 1,9 & 3,1 \\
Cromo3 & 3,2 & 2,0 & 4,2 & 2,3 & 2,0 & 3,2 & 2,6 & 3,08 & 3,9 & 0,1 & 2,3 & 1,6 & 3,1 \\
\hline Média & 3,5 & 1,9 & 3,0 & 2,3 & 2,2 & 3,5 & 2,8 & 4,5 & 3,6 & 1,9 & 2,6 & 2,0 & 6,4 \\
\hline Desvio Padrão & 0,2 & 0,4 & 1,1 & 0,2 & 0,5 & 0,3 & 0,2 & 1,7 & 0,4 & 1,5 & 0,5 & 0,4 & 5,7 \\
\hline \hline Cobre 1 & 3,0 & 2,0 & 2,6 & 1,9 & 3,0 & 3,8 & 2,2 & 4,72 & 4,1 & 4,1 & 3,7 & 2,4 & 4,1 \\
Cobre 2 & 2,2 & 1,8 & 1,7 & 2,9 & 2,1 & 3,3 & 4,1 & 0,24 & 5,4 & 5,2 & 4,9 & 3,1 & 3,9 \\
Cobre3 & 1,4 & 2,2 & 2,1 & 3,1 & 2,4 & 4,0 & 3,2 & 5,92 & 7,6 & 3,2 & 3,4 & 1,0 & 3,4 \\
\hline Média & 2,2 & 2,0 & 2,1 & 2,7 & 2,5 & 3,7 & 3,2 & 3,6 & 5,7 & 4,2 & 4,0 & 2,2 & 3,8 \\
\hline Desvio Padrão & 0,8 & 0,2 & 0,4 & 0,6 & 0,4 & 0,4 & 0,9 & 3,0 & 1,8 & 1,0 & 0,8 & 1,1 & 0,4 \\
\hline \hline
\end{tabular}


Tabela 63: Valores de material em suspensão orgânico $\left(\mathrm{mg}^{\mathrm{L}} \mathrm{L}^{-1}\right)$ determinados na água coleta em cada unidade experimental

\begin{tabular}{cccccccccccccc}
\hline \hline & 18.11 & 21.11 & 22.11 & 26.11 & 29.11 & 03.12 & 06.12 & 09.12 & 13.12 & 16.12 & 19.12 & 23.12 & 26.12 \\
\hline \hline Controle 1 & 5,64 & 3,64 & 2,12 & 3,44 & 3,16 & 4,88 & 4 & 0,92 & 5,6 & 6,08 & 5,92 & 2,4 & 6,68 \\
Controle 2 & 2,08 & 1,72 & 2,12 & 2,24 & 1,84 & 3,4 & 3,52 & 5,16 & 4,28 & 4,6 & 3,8 & $-0,24$ & 2,8 \\
Controle 3 & 2,24 & 1,44 & 2,04 & 2,6 & 2 & 3,32 & 2,44 & 3,84 & 4,6 & 3,28 & 4,48 & 3,4 & 2,4 \\
\hline Média & 3,3 & 2,3 & 2,1 & 2,8 & 2,3 & 3,9 & 3,3 & 3,3 & 4,8 & 4,7 & 4,7 & 1,9 & 4,0 \\
\hline Desvio Padrão & 2,0 & 1,2 & 0,0 & 0,6 & 0,7 & 0,9 & 0,8 & 2,2 & 0,7 & 1,4 & 1,1 & 1,9 & 2,4 \\
\hline \hline Cromo 1 & 3 & 1,4 & 2,24 & 2,4 & 2,68 & 3,76 & 3,04 & 3,92 & 3,72 & 2,96 & 3 & 2,48 & 5,04 \\
Cromo 2 & 3,04 & 2,24 & 2,48 & 2,08 & 1,48 & 3,52 & 2,72 & 1,76 & 3,16 & 2,52 & 2,4 & 1,88 & 2,8 \\
Cromo3 & 2,84 & 1,96 & 4,2 & 2,28 & 2 & 3,16 & 2,56 & 3,08 & 3,56 & 0,12 & 2,28 & 1,6 & 2,88 \\
\hline Média & 3,0 & 1,9 & 3,0 & 2,3 & 2,1 & 3,5 & 2,8 & 2,9 & 3,5 & 1,9 & 2,6 & 2,0 & 3,6 \\
\hline Desvio Padrão & 0,1 & 0,4 & 1,1 & 0,2 & 0,6 & 0,3 & 0,2 & 1,1 & 0,3 & 1,5 & 0,4 & 0,4 & 1,3 \\
\hline \hline Cobre 1 & 2,92 & 1,96 & 2,56 & 1,92 & 3 & 3,76 & 2,24 & 4,44 & 4,12 & 4,12 & 3,6 & 2,44 & 3,68 \\
Cobre 2 & 2,04 & 1,84 & 1,72 & 2,92 & 2,12 & 3,28 & 4,12 & 0,24 & 4,88 & 4,92 & 4,88 & 3,12 & 3,36 \\
Cobre3 & 1,44 & 2,16 & 2,12 & 3,12 & 2,4 & 4,04 & 3,16 & 3,4 & 5,88 & 3,24 & 2,72 & 1 & 2,72 \\
\hline Média & 2,1 & 2,0 & 2,1 & 2,7 & 2,5 & 3,7 & 3,2 & 2,7 & 5,0 & 4,1 & 3,7 & 2,2 & 3,3 \\
\hline Desvio Padrão & 0,7 & 0,2 & 0,4 & 0,6 & 0,4 & 0,4 & 0,9 & 2,2 & 0,9 & 0,8 & 1,1 & 1,1 & 0,5 \\
\hline \hline
\end{tabular}


Tabela 64: Valores de material em suspensão inorgânico $\left(\mathrm{mg}^{\mathrm{L}} \mathrm{L}^{-1}\right)$ determinados na água coleta em cada unidade experimental

\begin{tabular}{cccccccccccccc}
\hline \hline & 18.11 & 21.11 & 22.11 & 26.11 & 29.11 & 03.12 & 06.12 & 09.12 & 13.12 & 16.12 & 19.12 & 23.12 & 26.12 \\
\hline \hline Controle 1 & 6,4 & 0,32 & 0,08 & 0 & 0 & 0 & 0 & 3,08 & 0 & 0 & 0,24 & 0 & 0,72 \\
Controle 2 & 0 & 0 & 0 & 0 & 0 & 0 & 0 & 0,12 & 0,32 & 0,24 & 0 & 0 & 0,6 \\
Controle 3 & 0 & 0 & 0 & 0 & 0,24 & 0 & 0 & 0 & 0,52 & 0 & 0,8 & 0 & 0,76 \\
\hline Média & 2,1 & 0,1 & 0,0 & 0,0 & 0,1 & 0,0 & 0,0 & 1,1 & 0,3 & 0,1 & 0,3 & 0,0 & 0,7 \\
\hline Desvio Padrão & 3,7 & 0,2 & 0,0 & 0,0 & 0,1 & 0,0 & 0,0 & 1,7 & 0,3 & 0,1 & 0,4 & 0,0 & 0,1 \\
\hline \hline Cromo 1 & 0,48 & 0 & 0 & 0 & 0 & 0 & 0 & 0 & 0 & 0 & 0,12 & 0 & 7,88 \\
Cromo 2 & 0,64 & 0 & 0 & 0 & 0,32 & 0 & 0 & 4,68 & 0 & 0 & 0 & 0 & 0,32 \\
Cromo 3 & 0,4 & 0 & 0 & 0 & 0 & 0 & 0 & 0 & 0,32 & 0 & 0 & 0 & 0,24 \\
\hline Média & 0,5 & 0,0 & 0,0 & 0,0 & 0,1 & 0,0 & 0,0 & 1,6 & 0,1 & 0,0 & 0,0 & 0,0 & 2,8 \\
\hline Desvio Padrão & 0,1 & 0,0 & 0,0 & 0,0 & 0,2 & 0,0 & 0,0 & 2,7 & 0,2 & 0,0 & 0,1 & 0,0 & 4,4 \\
\hline \hline Cobre 1 & 0,12 & 0 & 0,04 & 0 & 0 & 0 & 0 & 0,28 & 0 & 0 & 0,08 & 0 & 0,4 \\
Cobre 2 & 0,2 & 0 & 0 & 0 & 0 & 0 & 0 & 0 & 0,48 & 0,28 & 0 & 0 & 0,52 \\
Cobre 3 & 0 & 0 & 0 & 0 & 0 & 0 & 0 & 2,52 & 1,72 & 0 & 0,64 & 0 & 0,64 \\
\hline Média & 0,1 & 0,0 & 0,0 & 0,0 & 0,0 & 0,0 & 0,0 & 0,9 & 0,7 & 0,1 & 0,2 & 0,0 & 0,5 \\
\hline Desvio Padrão & 0,1 & 0,0 & 0,0 & 0,0 & 0,0 & 0,0 & 0,0 & 1,4 & 0,9 & 0,2 & 0,3 & 0,0 & 0,1 \\
\hline \hline
\end{tabular}


Tabela 65: Concentrações de silicatos dissolvidos $\left(\mathrm{mg} \cdot \mathrm{L}^{-1}\right)$ determinados na água coleta em cada unidade experimental

\begin{tabular}{cccccccccccccc}
\hline \hline & 18.11 & 21.11 & 22.11 & 26.11 & 29.11 & 03.12 & 06.12 & 09.12 & 13.12 & 16.12 & 19.12 & 23.12 & 26.12 \\
\hline \hline Controle 1 & 1,06 & 0,67 & 0,75 & 1,16 & 1,02 & 0,58 & 0,52 & 0,76 & 0,57 & 0,38 & 0,39 & 1,06 & 0,77 \\
Controle 2 & 0,84 & 0,57 & 0,82 & 1,02 & 0,91 & 0,41 & 0,44 & 0,48 & 0,40 & 0,38 & 0,42 & 0,76 & 0,73 \\
Controle 3 & 0,90 & 0,59 & 0,76 & 0,93 & 1,11 & 0,47 & 0,80 & 0,44 & 0,46 & 0,39 & 0,45 & 0,88 & 0,87 \\
\hline Média & 0,93 & 0,61 & 0,77 & 1,04 & 1,01 & 0,49 & 0,59 & 0,56 & 0,48 & 0,38 & 0,42 & 0,90 & 0,79 \\
\hline Desvio Padrão & 0,12 & 0,05 & 0,04 & 0,12 & 0,10 & 0,09 & 0,19 & 0,17 & 0,09 & 0,00 & 0,03 & 0,15 & 0,07 \\
\hline \hline Cromo 1 & 0,78 & 0,47 & 0,77 & 1,05 & 0,93 & 0,62 & 0,76 & 0,74 & 0,46 & 0,43 & 0,45 & 0,79 & 0,80 \\
Cromo 2 & 0,89 & 0,52 & 0,77 & 1,09 & 1,01 & 0,45 & 0,80 & 0,37 & 0,46 & 0,38 & 0,42 & 1,00 & 0,77 \\
Cromo 3 & 0,84 & 0,45 & 0,89 & 1,01 & 1,00 & 0,46 & 0,62 & 0,59 & 0,50 & 0,42 & 0,45 & 0,80 & 0,89 \\
\hline Média & 0,83 & 0,48 & 0,81 & 1,05 & 0,98 & 0,51 & 0,73 & 0,57 & 0,47 & 0,41 & 0,44 & 0,86 & 0,82 \\
\hline Desvio Padrão & 0,06 & 0,03 & 0,07 & 0,04 & 0,05 & 0,10 & 0,09 & 0,19 & 0,02 & 0,03 & 0,02 & 0,12 & 0,06 \\
\hline \hline Cobre 1 & 0,80 & 0,48 & 0,84 & 1,02 & 0,93 & 0,52 & 1,42 & 0,40 & 0,50 & 0,41 & 0,43 & 0,90 & 0,78 \\
Cobre 2 & 0,88 & 0,53 & 0,82 & 0,97 & 0,96 & 0,43 & 0,55 & 0,47 & 0,55 & 0,37 & 0,44 & 0,75 & 0,80 \\
Cobre 3 & 1,04 & 0,49 & 0,72 & 0,97 & 0,89 & 0,39 & 0,54 & 0,66 & 0,34 & 0,42 & 0,46 & 0,77 & 0,82 \\
\hline Média & 0,91 & 0,50 & 0,79 & 0,99 & 0,93 & 0,45 & 0,84 & 0,51 & 0,46 & 0,40 & 0,44 & 0,81 & 0,80 \\
\hline Desvio Padrão & 0,12 & 0,03 & 0,06 & 0,03 & 0,03 & 0,07 & 0,51 & 0,13 & 0,11 & 0,02 & 0,02 & 0,08 & 0,02 \\
\hline \hline
\end{tabular}


Tabela 66: Concentrações de nitrato $\left(\mu \mathrm{g} \cdot \mathrm{L}^{-1}\right)$ determinados na água coleta em cada unidade experimental

\begin{tabular}{|c|c|c|c|c|c|c|c|c|c|c|c|c|c|}
\hline & 18.11 & 21.11 & 22.11 & 26.11 & 29.11 & 03.12 & 06.12 & 09.12 & 13.12 & 16.12 & 19.12 & 23.12 & 26.12 \\
\hline Controle 1 & 41,2 & 35,6 & 46,9 & 57,9 & 31,7 & 11,6 & 29,3 & 38,6 & 18,3 & 10,1 & 7,5 & 22,0 & 11,9 \\
\hline Controle 2 & 35,5 & 42,8 & 33,2 & 37,4 & 97,7 & 17,7 & 16,0 & 31,5 & 16,6 & 14,9 & 10,3 & 30,4 & 37,9 \\
\hline Controle 3 & 35,0 & 11,9 & 104,6 & 55,7 & 44,2 & 31,2 & 15,4 & 14,3 & 31,0 & 20,5 & 11,6 & 37,0 & 10,7 \\
\hline Média & 37,2 & 30,1 & 61,6 & 50,3 & 57,9 & 20,2 & 20,2 & 28,1 & 22,0 & 15,2 & 9,8 & 29,8 & 20,1 \\
\hline Desvio Padrão & 3,4 & 16,2 & 37,9 & 11,3 & 35,1 & 10,0 & 7,8 & 12,5 & 7,9 & 5,2 & 2,1 & 7,5 & 15,4 \\
\hline Cromo 1 & 25,1 & 36,2 & 40,3 & 74,1 & 63,5 & 26,1 & 24,5 & 34,7 & 27,4 & 27,3 & 21,5 & 33,0 & 96,6 \\
\hline Cromo 2 & 48,7 & 23,2 & 21,8 & 48,0 & 98,2 & 18,2 & 20,7 & 56,0 & 19,1 & 29,2 & 11,1 & 29,5 & 8,5 \\
\hline Cromo3 & 42,6 & 36,8 & 25,8 & 42,7 & 46,5 & 22,1 & 17,1 & 13,2 & 45,0 & 56,8 & 11,4 & 23,2 & 12,0 \\
\hline Média & 38,8 & 32,1 & 29,3 & 54,9 & 69,4 & 22,1 & 20,8 & 34,6 & 30,5 & 37,8 & 14,7 & 28,6 & 39,0 \\
\hline Desvio Padrão & 12,2 & 7,7 & 9,7 & 16,8 & 26,3 & 3,9 & 3,7 & 21,4 & 13,2 & 16,5 & 5,9 & 4,9 & 49,9 \\
\hline Cobre 1 & 24,2 & $\overline{31,5}$ & 28,5 & $\overline{28,6}$ & 95,3 & $\overline{16,9}$ & 22,9 & 477,2 & 79,0 & 23,0 & 20,3 & 34,2 & $\overline{72,1}$ \\
\hline Cobre 2 & 26,8 & 30,8 & 25,8 & 58,0 & 33,4 & 16,7 & 18,4 & 17,2 & 34,7 & 27,3 & 7,9 & 33,1 & 9,2 \\
\hline Cobre3 & 32,0 & 26,4 & 31,9 & 79,4 & 32,4 & 13,1 & 18,2 & 16,4 & 43,1 & 50,6 & 57,8 & 31,1 & 19,7 \\
\hline Média & 27,7 & 29,6 & 28,7 & 55,3 & 53,7 & 15,6 & 19,8 & 26,9 & 52,3 & 33,6 & 28,7 & 32,8 & 33,7 \\
\hline Desvio Padrão & 4,0 & 2,8 & 3,0 & 25,5 & 36,0 & 2,1 & 2,6 & 17,5 & 23,5 & 14,8 & 26,0 & 1,6 & 33,7 \\
\hline
\end{tabular}


Tabela 67: Concentrações de nitrito $\left(\mu \mathrm{g} \cdot \mathrm{L}^{-1}\right)$ determinados na água coleta em cada unidade experimental

\begin{tabular}{|c|c|c|c|c|c|c|c|c|c|c|c|c|c|}
\hline & 18.11 & 21.11 & 22.11 & 26.11 & 29.11 & 03.12 & 06.12 & 09.12 & 13.12 & 16.12 & 19.12 & 23.12 & 26.12 \\
\hline Controle 1 & 1,6 & 1,2 & 1,7 & 0,9 & 0,6 & 5,8 & 2,9 & 1,0 & 1,4 & 1,3 & 1,0 & 1,1 & 1,1 \\
\hline Controle 2 & 2,0 & 1,1 & 1,6 & 0,8 & 0,2 & 4,4 & 3,4 & 1,0 & 1,2 & 1,1 & 0,7 & 1,3 & 1,5 \\
\hline Controle 3 & 3,5 & 1,1 & 2,6 & 0,9 & 0,2 & 4,3 & 4,0 & 0,9 & 1,4 & 1,4 & 1,0 & 1,3 & 1,4 \\
\hline Média & 2,4 & 1,1 & 2,0 & 0,8 & 0,3 & 4,8 & 3,4 & 1,0 & 1,3 & 1,3 & 0,9 & 1,3 & 1,3 \\
\hline Desvio Padrão & 1,0 & 0,1 & 0,5 & 0,0 & 0,2 & 0,8 & 0,5 & 0,1 & 0,1 & 0,1 & 0,1 & 0,1 & 0,2 \\
\hline Cromo 1 & $\overline{1,6}$ & $\overline{1,8}$ & $\overline{1,9}$ & $\overline{1,4}$ & $\overline{0,7}$ & $\overline{6,4}$ & $\overline{3,1}$ & $\overline{1,4}$ & $\overline{11,6}$ & $\overline{3,1}$ & $\overline{0,9}$ & $\overline{11,4}$ & $\overline{11,5}$ \\
\hline Cromo 2 & 1,7 & 1,2 & 1,4 & 1,1 & 0,3 & 4,1 & 3,3 & 0,9 & 1,2 & 2,2 & 1,0 & 2,3 & 1,4 \\
\hline Cromo3 & 1,7 & 1,4 & 1,5 & 0,7 & 0,2 & 4,0 & 4,5 & 0,9 & 1,3 & 1,9 & 1,5 & 1,2 & 1,4 \\
\hline Média & 1,7 & 1,5 & 1,6 & 1,1 & 0,4 & 4,9 & 3,6 & 1,0 & 1,3 & 2,4 & 1,1 & 1,6 & 1,4 \\
\hline Desvio Padrão & 0,1 & 0,3 & 0,3 & 0,4 & 0,3 & 1,4 & 0,8 & 0,3 & 0,2 & 0,6 & 0,3 & 0,6 & 0,1 \\
\hline Cobre 1 & 1,7 & 1,4 & 1,5 & 0,8 & 0,3 & 4,6 & 2,8 & 0,9 & 1,2 & 1,7 & 1,0 & 1,7 & 1,3 \\
\hline Cobre 2 & 1,5 & 1,2 & 1,4 & 0,6 & 0,2 & 4,6 & 3,7 & 1,3 & 1,6 & 1,5 & 1,4 & 1,5 & 1,3 \\
\hline Cobre3 & 1,9 & 1,6 & 2,1 & 0,6 & 0,2 & 3,0 & 4,4 & 1,5 & 1,4 & 1,8 & 1,3 & 1,6 & 1,8 \\
\hline Média & 1,7 & 1,4 & 1,7 & 0,7 & 0,2 & 4,1 & 3,6 & 1,2 & 1,4 & 1,7 & 1,2 & 1,6 & 1,5 \\
\hline Desvio Padrão & 0,2 & 0,2 & 0,4 & 0,1 & 0,1 & 0,9 & 0,8 & 0,3 & 0,2 & 0,1 & 0,2 & 0,1 & 0,3 \\
\hline
\end{tabular}


Tabela 68: Concentrações de amônia $\left(\mu \mathrm{g} \cdot \mathrm{L}^{-1}\right)$ determinados na água coleta em cada unidade experimental

\begin{tabular}{|c|c|c|c|c|c|c|c|c|c|c|c|c|c|}
\hline & 18.11 & 21.11 & 22.11 & 26.11 & 29.11 & 03.12 & 06.12 & 09.12 & 13.12 & 16.12 & 19.12 & 23.12 & 26.12 \\
\hline Controle 1 & 142,0 & 395,4 & 23,2 & 52,0 & 85,2 & 18,1 & 9,5 & 31,3 & 19,4 & 21,2 & 10,5 & 9,6 & 5,4 \\
\hline Controle 2 & 135,9 & 526,7 & 31,3 & 63,8 & 136,5 & 12,4 & 20,5 & 35,8 & 30,0 & 20,1 & 8,1 & 13,6 & 5,8 \\
\hline Controle 3 & 328,5 & 646,8 & 41,5 & 57,9 & 208,3 & 7,6 & 11,8 & 17,0 & 50,1 & 25,3 & 5,2 & 10,0 & 6,8 \\
\hline Média & 202,2 & 523,0 & 32,0 & 57,9 & 143,3 & 12,7 & 14,0 & 28,0 & 33,2 & 22,2 & 7,9 & 11,1 & 6,0 \\
\hline Desvio Padrão & 109,5 & 125,8 & 9,1 & 5,9 & 61,9 & 5,2 & 5,8 & 9,8 & 15,6 & 2,7 & 2,7 & 2,2 & 0,7 \\
\hline Cromo 1 & 49,5 & 363,8 & 42,8 & 57,3 & 108,6 & 9,3 & 13,4 & 32,8 & 81,5 & 444,6 & 12,0 & 21,3 & 16,0 \\
\hline Cromo 2 & 186,7 & 492,2 & 27,2 & 63,8 & 95,9 & 6,6 & 39,3 & 31,1 & 25,5 & 17,3 & 8,4 & 17,7 & 5,2 \\
\hline Cromo3 & 395,6 & 547,9 & 32,1 & 62,1 & 237,3 & 10,0 & 17,3 & 19,6 & 79,5 & 34,7 & 13,8 & 19,4 & 4,9 \\
\hline Média & 210,6 & 468,0 & 34,0 & 61,1 & 147,3 & 8,6 & 23,3 & 27,8 & 62,2 & 32,2 & 11,4 & 19,5 & 8,7 \\
\hline Desvio Padrão & 174,3 & 94,4 & 8,0 & 3,4 & 78,3 & 1,8 & 13,9 & 7,2 & 31,8 & 13,8 & 2,7 & 1,8 & 6,3 \\
\hline Cobre 1 & 94,5 & 4438,3 & 37,1 & 38,1 & 156,7 & 8,7 & 12,9 & 445,2 & 63,1 & 14,7 & 14,9 & 20,2 & 9,2 \\
\hline Cobre 2 & 195,3 & 520,5 & 27,6 & 64,7 & 171,2 & 15,2 & 23,7 & 27,9 & 26,0 & 13,4 & 21,5 & 15,0 & 2,5 \\
\hline Cobre3 & 430,0 & 587,0 & 76,8 & 124,7 & 230,8 & 7,0 & 41,6 & 75,2 & 73,6 & 28,5 & 9,7 & 26,1 & 14,8 \\
\hline Média & 239,9 & 515,3 & 47,2 & 75,8 & 186,2 & 10,3 & 26,1 & 49,4 & 54,2 & 18,9 & 15,4 & 20,4 & 8,8 \\
\hline Desvio Padrão & 172,1 & 74,5 & 26,1 & 44,4 & 39,2 & 4,4 & 14,5 & 23,9 & 25,0 & 8,4 & 5,9 & 5,6 & 6,1 \\
\hline
\end{tabular}


Tabela 69: Concentrações de nitrogênio total $\left(\mathrm{mg} \cdot \mathrm{L}^{-1}\right)$ determinados na água coleta em cada unidade experimental

\begin{tabular}{|c|c|c|c|c|c|c|c|c|c|c|c|c|c|}
\hline & 18.11 & 21.11 & 22.11 & 26.11 & 29.11 & 03.12 & 06.12 & 09.12 & 13.12 & 16.12 & 19.12 & 23.12 & 26.12 \\
\hline Controle 1 & 0,59 & 0,47 & 0,45 & 0,92 & 0,53 & 0,66 & 0,49 & 0,63 & 0,98 & 0,42 & 0,89 & 0,95 & 0,45 \\
\hline Controle 2 & 0,51 & 0,24 & 0,55 & 0,57 & 0,43 & 0,27 & 0,43 & 0,49 & 0,92 & 0,70 & 0,27 & 0,56 & 0,55 \\
\hline Controle 3 & 0,55 & 0,31 & 0,55 & 1,17 & 0,42 & 0,43 & 0,35 & 0,68 & 1,00 & 0,32 & 0,44 & 0,64 & 0,55 \\
\hline Média & 0,55 & 0,34 & 0,52 & 0,89 & 0,46 & 0,45 & 0,42 & 0,60 & 0,97 & 0,48 & 0,53 & 0,72 & 0,52 \\
\hline Desvio Padrão & 0,04 & 0,12 & 0,06 & 0,30 & 0,06 & 0,20 & 0,07 & 0,10 & 0,04 & 0,20 & 0,32 & 0,21 & 0,06 \\
\hline Cromo 1 & 1,98 & 0,42 & 0,49 & 0,52 & 0,38 & 0,97 & 0,58 & 0,62 & 0,83 & 0,32 & 0,46 & 0,62 & 0,49 \\
\hline Cromo 2 & 0,49 & 0,44 & 0,49 & 0,57 & 0,41 & 0,72 & 0,26 & 0,48 & 0,73 & 0,42 & 0,49 & 0,52 & 0,49 \\
\hline Cromo 3 & 0,63 & 0,20 & 0,59 & 0,45 & 0,51 & 0,74 & 0,02 & 0,37 & 0,77 & 0,17 & 0,49 & 0,63 & 0,59 \\
\hline Média & 1,03 & 0,35 & 0,53 & 0,51 & 0,44 & 0,81 & 0,29 & 0,49 & 0,77 & 0,30 & 0,48 & 0,59 & 0,53 \\
\hline Desvio Padrão & 0,82 & 0,14 & 0,05 & 0,06 & 0,07 & 0,14 & 0,28 & 0,12 & 0,05 & 0,13 & 0,02 & 0,06 & 0,05 \\
\hline Cobre 1 & 0,41 & 0,06 & 0,56 & 0,68 & 0,44 & 0,58 & 0,47 & 0,54 & 1,17 & 0,49 & 0,57 & 0,60 & 0,56 \\
\hline Cobre 2 & 0,83 & 0,30 & 0,53 & 0,47 & 0,43 & 0,45 & 0,36 & 0,40 & 0,88 & 0,59 & 0,21 & 0,65 & 0,53 \\
\hline Cobre 3 & 0,09 & 0,44 & 0,49 & 0,47 & 0,49 & 0,39 & 0,10 & 0,00 & 0,47 & 0,46 & 0,38 & 0,72 & 0,49 \\
\hline Média & 0,44 & 0,26 & 0,53 & 0,54 & 0,45 & 0,47 & 0,31 & 0,31 & 0,84 & 0,51 & 0,39 & 0,66 & 0,53 \\
\hline Desvio Padrão & 0,37 & 0,19 & 0,03 & 0,12 & 0,04 & 0,10 & 0,19 & 0,28 & 0,35 & 0,07 & 0,18 & 0,06 & 0,03 \\
\hline
\end{tabular}


Tabela 70: Concentrações de fosfato inorgânico $\left(\mu \mathrm{g} \cdot \mathrm{L}^{-1}\right)$ determinados na água coleta em cada unidade experimental

\begin{tabular}{|c|c|c|c|c|c|c|c|c|c|c|c|c|c|}
\hline & 18.11 & 21.11 & 22.11 & 26.11 & 29.11 & 03.12 & 06.12 & 09.12 & 13.12 & 16.12 & 19.12 & 23.12 & 26.12 \\
\hline Controle 1 & 6,6 & 7,2 & 4,1 & 1,5 & 1,6 & 3,8 & 4,1 & 4,0 & 2,9 & 4,9 & 11,2 & 4,8 & 2,8 \\
\hline Controle 2 & 6,3 & 3,2 & 3,5 & 0,6 & 0,7 & 2,7 & 1,7 & 5,3 & 5,0 & 4,0 & 9,8 & 5,3 & 3,3 \\
\hline Controle 3 & 9,2 & 5,4 & 5,8 & 2,4 & 1,3 & 2,6 & 3,8 & 3,6 & 6,9 & 4,6 & 3,6 & 2,7 & 3,6 \\
\hline Média & 7,4 & 5,3 & 4,5 & 1,5 & 1,2 & 3,0 & 3,2 & 4,3 & 4,9 & 4,5 & 8,2 & 4,3 & 3,2 \\
\hline Desvio Padrão & 1,6 & 2,0 & 1,2 & 0,9 & 0,5 & 0,7 & 1,3 & 0,9 & 2,0 & 0,4 & 4,0 & 1,4 & 0,4 \\
\hline Cromo 1 & $7,7,8$ & $\overline{5,0}$ & 1,3 & 2,0 & 1,4 & 4,8 & 2,7 & 5,8 & 1,9 & 8,2 & 10,1 & $\overline{5,0}$ & $\overline{7,6}$ \\
\hline Cromo 2 & 4,0 & 3,6 & 3,5 & 3,7 & 0,7 & 3,0 & 3,0 & 4,0 & 2,5 & 6,0 & 6,3 & 4,6 & 4,2 \\
\hline Cromo 3 & 4,1 & 3,2 & 4,3 & 3,1 & 1,1 & 3,9 & 1,9 & 3,4 & 4,8 & 5,5 & 5,4 & 2,3 & 4,2 \\
\hline Média & 5,3 & 3,9 & 3,0 & 3,0 & 1,1 & 3,9 & 2,6 & 4,4 & 3,1 & 6,6 & 7,3 & 4,0 & 5,3 \\
\hline Desvio Padrão & 2,1 & 1,0 & 1,6 & 0,9 & 0,4 & 0,9 & 0,5 & 1,2 & 1,5 & 1,4 & 2,5 & 1,4 & 1,9 \\
\hline Cobre 1 & 6,2 & 4,1 & 3,7 & 2,8 & 0,8 & 3,1 & 4,0 & 2,7 & 3,7 & 5,3 & 3,2 & 7,2 & 1,2 \\
\hline Cobre 2 & 4,4 & 3,6 & 4,1 & 1,3 & 1,8 & 4,3 & 3,2 & 5,0 & 5,0 & 4,2 & 13,2 & 4,1 & 3,6 \\
\hline Cobre3 & 5,0 & 7,7 & 4,7 & 1,5 & 0,3 & 4,3 & 4,6 & 3,7 & 3,2 & 3,9 & 7,0 & 4,3 & 4,3 \\
\hline Média & 5,2 & 5,1 & 4,2 & 1,9 & 0,9 & 3,9 & 3,9 & 3,8 & 4,0 & 4,4 & 7,8 & 5,2 & 3,0 \\
\hline Desvio Padrão & 0,9 & 2,2 & 0,5 & 0,8 & 0,8 & 0,7 & 0,7 & 1,2 & 0,9 & 0,7 & 5,1 & 1,8 & 1,6 \\
\hline
\end{tabular}


Tabela 71: Concentrações de fósforo total dissolvido $\left(\mu \mathrm{g} \cdot \mathrm{L}^{-1}\right)$ determinados na água coleta em cada unidade experimental

\begin{tabular}{|c|c|c|c|c|c|c|c|c|c|c|c|c|c|}
\hline & $\overline{18.11}$ & 21.11 & 22.11 & 26.11 & 29.11 & 03.12 & 06.12 & 09.12 & 13.12 & 16.12 & 19.12 & 23.12 & 26.12 \\
\hline Controle 1 & 20,1 & 8,2 & 14,0 & 9,2 & 13,5 & 12,3 & 13,7 & 11,9 & 10,2 & 19,5 & 18,9 & 15,2 & 19,4 \\
\hline Controle 2 & 16,7 & 6,8 & 12,1 & 11,8 & 11,8 & 13,3 & 14,9 & 14,7 & 11,2 & 17,0 & 11,8 & 13,1 & 13,5 \\
\hline Controle 3 & 21,2 & 10,6 & 16,1 & 12,5 & 17,3 & 13,0 & 16,0 & 11,2 & 11,9 & 15,3 & 7,8 & 14,9 & 14,4 \\
\hline Média & 19,3 & 8,6 & 14,1 & 11,2 & 14,2 & 12,9 & 14,9 & 12,6 & 11,1 & 17,2 & 12,8 & 14,4 & 15,8 \\
\hline Desvio Padrão & 2,3 & 1,9 & 2,0 & 1,8 & 2,8 & 0,5 & 1,1 & 1,9 & 0,9 & 2,1 & 5,6 & 1,2 & 3,2 \\
\hline Cromo 1 & 20,5 & 7,7 & 13,0 & 7,9 & 11,5 & 10,4 & 12,2 & 14,6 & 8,9 & 21,8 & 19,9 & 11,7 & 12,4 \\
\hline Cromo 2 & 17,5 & 4,4 & 14,7 & 12,5 & 10,1 & 9,5 & 14,0 & 13,2 & 7,9 & 15,4 & 12,1 & 14,8 & 13,0 \\
\hline Cromo 3 & 14,8 & 11,1 & 12,2 & 13,1 & 12,7 & 12,5 & 13,2 & 13,4 & 10,9 & 15,7 & 7,5 & 11,7 & 11,9 \\
\hline Média & 17,6 & 7,7 & 13,3 & 11,1 & 11,4 & 10,8 & 13,1 & 13,7 & 9,3 & 17,6 & 13,2 & 12,8 & 12,4 \\
\hline Desvio Padrão & 2,8 & 3,3 & 1,3 & 2,8 & 1,3 & 1,5 & 0,9 & 0,8 & 1,5 & 3,6 & 6,3 & 1,8 & 0,5 \\
\hline Cobre 1 & 18,2 & 7,5 & 11,1 & 7,7 & 11,4 & 11,8 & 14,2 & 11,7 & 8,5 & 15,7 & 8,3 & 13,2 & 14,6 \\
\hline Cobre 2 & 16,1 & 10,1 & 13,3 & 12,1 & 12,5 & 12,7 & 14,8 & 13,9 & 10,8 & 13,3 & 15,4 & 11,9 & 13,4 \\
\hline Cobre3 & 14,9 & 9,3 & 13,1 & 11,8 & 13,4 & 11,9 & 12,5 & 14,9 & 7,4 & 13,2 & 8,3 & 9,8 & 10,4 \\
\hline Média & 16,4 & 9,0 & 12,5 & 10,5 & 12,5 & 12,1 & 13,8 & 13,5 & 8,9 & 14,1 & 10,7 & 11,6 & 12,8 \\
\hline Desvio Padrão & 1,7 & 1,4 & 1,2 & 2,4 & 1,0 & 0,5 & 1,2 & 1,6 & 1,7 & 1,4 & 4,1 & 1,7 & 2,1 \\
\hline
\end{tabular}


Tabela 72: Concentrações de fósforo total $\left(\mu \mathrm{g} \cdot \mathrm{L}^{-1}\right)$ determinados na água coleta em cada unidade experimental

\begin{tabular}{|c|c|c|c|c|c|c|c|c|c|c|c|c|c|}
\hline & 18.11 & 21.11 & 22.11 & 26.11 & 29.11 & 03.12 & 06.12 & 09.12 & 13.12 & 16.12 & 19.12 & 23.12 & 26.12 \\
\hline Controle 1 & 121,7 & 81,2 & 34,0 & 57,8 & 34,0 & 81,4 & 23,1 & 73,2 & 70,7 & 53,9 & 48,5 & 72,6 & 50,2 \\
\hline Controle 2 & 86,3 & 24,4 & 32,9 & 71,1 & 34,8 & 77,6 & 21,9 & 60,5 & 72,1 & 44,1 & 37,9 & 63,0 & 60,2 \\
\hline Controle 3 & 130,9 & 28,4 & 33,6 & 76,6 & 33,3 & 85,5 & 22,7 & 76,0 & 98,8 & 46,4 & 44,4 & 93,2 & 133,8 \\
\hline Média & 113,0 & 44,6 & 33,5 & 68,5 & 34,0 & 81,5 & 22,6 & 69,9 & 80,5 & 48,1 & 43,6 & 76,3 & 81,4 \\
\hline Desvio Padrão & 23,6 & 31,7 & 0,5 & 9,7 & 0,8 & 4,0 & 0,6 & 8,3 & 15,8 & 5,1 & 5,3 & 15,4 & 45,6 \\
\hline Cromo 1 & 112,7 & 59,1 & 39,2 & 61,7 & 19,2 & 77,7 & 22,6 & 63,8 & 77,7 & 32,2 & 38,0 & 69,2 & 69,0 \\
\hline Cromo 2 & 124,0 & 71,1 & 41,2 & 75,1 & 29,3 & 78,9 & 20,3 & 50,2 & 77,7 & 37,6 & 36,4 & 53,0 & 63,3 \\
\hline Cromo3 & 95,6 & 26,5 & 50,4 & 69,7 & 34,1 & 87,8 & 24,7 & 93,5 & 73,9 & 38,1 & 35,9 & 91,3 & 58,8 \\
\hline Média & 110,8 & 52,2 & 43,6 & 68,8 & 27,5 & 81,5 & 22,5 & 69,2 & 76,4 & 36,0 & 36,8 & 71,1 & 63,7 \\
\hline Desvio Padrão & 14,3 & 23,1 & 6,0 & 6,7 & 7,6 & 5,5 & 2,2 & 22,1 & 2,2 & 3,3 & 1,1 & 19,2 & 5,1 \\
\hline Cobre 1 & 108,9 & 101,8 & 36,6 & 68,4 & 30,2 & 699,6 & 21,6 & 77,7 & 89,7 & 41,7 & 36,2 & 62,6 & 41,3 \\
\hline Cobre 2 & 81,8 & 30,9 & 32,6 & 62,3 & 34,5 & 90,8 & 22,1 & 56,6 & 78,7 & 43,0 & 43,2 & 88,6 & 66,2 \\
\hline Cobre3 & 64,2 & 44,8 & 45,1 & 29,0 & 36,8 & 82,7 & 24,5 & 65,4 & 34,7 & 36,0 & 35,3 & 70,7 & 52,4 \\
\hline Média & 85,0 & 59,1 & 38,1 & 53,2 & 33,8 & 81,0 & 22,7 & 66,6 & 67,7 & 40,3 & 38,2 & 74,0 & 53,3 \\
\hline Desvio Padrão & 22,5 & 37,6 & 6,4 & 21,2 & 3,4 & 10,7 & 1,6 & 10,6 & 29,1 & 3,8 & 4,3 & 13,3 & 12,5 \\
\hline
\end{tabular}


Tabela 73: Concentrações de cobre $\left(\mu \mathrm{g} \cdot \mathrm{L}^{-1}\right)$ determinados na água coleta em cada unidade experimental $\begin{array}{lllllllllllll}18.11 & 20.11-20.11-21.11 & 22.11 & 26.11 & 29.11 & 03.12 & 06.12 & 09.12 & 12.12-12.12-13.12 & 16.12 & 19.12 & 23.12 & 26.12\end{array}$ Oh $\quad 3 h$ Oh $\quad 3 h$

\begin{tabular}{|c|c|c|c|c|c|c|c|c|c|c|c|c|c|c|c|c|c|}
\hline Controle 1 & 2,2 & 2,0 & 3,4 & 2,1 & 10,6 & 3,7 & 2,2 & 3,5 & 7,5 & 8,5 & 3,5 & 4,0 & 4,6 & 4,5 & 4,8 & 6,4 & 4,7 \\
\hline Controle 2 & 5,4 & 5,7 & 4,2 & 3,3 & 6,1 & 2,9 & 4,4 & 10,4 & 2,3 & 4,4 & 4,8 & 2,2 & 2,8 & 1,8 & 4,6 & 2,6 & 13,5 \\
\hline Controle 3 & 15,5 & 4,0 & 8,4 & 12,6 & $<\mathrm{LQ}$ & 2,6 & 2,1 & 2,7 & $<\mathrm{LQ}$ & 5,3 & $<L Q$ & 4,2 & 1,9 & 5,6 & $<\mathrm{LQ}$ & 5,1 & 1,3 \\
\hline Média & 7,7 & 3,9 & 5,3 & 6,0 & 8,4 & 3,1 & 2,9 & 5,6 & 5,4 & 6,1 & 4,1 & 3,5 & 3,1 & 4,0 & 4,7 & 4,7 & 6,5 \\
\hline Desvio Padrão & 7,0 & 1,9 & 2,7 & 5,8 & 4,6 & 0,6 & 1,3 & 4,2 & 3,3 & 2,2 & 2,3 & 1,1 & 1,4 & 2,0 & 1,9 & 2,0 & 6,3 \\
\hline Cobre 1 & 2,6 & 0,0 & 17,6 & 16,7 & 15,0 & 5,2 & $<\mathrm{LQ}$ & $\overline{3,3}$ & 3,2 & 3,0 & 4,5 & 22,7 & $\overline{~ 19,0}$ & 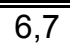 & $\overline{3,5}$ & 2,3 & $\overline{4,6}$ \\
\hline Cobre 2 & 6,2 & 0,0 & 14,8 & 25,9 & 10,3 & 10,2 & 2,6 & ND & 3,0 & 5,3 & 2,1 & 38,1 & 11,3 & 4,3 & 2,0 & 2,4 & 1,2 \\
\hline Cobre 3 & 5,6 & 0,0 & 37,7 & 18,9 & 7,5 & 5,6 & $<\mathrm{LQ}$ & $<\mathrm{LQ}$ & ND & 5,1 & 3,0 & 51,0 & 10,2 & 2,0 & $<\mathrm{LQ}$ & $<L Q$ & 4,0 \\
\hline Média & 4,8 & 0,0 & 23,4 & 20,5 & 10,9 & 7,0 & 2,6 & 3,3 & 2,1 & 4,5 & 3,2 & 37,3 & 13,5 & 4,4 & 2,5 & 2,3 & 3,3 \\
\hline Desvio Padrão & 1,9 & 0,0 & 12,5 & 4,8 & 3,8 & 2,8 & & & 1,7 & 1,3 & 1,2 & 14,1 & 4,8 & 2,4 & 1,3 & 0,7 & 1,9 \\
\hline
\end{tabular}


Tabela 74: Concentrações de cromo $\left(\mu \mathrm{g} \cdot \mathrm{L}^{-1}\right)$ determinados na água coleta em cada unidade experimental

\begin{tabular}{|c|c|c|c|c|c|c|c|c|c|c|c|c|c|c|c|c|c|}
\hline & 18.11 & 20.11 & $20.11-$ & 21.11 & 22.11 & 26.11 & 29.11 & 03.12 & 06.12 & 09.12 & 12.12 & $12.12-$ & 13.12 & 16.12 & 19.12 & 23.12 & 26.12 \\
\hline & & Oh & $3 h$ & & & & & & & & $\mathrm{Oh}$ & $3 h$ & & & & & \\
\hline Controle 1 & ND & ND & 39,4 & 18,3 & 3,5 & $<\mathrm{LQ}$ & ND & ND & ND & ND & ND & 60,2 & 18,2 & nd & ND & ND & ND \\
\hline Controle 2 & ND & ND & 53,6 & 42,0 & 22,6 & 6,7 & 2,1 & ND & 4,1 & ND & ND & 48,2 & 38,9 & $<L Q$ & 4,5 & $<L Q$ & ND \\
\hline Controle 3 & ND & ND & 46,5 & 32,2 & 21,0 & 5,9 & 0,9 & ND & ND & ND & ND & 31,7 & 33,0 & 10,6 & 2,1 & $<L Q$ & ND \\
\hline Média & & & 46,5 & 30,8 & 15,7 & 4,2 & 1,5 & & 4,1 & & & 46,7 & 30,0 & 5,7 & 3,3 & 0,5 & \\
\hline Desvio Padrão & & & 7,1 & 11,9 & 10,6 & 3,6 & 0,8 & & & & & 14,3 & 10,6 & 7,0 & 1,7 & 0,0 & \\
\hline
\end{tabular}


Tabela 75: Concentrações potencialmente disponíveis $\left(\mathrm{mg} \cdot \mathrm{kg}^{-1}\right)$ de $\mathrm{Cu}$ determinadas nas amostras de sedimento coletadas nos tanques.

\begin{tabular}{llll}
\hline \hline & 19.11 & 09.12 & 27.12 \\
\hline \hline Controle 1 & 13,6 & 11,1 & 13,3 \\
Controle 2 & 10,5 & 11,4 & 12,5 \\
Controle 3 & & 9,3 & 8,7 \\
\hline Média & 12,0 & 10,6 & 11,5 \\
\hline Desvio Padrão & 2,2 & 1,1 & 2,5 \\
\hline \hline Cobre 1 & 11,4 & 11,5 & 13,4 \\
Cobre 2 & 10,4 & 9,2 & 11,1 \\
Cobre 3 & 8,6 & 8,5 & 7,8 \\
\hline Média & 10,1 & 9,7 & 10,7 \\
\hline Desvio Padrão & 1,4 & 1,6 & 2,8 \\
\hline \hline
\end{tabular}

Tabela 76: Concentrações totais $\left(\mathrm{mg}^{\mathrm{kg}}{ }^{-1}\right)$ de $\mathrm{Cr}$ determinados nas amostras de sedimento coletadas nos tanques.

\begin{tabular}{llll}
\hline \hline & 19.11 & 09.12 & 27.12 \\
\hline \hline Controle 1 & 230,4 & 24,4 & 19,3 \\
Controle 2 & 162,5 & 49,0 & 55,6 \\
Controle 3 & & 58,6 & 72,5 \\
\hline Média & 196,5 & 44,0 & 49,1 \\
\hline Desvio Padrão & 48,1 & 17,6 & 27,2 \\
\hline \hline Cromo 1 & 98,5 & & \\
Cromo 2 & 162,2 & 37,9 & 59,3 \\
Cromo 3 & & 105,2 & 111,6 \\
\hline Média & 130,3 & 71,5 & 85,4 \\
\hline Desvio Padrão & 45,0 & 47,6 & 37,0 \\
\hline \hline
\end{tabular}


Tabela 77: Concentrações totais $\left(\mathrm{mg}^{\mathrm{kg}}{ }^{-1}\right)$ de $\mathrm{Cu}$ determinadas nas amostras de sedimento coletadas nos tanques.

\begin{tabular}{llll}
\hline \hline & 19.11 & 09.12 & 27.12 \\
\hline \hline Controle 1 & 57,7 & 48,9 & 89,5 \\
Controle 2 & 74,7 & 53,6 & 58,2 \\
Controle 3 & 94,5 & 52,6 & 65,3 \\
\hline Média & 75,6 & 51,7 & 71,0 \\
\hline Desvio Padrão & 18,4 & 2,5 & 16,4 \\
\hline \hline Cobre 1 & 61,9 & 48,1 & 61,3 \\
Cobre 2 & 80,8 & 47,1 & 88,0 \\
Cobre 3 & 64,5 & 42,5 & 81,7 \\
\hline Média & 69,1 & 45,9 & 77,0 \\
\hline Desvio Padrão & 10,3 & 3,0 & 13,9 \\
\hline \hline
\end{tabular}

Tabela 78: Concentrações $\left(\mu \mathrm{g} \cdot \mathrm{L}^{-1}\right)$ de $\mathrm{Cr}$ determinados nas amostras de água intersticial, separadas do sedimento, coletadas nos tanques controle e contaminados com $\mathrm{Cr}$.

\begin{tabular}{llll}
\hline \hline & 19.11 & 09.12 & 27.12 \\
\hline \hline Controle 1 & nd & nd & nd \\
Controle 2 & 1,1 & nd & 1,0 \\
Controle 3 & nd & 2,7 & 1,4 \\
\hline Média & 1,1 & 2,7 & 1,2 \\
\hline Desvio Padrão & & & 0,2 \\
\hline \hline Cromo 1 & 3,5 & nd & 2,7 \\
Cromo 2 & 1,3 & 1,7 & 2,8 \\
Cromo 3 & 2,0 & 1,6 & 3,0 \\
\hline Média & 2,3 & 1,2 & 2,8 \\
\hline Desvio Padrão & 1,1 & 0,8 & 0,2 \\
\hline \hline
\end{tabular}


Tabela 79: Concentrações $\left(\mu \mathrm{g} \cdot \mathrm{L}^{-1}\right)$ de $\mathrm{Cu}$ determinados nas amostras de água intersticial, separadas do sedimento, coletadas nos tanques controle e contaminados com $\mathrm{Cu}$.

\begin{tabular}{llll}
\hline \hline & 19.11 & 09.12 & 27.12 \\
\hline \hline Controle 1 & 141,3 & 69,6 & 71,1 \\
Controle 2 & 103,3 & 187,2 & 113,4 \\
Controle 3 & 81,8 & $\mathrm{nd}$ & $\mathrm{nd}$ \\
\hline Média & 108,8 & 128,4 & 92,3 \\
\hline Desvio Padrão & 30,1 & 83,2 & 29,9 \\
\hline \hline Cobre 1 & $\mathrm{nd}$ & 83,8 & $\mathrm{nd}$ \\
Cobre 2 & 61,7 & 83,6 & 31,0 \\
Cobre 3 & 110,2 & $\mathrm{nd}$ & 81,3 \\
\hline Média & 85,9 & 83,7 & 56,1 \\
\hline Desvio Padrão & 34,3 & 0,1 & 35,6 \\
\hline \hline
\end{tabular}

Tabela 80: Teores de matéria orgânica (\%, perda ao fogo $\left.550^{\circ} \mathrm{C}\right)$ determinados nas amostras de sedimento coletadas nos tanques.

\begin{tabular}{llll}
\hline \hline & 19.11 & 09.12 & 27.12 \\
\hline \hline Controle 1 & 14,8 & 15,1 & 21,0 \\
Controle 2 & 14,2 & 16,0 & 20,8 \\
Controle 3 & 14,4 & 14,9 & 16,3 \\
\hline Média & 14,5 & 15,3 & 19,4 \\
\hline Desvio Padrão & 0,3 & 0,6 & 2,7 \\
\hline \hline Cromo 1 & 14,1 & 15,8 & 18,5 \\
Cromo 2 & 13,8 & 13,6 & 18,9 \\
Cromo 3 & 14,2 & 14,7 & 18,9 \\
\hline Média & 14,0 & 14,7 & 18,8 \\
\hline Desvio Padrão & 0,2 & 1,1 & 0,2 \\
\hline \hline Cobre 1 & 13,8 & 13,9 & 23,1 \\
Cobre 2 & 14,1 & 17,1 & 21,4 \\
Cobre 3 & 14,2 & 15,8 & 18,0 \\
\hline Média & 14,0 & 15,6 & 20,9 \\
\hline Desvio Padrão & 0,2 & 1,6 & 2,6 \\
\hline \hline
\end{tabular}


Tabela 81: Concentração de nitrogênio (\%) determinados nas amostras de sedimento coletadas nos tanques.

\begin{tabular}{llll}
\hline \hline & 19.11 & 09.12 & 27.12 \\
\hline \hline Controle 1 & 0,12 & 0,10 & 0,10 \\
Controle 2 & 0,01 & 0,13 & 0,01 \\
Controle 3 & 0,01 & 0,13 & 0,01 \\
\hline Média & 0,04 & 0,12 & 0,04 \\
\hline Desvio Padrão & 0,06 & 0,01 & 0,06 \\
\hline \hline Cromo 1 & 0,12 & 0,01 & 0,11 \\
Cromo 2 & 0,09 & 0,12 & 0,09 \\
Cromo 3 & 0,11 & 0,10 & 0,09 \\
\hline Média & 0,11 & 0,07 & 0,10 \\
\hline Desvio Padrão & 0,02 & 0,06 & 0,01 \\
\hline \hline Cobre 1 & 0,11 & 0,10 & 0,13 \\
Cobre 2 & 0,10 & 0,11 & 0,10 \\
Cobre 3 & 0,01 & 0,11 & 0,11 \\
\hline Média & 0,07 & 0,11 & 0,11 \\
\hline Desvio Padrão & 0,06 & 0,00 & 0,01 \\
\hline \hline
\end{tabular}

Tabela 82: Concentrações de fósforo $\left(\mathrm{mg}^{\mathrm{kg}}{ }^{-1}\right)$ determinados nas amostras de sedimento coletadas nos tanques.

\begin{tabular}{llll}
\hline \hline & 19.11 & 09.12 & 27.12 \\
\hline \hline Controle 1 & 430,0 & 338,7 & 319,9 \\
Controle 2 & 340,5 & 407,1 & 383,1 \\
Controle 3 & 421,7 & 305,3 & 290,2 \\
\hline Média & 397,4 & 350,3 & 331,1 \\
\hline Desvio Padrão & 49,5 & 51,9 & 47,4 \\
\hline \hline Cromo 1 & 348,5 & 333,1 & 235,6 \\
Cromo 2 & 351,0 & 204,4 & 386,8 \\
Cromo 3 & 367,4 & 179,5 & 296,3 \\
\hline Média & 355,6 & 239,0 & 306,2 \\
\hline Desvio Padrão & 10,3 & 82,4 & 76,1 \\
\hline \hline Cobre 1 & 336,6 & 400,7 & 352,7 \\
Cobre 2 & 379,3 & 323,9 & 361,6 \\
Cobre 3 & 395,8 & 401,4 & 260,5 \\
\hline Média & 370,5 & 375,3 & 324,9 \\
\hline Desvio Padrão & 30,6 & 44,5 & 55,9 \\
\hline \hline
\end{tabular}


Tabela 83: Massa (g) das amostras de plâncton para análise de metais determinada em cada coleta.

\section{$\begin{array}{lllllllll}18.11 & 21.11 & 29.11 & 03.12 & 9.12 & 13.12 & 16.12 & 23.12 & 26.12\end{array}$}

\begin{tabular}{llllllllll}
\hline Controle 1 & 0,289 & 0,021 & 0,012 & 0,034 & 0,081 & 0,059 & 0,022 & 0,037 & 0,015 \\
Controle 2 & 0,046 & 0,017 & 0,026 & 0,014 & 0,018 & 0,035 & 0,023 & 0,025 & 0,026 \\
Controle 3 & 0,014 & 0,012 & 0,021 & 0,012 & 0,015 & 0,027 & 0,019 & 0,121 & 0,012 \\
\hline Média & 0,116 & 0,017 & 0,020 & 0,020 & 0,038 & 0,040 & 0,021 & 0,061 & 0,018 \\
\hline Desvio & 0,151 & 0,004 & 0,007 & 0,012 & 0,037 & 0,016 & 0,002 & 0,052 & 0,007 \\
Padrão & & & & & & & & & \\
\hline \hline Cromo 1 & 0,096 & 0,021 & 0,017 & 0,092 & 0,033 & 0,515 & 0,037 & 0,048 & 0,027 \\
Cromo 2 & 0,053 & 0,013 & 0,007 & & 0,012 & 0,069 & 0,016 & 0,038 & 0,017 \\
Cromo 3 & 0,012 & 0,009 & 0,017 & 0,022 & 0,020 & 0,030 & 0,017 & 0,034 & 0,009 \\
\hline Média & 0,054 & 0,014 & 0,014 & 0,057 & 0,022 & 0,204 & 0,023 & 0,040 & 0,018 \\
\hline Desvio & 0,042 & 0,006 & 0,006 & 0,050 & 0,011 & 0,270 & 0,012 & 0,007 & 0,009 \\
Padrão & & & & & & & & & \\
\hline \hline Cobre 1 & 0,058 & 0,019 & 0,006 & 0,036 & 0,012 & 0,026 & 0,011 & 0,022 & 0,009 \\
Cobre 2 & 0,018 & 0,036 & 0,008 & 0,013 & 0,024 & 0,054 & 0,019 & 0,022 & 0,015 \\
Cobre 3 & 0,012 & 0,022 & 0,033 & 0,020 & 0,016 & 0,048 & 0,014 & 0,020 & 0,016 \\
\hline Média & 0,029 & 0,026 & 0,016 & 0,023 & 0,017 & 0,043 & 0,015 & 0,021 & 0,013 \\
\hline Desvio & 0,025 & 0,009 & 0,015 & 0,012 & 0,006 & 0,014 & 0,004 & 0,001 & 0,004 \\
Padrão & & & & & & & & & \\
\hline \hline
\end{tabular}


Tabela 84: Concentrações de $\mathrm{Cu}\left(\mu \mathrm{g} \cdot \mathrm{g}^{-1}\right)$ determinadas nas amostras de plâncton

\begin{tabular}{llllllllll}
\hline \hline & 18.11 & 21.11 & 29.11 & 03.12 & 9.12 & 13.12 & 16.12 & 23.12 & 26.12 \\
\hline \hline Controle 1 & 59,5 & 139,9 & 118,4 & 160,5 & 68,0 & 54,6 & 55,3 & 74,7 & 168,9 \\
Controle 2 & 202,0 & 142,1 & 65,0 & 85,3 & 102,4 & 60,1 & 80,1 & 174,4 & 62,4 \\
Controle 3 & 90,0 & 93,9 & 95,8 & & 158,0 & 59,4 & 68,0 & & 126,2 \\
\hline Média & 117,2 & 125,3 & 93,1 & 122,9 & 109,5 & 58,0 & 67,8 & 124,6 & 119,2 \\
\hline Desvio & 75,0 & 27,2 & 26,8 & 53,1 & 45,4 & 3,0 & 12,4 & 70,5 & 53,6 \\
Padrão & & & & & & & & & \\
\hline Cobre 1 & 125,3 & 290,6 & 191,4 & & 167,6 & 226,7 & 225,2 & 278,4 & 185,6 \\
Cobre 2 & 110,9 & 155,2 & 306,3 & 122,6 & 248,3 & 121,4 & 152,2 & 104,1 & 88,9 \\
Cobre 3 & 198,0 & 272,0 & 95,0 & 106,5 & 116,4 & 150,7 & 105,2 & 81,5 & 66,8 \\
\hline Média & 144,7 & 239,3 & 197,6 & 114,6 & 177,4 & 166,2 & 160,9 & 154,7 & 113,8 \\
\hline Desvio & 46,7 & 73,4 & 105,8 & 11,4 & 66,5 & 54,4 & 60,5 & 107,8 & 63,2 \\
Padrão & & & & & & & & & \\
\hline \hline
\end{tabular}

Tabela 85: Concentrações de $\mathrm{Cr}\left(\mu \mathrm{g} \cdot \mathrm{g}^{-1}\right)$ determinadas nas amostras de plâncton

\begin{tabular}{llllllllll}
\hline \hline & 18.11 & 21.11 & 29.11 & 03.12 & 9.12 & 13.12 & 16.12 & 23.12 & 26.12 \\
\hline \hline Controle 1 & 5,1 & 19,7 & 66,5 & 5,7 & 20,4 & 8,1 & 52,2 & 37,9 & 10,6 \\
Controle 2 & 11,2 & 17,7 & 25,7 & 58,0 & & 23,1 & & 35,6 & 20,1 \\
Controle 3 & 16,0 & 65,8 & 19,6 & & 19,5 & 21,3 & 12,9 & 22,5 & 36,2 \\
\hline Média & 10,8 & 34,4 & 37,3 & 31,9 & 9,0 & 17,5 & 32,5 & 32,0 & 22,3 \\
\hline Desvio & 5,4 & 27,2 & 25,5 & 37,0 & 18,9 & 8,2 & 27,8 & 8,3 & 12,9 \\
Padrão & & & & & & & & & \\
\hline \hline Cromo 1 & 61,8 & 49,8 & 318,4 & & & 71,6 & 47,1 & 25,0 & 33,2 \\
Cromo 2 & 101,6 & 126,6 & 12,0 & 9,3 & 23,6 & & 50,4 & & 38,5 \\
Cromo 3 & 6,7 & 41,8 & 46,5 & 20,0 & 39,5 & 13,3 & 58,8 & 27,6 & 7,1 \\
\hline Média & 56,7 & 72,8 & 125,6 & 14,7 & 14,9 & 25,7 & 52,1 & 15,2 & 26,3 \\
\hline Desvio & 47,7 & 46,8 & 167,8 & 7,5 & 30,0 & 41,1 & 6,0 & 19,2 & 16,8 \\
Padrão & & & & & & & & & \\
\hline \hline
\end{tabular}


Tabela 86: Concentrações $\left(\mu \mathrm{g} \cdot \mathrm{g}^{-1}\right)$ de $\mathrm{Cr}$ determinados nas amostras de peixe (Oreochromis niloticus) coletadas nos tanques controle e contaminados com $\mathrm{Cr}$.

\begin{tabular}{lll}
\hline \hline & Média* $^{*}$ & Desvio Padrão* \\
\hline \hline Controle 1 & 0,81 & 0,39 \\
Controle 2 & & \\
Controle 3 & 0,26 & \\
\hline Média & 0,43 & \\
\hline Desvio Padrão & 0,24 & 0,02 \\
\hline \hline Cromo 1 & 0,65 & 0,19 \\
Cromo 2 & 1,51 & 0,19 \\
Cromo 3 & 1,16 & \\
\hline Média & 1,11 & \\
\hline Desvio Padrão & 0,44 & \\
\hline \hline
\end{tabular}

*Em relação às três amostras compostas formadas com os peixes de cada

tanque.

Tabela 87: Concentrações $\left(\mu \mathrm{g} \cdot \mathrm{g}^{-1}\right)$ de $\mathrm{Cu}$ determinadas nas amostras de peixe (Oreochromis niloticus) coletadas nos tanques controle e contaminados com $\mathrm{Cu}$.

\begin{tabular}{lll}
\hline \hline & Média & Desvio Padrão \\
\hline \hline Controle 1 & 4,86 & 0,8 \\
Controle 2 & & \\
Controle 3 & 3,96 & 3,9 \\
\hline Média & 4,4 & \\
\hline Desvio Padrão & 0,64 & 0,5 \\
\hline \hline Cobre 1 & 8,78 & 1,9 \\
Cobre 2 & 15,14 & 2,4 \\
Cobre 3 & 7,10 & \\
\hline Média & 10,34 & \\
\hline Desvio Padrão & 4,24 & \\
\hline \hline
\end{tabular}

*Em relação às três amostras compostas formadas com os peixes de cada tanque. 
Tabela 88: Concentrações $\left(\mu \mathrm{g} \cdot \mathrm{g}^{-1}\right)$ de $\mathrm{Cr}$ determinados nas amostras de macrófita (Pistia stratiotes) coletadas nos tanques controle e contaminados com $\mathrm{Cr}$.

\begin{tabular}{l|ll|ll}
\hline \hline & Parte Aérea & & \multicolumn{2}{|l}{ Parte Subterrânea } \\
& Média* $^{*}$ & Desvio Padrão* & Média* & Desvio Padrão* \\
\hline \hline Controle 1 & 2,4 & 0,2 & 5,9 & 0,9 \\
Controle 2 & 3,6 & 0,7 & 11,2 & 0,3 \\
Controle 3 & 2,2 & 0,4 & 12,1 & 1,7 \\
\hline Média & 2,8 & 0,8 & 9,7 & 3,4 \\
\hline \hline Cromo 1 & 3,7 & 1,0 & 23,4 & 0,6 \\
Cromo 2 & 6,3 & 0,1 & 42,5 & 0,6 \\
Cromo 3 & 9,1 & 1,6 & 52,9 & 2,4 \\
\hline Média & 6,3 & 0,7 & 39,6 & 1,0 \\
\hline \hline
\end{tabular}

*Em relação às três amostras compostas formadas com as macrófitas de cada tanque.

Tabela 89: Concentrações $\left(\mu \mathrm{g} \cdot \mathrm{g}^{-1}\right)$ de $\mathrm{Cu}$ determinadas nas amostras de macrófita (Pistia stratiotes) coletadas nos tanques controle e contaminados com Cu.

\begin{tabular}{l|ll|ll}
\hline \hline & Parte Aérea & & \multicolumn{2}{|l}{ Parte Subterrânea } \\
& Média* & Desvio Padrão* & Média* & Desvio Padrão* \\
\hline \hline Controle 1 & 6,7 & 4,6 & 39,5 & 15,7 \\
Controle 2 & 8,0 & 2,0 & 54,7 & 5,6 \\
Controle 3 & 4,5 & 10,7 & 60,5 & 9,0 \\
\hline Média & 6,4 & 1,8 & 51,6 & 10,8 \\
\hline \hline Cromo 1 & 15,6 & 1,8 & 135,4 & 38,8 \\
Cromo 2 & 5,4 & 0,8 & 77,7 & 5,7 \\
Cromo 3 & 7,2 & 4,3 & 47,0 & 2,9 \\
\hline Média & 9,4 & 5,4 & 86,7 & 44,9 \\
\hline \hline
\end{tabular}

*Em relação às três amostras compostas formadas com asmacrófitas de cada tanque. 
Tabela 90: Produção primária do fitoplâncton $\left(\mathrm{mg} \mathrm{O}_{2} \cdot \mathrm{L}^{-1}\right)$ determinada nos experimentos ante e após a contaminação.

\begin{tabular}{lllll}
\hline \hline & 18.11 & 20.11 & 10.12 & 12.12 \\
\hline Controle 1 & 0,58 & 0,52 & 0,27 & 0,79 \\
Controle 2 & 0,36 & 0,65 & 0,66 & 0,89 \\
Controle 3 & 0,34 & 0,69 & 0,44 & 0,87 \\
\hline Média & 0,43 & 0,62 & 0,46 & 0,85 \\
\hline Desvio Padrão & 0,14 & 0,09 & 0,20 & 0,05 \\
\hline \hline Cromo 1 & 0,31 & 0,29 & 0,32 & 0,40 \\
Cromo 2 & 0,46 & 0,37 & 0,40 & 0,12 \\
Cromo 3 & 0,30 & 0,09 & 0,67 & 0,29 \\
\hline Média & 0,36 & 0,25 & 0,46 & 0,27 \\
\hline Desvio Padrão & 0,09 & 0,15 & 0,19 & 0,14 \\
\hline \hline Cobre 1 & 0,37 & 0,21 & 0,04 & $-0,01$ \\
Cobre 2 & 0,35 & 0,19 & 0,67 & 0,16 \\
Cobre 3 & 0,38 & 0,12 & 0,36 & 0,11 \\
\hline Média & 0,37 & 0,17 & 0,36 & 0,09 \\
\hline Desvio Padrão & 0,01 & 0,05 & 0,31 & 0,09 \\
\hline \hline
\end{tabular}


Tabela 91: Comparação dos valores obtidos para as análises químicas e físico químicas entre as réplicas para todas as datas através de análise de variância.

\begin{tabular}{|c|c|c|c|c|}
\hline & & $\overline{\bar{F}}$ & valor-P & F crítico \\
\hline & Controle & 0,14 & 0,874 & 3,259 \\
\hline \multirow[t]{3}{*}{$\mathrm{pH}$} & Cromo & 0,12 & 0,886 & 3,259 \\
\hline & Cobre & 0,56 & 0,576 & 3,259 \\
\hline & Controle & 0,92 & 0,409 & 3,259 \\
\hline \multirow[t]{3}{*}{ OD } & Cromo & 1,35 & 0,271 & 3,259 \\
\hline & Cobre & 2,00 & 0,150 & 3,259 \\
\hline & Controle & 1,50 & 0,237 & 3,259 \\
\hline \multirow[t]{3}{*}{ Condutividade } & Cromo & 2,11 & 0,136 & 3,259 \\
\hline & Cobre & 0,67 & 0,520 & 3,259 \\
\hline & Controle & 0,00 & 1,00 & 3,259 \\
\hline \multirow[t]{3}{*}{ Temperatura } & Cromo & 0,07 & 0,937 & 3,259 \\
\hline & Cobre & 0,13 & 0,882 & 3,259 \\
\hline & Controle & 5,03 & 0,012 & 3,259 \\
\hline \multirow[t]{3}{*}{ MST } & Cromo & 1,13 & 0,315 & 3,259 \\
\hline & Cobre & 0,04 & 0,961 & 3,259 \\
\hline & Controle & 3,50 & 0,041 & 3,259 \\
\hline \multirow[t]{3}{*}{ MSO } & Cromo & 1,90 & 0,164 & 3,259 \\
\hline & Cobre & 0,15 & 0,858 & 3,259 \\
\hline & Controle & 1,75 & 0,189 & 3,259 \\
\hline \multirow[t]{3}{*}{ MSI } & Cromo & 0,53 & 0,594 & 3,259 \\
\hline & Cobre & 2,07 & 0,141 & 3,259 \\
\hline & Controle & 0,22 & 0,806 & 3,259 \\
\hline \multirow[t]{3}{*}{ PO4 } & Cromo & 1,51 & 0,234 & 3,259 \\
\hline & Cobre & 0,38 & 0,686 & 3,259 \\
\hline & Controle & 0,55 & 0,583 & 3,259 \\
\hline \multirow[t]{3}{*}{ PTD } & Cromo & 0,32 & 0,727 & 3,259 \\
\hline & Cobre & 128 & 0,289 & 3,259 \\
\hline & Controle & 1,06 & 0,358 & 3,259 \\
\hline \multirow[t]{3}{*}{ PT } & Cromo & 0,04 & 0,962 & 3,259 \\
\hline & Cobre & 0,96 & 0,392 & 3,259 \\
\hline & Controle & 0,31 & 0,734 & 3,259 \\
\hline \multirow[t]{3}{*}{$\mathrm{NH} 4$} & Cromo & 0,42 & 0,659 & 3,259 \\
\hline & Cobre & 0,57 & 0,573 & 3,259 \\
\hline & Controle & 0,20 & 0,824 & 3,259 \\
\hline \multirow[t]{3}{*}{ NO3 2- } & Cromo & 0,83 & 0,445 & 3,259 \\
\hline & Cobre & 1,70 & 0,197 & 3,259 \\
\hline & Controle & 0,17 & 0,847 & 3,259 \\
\hline \multirow[t]{3}{*}{ No3- } & Cromo & 0,35 & 0,707 & 3,259 \\
\hline & Cobre & 0,09 & 0,918 & 3,259 \\
\hline & Controle & 1,47 & 0,244 & 3,259 \\
\hline \multirow[t]{3}{*}{ NT } & Cromo & 1,70 & 0,197 & 3,259 \\
\hline & Cobre & 2,09 & 0,139 & 3,259 \\
\hline & Controle & 0,75 & 0,478 & 3,259 \\
\hline \multirow[t]{3}{*}{ Silicato } & Cromo & 0,01 & 0,992 & 3,259 \\
\hline & Cobre & 0,33 & 0,718 & 3,259 \\
\hline & Controle & 1,30 & 0,284 & 3,259 \\
\hline \multirow[t]{2}{*}{ Clorofila } & Cromo & 1,79 & 0,181 & 3,259 \\
\hline & Cobre & 0,53 & 0,593 & 3,259 \\
\hline Cromo & Cromo & 1,02 & 0,369 & 3,259 \\
\hline \multirow[t]{2}{*}{ Cobre } & Cobre & 0,32 & 0,725 & 3,259 \\
\hline & Controle & 0,072 & 0,9305 & 3,259 \\
\hline
\end{tabular}


Tabela 92: Porcentagem de mortalidade de $D$. similis nas amostras de água coletadas nos tanques durante o experimento.

\begin{tabular}{|c|c|c|c|c|c|c|c|c|c|c|c|c|c|c|c|c|c|}
\hline & 18.11 & 20.11 & 20.11 & 21.11 & 22.11 & 26.11 & 29.11 & 03.12 & 06.12 & 09.12 & 12.12 & 12.12 & 13.12 & 16.12 & 19.12 & 23.12 & 26.12 \\
\hline & & $-O h$ & $-2 h$ & & & & & & & & Ohs & -3 hs & & & & & \\
\hline Controle 1 & 0 & 0 & 50 & 0 & 33 & 8 & 0 & 0 & 0 & 0 & 11 & 0 & 0 & 0 & 0 & - & 10 \\
\hline Controle 2 & 0 & 20 & 0 & 11 & 11 & 0 & 0 & 0 & 0 & 0 & 11 & 0 & 0 & 0 & 0 & 0 & 0 \\
\hline Controle 3 & 0 & 0 & 0 & 11 & 55 & 40 & 0 & 0 & 0 & 11 & 0 & 11 & 20 & 0 & 0 & 0 & 0 \\
\hline Média & 0 & 7 & 17 & 7 & 33 & 16 & 0 & 0 & 0 & 4 & 7 & 4 & 7 & 0 & 0 & 0 & 3 \\
\hline Desvio & 0 & 12 & 29 & 6 & 22 & 21 & 0 & 0 & 0 & 6 & 6 & 6 & 12 & 0 & 0 & 0 & 6 \\
\hline \multicolumn{18}{|l|}{ Padrão } \\
\hline Cromo 1 & 0 & 0 & 100 & 100 & 90 & 25 & 0 & 11 & 0 & 20 & 0 & 100 & 11 & 0 & 0 & 45 & 0 \\
\hline Cromo 2 & 0 & 0 & 100 & 100 & 100 & 23 & 0 & 0 & 0 & 0 & 11 & 100 & 100 & 0 & 11 & 45 & 0 \\
\hline Cromo 3 & 0 & 0 & 100 & 100 & 100 & 22 & 0 & 0 & 0 & 0 & 0 & 100 & 100 & 0 & 0 & 0 & 0 \\
\hline Média & 0 & 0 & 100 & 100 & 97 & 23 & 0 & 4 & 0 & 7 & 4 & 100 & 70 & 0 & 4 & 30 & 0 \\
\hline Desvio & 0 & 0 & 0 & 0 & 6 & 2 & 0 & 6 & 0 & 12 & 6 & 0 & 51 & 0 & 6 & 26 & 0 \\
\hline \multicolumn{18}{|l|}{ Padrão } \\
\hline Cobre 1 & 0 & 0 & 100 & 100 & 11 & 0 & 0 & 0 & 0 & 0 & 11 & 20 & 11 & 0 & 0 & 30 & 0 \\
\hline Cobre 2 & 0 & 0 & 100 & 100 & 44 & 0 & 0 & 0 & 0 & 0 & 20 & 0 & 20 & 0 & 11 & 0 & 0 \\
\hline Cobre 3 & 0 & 0 & 100 & 67 & 22 & 0 & 0 & 0 & 0 & 0 & 0 & 100 & 45 & 0 & 0 & 0 & 0 \\
\hline Média & 0 & 0 & 100 & 89 & 26 & 0 & 0 & 0 & 0 & 0 & 10 & 40 & 25 & 0 & 4 & 10 & 0 \\
\hline Desvio & 0 & 0 & 0 & 19 & 17 & 0 & 0 & 0 & 0 & 0 & 10 & 53 & 18 & 0 & 6 & 17 & 0 \\
\hline Padrão & & & & & & & & & & & & & & & & & \\
\hline
\end{tabular}


Tabela 93: Matriz de correlação de Pearson entre pH, condutividade, oxigênio dissolvido, temperatura, material em suspensão total, orgânico e inorgânico, silicato, nitrato, nitrito, amônio, nitrogênio total, ortofosfato dissolvido, fósforo total dissolvido, fósforo total e clorofila utilizando-se os valores determinados na água superficial no controle e no experimento com $\mathrm{Cr}$ antes da inclusão dos peixes e macrófitas (primeira linha: $r$; segunda linha:p).

\begin{tabular}{|c|c|c|c|c|c|c|c|c|c|c|c|c|c|c|c|c|}
\hline & $\overline{O O D}$ & Cond & Temp & $\mathrm{pH}$ & MST & MSO & $\overline{\mathrm{MSI}}$ & Silicato & Nitrato & Nitrito & Amônio & NT & Ortofosf & 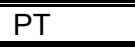 & PTD & Clorofil \\
\hline Cond & $\begin{array}{r}-0,102 \\
0,518\end{array}$ & & & & & & & & & & & & & & & \\
\hline Temp & $\begin{array}{l}0,130 \\
0,413 \\
\end{array}$ & $\begin{array}{r}-0,309 \\
0,046 \\
\end{array}$ & & & & & & & & & & & & & & \\
\hline $\mathrm{pH}$ & $\begin{array}{l}0,035 \\
0,824\end{array}$ & $\begin{array}{l}0,088 \\
0,582\end{array}$ & $\begin{array}{l}0,193 \\
0,221\end{array}$ & & & & & & & & & & & & & \\
\hline MST & $\begin{array}{l}0,146 \\
0,356\end{array}$ & $\begin{array}{r}-0,243 \\
0,121 \\
\end{array}$ & $\begin{array}{l}0,483 \\
0,001\end{array}$ & $\begin{array}{r}-0,094 \\
0,556 \\
\end{array}$ & & & & & & & & & & & & \\
\hline MSO & $\begin{array}{l}0,191 \\
0,225\end{array}$ & $\begin{array}{r}-0,374 \\
0,015\end{array}$ & $\begin{array}{l}0,353 \\
0,022\end{array}$ & $\begin{array}{r}-0,367 \\
0,017\end{array}$ & $\begin{array}{l}0,858 \\
0,000\end{array}$ & & & & & & & & & & & \\
\hline $\mathrm{MSI}$ & $\begin{array}{l}0,076 \\
0,632\end{array}$ & $\begin{array}{r}-0,061 \\
0,702\end{array}$ & $\begin{array}{l}0,482 \\
0,001\end{array}$ & $\begin{array}{l}0,191 \\
0,225\end{array}$ & $\begin{array}{l}0,876 \\
0,000\end{array}$ & $\begin{array}{l}0,504 \\
0,001\end{array}$ & & & & & & & & & & \\
\hline Silicato & $\begin{array}{l}0,204 \\
0,195\end{array}$ & $\begin{array}{l}0,338 \\
0,029\end{array}$ & $\begin{array}{r}-0,229 \\
0,144\end{array}$ & $\begin{array}{l}0,376 \\
0,014\end{array}$ & $\begin{array}{l}0,076 \\
0,633\end{array}$ & $\begin{array}{r}-0,109 \\
0,492\end{array}$ & $\begin{array}{l}0,231 \\
0,140\end{array}$ & & & & & & & & & \\
\hline Nitrato & $\begin{array}{l}0,168 \\
0,287\end{array}$ & $\begin{array}{l}0,358 \\
0,020 \\
\end{array}$ & $\begin{array}{r}-0,302 \\
0,052 \\
\end{array}$ & $\begin{array}{l}0,308 \\
0,047\end{array}$ & $\begin{array}{r}-0,177 \\
0,262 \\
\end{array}$ & $\begin{array}{r}-0,358 \\
0,020 \\
\end{array}$ & $\begin{array}{l}0,039 \\
0,804\end{array}$ & $\begin{array}{l}0,506 \\
0,001\end{array}$ & & & & & & & & \\
\hline Nitrito & $\begin{array}{l}0,106 \\
0,505\end{array}$ & $\begin{array}{r}-0,323 \\
0,037 \\
\end{array}$ & $\begin{array}{l}0,312 \\
0,045 \\
\end{array}$ & $\begin{array}{r}-0,740 \\
0,000 \\
\end{array}$ & $\begin{array}{l}0,206 \\
0,191 \\
\end{array}$ & $\begin{array}{l}0,460 \\
0,002 \\
\end{array}$ & $\begin{array}{r}-0,085 \\
0,594 \\
\end{array}$ & $\begin{array}{r}-0,597 \\
0,000 \\
\end{array}$ & $\begin{array}{r}-0,511 \\
0,001 \\
\end{array}$ & & & & & & & \\
\hline Amônio & $\begin{array}{r}-0,466 \\
0,002 \\
\end{array}$ & $\begin{array}{r}-0,031 \\
0,845 \\
\end{array}$ & $\begin{array}{r}-0,024 \\
0,880 \\
\end{array}$ & $\begin{array}{l}0,348 \\
0,024 \\
\end{array}$ & $\begin{array}{r}-0,198 \\
0,209 \\
\end{array}$ & $\begin{array}{r}-0,383 \\
0,012 \\
\end{array}$ & $\begin{array}{l}0,027 \\
0,865 \\
\end{array}$ & $\begin{array}{r}-0,172 \\
0,277 \\
\end{array}$ & $\begin{array}{r}-0,023 \\
0,887 \\
\end{array}$ & $\begin{array}{r}-0,370 \\
0,016 \\
\end{array}$ & & & & & & \\
\hline NT & $\begin{array}{l}0,083 \\
0,601\end{array}$ & $\begin{array}{r}-0,115 \\
0,467\end{array}$ & $\begin{array}{r}-0,055 \\
0,728\end{array}$ & $\begin{array}{r}-0,107 \\
0,499\end{array}$ & $\begin{array}{l}0,189 \\
0,231\end{array}$ & $\begin{array}{l}0,261 \\
0,095\end{array}$ & $\begin{array}{l}0,072 \\
0,652\end{array}$ & $\begin{array}{l}0,173 \\
0,272\end{array}$ & $\begin{array}{l}0,002 \\
0,992\end{array}$ & $\begin{array}{l}0,009 \\
0,957\end{array}$ & $\begin{array}{r}-0,264 \\
0,091\end{array}$ & & & & & \\
\hline Ortofosf & $\begin{array}{r}-0,005 \\
0,973\end{array}$ & $\begin{array}{r}-0,398 \\
0,009\end{array}$ & $\begin{array}{l}0,465 \\
0,002\end{array}$ & $\begin{array}{l}0,079 \\
0,619\end{array}$ & $\begin{array}{l}0,280 \\
0,073\end{array}$ & $\begin{array}{l}0,200 \\
0,204\end{array}$ & $\begin{array}{l}0,279 \\
0,073\end{array}$ & $\begin{array}{r}-0,184 \\
0,244\end{array}$ & $\begin{array}{r}-0,233 \\
0,137\end{array}$ & $\begin{array}{l}0,230 \\
0,142\end{array}$ & $\begin{array}{l}0,265 \\
0,090\end{array}$ & $\begin{array}{l}0,307 \\
0,048\end{array}$ & & & & \\
\hline PT & $\begin{array}{r}-0,005 \\
0,976\end{array}$ & $\begin{array}{r}-0,219 \\
0,163\end{array}$ & $\begin{array}{l}0,215 \\
0,172\end{array}$ & $\begin{array}{r}-0,073 \\
0,646\end{array}$ & $\begin{array}{r}-0,436 \\
0,004\end{array}$ & $\begin{array}{l}0,377 \\
0,014\end{array}$ & $\begin{array}{l}0,376 \\
0,014\end{array}$ & $\begin{array}{l}0,071 \\
0,655\end{array}$ & $\begin{array}{r}-0,108 \\
0,498\end{array}$ & $\begin{array}{l}0,176 \\
0,264\end{array}$ & $\begin{array}{l}0,027 \\
0,065\end{array}$ & $\begin{array}{l}0,475 \\
0,001\end{array}$ & $\begin{array}{l}0,558 \\
0,000\end{array}$ & & & \\
\hline PTD & $\begin{array}{l}0,454 \\
0,003 \\
\end{array}$ & $\begin{array}{r}-0,085 \\
0,591 \\
\end{array}$ & $\begin{array}{l}0,563 \\
0,000 \\
\end{array}$ & $\begin{array}{l}0,186 \\
0,238 \\
\end{array}$ & $\begin{array}{l}0,338 \\
0,029 \\
\end{array}$ & $\begin{array}{l}0,214 \\
0,173 \\
\end{array}$ & $\begin{array}{l}0,368 \\
0,017 \\
\end{array}$ & $\begin{array}{l}0,267 \\
0,087 \\
\end{array}$ & $\begin{array}{r}-0,063 \\
0,690 \\
\end{array}$ & $\begin{array}{l}0,118 \\
0,458 \\
\end{array}$ & $\begin{array}{r}-0,287 \\
0,065 \\
\end{array}$ & $\begin{array}{l}0,252 \\
0,107 \\
\end{array}$ & $\begin{array}{l}0,394 \\
0,010 \\
\end{array}$ & $\begin{array}{l}0,344 \\
0,026 \\
\end{array}$ & & \\
\hline Clorofil & $\begin{array}{l}0,196 \\
0,214\end{array}$ & $\begin{array}{r}0,027 \\
0,0863\end{array}$ & $\begin{array}{r}-0,022 \\
0,892 \\
\end{array}$ & $\begin{array}{l}0,075 \\
0,638 \\
\end{array}$ & $\begin{array}{l}0,321 \\
0,038\end{array}$ & $\begin{array}{l}0,281 \\
0,072\end{array}$ & $\begin{array}{l}0,275 \\
0,078\end{array}$ & $\begin{array}{l}0,324 \\
0,036 \\
\end{array}$ & $\begin{array}{l}0,266 \\
0,088\end{array}$ & $\begin{array}{r}-0,065 \\
0,683 \\
\end{array}$ & $\begin{array}{l}0,076 \\
0,633 \\
\end{array}$ & $\begin{array}{l}0,224 \\
0,154\end{array}$ & $\begin{array}{l}0,086 \\
0,587\end{array}$ & $\begin{array}{l}0,261 \\
0,095\end{array}$ & $\begin{array}{l}0,179 \\
0,256 \\
\end{array}$ & \\
\hline $\mathrm{Cr}$ & $\begin{array}{r}-0,367 \\
0,017\end{array}$ & $\begin{array}{l}0,028 \\
0,859\end{array}$ & $\begin{array}{r}-0,133 \\
0,400\end{array}$ & $\begin{array}{l}0,058 \\
0,713\end{array}$ & $\begin{array}{r}-0,142 \\
0,370\end{array}$ & $\begin{array}{r}-0,165 \\
0,296\end{array}$ & $\begin{array}{r}-0,087 \\
0,584\end{array}$ & $\begin{array}{r}-0,238 \\
0,129\end{array}$ & $\begin{array}{r}-0,152 \\
0,338\end{array}$ & $\begin{array}{r}-0,189 \\
0,230\end{array}$ & $\begin{array}{l}0,385 \\
0,012\end{array}$ & $\begin{array}{r}-0,170 \\
0,283 \\
\end{array}$ & $\begin{array}{l}0,030 \\
0,850\end{array}$ & $\begin{array}{r}-0,083 \\
0,600\end{array}$ & $\begin{array}{r}-0,358 \\
0,020\end{array}$ & $\begin{array}{r}-0,538 \\
0,000\end{array}$ \\
\hline
\end{tabular}

Cell Contents : Pearson correlation

$p$ - Value 
Tabela 94: Matriz de correlação de Pearson entre pH, condutividade, oxigênio dissolvido, temperatura, material em suspensão total, orgânico e inorgânico, silicato, nitrato, nitrito, amônio, nitrogênio total, ortofosfato dissolvido, fósforo total dissolvido, fósforo total e clorofila utilizando-se os valores determinados na água superficial no controle e no experimento com $\mathrm{Cr}$ após a inclusão dos peixes e macrófitas (primeira linha: $r$; segunda linha:p).

\begin{tabular}{|c|c|c|c|c|c|c|c|c|c|c|c|c|c|c|c|c|}
\hline & $\overline{O O D}$ & Cond & Temp & $\mathrm{pH}$ & $\overline{\mathrm{MST}}$ & $\mathrm{MSO}$ & $\overline{\mathrm{MSI}}$ & Silicato & Nitrato & Nitrito & Amônio & NT & Ortofosf & PT & $\begin{array}{l}\text { PTD } \\
\end{array}$ & Clorofil \\
\hline Cond & $\begin{array}{r}-0,018 \\
0,916\end{array}$ & & & & & & & & & & & & & & & \\
\hline Temp & $\begin{array}{l}0,119 \\
0,490\end{array}$ & $\begin{array}{r}-0,102 \\
0,554\end{array}$ & & & & & & & & & & & & & & \\
\hline $\mathrm{pH}$ & $\begin{array}{l}0,285 \\
0,092\end{array}$ & $\begin{array}{l}0,533 \\
0,001\end{array}$ & $\begin{array}{l}0,360 \\
0,031\end{array}$ & & & & & & & & & & & & & \\
\hline MST & $\begin{array}{l}0,005 \\
0,978\end{array}$ & $\begin{array}{r}-0,010 \\
0,953\end{array}$ & $\begin{array}{r}-0,170 \\
0,323\end{array}$ & $\begin{array}{l}0,047 \\
0,784\end{array}$ & & & & & & & & & & & & \\
\hline MSO & $\begin{array}{r}-0,017 \\
0,924\end{array}$ & $\begin{array}{l}0,080 \\
0,643\end{array}$ & $\begin{array}{r}-0,235 \\
0,168\end{array}$ & $\begin{array}{l}0,036 \\
0,835\end{array}$ & $\begin{array}{l}0,722 \\
0,000\end{array}$ & & & & & & & & & & & \\
\hline $\mathrm{MSI}$ & $\begin{array}{l}0,032 \\
0,855\end{array}$ & $\begin{array}{r}-0,092 \\
0,592\end{array}$ & $\begin{array}{r}-0,015 \\
0,933\end{array}$ & $\begin{array}{l}0,036 \\
0,836\end{array}$ & $\begin{array}{l}0,719 \\
0,000\end{array}$ & $\begin{array}{l}0,039 \\
0,822\end{array}$ & & & & & & & & & & \\
\hline Silicato & $\begin{array}{l}0,025 \\
0,884\end{array}$ & $\begin{array}{l}0,010 \\
0,956\end{array}$ & $\begin{array}{l}0,487 \\
0,003\end{array}$ & $\begin{array}{l}0,100 \\
0,560\end{array}$ & $\begin{array}{r}-0,100 \\
0,563\end{array}$ & $\begin{array}{r}-0,257 \\
0,130\end{array}$ & $\begin{array}{l}0,113 \\
0,512\end{array}$ & & & & & & & & & \\
\hline Nitrato & $\begin{array}{r}-0,072 \\
0,677\end{array}$ & $\begin{array}{l}0,072 \\
0,675\end{array}$ & $\begin{array}{r}-0,132 \\
0,444\end{array}$ & $\begin{array}{r}-0,094 \\
0,585\end{array}$ & $\begin{array}{l}0,362 \\
0,030\end{array}$ & $\begin{array}{r}-0,206 \\
0,227\end{array}$ & $\begin{array}{l}0,731 \\
0,000\end{array}$ & $\begin{array}{l}0,150 \\
0,383\end{array}$ & & & & & & & & \\
\hline Nitrito & $\begin{array}{r}-0,182 \\
0,288\end{array}$ & $\begin{array}{l}0,087 \\
0,613\end{array}$ & $\begin{array}{r}-0,395 \\
0,017\end{array}$ & $\begin{array}{r}-0,431 \\
0,009\end{array}$ & $\begin{array}{r}-0,217 \\
0,204\end{array}$ & $\begin{array}{r}-0,217 \\
0,205\end{array}$ & $\begin{array}{l}0,095 \\
0,581\end{array}$ & $\begin{array}{l}0,082 \\
0,633\end{array}$ & $\begin{array}{l}0,224 \\
0,189\end{array}$ & & & & & & & \\
\hline Amônio & $\begin{array}{r}-0,266 \\
0,117\end{array}$ & $\begin{array}{l}0,467 \\
0,004\end{array}$ & $\begin{array}{r}-0,432 \\
0,009 \\
\end{array}$ & $\begin{array}{l}0,045 \\
0,794\end{array}$ & $\begin{array}{r}-0,001 \\
0,994\end{array}$ & $\begin{array}{l}0,011 \\
0,950\end{array}$ & $\begin{array}{r}-0,010 \\
0,953\end{array}$ & $\begin{array}{r}-0,327 \\
0,051\end{array}$ & $\begin{array}{l}0,319 \\
0,058\end{array}$ & $\begin{array}{l}0,249 \\
0,143\end{array}$ & & & & & & \\
\hline NT & $\begin{array}{r}-0,338 \\
0,044\end{array}$ & $\begin{array}{l}0,172 \\
0,317\end{array}$ & $\begin{array}{l}0,072 \\
0,675\end{array}$ & $\begin{array}{l}0,144 \\
0,401\end{array}$ & $\begin{array}{l}0,137 \\
0,425\end{array}$ & $\begin{array}{l}0,271 \\
0,110\end{array}$ & $\begin{array}{r}-0,076 \\
0,662\end{array}$ & $\begin{array}{l}0,147 \\
0,394\end{array}$ & $\begin{array}{r}-0,102 \\
0,555\end{array}$ & $\begin{array}{r}-0,203 \\
0,236\end{array}$ & $\begin{array}{l}0,253 \\
0,137\end{array}$ & & & & & \\
\hline Ortofosf & $\begin{array}{r}-0,046 \\
0,789\end{array}$ & $\begin{array}{r}-0,130 \\
0,449\end{array}$ & $\begin{array}{l}0,027 \\
0,876\end{array}$ & $\begin{array}{c}-0227 \\
0,183\end{array}$ & $\begin{array}{l}0,144 \\
0,403\end{array}$ & $\begin{array}{l}0,118 \\
0,494\end{array}$ & $\begin{array}{l}0,087 \\
0,615\end{array}$ & $\begin{array}{r}-0,303 \\
0,073\end{array}$ & $\begin{array}{l}0,060 \\
0,727\end{array}$ & $\begin{array}{l}0,054 \\
0,755\end{array}$ & $\begin{array}{r}-0,086 \\
0,619\end{array}$ & $\begin{array}{r}-0,160 \\
0,351\end{array}$ & & & & \\
\hline$\overline{\mathrm{PT}}$ & $\begin{array}{r}-0,094 \\
0,587\end{array}$ & $\begin{array}{l}0,090 \\
0,601\end{array}$ & $\begin{array}{l}0,169 \\
0,326\end{array}$ & $\begin{array}{l}0,297 \\
0,079\end{array}$ & $\begin{array}{l}0,028 \\
0,873\end{array}$ & $\begin{array}{r}-0,017 \\
0,923\end{array}$ & $\begin{array}{l}0,055 \\
0,749\end{array}$ & $\begin{array}{l}0,446 \\
0,006\end{array}$ & $\begin{array}{l}0,038 \\
0,825\end{array}$ & $\begin{array}{r}-0,189 \\
0,270\end{array}$ & $\begin{array}{l}0,135 \\
0,433\end{array}$ & $\begin{array}{l}0,468 \\
0,004\end{array}$ & $\begin{array}{r}-0,454 \\
0,005\end{array}$ & & & \\
\hline PTD & $\begin{array}{l}0,208 \\
0,223\end{array}$ & $\begin{array}{r}-0,131 \\
0,448 \\
\end{array}$ & $\begin{array}{r}-0,279 \\
0,100 \\
\end{array}$ & $\begin{array}{r}-0,473 \\
0,004 \\
\end{array}$ & $\begin{array}{l}0,070 \\
0,685 \\
\end{array}$ & $\begin{array}{l}0,185 \\
0,279 \\
\end{array}$ & $\begin{array}{r}-0,086 \\
0,617 \\
\end{array}$ & $\begin{array}{r}-0,015 \\
0,929 \\
\end{array}$ & $\begin{array}{r}-0,034 \\
0,842 \\
\end{array}$ & $\begin{array}{l}0,270 \\
0,111 \\
\end{array}$ & $\begin{array}{r}-0,144 \\
0,401 \\
\end{array}$ & $\begin{array}{r}-0,301 \\
0,075 \\
\end{array}$ & $\begin{array}{l}0,424 \\
0,010 \\
\end{array}$ & $\begin{array}{r}-0,288 \\
0,089 \\
\end{array}$ & & \\
\hline Clorofil & $\begin{array}{r}-0,264 \\
0,119 \\
\end{array}$ & $\begin{array}{r}-0,075 \\
0,666 \\
\end{array}$ & $\begin{array}{r}-0,354 \\
0,034\end{array}$ & $\begin{array}{r}-0,304 \\
0,071 \\
\end{array}$ & $\begin{array}{l}0,394 \\
0,017\end{array}$ & $\begin{array}{l}0,609 \\
0,000 \\
\end{array}$ & $\begin{array}{r}-0,046 \\
0,788\end{array}$ & $\begin{array}{r}-0,079 \\
0,647 \\
\end{array}$ & $\begin{array}{r}-0,224 \\
0,190 \\
\end{array}$ & $\begin{array}{r}-0,062 \\
0,718 \\
\end{array}$ & $\begin{array}{r}-0,043 \\
0,803\end{array}$ & $\begin{array}{l}0,405 \\
0,014 \\
\end{array}$ & $\begin{array}{l}0,082 \\
0,636\end{array}$ & $\begin{array}{l}0,029 \\
0,867\end{array}$ & $\begin{array}{l}0,292 \\
0,084\end{array}$ & \\
\hline $\mathrm{Cr}$ & $\begin{array}{r}-0,445 \\
0,006\end{array}$ & $\begin{array}{l}0,169 \\
0,326\end{array}$ & $\begin{array}{r}-0,246 \\
0,147\end{array}$ & $\begin{array}{r}-0,073 \\
0,671\end{array}$ & $\begin{array}{r}-0,123 \\
0,476\end{array}$ & $\begin{array}{r}-0,067 \\
0,698\end{array}$ & $\begin{array}{r}-0,110 \\
0,522\end{array}$ & $\begin{array}{r}-0,207 \\
0,225\end{array}$ & $\begin{array}{l}0,115 \\
0,503\end{array}$ & $\begin{array}{l}0,029 \\
0,869\end{array}$ & $\begin{array}{l}0,550 \\
0,001\end{array}$ & $\begin{array}{l}0,178 \\
0,299\end{array}$ & $\begin{array}{r}-0,222 \\
0,194\end{array}$ & $\begin{array}{l}0,114 \\
0,507\end{array}$ & $\begin{array}{r}-0,366 \\
0,028\end{array}$ & $\begin{array}{r}-0,167 \\
0,330\end{array}$ \\
\hline
\end{tabular}

Cell Contents : Pearson correlation

$$
p \text { - Value }
$$


Tabela 95: Matriz de correlação de Pearson entre $\mathrm{pH}$, condutividade, oxigênio dissolvido, temperatura, material em suspensão total, orgânico e inorgânico, silicato, nitrato, nitrito, amônio, nitrogênio total, ortofosfato dissolvido, fósforo total dissolvido, fósforo total e clorofila utilizando-se os valores determinados na água superficial no controle e no experimento com Cu antes da inclusão dos peixes e macrófitas (primeira linha: $r$; segunda linha:p).

\begin{tabular}{|c|c|c|c|c|c|c|c|c|c|c|c|c|c|c|c|c|}
\hline & $\mathrm{OD}$ & Cond & Temp & $\mathrm{pH}$ & MST & MSO & $\mathrm{MSI}$ & Silicato & Nitrato & Nitrito & Amônio & NT & Ortofosf & $\begin{array}{l}\mathrm{PT} \\
\end{array}$ & 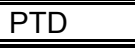 & $\begin{array}{l}\text { Clorofil } \\
\end{array}$ \\
\hline Cond & $\begin{array}{l}0,198 \\
0,332\end{array}$ & & & & & & & & & & & & & & & \\
\hline Temp & $\begin{array}{l}0,097 \\
0,637 \\
\end{array}$ & $\begin{array}{r}-0,052 \\
0,802 \\
\end{array}$ & & & & & & & & & & & & & & \\
\hline $\mathrm{pH}$ & $\begin{array}{l}0,309 \\
0,124 \\
\end{array}$ & $\begin{array}{l}0,231 \\
0,256 \\
\end{array}$ & $\begin{array}{l}0,476 \\
0,014 \\
\end{array}$ & & & & & & & & & & & & & \\
\hline MST & $\begin{array}{r}-0,071 \\
0,731 \\
\end{array}$ & $\begin{array}{r}-0,146 \\
0,477 \\
\end{array}$ & $\begin{array}{r}-0,272 \\
0,178 \\
\end{array}$ & $\begin{array}{r}-0,482 \\
0,013 \\
\end{array}$ & & & & & & & & & & & & \\
\hline $\mathrm{MSO}$ & $\begin{array}{r}-0,131 \\
0,522\end{array}$ & $\begin{array}{r}-0,165 \\
0,420\end{array}$ & $\begin{array}{r}-0,440 \\
0,025\end{array}$ & $\begin{array}{r}-0,613 \\
0,001\end{array}$ & $\begin{array}{l}0,911 \\
0,000\end{array}$ & & & & & & & & & & & \\
\hline $\mathrm{MSI}$ & $\begin{array}{l}0,073 \\
0,724\end{array}$ & $\begin{array}{r}-0,038 \\
0,853\end{array}$ & $\begin{array}{l}0,157 \\
0,444\end{array}$ & $\begin{array}{l}0,012 \\
0,953\end{array}$ & $\begin{array}{l}0,622 \\
0,001\end{array}$ & $\begin{array}{l}0,244 \\
0,229\end{array}$ & & & & & & & & & & \\
\hline Silicato & $\begin{array}{l}0,005 \\
0,979\end{array}$ & $\begin{array}{l}0,265 \\
0,191\end{array}$ & $\begin{array}{l}0,264 \\
0,193\end{array}$ & $\begin{array}{l}0,513 \\
0,007\end{array}$ & $\begin{array}{r}-0,506 \\
0,008\end{array}$ & $\begin{array}{r}-0,627 \\
0,001\end{array}$ & $\begin{array}{l}0,008 \\
0,970\end{array}$ & & & & & & & & & \\
\hline Nitrato & $\begin{array}{l}0,102 \\
0,619\end{array}$ & $\begin{array}{l}0,378 \\
0,057 \\
\end{array}$ & $\begin{array}{r}-0,190 \\
0,351 \\
\end{array}$ & $\begin{array}{l}0,393 \\
0,047 \\
\end{array}$ & $\begin{array}{r}-0,334 \\
0,095 \\
\end{array}$ & $\begin{array}{r}-0,397 \\
0,045 \\
\end{array}$ & $\begin{array}{r}-0,021 \\
0,920 \\
\end{array}$ & $\begin{array}{l}0,591 \\
0,001 \\
\end{array}$ & & & & & & & & \\
\hline Nitrito & $\begin{array}{l}0,158 \\
0,439 \\
\end{array}$ & $\begin{array}{r}-0,295 \\
0,144 \\
\end{array}$ & $\begin{array}{l}0,374 \\
0,060 \\
\end{array}$ & $\begin{array}{l}0,003 \\
0,987 \\
\end{array}$ & $\begin{array}{l}0,103 \\
0,617 \\
\end{array}$ & $\begin{array}{l}0,168 \\
0,413 \\
\end{array}$ & $\begin{array}{r}-0,079 \\
0,700 \\
\end{array}$ & $\begin{array}{r}-0,273 \\
0,177 \\
\end{array}$ & $\begin{array}{r}-0,445 \\
0,023 \\
\end{array}$ & & & & & & & \\
\hline Amônio & $\begin{array}{r}-0,350 \\
0,079 \\
\end{array}$ & $\begin{array}{r}-0,013 \\
0,952 \\
\end{array}$ & $\begin{array}{l}0,143 \\
0,486 \\
\end{array}$ & $\begin{array}{l}0,464 \\
0,017 \\
\end{array}$ & $\begin{array}{r}-0,358 \\
0,072 \\
\end{array}$ & $\begin{array}{r}-0,442 \\
0,024 \\
\end{array}$ & $\begin{array}{r}-0,004 \\
0,985 \\
\end{array}$ & $\begin{array}{l}0,077 \\
0,709 \\
\end{array}$ & $\begin{array}{l}0,144 \\
0,483 \\
\end{array}$ & $\begin{array}{r}-0,218 \\
0,285 \\
\end{array}$ & & & & & & \\
\hline NT & $\begin{array}{r}-0,401 \\
0,042\end{array}$ & $\begin{array}{l}0,001 \\
0,997\end{array}$ & $\begin{array}{r}-0,307 \\
0,128\end{array}$ & $\begin{array}{r}-0,343 \\
0,086\end{array}$ & $\begin{array}{l}0,301 \\
0,135\end{array}$ & $\begin{array}{l}0,312 \\
0,120\end{array}$ & $\begin{array}{l}0,119 \\
0,563\end{array}$ & $\begin{array}{l}0,152 \\
0,460\end{array}$ & $\begin{array}{l}0,227 \\
0,266\end{array}$ & $\begin{array}{r}-0,201 \\
0,325\end{array}$ & $\begin{array}{r}-0,367 \\
0,065\end{array}$ & & & & & \\
\hline Ortofosf & $\begin{array}{r}-0,081 \\
0,695 \\
\end{array}$ & $\begin{array}{r}-0,416 \\
0,034 \\
\end{array}$ & $\begin{array}{l}0,389 \\
0,049 \\
\end{array}$ & $\begin{array}{r}0,204 \\
0,318 \\
\end{array}$ & $\begin{array}{l}0,347 \\
0,082 \\
\end{array}$ & $\begin{array}{l}0,236 \\
0,245 \\
\end{array}$ & $\begin{array}{l}0,330 \\
0,100 \\
\end{array}$ & $\begin{array}{r}-0,477 \\
0,014 \\
\end{array}$ & $\begin{array}{l}0,471 \\
0,015 \\
\end{array}$ & $\begin{array}{l}0,071 \\
0,730 \\
\end{array}$ & $\begin{array}{l}0,102 \\
0,619 \\
\end{array}$ & $\begin{array}{r}-0,107 \\
0,603 \\
\end{array}$ & & & & \\
\hline PT & $\begin{array}{r}-0,299 \\
0,138\end{array}$ & $\begin{array}{r}-0,152 \\
0,459\end{array}$ & $\begin{array}{l}0,134 \\
0,516\end{array}$ & $\begin{array}{r}-0,154 \\
0,454\end{array}$ & $\begin{array}{l}0,326 \\
0,104\end{array}$ & $\begin{array}{l}0,116 \\
0,574\end{array}$ & $\begin{array}{l}0,551 \\
0,004\end{array}$ & $\begin{array}{l}0,062 \\
0,764\end{array}$ & $\begin{array}{r}-0,154 \\
0,451\end{array}$ & $\begin{array}{l}0,129 \\
0,529\end{array}$ & $\begin{array}{l}0,029 \\
0,889\end{array}$ & $\begin{array}{l}0,428 \\
0,029\end{array}$ & $\begin{array}{l}0,199 \\
0,329\end{array}$ & & & \\
\hline PTD & $\begin{array}{l}0,215 \\
0,292 \\
\end{array}$ & $\begin{array}{l}0,069 \\
0,739 \\
\end{array}$ & $\begin{array}{l}0,246 \\
0,226\end{array}$ & $\begin{array}{r}-0,016 \\
0,939 \\
\end{array}$ & $\begin{array}{l}0,199 \\
0,330\end{array}$ & $\begin{array}{l}0,046 \\
0,823 \\
\end{array}$ & $\begin{array}{l}0,384 \\
0,053\end{array}$ & $\begin{array}{l}0,225 \\
0,268\end{array}$ & $\begin{array}{r}-0,194 \\
0,343 \\
\end{array}$ & $\begin{array}{l}0,195 \\
0,339 \\
\end{array}$ & $\begin{array}{r}-0,288 \\
0,154 \\
\end{array}$ & $\begin{array}{r}-0,106 \\
0,608 \\
\end{array}$ & $\begin{array}{l}0,089 \\
0,666 \\
\end{array}$ & $\begin{array}{l}0,214 \\
0,293 \\
\end{array}$ & & \\
\hline Clorofil & $\begin{array}{r}-0,367 \\
0,065 \\
\end{array}$ & $\begin{array}{r}-0,123 \\
0,549 \\
\end{array}$ & $\begin{array}{r}-0,557 \\
0,003 \\
\end{array}$ & $\begin{array}{r}-0,838 \\
0,000 \\
\end{array}$ & $\begin{array}{l}0,564 \\
0,003 \\
\end{array}$ & $\begin{array}{l}0,675 \\
0,000 \\
\end{array}$ & $\begin{array}{l}0,057 \\
0,781\end{array}$ & $\begin{array}{r}-0,369 \\
0,064 \\
\end{array}$ & $\begin{array}{r}-0,208 \\
0,309 \\
\end{array}$ & $\begin{array}{r}-0,277 \\
0,171 \\
\end{array}$ & $\begin{array}{r}-0,411 \\
0,037 \\
\end{array}$ & $\begin{array}{l}0,436 \\
0,026 \\
\end{array}$ & $\begin{array}{l}0,189 \\
0,356 \\
\end{array}$ & $\begin{array}{l}0,069 \\
0,739 \\
\end{array}$ & $\begin{array}{l}0,087 \\
0,671 \\
\end{array}$ & \\
\hline $\mathrm{Cu}$ & $\begin{array}{r}-0,103 \\
0,616\end{array}$ & $\begin{array}{r}-0,049 \\
0,811\end{array}$ & $\begin{array}{r}-0,072 \\
0,727\end{array}$ & $\begin{array}{l}0,057 \\
0,784\end{array}$ & $\begin{array}{r}-0,038 \\
0,853\end{array}$ & $\begin{array}{r}-0,123 \\
0,550\end{array}$ & $\begin{array}{l}0,150 \\
0,464\end{array}$ & $\begin{array}{r}-0,103 \\
0,616\end{array}$ & $\begin{array}{r}0,0127 \\
0,537\end{array}$ & $\begin{array}{r}-0,083 \\
0,687\end{array}$ & $\begin{array}{l}0,513 \\
0,007\end{array}$ & $\begin{array}{r}-0,107 \\
0,604\end{array}$ & $\begin{array}{l}0,124 \\
0,546\end{array}$ & $\begin{array}{l}0,139 \\
0,498\end{array}$ & $\begin{array}{r}-0,296 \\
0,142\end{array}$ & $\begin{array}{r}-0,257 \\
0,204\end{array}$ \\
\hline
\end{tabular}

Cell Contents: Pearson correlation

$$
P \text { - Value }
$$


Tabela 96: Matriz de correlação de Pearson entre pH, condutividade, oxigênio dissolvido, temperatura, material em suspensão total, orgânico e inorgânico, silicato, nitrato, nitrito, amônio, nitrogênio total, ortofosfato dissolvido, fósforo total dissolvido, fósforo total e clorofila utilizando-se os valores determinados na água superficial no controle e no experimento com Cu após a inclusão dos peixes e macrófitas (primeira linha: $r$; segunda linha:p).

\begin{tabular}{|c|c|c|c|c|c|c|c|c|c|c|c|c|c|c|c|c|}
\hline & OD & Cond & $\overline{\text { Temp }}$ & $\mathrm{pH}$ & MST & MSO & $\mathrm{MSI}$ & Silicato & Nitrato & Nitrito & Amônio & NT & Ortofosf & PT & PTD & Clorofil \\
\hline Cond & $\begin{array}{l}0,100 \\
0,562\end{array}$ & & & & & & & & & & & & & & & \\
\hline Temp & $\begin{array}{l}0,132 \\
0,444\end{array}$ & $\begin{array}{r}-0,103 \\
0,551 \\
\end{array}$ & & & & & & & & & & & & & & \\
\hline $\mathrm{pH}$ & $\begin{array}{l}0,498 \\
0,002\end{array}$ & $\begin{array}{r}-0,039 \\
0,823 \\
\end{array}$ & $\begin{array}{l}0,531 \\
0,001\end{array}$ & & & & & & & & & & & & & \\
\hline MST & $\begin{array}{l}0,097 \\
0,572\end{array}$ & $\begin{array}{l}0,300 \\
0,075\end{array}$ & $\begin{array}{r}-0,408 \\
0,013 \\
\end{array}$ & $\begin{array}{r}-0,204 \\
0,233 \\
\end{array}$ & & & & & & & & & & & & \\
\hline MSO & $\begin{array}{r}-0,018 \\
0,916 \\
\end{array}$ & $\begin{array}{l}0,227 \\
0,183\end{array}$ & $\begin{array}{r}-0,436 \\
0,008 \\
\end{array}$ & $\begin{array}{r}-0,333 \\
0,047 \\
\end{array}$ & $\begin{array}{l}0,911 \\
0,000\end{array}$ & & & & & & & & & & & \\
\hline $\mathrm{MSI}$ & $\begin{array}{l}0,285 \\
0,092\end{array}$ & $\begin{array}{l}0,207 \\
0,225\end{array}$ & $\begin{array}{r}-0,004 \\
0,983 \\
\end{array}$ & $\begin{array}{l}0,271 \\
0,111\end{array}$ & $\begin{array}{l}0,342 \\
0,041\end{array}$ & $\begin{array}{r}-0,075 \\
0,664 \\
\end{array}$ & & & & & & & & & & \\
\hline Silicato & $\begin{array}{r}-0,147 \\
0,391 \\
\end{array}$ & $\begin{array}{r}-0,259 \\
0,127 \\
\end{array}$ & $\begin{array}{l}0,481 \\
0,003\end{array}$ & $\begin{array}{l}0,075 \\
0,664\end{array}$ & $\begin{array}{r}-0,404 \\
0,014 \\
\end{array}$ & $\begin{array}{r}-0,484 \\
0,003 \\
\end{array}$ & $\begin{array}{l}0,125 \\
0,466 \\
\end{array}$ & & & & & & & & & \\
\hline Nitrato & $\begin{array}{r}-0,262 \\
0,122 \\
\end{array}$ & $\begin{array}{l}0,245 \\
0,150\end{array}$ & $\begin{array}{r}-0,031 \\
0,858 \\
\end{array}$ & $\begin{array}{r}-0,027 \\
0,878 \\
\end{array}$ & $\begin{array}{r}-0,131 \\
0,448 \\
\end{array}$ & $\begin{array}{r}-0,156 \\
0,363 \\
\end{array}$ & $\begin{array}{r}0.049 \\
0,0776 \\
\end{array}$ & $\begin{array}{l}0,067 \\
0,696 \\
\end{array}$ & & & & & & & & \\
\hline Nitrito & $\begin{array}{r}-0,065 \\
0,707 \\
\end{array}$ & $\begin{array}{r}-0,141 \\
0,412 \\
\end{array}$ & $\begin{array}{r}-0,186 \\
0,276 \\
\end{array}$ & $\begin{array}{r}-0,232 \\
0,173 \\
\end{array}$ & $\begin{array}{r}-0,188 \\
0,272 \\
\end{array}$ & $\begin{array}{r}-0,180 \\
0,293 \\
\end{array}$ & $\begin{array}{r}-0,035 \\
0,837 \\
\end{array}$ & $\begin{array}{l}0,225 \\
0,187 \\
\end{array}$ & $\begin{array}{l}0,172 \\
0,315 \\
\end{array}$ & & & & & & & \\
\hline Amônio & $\begin{array}{r}-0,043 \\
0,801 \\
\end{array}$ & $\begin{array}{l}0,490 \\
0,002\end{array}$ & $\begin{array}{r}-0,242 \\
0,155 \\
\end{array}$ & $\begin{array}{l}0,073 \\
0,672\end{array}$ & $\begin{array}{l}0,288 \\
0,088\end{array}$ & $\begin{array}{l}0,129 \\
0,453 \\
\end{array}$ & $\begin{array}{l}0,414 \\
0,012 \\
\end{array}$ & $\begin{array}{r}-0,312 \\
0,064 \\
\end{array}$ & $\begin{array}{l}0,332 \\
0,048 \\
\end{array}$ & $\begin{array}{l}0,089 \\
0,607\end{array}$ & & & & & & \\
\hline NT & $\begin{array}{r}-0,589 \\
0,000 \\
\end{array}$ & $\begin{array}{r}-0,085 \\
0,621 \\
\end{array}$ & $\begin{array}{l}0,136 \\
0,429 \\
\end{array}$ & $\begin{array}{r}-0,282 \\
0,095 \\
\end{array}$ & $\begin{array}{r}-0,021 \\
0,901 \\
\end{array}$ & $\begin{array}{l}0,093 \\
0,590 \\
\end{array}$ & $\begin{array}{r}-0,259 \\
0,127 \\
\end{array}$ & $\begin{array}{l}0,111 \\
0,519 \\
\end{array}$ & $\begin{array}{l}0,252 \\
0,138 \\
\end{array}$ & $\begin{array}{r}-0,065 \\
0,707 \\
\end{array}$ & $\begin{array}{l}0,020 \\
0,482\end{array}$ & & & & & \\
\hline Ortofosf & $\begin{array}{l}0,117 \\
0,497\end{array}$ & $\begin{array}{r}-0,191 \\
0,265 \\
\end{array}$ & $\begin{array}{l}0,244 \\
0,152 \\
\end{array}$ & $\begin{array}{l}0,012 \\
0,943\end{array}$ & $\begin{array}{l}0,006 \\
0,971\end{array}$ & $\begin{array}{l}0,090 \\
0,601\end{array}$ & $\begin{array}{r}-0,198 \\
0,246 \\
\end{array}$ & $\begin{array}{r}-0,258 \\
0,129 \\
\end{array}$ & $\begin{array}{r}-0,329 \\
0,050 \\
\end{array}$ & $\begin{array}{r}-0,084 \\
0,628 \\
\end{array}$ & $\begin{array}{r}-0,092 \\
0,595 \\
\end{array}$ & $\begin{array}{r}-0,121 \\
0,482 \\
\end{array}$ & & & & \\
\hline PT & $\begin{array}{r}-0,305 \\
0,071 \\
\end{array}$ & $\begin{array}{r}-0,062 \\
0,720 \\
\end{array}$ & $\begin{array}{l}0,113 \\
0,511 \\
\end{array}$ & $\begin{array}{l}0,066 \\
0,700\end{array}$ & $\begin{array}{r}-0,177 \\
0,301 \\
\end{array}$ & $\begin{array}{r}-0,205 \\
0,230 \\
\end{array}$ & $\begin{array}{l}0,043 \\
0,803\end{array}$ & $\begin{array}{l}0,448 \\
0,006\end{array}$ & $\begin{array}{l}0,035 \\
0,841 \\
\end{array}$ & $\begin{array}{l}0,030 \\
0,862\end{array}$ & $\begin{array}{l}0,114 \\
0,508\end{array}$ & $\begin{array}{l}0,459 \\
0,005\end{array}$ & $\begin{array}{r}-0,207 \\
0,226 \\
\end{array}$ & & & \\
\hline PTD & $\begin{array}{l}0,112 \\
0,514\end{array}$ & $\begin{array}{r}-0,270 \\
0,112 \\
\end{array}$ & $\begin{array}{r}-0,250 \\
0,141 \\
\end{array}$ & $\begin{array}{l}0,411 \\
0,013\end{array}$ & $\begin{array}{l}0,149 \\
0,384\end{array}$ & $\begin{array}{r}-0,215 \\
0,208 \\
\end{array}$ & $\begin{array}{l}0,132 \\
0,444\end{array}$ & $\begin{array}{l}0,111 \\
0,519 \\
\end{array}$ & $\begin{array}{r}-0,385 \\
0,021 \\
\end{array}$ & $\begin{array}{r}-0,020 \\
0,907 \\
\end{array}$ & $\begin{array}{r}-0,263 \\
0,122 \\
\end{array}$ & $\begin{array}{r}-0,201 \\
0,241 \\
\end{array}$ & $\begin{array}{l}0,203 \\
0,236\end{array}$ & $\begin{array}{r}-0,039 \\
0,823 \\
\end{array}$ & & \\
\hline Clorofil & $\begin{array}{r}-0,293 \\
0,083 \\
\end{array}$ & $\begin{array}{r}-0,102 \\
0,554 \\
\end{array}$ & $\begin{array}{r}-0,530 \\
0,001 \\
\end{array}$ & $\begin{array}{r}-0,646 \\
0,000 \\
\end{array}$ & $\begin{array}{l}0,426 \\
0,010\end{array}$ & $\begin{array}{l}0,545 \\
0,001\end{array}$ & $\begin{array}{r}-0,215 \\
0,208 \\
\end{array}$ & $\begin{array}{r}-0,184 \\
0,283 \\
\end{array}$ & $\begin{array}{r}-0,302 \\
0,073 \\
\end{array}$ & $\begin{array}{l}0,166 \\
0,333\end{array}$ & $\begin{array}{r}-0,156 \\
0,362 \\
\end{array}$ & $\begin{array}{l}0,240 \\
0,159\end{array}$ & $\begin{array}{l}0,129 \\
0,452\end{array}$ & $\begin{array}{r}-0,194 \\
0,256 \\
\end{array}$ & $\begin{array}{l}0,364 \\
0,029\end{array}$ & \\
\hline $\mathrm{Cu}$ & $\begin{array}{r}-0,216 \\
0,206\end{array}$ & $\begin{array}{l}0,118 \\
0,494\end{array}$ & $\begin{array}{r}-0,280 \\
0,099\end{array}$ & $\begin{array}{r}-0,152 \\
0,378\end{array}$ & $\begin{array}{l}0,168 \\
0,326\end{array}$ & $\begin{array}{l}0,105 \\
0,541\end{array}$ & $\begin{array}{l}0,172 \\
0,314\end{array}$ & $\begin{array}{r}-0,035 \\
0,839\end{array}$ & $\begin{array}{l}0,432 \\
0,008\end{array}$ & $\begin{array}{r}-0,004 \\
0,983\end{array}$ & $\begin{array}{l}0,369 \\
0,027\end{array}$ & $\begin{array}{l}0,311 \\
0,064\end{array}$ & $\begin{array}{r}-0,182 \\
0,287\end{array}$ & $\begin{array}{l}0,085 \\
0,622\end{array}$ & $\begin{array}{r}-0,145 \\
0,400\end{array}$ & $\begin{array}{r}-0,051 \\
0,770\end{array}$ \\
\hline
\end{tabular}


Tabela 97: Matriz de correlação de Pearson entre matéria orgânica, fósforo, nitrogênio, cromo na fração fracamente ligada, cromo total, utilizando-se os valores determinados no sedimento no controle e no experimento com $\mathrm{Cr}$ em todas as datas (primeira linha: r; segunda linha:p).

\begin{tabular}{|c|c|c|c|c|c|}
\hline & $\mathrm{N}$ & $\bar{p}$ & Cr Bio & Cr Tot & $\overline{\mathrm{Al}}$ \\
\hline $\bar{p}$ & $\begin{array}{l}-0,183 \\
0,467\end{array}$ & & & & \\
\hline Cr Bio & $\begin{array}{l}* \\
* \\
\text { * }\end{array}$ & $\begin{array}{l}* \\
\text { * }\end{array}$ & & & \\
\hline Cr Tot & $\begin{array}{l}-0,024 \\
0,924\end{array}$ & $\begin{array}{l}0,183 \\
0,468 \\
\end{array}$ & * & & \\
\hline $\mathrm{Al}$ & $\begin{array}{l}0,338 \\
0,170\end{array}$ & $\begin{array}{l}0,393 \\
0,107\end{array}$ & * & $\begin{array}{l}-0,351 \\
0,961\end{array}$ & \\
\hline MO & $\begin{array}{l}-0,121 \\
0,634\end{array}$ & $\begin{array}{l}0,038 \\
0,881\end{array}$ & * & $\begin{array}{l}-0,351 \\
0,154\end{array}$ & $\begin{array}{l}0,097 \\
0,700\end{array}$ \\
\hline
\end{tabular}

Cell Contents: Pearson correlation

$p$ - Value

Tabela 98: Matriz de correlação de Pearson entre matéria orgânica, fósforo, nitrogênio, cobre na fração fracamente ligada, cobre total e cobre na água intersticial, utilizandose os valores determinados no sedimento no controle e no experimento com $\mathrm{Cu}$ em todas as datas (primeira linha: $r$; segunda linha:p).

\begin{tabular}{|c|c|c|c|c|c|}
\hline & $\mathrm{N}$ & $p$ & Cu Bio & Cu Tot & $\mathrm{Al}$ \\
\hline$p$ & $\begin{array}{l}-0,100 \\
0,693\end{array}$ & & & & \\
\hline Cu Bio & $\begin{array}{l}0,262 \\
0,294\end{array}$ & $\begin{array}{l}0,320 \\
0,196\end{array}$ & & & \\
\hline Cu Tot & $\begin{array}{l}-0,297 \\
0,231\end{array}$ & $\begin{array}{l}-0,135 \\
0,594\end{array}$ & $\begin{array}{l}-0,010 \\
0,969\end{array}$ & & \\
\hline $\mathrm{Al}$ & $\begin{array}{l}-0,002 \\
0,995 \\
\end{array}$ & $\begin{array}{l}0,450 \\
0,061\end{array}$ & $\begin{array}{l}0,148 \\
0,558\end{array}$ & $\begin{array}{l}-0,431 \\
0,074 \\
\end{array}$ & \\
\hline $\mathrm{MO}$ & $\begin{array}{l}0,139 \\
0,581\end{array}$ & $\begin{array}{l}-0,240 \\
0,338\end{array}$ & $\begin{array}{l}0,403 \\
0,097\end{array}$ & $\begin{array}{l}0,233 \\
0,353\end{array}$ & $\begin{array}{l}-0,234 \\
0,351\end{array}$ \\
\hline
\end{tabular}

Cell Contents: Pearson correlation p-Value 